\title{
LEHD INFRASTRUCTURE FILES IN THE CENSUS RDC: OVERVIEW OF S2004 SNAPSHOT
}

\author{
by \\ Kevin L. McKinney* \\ U.S. Bureau of the Census \\ and \\ Lars Vilhuber * \\ Cornell University and U.S. Bureau of the Census
}

CES 11-13 April, 2011

The research program of the Center for Economic Studies (CES) produces a wide range of economic analyses to improve the statistical programs of the U.S. Census Bureau. Many of these analyses take the form of CES research papers. The papers have not undergone the review accorded Census Bureau publications and no endorsement should be inferred. Any opinions and conclusions expressed herein are those of the author(s) and do not necessarily represent the views of the U.S. Census Bureau. All results have been reviewed to ensure that no confidential information is disclosed. Republication in whole or part must be cleared with the authors.

To obtain information about the series, see www.census.gov/ces or contact Cheryl Grim, Editor, Discussion Papers, U.S. Census Bureau, Center for Economic Studies 2K130B, 4600 Silver Hill Road, Washington, DC 20233, CES.Papers.List@census.gov. 


\begin{abstract}
The Longitudinal Employer-Household Dynamics (LEHD) Program at the U.S. Census Bureau, with the support of several national research agencies, has built a set of infrastructure files using administrative data provided by state agencies, enhanced with information from other administrative data sources, demographic and economic (business) surveys and censuses. The LEHD Infrastructure Files provide a detailed and comprehensive picture of workers, employers, and their interaction in the U.S. economy.

This document describes the structure and content of the 2004 Snapshot of the LEHD Infrastructure files as they are made available in the Census Bureau's Research Data Center network.
\end{abstract}

JEL Codes: J00, J10, J20, J30, J40, J60, M50

Keywords: LEHD, linked employer-employee data, workers, employers, jobs, hires, separations, recalls, mobility

* This document reports the results of research and analysis undertaken by the U.S. Census Bureau staff. It is released to inform interested parties of ongoing research and to encourage discussion of work in progress. This research is a part of the U.S. Census Bureau's Longitudinal Employer-Household Dynamics Program (LEHD), which was partially supported by the following National Science Foundation Grants SES-9978093, SES-0339191 and ITR0427889; National Institute on Aging Grant 5 R01 AG018854-02, and grants from the Alfred P. Sloan Foundation. Any opinions and conclusions expressed herein are those of the author(s) and do not necessarily represent the views of the U.S. Census Bureau. All results have been reviewed to ensure that no confidential information is disclosed. The U.S. Census Bureau supports external researchers use of these data through the Research Data Centers (see www.census.gov/ces). 


\section{Contents}

1 Overview of LEHD Infrastructure 11

1.1 Updates . . . . . . . . . . . . . . . . . . . . . . . . . . 11

1.2 Treatment of Federal Tax Information . . . . . . . . . . . . . . . . . . . . . 13

1.3 Identifiers . . . . . . . . . . . . . . . . . . . . . . . . . 13

1.4 Availability of data . . . . . . . . . . . . . . . . . . . . . . . . 14

1.5 Processing files . . . . . . . . . . . . . . . . . . . . . . . . 20

1.6 Disclosure limitation . . . . . . . . . . . . . . . . . . . . . . . 20

2 Business Register Bridge (BRB) 21

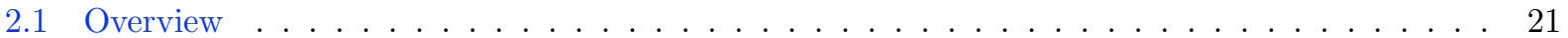

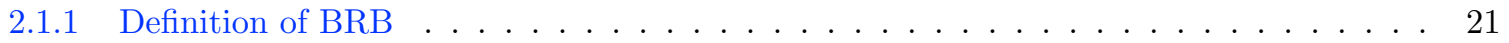

2.1.2 Update frequency. . . . . . . . . . . . . . . . . . . . . . . 21

2.1.3 Acquisition process . . . . . . . . . . . . . . . . . . . . . 21

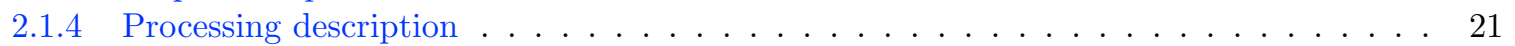

2.1.5 Naming conventions . . . . . . . . . . . . . . . . . . . . . . . . 21

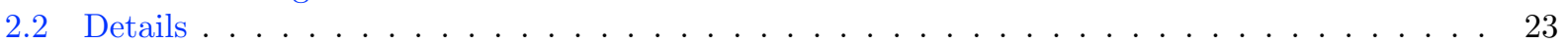

2.3 Characterizing the Bridge Between LEHD Data and Census Business Data . . . . . . . . . . 23

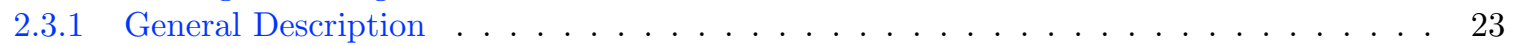

2.3.2 File Structure and Contents . . . . . . . . . . . . . . . . . . . . . . 23

2.3.3 How to Use The BRB . . . . . . . . . . . . . . . . . . . . . . . . . 25

2.3.4 Some warnings and caveats . . . . . . . . . . . . . . . . . . . . . . . . . . . . . . . . . . . . . . . .

2.4 Data set descriptions . . . . . . . . . . . . . . . . . . . . . . . . . 29

2.4.1 Naming scheme . . . . . . . . . . . . . . . . . . . . . . . . 29

2.4 Data location . . . . . . . . . . . . . . . . . . . . . . . . 29

2.4.3 Main file: Crosswalk, brb_us_xwalk . . . . . . . . . . . . . . . . . 30

2.4.4 Business Register list: brb_us_brlist . . . . . . . . . . . . . . . . . . . 30

2.4.5 ECF list: brb_us_ecflist . . . . . . . . . . . . . . . . . . . 31

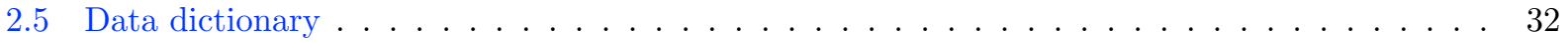

2.5.1 Crosswalk . . . . . . . . . . . . . . . . . . . . . 32

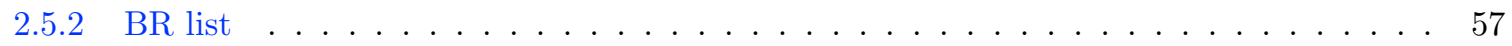

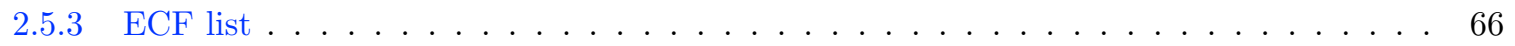

2.5.4 Summary information on datasets . . . . . . . . . . . . . . . . . . 75

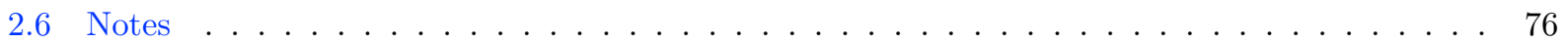

3 Employer Characteristics File (ECF) 77

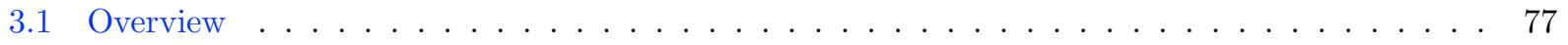

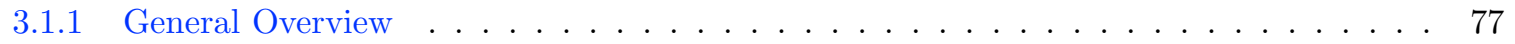

3.1 .2 Input Files . . . . . . . . . . . . . . . . . . . . . . . . . . . . 77

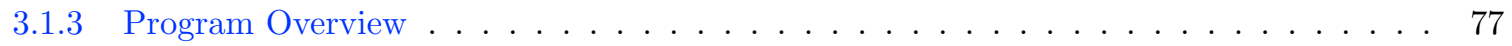

3.2 ECF files and Title 26 in the RDC environment . . . . . . . . . . . . . . . . . . 78 
3.3 Data set descriptions ...............................779

3.3.1 Naming scheme. . . . . . . . . . . . . . . . . . . . . . . . 79

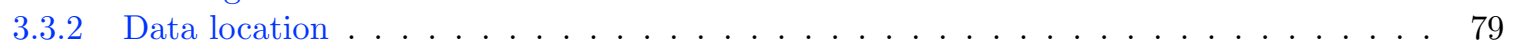

3.3.3 Main SEINUNIT dataset: ecf_zz_seinunit .................... . . 80

3.3.4 Main SEIN dataset: ecf_zz_sein . . . . . . . . . . . . . . . . . . . . . 85

3.3.5 Auxiliary SEINUNIT T26 dataset: ecf_zz_seinunit_t26 . . . . . . . . . . . . 88

3.3.6 Auxiliary SEIN T26 dataset: ecf_zZ_sein_t26 . . . . . . . . . . . . . . . . 89

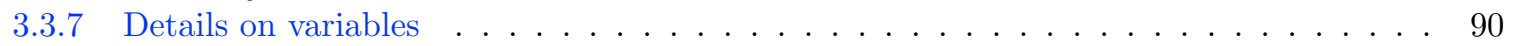

3.4 NAICS codes on the ECF . . . . . . . . . . . . . . . . . . . . . . . 96

3.4.1 A note on naming conventions . . . . . . . . . . . . . . . . . . . 96

3.4.2 LDB versus LEHD NAICS backcoding . . . . . . . . . . . . . . . . . . . . . . 96

3.4 .3 Variable List . . . . . . . . . . . . . . . . . . . . . . . . . . 97

3.4.4 Coding of MISS and SRC . . . . . . . . . . . . . . . . . . . . 98

3.4.5 NAICS algorithm precedence ordering . . . . . . . . . . . . . . . . . . 99

3.4.6 ESO and FNL variables . . . . . . . . . . . . . . . . . . . . . 100

3.4.7 Employment Flag Variable Codes . . . . . . . . . . . . . . . . . . . . . . 100

3.4 Multi-Unit Code or MEEI . . . . . . . . . . . . . . . . . . . . . . . . 101

3.4.9 Auxiliary Code . . . . . . . . . . . . . . . . . . . . . . . 102

3.4.10 Summary information on datasets . . . . . . . . . . . . . . . . . . . . 103

3.5 Helpful programs . . . . . . . . . . . . . . . . . . . . . . . . . . . 104

3.5.1 Combining regular ECF data with ECF T26 files . . . . . . . . . . . . . . . . . . 104

3.5.2 Selecting a random sample of establishments . . . . . . . . . . . . . . . 105

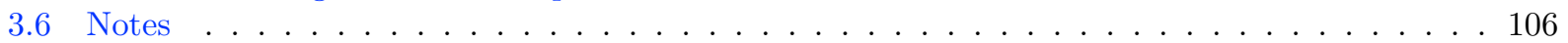

4 Employment History Files (EHF) 107

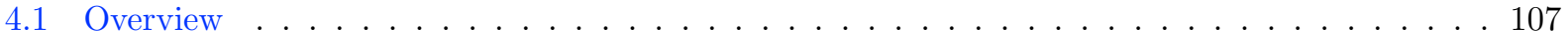

4.2 Input files . . . . . . . . . . . . . . . . . . . . . . . . 108

4.2.1 Wage records: UI . . . . . . . . . . . . . . . . . . . . . 108

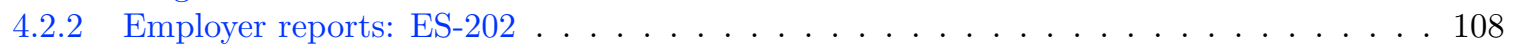

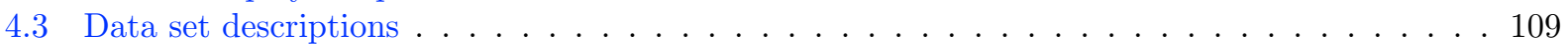

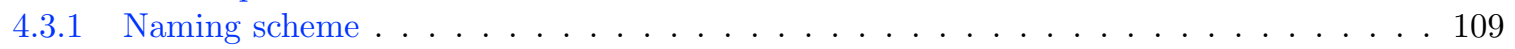

4.3 .2 Data location . . . . . . . . . . . . . . . . . . . . . . . . 109

4.3 .3 UI-based Output Files . . . . . . . . . . . . . . . . . . . . . . . 110

4.3.4 ES202-based Output Files . . . . . . . . . . . . . . . . . . . . 115

4.3.5 Summary information on datasets . . . . . . . . . . . . . . . . . . 127

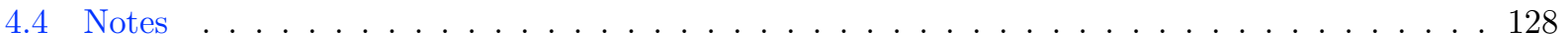

5 Geo-coded Address List (GAL) 131

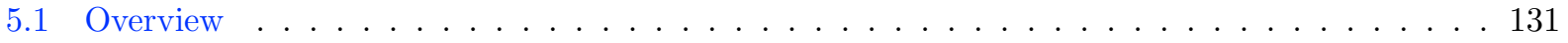

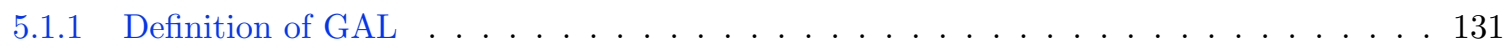

5.1 .2 Update frequency . . . . . . . . . . . . . . . . . . . . . . 131

5.1 .3 Acquisition process . . . . . . . . . . . . . . . . . . . 131

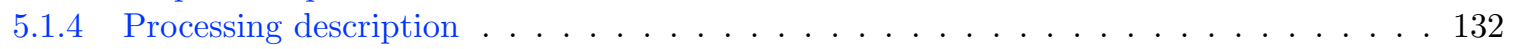

5.2 Details . . . . . . . . . . . . . . . . . . . . . . . . . 133

5.2 .1 Important Variables . . . . . . . . . . . . . . . . . . . . . . . 133

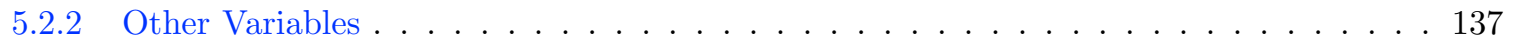

5.2.3 Accessing the GAL: the GAL Crosswalks . . . . . . . . . . . . . . . . . . . 137

5.2 .4 Resources for geographic information . . . . . . . . . . . . . . . . . . 138

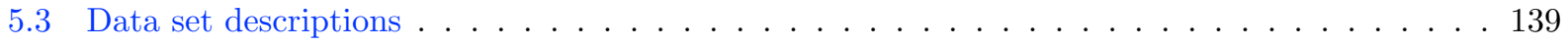

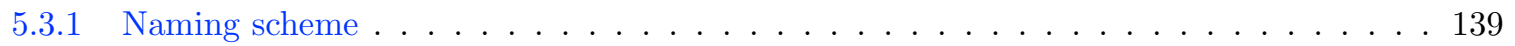

5.3 .2 Data location . . . . . . . . . . . . . . . . . . . . . . . . . . . . . . . . . . . . . . . . . . . . . . . . . . . . . . . . .

5.3 .3 Main dataset: GAL_ZZ_2003 . . . . . . . . . . . . . . . . . . . 140 


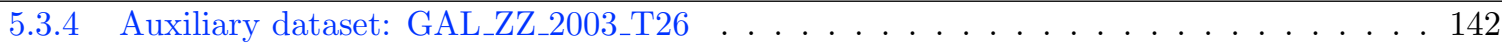

5.3.5 Auxiliary dataset: GAL_ZZ_2003_T26flags . . . . . . . . . . . . . . . . . 143

5.3 .6 Auxiliary dataset: GAL_ZZ_2003_ES202ONLY . . . . . . . . . . . . . . . . . 144

5.3.7 Auxiliary dataset: GAL_ZZ_2003_TCCB . . . . . . . . . . . . . . . . . . 145

5.3.8 ACS Place-of-work Crosswalk: GAL_ZZ_2003_POW_YYYY . . . . . . . . . . . . 146

5.3 .9 AHS Crosswalk: GAL_ZZ_2003_AHS_YYYY . . . . . . . . . . . . . . . . . 147

5.3.10 Business Register Crosswalk: GAL_ZZ_2003_BR_YYYY . . . . . . . . . . . . 148

5.3.11 ES202 Crosswalk: GAL_ZZ_2003_XWALK_YYYY . . . . . . . . . . . . . 149

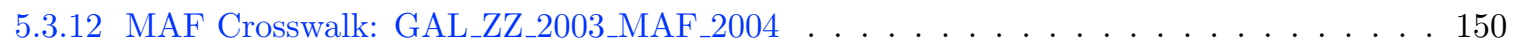

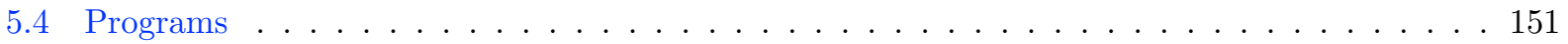

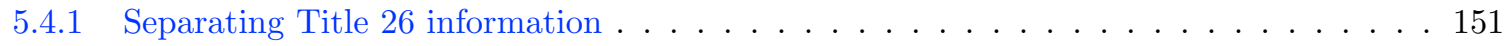

5.4 Recombining GAL component files . . . . . . . . . . . . . . . . 152

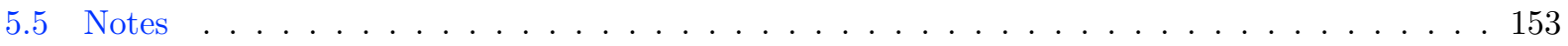

6 Individual Characteristics File (ICF) 155

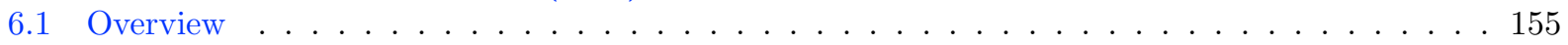

6.1 .1 Age and sex imputation . . . . . . . . . . . . . . . 155

6.1 .2 Place of residence imputation . . . . . . . . . . . . . . . . . 156

6.1 .3 Education imputation . . . . . . . . . . . . . . . . . . . 156

6.2 Data set descriptions . . . . . . . . . . . . . . . . . . . . . . 157

6.2 .1 Unique record identifier . . . . . . . . . . . . . . . . . . 157

6.2 .2 Naming scheme . . . . . . . . . . . . . . . . . . . . . . . . 157

6.2 .3 Data location . . . . . . . . . . . . . . . . . . . . . . . 157

6.2 .4 Main dataset: $\mathrm{ICF}_{z z} \ldots \ldots \ldots \ldots \ldots \ldots \ldots \ldots$

6.2.5 Age and sex implicates: ICF_zz_implicates_age_sex _ . . . . . . . . . . . . . . 159

6.2 .6 Residence implicates: ICF_zz_implicates_county . . . . . . . . . . . . . . . . . . 160

6.2 .7 Education implicates: ICF_zz_implicates_education . . . . . . . . . . . . . . 161

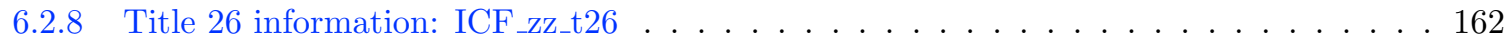

6.2 .9 Summary information on datasets . . . . . . . . . . . . . . . . 163

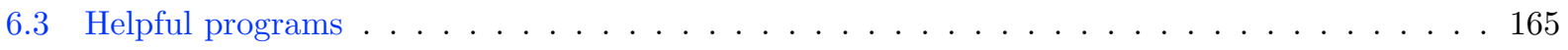

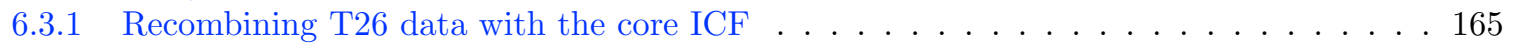

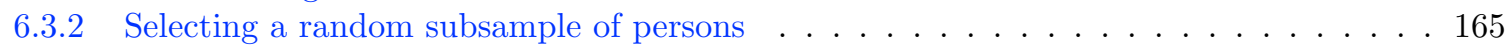

6.4 Notes . . . . . . . . . . . . . . . . . . . . . . . 167

7 Quarterly Workforce Indicators - SEINUNIT file (QWI) 169

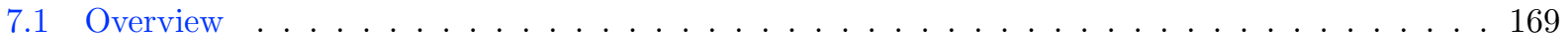

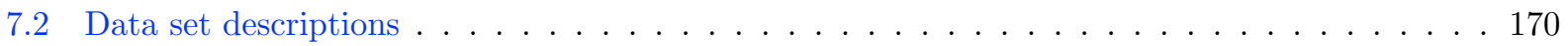

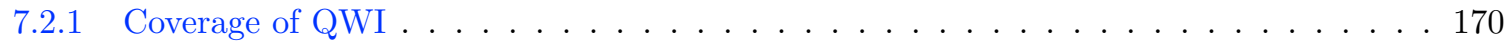

7.2 .2 Naming scheme . . . . . . . . . . . . . . . . . . . . . . 170

7.2 .3 Data location . . . . . . . . . . . . . . . . . . . 170

7.2 .4 Main dataset: QWI_ZZ_SEINUNIT . . . . . . . . . . . . . . . . 170

7.2 .5 Summary information on datasets . . . . . . . . . . . . . . . . 232

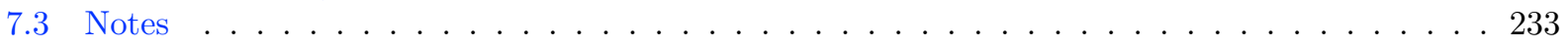

8 Unit-to-Worker Impute - Job location impute (U2W) 235

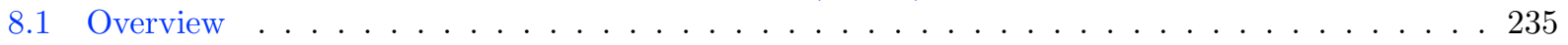

8.1 .1 A probability model for employment location . . . . . . . . . . . . 236

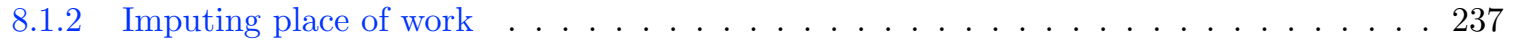

8.2 Data set descriptions . . . . . . . . . . . . . . . . . . . . . . 240

8.2 .1 Naming scheme . . . . . . . . . . . . . . . . . . . . . . . 240

8.2 .2 Data location . . . . . . . . . . . . . . . . . . . . . 240

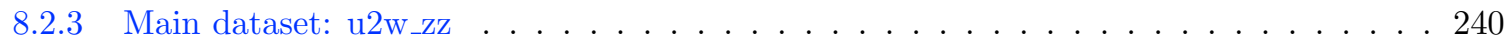


CONTENTS

8.2 .4 Summary information on datasets . . . . . . . . . . . . . . . . . . . 241

8.3 Notes . . . . . . . . . . . . . . . . . . . . . . . . . . . . 242

8.4 Acronyms used . . . . . . . . . . . . . . . . . . . . . . . . . . . 244

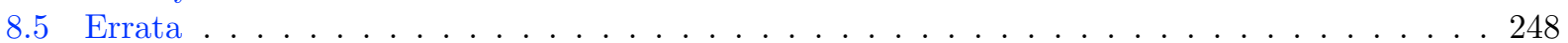




\section{List of Tables}

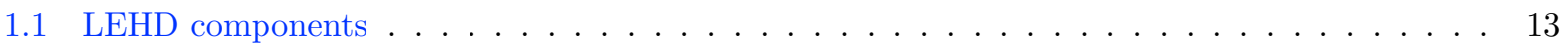

1.2 RDC usage permission, by state . . . . . . . . . . . . . . . . . . . . . . 15

1.3 Data availability, by state and process . . . . . . . . . . . . . . . . . 16

2.47 File information for BRB . . . . . . . . . . . . . . . . . . . . . 75

3.6 MISS Variable Codes . . . . . . . . . . . . . . . . . . . . . . . . . . 99

3.7 SRC Variable: ESO, FNL . . . . . . . . . . . . . . . . . . . . . . . . . . . 99

3.8 SRC Variable: AUX, LDB, NAICS . . . . . . . . . . . . . . . . . . . . . . . 99

3.9 File information, by state, by group, for ECF . . . . . . . . . . . . . . . . . . 103

4.7 File information, by state, for EHF . . . . . . . . . . . . . . . . . . . . . . . . 127

4.8 UI/EHF Summary of Information and Known Issues with Data Coverage and Quality . . . . 128

6.6 File information, by state, by group, for ICF . . . . . . . . . . . . . . . . 163

7.2 File information, by state, for QWI . . . . . . . . . . . . . . . . . . . . . 232

8.2 File information, by state, for $\mathrm{U} 2 \mathrm{~W}$. . . . . . . . . . . . . . . . . . . . . . 241 
LIST OF TABLES 


\section{List of Figures}

1.1 Data flow view of LEHD Infrastructure $\ldots \ldots \ldots \ldots \ldots$

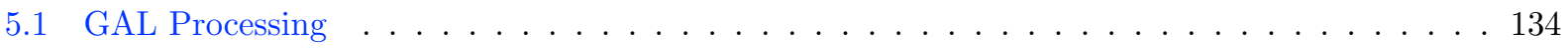


LIST OF FIGURES 


\section{Chapter 1. Overview of LEHD Infrastructure}

The Longitudinal Employer-Household Dynamics (LEHD) Infrastructure files available in the Research Data Center (RDC) is structured as individual components. A big-picture overview of it can be found at http://lehd.did.census.gov/led/library/techpapers/tp-2006-01.pdf. Figure 1.1 provides an overview of the flow of data elements through the LEHD data creation process.

Currently, the core outputs of the data creation process are the Quarterly Workforce Indicators (QWI), shown in Figure 1.1, and the OnTheMap (OTM) data. The LEHD Infrastructure files in the RDC environment do not contain any public-use data (both the aggregated QWI and the OTM data are available to the general public), nor does it contain any information related to the disclosure limitation measures used in the QWI (for more information on the disclosure limitation techniques, see Abowd et al. (2006) and Abowd et al. (2006) for a discussion).

\subsection{UPDATES}

This is the first release of the LEHD Infrastructure files. It contains data that covers the years up to and including 2004Q1. We refer to it as the 'S2004' snapshot of the LEHD Infrastructure files. The data was pulled from LEHD archives as a coherent ensemble over the course of 2005 and 2006.

Improvements are made to the files, fixing minor data inconsistencies or updating documentation. To identify the version of the files in the data archive, a file called version.txt is at the root of each data directory, e.g., u2w/version.txt. The file will contain the name of the data, the snapshot number, and the date stamp of the most recent file within the data. As of the writing of this document,

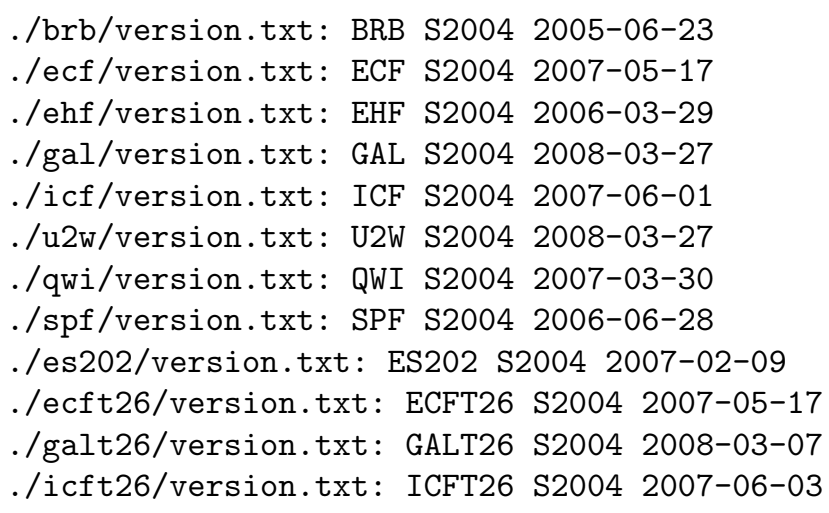

Plans are to update the LEHD Infrastructure files every two-three years, as resources to build it become available. The next update is planned to occur starting in 2008Q1, containing all available states at that time in regular LEHD production, and covering years up to and including 2007Q1. Due to the post-processing required to make researcher-friendly files, and the quantity of data that needs to be moved into the RDC environment, we expect the 'S2007' version to become available in early 2009. 
Figure 1.1: Data flow view of LEHD Infrastructure

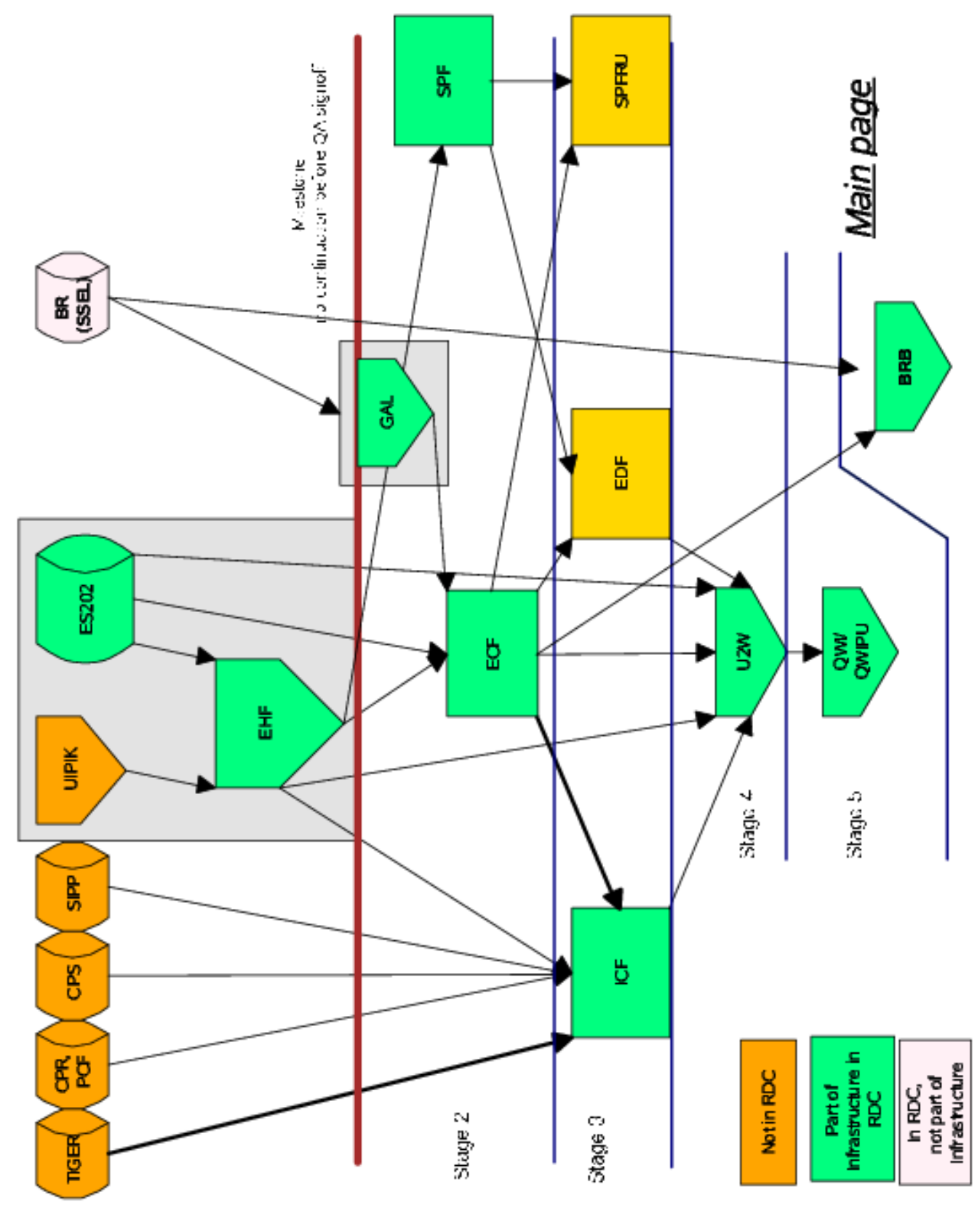


Table 1.1: LEHD components

\begin{tabular}{l|c|l|l}
\hline $\begin{array}{l}\text { Name and } \\
\text { abbreviation }\end{array}$ & $\begin{array}{l}\text { CES abbr. } \\
\text { if different }\end{array}$ & $\begin{array}{l}\text { Name of } \\
\text { FTI version }\end{array}$ & $\begin{array}{l}\text { CES abbreviation } \\
\text { of FTI version }\end{array}$ \\
\hline $\begin{array}{l}\text { Business Register Bridge (BRB) } \\
\text { Employer Characteristics File (ECF) }\end{array}$ & & (all) & \\
$\begin{array}{l}\text { Employment History Files (EHF) } \\
\text { ES-202 (ES-202) }\end{array}$ & es2 & ECFT26 & ect \\
$\begin{array}{l}\text { Individual Characteristics File (ICF) } \\
\text { Geocoded Address List (GAL) }\end{array}$ & & ect \\
Quarterly Workforce Indicators (QWI) & & GALT26 & ict \\
(establishment level) & & & \\
$\begin{array}{l}\text { Successor-Predecessor File (SPF) } \\
\text { Unit-to-Worker Impute (U2W) }\end{array}$ & & & \\
\hline
\end{tabular}

\subsection{TREATMENT OF FEDERAL TAX INFORMATION}

Some components have Title-26 protected variables, which are kept as separate components for tracking and monitoring purposes, but are not documented separately. Such T26 components need to be requested separately, and as of the writing of this documentation, will trigger additional proposal review. Table 1.1 shows the nine components and their Federal Tax Information (FTI) counterparts, if present, as they are available in the RDC.

\section{$1.3 \quad$ IDENTIFIERS}

In general, linkages between the different files are created using deterministic match-merge techniques. Person, firm, and establishment identifiers allow users to link all LEHD Infrastructure files. Throughout, all Social Security Numbers (SSNs) have been replaced by Protected Identity Keys (PIKs) - no SSNs are available anywhere in this data. In addition to within LEHD identifiers such as the PIK, the ICF also contains additional person identifiers linking to Census survey data: (Current Population Survey (CPS), and Survey of Income and Program Participation (SIPP)). Note that these are generally the Census-internal identifiers and may not have a direct correspondence to the identifiers on the public-use files.

Firm identifiers are called State employer identification numbers (SEINs). The identifiers are constructed internally by LEHD, and generally, but not always, reflect an entity reporting unemployment insurance (UI) taxes to state authorities. "Establishments" (more precisely: reporting units) are identified by SEIN reporting unit (SEINUNIT). Establishments and firms are structured as one would expect with establishments listed hierarchically within each firm. Therefore to uniquely identify an establishment both the SEIN and SEINUNIT must be used. The firm and establishment identifiers are state and firm-structure-specific within the LEHD Infrastructure files, there is no straighforward method of linking units of a firm with multiple tax reporting entities (SEINs). Although the vast majority of firms have only one SEIN, a firm, depending on its structure may have multiple SEINs operating both within and across state boundaries. Although the federal Employer Identification Number (EIN) is available and can be used to link SEINs within and across states, the EIN suffers from similar problems as the SEIN. The identifier is not necessarily unique within a firm, is designed for tax reporting, and the structure of EINs within a firm is arbitrary. The Census Bureau recognizes the limitations of administrative identifiers and has addressed this problem on the Business Register (BR). The BRB is used to link to the Business Register (BR) and other Census economic data. Note that the BRB is in general a many-to-many link file. The BRB does permit assigning all SEINs and SEINUNITs to a common alpha (the overall firm identifier inthe BR). However, exact identifierbased establishment-to-establishment matches between BR and LEHD data are generally not possible for establishments part of multi-establishment firms. 
For any further information, refer to the component-specific documentation.

\subsection{AVAILABILITY OF DATA}

Availability of LEHD Infrastructure files is conditional on (i) the data files having been processed in the LEHD QWI Production system, and subsequently integrated into the LEHD Infrastructure and (ii) permission for use in research having been granted by LEHD's state partner.

The standard Memorandum of Understanding (MOU) between the Census Bureau and its state partners precludes access to person and firm names and physical addresses as provided in the ES-202 data. As described below, there are geographic identifiers that are derived in the GAL that can be used for analysis and integrating data for appropriate and approved purposes.

As of April 13, 2011, 31 states have been processed for the complete set of LEHD data files and integrated. The GAL is available for all 50 states plus the District of Columbia, but certain crosswalks do not exist if ES-202 records were not available for that state. As of February 1, 2008, 30 states have granted permission to use the files in the RDC network. Table 1.2 lists permissions by state. LEHD continues to work on expanding the list of permissions. Check with the RDC administrators for the most up-to-date list.

In general, LEHD Infrastructure files are available from 2000 onwards. However, the availability of historical data prior to 2000 varies significantly across states. Table 1.3 tabulates the availability by component and state in the S2004 snapshot. This table should be cross-referenced with Table 1.2 when evaluating the feasibility of a project. 
Table 1.2: RDC usage permission, by state

\begin{tabular}{|c|c|}
\hline Alaska (AK): (pending) & Mississippi (MS): (pending) \\
\hline Alabama (AL): (pending) & Montana (MT): yes \\
\hline Arkansas (AR): yes & North Carolina (NC): yes \\
\hline Arizona (AZ): (pending) & North Dakota (ND): (pending) \\
\hline California (CA): yes & Nebraska (NE): (pending) \\
\hline Colorado $(\mathrm{CO})$ : yes & New Hampshire (NH): (pending) \\
\hline Connecticut (CT): (pending) & New Jersey (NJ): yes \\
\hline District of Columbia (DC): (pending) & New Mexico (NM): yes \\
\hline Delaware (DE): no & Nevada (NV): yes \\
\hline Florida (FL): yes & New York (NY): no \\
\hline Georgia (GA): yes & Ohio (OH): (pending) \\
\hline Hawaii (HI): yes & Oklahoma (OK): yes \\
\hline Iowa (IA): yes & $\begin{array}{l}\text { Oregon (OR): yes } \\
\text { Pennsylvania (PA): (pending) }\end{array}$ \\
\hline Idaho (ID): yes & Rhode Island (RI): yes \\
\hline Illinois (IL): yes & South Carolina (SC): yes \\
\hline Indiana (IN): yes & South Dakota (SD): (pending) \\
\hline Kansas (KS): (pending) & Tennessee (TN): yes \\
\hline Kentucky (KY): (pending) & Texas (TX): yes \\
\hline Louisiana (LA): yes & Utah (UT): yes \\
\hline Massachusetts (MA): (pending) & Virginia (VA): yes \\
\hline Maryland (MD): yes & Vermont (VT): yes \\
\hline Maine (ME): yes & Washington (WA): yes \\
\hline Michigan (MI): no & Wisconsin (WI): yes \\
\hline Minnesota (MN): (pending) & West Virginia (WV): yes \\
\hline Missouri (MO): (pending) & Wyoming (WY): (pending) \\
\hline
\end{tabular}




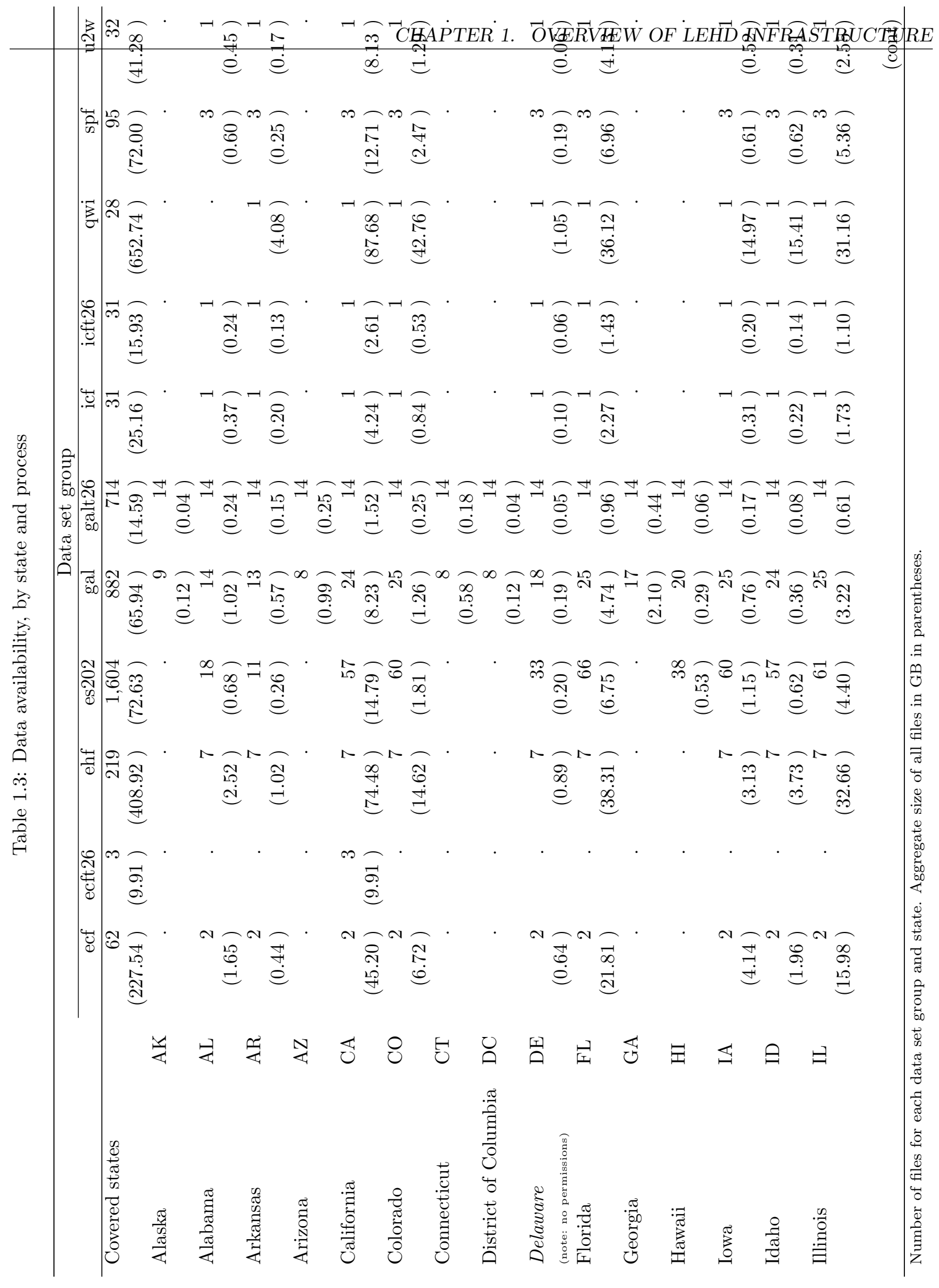




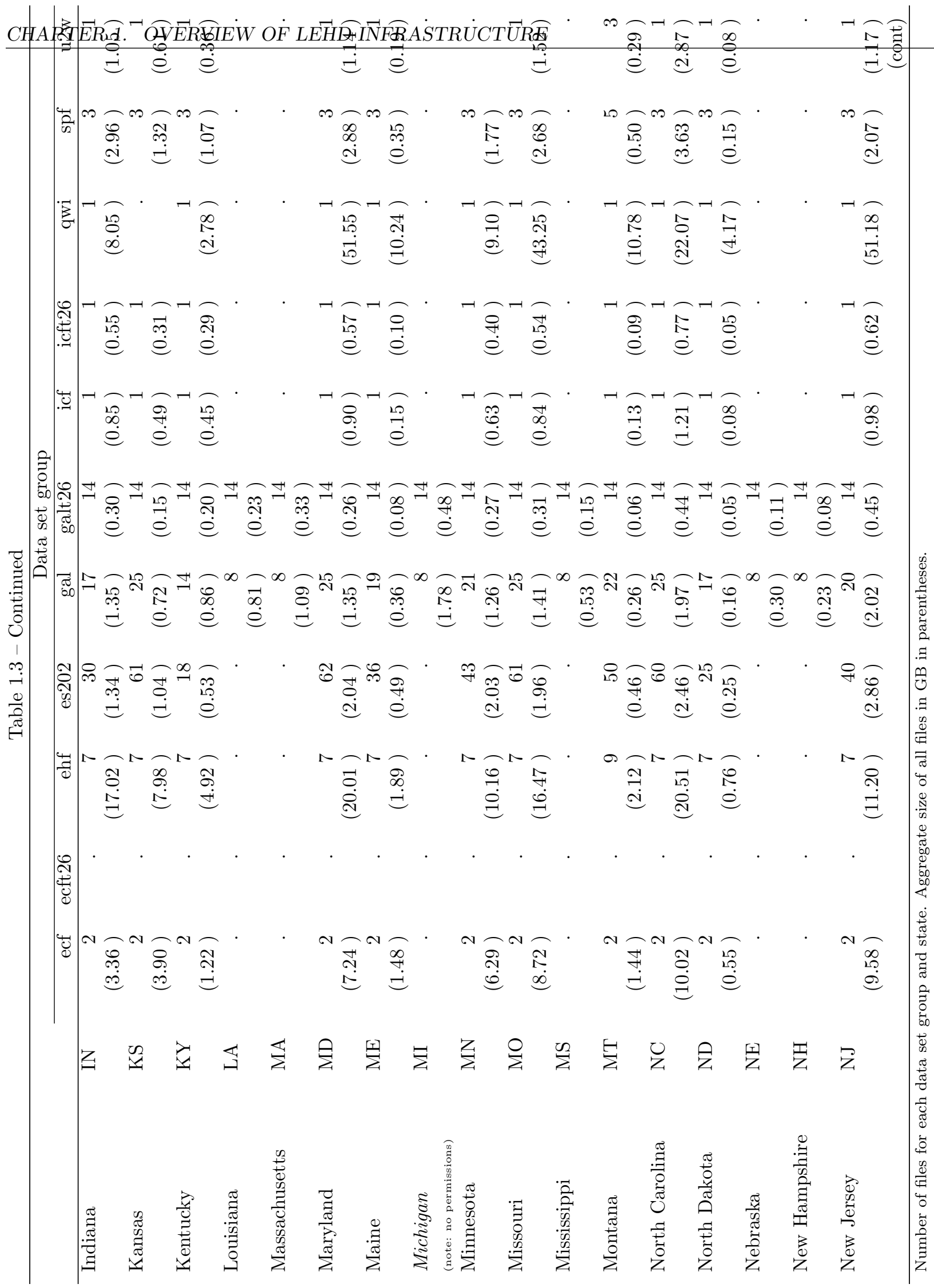




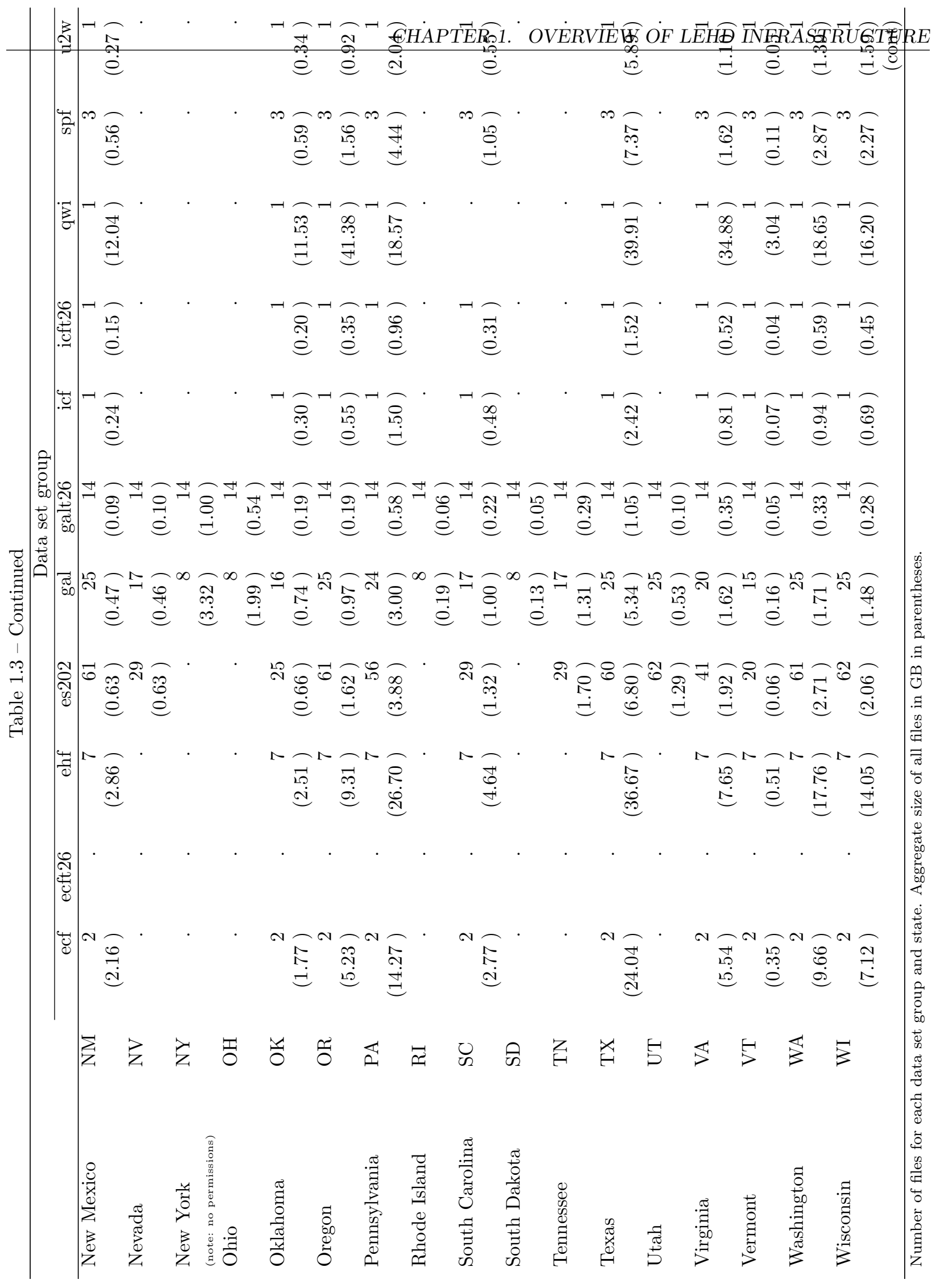




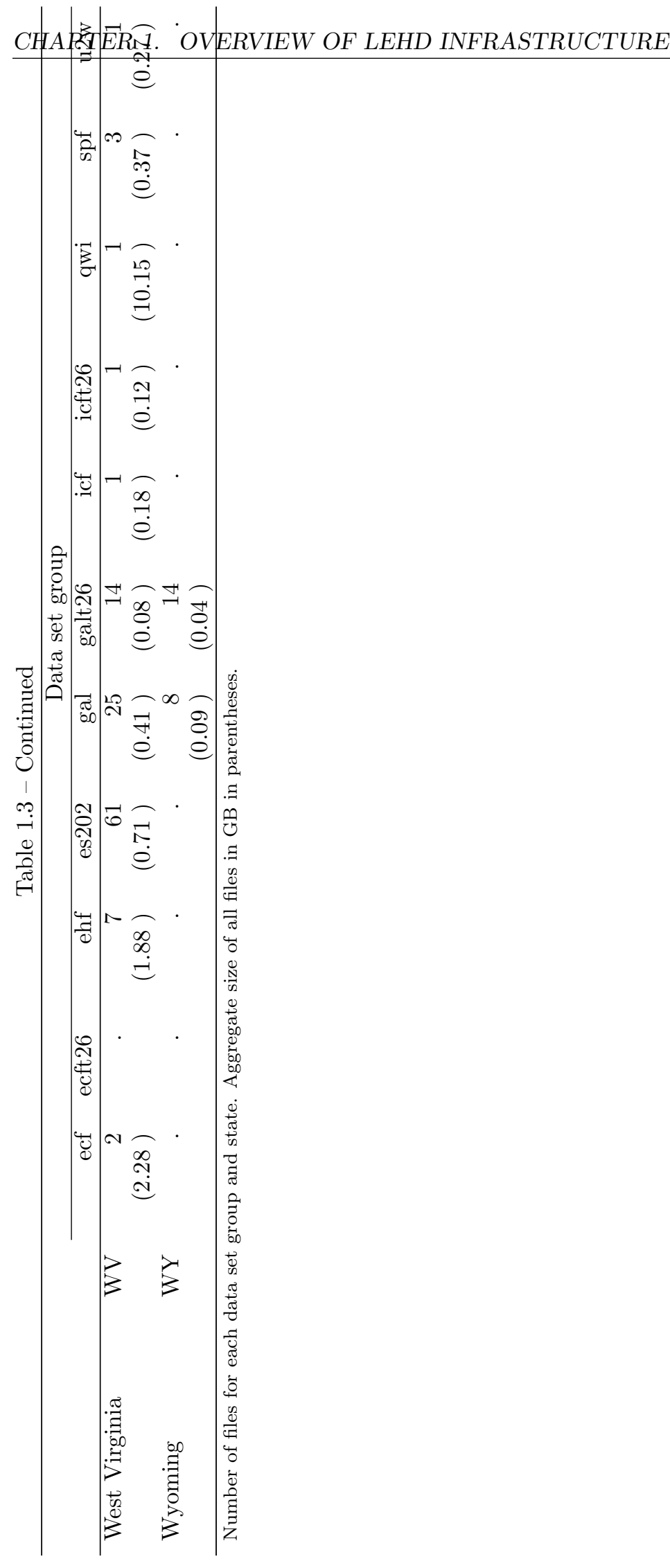


Files not currently available may become available in the next update to the LEHD Infrastructure (see Section 1.1). At the time of writing of this document, we expect the next version to contain up to 46 states. Availablility of core Infrastructure files is dependent on a state's participation in the Local Employment Dynamics (LED) program. The latest participant list can be found at the LEHD website at http://lehd.did.census.gov.

\subsection{PROCESSING FILES}

LEHD Infrastructure files are significantly larger than even traditionally large research files such as the decennial census. In the current version, in all available states and years combined, information on 754,775,697 jobs is presented. There are 226,639,116 quarterly observations on firms. Careful planning is required to ensure that adequate resources are available. To facilitate researchers in this endeavor, the research versions of the LEHD Infrastructure files in the RDC environment have additional random variables that allow for the selection of uniform random subsamples of firms (SEIN), establishments (SEINUNIT), and individuals (PIK). No such random variable is available on the EHF, since there is no single good strategy for selecting jobs. Tables in the documentation for individual components also contains information about the size on-disk of each file.

\subsection{DISCLOSURE LIMITATION}

Special disclosure and data use rules apply to analyses based on the micro-data from the LEHD Infrastructure file system. These data underlie the QWI, and research results are therefore subject to restrictions that insure the QWI disclosure limitation mechanism is not compromised. Disclosure limitation for the QWI uses noise infusion of the micro-data. The Disclosure Review Board (DRB) does not allow the release of any tabulations for sub-state geography that do not use the QWI noise infusion process. In addition, the required noise factors have not been placed on the RDC snapshot files as part of the DRB's normal rules limiting access to the specific parameters of its approved disclosure limitation methods. Only the DRB may approve the release of tabular output from the LEHD infrastructure file system. Sub-state geography tables will not be approved. National or multi-state tables may be approved provided they do not compromise the protection system. Model-based output is normally allowed. The chief disclosure officer for the RDC network will coordinate the reviews.

The underlying micro-data in the LEHD infrastructure file system were provided to the Census Bureau by states' Labor Market Information (LMI) offices under Memoranda of Understanding (also called Data Use Agreements) negotiated with each state. This process is part of the LED federal/state partnership, and places additional restrictions on the results that may be published. Current members of the LED partnership are shown on the LEHD main web page.

Publicly disclosing a single state's data, or any sub-state information such as Metropolitan Statistical Area (MSA) or Core-Based Statistical Area (CBSA), in identifiable form requires the permission of the state's LMI officer. When reporting results from studies that include multiple states, the results should be pooled across the states. State-specific controls can be included, but no coefficients therefrom reported. The identity of the LED member states is obviously not confidential. You may say which states were used in your analysis, and that you controlled for state-specific factors. The chief disclosure officer for the RDC network will review compliance with this requirement in consultation with the Assistant Division Chief for LEHD. 


\section{Chapter 2. \\ Business Register Bridge (BRB)}

\subsection{OVERVIEW}

\subsubsection{Definition of BRB}

The LEHD employer-level data are at an establishment-level and can be linked to Census Bureau establishment and firm level micro data (e.g. Economic Censuses and Surveys) via this bridge . The bridge provides a crosswalk at various levels of business-unit aggregation. The most detailed exact crosswalk is at an EIN, State, 4-digit industry, county level. The bridge includes the full list of establishments in the LEHD data and in the BR that are associated with the business units (e.g., EIN/4-digit SIC/State/County) in the crosswalk and measures of activity (e.g., employment, sales) that can be used to aggregate the establishment level data.

\subsubsection{Update frequency}

Updates occur annually.

\subsubsection{Acquisition process}

The Business Register Bridge (BRB) requires presence of Business Register (BR) (see the BR codebook, yearly acquisition) and the ECF (quarterly updates).

\subsubsection{Processing description}

Extracts of the Business Register (BR) and the ECF are built, properly aggregated, and output into a single file. A more detailed description is available in Section 2.3.

\subsubsection{Naming conventions}

Three data files are produced and transferred. The data files from this process conform to LEHD naming conventions and are called

- brb_us_xwalk: the actual bridge, by year, at different levels of aggregation.

- brb_us_ecflist: list of SEINUNITs on the ECF, by quarter

- brb_us_brlist: list of EINs on the BR, by year

Once on the Center for Economic Studies (CES) system, these files are identified as "LEHD-BRB" and renamed to

- lehd_us_brb: the actual Business Register Bridge (BRB), by year, at different levels of aggregation.

- lehd_us_brb_ecflist: list of SEINUNITs on the ECF, by quarter 
CHAPTER 2. BUSINESS REGISTER BRIDGE (BRB)

- lehd_us_brb_brlist: list of EINs on the BR, by year 


\subsection{DETAILS}

\subsection{CHARACTERIZING THE BRIDGE BETWEEN LEHD DATA AND CEN- SUS BUSINESS DATA}

\subsubsection{General Description}

One of the many advantages of the LEHD database is the ability it offers to link information from Census Bureau business-level surveys (such as the Annual Survey of Manufacturers (ASM), or Business Expenditure Survey (BES)) to the set of workers employed by these units. The LEHD Business Register Bridge (BRB) provides researchers with the tool to make this linkage.

The LEHD data available through the RDCs is described in detail in other documents. In this document, we provide a description of the BRB itself as well as an overview of the business data that is available through this link.

The primary bridge between the LEHD data and the business data is the U.S. Census Bureau's annual Business Register (BR), a list of establishments the Bureau uses to develop the initial mailing list for the economic censuses and surveys. The BR contains data from several different sources. Primarily, however, the BR contains very reliable information on business identifiers, business organizational structure, and business location. All of this detail helps us to form links to the LEHD data.

Unfortunately, we are not able to directly form establishment-to-establishment linkages between LEHD data and the BR. The establishment identification system for the Business Register is the same as for all other Census Bureau business data products but different from the LEHD establishment identifier. Unfortunately, there is no one best way to form linkages between these data sources. There are many alternatives, and the optimal linking strategy depends on the research objective. To provide researchers with as much flexibility as possible, the BRB has been constructed as a crosswalk that allows for a number of different ways to integrate these data sources

\subsubsection{File Structure and Contents}

\subsubsection{Identifiers}

We use three types of identifying variables in the construction of the crosswalk file. These are: business identifier, geographic information, and industry code. Employer Identification Number (EIN) is a nine-digit taxpayer identification number assigned by the Internal Revenue Service (IRS). It is a unique identifier for single units but not for multi-units. Geographic information such as state or county is available. 1987 Standard Industry Classification (SIC) codes are available in 4-digit level

\subsubsection{Unit of observation}

The unit of observation on the BRB file is a unique EIN-State-SIC4-County record. All unique combinations of these identifiers that are found on either the LEHD data, the BR, or both will appear on the crosswalk.

We will use the EIN with 15 different combinations of geographic and industry information as follows:

- EIN

- EIN/SIC1

- $\mathrm{EIN} / \mathrm{SIC} 2$

- EIN/SIC3

- $\mathrm{EIN} / \mathrm{SIC} 4$

- EIN/STATE

- EIN/STATE/SIC1 
- EIN/STATE/SIC2

- EIN/STATE/SIC3

- EIN/STATE/SIC4

- EIN/STATE/COUNTY

- EIN/STATE/COUNTY/SIC1

- EIN/STATE/COUNTY/SIC2

- EIN/STATE/COUNTY/SIC3

- EIN/STATE/COUNTY/SIC4

\subsubsection{Structure of output files}

For complete technical description, see Section 2.5.

Crosswalk file The crosswalk file contains the following variables

Alpha: Ten-digit enterprise identifier

County: Three-digit county identifier

EIN: Nine-digit employer identifier

Flag_xxx: 15 one-digit match type flags. These flags represent the status of the match corresponding to each level of aggregation, one flag per unique id variable combination. Each flag takes on the value "M", "L", or "B". For example, flag_e_c_2 is the flag variable when we use EIN/County/SIC2 as linking unit and flag_e_s_4 is the flag when we use EIN/State/SIC4 as unit of matching.

M means that the business unit at this level of aggregation is matched.

L means that this business unit is observed only in the LEHD database.

B means that this business unit is observed only in the Business Register.

EIN/County/SIC4 is the most disaggregate level of aggregation we can use to match. So, it is obvious that if the flag value for the EIN State SIC4 County match is "M" then all 15 flags are "M".

SIC1: one-digit 1987 SIC

SIC2: two-digit 1987 SIC

SIC3: three-digit 1987 SIC

SIC4: four-digit 1987 SIC

State: Two-digit state abbreviation (e.g. md)

Stgeo: Two-digit State FIPS code (e.g. 24)

Year: Calendar year 
List files List files link different business identifiers that are only observed in one database to one of the fifteen level of aggregation used in matching

Business Register Identifiers: Census File Number (CFN), Permanent Plant Number (PPN), Alpha, etc. are captured on brb_us_brlist.sas7bdat

LEHD Identifiers: SEIN, SEINUNIT, etc. are captured on brb_us_ecflist.sas7bdat. IMPORTANT: The ECF list file is a quarterly file, not a yearly file!

\subsubsection{How to Use The BRB}

\subsubsection{Some considerations}

Because there are many ways to use the BRB, finding the optimal way to use it for any given research project requires some researcher planning. The steps outlined here summarize the experience of the LEHD researcher staff in using this crosswalk for a variety of different research projects.

Before making use of the BRB, there are a number of questions a researcher must address, and the answer to these questions will determine how the BRB will be used. To illustrate this point, we take a research topic and cover, step by step, the decisions a researcher would face when identifying the best way to make use of the BRB to build an analytic dataset for the project.

Because there is not a common establishment ID variable on the Census and LEHD business files, the link between the files must be formed at a level of aggregation that is, for many multi-unit businesses, higher than an establishment. Both the set of link variables as well as the unit of observation for the analytic dataset must be selected by the researcher. Note that these need not be the same.

\subsubsection{Choosing the Link Variables}

As noted, the BRB identifies all variables - state, county, and one-, two-, three-, and four-digit industry code - on which an EIN found among LEHD workforce traits and an EIN found on Census business data agree. In addition to EIN, any (or none) of these link variables may be chosen to merge together workforce traits and other business traits for analysis. When making this decision, observation counts in the resulting matched dataset as well as other factors should be considered. For example, if the analysis will focus on particular industries or regions, researchers may wish to require that linked business data agree on SIC or on state and county. In this case, any EIN the BRB indicates to be found on both files but not agreeing on state or industry would not be included in analysis. As we will discuss in the next section, it should be noted that the link variables do not necessarily determine the unit of observation for the analysis

\subsubsection{Choosing the Base File and Unit of Observation}

There are three types of ways the LEHD data may be combined with Census business data to create researchready datasets. These types are:

1. LEHD workforce traits (such as worker churning rates) at the establishment level (or higher) may be linked to more highly aggregated Census business traits (such as labor productivity). In this situation, the LEHD establishments form the "base file."

2. Establishment-level Census business traits (such as technology spending relative to a scaling measure) may be linked to more highly aggregated LEHD workforce traits. Here, Census data (such as the Annual Survey of Manufacturers) form the base file.

3. Traits aggregated on both sides may be combined using the crosswalk.

In short, researchers linking LEHD workforce traits to other Census business files may choose to aggregate LEHD traits, other business traits, or both. Note that by "aggregate," we mean that establishment-level data should be aggregated to the level of the link (EIN-county, 4-digit SIC, for example), or higher. The 
researcher must decide on which side (workforce traits or other business characteristics) it is important to preserve more detail.

\subsubsection{Example}

Suppose we are interested in exploring how worker turnover impacts labor productivity for restaurants. There are two key decisions regarding identifier variables that must be made. Link traits as well as the unit of observation must be chosen. We hope to make it very clear that the two decisions need not be the same, and both will vary with the nature of the research question

A. Choosing the Link Level Because we are interested in restaurants only and because this is a two-digit industry trait, we will most likely want to use records from the BRB where flag_e_2 (at a minimum)='M'. Noting that county-level match rates are high and that a franchised restaurant in downtown Chicago may behave very differently from the same franchise in rural Illinois, we may also require that observations entering our sample all agree on state and county as well and thus choose only to keep those BRB records where flag_e_c_2='M'

B. Choosing the Base File, Supplemental Files, and Unit of Observation From which data source - Census business data or LEHD data - would we like to preserve the most detailed data? Some researchers may in fact choose to sacrifice detail on both sides in favor of uniformity of variable construction. Regardless, because all variables that will characterize the unit of observation are available from other files, the BRB is not needed to obtain them. However, the unit of observation and the linkage unit are closely tied.

For this example, our goal is to characterize variation in labor productivity across restaurants and to determine if those with more worker turnover are less productive. Thus, we will most likely select Census business data as our "base" data source and will link establishment detail on productivity and other business traits to more aggregated workforce traits (in this example, the LEHD workforce aggregated would be the "supplemental" file). Note that this linking assumes that worker churning is similar for all restaurants in the same EIN state and county

\subsubsection{Summary of How to Use This File:}

Step 1 Make an extract from the BRB sub-setting on all records for each state and year that have a value of "M" for the match flag corresponding to these match variables. The variables to keep include all ID variables needed to make the match. For example, if we sub-set on flag_e_c_2='M', the match variables we keep from the BRB will be:

- EIN

- State

- $\mathrm{SIC} 2$

- County

- Year

CAUTION: One should make sure to sort the crosswalk to get unique observation per linking unit when using linking units less detailed than EIN/County/SIC4.

Step 2 Some Base and supplemental files have all the necessary variables such as EIN, State, SIC2, County, and Year. For example, the ASM and Census of Manufactures (CM) have these link variables as well as establishment identifiers such as CFN and PPN. In this case we can match the extract from the BRB with the base file or supplement file (after some aggregation). However, some files do have their own identifiers but not all link variables. In this case, we have to get additional variables from the list files we provide before 
matching the extract from the BRB with the files of interest. For example, some files have only CFN and year but not EIN. Thus, we must first obtain the CFN from BR list file before matching.

Step 3 Select a base file (Census business data or LEHD business data), a supplemental file, and a unit of observation for the final analytic dataset. The base file should be the file from which we could like to preserve the most detail (if aggregation level differences within the same observation are desired).

Step 4 From the base file, pull off all observations (matching by the link variables selecting in Step 2) that match to the BRB extract. If allowing for more detailed data from the base file, the dataset resulting from this step will have more observations than the BRB extract.

Step 5 If the LEHD data has been selected as the base file in Step 3, some collection of Census business data files will be used to construct the supplemental file. The most dis-aggregated level of detail that may be maintained on the supplemental file is defined by the link variables (EIN, state, one-digit SIC, county and year in this example). If the business data variables of interest are reported on the files at this level of aggregation or smaller (typically this will be at an establishment level), then the business data must be aggregated to the level defined by the link variables. Note that some business files contain records reported at higher levels of aggregation. In these cases, no additional aggregation is needed in the construction of the supplemental file. CAUTION: When adding variables at a higher level of aggregation, it is often preferred to use ratios of variables from the same dataset rather than levels of one variable only. For example, rather than using aggregated sales, it is often preferable to weight sales at each establishment by some fraction (where the fractions for each establishment sum to one) before aggregating across establishments.

Step 6 Link the supplemental file to the joined base file and BRB extract. Use the same variables used to define the level of aggregation of the supplemental file.

Step 7 The construction of the analytic dataset is now complete. Note, however, that not all records in the dataset need be constructed at the same level of aggregation.

\subsubsection{Some warnings and caveats}

\subsubsection{Active establishments}

In the construction of the crosswalk, duplicates and non-active establishments are deleted (not included) based on Census activity flags from the BR. Invalid, missing, illegible, or out-of-scope industry code, invalid geography, or even zero payroll are not grounds for exclusion from the BRB. In particular, invalid codes can and do appear on the BR, and are carried through unchanged.

\subsubsection{Discrepancies in geo and industry codes}

There may be discrepancies between the BR and ES-202 based data for a variety of reasons. Processing issues imply that geo and industry codes may be missing or out of bounds on BR, especially for entrants. It is an open question whether the ES-202 might get information on industry and geo faster than the BR. Note that there is some evidence that suggests that this is the case: Census currently receives a list of industry codes from Bureau of Labor Statistics (BLS) (from its ES-202 processing) for new EINs. Census has typically found these industry codes to be more reliable than either the PBA (principal business activity from income tax forms for businesses) codes they receive from IRS or the industry codes from Social Security Administration (SSA) extracted from the SS-4 form (the form used to apply for an EIN).

In terms of preference, the preference ordering that Census typically uses for industry codes is:

1. Direct Census collection in economic censuses or annual surveys (for most businesses this means only once every five years). 
2. BLS codes

3. SSA codes

4. IRS codes 
CHAPTER 2. BUSINESS REGISTER BRIDGE (BRB)

\subsection{DATA SET DESCRIPTIONS}

\subsubsection{Naming scheme}

There are three files in the BRB group:

brb_us_brlist.sas7bdat

brb_us_ecflist.sas7bdat

brb_us_xwalk.sas7bdat

us indicates that these are files of national scope. All BRB files are considered FTI.

\subsubsection{Data location}

The files are stored in a directory underneath the general LEHD directory structure:

brb/us/

On the RDC network, the directory can be found under

/mixed/lehd/current 


\subsubsection{Main file: Crosswalk, brb_us_xwalk}

Record identifier: year EIN state county sic4 ???

Sort order: year ein state county sic4

File indexes: none

Entity Link record (many-to-many)

Unique Entity Key year EIN state county sic4

\begin{tabular}{l|l|c|c|c}
\hline \multicolumn{1}{c|}{ Field name } & $\begin{array}{l}\text { Data dictionary } \\
\text { reference name }\end{array}$ & $\begin{array}{l}\text { Starting } \\
\text { position }\end{array}$ & $\begin{array}{l}\text { Field } \\
\text { size }\end{array}$ & $\begin{array}{l}\text { Data } \\
\text { type }\end{array}$ \\
\hline Cleaned EIN & EIN & 00026 & 9 & A/N \\
Cleaned ES202 FIPS County CCC & COUNTY & 00035 & 3 & A/N \\
Cleaned SIC Code IIII & SIC4 & 00020 & 4 & A/N \\
ES202 FIPS State SS & STGEO & 00024 & 2 & A/N \\
Enterprise identifier & ALPHA & 00008 & 10 & A/N \\
Match flag EIN level & FLAG_E & 00058 & 1 & A/N \\
Match flag EIN/SIC1 level & FLAG_E_1 & 00057 & 1 & A/N \\
Match flag EIN/SIC2 level & FLAG_E_2 & 00056 & 1 & $\mathrm{~A} / \mathrm{N}$ \\
Match flag EIN/SIC3 level & FLAG_E_3 & 00055 & 1 & $\mathrm{~A} / \mathrm{N}$ \\
Match flag EIN/SIC4 level & FLAG_E_4 & 00054 & 1 & $\mathrm{~A} / \mathrm{N}$ \\
Match flag EIN/STATE level & FLAG_E_S & 00053 & 1 & $\mathrm{~A} / \mathrm{N}$ \\
Match flag EIN/STATE/COUNTY level & FLAG_E_S_C & 00048 & 1 & $\mathrm{~A} / \mathrm{N}$ \\
Match flag EIN/STATE/COUNTY/SIC1 & FLAG_E_S_C_1 & 00047 & 1 & $\mathrm{~A} / \mathrm{N}$ \\
Match flag EIN/STATE/COUNTY/SIC2 & FLAG_E_S_C_2 & 00046 & 1 & $\mathrm{~A} / \mathrm{N}$ \\
Match flag EIN/STATE/COUNTY/SIC3 & FLAG_E_S_C_3 & 00045 & 1 & $\mathrm{~A} / \mathrm{N}$ \\
Match flag EIN/STATE/COUNTY/SIC4 & FLAG_E_S_C_4 & 00044 & 1 & $\mathrm{~A} / \mathrm{N}$ \\
Match flag EIN/STATE/SIC1 level & FLAG_E_S_1 & 00052 & 1 & $\mathrm{~A} / \mathrm{N}$ \\
Match flag EIN/STATE/SIC2 level & FLAG_E_S_2 & 00051 & 1 & $\mathrm{~A} / \mathrm{N}$ \\
Match flag EIN/STATE/SIC3 level & FLAG_E_S_3 & 00050 & 1 & $\mathrm{~A} / \mathrm{N}$ \\
Match flag EIN/STATE/SIC4 level & FLAG_E_S_4 & 00049 & 1 & $\mathrm{~A} / \mathrm{N}$ \\
One-digit SIC code & SIC1 & 00043 & 1 & $\mathrm{~A} / \mathrm{N}$ \\
State FIPS code & STATE & 00018 & 2 & $\mathrm{~A} / \mathrm{N}$ \\
Three-digit SIC Code & SIC3 & 00038 & 3 & $\mathrm{~A} / \mathrm{N}$ \\
Two-digit SIC code & SIC2 & 00041 & 2 & $\mathrm{~A} / \mathrm{N}$ \\
Year YYYY & YEAR & 00000 & 8 & $\mathrm{~N}$
\end{tabular}

\subsubsection{Business Register list: brb_us_brlist}

Record identifier: year ein state county sic4 cfn

Sort order: year ein state county sic $4 \mathrm{cfn}$

File indexes: none

Entity Establishment (Census File Number)

Unique Entity Key cfn 
CHAPTER 2. BUSINESS REGISTER BRIDGE (BRB)

\begin{tabular}{l|l|c|cc}
\multicolumn{1}{c|}{ Field name } & $\begin{array}{l}\text { Data dictionary } \\
\text { reference name }\end{array}$ & $\begin{array}{l}\text { Starting } \\
\text { position }\end{array}$ & $\begin{array}{l}\text { Field } \\
\text { size }\end{array}$ & $\begin{array}{l}\text { Data } \\
\text { type }\end{array}$ \\
\hline Census File Number & CFN & 00008 & 10 & $\mathrm{~A} / \mathrm{N}$ \\
Employer Identification Number & EIN & 00036 & 9 & $\mathrm{~A} / \mathrm{N}$ \\
Enterprise identifier & ALPHA & 00018 & 10 & $\mathrm{~A} / \mathrm{N}$ \\
FIPS State SS & STATE & 00028 & 2 & $\mathrm{~A} / \mathrm{N}$ \\
FIPS State xx & STGEO & 00034 & 2 & $\mathrm{~A} / \mathrm{N}$ \\
FIPS county Xxx & COUNTY & 00055 & 3 & $\mathrm{~A} / \mathrm{N}$ \\
Four-digit 1987 SIC & SIC4 & 00030 & 4 & $\mathrm{~A} / \mathrm{N}$ \\
Permanent Plant Number & PPN & 00045 & 10 & $\mathrm{~A} / \mathrm{N}$ \\
Year YYYY & YEAR & 00000 & 8 & $\mathrm{~N}$
\end{tabular}

\subsubsection{ECF list: brb_us_ecflist}

Record identifier: sein seinunit year quarter

Sort order: year ein state county sic4 sein seinunit quarter

File indexes: none

Entity Reporting unit (State Employment Security Agency (SESA))

Unique Entity Key sein seinunit year quarter

\begin{tabular}{|c|c|c|c|c|}
\hline Field name & $\begin{array}{l}\text { Data dictionary } \\
\text { reference name }\end{array}$ & $\begin{array}{l}\text { Starting } \\
\text { position }\end{array}$ & $\begin{array}{l}\text { Field } \\
\text { size }\end{array}$ & $\begin{array}{l}\text { Data } \\
\text { type }\end{array}$ \\
\hline Cleaned EIN & EIN & 00026 & 9 & $\mathrm{~A} / \mathrm{N}$ \\
\hline Cleaned ES202 FIPS County CCC & COUNTY & 00023 & 3 & $\mathrm{~A} / \mathrm{N}$ \\
\hline Cleaned SIC Code IIII & SIC4 & 00019 & 4 & $\mathrm{~A} / \mathrm{N}$ \\
\hline ES202 FIPS State SS & STGEO & 00017 & 2 & $\mathrm{~A} / \mathrm{N}$ \\
\hline FIPS State SS & STATE & 00035 & 2 & $\mathrm{~A} / \mathrm{N}$ \\
\hline Quarter QQ & QUARTER & 00040 & 3 & $\mathrm{~N}$ \\
\hline State Employer ID Number & SEIN & 00000 & 12 & $\mathrm{~A} / \mathrm{N}$ \\
\hline State UI Reporting Unit Number & SEINUNIT & 00012 & 5 & $\mathrm{~A} / \mathrm{N}$ \\
\hline Year YYYY & YEAR & 00037 & 3 & $\mathrm{~N}$ \\
\hline
\end{tabular}




\subsection{DATA DICTIONARY}

\subsubsection{Crosswalk}

\begin{tabular}{c|l|l|l|l}
\hline \multicolumn{1}{c|}{ Field name } & $\begin{array}{l}\text { Data dictionary } \\
\text { reference name }\end{array}$ & $\begin{array}{l}\text { Starting } \\
\text { position }\end{array}$ & $\begin{array}{l}\text { Field } \\
\text { size }\end{array}$ & $\begin{array}{l}\text { Data } \\
\text { type }\end{array}$ \\
\hline Cleaned EIN & EIN & 00026 & 9 & A/N \\
\hline
\end{tabular}

CHARACTERISTICS

$\begin{aligned} & \text { Units } \text { Identifier } \\ & \text { AlGORITHM } \text { read-in } \\ & \text { SourCEFILE } \text { BR and ECF, if available } \\ & \text { n.a. }\end{aligned}$

VALUE TABLE 
CHAPTER 2. BUSINESS REGISTER BRIDGE (BRB)

\begin{tabular}{|c|c|c|c|c|c|}
\hline Field name & $\begin{array}{l}\text { Data dictionary } \\
\text { reference name }\end{array}$ & & $\begin{array}{l}\text { Starting } \\
\text { position }\end{array}$ & $\begin{array}{l}\text { Field } \\
\text { size }\end{array}$ & $\begin{array}{l}\text { Data } \\
\text { type }\end{array}$ \\
\hline Cleaned ES202 FIPS County CCC & COUNTY & & 00035 & 3 & $\mathrm{~A} / \mathrm{N}$ \\
\hline \multicolumn{6}{|l|}{ CHARACTERISTICS } \\
\hline \multicolumn{2}{|c|}{$\begin{array}{r}\text { Units } \\
\text { Algorithm } \\
\text { SourCEFILE } \\
\text { Alternate Documentation }\end{array}$} & $\begin{array}{l}\text { Geography } \\
\text { read-in } \\
\text { ECF/BR } \\
\text { n.a. }\end{array}$ & & & \\
\hline \multicolumn{2}{|l|}{ VALUE TABLE } & & & & \\
\hline
\end{tabular}


CHAPTER 2. BUSINESS REGISTER BRIDGE (BRB)

\begin{tabular}{c|l|l|l|l}
\hline \multicolumn{1}{c|}{ Field name } & $\begin{array}{l}\text { Data dictionary } \\
\text { reference name }\end{array}$ & $\begin{array}{l}\text { Starting } \\
\text { position }\end{array}$ & $\begin{array}{l}\text { Field } \\
\text { size }\end{array}$ & $\begin{array}{l}\text { Data } \\
\text { type }\end{array}$ \\
\hline Cleaned SIC Code IIII & SIC4 & 00020 & 4 & A/N \\
\hline
\end{tabular}

CHARACTERISTICS

$\begin{array}{rll}\text { Units } & & \text { Industry } \\ \text { Algorithim } & & \text { read-in } \\ \text { Sourcefile } & & \text { ECF/BR } \\ \text { Alternate documentation } & \text { n.a. }\end{array}$

VALUE TABLE 
CHAPTER 2. BUSINESS REGISTER BRIDGE (BRB)

\begin{tabular}{c|l|l|l|l}
\hline \multicolumn{1}{c|}{ Field name } & $\begin{array}{l}\text { Data dictionary } \\
\text { reference name }\end{array}$ & $\begin{array}{l}\text { Starting } \\
\text { position }\end{array}$ & $\begin{array}{l}\text { Field } \\
\text { size }\end{array}$ & $\begin{array}{l}\text { Data } \\
\text { type }\end{array}$ \\
\hline ES202 FIPS State SS & STGEO & 00024 & 2 & A/N \\
\hline
\end{tabular}

\section{CHARACTERISTICS}

Ulits
Algorithm
Sourcefile
Alternate documentation
VALUE TABLE

Geography

read-in

BR

n.a. 
CHAPTER 2. BUSINESS REGISTER BRIDGE (BRB)

\begin{tabular}{c|l|l|l|l}
\hline \multicolumn{1}{c|}{ Field name } & $\begin{array}{l}\text { Data dictionary } \\
\text { reference name }\end{array}$ & $\begin{array}{l}\text { Starting } \\
\text { position }\end{array}$ & $\begin{array}{l}\text { Field } \\
\text { size }\end{array}$ & $\begin{array}{l}\text { Data } \\
\text { type }\end{array}$ \\
\hline Enterprise identifier & ALPHA & 00008 & 10 & A/N \\
\hline
\end{tabular}

CHARACTERISTICS

Ulits
Algorithm
Sourcefile
Alternate documentation
VALUE TABLE

Identifier

read-in

BR

n.a. 
CHAPTER 2. BUSINESS REGISTER BRIDGE (BRB)

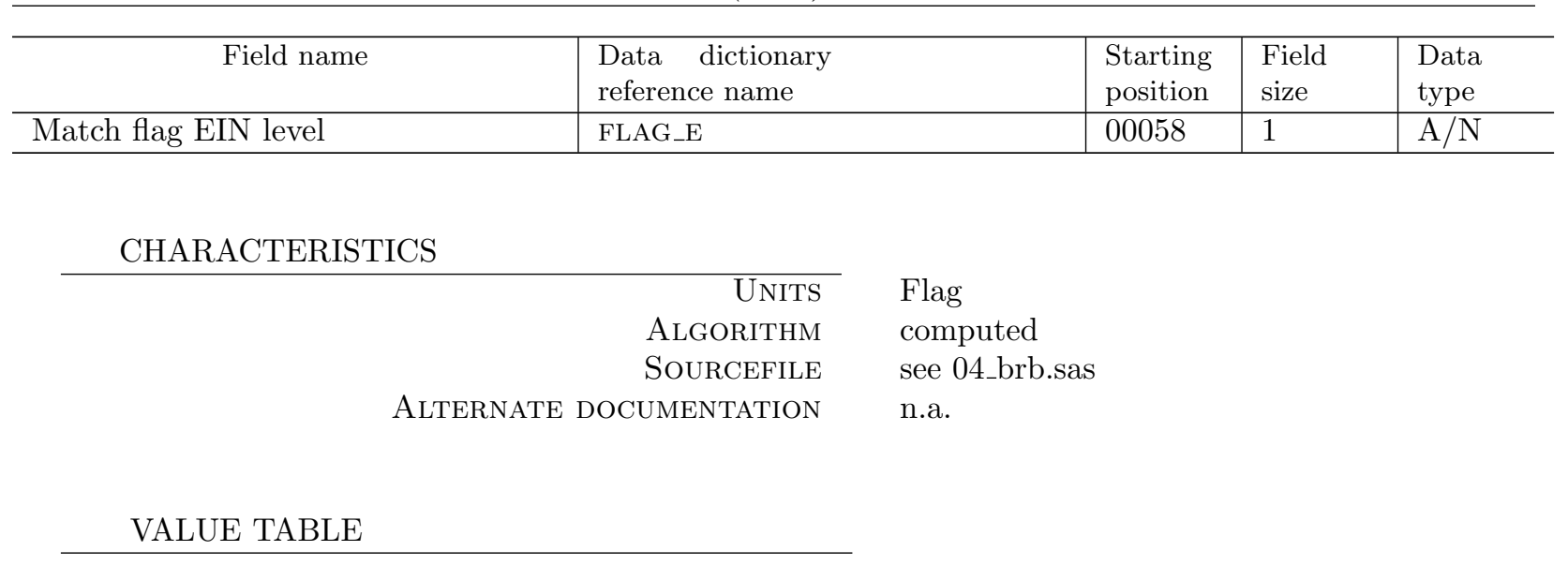

B: only in BR

L: only in LEHD

M: matched in EIN level 
CHAPTER 2. BUSINESS REGISTER BRIDGE (BRB)

\begin{tabular}{c|l|l|l|l}
\hline \multicolumn{1}{c|}{ Field name } & $\begin{array}{l}\text { Data dictionary } \\
\text { reference name }\end{array}$ & $\begin{array}{l}\text { Starting } \\
\text { position }\end{array}$ & $\begin{array}{l}\text { Field } \\
\text { size }\end{array}$ & $\begin{array}{l}\text { Data } \\
\text { type }\end{array}$ \\
\hline Match flag EIN/SIC1 level & FLAG_E_1 & 00057 & 1 & A/N \\
\hline
\end{tabular}

\section{CHARACTERISTICS}

Ulits
Algorithm
Sourcefile
Alternate documentation
VALUE TABLE

B: only in BR

L: only in LEHD

M: matched in EIN/SIC1 level
Flag

computed

see 04_brb.sas

n.a. 
CHAPTER 2. BUSINESS REGISTER BRIDGE (BRB)

\begin{tabular}{c|l|l|l|l}
\hline \multicolumn{1}{c|}{ Field name } & $\begin{array}{l}\text { Data dictionary } \\
\text { reference name }\end{array}$ & $\begin{array}{l}\text { Starting } \\
\text { position }\end{array}$ & $\begin{array}{l}\text { Field } \\
\text { size }\end{array}$ & $\begin{array}{l}\text { Data } \\
\text { type }\end{array}$ \\
\hline Match flag EIN/SIC2 level & FLAG_E_2 & 00056 & 1 & A/N \\
\hline
\end{tabular}

\section{CHARACTERISTICS}

Ulits
Algorithm
Sourcefile
Alternate documentation
VALUE TABLE

B: only in BR

L: only in LEHD

M: matched in EIN/SIC2 level
Flag

computed

see 04_brb.sas

n.a. 
CHAPTER 2. BUSINESS REGISTER BRIDGE (BRB)

\begin{tabular}{c|l|l|l|l}
\hline \multicolumn{1}{c|}{ Field name } & $\begin{array}{l}\text { Data dictionary } \\
\text { reference name }\end{array}$ & $\begin{array}{l}\text { Starting } \\
\text { position }\end{array}$ & $\begin{array}{l}\text { Field } \\
\text { size }\end{array}$ & $\begin{array}{l}\text { Data } \\
\text { type }\end{array}$ \\
\hline Match flag EIN/SIC3 level & FLAG_E_3 & 00055 & 1 & A/N \\
\hline
\end{tabular}

\section{CHARACTERISTICS}

Ulits
Algorithm
Sourcefile
Alternate documentation
VALUE TABLE

B: only in BR

L: only in LEHD

M: matched in EIN/SIC3 level
Flag

computed

see 04_brb.sas

n.a. 
CHAPTER 2. BUSINESS REGISTER BRIDGE (BRB)

\begin{tabular}{c|l|l|l|l}
\hline \multicolumn{1}{c|}{ Field name } & $\begin{array}{l}\text { Data dictionary } \\
\text { reference name }\end{array}$ & $\begin{array}{l}\text { Starting } \\
\text { position }\end{array}$ & $\begin{array}{l}\text { Field } \\
\text { size }\end{array}$ & $\begin{array}{l}\text { Data } \\
\text { type }\end{array}$ \\
\hline Match flag EIN/SIC4 level & FLAG_E_4 & 00054 & 1 & A/N \\
\hline
\end{tabular}

\section{CHARACTERISTICS}

Ulits
Algorithm
Sourcefile
Alternate documentation
VALUE TABLE

B: only in BR

L: only in LEHD

M: matched in EIN/SIC4 level
Flag

computed

see 04_brb.sas

n.a. type 
CHAPTER 2. BUSINESS REGISTER BRIDGE (BRB)

\begin{tabular}{c|l|l|l|l}
\hline \multicolumn{1}{c|}{ Field name } & $\begin{array}{l}\text { Data dictionary } \\
\text { reference name }\end{array}$ & $\begin{array}{l}\text { Starting } \\
\text { position }\end{array}$ & $\begin{array}{l}\text { Field } \\
\text { size }\end{array}$ & $\begin{array}{l}\text { Data } \\
\text { type }\end{array}$ \\
\hline Match flag EIN/STATE level & FLAG_E_S & 00053 & 1 & A/N \\
\hline
\end{tabular}

\section{CHARACTERISTICS}

Ulits
Algorithm
Sourcefile
Alternate documentation
VALUE TABLE

B: only in BR

L: only in LEHD

M: matched in EIN/STATE level
Flag

computed

see 04_brb.sas

n.a. 
CHAPTER 2. BUSINESS REGISTER BRIDGE (BRB)

\begin{tabular}{ll|l|l|l|l}
\hline & \multicolumn{2}{l}{} \\
\hline \multicolumn{2}{c|}{ Field name } & $\begin{array}{l}\text { Data dictionary } \\
\text { reference name }\end{array}$ & $\begin{array}{l}\text { Starting } \\
\text { position }\end{array}$ & $\begin{array}{l}\text { Field } \\
\text { size }\end{array}$ & $\begin{array}{l}\text { Data } \\
\text { type }\end{array}$ \\
\hline $\begin{array}{l}\text { Match flag EIN/STATE/COUNTY } \\
\text { level }\end{array}$ & FLAG_E_S_C & 00048 & 1 & A/N \\
\hline
\end{tabular}

\section{CHARACTERISTICS}

Algorit
SourceF
Alternate documentat
VALUE TABLE
B: only in BR
L: only in LEHD
M: matched in EIN/STATE/COUNTY level

: only in LEHD

M: matched in EIN/STATE/COUNTY level
Flag

computed

see 04_brb.sas

n.a. 
CHAPTER 2. BUSINESS REGISTER BRIDGE (BRB)

\begin{tabular}{cc|l|l|l|l}
\hline \multicolumn{1}{c|}{ Field name } & $\begin{array}{l}\text { Data dictionary } \\
\text { reference name }\end{array}$ & $\begin{array}{l}\text { Starting } \\
\text { position }\end{array}$ & $\begin{array}{l}\text { Field } \\
\text { size }\end{array}$ & $\begin{array}{l}\text { Data } \\
\text { type }\end{array}$ \\
\hline $\begin{array}{l}\text { Match flag } \\
\text { EIN/STATE/COUNTY/SIC1 }\end{array}$ & FLAG_E_S_C_1 & 00047 & 1 & A/N \\
\hline
\end{tabular}

CHARACTERISTICS

Alrorithm
Sourcefile
Alternate documentation
VALUE TABLE

Flag

computed

see 04_brb.sas

n.a. 
CHAPTER 2. BUSINESS REGISTER BRIDGE (BRB)

\begin{tabular}{l|l|l|l|l}
\hline \multicolumn{1}{c|}{ Field name } & $\begin{array}{l}\text { Data dictionary } \\
\text { reference name }\end{array}$ & $\begin{array}{l}\text { Starting } \\
\text { position }\end{array}$ & $\begin{array}{l}\text { Field } \\
\text { size }\end{array}$ & $\begin{array}{l}\text { Data } \\
\text { type }\end{array}$ \\
\hline $\begin{array}{l}\text { Match flag } \\
\text { EIN/STATE/COUNTY/SIC2 }\end{array}$ & FLAG_E_S_C_2 & 00046 & 1 & A/N \\
\hline
\end{tabular}

\section{CHARACTERISTICS}

Units
Algorithm
Sourcefile
Alternate Documentation

L: only in LEHD

M. matched in EIN/STATE/COUNTY/SIC2 level
Flag

computed

see 04_brb.sas

n.a. 
CHAPTER 2. BUSINESS REGISTER BRIDGE (BRB)

\begin{tabular}{c|l|l|l|l}
\hline \multicolumn{1}{c|}{ Field name } & $\begin{array}{l}\text { Data dictionary } \\
\text { reference name }\end{array}$ & $\begin{array}{l}\text { Starting } \\
\text { position }\end{array}$ & $\begin{array}{l}\text { Field } \\
\text { size }\end{array}$ & $\begin{array}{l}\text { Data } \\
\text { type }\end{array}$ \\
\hline $\begin{array}{l}\text { Match flag } \\
\text { EIN/STATE/COUNTY/SIC3 }\end{array}$ & FLAG_E_S_C_3 & 00045 & 1 & A/N \\
\hline
\end{tabular}

CHARACTERISTICS

Alrorithm
Sourcefile
Alternate documentation
VALUE TABLE

Flag

computed

see 04_brb.sas

n.a. 
CHAPTER 2. BUSINESS REGISTER BRIDGE (BRB)

\begin{tabular}{l|l|l|l|l}
\hline \multicolumn{1}{c|}{ Field name } & $\begin{array}{l}\text { Data dictionary } \\
\text { reference name }\end{array}$ & $\begin{array}{l}\text { Starting } \\
\text { position }\end{array}$ & $\begin{array}{l}\text { Field } \\
\text { size }\end{array}$ & $\begin{array}{l}\text { Data } \\
\text { type }\end{array}$ \\
\hline $\begin{array}{l}\text { Match flag } \\
\text { EIN/STATE/COUNTY/SIC4 }\end{array}$ & FLAG_E_S_C_4 & 00044 & 1 & A/N \\
\hline
\end{tabular}

\section{CHARACTERISTICS}

Units
Algorithm
Sourcefile
Alternate Documentation

L: only in LEHD

M. matched in EIN/STATE/COUNTY/SIC4 level
Flag

computed

see 04_brb.sas

n.a. 
CHAPTER 2. BUSINESS REGISTER BRIDGE (BRB)

\begin{tabular}{c|l|l|l|l}
\hline Field name & $\begin{array}{l}\text { Data dictionary } \\
\text { reference name }\end{array}$ & $\begin{array}{l}\text { Starting } \\
\text { position }\end{array}$ & $\begin{array}{l}\text { Field } \\
\text { size }\end{array}$ & $\begin{array}{l}\text { Data } \\
\text { type }\end{array}$ \\
\hline Match flag EIN/STATE/SIC1 level & FLAG_E_S_1 & 00052 & 1 & A/N \\
\hline
\end{tabular}

\section{CHARACTERISTICS}

Ulits
Algorithm
Sourcefile
Alternate documentation
VALUE TABLE

B: only in BR

L: only in LEHD

M: matched in EIN/STATE/SIC1 level
Flag

computed

see 04_brb.sas

n.a. 
CHAPTER 2. BUSINESS REGISTER BRIDGE (BRB)

\begin{tabular}{|c|c|c|c|c|}
\hline Field name & $\begin{array}{l}\text { Data dictionary } \\
\text { reference name }\end{array}$ & $\begin{array}{l}\text { Starting } \\
\text { position }\end{array}$ & $\begin{array}{l}\text { Field } \\
\text { size }\end{array}$ & $\begin{array}{l}\text { Data } \\
\text { type }\end{array}$ \\
\hline Match flag EIN/STATE/SIC2 level & FLAG_E_S_2 & 00051 & 1 & $\mathrm{~A} / \mathrm{N}$ \\
\hline
\end{tabular}

\section{CHARACTERISTICS}

$\begin{array}{r}\text { Units } \\ \text { Algorithm } \\ \text { Sourcefile } \\ \text { Alternate documentation } \\ \text { VALUE TABLE } \\ \hline\end{array}$

B: only in BR

L: only in LEHD

M: matched in EIN/STATE/SIC2 level
Flag

computed

see 04_brb.sas

n.a. position 1 type 
CHAPTER 2. BUSINESS REGISTER BRIDGE (BRB)

\begin{tabular}{c|l|l|l|l}
\hline Field name & $\begin{array}{l}\text { Data dictionary } \\
\text { reference name }\end{array}$ & $\begin{array}{l}\text { Starting } \\
\text { position }\end{array}$ & $\begin{array}{l}\text { Field } \\
\text { size }\end{array}$ & $\begin{array}{l}\text { Data } \\
\text { type }\end{array}$ \\
\hline Match flag EIN/STATE/SIC3 level & FLAG_E_S_3 & 00050 & 1 & A/N \\
\hline
\end{tabular}

\section{CHARACTERISTICS}

Ulits
Algorithm
Sourcefile
Alternate documentation
VALUE TABLE

B: only in BR

L: only in LEHD

M: matched in EIN/STATE/SIC3 level
Flag

computed

see 04_brb.sas

n.a. 
CHAPTER 2. BUSINESS REGISTER BRIDGE (BRB)

\begin{tabular}{|c|c|c|c|c|}
\hline Field name & $\begin{array}{l}\text { Data dictionary } \\
\text { reference name }\end{array}$ & $\begin{array}{l}\text { Starting } \\
\text { position }\end{array}$ & $\begin{array}{l}\text { Field } \\
\text { size }\end{array}$ & $\begin{array}{l}\text { Data } \\
\text { type }\end{array}$ \\
\hline Match flag EIN/STATE/SIC4 level & FLAG_E_S_4 & 00049 & 1 & $\mathrm{~A} / \mathrm{N}$ \\
\hline
\end{tabular}

\section{CHARACTERISTICS}

Ulits
Algorithm
Sourcefile
Alternate documentation
VALUE TABLE

B: only in BR

L: only in LEHD

M: matched in EIN/STATE/SIC4 level
Flag

computed

see 04_brb.sas

n.a. 
CHAPTER 2. BUSINESS REGISTER BRIDGE (BRB)

\begin{tabular}{c|l|l|l|l}
\hline Field name & $\begin{array}{l}\text { Data dictionary } \\
\text { reference name }\end{array}$ & $\begin{array}{l}\text { Starting } \\
\text { position }\end{array}$ & $\begin{array}{l}\text { Field } \\
\text { size }\end{array}$ & $\begin{array}{l}\text { Data } \\
\text { type }\end{array}$ \\
\hline One-digit SIC code & SIC1 & 00043 & 1 & $\mathrm{~A} / \mathrm{N}$ \\
\hline
\end{tabular}

CHARACTERISTICS

Ulits
Algorithm
Sourcefile
Alternate documentation
VALUE TABLE

Industry derived $\operatorname{sic} 1=\operatorname{substr}(\operatorname{sic} 4,1,1)$

n.a. 
CHAPTER 2. BUSINESS REGISTER BRIDGE (BRB)

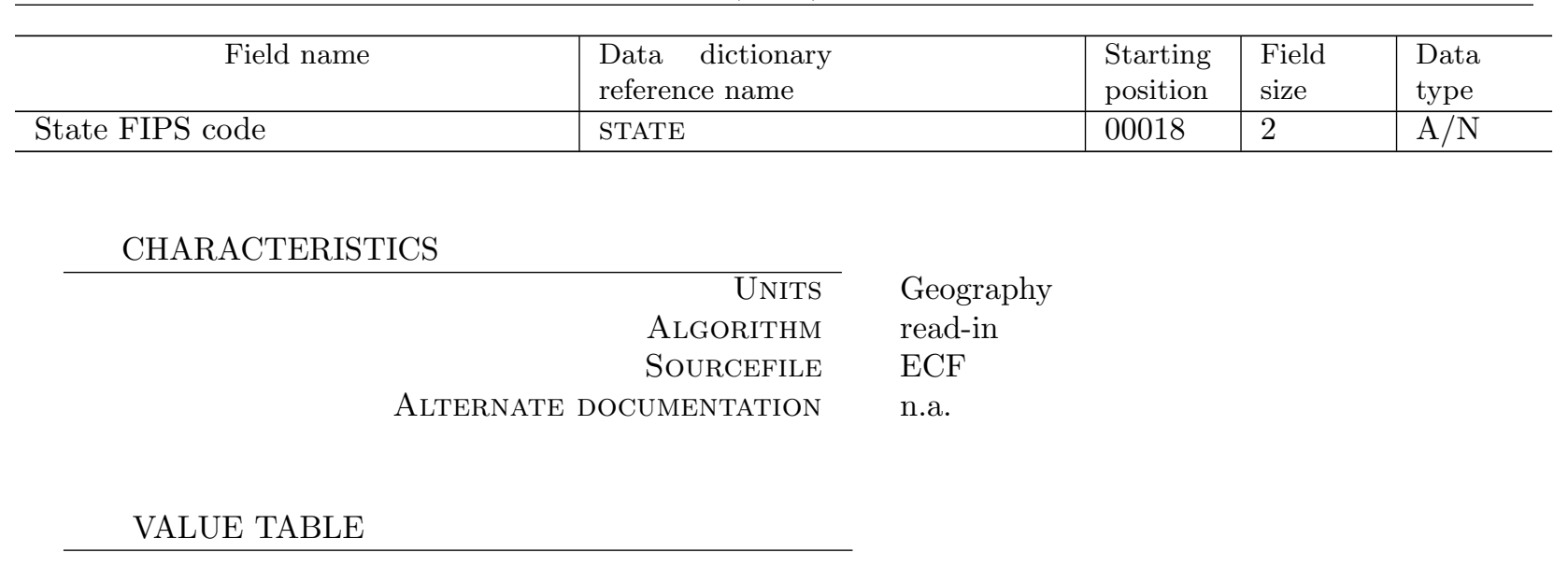


CHAPTER 2. BUSINESS REGISTER BRIDGE (BRB)

\begin{tabular}{c|l|l|l|l}
\hline \multicolumn{1}{c|}{ Field name } & $\begin{array}{l}\text { Data dictionary } \\
\text { reference name }\end{array}$ & $\begin{array}{l}\text { Starting } \\
\text { position }\end{array}$ & $\begin{array}{l}\text { Field } \\
\text { size }\end{array}$ & $\begin{array}{l}\text { Data } \\
\text { type }\end{array}$ \\
\hline Three-digit SIC Code & SIC3 & 00038 & 3 & A/N \\
\hline
\end{tabular}

CHARACTERISTICS

Ulits
Algorithm
Sourcefile
Alternate documentation
VALUE TABLE

Industry derived

$\operatorname{sic} 3=\operatorname{substr}(\operatorname{sic} 4,1,3)$

n.a. 
CHAPTER 2. BUSINESS REGISTER BRIDGE (BRB)

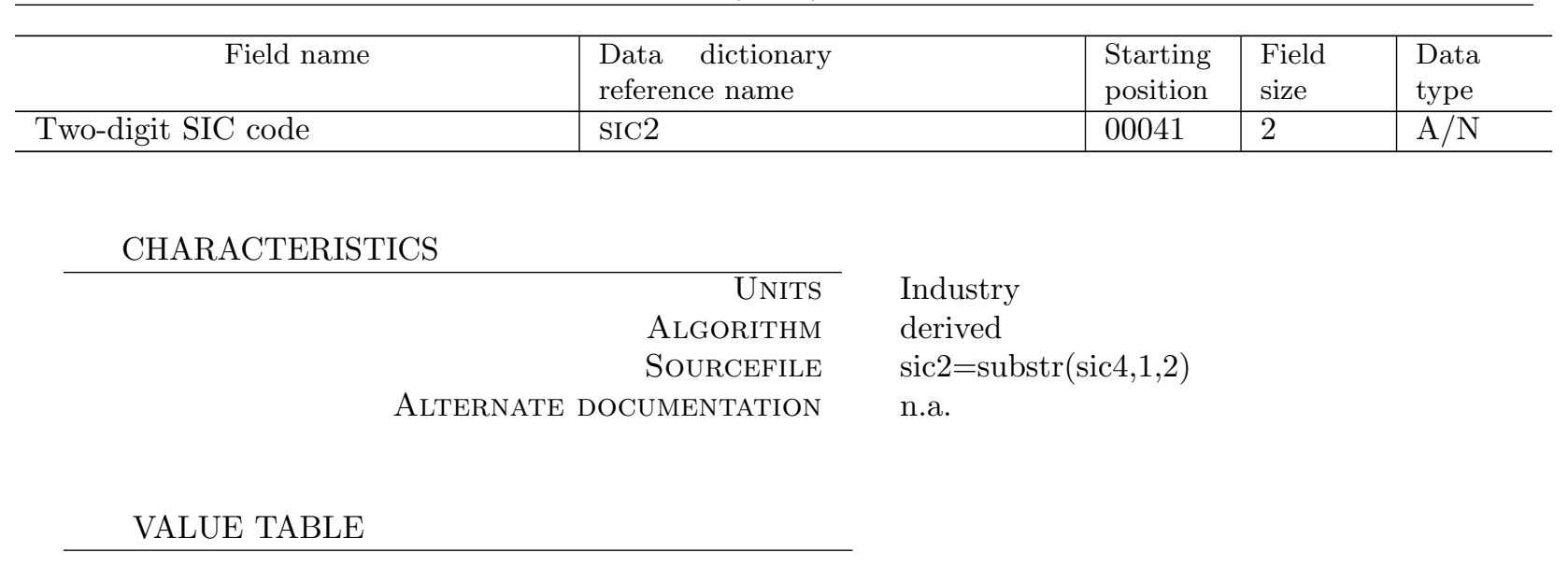


CHAPTER 2. BUSINESS REGISTER BRIDGE (BRB)

\begin{tabular}{l|l|l|l|l}
\hline \multicolumn{1}{c|}{ Field name } & $\begin{array}{l}\text { Data dictionary } \\
\text { reference name }\end{array}$ & $\begin{array}{l}\text { Starting } \\
\text { position }\end{array}$ & $\begin{array}{l}\text { Field } \\
\text { size }\end{array}$ & $\begin{array}{l}\text { Data } \\
\text { type }\end{array}$ \\
\hline Year YYYY & YEAR & 00000 & 8 & $\mathrm{~N}$ \\
\hline
\end{tabular}

\section{CHARACTERISTICS}

$\begin{array}{rll}\text { Units } & & \text { Calendar } \\ \text { Algorithm } & & \text { read-in } \\ \text { Sourcefile } & & \text { ECF and BR } \\ \text { Alternate documentation } & \text { n.a. }\end{array}$


CHAPTER 2. BUSINESS REGISTER BRIDGE (BRB)

\subsubsection{BR list}

\begin{tabular}{r|l|l|l|l}
\hline \multicolumn{1}{c|}{ Field name } & $\begin{array}{l}\text { Data dictionary } \\
\text { reference name }\end{array}$ & $\begin{array}{l}\text { Starting } \\
\text { position }\end{array}$ & $\begin{array}{l}\text { Field } \\
\text { size }\end{array}$ & $\begin{array}{l}\text { Data } \\
\text { type }\end{array}$ \\
\hline Census File Number & CFN & 00008 & 10 & A/N \\
\hline
\end{tabular}

CHARACTERISTICS

$\begin{array}{rll}\text { Units } & & \text { Identifier } \\ \text { Algorithm } & \text { read-in } \\ \text { Sourcefile } & \text { BR } \\ \text { Alternate Documentation } & \text { n.a. }\end{array}$


CHAPTER 2. BUSINESS REGISTER BRIDGE (BRB)

\begin{tabular}{c|l|l|l|l}
\hline \multicolumn{1}{c|}{ Field name } & $\begin{array}{l}\text { Data dictionary } \\
\text { reference name }\end{array}$ & $\begin{array}{l}\text { Starting } \\
\text { position }\end{array}$ & $\begin{array}{l}\text { Field } \\
\text { size }\end{array}$ & $\begin{array}{l}\text { Data } \\
\text { type }\end{array}$ \\
\hline Employer Identification Number & EIN & 00036 & 9 & A/N \\
\hline
\end{tabular}

\section{CHARACTERISTICS}

$\begin{array}{rll}\text { Units } & & \text { Identifier } \\ \text { Algorithm } & \text { read-in } \\ \text { Sourcefile } & \text { BR } \\ \text { Alternate Documentation } & \text { n.a. }\end{array}$


CHAPTER 2. BUSINESS REGISTER BRIDGE (BRB)

\begin{tabular}{|c|c|c|c|c|c|}
\hline Field name & \multicolumn{2}{|l|}{$\begin{array}{l}\text { Data dictionary } \\
\text { reference name }\end{array}$} & $\begin{array}{l}\text { Starting } \\
\text { position }\end{array}$ & $\begin{array}{l}\text { Field } \\
\text { size }\end{array}$ & $\begin{array}{l}\text { Data } \\
\text { type }\end{array}$ \\
\hline Enterprise identifier & \multicolumn{2}{|l|}{ ALPHA } & 00018 & 10 & $\mathrm{~A} / \mathrm{N}$ \\
\hline \multicolumn{6}{|c|}{ CHARACTERISTICS } \\
\hline & $\begin{array}{r}\text { Units } \\
\text { AlgORITHM } \\
\text { SouRCEFILE } \\
\text { DOCUMENTATION }\end{array}$ & $\begin{array}{l}\text { Identifier } \\
\text { read-in } \\
\text { BR } \\
\text { n.a. }\end{array}$ & & & \\
\hline
\end{tabular}


CHAPTER 2. BUSINESS REGISTER BRIDGE (BRB)

\begin{tabular}{c|l|l|l|l}
\hline \multicolumn{1}{c|}{ Field name } & $\begin{array}{l}\text { Data dictionary } \\
\text { reference name }\end{array}$ & $\begin{array}{l}\text { Starting } \\
\text { position }\end{array}$ & $\begin{array}{l}\text { Field } \\
\text { size }\end{array}$ & $\begin{array}{l}\text { Data } \\
\text { type }\end{array}$ \\
\hline FIPS State SS & STATE & 00028 & 2 & A/N \\
\hline
\end{tabular}

\section{CHARACTERISTICS}

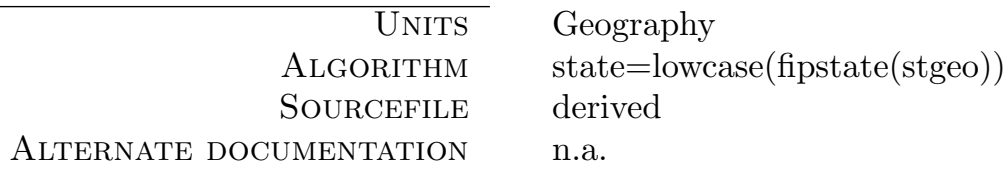


CHAPTER 2. BUSINESS REGISTER BRIDGE (BRB)

\begin{tabular}{c|l|l|l|l}
\hline \multicolumn{1}{c|}{ Field name } & $\begin{array}{l}\text { Data dictionary } \\
\text { reference name }\end{array}$ & $\begin{array}{l}\text { Starting } \\
\text { position }\end{array}$ & $\begin{array}{l}\text { Field } \\
\text { size }\end{array}$ & $\begin{array}{l}\text { Data } \\
\text { type }\end{array}$ \\
\hline FIPS State $x x$ & STGEO & 00034 & 2 & A/N \\
\hline
\end{tabular}

\section{CHARACTERISTICS}

$\begin{array}{rll}\text { Units } & & \text { Geography } \\ \text { Algorithm } & \text { read-in } \\ \text { SOURCEFILE } & \text { BR }\end{array}$


CHAPTER 2. BUSINESS REGISTER BRIDGE (BRB)

\begin{tabular}{c|l|l|l|l}
\hline \multicolumn{1}{c|}{ Field name } & $\begin{array}{l}\text { Data dictionary } \\
\text { reference name }\end{array}$ & $\begin{array}{l}\text { Starting } \\
\text { position }\end{array}$ & $\begin{array}{l}\text { Field } \\
\text { size }\end{array}$ & $\begin{array}{l}\text { Data } \\
\text { type }\end{array}$ \\
\hline FIPS county xxx & COUNTY & 00055 & 3 & A/N \\
\hline
\end{tabular}

\section{CHARACTERISTICS}

$\begin{array}{rll}\text { Units } & & \text { Geography } \\ \text { Algorithm } & \text { read-in } \\ \text { SourCEFILE } & \text { BR } \\ \text { ALternate DoCUMENTATION } & \text { n.a. }\end{array}$

Alternate Documentation n.a. 
CHAPTER 2. BUSINESS REGISTER BRIDGE (BRB)

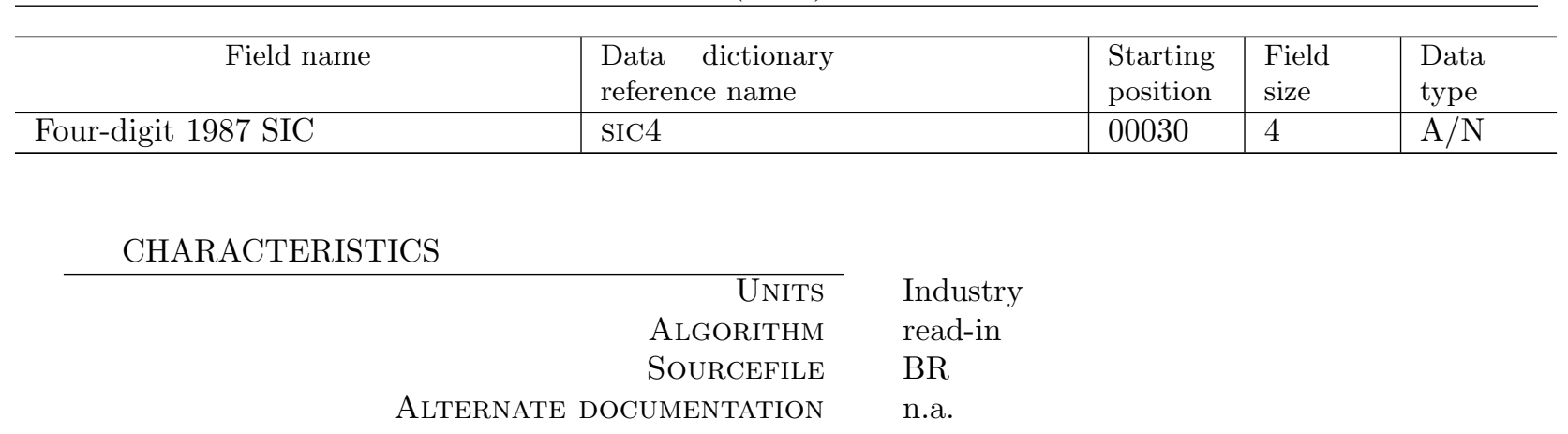


CHAPTER 2. BUSINESS REGISTER BRIDGE (BRB)

\begin{tabular}{c|l|l|l|l}
\hline \multicolumn{1}{c|}{ Field name } & $\begin{array}{l}\text { Data dictionary } \\
\text { reference name }\end{array}$ & $\begin{array}{l}\text { Starting } \\
\text { position }\end{array}$ & $\begin{array}{l}\text { Field } \\
\text { size }\end{array}$ & $\begin{array}{l}\text { Data } \\
\text { type }\end{array}$ \\
\hline Permanent Plant Number & PPN & 00045 & 10 & A/N \\
\hline
\end{tabular}

\section{CHARACTERISTICS}

$\begin{array}{rll}\text { Units } & & \text { Identifier } \\ \text { Algorithm } & \text { read-in } \\ \text { Sourcefile } & \text { BR } \\ \text { Alternate Documentation } & \text { n.a. }\end{array}$


CHAPTER 2. BUSINESS REGISTER BRIDGE (BRB)

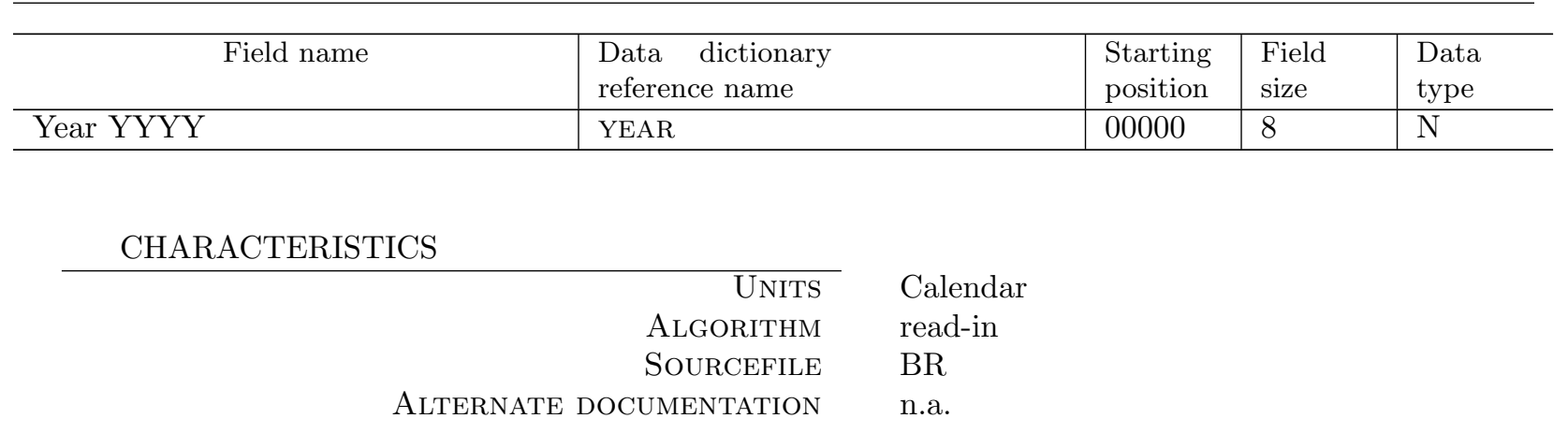


CHAPTER 2. BUSINESS REGISTER BRIDGE (BRB)

\subsubsection{ECF list}

\begin{tabular}{r|l|l|l|l}
\hline \multicolumn{1}{c|}{ Field name } & $\begin{array}{l}\text { Data dictionary } \\
\text { reference name }\end{array}$ & $\begin{array}{l}\text { Starting } \\
\text { position }\end{array}$ & $\begin{array}{l}\text { Field } \\
\text { size }\end{array}$ & $\begin{array}{l}\text { Data } \\
\text { type }\end{array}$ \\
\hline Cleaned EIN & EIN & 00026 & 9 & A/N \\
\hline
\end{tabular}

\section{CHARACTERISTICS}

$\begin{array}{rll}\text { Units } & & \text { Identifier } \\ \text { Algorithm } & \text { read-in } \\ \text { SourCEFILE } & \text { ECF (availability differs across states) } \\ \text { Alternate DOCUMENTATION } & \text { ECF documentation }\end{array}$

Identifier

ECF (availability differs across states)

ECF documentation 
CHAPTER 2. BUSINESS REGISTER BRIDGE (BRB)

\begin{tabular}{|c|c|c|c|c|}
\hline Field name & $\begin{array}{l}\text { Data dictionary } \\
\text { reference name }\end{array}$ & $\begin{array}{l}\text { Starting } \\
\text { position }\end{array}$ & $\begin{array}{l}\text { Field } \\
\text { size }\end{array}$ & $\begin{array}{l}\text { Data } \\
\text { type }\end{array}$ \\
\hline Cleaned ES202 FIPS County CCC & COUNTY & 00023 & 3 & $\mathrm{~A} / \mathrm{N}$ \\
\hline
\end{tabular}

\section{CHARACTERISTICS}

$\begin{aligned} \text { Units } & \text { Geography } \\ \text { Algorithm } & \text { read-in } \\ \text { SourCEFILE } & \text { ECF } \\ \text { ALtERnATE DOCUMENTATION } & \text { ECF documentation }\end{aligned}$


CHAPTER 2. BUSINESS REGISTER BRIDGE (BRB)

\begin{tabular}{c|l|l|l|l}
\hline \multicolumn{1}{c|}{ Field name } & $\begin{array}{l}\text { Data dictionary } \\
\text { reference name }\end{array}$ & $\begin{array}{l}\text { Starting } \\
\text { position }\end{array}$ & $\begin{array}{l}\text { Field } \\
\text { size }\end{array}$ & $\begin{array}{l}\text { Data } \\
\text { type }\end{array}$ \\
\hline Cleaned SIC Code IIII & SIC4 & 00019 & 4 & A/N \\
\hline
\end{tabular}

\section{CHARACTERISTICS}

$\begin{array}{rll}\text { Units } & & \text { Industry } \\ \text { Algorithm } & \text { read-in } \\ \text { SourCEFILE } & \text { ECF } \\ \text { Alternate DOCUMENTATION } & \text { ECF documentation }\end{array}$


CHAPTER 2. BUSINESS REGISTER BRIDGE (BRB)

\begin{tabular}{c|l|l|l|l}
\hline \multicolumn{1}{c|}{ Field name } & $\begin{array}{l}\text { Data dictionary } \\
\text { reference name }\end{array}$ & $\begin{array}{l}\text { Starting } \\
\text { position }\end{array}$ & $\begin{array}{l}\text { Field } \\
\text { size }\end{array}$ & $\begin{array}{l}\text { Data } \\
\text { type }\end{array}$ \\
\hline ES202 FIPS State SS & STGEO & 00017 & 2 & A/N \\
\hline
\end{tabular}

\section{CHARACTERISTICS}

$\begin{array}{rll}\text { Units } & & \text { Geography } \\ \text { Algorithm } & & \text { rename es_state=stgeo } \\ \text { SourCefile } & & \text { ECF } \\ \text { Alternate documentation } & & \text { ECF documentation }\end{array}$


CHAPTER 2. BUSINESS REGISTER BRIDGE (BRB)

\begin{tabular}{c|l|l|l|l}
\hline \multicolumn{1}{c|}{ Field name } & $\begin{array}{l}\text { Data dictionary } \\
\text { reference name }\end{array}$ & $\begin{array}{l}\text { Starting } \\
\text { position }\end{array}$ & $\begin{array}{l}\text { Field } \\
\text { size }\end{array}$ & $\begin{array}{l}\text { Data } \\
\text { type }\end{array}$ \\
\hline FIPS State SS & STATE & 00035 & 2 & A/N \\
\hline
\end{tabular}

\section{CHARACTERISTICS}

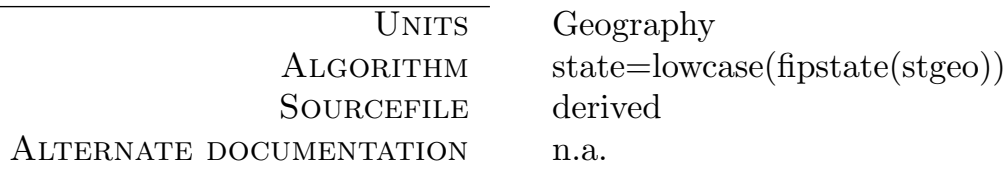


CHAPTER 2. BUSINESS REGISTER BRIDGE (BRB)

\begin{tabular}{|c|c|c|c|c|}
\hline Field name & $\begin{array}{l}\text { Data dictionary } \\
\text { reference name }\end{array}$ & $\begin{array}{l}\text { Starting } \\
\text { position }\end{array}$ & $\begin{array}{l}\text { Field } \\
\text { size }\end{array}$ & $\begin{array}{l}\text { Data } \\
\text { type }\end{array}$ \\
\hline Quarter QQ & QUARTER & 00040 & 3 & $\mathrm{~N}$ \\
\hline
\end{tabular}

\section{CHARACTERISTICS}

$\begin{array}{rll}\text { Units } & & \text { Calendar } \\ \text { Algorithm } & & \text { read-in } \\ \text { SourCefile } & \text { ECF } \\ \text { Alternate documentation } & \text { n.a. }\end{array}$


CHAPTER 2. BUSINESS REGISTER BRIDGE (BRB)

\begin{tabular}{c|l|l|l|l}
\hline \multicolumn{1}{c|}{ Field name } & $\begin{array}{l}\text { Data dictionary } \\
\text { reference name }\end{array}$ & $\begin{array}{l}\text { Starting } \\
\text { position }\end{array}$ & $\begin{array}{l}\text { Field } \\
\text { size }\end{array}$ & $\begin{array}{l}\text { Data } \\
\text { type }\end{array}$ \\
\hline State Employer ID Number & SEIN & 00000 & 12 & A/N \\
\hline
\end{tabular}

\section{CHARACTERISTICS}

$\begin{array}{rlrl}\text { Units } & & \text { (State-specific) Identifier } \\ \text { Algorithm } & \text { read-in } \\ \text { SourCEFILE } & \text { ECF } \\ \text { ALternate DoCUMENTATION } & \text { ECF documentation }\end{array}$


CHAPTER 2. BUSINESS REGISTER BRIDGE (BRB)

\begin{tabular}{c|l|l|l|l}
\hline \multicolumn{1}{c|}{ Field name } & $\begin{array}{l}\text { Data dictionary } \\
\text { reference name }\end{array}$ & $\begin{array}{l}\text { Starting } \\
\text { position }\end{array}$ & $\begin{array}{l}\text { Field } \\
\text { size }\end{array}$ & $\begin{array}{l}\text { Data } \\
\text { type }\end{array}$ \\
\hline State UI Reporting Unit Number & SEINUNIT & 00012 & 5 & A/N \\
\hline
\end{tabular}

\section{CHARACTERISTICS}

$\begin{array}{rll}\text { Units } & & \text { (State-specific) Identifier } \\ \text { Algorithm } & \text { read-in } \\ \text { SourCEFILE } & \text { ECF } \\ \text { Alternate DoCUMENTATION } & \text { ECF documentation }\end{array}$


CHAPTER 2. BUSINESS REGISTER BRIDGE (BRB)

\begin{tabular}{l|l|l|l|l}
\hline \multicolumn{1}{c|}{ Field name } & $\begin{array}{l}\text { Data dictionary } \\
\text { reference name }\end{array}$ & $\begin{array}{l}\text { Starting } \\
\text { position }\end{array}$ & $\begin{array}{l}\text { Field } \\
\text { size }\end{array}$ & $\begin{array}{l}\text { Data } \\
\text { type }\end{array}$ \\
\hline Year YYYY & YEAR & 00037 & 3 & $\mathrm{~N}$ \\
\hline
\end{tabular}

\section{CHARACTERISTICS}

$\begin{aligned} \text { Units } & \text { Calendar } \\ \text { Algorithm } & \text { read-in } \\ \text { SourCEFILE } & \text { ECF } \\ \text { Alternate DOCUMENTATION } & \text { ECF documentation }\end{aligned}$


CHAPTER 2. BUSINESS REGISTER BRIDGE (BRB)

2.5.4 Summary information on datasets

Table 2.47: File information for BRB

\begin{tabular}{|c|c|c|c|c|c|c|c|}
\hline State & & Group & $\begin{array}{r}\text { Number of } \\
\text { datafiles }\end{array}$ & Records & $\begin{array}{r}\text { Filesizes } \\
(\mathrm{MB})\end{array}$ & Start & End \\
\hline National & US & $\mathrm{BRB}$ & 3 & $450,754,439$ & $27,952.56$ & n.a. & n.a. \\
\hline
\end{tabular}


CHAPTER 2. BUSINESS REGISTER BRIDGE (BRB)

\subsection{NOTES}




\section{Chapter 3. Employer Characteristics File (ECF)}

\subsection{OVERVIEW}

\subsubsection{General Overview}

The Employer Characteristics File (ECF) consolidates most firm level information (size, location, industry, etc.) into two easily accessible files. The firm or SEIN level file contains one record for every YEAR QUARTER a firm is present in either the ES-202 or the UI, with more detailed information available for the establishments of multi-unit firms in the SEIN SEINUNIT file. The SEIN file is built up from the SEINUNIT file and contains no additional information, but should be viewed merely as an easier and/or more efficient way to access firm level data.

\subsubsection{Input Files}

- The ES202 data from the states is the primary input to the ECF file creation process.

- UI data is also used to supplement information on the ES202. As part of the creation of the Employment History Files (EHF), ehf_sein_employment is created. This file contains E (end of period employment), $\mathrm{B}$ (beginning of period employment), $\mathrm{M}$ (employed anytime in the quarter), and W1 (total wages) calculated similarly to the same measures on the QWI (see Abowd et al., 2006, 2009).

- GAL data containing lat/long coordinates of the establishments, plus county, wib and pmsa geo also.

- Existing files with permanent distortion factors must be available if data for the state has been officially released. (these files are not available in the RDC network.

- SIC and NAICS impute datasets: available upon demand.

- BLS-derived control totals, produced by the EHF.

\subsubsection{Program Overview}

First data is read in from the yearly ES202 files and stacked one on top of the other. General and state specific consistency checks are then performed. The COUNTY, NAICS, and EIN data are checked for invalid values. The SIC invalid check is a little more sophisticated. If a 4 digit SIC code is present, but is not valid, then the SIC code undergoes a conditional impute based on the first 2 or 3 digits. If the first 2 or 3 digits are not valid either, then SIC is set to missing (this value will eventually be filled).

The ES202 data contains a "master" record for multi-unit firms that must be removed. Information in the master record is preserved if data is not available in the establishment records (data is initially allocated equally to each establishment). Various inconsistencies in the record structure are also dealt with, such as 2 records (master and establishment) appearing for a single-unit.

The UI data is integrated with the ES202 data and totals are calculated at the SEIN YEAR QUARTER level. 
CHAPTER 3. EMPLOYER CHARACTERISTICS FILE (ECF)

Using both UI and ES202 data a "best" series of variables for payroll and employment is created.

The allocation process implemented above (master to establishments) does not incorporate any information on the structure of the firm. A flat prior is used in the allocation process (each establishment is assumed to have equal employment and payroll). We improve on this by examining firms with allocated data that previously reported as a multi-unit. The structure of their reports from a previous quarter is then used to allocate payroll and employment. The new records are integrated back into the data, hopefully improving longitudinal consistency at the establishment level.

At this point, the SEIN YEAR QUARTER SEINUNIT dataset record structure is finalized.

The GAL is brought into the ECF (this used to be the separate LEG process).

The COUNTY, SIC, NAICS, and EIN data are transformed from long to wide format for each SEINUNIT. This dataset is used to fill missing values in these variables with information from other periods for the same establishment.

The modal COUNTY, SIC, NAICS, OWNER_CODE, and EIN are calculated (both establishment and employment weighted) for each SEIN in a given YEAR and QUARTER.

The SEIN level mode variables (SIC, NAICS, etc) are then transformed from long to wide and the missing values are filled with data from the closest YEAR and QUARTER, if available.

At this point, if an SEIN mode variable has a missing value, then that missing value must be present for every YEAR and QUARTER. The distribution of employment across 4 digit SIC in 1997 is calculated and is used to impute the industry code for each SEIN with missing SIC. These SIC codes are also assigned to the SEINUNIT level data.

The weights are calculated, based on the expanded BLS controltotals acquired from the EHF.

The final step is to apply fuzz (noise distortion) factors to each dataset. The fuzz factor process is done separately for the SEIN and the SEINUNIT data. Once this is completed the datasets are written to their final location and the master fuzz files are updated.

\subsection{ECF FILES AND TITLE 26 IN THE RDC ENVIRONMENT}

Because some data elements on the internal-use ECF are considered Title 26-protected, the structure of the files has been slightly modified for the RDC environment to facilitate and streamline project proposals by clearly identifying files without any Title 26-protected data (from Fall 2006 onwards).

All Title 26-protected information has been stripped out of the main ECF files, and stored in strip files with the same record count, but only those variables that are Title 26 protected.

Users will find all Title 13-protected content in the directories

ecf/ecf_XX_sein.sas7bdat

ecf/ecf_XX_seinunit.sas7bdat

Title 26-protected content can be found in

ecft26/ecf_XX_sein_t26.sas7bdat

ecft26/ecf_XX_seinunit_t26.sas7bdat

Sample code to merge the two types of files back together again is listed in Section 3.5. 
CHAPTER 3. EMPLOYER CHARACTERISTICS FILE (ECF)

\subsection{DATA SET DESCRIPTIONS}

\subsubsection{Naming scheme}

There are four files in the ECF/ECFT26 group:

ecf_zz_sein.sas7bdat

ecf_zz_seinunit.sas7bdat

ecf_zz_sein_t26.sas7bdat

ecf_zz_seinunit_t26.sas7bdat

ZZ stands for the state postal abbreviation. Files with _t26 contain FTI, are stored in separate subdirectories and require a separate set of permissions. They are of little use without the regular ECF group data. You will find zero-observation SAS datasets attached to this document - see the attachment tab.

\subsubsection{Data location}

The files are stored in two main directories, with state-specific subdirectories:

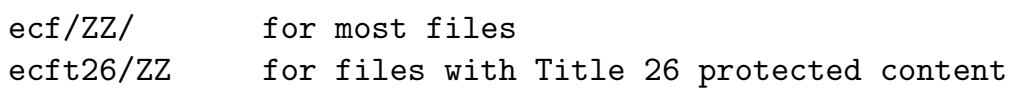

On the RDC network, both directories can be found under

/mixed/lehd/current 


\subsubsection{Main SEINUNIT dataset: ecf_zz_seinunit}

SEINUNIT-level file, with some SEIN-level variables available.

Record identifier: SEIN SEINUNIT YEAR QUARTER

Sort order: SEIN SEINUNIT YEAR QUARTER

File indexes: SEIN_YEAR_QUARTER_SEINUNIT (on ia64 systems only)

Entity "establishment" or SESA

Unique Entity Key SEIN SEINUNIT

Note that SEINUNIT is only unique within any given time period within SEIN.

\begin{tabular}{|c|c|c|c|c|}
\hline Field name & $\begin{array}{l}\text { Data dictionary } \\
\text { reference name }\end{array}$ & $\begin{array}{l}\text { Starting } \\
\text { position }\end{array}$ & $\begin{array}{l}\text { Field } \\
\text { size }\end{array}$ & $\begin{array}{l}\text { Data } \\
\text { type }\end{array}$ \\
\hline 0 if seinunit $=00000$ & SEINUNIT_TYPE & 00138 & 3 & $\mathrm{~N}$ \\
\hline $0=\mathrm{ok}, 1=$ not found, $2+$ found off $\mathrm{qtr}$ & ES_COUNTY_MISS & 00258 & 3 & $\mathrm{~N}$ \\
\hline $0=\mathrm{ok}, 1=$ not found, $2+$ found off $\mathrm{qtr}$ & ES_EIN_MISS & 00264 & 3 & $\mathrm{~N}$ \\
\hline $0=\mathrm{ok}, 1=$ not found, $2+$ found off $\mathrm{qtr}$ & ES_NAICS1997_MISS & 00240 & 3 & $\mathrm{~N}$ \\
\hline $0=\mathrm{ok}, 1=$ not found, $2+$ found off $\mathrm{qtr}$ & ES_NAICS2002_MISS & 00243 & 3 & $\mathrm{~N}$ \\
\hline $0=\mathrm{ok}, 1=$ not found, $2+$ found off $\mathrm{qtr}$ & ES_NAICS_AUX1997_MISS & 00246 & 3 & $\mathrm{~N}$ \\
\hline $0=\mathrm{ok}, 1=$ not found, $2+$ found off $\mathrm{qtr}$ & ES_NAICS_AUX2002_MISS & 00249 & 3 & $\mathrm{~N}$ \\
\hline $0=\mathrm{ok}, 1=$ not found, $2+$ found off $\mathrm{qtr}$ & ES_NAICS_ESO1997_MISS & 00318 & 3 & $\mathrm{~N}$ \\
\hline $0=\mathrm{ok}, 1=$ not found, $2+$ found off $\mathrm{qtr}$ & ES_NAICS_ESO2002_MISS & 00321 & 3 & $\mathrm{~N}$ \\
\hline $0=\mathrm{ok}, 1=$ not found, $2+$ found off $\mathrm{qtr}$ & ES_NAICS_FNL1997_MISS & 00324 & 3 & $\mathrm{~N}$ \\
\hline $0=\mathrm{ok}, 1=$ not found, $2+$ found off $\mathrm{qtr}$ & ES_NAICS_FNL2002_MISS & 00327 & 3 & $\mathrm{~N}$ \\
\hline $0=\mathrm{ok}, 1=$ not found, $2+$ found off $\mathrm{qtr}$ & ES_NAICS_IMP1997_MISS & 00016 & 8 & $\mathrm{~N}$ \\
\hline $0=\mathrm{ok}, 1=$ not found, $2+$ found off $\mathrm{qtr}$ & ES_NAICS_IMP2002_MISS & 00024 & 8 & $\mathrm{~N}$ \\
\hline $0=\mathrm{ok}, 1=$ not found, $2+$ found off $\mathrm{qtr}$ & ES_NAICS_LDB1997_MISS & 00252 & 3 & $\mathrm{~N}$ \\
\hline $0=\mathrm{ok}, 1=$ not found, $2+$ found off $\mathrm{qtr}$ & ES_NAICS_LDB2002_MISS & 00255 & 3 & $\mathrm{~N}$ \\
\hline $0=\mathrm{ok}, 1=$ not found, $2+$ found off $\mathrm{qtr}$ & ES_OWNER_CODE_MISS & 00261 & 3 & $\mathrm{~N}$ \\
\hline $0=\mathrm{ok}, 1=$ not found, $2+$ found off $\mathrm{qtr}$ & ES_SIC_MISS & 00237 & 3 & $\mathrm{~N}$ \\
\hline $1=\mathrm{UI}$ only, $2=202$ only, $3=$ both & SOURCE & 00189 & 3 & $\mathrm{~N}$ \\
\hline Auxiliary Code & AUXILIARY_CODE & 00543 & 1 & $\mathrm{~A} / \mathrm{N}$ \\
\hline Best SEIN UI Employment & EMP1_UI & 00096 & 4 & $\mathrm{~N}$ \\
\hline Best SEIN UI Employment & EMP2_UI & 00100 & 4 & $\mathrm{~N}$ \\
\hline Best SEIN UI Employment & EMP3_UI & 00104 & 4 & $\mathrm{~N}$ \\
\hline Best UI/202 Employment Month 1 & BEST_EMP1 & 00108 & 4 & $\mathrm{~N}$ \\
\hline Best UI/202 Employment Month 2 & BEST_EMP2 & 00112 & 4 & $\mathrm{~N}$ \\
\hline Best UI/202 Employment Month 3 & BEST_EMP3 & 00116 & 4 & $\mathrm{~N}$ \\
\hline Best UI/202 Wages & BEST_WAGES & 00206 & 5 & $\mathrm{~N}$ \\
\hline Cleaned 1997 NAICS Code NNNNNN & ES_NAICS1997 & 00657 & 6 & $\mathrm{~A} / \mathrm{N}$ \\
\hline Cleaned 1997 NAICS Code NNNNNN & ES_NAICS2002 & 00663 & 6 & $\mathrm{~A} / \mathrm{N}$ \\
\hline Cleaned 1997 NAICS Code NNNNNN & ES_NAICS_AUX1997 & 00669 & 6 & $\mathrm{~A} / \mathrm{N}$ \\
\hline Cleaned 1997 NAICS Code NNNNNN & ES_NAICS_LDB1997 & 00681 & 6 & $\mathrm{~A} / \mathrm{N}$ \\
\hline Cleaned 2002 NAICS Code NNNNNN & ES_NAICS_AUX2002 & 00675 & 6 & $\mathrm{~A} / \mathrm{N}$ \\
\hline Cleaned 2002 NAICS Code NNNNNN & ES_NAICS_LDB2002 & 00687 & 6 & $\mathrm{~A} / \mathrm{N}$ \\
\hline Cleaned EIN & ES_EIN & 00648 & 9 & $\mathrm{~A} / \mathrm{N}$ \\
\hline Cleaned ES202 FIPS County CCC & ES_COUNTY & 00645 & 3 & $\mathrm{~A} / \mathrm{N}$ \\
\hline Cleaned GEO FIPS County CCC & LEG_COUNTY & 00638 & 3 & $\mathrm{~A} / \mathrm{N}$ \\
\hline Cleaned GEO State SS & LEG_STATE & 00634 & 2 & $\mathrm{~A} / \mathrm{N}$ \\
\hline Cleaned OWNER_CODE O & ES_OWNER_CODE & 00693 & 1 & $\mathrm{~A} / \mathrm{N}$ \\
\hline Cleaned SIC Code II & ES_SIC_2 & 00927 & 2 & $\mathrm{~A} / \mathrm{N}$ \\
\hline Cleaned SIC Code III & ES_SIC_3 & 00929 & 3 & $\mathrm{~A} / \mathrm{N}$ \\
\hline Cleaned SIC Code IIII & ES_SIC & 00641 & 4 & $\mathrm{~A} / \mathrm{N}$ \\
\hline Cleaned SIC Division I & ES_SIC_DIV & 00942 & 1 & $\mathrm{~A} / \mathrm{N}$ \\
\hline Continuous Time YEAR QUARTER & YR_QTR & 00498 & 6 & $\mathrm{~A} / \mathrm{N}$ \\
\hline EIN in known IRD & VALID_EIN & 00223 & 3 & $\mathrm{~N}$ \\
\hline ES202 FIPS State SS & ES_STATE & 00636 & 2 & $\mathrm{~A} / \mathrm{N}$ \\
\hline ES202 Multi Unit Code & MULTI_UNIT_CODE & 00509 & 1 & $\mathrm{~A} / \mathrm{N}$ \\
\hline ES202 ONLY 1997 NAICS Code NNNNNN & ES_NAICS_ESO1997 & 00706 & 6 & $\mathrm{~A} / \mathrm{N}$ \\
\hline
\end{tabular}


CHAPTER 3. EMPLOYER CHARACTERISTICS FILE (ECF)

\begin{tabular}{|c|c|c|c|c|}
\hline Field name & $\begin{array}{l}\text { Data dictionary } \\
\text { reference name }\end{array}$ & $\begin{array}{l}\text { Starting } \\
\text { position }\end{array}$ & $\begin{array}{l}\text { Field } \\
\text { size }\end{array}$ & $\begin{array}{l}\text { Data } \\
\text { type }\end{array}$ \\
\hline ES202 ONLY 2002 NAICS Code NNNNNN & ES_NAICS_ESO2002 & 00712 & 6 & $\mathrm{~A} / \mathrm{N}$ \\
\hline Emp Mode Cleaned County & MODE_ES_COUNTY_EMP & 00814 & 3 & $\mathrm{~A} / \mathrm{N}$ \\
\hline Emp Mode Cleaned EIN & MODE_ES_EIN_EMP & 00817 & 9 & $\mathrm{~A} / \mathrm{N}$ \\
\hline Emp Mode Cleaned GEO COUNTY & MODE_LEG_COUNTY_EMP & 00886 & 3 & $\mathrm{~A} / \mathrm{N}$ \\
\hline Emp Mode Cleaned GEO COUNTY & MODE_LEG_SUBCTYGEO_EMP & 00899 & 10 & $\mathrm{~A} / \mathrm{N}$ \\
\hline Emp Mode Cleaned GEO MSAPMSA & MODE_LEG_MSAPMSA_EMP & 00871 & 8 & $\mathrm{~A} / \mathrm{N}$ \\
\hline Emp Mode Cleaned GEO STATE & MODE_LEG_STATE_EMP & 00881 & 2 & $\mathrm{~A} / \mathrm{N}$ \\
\hline Emp Mode Cleaned GEO WIB & MODE_LEG_WIB_EMP & 00857 & 6 & $\mathrm{~A} / \mathrm{N}$ \\
\hline Emp Mode Cleaned NAICS 1997 & MODE_ES_NAICS_ESO1997_EMP & 00826 & 6 & $\mathrm{~A} / \mathrm{N}$ \\
\hline Emp Mode Cleaned NAICS 1997 & MODE_ES_NAICS_FNL1997_EMP & 00838 & 6 & $\mathrm{~A} / \mathrm{N}$ \\
\hline Emp Mode Cleaned NAICS 2002 & MODE_ES_NAICS_ESO2002_EMP & 00832 & 6 & $\mathrm{~A} / \mathrm{N}$ \\
\hline Emp Mode Cleaned NAICS 2002 & MODE_ES_NAICS_FNL2002_EMP & 00844 & 6 & $\mathrm{~A} / \mathrm{N}$ \\
\hline Emp Mode Cleaned OWNER_CODE & MODE_ES_OWNER_CODE_EMP & 00850 & 1 & $\mathrm{~A} / \mathrm{N}$ \\
\hline Emp Mode Cleaned SIC & MODE_ES_SIC_EMP & 00810 & 4 & $\mathrm{~A} / \mathrm{N}$ \\
\hline Final 1997 NAICS Code NN & ES_NAICS_FNL1997_2 & 00932 & 2 & $\mathrm{~A} / \mathrm{N}$ \\
\hline Final 1997 NAICS Code NN & ES_NAICS_FNL2002_2 & 00937 & 2 & $\mathrm{~A} / \mathrm{N}$ \\
\hline Final 1997 NAICS Code NNN & ES_NAICS_FNL1997_3 & 00934 & 3 & $\mathrm{~A} / \mathrm{N}$ \\
\hline Final 1997 NAICS Code NNN & ES_NAICS_FNL2002_3 & 00939 & 3 & $\mathrm{~A} / \mathrm{N}$ \\
\hline Final 1997 NAICS Code NNNN & ES_NAICS_FNL1997_4 & 00943 & 6 & $\mathrm{~A} / \mathrm{N}$ \\
\hline Final 1997 NAICS Code NNNN & ES_NAICS_FNL2002_4 & 00949 & 4 & $\mathrm{~A} / \mathrm{N}$ \\
\hline Final 1997 NAICS Code NNNNN & ES_NAICS_FNL1997_5 & 00953 & 6 & $\mathrm{~A} / \mathrm{N}$ \\
\hline Final 1997 NAICS Code NNNNN & ES_NAICS_FNL2002_5 & 00959 & 5 & $\mathrm{~A} / \mathrm{N}$ \\
\hline Final 1997 NAICS Code NNNNNN & ES_NAICS_FNL1997 & 00694 & 6 & $\mathrm{~A} / \mathrm{N}$ \\
\hline Final 2002 NAICS Code NNNNNN & ES_NAICS_FNL2002 & 00700 & 6 & $\mathrm{~A} / \mathrm{N}$ \\
\hline Final GALID & LEG_GALID & 00619 & 15 & $\mathrm{~A} / \mathrm{N}$ \\
\hline First Quarter SEIN on 202 & MULTI_FIRST_QUARTER & 00160 & 3 & $\mathrm{~N}$ \\
\hline First Year SEIN on 202 & MULTI_FIRST_YEAR & 00157 & 3 & $\mathrm{~N}$ \\
\hline Flag, number of quarters to find geocodes & LEG_FLAG_GEO & 00234 & 3 & $\mathrm{~N}$ \\
\hline GALID of address on es 202 & ES_GALID & 00580 & 15 & $\mathrm{~A} / \mathrm{N}$ \\
\hline Indicator code Month 1 & EMPL_MONTH1_FLG & 00510 & 1 & $\mathrm{~A} / \mathrm{N}$ \\
\hline Indicator code Month 2 & EMPL_MONTH2_FLG & 00511 & 1 & $\mathrm{~A} / \mathrm{N}$ \\
\hline Indicator code Month 3 & EMPL_MONTH3_FLG & 00512 & 1 & $\mathrm{~A} / \mathrm{N}$ \\
\hline Indicator code Total wages & TOTAL_WAGES_FLG & 00513 & 1 & $\mathrm{~A} / \mathrm{N}$ \\
\hline Latitude, 6 implied decimal places & LEG_LATITUDE & 00000 & 8 & $\mathrm{~N}$ \\
\hline Letters a-z,A-Z in EIN & EIN_BAD & 00217 & 3 & $\mathrm{~N}$ \\
\hline Longitude, 6 implied decimal places & LEG_LONGITUDE & 00008 & 8 & $\mathrm{~N}$ \\
\hline MSAPMSA metro area code, mmmmmmmm & LEG_MSAPMSA & 00595 & 8 & $\mathrm{~A} / \mathrm{N}$ \\
\hline MULTI ever ES202 wages & EVER_WAGES & 00166 & 3 & $\mathrm{~N}$ \\
\hline MULTI ever has ES202 month 1 employment & EVER_EMP1 & 00169 & 3 & $\mathrm{~N}$ \\
\hline MULTI ever has ES202 month 2 employment & EVER_EMP2 & 00172 & 3 & $\mathrm{~N}$ \\
\hline MULTI ever has ES202 month 3 employment & EVER_EMP3 & 00175 & 3 & $\mathrm{~N}$ \\
\hline Missing Value & MODE_ES_COUNTY_EMP_MISS & 00423 & 3 & $\mathrm{~N}$ \\
\hline Missing Value & MODE_ES_COUNTY_MISS & 00345 & 3 & $\mathrm{~N}$ \\
\hline Missing Value & MODE_ES_EIN_EMP_MISS & 00429 & 3 & $\mathrm{~N}$ \\
\hline Missing Value & MODE_ES_EIN_MISS & 00351 & 3 & $\mathrm{~N}$ \\
\hline Missing Value & MODE_ES_NAICS_ESO1997_EMP_MISS & 00411 & 3 & $\mathrm{~N}$ \\
\hline Missing Value & MODE_ES_NAICS_ESO1997_MISS & 00333 & 3 & $\mathrm{~N}$ \\
\hline Missing Value & MODE_ES_NAICS_ESO2002_EMP_MISS & 00414 & 3 & $\mathrm{~N}$ \\
\hline Missing Value & MODE_ES_NAICS_ESO2002_MISS & 00336 & 3 & $\mathrm{~N}$ \\
\hline Missing Value & MODE_ES_NAICS_FNL1997_EMP_MISS & 00417 & 3 & $\mathrm{~N}$ \\
\hline Missing Value & MODE_ES_NAICS_FNL1997_MISS & 00339 & 3 & $\mathrm{~N}$ \\
\hline Missing Value & MODE_ES_NAICS_FNL2002_EMP_MISS & 00420 & 3 & $\mathrm{~N}$ \\
\hline Missing Value & MODE_ES_NAICS_FNL2002_MISS & 00342 & 3 & $\mathrm{~N}$ \\
\hline Missing Value & MODE_ES_OWNER_CODE_EMP_MISS & 00426 & 3 & $\mathrm{~N}$ \\
\hline Missing Value & MODE_ES_OWNER_CODE_MISS & 00348 & 3 & $\mathrm{~N}$ \\
\hline Missing Value & MODE_ES_SIC_EMP_MISS & 00408 & 3 & $\mathrm{~N}$ \\
\hline Missing Value & MODE_ES_SIC_MISS & 00330 & 3 & $\mathrm{~N}$ \\
\hline Missing Value & MODE_LEG_COUNTY_EMP_MISS & 00441 & 3 & $\mathrm{~N}$ \\
\hline Missing Value & MODE_LEG_COUNTY_MISS & 00363 & 3 & $\mathrm{~N}$ \\
\hline Missing Value & MODE_LEG_MSAPMSA_EMP_MISS & 00435 & 3 & $\mathrm{~N}$ \\
\hline Missing Value & MODE_LEG_MSAPMSA_MISS & 00357 & 3 & $\mathrm{~N}$ \\
\hline Missing Value & MODE_LEG_STATE_EMP_MISS & 00438 & 3 & $\mathrm{~N}$ \\
\hline Missing Value & MODE_LEG_STATE_MISS & 00360 & 3 & $\mathrm{~N}$ \\
\hline
\end{tabular}


CHAPTER 3. EMPLOYER CHARACTERISTICS FILE (ECF)

\begin{tabular}{|c|c|c|c|c|}
\hline Field name & $\begin{array}{l}\text { Data dictionary } \\
\text { reference name }\end{array}$ & $\begin{array}{l}\text { Starting } \\
\text { position }\end{array}$ & $\begin{array}{l}\text { Field } \\
\text { size }\end{array}$ & $\begin{array}{l}\text { Data } \\
\text { type }\end{array}$ \\
\hline Missing Value & MODE_LEG_SUBCTYGEO_EMP_MISS & 00444 & 3 & $\mathrm{~N}$ \\
\hline Missing Value & MODE_LEG_SUBCTYGEO_MISS & 00366 & 3 & $\mathrm{~N}$ \\
\hline Missing Value & MODE_LEG_WIB_EMP_MISS & 00432 & 3 & $\mathrm{~N}$ \\
\hline Missing Value & MODE_LEG_WIB_MISS & 00354 & 3 & $\mathrm{~N}$ \\
\hline Multiunit Imputed Record Structure & STRUCTURE_FIX & 00211 & 3 & $\mathrm{~N}$ \\
\hline NAICS Code not Valid & NAICS_1997_INVALID & 00545 & 1 & $\mathrm{~A} / \mathrm{N}$ \\
\hline NAICS Code not Valid & NAICS_2002_INVALID & 00546 & 1 & $\mathrm{~A} / \mathrm{N}$ \\
\hline NAICS Code not Valid & NAICS_AUX_1997_INVALID & 00547 & 1 & $\mathrm{~A} / \mathrm{N}$ \\
\hline NAICS Code not Valid & NAICS_AUX_2002_INVALID & 00548 & 1 & $\mathrm{~A} / \mathrm{N}$ \\
\hline NAICS Code not Valid & NAICS_LDB_1997_INVALID & 00566 & 1 & $\mathrm{~A} / \mathrm{N}$ \\
\hline NAICS Code not Valid & NAICS_LDB_2002_INVALID & 00567 & 1 & $\mathrm{~A} / \mathrm{N}$ \\
\hline Number of Establishments & NUM_ESTABS & 00056 & 4 & $\mathrm{~N}$ \\
\hline Original ES202 County & COUNTY & 00563 & 3 & $\mathrm{~A} / \mathrm{N}$ \\
\hline Original ES202 EIN & EIN & 00554 & 9 & $\mathrm{~A} / \mathrm{N}$ \\
\hline Original ES202 Employment Month 1 & EMPL_MONTH1 & 00084 & 4 & $\mathrm{~N}$ \\
\hline Original ES202 Employment Month 2 & EMPL_MONTH2 & 00088 & 4 & $\mathrm{~N}$ \\
\hline Original ES202 Employment Month 3 & EMPL_MONTH3 & 00092 & 4 & $\mathrm{~N}$ \\
\hline Original ES202 SIC & SIC & 00550 & 4 & $\mathrm{~A} / \mathrm{N}$ \\
\hline Original ES202 wages & TOTAL_WAGES & 00184 & 5 & $\mathrm{~N}$ \\
\hline Original NAICS 1997 Code & NAICS 1997 & 00519 & 6 & $\mathrm{~A} / \mathrm{N}$ \\
\hline Original NAICS 2002 Code & NAICS 2002 & 00525 & 6 & $\mathrm{~A} / \mathrm{N}$ \\
\hline Original NAICS AUX 1997 Code & NAICS_AUX1997 & 00531 & 6 & $\mathrm{~A} / \mathrm{N}$ \\
\hline Original NAICS AUX 2002 Code & NAICS_AUX2002 & 00537 & 6 & $\mathrm{~A} / \mathrm{N}$ \\
\hline Original NAICS LDB 1997 Code & NAICS_LDB1997 & 00568 & 6 & $\mathrm{~A} / \mathrm{N}$ \\
\hline Original NAICS LDB 2002 Code & NAICS_LDB2002 & 00574 & 6 & $\mathrm{~A} / \mathrm{N}$ \\
\hline Original Owner Code & OWNER_CODE & 00544 & 1 & $\mathrm{~A} / \mathrm{N}$ \\
\hline Original UI Payroll Info W1 & PAYROLL & 00147 & 5 & $\mathrm{~N}$ \\
\hline Problem with EIN & EIN_DEFECT & 00220 & 3 & $\mathrm{~N}$ \\
\hline Quality of final geography & LEG_GEO_QUAL & 00231 & 3 & $\mathrm{~N}$ \\
\hline Quarter QQ & QUARTER & 00144 & 3 & $\mathrm{~N}$ \\
\hline Quarters Away County data found & ES_COUNTY_FLAG & 00288 & 3 & $\mathrm{~N}$ \\
\hline Quarters Away Data Found & MODE_ES_COUNTY_EMP_FLAG & 00462 & 3 & $\mathrm{~N}$ \\
\hline Quarters Away Data Found & MODE_ES_COUNTY_FLAG & 00384 & 3 & $\mathrm{~N}$ \\
\hline Quarters Away Data Found & MODE_ES_EIN_EMP_FLAG & 00468 & 3 & $\mathrm{~N}$ \\
\hline Quarters Away Data Found & MODE_ES_EIN_FLAG & 00390 & 3 & $\mathrm{~N}$ \\
\hline Quarters Away Data Found & MODE_ES_NAICS_ESO1997_EMP_FLAG & 00450 & 3 & $\mathrm{~N}$ \\
\hline Quarters Away Data Found & MODE_ES_NAICS_ESO1997_FLAG & 00372 & 3 & $\mathrm{~N}$ \\
\hline Quarters Away Data Found & MODE_ES_NAICS_ESO2002_EMP_FLAG & 00453 & 3 & $\mathrm{~N}$ \\
\hline Quarters Away Data Found & MODE_ES_NAICS_ESO2002_FLAG & 00375 & 3 & $\mathrm{~N}$ \\
\hline Quarters Away Data Found & MODE_ES_NAICS_FNL1997_EMP_FLAG & 00456 & 3 & $\mathrm{~N}$ \\
\hline Quarters Away Data Found & MODE_ES_NAICS_FNL1997_FLAG & 00378 & 3 & $\mathrm{~N}$ \\
\hline Quarters Away Data Found & MODE_ES_NAICS_FNL2002_EMP_FLAG & 00459 & 3 & $\mathrm{~N}$ \\
\hline Quarters Away Data Found & MODE_ES_NAICS_FNL2002_FLAG & 00381 & 3 & $\mathrm{~N}$ \\
\hline Quarters Away Data Found & MODE_ES_OWNER_CODE_EMP_FLAG & 00465 & 3 & $\mathrm{~N}$ \\
\hline Quarters Away Data Found & MODE_ES_OWNER_CODE_FLAG & 00387 & 3 & $\mathrm{~N}$ \\
\hline Quarters Away Data Found & MODE_ES_SIC_EMP_FLAG & 00447 & 3 & $\mathrm{~N}$ \\
\hline Quarters Away Data Found & MODE_ES_SIC_FLAG & 00369 & 3 & $\mathrm{~N}$ \\
\hline Quarters Away Data Found & MODE_LEG_COUNTY_EMP_FLAG & 00480 & 3 & $\mathrm{~N}$ \\
\hline Quarters Away Data Found & MODE_LEG_COUNTY_FLAG & 00402 & 3 & $\mathrm{~N}$ \\
\hline Quarters Away Data Found & MODE_LEG_MSAPMSA_EMP_FLAG & 00474 & 3 & $\mathrm{~N}$ \\
\hline Quarters Away Data Found & MODE_LEG_MSAPMSA_FLAG & 00396 & 3 & $\mathrm{~N}$ \\
\hline Quarters Away Data Found & MODE_LEG_STATE_EMP_FLAG & 00477 & 3 & $\mathrm{~N}$ \\
\hline Quarters Away Data Found & MODE_LEG_STATE_FLAG & 00399 & 3 & $\mathrm{~N}$ \\
\hline Quarters Away Data Found & MODE_LEG_SUBCTYGEO_EMP_FLAG & 00483 & 3 & $\mathrm{~N}$ \\
\hline Quarters Away Data Found & MODE_LEG_SUBCTYGEO_FLAG & 00405 & 3 & $\mathrm{~N}$ \\
\hline Quarters Away Data Found & MODE_LEG_WIB_EMP_FLAG & 00471 & 3 & $\mathrm{~N}$ \\
\hline Quarters Away Data Found & MODE_LEG_WIB_FLAG & 00393 & 3 & $\mathrm{~N}$ \\
\hline Quarters Away EIN data found & ES_EIN_FLAG & 00294 & 3 & $\mathrm{~N}$ \\
\hline Quarters Away NAICS data found & ES_NAICS1997_FLAG & 00270 & 3 & $\mathrm{~N}$ \\
\hline Quarters Away NAICS data found & ES_NAICS2002_FLAG & 00273 & 3 & $\mathrm{~N}$ \\
\hline Quarters Away NAICS data found & ES_NAICS_AUX1997_FLAG & 00276 & 3 & $\mathrm{~N}$ \\
\hline Quarters Away NAICS data found & ES_NAICS_AUX2002_FLAG & 00279 & 3 & $\mathrm{~N}$ \\
\hline Quarters Away NAICS data found & ES_NAICS_LDB1997_FLAG & 00282 & 3 & $\mathrm{~N}$ \\
\hline
\end{tabular}


CHAPTER 3. EMPLOYER CHARACTERISTICS FILE (ECF)

\begin{tabular}{|c|c|c|c|c|}
\hline Field name & $\begin{array}{l}\text { Data dictionary } \\
\text { reference name }\end{array}$ & $\begin{array}{l}\text { Starting } \\
\text { position }\end{array}$ & $\begin{array}{l}\text { Field } \\
\text { size }\end{array}$ & $\begin{array}{l}\text { Data } \\
\text { type }\end{array}$ \\
\hline Quarters Away NAICS data found & ES_NAICS_LDB2002_FLAG & 00285 & 3 & $\mathrm{~N}$ \\
\hline Quarters Away OWNER_CODE data found & ES_OWNER_CODE_FLAG & 00291 & 3 & $\mathrm{~N}$ \\
\hline Quarters Away SIC data found & ES_SIC_FLAG & 00267 & 3 & $\mathrm{~N}$ \\
\hline Random sample selector for SEIN & SAMPLE_SEIN & 00040 & 8 & $\mathrm{~N}$ \\
\hline Random sample selector for SEINUNIT & SAMPLE_SEINUNIT & 00048 & 8 & $\mathrm{~N}$ \\
\hline SEIN 202 Employment Month 1 & SEIN_EMP1 & 00072 & 4 & $\mathrm{~N}$ \\
\hline SEIN 202 Employment Month 2 & SEIN_EMP2 & 00076 & 4 & $\mathrm{~N}$ \\
\hline SEIN 202 Employment Month 3 & SEIN_EMP3 & 00080 & 4 & $\mathrm{~N}$ \\
\hline SEIN 202 Wages & SEIN_WAGES & 00152 & 5 & $\mathrm{~N}$ \\
\hline SEIN Best UI/202 Month 1, Employment & SEIN_BEST_EMP1 & 00120 & 4 & $\mathrm{~N}$ \\
\hline SEIN Best UI/202 Month 2, Employment & SEIN_BEST_EMP2 & 00124 & 4 & $\mathrm{~N}$ \\
\hline SEIN Best UI/202 Month 3, Employment & SEIN_BEST_EMP3 & 00128 & 4 & $\mathrm{~N}$ \\
\hline SEIN Best UI/202 Payroll & SEIN_BEST_WAGES & 00226 & 5 & $\mathrm{~N}$ \\
\hline SEIN UI Wages & WAGES_UI & 00201 & 5 & $\mathrm{~N}$ \\
\hline SEIN ever multi unit & EVER_MULTI & 00163 & 3 & $\mathrm{~N}$ \\
\hline SEIN ever on 202 & EVER_202 & 00178 & 3 & $\mathrm{~N}$ \\
\hline SEIN ever on UI & EVER_UI & 00181 & 3 & $\mathrm{~N}$ \\
\hline SEIN in ES202 & IN_202 & 00195 & 3 & $\mathrm{~N}$ \\
\hline SEIN in UI & IN_UI & 00192 & 3 & $\mathrm{~N}$ \\
\hline SEIN w/2+ records on 202 & MULTI_UNIT & 00135 & 3 & $\mathrm{~N}$ \\
\hline SEINUNIT data non-numeric & SEINUNIT_BAD & 00132 & 3 & $\mathrm{~N}$ \\
\hline SIC Code not Valid & SIC_INVALID & 00549 & 1 & $\mathrm{~A} / \mathrm{N}$ \\
\hline SIC IMP 1997 NAICS Code NNNNNN & ES_NAICS_IMP1997 & 00718 & 6 & $\mathrm{~A} / \mathrm{N}$ \\
\hline SIC IMP 2002 NAICS Code NNNNNN & ES_NAICS_IMP2002 & 00724 & 6 & $\mathrm{~A} / \mathrm{N}$ \\
\hline Seinunit has some NAICS info & ES_NAICS1997_VALID & 00300 & 3 & $\mathrm{~N}$ \\
\hline Seinunit has some NAICS info & ES_NAICS2002_VALID & 00303 & 3 & $\mathrm{~N}$ \\
\hline Seinunit has some NAICS info & ES_NAICS_AUX1997_VALID & 00306 & 3 & $\mathrm{~N}$ \\
\hline Seinunit has some NAICS info & ES_NAICS_AUX2002_VALID & 00309 & 3 & $\mathrm{~N}$ \\
\hline Seinunit has some NAICS info & ES_NAICS_LDB1997_VALID & 00312 & 3 & $\mathrm{~N}$ \\
\hline Seinunit has some NAICS info & ES_NAICS_LDB2002_VALID & 00315 & 3 & $\mathrm{~N}$ \\
\hline Seinunit has some SIC info & ES_SIC_VALID & 00297 & 3 & $\mathrm{~N}$ \\
\hline Source of Ind Code & ES_NAICS1997_SRC & 00733 & 3 & $\mathrm{~A} / \mathrm{N}$ \\
\hline Source of Ind Code & ES_NAICS2002_SRC & 00736 & 3 & $\mathrm{~A} / \mathrm{N}$ \\
\hline Source of Ind Code & ES_NAICS_AUX1997_SRC & 00739 & 3 & $\mathrm{~A} / \mathrm{N}$ \\
\hline Source of Ind Code & ES_NAICS_AUX2002_SRC & 00742 & 3 & $\mathrm{~A} / \mathrm{N}$ \\
\hline Source of Ind Code & ES_NAICS_ESO1997_SRC & 00763 & 3 & $\mathrm{~A} / \mathrm{N}$ \\
\hline Source of Ind Code & ES_NAICS_ESO2002_SRC & 00766 & 3 & $\mathrm{~A} / \mathrm{N}$ \\
\hline Source of Ind Code & ES_NAICS_FNL1997_SRC & 00751 & 3 & $\mathrm{~A} / \mathrm{N}$ \\
\hline Source of Ind Code & ES_NAICS_FNL2002_SRC & 00754 & 3 & $\mathrm{~A} / \mathrm{N}$ \\
\hline Source of Ind Code & ES_NAICS_IMP1997_SRC & 00757 & 3 & $\mathrm{~A} / \mathrm{N}$ \\
\hline Source of Ind Code & ES_NAICS_IMP2002_SRC & 00760 & 3 & $\mathrm{~A} / \mathrm{N}$ \\
\hline Source of Ind Code & ES_NAICS_LDB1997_SRC & 00745 & 3 & $\mathrm{~A} / \mathrm{N}$ \\
\hline Source of Ind Code & ES_NAICS_LDB2002_SRC & 00748 & 3 & $\mathrm{~A} / \mathrm{N}$ \\
\hline Source of Ind Code & ES_SIC_SRC & 00730 & 3 & $\mathrm{~A} / \mathrm{N}$ \\
\hline Source of best_ data & BEST_FLAG & 00214 & 3 & $\mathrm{~N}$ \\
\hline State Employer ID Number & SEIN & 00486 & 12 & $\mathrm{~A} / \mathrm{N}$ \\
\hline State UI Reporting Unit Number & SEINUNIT & 00504 & 5 & $\mathrm{~A} / \mathrm{N}$ \\
\hline Stored Master Multi Code & MASTER_MULTI_UNIT_CODE & 00518 & 1 & $\mathrm{~A} / \mathrm{N}$ \\
\hline Stored Master Record Flag & MASTER_EMPL_MONTH1_FLG & 00514 & 1 & $\mathrm{~A} / \mathrm{N}$ \\
\hline Stored Master Record Flag & MASTER_EMPL_MONTH2_FLG & 00515 & 1 & $\mathrm{~A} / \mathrm{N}$ \\
\hline Stored Master Record Flag & MASTER_EMPL_MONTH3_FLG & 00516 & 1 & $\mathrm{~A} / \mathrm{N}$ \\
\hline Stored Master Record Flag & MASTER_TOTAL_WAGES_FLG & 00517 & 1 & $\mathrm{~A} / \mathrm{N}$ \\
\hline Sub-county geocode & LEG_SUBCTYGEO & 00609 & 10 & $\mathrm{~A} / \mathrm{N}$ \\
\hline UI Employment B & SEINSIZE_B & 00068 & 4 & $\mathrm{~N}$ \\
\hline UI Employment E & SEINSIZE_E & 00064 & 4 & $\mathrm{~N}$ \\
\hline UI Employment M & SEINSIZE_M & 00060 & 4 & $\mathrm{~N}$ \\
\hline Unit Mode Cleaned County & MODE_ES_COUNTY & 00773 & 3 & $\mathrm{~A} / \mathrm{N}$ \\
\hline Unit Mode Cleaned EIN & MODE_ES_EIN & 00776 & 9 & $\mathrm{~A} / \mathrm{N}$ \\
\hline Unit Mode Cleaned GEO COUNTY & MODE_LEG_COUNTY & 00883 & 3 & $\mathrm{~A} / \mathrm{N}$ \\
\hline Unit Mode Cleaned GEO COUNTY & MODE_LEG_SUBCTYGEO & 00889 & 10 & $\mathrm{~A} / \mathrm{N}$ \\
\hline Unit Mode Cleaned GEO MSAPMSA & MODE_LEG_MSAPMSA & 00863 & 8 & $\mathrm{~A} / \mathrm{N}$ \\
\hline Unit Mode Cleaned GEO STATE & MODE_LEG_STATE & 00879 & 2 & $\mathrm{~A} / \mathrm{N}$ \\
\hline Unit Mode Cleaned GEO WIB & MODE_LEG_WIB & 00851 & 6 & $\mathrm{~A} / \mathrm{N}$ \\
\hline
\end{tabular}


CHAPTER 3. EMPLOYER CHARACTERISTICS FILE (ECF)

\begin{tabular}{|c|c|c|c|c|}
\hline Field name & $\begin{array}{l}\text { Data dictionary } \\
\text { reference name }\end{array}$ & $\begin{array}{l}\text { Starting } \\
\text { position }\end{array}$ & $\begin{array}{l}\text { Field } \\
\text { size }\end{array}$ & $\begin{array}{l}\text { Data } \\
\text { type }\end{array}$ \\
\hline Unit Mode Cleaned NAICS 1997 & MODE_ES_NAICS_ESO1997 & 00785 & 6 & $\mathrm{~A} / \mathrm{N}$ \\
\hline Unit Mode Cleaned NAICS 1997 & MODE_ES_NAICS_FNL1997 & 00797 & 6 & $\mathrm{~A} / \mathrm{N}$ \\
\hline Unit Mode Cleaned NAICS 2002 & MODE_ES_NAICS_ESO2002 & 00791 & 6 & $\mathrm{~A} / \mathrm{N}$ \\
\hline Unit Mode Cleaned NAICS 2002 & MODE_ES_NAICS_FNL2002 & 00803 & 6 & $\mathrm{~A} / \mathrm{N}$ \\
\hline Unit Mode Cleaned OWNER_CODE & MODE_ES_OWNER_CODE & 00809 & 1 & $\mathrm{~A} / \mathrm{N}$ \\
\hline Unit Mode Cleaned SIC & MODE_ES_SIC & 00769 & 4 & $\mathrm{~A} / \mathrm{N}$ \\
\hline WIB code, wwwwww & LEG_WIB & 00603 & 6 & $\mathrm{~A} / \mathrm{N}$ \\
\hline Weight $\operatorname{sum}\left(B_{-} U I\right)=\operatorname{sum}($ month1_BLS $)$ & QWI_UNIT_WEIGHT & 00032 & 8 & $\mathrm{~N}$ \\
\hline Year YYYY & YEAR & 00141 & 3 & $\mathrm{~N}$ \\
\hline candidate for structure fix & SPECIAL_HANDLE & 00198 & 3 & $\mathrm{~N}$ \\
\hline
\end{tabular}


CHAPTER 3. EMPLOYER CHARACTERISTICS FILE (ECF)

\subsubsection{Main SEIN dataset: ecf_zz_sein}

SEIN-level file, with variables aggregated from the establishment level.

Record identifier: SEIN YEAR QUARTER

Sort order: SEIN YEAR QUARTER

File indexes: none

Entity "firm"

\section{Unique Entity Key SEIN}

Note that SEIN is unique within any given time period across all states, but may not be uniquely identify an entity over time within a state, as the underlying UI account numbers can and do get re-used.

\begin{tabular}{|c|c|c|c|c|}
\hline Field name & $\begin{array}{l}\text { Data dictionary } \\
\text { reference name }\end{array}$ & $\begin{array}{l}\text { Starting } \\
\text { position }\end{array}$ & $\begin{array}{l}\text { Field } \\
\text { size }\end{array}$ & $\begin{array}{l}\text { Data } \\
\text { type }\end{array}$ \\
\hline $1=\mathrm{UI}$ only, $2=202$ only, $3=$ both & SOURCE & 00114 & 3 & $\mathrm{~N}$ \\
\hline Best SEIN UI Employment & EMP1_UI & 00044 & 4 & $\mathrm{~N}$ \\
\hline Best SEIN UI Employment & EMP2_UI & 00048 & 4 & $\mathrm{~N}$ \\
\hline Best SEIN UI Employment & EMP3_UI & 00052 & 4 & $\mathrm{~N}$ \\
\hline Continuous Time YEAR QUARTER & YR_QTR & 00301 & 6 & $\mathrm{~A} / \mathrm{N}$ \\
\hline ES202 FIPS State SS & ES_STATE & 00307 & 2 & $\mathrm{~A} / \mathrm{N}$ \\
\hline Emp Mode Cleaned County & MODE_ES_COUNTY_EMP & 00354 & 3 & $\mathrm{~A} / \mathrm{N}$ \\
\hline Emp Mode Cleaned EIN & MODE_ES_EIN_EMP & 00357 & 9 & $\mathrm{~A} / \mathrm{N}$ \\
\hline Emp Mode Cleaned GEO COUNTY & MODE_LEG_COUNTY_EMP & 00426 & 3 & $\mathrm{~A} / \mathrm{N}$ \\
\hline Emp Mode Cleaned GEO COUNTY & MODE_LEG_SUBCTYGEO_EMP & 00439 & 10 & $\mathrm{~A} / \mathrm{N}$ \\
\hline Emp Mode Cleaned GEO MSAPMSA & MODE_LEG_MSAPMSA_EMP & 00411 & 8 & $\mathrm{~A} / \mathrm{N}$ \\
\hline Emp Mode Cleaned GEO STATE & MODE_LEG_STATE_EMP & 00421 & 2 & $\mathrm{~A} / \mathrm{N}$ \\
\hline Emp Mode Cleaned GEO WIB & MODE_LEG_WIB_EMP & 00397 & 6 & $\mathrm{~A} / \mathrm{N}$ \\
\hline Emp Mode Cleaned NAICS 1997 & MODE_ES_NAICS_ESO1997_EMP & 00366 & 6 & $\mathrm{~A} / \mathrm{N}$ \\
\hline Emp Mode Cleaned NAICS 1997 & MODE_ES_NAICS_FNL1997_EMP & 00378 & 6 & $\mathrm{~A} / \mathrm{N}$ \\
\hline Emp Mode Cleaned NAICS 2002 & MODE_ES_NAICS_ESO2002_EMP & 00372 & 6 & $\mathrm{~A} / \mathrm{N}$ \\
\hline Emp Mode Cleaned NAICS 2002 & MODE_ES_NAICS_FNL2002_EMP & 00384 & 6 & $\mathrm{~A} / \mathrm{N}$ \\
\hline Emp Mode Cleaned OWNER_CODE & MODE_ES_OWNER_CODE_EMP & 00390 & 1 & $\mathrm{~A} / \mathrm{N}$ \\
\hline Emp Mode Cleaned SIC & MODE_ES_SIC_EMP & 00350 & 4 & $\mathrm{~A} / \mathrm{N}$ \\
\hline First Quarter SEIN on 202 & MULTI_FIRST_QUARTER & 00090 & 3 & $\mathrm{~N}$ \\
\hline First Year SEIN on 202 & MULTI_FIRST_YEAR & 00087 & 3 & $\mathrm{~N}$ \\
\hline MULTI ever ES202 wages & EVER_WAGES & 00096 & 3 & $\mathrm{~N}$ \\
\hline MULTI ever has ES202 month 1 employment & EVER_EMP1 & 00099 & 3 & $\mathrm{~N}$ \\
\hline MULTI ever has ES202 month 2 employment & EVER_EMP2 & 00102 & 3 & $\mathrm{~N}$ \\
\hline MULTI ever has ES202 month 3 employment & EVER_EMP3 & 00105 & 3 & $\mathrm{~N}$ \\
\hline Missing Value & MODE_ES_COUNTY_EMP_MISS & 00226 & 3 & $\mathrm{~N}$ \\
\hline Missing Value & MODE_ES_COUNTY_MISS & 00148 & 3 & $\mathrm{~N}$ \\
\hline Missing Value & MODE_ES_EIN_EMP_MISS & 00232 & 3 & $\mathrm{~N}$ \\
\hline Missing Value & MODE_ES_EIN_MISS & 00154 & 3 & $\mathrm{~N}$ \\
\hline Missing Value & MODE_ES_NAICS_ESO1997_EMP_MISS & 00214 & 3 & $\mathrm{~N}$ \\
\hline Missing Value & MODE_ES_NAICS_ESO1997_MISS & 00136 & 3 & $\mathrm{~N}$ \\
\hline Missing Value & MODE_ES_NAICS_ESO2002_EMP_MISS & 00217 & 3 & $\mathrm{~N}$ \\
\hline Missing Value & MODE_ES_NAICS_ESO2002_MISS & 00139 & 3 & $\mathrm{~N}$ \\
\hline Missing Value & MODE_ES_NAICS_FNL1997_EMP_MISS & 00220 & 3 & $\mathrm{~N}$ \\
\hline Missing Value & MODE_ES_NAICS_FNL1997_MISS & 00142 & 3 & $\mathrm{~N}$ \\
\hline Missing Value & MODE_ES_NAICS_FNL2002_EMP_MISS & 00223 & 3 & $\mathrm{~N}$ \\
\hline Missing Value & MODE_ES_NAICS_FNL2002_MISS & 00145 & 3 & $\mathrm{~N}$ \\
\hline Missing Value & MODE_ES_OWNER_CODE_EMP_MISS & 00229 & 3 & $\mathrm{~N}$ \\
\hline Missing Value & MODE_ES_OWNER_CODE_MISS & 00151 & 3 & $\mathrm{~N}$ \\
\hline Missing Value & MODE_ES_SIC_EMP_MISS & 00211 & 3 & $\mathrm{~N}$ \\
\hline Missing Value & MODE_ES_SIC_MISS & 00133 & 3 & $\mathrm{~N}$ \\
\hline Missing Value & MODE_LEG_COUNTY_EMP_MISS & 00244 & 3 & $\mathrm{~N}$ \\
\hline Missing Value & MODE_LEG_COUNTY_MISS & 00166 & 3 & $\mathrm{~N}$ \\
\hline Missing Value & MODE_LEG_MSAPMSA_EMP_MISS & 00238 & 3 & $\mathrm{~N}$ \\
\hline Missing Value & MODE_LEG_MSAPMSA_MISS & 00160 & 3 & $\mathrm{~N}$ \\
\hline
\end{tabular}


CHAPTER 3. EMPLOYER CHARACTERISTICS FILE (ECF)

\begin{tabular}{|c|c|c|c|c|}
\hline Field name & $\begin{array}{l}\text { Data dictionary } \\
\text { reference name }\end{array}$ & $\begin{array}{l}\text { Starting } \\
\text { position }\end{array}$ & $\begin{array}{l}\text { Field } \\
\text { size }\end{array}$ & $\begin{array}{l}\text { Data } \\
\text { type }\end{array}$ \\
\hline Missing Value & MODE_LEG_STATE_EMP_MISS & 00241 & 3 & $\mathrm{~N}$ \\
\hline Missing Value & MODE_LEG_STATE_MISS & 00163 & 3 & $\mathrm{~N}$ \\
\hline Missing Value & MODE_LEG_SUBCTYGEO_EMP_MISS & 00247 & 3 & $\mathrm{~N}$ \\
\hline Missing Value & MODE_LEG_SUBCTYGEO_MISS & 00169 & 3 & $\mathrm{~N}$ \\
\hline Missing Value & MODE_LEG_WIB_EMP_MISS & 00235 & 3 & $\mathrm{~N}$ \\
\hline Missing Value & MODE_LEG_WIB_MISS & 00157 & 3 & $\mathrm{~N}$ \\
\hline Number of Establishments & NUM_ESTABS & 00016 & 4 & $\mathrm{~N}$ \\
\hline Original UI Payroll Info W1 & PAYROLL & 00077 & 5 & $\mathrm{~N}$ \\
\hline Quarter QQ & QUARTER & 00074 & 3 & $\mathrm{~N}$ \\
\hline Quarters Away Data Found & MODE_ES_COUNTY_EMP_FLAG & 00265 & 3 & $\mathrm{~N}$ \\
\hline Quarters Away Data Found & MODE_ES_COUNTY_FLAG & 00187 & 3 & $\mathrm{~N}$ \\
\hline Quarters Away Data Found & MODE_ES_EIN_EMP_FLAG & 00271 & 3 & $\mathrm{~N}$ \\
\hline Quarters Away Data Found & MODE_ES_EIN_FLAG & 00193 & 3 & $\mathrm{~N}$ \\
\hline Quarters Away Data Found & MODE_ES_NAICS_ESO1997_EMP_FLAG & 00253 & 3 & $\mathrm{~N}$ \\
\hline Quarters Away Data Found & MODE_ES_NAICS_ESO1997_FLAG & 00175 & 3 & $\mathrm{~N}$ \\
\hline Quarters Away Data Found & MODE_ES_NAICS_ESO2002_EMP_FLAG & 00256 & 3 & $\mathrm{~N}$ \\
\hline Quarters Away Data Found & MODE_ES_NAICS_ESO2002_FLAG & 00178 & 3 & $\mathrm{~N}$ \\
\hline Quarters Away Data Found & MODE_ES_NAICS_FNL1997_EMP_FLAG & 00259 & 3 & $\mathrm{~N}$ \\
\hline Quarters Away Data Found & MODE_ES_NAICS_FNL1997_FLAG & 00181 & 3 & $\mathrm{~N}$ \\
\hline Quarters Away Data Found & MODE_ES_NAICS_FNL2002_EMP_FLAG & 00262 & 3 & $\mathrm{~N}$ \\
\hline Quarters Away Data Found & MODE_ES_NAICS_FNL2002_FLAG & 00184 & 3 & $\mathrm{~N}$ \\
\hline Quarters Away Data Found & MODE_ES_OWNER_CODE_EMP_FLAG & 00268 & 3 & $\mathrm{~N}$ \\
\hline Quarters Away Data Found & MODE_ES_OWNER_CODE_FLAG & 00190 & 3 & $\mathrm{~N}$ \\
\hline Quarters Away Data Found & MODE_ES_SIC_EMP_FLAG & 00250 & 3 & $\mathrm{~N}$ \\
\hline Quarters Away Data Found & MODE_ES_SIC_FLAG & 00172 & 3 & $\mathrm{~N}$ \\
\hline Quarters Away Data Found & MODE_LEG_COUNTY_EMP_FLAG & 00283 & 3 & $\mathrm{~N}$ \\
\hline Quarters Away Data Found & MODE_LEG_COUNTY_FLAG & 00205 & 3 & $\mathrm{~N}$ \\
\hline Quarters Away Data Found & MODE_LEG_MSAPMSA_EMP_FLAG & 00277 & 3 & $\mathrm{~N}$ \\
\hline Quarters Away Data Found & MODE_LEG_MSAPMSA_FLAG & 00199 & 3 & $\mathrm{~N}$ \\
\hline Quarters Away Data Found & MODE_LEG_STATE_EMP_FLAG & 00280 & 3 & $\mathrm{~N}$ \\
\hline Quarters Away Data Found & MODE_LEG_STATE_FLAG & 00202 & 3 & $\mathrm{~N}$ \\
\hline Quarters Away Data Found & MODE_LEG_SUBCTYGEO_EMP_FLAG & 00286 & 3 & $\mathrm{~N}$ \\
\hline Quarters Away Data Found & MODE_LEG_SUBCTYGEO_FLAG & 00208 & 3 & $\mathrm{~N}$ \\
\hline Quarters Away Data Found & MODE_LEG_WIB_EMP_FLAG & 00274 & 3 & $\mathrm{~N}$ \\
\hline Quarters Away Data Found & MODE_LEG_WIB_FLAG & 00196 & 3 & $\mathrm{~N}$ \\
\hline Random sample selector for SEIN & SAMPLE_SEIN & 00008 & 8 & $\mathrm{~N}$ \\
\hline SEIN 202 Employment Month 1 & SEIN_EMP1 & 00032 & 4 & $\mathrm{~N}$ \\
\hline SEIN 202 Employment Month 2 & SEIN_EMP2 & 00036 & 4 & $\mathrm{~N}$ \\
\hline SEIN 202 Employment Month 3 & SEIN_EMP3 & 00040 & 4 & $\mathrm{~N}$ \\
\hline SEIN 202 Wages & SEIN_WAGES & 00082 & 5 & $\mathrm{~N}$ \\
\hline SEIN Best UI/202 Month 1, Employment & SEIN_BEST_EMP1 & 00056 & 4 & $\mathrm{~N}$ \\
\hline SEIN Best UI/202 Month 2, Employment & SEIN_BEST_EMP2 & 00060 & 4 & $\mathrm{~N}$ \\
\hline SEIN Best UI/202 Month 3, Employment & SEIN_BEST_EMP3 & 00064 & 4 & $\mathrm{~N}$ \\
\hline SEIN Best UI/202 Payroll & SEIN_BEST_WAGES & 00128 & 5 & $\mathrm{~N}$ \\
\hline SEIN UI Wages & WAGES_UI & 00123 & 5 & $\mathrm{~N}$ \\
\hline SEIN ever multi unit & EVER_MULTI & 00093 & 3 & $\mathrm{~N}$ \\
\hline SEIN ever on 202 & EVER_202 & 00108 & 3 & $\mathrm{~N}$ \\
\hline SEIN ever on UI & EVER_UI & 00111 & 3 & $\mathrm{~N}$ \\
\hline SEIN in ES202 & IN_202 & 00120 & 3 & $\mathrm{~N}$ \\
\hline SEIN in UI & IN_UI & 00117 & 3 & $\mathrm{~N}$ \\
\hline SEIN w/2+ records on 202 & MULTI_UNIT & 00068 & 3 & $\mathrm{~N}$ \\
\hline State Employer ID Number & SEIN & 00289 & 12 & $\mathrm{~A} / \mathrm{N}$ \\
\hline UI Employment B & SEINSIZE_B & 00028 & 4 & $\mathrm{~N}$ \\
\hline UI Employment E & SEINSIZE_E & 00024 & 4 & $\mathrm{~N}$ \\
\hline UI Employment M & SEINSIZE_M & 00020 & 4 & $\mathrm{~N}$ \\
\hline Unit Mode Cleaned County & MODE_ES_COUNTY & 00313 & 3 & $\mathrm{~A} / \mathrm{N}$ \\
\hline Unit Mode Cleaned EIN & MODE_ES_EIN & 00316 & 9 & $\mathrm{~A} / \mathrm{N}$ \\
\hline Unit Mode Cleaned GEO COUNTY & MODE_LEG_COUNTY & 00423 & 3 & $\mathrm{~A} / \mathrm{N}$ \\
\hline Unit Mode Cleaned GEO COUNTY & MODE_LEG_SUBCTYGEO & 00429 & 10 & $\mathrm{~A} / \mathrm{N}$ \\
\hline Unit Mode Cleaned GEO MSAPMSA & MODE_LEG_MSAPMSA & 00403 & 8 & $\mathrm{~A} / \mathrm{N}$ \\
\hline Unit Mode Cleaned GEO STATE & MODE_LEG_STATE & 00419 & 2 & $\mathrm{~A} / \mathrm{N}$ \\
\hline Unit Mode Cleaned GEO WIB & MODE_LEG_WIB & 00391 & 6 & $\mathrm{~A} / \mathrm{N}$ \\
\hline Unit Mode Cleaned NAICS 1997 & MODE_ES_NAICS_ESO1997 & 00325 & 6 & $\mathrm{~A} / \mathrm{N}$ \\
\hline
\end{tabular}


CHAPTER 3. EMPLOYER CHARACTERISTICS FILE (ECF)

\begin{tabular}{|c|c|c|c|c|}
\hline Field name & $\begin{array}{l}\text { Data dictionary } \\
\text { reference name }\end{array}$ & $\begin{array}{l}\text { Starting } \\
\text { position }\end{array}$ & $\begin{array}{l}\text { Field } \\
\text { size }\end{array}$ & $\begin{array}{l}\text { Data } \\
\text { type }\end{array}$ \\
\hline Unit Mode Cleaned NAICS 1997 & MODE_ES_NAICS_FNL1997 & 00337 & 6 & $\mathrm{~A} / \mathrm{N}$ \\
\hline Unit Mode Cleaned NAICS 2002 & MODE_ES_NAICS_ESO2002 & 00331 & 6 & $\mathrm{~A} / \mathrm{N}$ \\
\hline Unit Mode Cleaned NAICS 2002 & MODE_ES_NAICS_FNL2002 & 00343 & 6 & $\mathrm{~A} / \mathrm{N}$ \\
\hline Unit Mode Cleaned OWNER_CODE & MODE_ES_OWNER_CODE & 00349 & 1 & $\mathrm{~A} / \mathrm{N}$ \\
\hline Unit Mode Cleaned SIC & MODE_ES_SIC & 00309 & 4 & $\mathrm{~A} / \mathrm{N}$ \\
\hline Weight $\operatorname{sum}\left(\mathrm{B}_{-} \mathrm{UI}\right)=\operatorname{sum}($ month1_BLS$)$ & QWI_UNIT_WEIGHT & 00000 & 8 & $\mathrm{~N}$ \\
\hline Year YYYY & YEAR & 00071 & 3 & $\mathrm{~N}$ \\
\hline
\end{tabular}




\subsubsection{Auxiliary SEINUNIT T26 dataset: ecf_zz_seinunit_t26}

T26 variables associated with the SEINUNIT-level file. Note that as of the S2004 version, only California (CA) has such files.

Record identifier: SEIN SEINUNIT YEAR QUARTER

Sort order: SEIN SEINUNIT YEAR QUARTER

File indexes: none

Entity "establishment" or SESA

Unique Entity Key SEIN SEINUNIT

\begin{tabular}{l|l|c|cc}
\hline \multicolumn{1}{c|}{ Field name } & $\begin{array}{l}\text { Data_dictionary } \\
\text { reference name }\end{array}$ & $\begin{array}{l}\text { Starting } \\
\text { position }\end{array}$ & $\begin{array}{l}\text { Field } \\
\text { size }\end{array}$ & $\begin{array}{l}\text { Data } \\
\text { type }\end{array}$ \\
\hline 0=ok,1=not found,2+found off qtr & ES_EIN_MISS & 00024 & 8 & $\mathrm{~N}$ \\
Cleaned EIN & ES_EIN & 00072 & 9 & $\mathrm{~A} / \mathrm{N}$ \\
EIN in known IRD & VALID_EIN & 00032 & 8 & $\mathrm{~N}$ \\
Emp Mode Cleaned EIN & MODE_ES_EIN_EMP & 00090 & 9 & $\mathrm{~A} / \mathrm{N}$ \\
Letters a-z,A-Z in EIN & EIN_BAD & 00000 & 8 & $\mathrm{~N}$ \\
Original ES202 EIN & EIN & 00063 & 9 & $\mathrm{~A} / \mathrm{N}$ \\
Problem with EIN & EIN_DEFECT & 00008 & 8 & $\mathrm{~N}$ \\
Quarter QQ & QUARTER & 00043 & 3 & $\mathrm{~N}$ \\
Quarters Away EIN data found & ES_EIN_FLAG & 00016 & 8 & $\mathrm{~N}$ \\
State Employer ID Number & SEIN & 00046 & 12 & $\mathrm{~A} / \mathrm{N}$ \\
State UI Reporting Unit Number & SEINUNIT & 00058 & 5 & $\mathrm{~A} / \mathrm{N}$ \\
Unit Mode Cleaned EIN & MODE_ES_EIN & 00081 & 9 & $\mathrm{~A} / \mathrm{N}$ \\
Year YYYY & YEAR & 00040 & 3 & $\mathrm{~N}$
\end{tabular}


CHAPTER 3. EMPLOYER CHARACTERISTICS FILE (ECF)

3.3.6 Auxiliary SEIN T26 dataset: ecf_zz_sein_t26

T26 variables associated with the SEIN-level file. Note that as of the S2004 version, only California (CA) has such files.

Record identifier: SEIN YEAR QUARTER

Sort order: SEIN YEAR QUARTER

File indexes: none

Entity "firm"

Unique Entity Key SEIN

\begin{tabular}{l|l|c|c|c}
\hline \multicolumn{1}{c|}{ Field name } & $\begin{array}{l}\text { Data_dictionary } \\
\text { reference name }\end{array}$ & $\begin{array}{l}\text { Starting } \\
\text { position }\end{array}$ & $\begin{array}{l}\text { Field } \\
\text { size }\end{array}$ & $\begin{array}{l}\text { Data } \\
\text { type }\end{array}$ \\
\hline Emp Mode Cleaned EIN & MODE_ES_EIN_EMP & 00027 & 9 & A/N \\
Quarter QQ & QUARTER & 00003 & 3 & $\mathrm{~N}$ \\
State Employer ID Number & SEIN & 00006 & 12 & $\mathrm{~A} / \mathrm{N}$ \\
Unit Mode Cleaned EIN & MODE_ES_EIN & 00018 & 9 & $\mathrm{~A} / \mathrm{N}$ \\
Year YYYY & YEAR & 00000 & 3 & $\mathrm{~N}$
\end{tabular}




\subsubsection{Details on variables}

sein Variables read in from the ES202 yearly files.

12 digit firm identifier (first 2 digits are the state FIPS code)

year

quarter

seinunit 5 digit code identifying the establishment. Generally used in combination with the SEIN to uniquely identify an establihment. The identifier itself is only unique within a firm or SEIN.

owner_code see ES_OWNER_CODE

\section{EIN}

county

SIC

NAICS

empl_month1

empl_month2

empl_month3

total_wages End of variables read in from the ES202 yearly files.

Sein_bad $\quad 0=$ SEIN contains only characters 0-9

$1=$ SEIN contains a character outside the above range

Ein_bad $0=$ EIN contains only characters 0-9

$1=$ EIN contains a character outside the above range

Valid_ein 0 = first 2 digits of EIN do not represent a valid IRS Revenue district code $1=$ first 2 digits are valid

Ein_defect $0=$ no defect found

$1=\mathrm{EIN}$ it is all nines or all zeros

$2=$ ein_bad=1, EIN contains characters outside the range $0-9$

$3=\mathrm{EIN}$ is a 7 digit or less number. An EIN must be at least eight characters

4 = valid_ein=0, the first two digits of the EIN do not represent a valid IRS Revenue district code

Sic_invalid $0=\mathrm{SIC}$ is $\mathrm{OK}$

$1=$ SIC not valid

2 = first 2 digits valid, last 2 digits imputed

$3=$ first 3 digits valid, last digit imputed 
NUM_RECORDS $1-\mathrm{N}=$ the number of records for each SEIN in a given year and quarter

All_miss_(pay,emp1,emp2,emp3,sic,county) $\quad 0=$ at least one or more subunits has data $1=$ all subunits have missing data

num_estabs $\quad 1-\mathrm{N}=$ the number of establishments for each SEIN in a given year and quarter

multi_unit $\quad 0=$ not a multi unit

$1=$ multi unit

impute_(wage,emp1,emp2,emp3,sic,county) $0=$ data not available or imputation unnecessary $1=$ data available in master record and no data in subunits

no_(wages,emp1,emp2,emp3,sic,county) $\quad 0=$ data available in either master record or subunits $1=$ no data in either master record or subunits

master_(wage,emp1,emp2,emp3,sic,county) Information contained in the master record is stored here

seinunit_type $0=$ seinunit $=" 00000 "$

$1=$ seinunit $\sim=" 00000 "$

seinsize_m variables read in from the UI SEIN YEAR QUARTER summary file.

Count of PIK level wage records that appear at an SEIN in a given YEAR QUARTER.

seinsize_b Count of PIK level wage records that appear at an SEIN in both the current and previous YEAR QUARTER

seinsize_e Count of PIK level wage records that appear at an SEIN in both the current and subsequent YEAR QUARTER.

Payroll Sum of earnings for PIK level wage records at the SEIN in a given YEAR QUARTER.

ever_(multi,wages,emp1,emp2,emp3) $\quad 0=$ the SEIN never reports data on the ES202

$1=$ the SEIN is a multi unit at some time or reports payroll or employment at some time during the observed period on the ES202.

sein_(emp1,emp2,emp3,wages) SEIN level totals for payroll and employment from the ES202

multi_first_year The first year when an SEIN appears as a multi unit on the ES202

multi_first_quarter The first quarter when an SEIN appears as a multi unit on the ES202

in_UI $0=$ SEIN is not on the UI in a given year and quarter $1=$ SEIN appears on the UI in given year and quarter

in_202 $0=$ SEIN is not on the ES202 a given year and quarter $1=$ SEIN appears on the ES202 in a given year and quarter 
source $1=\mathrm{UI}$ only

$2=\mathrm{ES} 202$ only

$3=$ both UI and ES202

ever $\_202 \quad 0=$ not on ES202

$1=$ SEIN appears on the ES202 at some time during observed period

yr_qtr A 6 character sequential year variable. Format is YYYY:Q. A 4 digit year, a colon, and a 1 digit quarter.

$\operatorname{emp}(\mathbf{1 , 2 , 3 )}$ _UI Attempt to create the best possible approximation of ES202 employment and payroll using UI data.

Emp1_UI $=$ seinsize_b if available, then seinsize_e, and finally seinsize_m.

Emp2_UI $=$ seinsize_b if available, then seinsize_e, and finally seinsize_m.

Emp1_UI $=$ seinsize_e if available, then seinsize_b, and finally seinsize_m.

best_(wages,emp1,emp2,emp3) My best estimate of payroll and employment for a subunit using as much information available in the UI and ES202. I use both contemporaneous information and information about the firm in other years and quarters. If information is available in the ES202 then that data takes precedence over information in the UI.

best_flag NOTE: The best_flag variable when combined with the structure_fix variable can be used to identify the type of edits and data source of the best_xx variables.

$0=$ no wage or employment information on the ES202 or UI

In both UI and ES202 $1=\mathrm{SU}, \mathrm{ES} 202$ wages, UI employment is used $2=\mathrm{SU}$, UI wages, ES202 employment is used $3=\mathrm{SU}$, ES202 wages and employment are used $4=\mathrm{SU}$, UI wages and employment are used

In ES202 only $5=\mathrm{SU}$, ES202 wages and employment are used

In UI only $6=\mathrm{SU}$, UI wages and employment are used

In both UI and ES202 7 = MU, ES202 wages, UI employment allocated based on ES202 wages $8=$ MU, UI payroll allocated based on ES202 employment, ES202 employment is used $9=$ MU, ES202 wages and employment are used $10=\mathrm{MU}$, UI payroll and employment allocated equally across all establishments

In ES202 only $11=$ MU, ES202 wages and employment are used

In UI only for multi-units does not exist

info_202 $0=$ no ES202 info

$1=$ only wages available on ES202

$2=$ only employment available on ES202

$3=$ both wages and employment available on ES202

noemp_202 $0=$ positive ES202 employment

$1=$ employment is not $i 0$ on the ES202

emp_202_miss $0=$ not in the ES202 and non-missing ES202 employment

$1=$ in the ES202 and all ES202 employment is missing. 
special_handle $0=$ no special handling required

$1=$ in_UI $=1$ and in_202 $=0$ and ever_multi $=1$

$2=$ in_UI $=0$ and in $\_202=1$ and impute_data $=1$

$3=$ in_UI $=1$ and in $\_202=1$ and no_data $=1$ and multi_unit $=1$

$4=$ in_UI $=1$ and in $\_202=1$ and impute_data $=1$

no_get_data $0=$ get_XX $=1$ for at least one variable

$1=$ get_XX $=0$ for all variables

data_avail $0=$ no data available

$1=$ in $\_202=1$ and some subunit data available that period

impute_data $0=$ no allocation of master to subunit that period

$1=$ allocation of master to subunit that period

no_data $0=$ data available

$1=$ no data in master or subunit available that period

get_(wages,emp1,emp2,emp3) $0=$ special_handle $=0$ or special_handle=1 and no subunit wages available in other periods

$1=$ special_handle $\_0$ and subunit data is available in other periods

(wages,emp1,emp2,emp3)_202 Renamed sein_XX variables on the special_handle_06.sas7bdat dataset. This is necessary in the next program when I match a record with missing subunit information the to another record in another year and quarter.

Wages_UI Payroll is renamed similarly to $\operatorname{emp}(1,2,3,)_{-}$UI variables.

qtime_master Continuous quarter time from1985 quarter 1 for the record for which I am trying to determine subunit structure.

qtime_first The first quarter in continuous time that an SEIN appears as a multi unit

year_found The closest year that contains subunit structure

quarter_found The closest quarter that contains subunit structure

Stop $0=$ record not found

$1=$ record with subunit structure found

best_(wages,emp1,emp2,emp3) Update of original values computed in 05_best_vars.sas. My best estimate of payroll and employment for a subunit using as much information available in the UI and ES202. I use both contemporaneous information and information about the firm in other years and quarters. If information is available in the ES202 then that data takes precedence over information in the UI.

sein_best_(wages, emp1, emp2, emp3) SEIN YEAR QUARTER summaries of the best_XX variables. 
structure_fix NOTE: The best_flag variable when combined with the structure_fix variable can be used to identify the type of edits and data source of the best_xx variables.

$0=$ record not selected for structure imputation

$1=$ record selected for structure imputation

leg_state See the LEG documentation for more information on these variables

leg_county

leg_wib

leg_msapmsa

leg_geo_qual

leg_longitude

leg_latitude

leg_flag_geo

es_state FIPS code of the state

es_ein cleaned SEINUNIT EIN

9 digit federal firm identifier. Generally not unique within a state. There may be multiple state level firms for a given federal firm identifier.

es_county cleaned SEINUNIT county

3 digit FIPS county code.

es_naics cleaned SEINUNIT NAICS

es_owner_code cleaned SEINUNIT ownership code

$1=$ Federal Government

$2=$ State Government

$3=$ Local Government

$5=$ Private Sector

es_sic cleaned SEINUNIT SIC

es_(sic, naics, county, owner_code, ein)_miss $\quad 0=$ Variable is not missing

$1=$ Variable is missing before using information from other quarters.

$2=$ Variable is not missing after search for off quarter information.

mode_es_XXX_emp $+4=$ Variable is missing, filled with the SEIN employment weighted mode value.

es_(sic, naics, county, owner_code, ein)_flag Missing $=$ No information in other quarters

$0=$ Variable is not missing in current quarter

$\iota^{0}=$ quarter after the current quarter where replacement value is found

$¡ 0=$ quarter before the current quarter where replacement value is found 
mode_(es_sic, es_naics, es_county, es_owner_code, es_ein, leg_wib, leg_msapmsa, leg_state, leg_county, leg_subctygeo) The modal value of the variable in an SEIN YEAR QUARTER (unit weighted)

mode_( es_sic, es_naics, es_county, es_owner_code, es_ein, leg_wib, leg_msapmsa, leg_state, leg_county, leg_subctygeo)_emp The modal value of the variable in an SEIN YEAR QUARTER (employment weighted)

Place SIC, NAICS, COUNTY, ownership code, EIN and LEG SEIN level variables in arrays

mode_es_(sic, naics, county, owner_code, ein)_miss $\quad 0=$ Variable is not missing

$1=$ Variable is missing before using information from other quarters.

$2=$ Variable is not missing after search for off quarter information.

$6=$ Variable is missing, filled with imputed value. Currently only used for SIC.

11 = variable missing, but value set to 5. Currently only used for owner_code. Assume records with missing ownership codes are private firms.

mode_es_(sic, naics, county, owner_code, ein)_emp_miss $\quad 0=$ Variable is not missing

$1=$ Variable is missing before using information from other quarters.

$2=$ Variable is missing, filled with off quarter information.

$5=$ Variable is missing, filled with the corresponding unit weighted value

$6=$ Variable is missing, filled with imputed value. Currently only used for SIC.

11 = variable missing, but value set to 5. Currently only used for owner_code. Assume records with missing ownership codes are private firms.

mode_es_(sic, naics, county, owner_code, ein)_flag $\quad$ Missing $=$ No information in other quarters

$0=$ Variable is not missing in current quarter

$\iota_{0}=$ quarter after the current quarter where replacement value is found

$¡ 0=$ quarter before the current quarter where replacement value is found

SEIN mode variables missing values are replaced. Missing codes are adjusted. See program 13 for an explanation of valid values.

SEINUNIT mode variables missing values are replaced. Missing codes are adjusted. See program 10 for an explanation of valid values.

es_sic_div SIC divisions $(\mathrm{A}, \mathrm{B}, \mathrm{C}, \ldots, \mathrm{Z})$

ES_SIC_2 First 2 digits of the 4 digit SIC

ES_SIC_3 First 3 digits of the 4 digit SIC

ES_NAICS_2 First 2 digits of the 6 digit NAICS

ES_NAICS_3 First 3 digits of the 6 digit NAICS

Only temporary variables used in the calculation of the weights are created.

qwi_unit_weight = Final ECF weight. See technical documentation for the weights for detailed information.

$$
\text { Suppressed for confidentiality }
$$

No new variables are created.

DATE_(SEIN, SEINUNIT)_FUZZ SAS date value for when the fuzz factor was created. 
UPDATE_NUMBER_(SEIN, SEINUNIT) Sequential update number. The first time the ECF is created all fuzz factors receive a value of 0 . The value is incremented by 1 each time any fuzz factors are added to the master file.

\subsection{NAICS CODES ON THE ECF}

Enhanced North American Industry Coding System (NAICS) variables are available on all ECF since February 2003. The variable list below shows that there are 75 new variables for NAICS alone. The variables can be differentiated mainly by the source(s) and coding system used in their creation. There are two sources of data; the ES202 and the Longitudinal Data Base (LDB) from the BLS: and two coding systems; NAICS1997 and NAICS2002 (see the Census web site for more info.). Every NAICS variable uses at least one source and one coding system.

The ESO and FNL variables are of primary importance to the user community. The ESO variables use ONLY information from the ES202 and ignore any information that may be available on the LDB (see Section3.4.2 for some analysis on why this may be preferred). The FNL variables incorporate information from both the ES202 and the LDB, with the LDB being the dominant source. The ES_NAICS_FNL1997 and ES_NAICS_FNL2002 should be used to create the QWI estimates. Neither the ESO and the FNL variables contain missing values.

\subsubsection{A note on naming conventions}

The variable naming conventions used for internal LEHD files, from which the RDC version of the ECF is derived, stems from the early days of the LEHD program in 1999, and the ES-202 file layout at the time. Since then, the BLS and its partners have implemented a name change for NAICS-related variables (see ES-202 Technical Memorandum No. S-02-01):

- NAICS $\rightarrow$ NSTA (NAICS-SIC Treatment of Auxiliaries)

- AUXNAICS $\rightarrow$ NAICS (official NAICS coding)

At LEHD, the internal ES202 variable naming scheme for NAICS/NAICS_AUX remains unchanged for compatibility reasons, and this naming scheme carries through into the ECF. Please keep this in mind while reading this document, and while using the ECF.

\subsubsection{LDB versus LEHD NAICS backcoding}

The LDB algorithm is to some extent a black box and testing has shown that it does a relatively poor job of capturing firm industry changes that occurred during the 1990's. In fact, the LDB appears to be a simple backfill that does not take into account a firm's entire SIC history.

Although some of the SIC changes over time may be spurious, a firm's SIC code history contains valuable information that we have attempted to preserve in our imputation algorithm. Overall, the effect of the different approaches is relatively small, since very few firms change industry, in particular relative to the proportion of firms that change geography.

In the following, we present a summary of research done on the ESO vs. FNL NAICS codes.

The NAICS_LDB variable is used for about $85 \%$ of the records for Illinois, the rest are filled with information from the ES202 (not sure why only $85 \%$ of the records on our ES202 files are in the LDB. The results weighted by employment are about the same suggesting that activity was not a criterion for being included on the LDB). First and not surprisingly, in later years and quarters (1999+) when NAICS is actively coded by the states, the codes look almost identical when available.

Second, there is little variation in the LDB NAICS codes over time compared with SIC. Among all of the active SEIN SEINUNITs over the period, a little over $8 \%$ experience at least one SIC change compared with about $1.5 \%$ on the LDB (almost all of these are 1999+). While this is not entirely unexpected, it is 
CHAPTER 3. EMPLOYER CHARACTERISTICS FILE (ECF)

something to keep in mind when comparing NAICS_FNL versus SIC or NAICS_ESO employment totals. Many of these changes in industry appear to be real and are not captured on the LDB.

One effect of this is that as we go back in time a larger portion of employment can be found in NAICS_FNL codes that are different than one would expect given the SIC code on the ECF. For example, in 1990 about $13 \%$ of employment is in a NAICS_FNL code that is different than what we would expect based on the SIC. By 2001 this number falls to 3\%. The ES202 based NAICS variable does a better job tracking SIC, since more SIC information is used in putting it together (about $3 \%$ consistently over the period).

The main source of the discrepancy is due to entities that experience a change in their SIC code prior to 2000. The LDB appears to ignore this change, while the ESO NAICS variable uses an SIC based impute for these SEINUNITS. The result is a series that exhibits similar patterns of change over time as SIC, while still preserving the value added in the NAICS codes for entities that did not experience a change.

Also, users should keep in mind that for early years (i1997) some of the NAICS industries have yet to come into existence. I have no estimates on the prevalence of this problem.

\subsubsection{Variable List}

\begin{tabular}{|l|l|l|}
\hline Variable Name & Source & Notes \\
\hline \hline es_naics_aux1997 & ES202 NAICS AUX variable & BLS coding of aux estabs \\
\hline es_naics_aux1997_flag & & \\
\hline es_naics_aux1997_miss & & \\
\hline es_naics_aux1997_src & & \\
\hline es_naics_aux2002 & & \\
\hline es_naics_aux2002_flag & & \\
\hline es_naics_aux2002_miss & & \\
\hline es_naics_aux2002_src & ES202 NAICS AUX, NAICS, SIC & Only ES202 info used \\
\hline es_naics_eso1997 & & \\
\hline es_naics_eso1997_miss & & \\
\hline es_naics_eso1997_src & & \\
\hline es_naics_eso2002 & & \\
\hline es_naics_eso2002_miss & & All industry info used \\
\hline es_naics_eso2002_src & BLS LDB and ESO Input vars. & \\
\hline es_naics_fnl1997 & & \\
\hline es_naics_fnl1997_2 & & \\
\hline es_naics_fnl1997_3 & & \\
\hline es_naics_fnl1997_4 & & \\
\hline es_naics_fnl1997_5 & & \\
\hline es_naics_fnl1997_miss & & \\
\hline es_naics_fnl1997_src & & \\
\hline es_naics_fnl2002 & & \\
\hline es_naics_fnl2002_2 & & \\
\hline es_naics_fnl2002_3 & & \\
\hline es_naics_fnl2002_4 & & \\
\hline es_naics_fnl2002_5 & & \\
\hline es_naics_fnl2002_miss & & \\
\hline es_naics_fnl2002_src & & \\
\hline es_naics_imp1997 & & \\
\hline es_naics_imp1997_miss & & \\
\hline es_naics_imp1997_src & & \\
\hline es_naics_imp2002 & & \\
\hline es_naics_imp2002_miss & & \\
\hline & & \\
\hline
\end{tabular}


CHAPTER 3. EMPLOYER CHARACTERISTICS FILE (ECF)

\begin{tabular}{|c|c|c|}
\hline Variable Name & Source & Notes \\
\hline es_naics_imp2002_src & & \\
\hline es_naics_ldb1997 & BLS LDB NAICS variable & \\
\hline es_naics_ldb1997_flag & & \\
\hline es_naics_ldb1997_miss & & \\
\hline es_naics_ldb1997_src & & \\
\hline es_naics_ldb2002 & & \\
\hline es_naics_ldb2002_flag & & \\
\hline es_naics_ldb2002_miss & & \\
\hline es_naics_ldb2002_src & & \\
\hline es_naics1997 & ES202 NAICS Only & \\
\hline es_naics1997_flag & & \\
\hline es_naics1997_miss & & \\
\hline es_naics1997_src & & \\
\hline es_naics2002 & & \\
\hline es_naics2002_flag & & \\
\hline es_naics2002_miss & & \\
\hline es_naics2002_src & & \\
\hline mode_es_naics_eso1997 & Mode of ESO SEINUNIT var & \\
\hline mode_es_naics_eso1997_emp & & \\
\hline mode_es_naics_eso1997_emp_flag & & \\
\hline mode_es_naics_eso1997_emp_miss & & \\
\hline mode_es_naics_eso1997_flag & & \\
\hline mode_es_naics_eso1997_miss & & \\
\hline mode_es_naics_eso2002 & & \\
\hline mode_es_naics_eso2002_emp & & \\
\hline mode_es_naics_eso2002_emp_flag & & \\
\hline mode_es_naics_eso2002_emp_miss & & \\
\hline mode_es_naics_eso2002_flag & & \\
\hline mode_es_naics_eso2002_miss & & \\
\hline mode_es_naics_fnl1997 & Mode of FNL SEINUNIT var & \\
\hline mode_es_naics_fnl1997_emp & & \\
\hline mode_es_naics_fnl1997_emp_flag & & \\
\hline mode_es_naics_fnl1997_emp_miss & & \\
\hline mode_es_naics_fnl1997_flag & & \\
\hline mode_es_naics_fnl1997_miss & & \\
\hline mode_es_naics_fnl2002 & & \\
\hline mode_es_naics_fnl2002_emp & & \\
\hline mode_es_naics_fnl2002_emp_flag & & \\
\hline mode_es_naics_fnl2002_emp_miss & & \\
\hline mode_es_naics_fnl2002_flag & & \\
\hline mode_es_naics_fnl2002_miss & & \\
\hline
\end{tabular}

\subsubsection{Coding of MISS and SRC}

Each new NAICS variable has several associated variables of which the miss and src variable are the most important. 


\subsubsection{MISS Variable Codes}

If information from another period is used, the flag variable reports how many quarters away the NAICS value was found. Values greater than six should only appear in SEINUNIT level variables. If NAICS is missing for all quarters, then the SEINUNIT value has been filled with the SEIN value. The SEINUNIT codes represent the SEIN value +5 .

Table 3.6: MISS Variable Codes

$\begin{aligned} 0= & \text { Valid value available in that period } \\ 1= & \text { Missing } \\ 1.5= & \text { (1999 and earlier only) Filled using impute based on SIC due to } \\ 2= & \text { Filled using own code from another period } \\ 3= & \text { Filled from another source contemporaneously } \\ 5= & \text { Filled using the non-employ weight mode (SEIN mode var only) } \\ 6= & \text { Unconditionally imputed (SEIN mode var only) } \\ 6= & \text { NAICS imputed using SIC unconditional impute (SEIN mode var } \\ 7= & \text { Filled using the SEIN mode from another period (sic, fnl and eso } \\ & \text { vars only) } \\ & \text { Filled using unconditional impute of SEIN value (sic, fnl and eso } \\ & \text { vars only) }\end{aligned}$

\subsubsection{SRC Variable Codes}

The ESO and FNL variables use the following source codes. If more detail is desired about the source of the NAICS code, the user must look to the SRC code for that source. For example, if the ESO source code for ES_NAICS_ESO1997 says NCS, then the actual SRC information will be found in ES_NAICS1997_SRC.

Table 3.7: SRC Variable: ESO, FNL

$\begin{aligned} \text { AUX } & =\text { Source is the ES202 NAICS AUX variable } \\ \text { LDB } & =\text { Source is the LDB NAICS variable } \\ \text { NCS } & =\text { Source is the ES202 NAICS variable } \\ \text { SIC } & =\text { Source is the ES202 SIC code }\end{aligned}$

The AUX, LDB and standard NAICS codes have the following source variables.

Table 3.8: SRC Variable: AUX, LDB, NAICS

SIC $=$ Source is the ES202 SIC code

$\mathrm{NO} 2=$ Source is a NAICS 2002 Code

N97 $=$ Source is a NAICS 1997 Code

\subsubsection{NAICS algorithm precedence ordering}

Four basic sources of industry information are available on the ECF; NAICS, NAICS_AUX, SIC, and the NAICS_LDB. The NAICS, NAICS_AUX, and NAICS_LDB missing values were filled using the following 
preference ordering. SIC is filled similarly, except miss $=1.5$ is not used and NAICS, not SIC, would be the basis for the impute when miss $=3$.

1. Valid 6 digit industry code $($ miss $=0)$

2. Imputed code based on first 3,4 , or 5 digits when no valid six digit code is available in another period $($ miss $=0)$

3. Imputed code based on contemporaneous SIC if SIC changed prior to 2000 (miss=1.5)

4. Valid 6 digit code from another period $(\operatorname{miss}=2)$

5. Valid code from another source (for example if NAICS1997 is missing, NAICS2002 or SIC may be available) $($ miss $=3)$

6. Use SEIN mode value $($ miss $=5,7)$

7. Unconditional impute (miss $=6,11)$

\subsubsection{ESO and FNL variables}

The ESO and FNL variables are made up of combinations of the various sources of industry information. The ESO variable uses the NAICS and NAICS_AUX variables as input. Information from the variable with the lowest MISS value is preferred although in case of a tie the NAICS_AUX value is used.

The FNL variable uses the ESO and LDB variables. Information from the variable with the lowest MISS value is preferred although in case of a tie the NAICS_LDB value is used. Keep in mind that although the source of an ESO or FNL variable may be equal to NCS, the actual source can only be ascertained by going back to the original.

\subsubsection{Employment Flag Variable Codes}

All current uses of the ECF have been forced to assume that employment and payroll information has been reported by the firm, although under certain conditions the ES202 processing specifications require imputation of missing values. The flag values below allow the user to determine when imputation has occurred.

The master record contains valuable information that has been preserved in the master_empl_month1_flg -master_total_wages_flg variables. For example, one should theoretically be able to distinguish 0 prorated codes from 0 unknowns by looking at multi units with masters that reported (code $=1)$ and subunits with a zero.

The following information stems from an email exchange between Kevin McKinney (U.S. Census Bureau) and George Putnam (Illinois) on 12/15/2003.

Employment Flag Variable Codes Prior to late 1995:

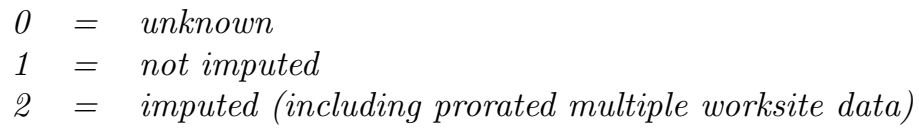

Late 1995 or early 1996:

$0=$ prorated data (multiple worksites)

$1=$ actual or not imputed data

$2=$ estimated data

1997 first quarter forward (ES202 processing manual, Appendix B): 


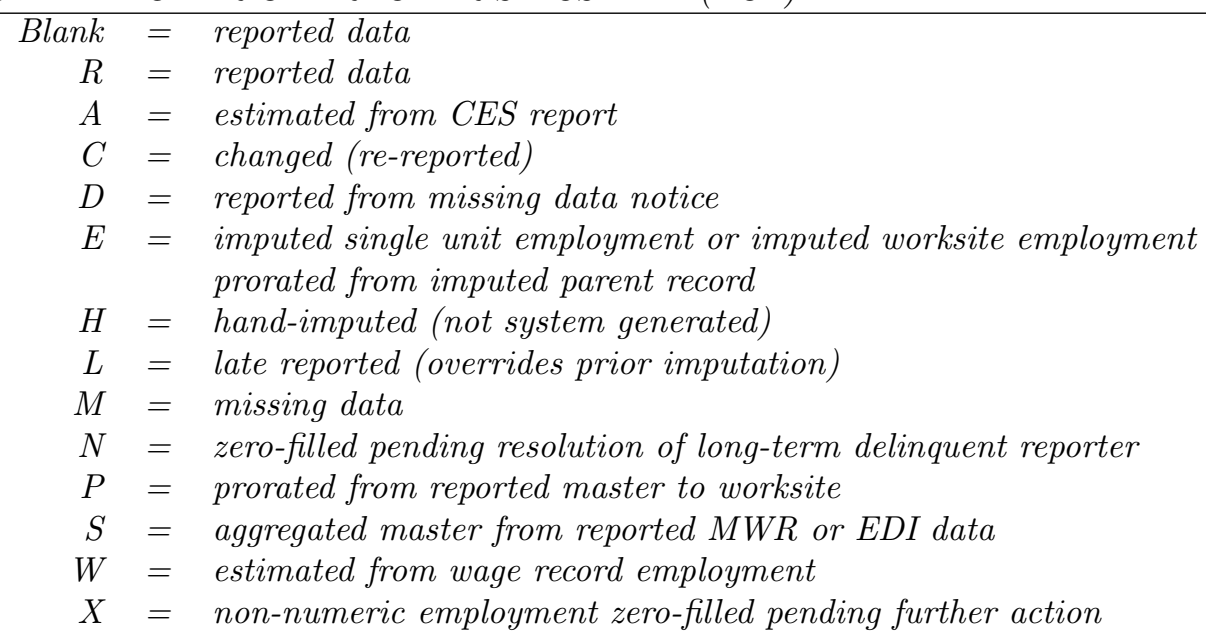

\subsubsection{Multi-Unit Code or MEEI}

The MULTI_UNIT variable on the ECF is determined by counting the number of SEINUNIT records for a given SEIN once the master records have been removed. However, some multiunit firms refuse to report detailed information for their sub-units and appear as single units on the ECF. The table below provides an estimate of the magnitude of multiunit firms refusing to report detailed unit information using data from Illinois.

\begin{tabular}{lll} 
& & MULTI_UNIT \\
\hline MULTI_UNIT_CODE & 0 & 1 \\
\hline 1 & $1,483,808$ & 0 \\
2 & 1 & 0 \\
3 & 120 & 155859 \\
4 & 5808 & 0 \\
5 & 0 & 33 \\
6 & 13899 & 0 \\
\hline
\end{tabular}

Prior to 1997 (ES202 processing manual sent from George Putnam):

$$
\begin{aligned}
1= & \text { Single establishment unit } \\
2= & \text { Multi-unit master record } \\
3= & \text { Subunit establishment level record for a multi-unit employer } \\
4= & \text { Multi-establishment employer reporting as a single unit due to } \\
& \text { unavailability of data, including refusals } \\
5= & \text { A subunit record that actually represents a combination of estab- } \\
& \text { lishments; finer level breakouts are not yet available } \\
6= & \begin{array}{l}
\text { Known multi establishment employer reporting as a single unit } \\
\text { and not solicited for disaggregation because of small employment } \\
\\
(<10) \text { in all secondary establishments combined }
\end{array}
\end{aligned}
$$

1997 first quarter forward (ES202 processing manual, Appendix B): 


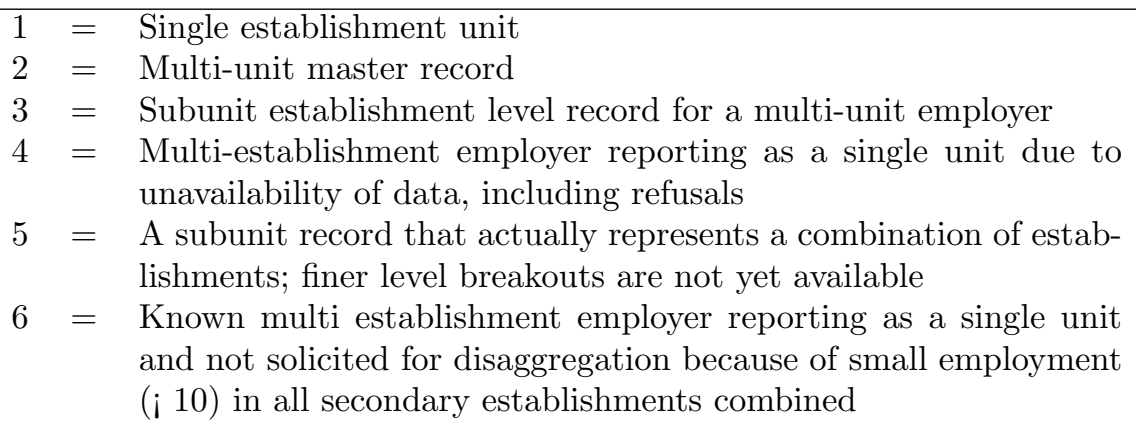

\subsubsection{Auxiliary Code}

This variable gives detailed information about firm locations that do not directly engage in production related activities.

Prior to 1997 (ES202 processing manual sent from George Putnam):

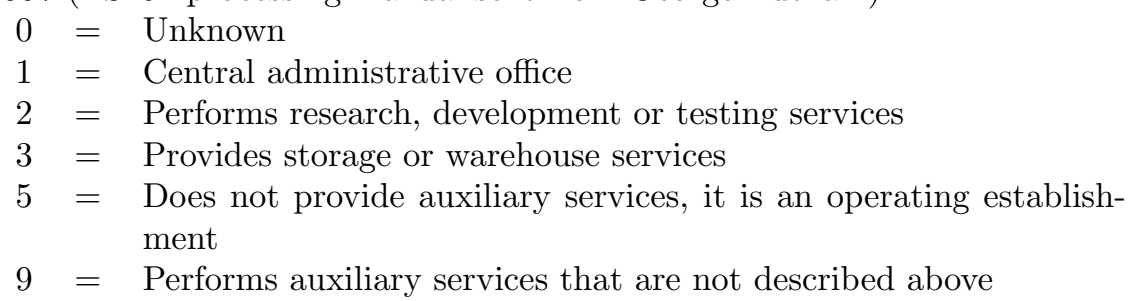

1997 first quarter forward (ES202 processing manual, Appendix B):

$0=$ Auxiliary status not known

$1=$ Central administrative office

$2=$ Performs research, development or testing services

$3=$ Provides storage or warehouse services

$5=$ Does not provide auxiliary services, it is an operating establishment

$6=$ Headquarters

$7=$ Administrative, Other than Headquarters

$9=$ Performs auxiliary services that are not described above 
CHAPTER 3. EMPLOYER CHARACTERISTICS FILE (ECF)

\subsubsection{Summary information on datasets}

Table 3.9: File information, by state, by group, for ECF

\begin{tabular}{|c|c|c|c|c|c|c|c|}
\hline State & & Group & $\begin{array}{r}\text { Number of } \\
\text { datafiles }\end{array}$ & Records & $\begin{array}{r}\text { Filesizes } \\
(\mathrm{MB})\end{array}$ & Start & End \\
\hline Covered states & & & 64 & $587,237,341$ & $240,012.05$ & 1989Q1 & 2004Q3 \\
\hline Alabama & $\mathrm{AL}$ & ecf & 2 & $3,426,165$ & $1,685.48$ & 2001Q1 & $2004 \mathrm{Q} 2$ \\
\hline Arkansas & $\mathrm{AR}$ & ecf & 2 & 954,157 & 452.49 & 2002Q3 & 2004Q1 \\
\hline California & CA & ecf & 2 & $99,129,182$ & $46,282.81$ & 1991Q1 & 2003Q4 \\
\hline California & CA & ecft26 & 2 & $99,129,182$ & $7,009.10$ & 1991Q1 & 2003Q4 \\
\hline Colorado & $\mathrm{CO}$ & ecf & 2 & $14,146,330$ & $6,879.70$ & 1990Q1 & 2004Q1 \\
\hline Delaware & $\mathrm{DE}$ & ecf & 2 & $1,416,157$ & 652.81 & 1997Q1 & 2004Q1 \\
\hline Florida & FL & ecf & 2 & $47,026,785$ & $22,337.79$ & 1989Q1 & 2004Q1 \\
\hline Iowa & IA & ecf & 2 & $9,009,472$ & $4,238.50$ & 1990Q1 & 2004Q1 \\
\hline Idaho & ID & ecf & 2 & $4,144,272$ & $2,002.11$ & 1991Q1 & 2004Q1 \\
\hline Illinois & IL & ecf & 2 & $34,401,303$ & $16,368.45$ & 1990Q1 & 2004Q1 \\
\hline Indiana & IN & ecf & 2 & $7,052,084$ & $3,441.49$ & 1998Q1 & 2004Q1 \\
\hline Kansas & $\mathrm{KS}$ & ecf & 2 & $8,318,828$ & $3,989.95$ & 1990Q1 & 2004Q1 \\
\hline Kentucky & $\mathrm{KY}$ & ecf & 2 & $2,601,098$ & $1,250.75$ & 2001Q1 & 2004Q1 \\
\hline Maryland & $\mathrm{MD}$ & ecf & 2 & $15,154,168$ & $7,418.82$ & 1990Q1 & 2004Q1 \\
\hline Maine & $\mathrm{ME}$ & ecf & 2 & $3,224,812$ & $1,520.61$ & 1996Q1 & 2004Q1 \\
\hline Minnesota & $\mathrm{MN}$ & ecf & 2 & $12,615,016$ & $6,443.17$ & 1994Q3 & 2004Q3 \\
\hline Missouri & MO & ecf & 2 & $18,680,950$ & $8,929.59$ & 1990Q1 & 2004Q1 \\
\hline Montana & MT & ecf & 2 & $3,129,539$ & $1,470.77$ & 1993Q1 & 2004Q1 \\
\hline North Carolina & $\mathrm{NC}$ & ecf & 2 & $21,788,368$ & $10,261.29$ & 1990Q1 & 2003Q4 \\
\hline North Dakota & ND & ecf & 2 & $1,185,496$ & 563.73 & 1998Q1 & 2004Q2 \\
\hline New Jersey & NJ & ecf & 2 & $20,480,777$ & $9,808.47$ & 1995Q1 & 2004Q1 \\
\hline New Mexico & NM & ecf & 2 & $4,869,480$ & $2,209.05$ & 1990Q1 & 2004Q1 \\
\hline Oklahoma & OK & ecf & 2 & $3,836,973$ & $1,809.45$ & 1999Q1 & 2004Q1 \\
\hline Oregon & OR & ecf & 2 & $11,116,430$ & $5,359.66$ & 1990Q1 & 2004Q1 \\
\hline Pennsylvania & PA & ecf & 2 & $30,066,151$ & $14,616.05$ & 1991Q1 & 2004Q1 \\
\hline South Carolina & $\mathrm{SC}$ & ecf & 2 & $5,673,122$ & $2,835.70$ & 1998Q1 & 2004Q3 \\
\hline Texas & TX & ecf & 2 & $51,261,545$ & $24,614.88$ & 1990Q1 & 2004Q2 \\
\hline Virginia & VA & ecf & 2 & $11,760,264$ & $5,676.17$ & 1995Q3 & 2004Q1 \\
\hline Vermont & VT & ecf & 2 & 767,752 & 361.20 & 2000Q1 & 2004Q1 \\
\hline Washington & WA & ecf & 2 & $20,776,265$ & $9,895.98$ & 1990Q1 & 2004Q1 \\
\hline Wisconsin & WI & ecf & 2 & $15,102,565$ & $7,288.20$ & 1990Q1 & 2004Q1 \\
\hline West Virginia & WV & ecf & 2 & $4,992,653$ & $2,337.84$ & 1990Q1 & 2004Q1 \\
\hline
\end{tabular}




\subsection{HELPFUL PROGRAMS}

The following programs might be found to be useful when using the data.

\subsubsection{Combining regular ECF data with ECF T26 files}

The following program was used to verify that the T26 data split from the ECF for California cleanly matches back on. It can be used by researches wishing to integrate the T26 into their ECF-based analytical files.

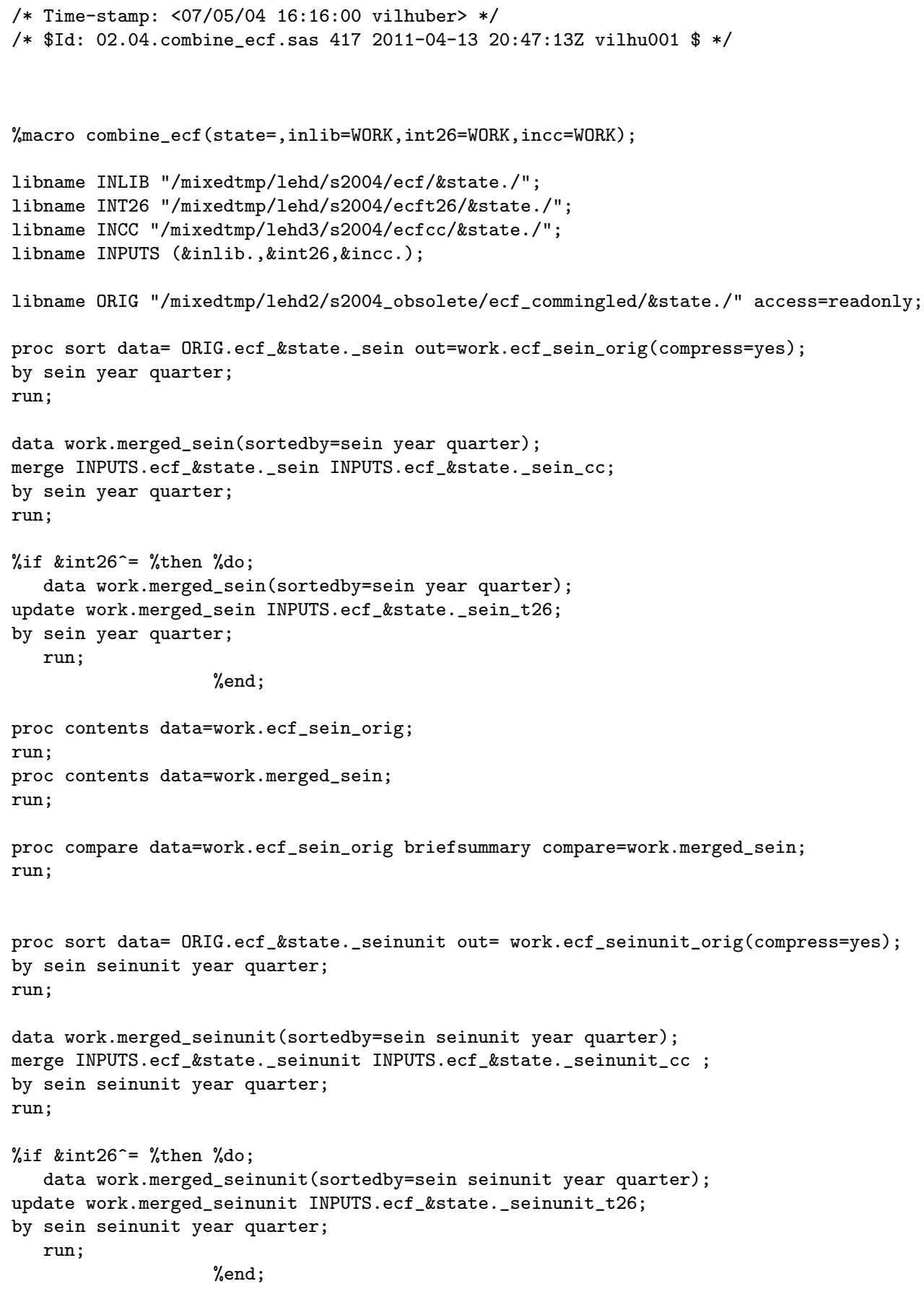




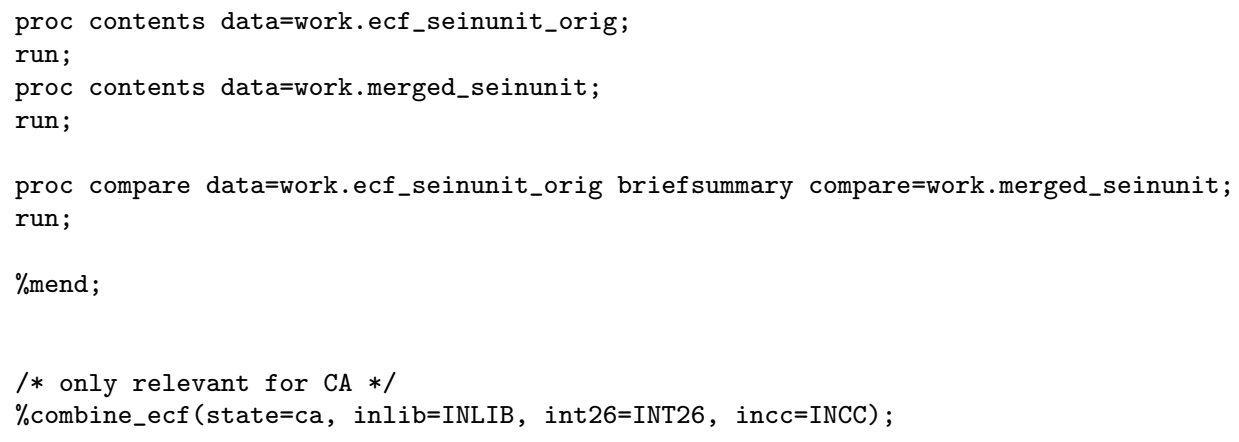

\subsubsection{Selecting a random sample of establishments}

The ECF files can be large, and researchers may wish to analyze only a random subsample of firms. The variables SAMPLE_SEIN and SAMPLE_SEINUNIT can be used to select a random sample of the ECF. To do this in a space-efficient way, the following code can be used as a template.

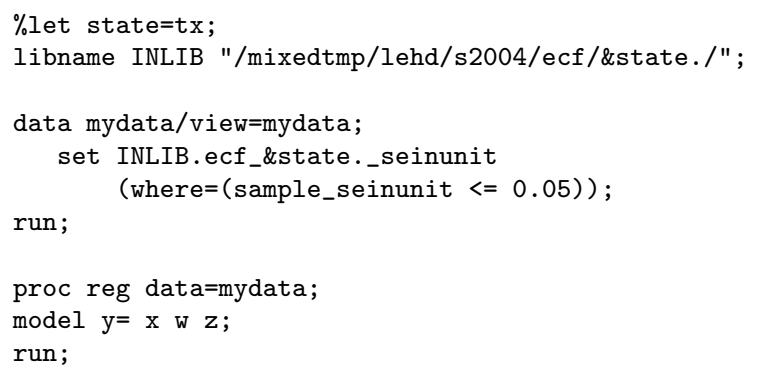

The code above uses a VIEW, which means the dataset is constructed on the fly as it is used in the analysis procedure. Although overall disk usage is not necessarily smaller when using random access (as the SAS regression procedure apparently does), it is still faster. For other processes using sequential access only, in particular simple DATA steps, a view will be space-efficient because only the relevant observations are streamed into any intermediate data files. 


\subsection{NOTES}

- In the current (S2004) files, there are no es_galid or leg_galid variables on the NC and NM ECF_state_seinunit files. Solution: Use the GAL_state_xwlk_YYYY files if needing to link to the GAL. 


\section{Chapter 4. Employment History Files (EHF)}

\subsection{OVERVIEW}

The Employment History Files (EHF) are designed to store the complete in-state work history for each individual that appears in the UI wage records. The EHF for each state contains one record for each employeeemployer combination-a job-in that state in each year. Both annual and quarterly earnings variables are available in the EHF. Individuals who are employed, but never have strictly positive earnings at their employing SEIN (a theoretical possibility) in a given year do not have a record in the EHF for that year. To facilitate analysis, the EHF data are restructured into another file containing one observation per job (PIK-SEIN combination), with all quarterly earnings and activity information available on that record. The restructured file is called the Person History File (PHF). It should be noted that the actual file structure is at the PIK-SEIN-SEINUNIT-YEAR level for the EHF, and at the PIK-SEIN-SEINUNIT level for the PHF. Although only one state (Minnesota) has non-zero values for SEINUNIT, this allows the file structure to be homogeneous across states. An active job within a quarter, the primary job-level economic activity measure, is defined as having strictly positive quarterly earnings for the individual-employer pair that define the job.

A time-series similar to the aggregated job data, but based on observed activity (positive employment) in the ES-202 records, is available and computed at the SEINUNIT level (Unit History File, UHF) and the SEIN level (SEIN History File, SHF). 


\section{$4.2 \quad$ INPUT FILES}

\subsubsection{Wage records: UI}

Wage records correspond to the report of an individual's UI-covered earnings by an employing entity, identified by a state UI account number (called the SEIN in the LEHD system). An individual's UI wage record is retained in the processing if at least one employer reports earnings of at least one dollar for that individual during the quarter. Thus, an in-scope job must produce at least one dollar of UI-covered earnings during a given quarter in the LEHD universe. Maximum earnings reported are defined in a specific state's unemployment insurance system, and observed top-coding varies across states and over time.

A record is completed with information on the individual's Social Security Number (later replaced with the PIK within the LEHD system), first name, last name, and middle initial. A few states include additional information: the firm's reporting unit or establishment (SEINUNIT), available for Minnesota, and a crucial component to the Unit-to-Worker impute described later; weeks worked, available for some years in Florida; hours worked, available for Washington and Minnesota state.

Current UI wage records are reported for the quarter that ended approximately six months prior to the reporting date at Census (the first day of the calendar quarter). Wage records are also reported for the quarter that the state considers "final" in the sense that revisions to its administrative UI wage record data base after that date are relatively rare. This quarter typically ends nine months prior to the reporting date. Historical UI wage records were assembled by the partner states from their administrative record backup systems.

\subsubsection{Employer reports: ES-202}

The employer reports are based on information from each state's Department of Employment Security. The data are collected as part of the Covered Employment and Wages (CEW) program, also known as the ES-202 program, which is jointly administered by the BLS and the Employment Security Agencies in a federal-state partnership. This cooperative program between the states and the federal government collects employment, payroll, and economic activity, and physical location information from employers covered by state unemployment insurance programs and from employers subject to the reporting requirements of the ES-202 system. The employer and work place reports from this system are the same as the data reported to the BLS as part of the Quarterly Census of Employment and Wages (QCEW), but are referred to in the LEHD system by their old acronym "ES-202." The universe for these data is a 'reporting unit,' which is the QCEW establishment-the place where the employees actually perform their work. Most employers have one establishment ('single-units'), but most employment is with employers who have multiple establishments ('multi-units'). One report per establishment per quarter is filed. These data are also used to compile the QCEW and the Business Employment Dynamics (BED) data at the BLS.

The information contained in the ES-202 reports has increased substantially over the years. Employers report wages subject to statutory payroll taxes on this form, together with some other information. Common to all years, and critical to LEHD processing, are information on the employer's identity (the SEIN), the reporting unit's identify (SEINUNIT), ownership information, employment on the 12th of each month covered by the quarter, and total wages paid over the course of the quarter. Additional information pertains to industry classifications (initially SIC, and later NAICS). Other information include the federal EIN, geography both at a high level (county or MSA) and low level (physical location street address and mailing address). A recent expansion of the standard report's record layout has increased the informational content substantially. The LEHD Infrastructure File system is, fundamentally, a job-based frame designed to be represent the universe of individual-employer pairs covered by state unemployment insurance system reporting requirements. Thus, the underlying data are wage records extracted from Unemployment Insurance (UI) administrative files from each LED partner state. In addition to the UI wage records, LED partner states also deliver an extract of the file reported to the Bureau of Labor Statistic's Quarterly Census of Employment and Wages (QCEW, formerly known as ES-202). These data are received by LEHD on a quarterly basis, with historical time series extending back to the early 1990s for many states. 


\subsection{DATA SET DESCRIPTIONS}

\subsubsection{Naming scheme}

All files start with ehf:

ehf_zz_controltotals.sas7bdat

ehf_zz_phf .sas7bdat

ehf_zz.sas7bdat

ehf_zz_sein_employment.sas7bdat

ehf_zz_shf.sas7bdat

ehf_zz_uhf .sas7bdat

ehf_zz_uniqpik.sas7bdat

ZZ stands for the state postal abbreviation. The main EHF file has no suffix, other files have a suffix. You will find zero-observation SAS datasets attached to this document - see the attachment tab.

\subsubsection{Data location}

The files are stored in two main directories, with state-specific subdirectories:

ehf/ZZ/ for most files

No files in the EHF process contain Title 26 data. On the RDC network, the directory can be found under /mixed/lehd/current 


\subsubsection{UI-based Output Files}

\subsubsection{EHF}

The EHF is designed to store the complete in-state work history for each individual that appears in the UI wage records. The EHF for each state contains one record for each employee-employer combination in that state in each year. Every individual who is employed during a given year will then have one observation per employer for that year. Annual earnings and quarterly earnings variables are present on the file. The presence of positive quarterly earnings is used in the job flow analysis not only to compute earnings and payroll statistics but also to determine an individual's employment status each quarter.

The EHF (ehf_\&state.) is organized by PIK-SEIN-SEINUNIT-YEAR. Note that all states except Minnesota (MN) have SEINUNIT='00000', so this reverts back to PIK-SEIN-YEAR for all states except $\mathrm{MN}$.

Record identifier PIK-SEIN-SEINUNIT-YEAR

Sort order PIK-SEIN-SEINUNIT-YEAR

Entity Job

Unique Entity Key PIK-SEIN-SEINUNIT

\begin{tabular}{l|l|c|c|c}
\hline \multicolumn{1}{c|}{ Field name } & $\begin{array}{l}\text { Data dictionary } \\
\text { reference name }\end{array}$ & $\begin{array}{l}\text { Starting } \\
\text { position }\end{array}$ & $\begin{array}{l}\text { Field } \\
\text { size }\end{array}$ & $\begin{array}{l}\text { Data } \\
\text { type }\end{array}$ \\
\hline Annual earnings & EARN_ANN & 00003 & 5 & $\mathrm{~N}$ \\
Calendar year & YEAR & 00000 & 3 & $\mathrm{~N}$ \\
Protected Identification Key & PIK & 00028 & 9 & $\mathrm{~A} / \mathrm{N}$ \\
Qtr 1 earnings & EARN1 & 00008 & 5 & $\mathrm{~N}$ \\
Qtr 2 earnings & EARN2 & 00013 & 5 & $\mathrm{~N}$ \\
Qtr 3 earnings & EARN3 & 00018 & 5 & $\mathrm{~N}$ \\
Qtr 4 earnings & EARN4 & 00023 & 5 & $\mathrm{~N}$ \\
Source of data (FIPS state code/0=Fed) & SOURCE & 00037 & 2 & $\mathrm{~A} / \mathrm{N}$ \\
State Employer Identification Number & SEIN & 00041 & 12 & $\mathrm{~A} / \mathrm{N}$ \\
State UI Reporting Unit Number & SEINUNIT & 00053 & 5 & $\mathrm{~A} / \mathrm{N}$ \\
Type of source & SOURCETP & 00039 & 2 & $\mathrm{~A} / \mathrm{N}$
\end{tabular}




\subsubsection{2 (proto-)PHF}

The proto PHF is a reformatted version of the EHF. Rather than having one record per year, the PHF is organized by "job", or unique employee-employer combination, identified by PIK-SEIN(-SEINUNIT), with cmplete historical arrays for earnings and employment status. It is not to be confused with the PHF_B of the QWI sequence, which is augmented with information from the U2W process for non-MN states.

The PHF (ehf_\&state._phf) is organized by PIK-SEIN-SEINUNIT. Note that all states except MN have SEINUNIT='00000', so this reverts back to PIK-SEIN for all states except MN.

\section{Record identifier PIK-SEIN-SEINUNIT}

\section{Sort order PIK-SEIN-SEINUNIT}

Entity Job

Unique Entity Key PIK-SEIN-SEINUNIT

\begin{tabular}{|c|c|c|c|c|}
\hline Field name & $\begin{array}{l}\text { Data dictionary } \\
\text { reference name }\end{array}$ & $\begin{array}{l}\text { Starting } \\
\text { position }\end{array}$ & $\begin{array}{l}\text { Field } \\
\text { size }\end{array}$ & $\begin{array}{l}\text { Data } \\
\text { type }\end{array}$ \\
\hline Binary workhistory $\ldots 00111000 \ldots 1=$ employed & WORK & 00264 & 80 & $\mathrm{~A} / \mathrm{N}$ \\
\hline Employment in QTIME $=33$ & E33 & 00000 & 5 & $\mathrm{~N}$ \\
\hline Employment in QTIME $=34$ & E34 & 00005 & 5 & $\mathrm{~N}$ \\
\hline Employment in QTIME $=35$ & E35 & 00010 & 5 & $\mathrm{~N}$ \\
\hline Employment in QTIME $=36$ & E36 & 00015 & 5 & $\mathrm{~N}$ \\
\hline Employment in QTIME $=37$ & E37 & 00020 & 5 & $\mathrm{~N}$ \\
\hline Employment in QTIME $=38$ & E38 & 00025 & 5 & $\mathrm{~N}$ \\
\hline Employment in QTIME $=39$ & E39 & 00030 & 5 & $\mathrm{~N}$ \\
\hline Employment in QTIME $=40$ & E40 & 00035 & 5 & $\mathrm{~N}$ \\
\hline Employment in QTIME $=41$ & E41 & 00040 & 5 & $\mathrm{~N}$ \\
\hline Employment in QTIME $=42$ & $\mathrm{E} 42$ & 00045 & 5 & $\mathrm{~N}$ \\
\hline Employment in QTIME $=43$ & E43 & 00050 & 5 & $\mathrm{~N}$ \\
\hline Employment in QTIME $=44$ & E44 & 00055 & 5 & $\mathrm{~N}$ \\
\hline Employment in QTIME $=45$ & Е45 & 00060 & 5 & $\mathrm{~N}$ \\
\hline Employment in QTIME $=46$ & E46 & 00065 & 5 & $\mathrm{~N}$ \\
\hline Employment in QTIME $=47$ & $\mathrm{E} 47$ & 00070 & 5 & $\mathrm{~N}$ \\
\hline Employment in QTIME $=48$ & $\mathrm{E} 48$ & 00075 & 5 & $\mathrm{~N}$ \\
\hline Employment in QTIME $=49$ & E49 & 00080 & 5 & $\mathrm{~N}$ \\
\hline Employment in QTIME $=50$ & E50 & 00085 & 5 & $\mathrm{~N}$ \\
\hline Employment in QTIME $=51$ & E51 & 00090 & 5 & $\mathrm{~N}$ \\
\hline Employment in QTIME $=52$ & E52 & 00095 & 5 & $\mathrm{~N}$ \\
\hline Employment in QTIME $=53$ & E53 & 00100 & 5 & $\mathrm{~N}$ \\
\hline Employment in QTIME $=54$ & E54 & 00105 & 5 & $\mathrm{~N}$ \\
\hline Employment in QTIME $=55$ & E55 & 00110 & 5 & $\mathrm{~N}$ \\
\hline Employment in QTIME $=56$ & E56 & 00115 & 5 & $\mathrm{~N}$ \\
\hline Employment in QTIME $=57$ & E57 & 00120 & 5 & $\mathrm{~N}$ \\
\hline Employment in QTIME $=58$ & E58 & 00125 & 5 & $\mathrm{~N}$ \\
\hline Employment in QTIME $=59$ & E59 & 00130 & 5 & $\mathrm{~N}$ \\
\hline Employment in QTIME $=60$ & E60 & 00135 & 5 & $\mathrm{~N}$ \\
\hline Employment in QTIME $=61$ & E61 & 00140 & 5 & $\mathrm{~N}$ \\
\hline Employment in QTIME $=62$ & E62 & 00145 & 5 & $\mathrm{~N}$ \\
\hline Employment in QTIME $=63$ & E63 & 00150 & 5 & $\mathrm{~N}$ \\
\hline Employment in QTIME $=64$ & E64 & 00155 & 5 & $\mathrm{~N}$ \\
\hline Employment in QTIME $=65$ & E65 & 00160 & 5 & $\mathrm{~N}$ \\
\hline
\end{tabular}


CHAPTER 4. EMPLOYMENT HISTORY FILES (EHF)

\begin{tabular}{|c|c|c|c|c|}
\hline Field name & $\begin{array}{l}\text { Data dictionary } \\
\text { reference name }\end{array}$ & $\begin{array}{l}\text { Starting } \\
\text { position }\end{array}$ & $\begin{array}{l}\text { Field } \\
\text { size }\end{array}$ & $\begin{array}{l}\text { Data } \\
\text { type }\end{array}$ \\
\hline Employment in QTIME $=66$ & E66 & 00165 & 5 & $\mathrm{~N}$ \\
\hline Employment in QTIME $=67$ & E67 & 00170 & 5 & $\mathrm{~N}$ \\
\hline Employment in QTIME $=68$ & E68 & 00175 & 5 & $\mathrm{~N}$ \\
\hline Employment in QTIME $=69$ & E69 & 00180 & 5 & $\mathrm{~N}$ \\
\hline Employment in QTIME $=70$ & E70 & 00185 & 5 & $\mathrm{~N}$ \\
\hline Employment in QTIME $=71$ & E71 & 00190 & 5 & $\mathrm{~N}$ \\
\hline Employment in QTIME $=72$ & E72 & 00195 & 5 & $\mathrm{~N}$ \\
\hline Employment in QTIME $=73$ & E73 & 00200 & 5 & $\mathrm{~N}$ \\
\hline Employment in QTIME $=74$ & E74 & 00205 & 5 & $\mathrm{~N}$ \\
\hline Employment in QTIME $=75$ & E75 & 00210 & 5 & $\mathrm{~N}$ \\
\hline Employment in QTIME $=76$ & E76 & 00215 & 5 & $\mathrm{~N}$ \\
\hline Employment in QTIME $=77$ & E77 & 00220 & 5 & $\mathrm{~N}$ \\
\hline Employment in QTIME $=78$ & E78 & 00225 & 5 & $\mathrm{~N}$ \\
\hline Employment in QTIME $=79$ & E79 & 00230 & 5 & $\mathrm{~N}$ \\
\hline Employment in QTIME $=80$ & E80 & 00235 & 5 & $\mathrm{~N}$ \\
\hline Protected Identification Key & PIK & 00243 & 9 & $\mathrm{~A} / \mathrm{N}$ \\
\hline SEINUNIT imputed (never true, compatibility) & FLAG_SEINUNIT_IMPUTED & 00240 & 3 & $\mathrm{~N}$ \\
\hline State Employer Identification Number & SEIN & 00252 & 12 & $\mathrm{~A} / \mathrm{N}$ \\
\hline State UI Reporting Unit Number & SEINUNIT & 00344 & 5 & $\mathrm{~A} / \mathrm{N}$ \\
\hline
\end{tabular}




\subsubsection{UNIQPIK file}

The UNIQPIK file is an input to the ICF. It also contains some diagnostic information, such as the number of records overall per PIK. It used to be produced by the (legacy) UIPIK sequence (called ssnall there).

The UNIQPIK file (ehf_\&state._uniqpik) is organized by PIK.

Record identifier PIK

Sort order PIK

Entity Person

Unique Entity Key PIK

\begin{tabular}{l|l|c|c|c}
\hline \multicolumn{1}{c|}{ Field name } & $\begin{array}{l}\text { Data dictionary } \\
\text { reference name }\end{array}$ & $\begin{array}{l}\text { Starting } \\
\text { position }\end{array}$ & $\begin{array}{l}\text { Field } \\
\text { size }\end{array}$ & $\begin{array}{l}\text { Data } \\
\text { type }\end{array}$ \\
\hline Illegal SSN Range Flag & SSNFLAG & 00000 & 1 & $\mathrm{~A} / \mathrm{N}$ \\
Protected Identification Key & PIK & 00001 & 9 & $\mathrm{~A} / \mathrm{N}$ \\
cut=substr(pik,1,2) & CUT & 00010 & 9 & $\mathrm{~A} / \mathrm{N}$
\end{tabular}




\subsubsection{SEIN_EMPLOYMENT}

The SEIN_EMPLOYMENT is a SEIN-level measure of employment based on UI data.

The SEIN_EMPLOYMENT file (ehf_\&state._sein_employment) is organized by SEIN-YEAR. No SEINUNIT version exists.

\section{Record identifier SEIN-YEAR}

Sort order SEIN-YEAR

Entity Firm

\section{Unique Entity Key SEIN}

\begin{tabular}{l|l|c|c|c}
\hline \multicolumn{1}{c|}{ Field name } & $\begin{array}{l}\text { Data dictionary } \\
\text { reference name }\end{array}$ & $\begin{array}{l}\text { Starting } \\
\text { position }\end{array}$ & $\begin{array}{l}\text { Field } \\
\text { size }\end{array}$ & $\begin{array}{l}\text { Data } \\
\text { type }\end{array}$ \\
\hline Beginning of quarter employment & $\mathrm{B}$ & 00016 & 8 & $\mathrm{~N}$ \\
Beginning of quarter employment & $\mathrm{E}$ & 00008 & 8 & $\mathrm{~N}$ \\
Flow employment & $\mathrm{M}$ & 00000 & 8 & $\mathrm{~N}$ \\
Quarter & QUARTER & 00035 & 3 & $\mathrm{~N}$ \\
State Employer Identification Number & SEIN & 00038 & 12 & $\mathrm{~A} / \mathrm{N}$ \\
Total earnings during the quarter & W1 & 00024 & 8 & $\mathrm{~N}$ \\
Year & YEAR & 00032 & 3 & $\mathrm{~N}$ \\
Year-Quarter YYYY:Q & YR_QTR & 00050 & 6 & $\mathrm{~A} / \mathrm{N}$
\end{tabular}




\subsubsection{ES202-based Output Files}

\subsubsection{UHF}

The UHF (Unit History File) used to be produced by the SPF (prior to version 3.1.12). It contains a full history of activity for each SEIN-SEINUNIT (wide file). It is still used as an input to the SPF. It replaces seinunit_history_es.sas7bdat.

The UHF file (ehf_\&state._uhf) is organized by SEIN-SEINUNIT.

\section{Record identifier SEIN-SEINUNIT}

Sort order SEIN-SEINUNIT

Entity Establishment

Unique Entity Key SEIN-SEINUNIT

\begin{tabular}{|c|c|c|c|c|}
\hline Field name & $\begin{array}{l}\text { Data dictionary } \\
\text { reference name }\end{array}$ & $\begin{array}{l}\text { Starting } \\
\text { position }\end{array}$ & $\begin{array}{l}\text { Field } \\
\text { size }\end{array}$ & $\begin{array}{l}\text { Data } \\
\text { type }\end{array}$ \\
\hline $\begin{array}{l}\ldots 1 \ldots \text { if part of multi-establishment, } \ldots 2 \ldots \text { if } \\
\text { master unit }\end{array}$ & MU_CODE & 02034 & 80 & $\mathrm{~A} / \mathrm{N}$ \\
\hline$=\ldots 1 \ldots$ if positive employment in quarter $\mathrm{i}$ & ACTIVE_EMPLOY_ES & 01954 & 80 & $\mathrm{~A} / \mathrm{N}$ \\
\hline Ever had positive employment & ACTIVE_EVER_ES & 01920 & 8 & $\mathrm{~N}$ \\
\hline First QTIME with positive employment & ACTIVE_BEG_QTR_ES & 01928 & 3 & $\mathrm{~N}$ \\
\hline Last QTIME with positive employment & ACTIVE_END_QTR_ES & 01931 & 3 & $\mathrm{~N}$ \\
\hline Maximum monthly employment in QTIME $=1$ & EMP_ES1 & 00640 & 8 & $\mathrm{~N}$ \\
\hline Maximum monthly employment in QTIME $=10$ & EMP_ES10 & 00712 & 8 & $\mathrm{~N}$ \\
\hline Maximum monthly employment in QTIME $=11$ & EMP_ES11 & 00720 & 8 & $\mathrm{~N}$ \\
\hline Maximum monthly employment in QTIME $=12$ & EMP_ES12 & 00728 & 8 & $\mathrm{~N}$ \\
\hline Maximum monthly employment in QTIME $=13$ & EMP_ES13 & 00736 & 8 & $\mathrm{~N}$ \\
\hline Maximum monthly employment in QTIME $=14$ & EMP_ES14 & 00744 & 8 & $\mathrm{~N}$ \\
\hline Maximum monthly employment in QTIME $=15$ & EMP_ES15 & 00752 & 8 & $\mathrm{~N}$ \\
\hline Maximum monthly employment in QTIME $=16$ & EMP_ES16 & 00760 & 8 & $\mathrm{~N}$ \\
\hline Maximum monthly employment in QTIME $=17$ & EMP_ES17 & 00768 & 8 & $\mathrm{~N}$ \\
\hline Maximum monthly employment in QTIME $=18$ & EMP_ES18 & 00776 & 8 & $\mathrm{~N}$ \\
\hline Maximum monthly employment in QTIME $=19$ & EMP_ES19 & 00784 & 8 & $\mathrm{~N}$ \\
\hline Maximum monthly employment in QTIME $=2$ & EMP_ES2 & 00648 & 8 & $\mathrm{~N}$ \\
\hline Maximum monthly employment in QTIME $=20$ & EMP_ES20 & 00792 & 8 & $\mathrm{~N}$ \\
\hline Maximum monthly employment in QTIME $=21$ & EMP_ES21 & 00800 & 8 & $\mathrm{~N}$ \\
\hline Maximum monthly employment in QTIME $=22$ & EMP_ES22 & 00808 & 8 & $\mathrm{~N}$ \\
\hline Maximum monthly employment in QTIME $=23$ & EMP_ES23 & 00816 & 8 & $\mathrm{~N}$ \\
\hline Maximum monthly employment in QTIME $=24$ & EMP_ES24 & 00824 & 8 & $\mathrm{~N}$ \\
\hline Maximum monthly employment in QTIME $=25$ & EMP_ES25 & 00832 & 8 & $\mathrm{~N}$ \\
\hline Maximum monthly employment in QTIME $=26$ & EMP_ES26 & 00840 & 8 & $\mathrm{~N}$ \\
\hline Maximum monthly employment in QTIME $=27$ & EMP_ES27 & 00848 & 8 & $\mathrm{~N}$ \\
\hline Maximum monthly employment in QTIME $=28$ & EMP_ES28 & 00856 & 8 & $\mathrm{~N}$ \\
\hline Maximum monthly employment in QTIME $=29$ & EMP_ES29 & 00864 & 8 & $\mathrm{~N}$ \\
\hline Maximum monthly employment in QTIME $=3$ & EMP_ES3 & 00656 & 8 & $\mathrm{~N}$ \\
\hline Maximum monthly employment in QTIME $=30$ & EMP_ES30 & 00872 & 8 & $\mathrm{~N}$ \\
\hline Maximum monthly employment in QTIME $=31$ & EMP_ES31 & 00880 & 8 & $\mathrm{~N}$ \\
\hline Maximum monthly employment in QTIME $=32$ & EMP_ES32 & 00888 & 8 & $\mathrm{~N}$ \\
\hline Maximum monthly employment in QTIME $=33$ & EMP_ES33 & 00896 & 8 & $\mathrm{~N}$ \\
\hline Maximum monthly employment in QTIME $=34$ & EMP_ES34 & 00904 & 8 & $\mathrm{~N}$ \\
\hline Maximum monthly employment in QTIME $=35$ & EMP_ES35 & 00912 & 8 & $\mathrm{~N}$ \\
\hline
\end{tabular}


CHAPTER 4. EMPLOYMENT HISTORY FILES (EHF)

\begin{tabular}{|c|c|c|c|c|}
\hline Field name & $\begin{array}{l}\text { Data dictionary } \\
\text { reference name }\end{array}$ & $\begin{array}{l}\text { Starting } \\
\text { position }\end{array}$ & $\begin{array}{l}\text { Field } \\
\text { size }\end{array}$ & $\begin{array}{l}\text { Data } \\
\text { type }\end{array}$ \\
\hline Maximum monthly employment in QTIME $=36$ & EMP_ES36 & 00920 & 8 & $\mathrm{~N}$ \\
\hline Maximum monthly employment in QTIME $=37$ & EMP_ES37 & 00928 & 8 & $\mathrm{~N}$ \\
\hline Maximum monthly employment in QTIME $=38$ & EMP_ES38 & 00936 & 8 & $\mathrm{~N}$ \\
\hline Maximum monthly employment in QTIME $=39$ & EMP_ES39 & 00944 & 8 & $\mathrm{~N}$ \\
\hline Maximum monthly employment in QTIME $=4$ & EMP_ES4 & 00664 & 8 & $\mathrm{~N}$ \\
\hline Maximum monthly employment in QTIME $=40$ & EMP_ES40 & 00952 & 8 & $\mathrm{~N}$ \\
\hline Maximum monthly employment in QTIME $=41$ & EMP_ES41 & 00960 & 8 & $\mathrm{~N}$ \\
\hline Maximum monthly employment in QTIME $=42$ & EMP_ES42 & 00968 & 8 & $\mathrm{~N}$ \\
\hline Maximum monthly employment in QTIME $=43$ & EMP_ES43 & 00976 & 8 & $\mathrm{~N}$ \\
\hline Maximum monthly employment in QTIME $=44$ & EMP_ES44 & 00984 & 8 & $\mathrm{~N}$ \\
\hline Maximum monthly employment in QTIME $=45$ & EMP_ES45 & 00992 & 8 & $\mathrm{~N}$ \\
\hline Maximum monthly employment in QTIME $=46$ & EMP_ES46 & 01000 & 8 & $\mathrm{~N}$ \\
\hline Maximum monthly employment in QTIME $=47$ & EMP_ES47 & 01008 & 8 & $\mathrm{~N}$ \\
\hline Maximum monthly employment in QTIME $=48$ & EMP_ES48 & 01016 & 8 & $\mathrm{~N}$ \\
\hline Maximum monthly employment in QTIME $=49$ & EMP_ES49 & 01024 & 8 & $\mathrm{~N}$ \\
\hline Maximum monthly employment in QTIME $=5$ & EMP_ES5 & 00672 & 8 & $\mathrm{~N}$ \\
\hline Maximum monthly employment in QTIME $=50$ & EMP_ES50 & 01032 & 8 & $\mathrm{~N}$ \\
\hline Maximum monthly employment in QTIME $=51$ & EMP_ES51 & 01040 & 8 & $\mathrm{~N}$ \\
\hline Maximum monthly employment in QTIME $=52$ & EMP_ES52 & 01048 & 8 & $\mathrm{~N}$ \\
\hline Maximum monthly employment in QTIME $=53$ & EMP_ES53 & 01056 & 8 & $\mathrm{~N}$ \\
\hline Maximum monthly employment in QTIME $=54$ & EMP_ES54 & 01064 & 8 & $\mathrm{~N}$ \\
\hline Maximum monthly employment in QTIME $=55$ & EMP_ES55 & 01072 & 8 & $\mathrm{~N}$ \\
\hline Maximum monthly employment in QTIME $=56$ & EMP_ES56 & 01080 & 8 & $\mathrm{~N}$ \\
\hline Maximum monthly employment in QTIME $=57$ & EMP_ES57 & 01088 & 8 & $\mathrm{~N}$ \\
\hline Maximum monthly employment in QTIME $=58$ & EMP_ES58 & 01096 & 8 & $\mathrm{~N}$ \\
\hline Maximum monthly employment in QTIME $=59$ & EMP_ES59 & 01104 & 8 & $\mathrm{~N}$ \\
\hline Maximum monthly employment in QTIME $=6$ & EMP_ES6 & 00680 & 8 & $\mathrm{~N}$ \\
\hline Maximum monthly employment in QTIME $=60$ & EMP_ES60 & 01112 & 8 & $\mathrm{~N}$ \\
\hline Maximum monthly employment in QTIME $=61$ & EMP_ES61 & 01120 & 8 & $\mathrm{~N}$ \\
\hline Maximum monthly employment in QTIME $=62$ & EMP_ES62 & 01128 & 8 & $\mathrm{~N}$ \\
\hline Maximum monthly employment in QTIME $=63$ & EMP_ES63 & 01136 & 8 & $\mathrm{~N}$ \\
\hline Maximum monthly employment in QTIME $=64$ & EMP_ES64 & 01144 & 8 & $\mathrm{~N}$ \\
\hline Maximum monthly employment in QTIME $=65$ & EMP_ES65 & 01152 & 8 & $\mathrm{~N}$ \\
\hline Maximum monthly employment in QTIME $=66$ & EMP_ES66 & 01160 & 8 & $\mathrm{~N}$ \\
\hline Maximum monthly employment in QTIME $=67$ & EMP_ES67 & 01168 & 8 & $\mathrm{~N}$ \\
\hline Maximum monthly employment in QTIME $=68$ & EMP_ES68 & 01176 & 8 & $\mathrm{~N}$ \\
\hline Maximum monthly employment in QTIME $=69$ & EMP_ES69 & 01184 & 8 & $\mathrm{~N}$ \\
\hline Maximum monthly employment in QTIME $=7$ & EMP_ES7 & 00688 & 8 & $\mathrm{~N}$ \\
\hline Maximum monthly employment in QTIME $=70$ & EMP_ES70 & 01192 & 8 & $\mathrm{~N}$ \\
\hline Maximum monthly employment in QTIME $=71$ & EMP_ES71 & 01200 & 8 & $\mathrm{~N}$ \\
\hline Maximum monthly employment in QTIME $=72$ & EMP_ES72 & 01208 & 8 & $\mathrm{~N}$ \\
\hline Maximum monthly employment in QTIME $=73$ & EMP_ES73 & 01216 & 8 & $\mathrm{~N}$ \\
\hline Maximum monthly employment in QTIME $=74$ & EMP_ES74 & 01224 & 8 & $\mathrm{~N}$ \\
\hline Maximum monthly employment in QTIME $=75$ & EMP_ES75 & 01232 & 8 & $\mathrm{~N}$ \\
\hline Maximum monthly employment in QTIME $=76$ & EMP_ES76 & 01240 & 8 & $\mathrm{~N}$ \\
\hline Maximum monthly employment in QTIME $=77$ & EMP_ES77 & 01248 & 8 & $\mathrm{~N}$ \\
\hline Maximum monthly employment in QTIME $=78$ & EMP_ES78 & 01256 & 8 & $\mathrm{~N}$ \\
\hline Maximum monthly employment in QTIME $=79$ & EMP_ES79 & 01264 & 8 & $\mathrm{~N}$ \\
\hline Maximum monthly employment in QTIME $=8$ & EMP_ES8 & 00696 & 8 & $\mathrm{~N}$ \\
\hline Maximum monthly employment in QTIME $=80$ & EMP_ES80 & 01272 & 8 & $\mathrm{~N}$ \\
\hline
\end{tabular}


CHAPTER 4. EMPLOYMENT HISTORY FILES (EHF)

\begin{tabular}{|c|c|c|c|c|}
\hline Field name & $\begin{array}{l}\text { Data dictionary } \\
\text { reference name }\end{array}$ & $\begin{array}{l}\text { Starting } \\
\text { position }\end{array}$ & $\begin{array}{l}\text { Field } \\
\text { size }\end{array}$ & $\begin{array}{l}\text { Data } \\
\text { type }\end{array}$ \\
\hline Maximum monthly employment in QTIME $=9$ & EMP_ES9 & 00704 & 8 & $\mathrm{~N}$ \\
\hline Month 1 employment in QTIME $=1$ & BPEMP_ES1 & 00000 & 8 & $\mathrm{~N}$ \\
\hline Month 1 employment in QTIME $=10$ & BPEMP_ES10 & 00072 & 8 & $\mathrm{~N}$ \\
\hline Month 1 employment in QTIME $=11$ & BPEMP_ES11 & 00080 & 8 & $\mathrm{~N}$ \\
\hline Month 1 employment in QTIME $=12$ & BPEMP_ES12 & 00088 & 8 & $\mathrm{~N}$ \\
\hline Month 1 employment in QTIME $=13$ & BPEMP_ES13 & 00096 & 8 & $\mathrm{~N}$ \\
\hline Month 1 employment in QTIME $=14$ & BPEMP_ES14 & 00104 & 8 & $\mathrm{~N}$ \\
\hline Month 1 employment in QTIME $=15$ & BPEMP_ES15 & 00112 & 8 & $\mathrm{~N}$ \\
\hline Month 1 employment in QTIME $=16$ & BPEMP_ES16 & 00120 & 8 & $\mathrm{~N}$ \\
\hline Month 1 employment in QTIME $=17$ & BPEMP_ES17 & 00128 & 8 & $\mathrm{~N}$ \\
\hline Month 1 employment in QTIME $=18$ & BPEMP_ES18 & 00136 & 8 & $\mathrm{~N}$ \\
\hline Month 1 employment in QTIME $=19$ & BPEMP_ES19 & 00144 & 8 & $\mathrm{~N}$ \\
\hline Month 1 employment in QTIME=2 & BPEMP_ES2 & 00008 & 8 & $\mathrm{~N}$ \\
\hline Month 1 employment in QTIME $=20$ & BPEMP_ES20 & 00152 & 8 & $\mathrm{~N}$ \\
\hline Month 1 employment in QTIME $=21$ & BPEMP_ES21 & 00160 & 8 & $\mathrm{~N}$ \\
\hline Month 1 employment in QTIME $=22$ & BPEMP_ES22 & 00168 & 8 & $\mathrm{~N}$ \\
\hline Month 1 employment in QTIME $=23$ & BPEMP_ES23 & 00176 & 8 & $\mathrm{~N}$ \\
\hline Month 1 employment in QTIME $=24$ & BPEMP_ES24 & 00184 & 8 & $\mathrm{~N}$ \\
\hline Month 1 employment in QTIME $=25$ & BPEMP_ES25 & 00192 & 8 & $\mathrm{~N}$ \\
\hline Month 1 employment in QTIME $=26$ & BPEMP_ES26 & 00200 & 8 & $\mathrm{~N}$ \\
\hline Month 1 employment in QTIME $=27$ & BPEMP_ES27 & 00208 & 8 & $\mathrm{~N}$ \\
\hline Month 1 employment in QTIME $=28$ & BPEMP_ES28 & 00216 & 8 & $\mathrm{~N}$ \\
\hline Month 1 employment in QTIME $=29$ & BPEMP_ES29 & 00224 & 8 & $\mathrm{~N}$ \\
\hline Month 1 employment in QTIME=3 & BPEMP_ES3 & 00016 & 8 & $\mathrm{~N}$ \\
\hline Month 1 employment in QTIME $=30$ & BPEMP_ES30 & 00232 & 8 & $\mathrm{~N}$ \\
\hline Month 1 employment in QTIME $=31$ & BPEMP_ES31 & 00240 & 8 & $\mathrm{~N}$ \\
\hline Month 1 employment in QTIME $=32$ & BPEMP_ES32 & 00248 & 8 & $\mathrm{~N}$ \\
\hline Month 1 employment in QTIME $=33$ & BPEMP_ES33 & 00256 & 8 & $\mathrm{~N}$ \\
\hline Month 1 employment in QTIME $=34$ & BPEMP_ES34 & 00264 & 8 & $\mathrm{~N}$ \\
\hline Month 1 employment in QTIME $=35$ & BPEMP_ES35 & 00272 & 8 & $\mathrm{~N}$ \\
\hline Month 1 employment in QTIME $=36$ & BPEMP_ES36 & 00280 & 8 & $\mathrm{~N}$ \\
\hline Month 1 employment in QTIME $=37$ & BPEMP_ES37 & 00288 & 8 & $\mathrm{~N}$ \\
\hline Month 1 employment in QTIME $=38$ & BPEMP_ES38 & 00296 & 8 & $\mathrm{~N}$ \\
\hline Month 1 employment in QTIME $=39$ & BPEMP_ES39 & 00304 & 8 & $\mathrm{~N}$ \\
\hline Month 1 employment in QTIME $=4$ & BPEMP_ES4 & 00024 & 8 & $\mathrm{~N}$ \\
\hline Month 1 employment in QTIME $=40$ & BPEMP_ES40 & 00312 & 8 & $\mathrm{~N}$ \\
\hline Month 1 employment in QTIME $=41$ & BPEMP_ES41 & 00320 & 8 & $\mathrm{~N}$ \\
\hline Month 1 employment in QTIME $=42$ & BPEMP_ES42 & 00328 & 8 & $\mathrm{~N}$ \\
\hline Month 1 employment in QTIME $=43$ & BPEMP_ES43 & 00336 & 8 & $\mathrm{~N}$ \\
\hline Month 1 employment in QTIME $=44$ & BPEMP_ES44 & 00344 & 8 & $\mathrm{~N}$ \\
\hline Month 1 employment in QTIME $=45$ & BPEMP_ES45 & 00352 & 8 & $\mathrm{~N}$ \\
\hline Month 1 employment in QTIME $=46$ & BPEMP_ES46 & 00360 & 8 & $\mathrm{~N}$ \\
\hline Month 1 employment in QTIME $=47$ & BPEMP_ES47 & 00368 & 8 & $\mathrm{~N}$ \\
\hline Month 1 employment in QTIME $=48$ & BPEMP_ES48 & 00376 & 8 & $\mathrm{~N}$ \\
\hline Month 1 employment in QTIME $=49$ & BPEMP_ES49 & 00384 & 8 & $\mathrm{~N}$ \\
\hline Month 1 employment in QTIME $=5$ & BPEMP_ES5 & 00032 & 8 & $\mathrm{~N}$ \\
\hline Month 1 employment in QTIME $=50$ & BPEMP_ES50 & 00392 & 8 & $\mathrm{~N}$ \\
\hline Month 1 employment in QTIME $=51$ & BPEMP_ES51 & 00400 & 8 & $\mathrm{~N}$ \\
\hline Month 1 employment in QTIME $=52$ & BPEMP_ES52 & 00408 & 8 & $\mathrm{~N}$ \\
\hline Month 1 employment in QTIME $=53$ & BPEMP_ES53 & 00416 & 8 & $\mathrm{~N}$ \\
\hline
\end{tabular}


CHAPTER 4. EMPLOYMENT HISTORY FILES (EHF)

\begin{tabular}{|c|c|c|c|c|}
\hline Field name & $\begin{array}{l}\text { Data dictionary } \\
\text { reference name }\end{array}$ & $\begin{array}{l}\text { Starting } \\
\text { position }\end{array}$ & $\begin{array}{l}\text { Field } \\
\text { size }\end{array}$ & $\begin{array}{l}\text { Data } \\
\text { type }\end{array}$ \\
\hline Month 1 employment in QTIME $=54$ & BPEMP_ES54 & 00424 & 8 & $\mathrm{~N}$ \\
\hline Month 1 employment in QTIME $=55$ & BPEMP_ES55 & 00432 & 8 & $\mathrm{~N}$ \\
\hline Month 1 employment in QTIME $=56$ & BPEMP_ES56 & 00440 & 8 & $\mathrm{~N}$ \\
\hline Month 1 employment in QTIME $=57$ & BPEMP_ES57 & 00448 & 8 & $\mathrm{~N}$ \\
\hline Month 1 employment in QTIME $=58$ & BPEMP_ES58 & 00456 & 8 & $\mathrm{~N}$ \\
\hline Month 1 employment in $\mathrm{QTIME}=59$ & BPEMP_ES59 & 00464 & 8 & $\mathrm{~N}$ \\
\hline Month 1 employment in QTIME=6 & BPEMP_ES6 & 00040 & 8 & $\mathrm{~N}$ \\
\hline Month 1 employment in QTIME $=60$ & BPEMP_ES60 & 00472 & 8 & $\mathrm{~N}$ \\
\hline Month 1 employment in QTIME $=61$ & BPEMP_ES61 & 00480 & 8 & $\mathrm{~N}$ \\
\hline Month 1 employment in QTIME $=62$ & BPEMP_ES62 & 00488 & 8 & $\mathrm{~N}$ \\
\hline Month 1 employment in QTIME $=63$ & BPEMP_ES63 & 00496 & 8 & $\mathrm{~N}$ \\
\hline Month 1 employment in QTIME $=64$ & BPEMP_ES64 & 00504 & 8 & $\mathrm{~N}$ \\
\hline Month 1 employment in QTIME $=65$ & BPEMP_ES65 & 00512 & 8 & $\mathrm{~N}$ \\
\hline Month 1 employment in QTIME $=66$ & BPEMP_ES66 & 00520 & 8 & $\mathrm{~N}$ \\
\hline Month 1 employment in QTIME $=67$ & BPEMP_ES67 & 00528 & 8 & $\mathrm{~N}$ \\
\hline Month 1 employment in QTIME $=68$ & BPEMP_ES68 & 00536 & 8 & $\mathrm{~N}$ \\
\hline Month 1 employment in QTIME $=69$ & BPEMP_ES69 & 00544 & 8 & $\mathrm{~N}$ \\
\hline Month 1 employment in QTIME=7 & BPEMP_ES7 & 00048 & 8 & $\mathrm{~N}$ \\
\hline Month 1 employment in QTIME $=70$ & BPEMP_ES70 & 00552 & 8 & $\mathrm{~N}$ \\
\hline Month 1 employment in QTIME $=71$ & BPEMP_ES71 & 00560 & 8 & $\mathrm{~N}$ \\
\hline Month 1 employment in QTIME $=72$ & BPEMP_ES72 & 00568 & 8 & $\mathrm{~N}$ \\
\hline Month 1 employment in QTIME $=73$ & BPEMP_ES73 & 00576 & 8 & $\mathrm{~N}$ \\
\hline Month 1 employment in QTIME $=74$ & BPEMP_ES74 & 00584 & 8 & $\mathrm{~N}$ \\
\hline Month 1 employment in QTIME $=75$ & BPEMP_ES75 & 00592 & 8 & $\mathrm{~N}$ \\
\hline Month 1 employment in QTIME $=76$ & BPEMP_ES76 & 00600 & 8 & $\mathrm{~N}$ \\
\hline Month 1 employment in QTIME $=77$ & BPEMP_ES77 & 00608 & 8 & $\mathrm{~N}$ \\
\hline Month 1 employment in QTIME $=78$ & BPEMP_ES78 & 00616 & 8 & $\mathrm{~N}$ \\
\hline Month 1 employment in QTIME $=79$ & BPEMP_ES79 & 00624 & 8 & $\mathrm{~N}$ \\
\hline Month 1 employment in QTIME=8 & BPEMP_ES8 & 00056 & 8 & $\mathrm{~N}$ \\
\hline Month 1 employment in QTIME $=80$ & BPEMP_ES80 & 00632 & 8 & $\mathrm{~N}$ \\
\hline Month 1 employment in QTIME $=9$ & BPEMP_ES9 & 00064 & 8 & $\mathrm{~N}$ \\
\hline Number of establishments in QTIME $=1$ & NUMRUNS1 & 01280 & 8 & $\mathrm{~N}$ \\
\hline Number of establishments in QTIME $=10$ & NUMRUNS10 & 01352 & 8 & $\mathrm{~N}$ \\
\hline Number of establishments in QTIME $=11$ & NUMRUNS11 & 01360 & 8 & $\mathrm{~N}$ \\
\hline Number of establishments in QTIME $=12$ & NUMRUNS12 & 01368 & 8 & $\mathrm{~N}$ \\
\hline Number of establishments in QTIME $=13$ & NUMRUNS13 & 01376 & 8 & $\mathrm{~N}$ \\
\hline Number of establishments in QTIME $=14$ & NUMRUNS14 & 01384 & 8 & $\mathrm{~N}$ \\
\hline Number of establishments in QTIME $=15$ & NUMRUNS15 & 01392 & 8 & $\mathrm{~N}$ \\
\hline Number of establishments in QTIME $=16$ & NUMRUNS16 & 01400 & 8 & $\mathrm{~N}$ \\
\hline Number of establishments in QTIME $=17$ & NUMRUNS17 & 01408 & 8 & $\mathrm{~N}$ \\
\hline Number of establishments in QTIME $=18$ & NUMRUNS18 & 01416 & 8 & $\mathrm{~N}$ \\
\hline Number of establishments in QTIME $=19$ & NUMRUNS19 & 01424 & 8 & $\mathrm{~N}$ \\
\hline Number of establishments in QTIME $=2$ & NUMRUNS2 & 01288 & 8 & $\mathrm{~N}$ \\
\hline Number of establishments in QTIME $=20$ & NUMRUNS20 & 01432 & 8 & $\mathrm{~N}$ \\
\hline Number of establishments in QTIME $=21$ & NUMRUNS21 & 01440 & 8 & $\mathrm{~N}$ \\
\hline Number of establishments in QTIME $=22$ & NUMRUNS22 & 01448 & 8 & $\mathrm{~N}$ \\
\hline Number of establishments in QTIME $=23$ & NUMRUNS23 & 01456 & 8 & $\mathrm{~N}$ \\
\hline Number of establishments in QTIME $=24$ & NUMRUNS24 & 01464 & 8 & $\mathrm{~N}$ \\
\hline Number of establishments in QTIME $=25$ & NUMRUNS25 & 01472 & 8 & $\mathrm{~N}$ \\
\hline Number of establishments in QTIME $=26$ & NUMRUNS26 & 01480 & 8 & $\mathrm{~N}$ \\
\hline
\end{tabular}


CHAPTER 4. EMPLOYMENT HISTORY FILES (EHF)

\begin{tabular}{|c|c|c|c|c|}
\hline Field name & $\begin{array}{l}\text { Data dictionary } \\
\text { reference name }\end{array}$ & $\begin{array}{l}\text { Starting } \\
\text { position }\end{array}$ & $\begin{array}{l}\text { Field } \\
\text { size }\end{array}$ & $\begin{array}{l}\text { Data } \\
\text { type }\end{array}$ \\
\hline Number of establishments in QTIME $=27$ & NUMRUNS27 & 01488 & 8 & $\mathrm{~N}$ \\
\hline Number of establishments in QTIME $=28$ & NUMRUNS28 & 01496 & 8 & $\mathrm{~N}$ \\
\hline Number of establishments in QTIME $=29$ & NUMRUNS29 & 01504 & 8 & $\mathrm{~N}$ \\
\hline Number of establishments in QTIME $=3$ & NUMRUNS3 & 01296 & 8 & $\mathrm{~N}$ \\
\hline Number of establishments in QTIME $=30$ & NUMRUNS30 & 01512 & 8 & $\mathrm{~N}$ \\
\hline Number of establishments in QTIME $=31$ & NUMRUNS31 & 01520 & 8 & $\mathrm{~N}$ \\
\hline Number of establishments in QTIME $=32$ & NUMRUNS32 & 01528 & 8 & $\mathrm{~N}$ \\
\hline Number of establishments in QTIME $=33$ & NUMRUNS33 & 01536 & 8 & $\mathrm{~N}$ \\
\hline Number of establishments in QTIME $=34$ & NUMRUNS34 & 01544 & 8 & $\mathrm{~N}$ \\
\hline Number of establishments in QTIME $=35$ & NUMRUNS35 & 01552 & 8 & $\mathrm{~N}$ \\
\hline Number of establishments in QTIME $=36$ & NUMRUNS36 & 01560 & 8 & $\mathrm{~N}$ \\
\hline Number of establishments in QTIME $=37$ & NUMRUNS37 & 01568 & 8 & $\mathrm{~N}$ \\
\hline Number of establishments in QTIME $=38$ & NUMRUNS38 & 01576 & 8 & $\mathrm{~N}$ \\
\hline Number of establishments in QTIME $=39$ & NUMRUNS39 & 01584 & 8 & $\mathrm{~N}$ \\
\hline Number of establishments in QTIME $=4$ & NUMRUNS4 & 01304 & 8 & $\mathrm{~N}$ \\
\hline Number of establishments in QTIME $=40$ & NUMRUNS40 & 01592 & 8 & $\mathrm{~N}$ \\
\hline Number of establishments in QTIME $=41$ & NUMRUNS41 & 01600 & 8 & $\mathrm{~N}$ \\
\hline Number of establishments in QTIME $=42$ & NUMRUNS42 & 01608 & 8 & $\mathrm{~N}$ \\
\hline Number of establishments in QTIME $=43$ & NUMRUNS43 & 01616 & 8 & $\mathrm{~N}$ \\
\hline Number of establishments in QTIME $=44$ & NUMRUNS44 & 01624 & 8 & $\mathrm{~N}$ \\
\hline Number of establishments in QTIME $=45$ & NUMRUNS45 & 01632 & 8 & $\mathrm{~N}$ \\
\hline Number of establishments in QTIME $=46$ & NUMRUNS46 & 01640 & 8 & $\mathrm{~N}$ \\
\hline Number of establishments in QTIME $=47$ & NUMRUNS47 & 01648 & 8 & $\mathrm{~N}$ \\
\hline Number of establishments in QTIME $=48$ & NUMRUNS48 & 01656 & 8 & $\mathrm{~N}$ \\
\hline Number of establishments in QTIME $=49$ & NUMRUNS49 & 01664 & 8 & $\mathrm{~N}$ \\
\hline Number of establishments in QTIME $=5$ & NUMRUNS5 & 01312 & 8 & $\mathrm{~N}$ \\
\hline Number of establishments in QTIME $=50$ & NUMRUNS50 & 01672 & 8 & $\mathrm{~N}$ \\
\hline Number of establishments in QTIME $=51$ & NUMRUNS51 & 01680 & 8 & $\mathrm{~N}$ \\
\hline Number of establishments in QTIME $=52$ & NUMRUNS52 & 01688 & 8 & $\mathrm{~N}$ \\
\hline Number of establishments in QTIME $=53$ & NUMRUNS53 & 01696 & 8 & $\mathrm{~N}$ \\
\hline Number of establishments in QTIME $=54$ & NUMRUNS54 & 01704 & 8 & $\mathrm{~N}$ \\
\hline Number of establishments in QTIME $=55$ & NUMRUNS55 & 01712 & 8 & $\mathrm{~N}$ \\
\hline Number of establishments in QTIME $=56$ & NUMRUNS56 & 01720 & 8 & $\mathrm{~N}$ \\
\hline Number of establishments in QTIME $=57$ & NUMRUNS57 & 01728 & 8 & $\mathrm{~N}$ \\
\hline Number of establishments in QTIME $=58$ & NUMRUNS58 & 01736 & 8 & $\mathrm{~N}$ \\
\hline Number of establishments in QTIME $=59$ & NUMRUNS59 & 01744 & 8 & $\mathrm{~N}$ \\
\hline Number of establishments in QTIME $=6$ & NUMRUNS6 & 01320 & 8 & $\mathrm{~N}$ \\
\hline Number of establishments in QTIME $=60$ & NUMRUNS60 & 01752 & 8 & $\mathrm{~N}$ \\
\hline Number of establishments in QTIME $=61$ & NUMRUNS61 & 01760 & 8 & $\mathrm{~N}$ \\
\hline Number of establishments in QTIME $=62$ & NUMRUNS62 & 01768 & 8 & $\mathrm{~N}$ \\
\hline Number of establishments in QTIME $=63$ & NUMRUNS63 & 01776 & 8 & $\mathrm{~N}$ \\
\hline Number of establishments in QTIME $=64$ & NUMRUNS64 & 01784 & 8 & $\mathrm{~N}$ \\
\hline Number of establishments in QTIME $=65$ & NUMRUNS65 & 01792 & 8 & $\mathrm{~N}$ \\
\hline Number of establishments in QTIME $=66$ & NUMRUNS66 & 01800 & 8 & $\mathrm{~N}$ \\
\hline Number of establishments in QTIME $=67$ & NUMRUNS67 & 01808 & 8 & $\mathrm{~N}$ \\
\hline Number of establishments in QTIME $=68$ & NUMRUNS68 & 01816 & 8 & $\mathrm{~N}$ \\
\hline Number of establishments in QTIME $=69$ & NUMRUNS69 & 01824 & 8 & $\mathrm{~N}$ \\
\hline Number of establishments in QTIME $=7$ & NUMRUNS7 & 01328 & 8 & $\mathrm{~N}$ \\
\hline Number of establishments in QTIME $=70$ & NUMRUNS70 & 01832 & 8 & $\mathrm{~N}$ \\
\hline Number of establishments in QTIME $=71$ & NUMRUNS71 & 01840 & 8 & $\mathrm{~N}$ \\
\hline
\end{tabular}


CHAPTER 4. EMPLOYMENT HISTORY FILES (EHF)

\begin{tabular}{|c|c|c|c|c|}
\hline Field name & $\begin{array}{l}\text { Data dictionary } \\
\text { reference name }\end{array}$ & $\begin{array}{l}\text { Starting } \\
\text { position }\end{array}$ & $\begin{array}{l}\text { Field } \\
\text { size }\end{array}$ & $\begin{array}{l}\text { Data } \\
\text { type }\end{array}$ \\
\hline Number of establishments in QTIME $=72$ & NUMRUNS72 & 01848 & 8 & $\mathrm{~N}$ \\
\hline Number of establishments in QTIME $=73$ & NUMRUNS73 & 01856 & 8 & $\mathrm{~N}$ \\
\hline Number of establishments in QTIME $=74$ & NUMRUNS74 & 01864 & 8 & $\mathrm{~N}$ \\
\hline Number of establishments in QTIME $=75$ & NUMRUNS75 & 01872 & 8 & $\mathrm{~N}$ \\
\hline Number of establishments in QTIME $=76$ & NUMRUNS76 & 01880 & 8 & $\mathrm{~N}$ \\
\hline Number of establishments in QTIME $=77$ & NUMRUNS77 & 01888 & 8 & $\mathrm{~N}$ \\
\hline Number of establishments in QTIME $=78$ & NUMRUNS78 & 01896 & 8 & $\mathrm{~N}$ \\
\hline Number of establishments in QTIME $=79$ & NUMRUNS79 & 01904 & 8 & $\mathrm{~N}$ \\
\hline Number of establishments in QTIME $=8$ & NUMRUNS8 & 01336 & 8 & $\mathrm{~N}$ \\
\hline Number of establishments in QTIME $=80$ & NUMRUNS80 & 01912 & 8 & $\mathrm{~N}$ \\
\hline Number of establishments in QTIME $=9$ & NUMRUNS9 & 01344 & 8 & $\mathrm{~N}$ \\
\hline Number of quarters with positive employment & ACTIVE_QTRS_ES & 01934 & 3 & $\mathrm{~N}$ \\
\hline State Employer ID Number & SEIN & 01937 & 12 & $\mathrm{~A} / \mathrm{N}$ \\
\hline State UI Reporting Unit Number & SEINUNIT & 01949 & 5 & $\mathrm{~A} / \mathrm{N}$ \\
\hline
\end{tabular}




\subsubsection{SHF}

The SHF (SEIN History File) used to be produced by the SPF (prior to version 3.1.12) as an internal file only. It contains a full history of activity for each SEIN (wide file). It is still used as an input to the SPF. It replaces sein_history_es.sas7bdat.

The SHF file (ehf_\&state._shf) is organized by SEIN.

\section{Record identifier SEIN}

Sort order SEIN

Entity Firm

Unique Entity Key SEIN

\begin{tabular}{|c|c|c|c|c|}
\hline Field name & $\begin{array}{l}\text { Data dictionary } \\
\text { reference name }\end{array}$ & $\begin{array}{l}\text { Starting } \\
\text { position }\end{array}$ & $\begin{array}{l}\text { Field } \\
\text { size }\end{array}$ & $\begin{array}{l}\text { Data } \\
\text { type }\end{array}$ \\
\hline in $\mathrm{QTIME}=1$ & ESTABS_ES1 & 01280 & 8 & $\mathrm{~N}$ \\
\hline in $\mathrm{QTIME}=10$ & ESTABS_ES10 & 01352 & 8 & $\mathrm{~N}$ \\
\hline in $\mathrm{QTIME}=11$ & ESTABS_ES11 & 01360 & 8 & $\mathrm{~N}$ \\
\hline in $\mathrm{QTIME}=12$ & ESTABS_ES12 & 01368 & 8 & $\mathrm{~N}$ \\
\hline in $\mathrm{QTIME}=13$ & ESTABS_ES13 & 01376 & 8 & $\mathrm{~N}$ \\
\hline in $\mathrm{QTIME}=14$ & ESTABS_ES14 & 01384 & 8 & $\mathrm{~N}$ \\
\hline in $\mathrm{QTIME}=15$ & ESTABS_ES15 & 01392 & 8 & $\mathrm{~N}$ \\
\hline in $\mathrm{QTIME}=16$ & ESTABS_ES16 & 01400 & 8 & $\mathrm{~N}$ \\
\hline in $\mathrm{QTIME}=17$ & ESTABS_ES17 & 01408 & 8 & $\mathrm{~N}$ \\
\hline in $\mathrm{QTIME}=18$ & ESTABS_ES18 & 01416 & 8 & $\mathrm{~N}$ \\
\hline in $\mathrm{QTIME}=19$ & ESTABS_ES19 & 01424 & 8 & $\mathrm{~N}$ \\
\hline in QTIME $=2$ & ESTABS_ES2 & 01288 & 8 & $\mathrm{~N}$ \\
\hline in $\mathrm{QTIME}=20$ & ESTABS_ES20 & 01432 & 8 & $\mathrm{~N}$ \\
\hline in $\mathrm{QTIME}=21$ & ESTABS_ES21 & 01440 & 8 & $\mathrm{~N}$ \\
\hline in $\mathrm{QTIME}=22$ & ESTABS_ES22 & 01448 & 8 & $\mathrm{~N}$ \\
\hline in $\mathrm{QTIME}=23$ & ESTABS_ES23 & 01456 & 8 & $\mathrm{~N}$ \\
\hline in $\mathrm{QTIME}=24$ & ESTABS_ES24 & 01464 & 8 & $\mathrm{~N}$ \\
\hline in $\mathrm{QTIME}=25$ & ESTABS_ES25 & 01472 & 8 & $\mathrm{~N}$ \\
\hline in $\mathrm{QTIME}=26$ & ESTABS_ES26 & 01480 & 8 & $\mathrm{~N}$ \\
\hline in $\mathrm{QTIME}=27$ & ESTABS_ES27 & 01488 & 8 & $\mathrm{~N}$ \\
\hline in $\mathrm{QTIME}=28$ & ESTABS_ES28 & 01496 & 8 & $\mathrm{~N}$ \\
\hline in $\mathrm{QTIME}=29$ & ESTABS_ES29 & 01504 & 8 & $\mathrm{~N}$ \\
\hline in $\mathrm{QTIME}=3$ & ESTABS_ES3 & 01296 & 8 & $\mathrm{~N}$ \\
\hline in $\mathrm{QTIME}=30$ & ESTABS_ES30 & 01512 & 8 & $\mathrm{~N}$ \\
\hline in $\mathrm{QTIME}=31$ & ESTABS_ES31 & 01520 & 8 & $\mathrm{~N}$ \\
\hline in $\mathrm{QTIME}=32$ & ESTABS_ES32 & 01528 & 8 & $\mathrm{~N}$ \\
\hline in $\mathrm{QTIME}=33$ & ESTABS_ES33 & 01536 & 8 & $\mathrm{~N}$ \\
\hline in $\mathrm{QTIME}=34$ & ESTABS_ES34 & 01544 & 8 & $\mathrm{~N}$ \\
\hline in QTIME $=35$ & ESTABS_ES35 & 01552 & 8 & $\mathrm{~N}$ \\
\hline in $\mathrm{QTIME}=36$ & ESTABS_ES36 & 01560 & 8 & $\mathrm{~N}$ \\
\hline in $\mathrm{QTIME}=37$ & ESTABS_ES37 & 01568 & 8 & $\mathrm{~N}$ \\
\hline in $\mathrm{QTIME}=38$ & ESTABS_ES38 & 01576 & 8 & $\mathrm{~N}$ \\
\hline in $\mathrm{QTIME}=39$ & ESTABS_ES39 & 01584 & 8 & $\mathrm{~N}$ \\
\hline in QTIME $=4$ & ESTABS_ES4 & 01304 & 8 & $\mathrm{~N}$ \\
\hline in $\mathrm{QTIME}=40$ & ESTABS_ES40 & 01592 & 8 & $\mathrm{~N}$ \\
\hline in $\mathrm{QTIME}=41$ & ESTABS_ES41 & 01600 & 8 & $\mathrm{~N}$ \\
\hline
\end{tabular}


CHAPTER 4. EMPLOYMENT HISTORY FILES (EHF)

\begin{tabular}{|c|c|c|c|c|}
\hline Field name & $\begin{array}{l}\text { Data dictionary } \\
\text { reference name }\end{array}$ & $\begin{array}{l}\text { Starting } \\
\text { position }\end{array}$ & $\begin{array}{l}\text { Field } \\
\text { size }\end{array}$ & $\begin{array}{l}\text { Data } \\
\text { type }\end{array}$ \\
\hline in QTIME $=42$ & ESTABS_ES42 & 01608 & 8 & $\mathrm{~N}$ \\
\hline in $\mathrm{QTIME}=43$ & ESTABS_ES43 & 01616 & 8 & $\mathrm{~N}$ \\
\hline in $\mathrm{QTIME}=44$ & ESTABS_ES44 & 01624 & 8 & $\mathrm{~N}$ \\
\hline in $\mathrm{QTIME}=45$ & ESTABS_ES45 & 01632 & 8 & $\mathrm{~N}$ \\
\hline in $\mathrm{QTIME}=46$ & ESTABS_ES46 & 01640 & 8 & $\mathrm{~N}$ \\
\hline in $\mathrm{QTIME}=47$ & ESTABS_ES47 & 01648 & 8 & $\mathrm{~N}$ \\
\hline in $\mathrm{QTIME}=48$ & ESTABS_ES48 & 01656 & 8 & $\mathrm{~N}$ \\
\hline in $\mathrm{QTIME}=49$ & ESTABS_ES49 & 01664 & 8 & $\mathrm{~N}$ \\
\hline in QTIME $=5$ & ESTABS_ES5 & 01312 & 8 & $\mathrm{~N}$ \\
\hline in $\mathrm{QTIME}=50$ & ESTABS_ES50 & 01672 & 8 & $\mathrm{~N}$ \\
\hline in $\mathrm{QTIME}=51$ & ESTABS_ES51 & 01680 & 8 & $\mathrm{~N}$ \\
\hline in $\mathrm{QTIME}=52$ & ESTABS_ES52 & 01688 & 8 & $\mathrm{~N}$ \\
\hline in $\mathrm{QTIME}=53$ & ESTABS_ES53 & 01696 & 8 & $\mathrm{~N}$ \\
\hline in $\mathrm{QTIME}=54$ & ESTABS_ES54 & 01704 & 8 & $\mathrm{~N}$ \\
\hline in $\mathrm{QTIME}=55$ & ESTABS_ES55 & 01712 & 8 & $\mathrm{~N}$ \\
\hline in $\mathrm{QTIME}=56$ & ESTABS_ES56 & 01720 & 8 & $\mathrm{~N}$ \\
\hline in $\mathrm{QTIME}=57$ & ESTABS_ES 57 & 01728 & 8 & $\mathrm{~N}$ \\
\hline in $\mathrm{QTIME}=58$ & ESTABS_ES58 & 01736 & 8 & $\mathrm{~N}$ \\
\hline in $\mathrm{QTIME}=59$ & ESTABS_ES59 & 01744 & 8 & $\mathrm{~N}$ \\
\hline in QTIME $=6$ & ESTABS_Es6 & 01320 & 8 & $\mathrm{~N}$ \\
\hline in $\mathrm{QTIME}=60$ & ESTABS_ES60 & 01752 & 8 & $\mathrm{~N}$ \\
\hline in $\mathrm{QTIME}=61$ & ESTABS_ES61 & 01760 & 8 & $\mathrm{~N}$ \\
\hline in $\mathrm{QTIME}=62$ & ESTABS_ES62 & 01768 & 8 & $\mathrm{~N}$ \\
\hline in $\mathrm{QTIME}=63$ & ESTABS_ES63 & 01776 & 8 & $\mathrm{~N}$ \\
\hline in $\mathrm{QTIME}=64$ & ESTABS_ES64 & 01784 & 8 & $\mathrm{~N}$ \\
\hline in $\mathrm{QTIME}=65$ & ESTABS_ES65 & 01792 & 8 & $\mathrm{~N}$ \\
\hline in $\mathrm{QTIME}=66$ & ESTABS_ES66 & 01800 & 8 & $\mathrm{~N}$ \\
\hline in $\mathrm{QTIME}=67$ & ESTABS_ES67 & 01808 & 8 & $\mathrm{~N}$ \\
\hline in $\mathrm{QTIME}=68$ & ESTABS_ES68 & 01816 & 8 & $\mathrm{~N}$ \\
\hline in $\mathrm{QTIME}=69$ & ESTABS_ES69 & 01824 & 8 & $\mathrm{~N}$ \\
\hline in $\mathrm{QTIME}=7$ & ESTABS_ES7 & 01328 & 8 & $\mathrm{~N}$ \\
\hline in $\mathrm{QTIME}=70$ & ESTABS_ES70 & 01832 & 8 & $\mathrm{~N}$ \\
\hline in $\mathrm{QTIME}=71$ & ESTABS_ES71 & 01840 & 8 & $\mathrm{~N}$ \\
\hline in $\mathrm{QTIME}=72$ & ESTABS_ES72 & 01848 & 8 & $\mathrm{~N}$ \\
\hline in $\mathrm{QTIME}=73$ & ESTABS_ES73 & 01856 & 8 & $\mathrm{~N}$ \\
\hline in $\mathrm{QTIME}=74$ & ESTABS_ES74 & 01864 & 8 & $\mathrm{~N}$ \\
\hline in $\mathrm{QTIME}=75$ & ESTABS_ES75 & 01872 & 8 & $\mathrm{~N}$ \\
\hline in $\mathrm{QTIME}=76$ & ESTABS_ES76 & 01880 & 8 & $\mathrm{~N}$ \\
\hline in $\mathrm{QTIME}=77$ & ESTABS_ES77 & 01888 & 8 & $\mathrm{~N}$ \\
\hline in $\mathrm{QTIME}=78$ & ESTABS_ES78 & 01896 & 8 & $\mathrm{~N}$ \\
\hline in $\mathrm{QTIME}=79$ & ESTABS_ES79 & 01904 & 8 & $\mathrm{~N}$ \\
\hline in $\mathrm{QTIME}=8$ & ESTABS_ES8 & 01336 & 8 & $\mathrm{~N}$ \\
\hline in $\mathrm{QTIME}=80$ & ESTABS_ES 80 & 01912 & 8 & $\mathrm{~N}$ \\
\hline in $\mathrm{QTIME}=9$ & ESTABS_ES9 & 01344 & 8 & $\mathrm{~N}$ \\
\hline$=\ldots 1 \ldots$ if positive employment in quarter $\mathrm{i}$ & ACTIVE_EMPLOY_ES & 01957 & 80 & $\mathrm{~A} / \mathrm{N}$ \\
\hline Ever had positive employment & ACTIVE_EVER_ES & 01920 & 8 & $\mathrm{~N}$ \\
\hline First QTIME with positive employment & ACTIVE_BEG_QTR_ES & 01936 & 3 & $\mathrm{~N}$ \\
\hline Last QTIME with positive employment & ACTIVE_END_QTR_ES & 01939 & 3 & $\mathrm{~N}$ \\
\hline Maximum monthly employment in QTIME $=1$ & EMP_ES1 & 00640 & 8 & $\mathrm{~N}$ \\
\hline Maximum monthly employment in QTIME $=10$ & EMP_ES10 & 00712 & 8 & $\mathrm{~N}$ \\
\hline
\end{tabular}


CHAPTER 4. EMPLOYMENT HISTORY FILES (EHF)

\begin{tabular}{|c|c|c|c|c|}
\hline Field name & $\begin{array}{l}\text { Data dictionary } \\
\text { reference name }\end{array}$ & $\begin{array}{l}\text { Starting } \\
\text { position }\end{array}$ & $\begin{array}{l}\text { Field } \\
\text { size }\end{array}$ & $\begin{array}{l}\text { Data } \\
\text { type }\end{array}$ \\
\hline Maximum monthly employment in QTIME $=11$ & EMP_ES11 & 00720 & 8 & $\mathrm{~N}$ \\
\hline Maximum monthly employment in QTIME $=12$ & EMP_ES12 & 00728 & 8 & $\mathrm{~N}$ \\
\hline Maximum monthly employment in $\mathrm{QTIME}=13$ & EMP_ES13 & 00736 & 8 & $\mathrm{~N}$ \\
\hline Maximum monthly employment in QTIME $=14$ & EMP_ES14 & 00744 & 8 & $\mathrm{~N}$ \\
\hline Maximum monthly employment in QTIME $=15$ & EMP_ES15 & 00752 & 8 & $\mathrm{~N}$ \\
\hline Maximum monthly employment in $\mathrm{QTIME}=16$ & EMP_ES16 & 00760 & 8 & $\mathrm{~N}$ \\
\hline Maximum monthly employment in $\mathrm{QTIME}=17$ & EMP_Es17 & 00768 & 8 & $\mathrm{~N}$ \\
\hline Maximum monthly employment in QTIME $=18$ & EMP_Es18 & 00776 & 8 & $\mathrm{~N}$ \\
\hline Maximum monthly employment in QTIME $=19$ & EMP_ES19 & 00784 & 8 & $\mathrm{~N}$ \\
\hline Maximum monthly employment in QTIME $=2$ & EMP_ES2 & 00648 & 8 & $\mathrm{~N}$ \\
\hline Maximum monthly employment in $\mathrm{QTIME}=20$ & EMP_ES20 & 00792 & 8 & $\mathrm{~N}$ \\
\hline Maximum monthly employment in QTIME $=21$ & EMP_ES21 & 00800 & 8 & $\mathrm{~N}$ \\
\hline Maximum monthly employment in $\mathrm{QTIME}=22$ & EMP_ES22 & 00808 & 8 & $\mathrm{~N}$ \\
\hline Maximum monthly employment in QTIME $=23$ & EMP_ES23 & 00816 & 8 & $\mathrm{~N}$ \\
\hline Maximum monthly employment in QTIME $=24$ & EMP_ES24 & 00824 & 8 & $\mathrm{~N}$ \\
\hline Maximum monthly employment in QTIME $=25$ & EMP_ES25 & 00832 & 8 & $\mathrm{~N}$ \\
\hline Maximum monthly employment in QTIME $=26$ & EMP_ES26 & 00840 & 8 & $\mathrm{~N}$ \\
\hline Maximum monthly employment in QTIME $=27$ & EMP_ES27 & 00848 & 8 & $\mathrm{~N}$ \\
\hline Maximum monthly employment in QTIME $=28$ & EMP_ES28 & 00856 & 8 & $\mathrm{~N}$ \\
\hline Maximum monthly employment in QTIME $=29$ & EMP_ES29 & 00864 & 8 & $\mathrm{~N}$ \\
\hline Maximum monthly employment in QTIME $=3$ & EMP_ES3 & 00656 & 8 & $\mathrm{~N}$ \\
\hline Maximum monthly employment in QTIME $=30$ & EMP_ES30 & 00872 & 8 & $\mathrm{~N}$ \\
\hline Maximum monthly employment in QTIME $=31$ & EMP_ES31 & 00880 & 8 & $\mathrm{~N}$ \\
\hline Maximum monthly employment in QTIME $=32$ & EMP_ES32 & 00888 & 8 & $\mathrm{~N}$ \\
\hline Maximum monthly employment in QTIME $=33$ & EMP_ES33 & 00896 & 8 & $\mathrm{~N}$ \\
\hline Maximum monthly employment in QTIME $=34$ & EMP_ES34 & 00904 & 8 & $\mathrm{~N}$ \\
\hline Maximum monthly employment in QTIME $=35$ & EMP_ES35 & 00912 & 8 & $\mathrm{~N}$ \\
\hline Maximum monthly employment in QTIME $=36$ & EMP_ES36 & 00920 & 8 & $\mathrm{~N}$ \\
\hline Maximum monthly employment in QTIME $=37$ & EMP_Es37 & 00928 & 8 & $\mathrm{~N}$ \\
\hline Maximum monthly employment in QTIME $=38$ & EMP_ES38 & 00936 & 8 & $\mathrm{~N}$ \\
\hline Maximum monthly employment in QTIME $=39$ & EMP_ES39 & 00944 & 8 & $\mathrm{~N}$ \\
\hline Maximum monthly employment in QTIME=4 & EMP_ES4 & 00664 & 8 & $\mathrm{~N}$ \\
\hline Maximum monthly employment in QTIME $=40$ & EMP_ES40 & 00952 & 8 & $\mathrm{~N}$ \\
\hline Maximum monthly employment in QTIME $=41$ & EMP_ES41 & 00960 & 8 & $\mathrm{~N}$ \\
\hline Maximum monthly employment in QTIME $=42$ & EMP_ES42 & 00968 & 8 & $\mathrm{~N}$ \\
\hline Maximum monthly employment in QTIME $=43$ & EMP_ES43 & 00976 & 8 & $\mathrm{~N}$ \\
\hline Maximum monthly employment in QTIME $=44$ & EMP_ES44 & 00984 & 8 & $\mathrm{~N}$ \\
\hline Maximum monthly employment in QTIME $=45$ & EMP_ES45 & 00992 & 8 & $\mathrm{~N}$ \\
\hline Maximum monthly employment in QTIME $=46$ & EMP_ES46 & 01000 & 8 & $\mathrm{~N}$ \\
\hline Maximum monthly employment in QTIME $=47$ & EMP_ES47 & 01008 & 8 & $\mathrm{~N}$ \\
\hline Maximum monthly employment in QTIME $=48$ & EMP_ES48 & 01016 & 8 & $\mathrm{~N}$ \\
\hline Maximum monthly employment in $\mathrm{QTIME}=49$ & EMP_ES49 & 01024 & 8 & $\mathrm{~N}$ \\
\hline Maximum monthly employment in QTIME $=5$ & EMP_ES5 & 00672 & 8 & $\mathrm{~N}$ \\
\hline Maximum monthly employment in QTIME $=50$ & EMP_ES50 & 01032 & 8 & $\mathrm{~N}$ \\
\hline Maximum monthly employment in QTIME $=51$ & EMP_ES51 & 01040 & 8 & $\mathrm{~N}$ \\
\hline Maximum monthly employment in QTIME $=52$ & EMP_ES52 & 01048 & 8 & $\mathrm{~N}$ \\
\hline Maximum monthly employment in QTIME $=53$ & EMP_ES53 & 01056 & 8 & $\mathrm{~N}$ \\
\hline Maximum monthly employment in QTIME $=54$ & EMP_ES54 & 01064 & 8 & $\mathrm{~N}$ \\
\hline Maximum monthly employment in QTIME $=55$ & EMP_ES55 & 01072 & 8 & $\mathrm{~N}$ \\
\hline Maximum monthly employment in ( & EMP_ES56 & 01080 & 8 & \\
\hline
\end{tabular}


CHAPTER 4. EMPLOYMENT HISTORY FILES (EHF)

\begin{tabular}{|c|c|c|c|c|}
\hline Field name & $\begin{array}{l}\text { Data dictionary } \\
\text { reference name }\end{array}$ & $\begin{array}{l}\text { Starting } \\
\text { position }\end{array}$ & $\begin{array}{l}\text { Field } \\
\text { size }\end{array}$ & $\begin{array}{l}\text { Data } \\
\text { type }\end{array}$ \\
\hline Maximum monthly employment in QTIME $=57$ & EMP_ES57 & 01088 & 8 & $\mathrm{~N}$ \\
\hline Maximum monthly employment in QTIME $=58$ & EMP_ES58 & 01096 & 8 & $\mathrm{~N}$ \\
\hline Maximum monthly employment in QTIME $=59$ & EMP_ES59 & 01104 & 8 & $\mathrm{~N}$ \\
\hline Maximum monthly employment in QTIME $=6$ & EMP_ES6 & 00680 & 8 & $\mathrm{~N}$ \\
\hline Maximum monthly employment in QTIME $=60$ & EMP_ES60 & 01112 & 8 & $\mathrm{~N}$ \\
\hline Maximum monthly employment in QTIME $=61$ & EMP_ES61 & 01120 & 8 & $\mathrm{~N}$ \\
\hline Maximum monthly employment in QTIME $=62$ & EMP_ES62 & 01128 & 8 & $\mathrm{~N}$ \\
\hline Maximum monthly employment in QTIME $=63$ & EMP_ES63 & 01136 & 8 & $\mathrm{~N}$ \\
\hline Maximum monthly employment in QTIME $=64$ & EMP_ES64 & 01144 & 8 & $\mathrm{~N}$ \\
\hline Maximum monthly employment in QTIME $=65$ & EMP_ES65 & 01152 & 8 & $\mathrm{~N}$ \\
\hline Maximum monthly employment in QTIME $=66$ & EMP_ES66 & 01160 & 8 & $\mathrm{~N}$ \\
\hline Maximum monthly employment in QTIME $=67$ & EMP_ES67 & 01168 & 8 & $\mathrm{~N}$ \\
\hline Maximum monthly employment in QTIME $=68$ & EMP_ES68 & 01176 & 8 & $\mathrm{~N}$ \\
\hline Maximum monthly employment in QTIME $=69$ & EMP_ES69 & 01184 & 8 & $\mathrm{~N}$ \\
\hline Maximum monthly employment in QTIME $=7$ & EMP_ES7 & 00688 & 8 & $\mathrm{~N}$ \\
\hline Maximum monthly employment in QTIME $=70$ & EMP_ES70 & 01192 & 8 & $\mathrm{~N}$ \\
\hline Maximum monthly employment in QTIME $=71$ & EMP_ES71 & 01200 & 8 & $\mathrm{~N}$ \\
\hline Maximum monthly employment in QTIME $=72$ & EMP_ES72 & 01208 & 8 & $\mathrm{~N}$ \\
\hline Maximum monthly employment in QTIME $=73$ & EMP_ES73 & 01216 & 8 & $\mathrm{~N}$ \\
\hline Maximum monthly employment in QTIME $=74$ & EMP_ES74 & 01224 & 8 & $\mathrm{~N}$ \\
\hline Maximum monthly employment in QTIME $=75$ & EMP_ES75 & 01232 & 8 & $\mathrm{~N}$ \\
\hline Maximum monthly employment in QTIME $=76$ & EMP_ES76 & 01240 & 8 & $\mathrm{~N}$ \\
\hline Maximum monthly employment in QTIME $=77$ & EMP_ES77 & 01248 & 8 & $\mathrm{~N}$ \\
\hline Maximum monthly employment in QTIME $=78$ & EMP_ES78 & 01256 & 8 & $\mathrm{~N}$ \\
\hline Maximum monthly employment in QTIME $=79$ & EMP_ES79 & 01264 & 8 & $\mathrm{~N}$ \\
\hline Maximum monthly employment in QTIME=8 & EMP_ES8 & 00696 & 8 & $\mathrm{~N}$ \\
\hline Maximum monthly employment in QTIME $=80$ & EMP_ES80 & 01272 & 8 & $\mathrm{~N}$ \\
\hline Maximum monthly employment in QTIME=9 & EMP_ES9 & 00704 & 8 & $\mathrm{~N}$ \\
\hline Month 1 employment in QTIME=1 & BPEMP_ES1 & 00000 & 8 & $\mathrm{~N}$ \\
\hline Month 1 employment in QTIME $=10$ & BPEMP_ES10 & 00072 & 8 & $\mathrm{~N}$ \\
\hline Month 1 employment in QTIME $=11$ & BPEMP_ES11 & 00080 & 8 & $\mathrm{~N}$ \\
\hline Month 1 employment in QTIME $=12$ & BPEMP_ES12 & 00088 & 8 & $\mathrm{~N}$ \\
\hline Month 1 employment in QTIME $=13$ & BPEMP_ES13 & 00096 & 8 & $\mathrm{~N}$ \\
\hline Month 1 employment in QTIME $=14$ & BPEMP_ES14 & 00104 & 8 & $\mathrm{~N}$ \\
\hline Month 1 employment in QTIME $=15$ & BPEMP_ES15 & 00112 & 8 & $\mathrm{~N}$ \\
\hline Month 1 employment in QTIME $=16$ & BPEMP_ES16 & 00120 & 8 & $\mathrm{~N}$ \\
\hline Month 1 employment in QTIME $=17$ & BPEMP_ES17 & 00128 & 8 & $\mathrm{~N}$ \\
\hline Month 1 employment in QTIME $=18$ & BPEMP_ES18 & 00136 & 8 & $\mathrm{~N}$ \\
\hline Month 1 employment in QTIME=19 & BPEMP_ES19 & 00144 & 8 & $\mathrm{~N}$ \\
\hline Month 1 employment in QTIME=2 & BPEMP_ES2 & 00008 & 8 & $\mathrm{~N}$ \\
\hline Month 1 employment in QTIME $=20$ & BPEMP_ES20 & 00152 & 8 & $\mathrm{~N}$ \\
\hline Month 1 employment in QTIME $=21$ & BPEMP_ES21 & 00160 & 8 & $\mathrm{~N}$ \\
\hline Month 1 employment in QTIME $=22$ & BPEMP_ES22 & 00168 & 8 & $\mathrm{~N}$ \\
\hline Month 1 employment in QTIME $=23$ & BPEMP_ES23 & 00176 & 8 & $\mathrm{~N}$ \\
\hline Month 1 employment in QTIME $=24$ & BPEMP_ES24 & 00184 & 8 & $\mathrm{~N}$ \\
\hline Month 1 employment in QTIME $=25$ & BPEMP_ES25 & 00192 & 8 & $\mathrm{~N}$ \\
\hline Month 1 employment in QTIME $=26$ & BPEMP_ES26 & 00200 & 8 & $\mathrm{~N}$ \\
\hline Month 1 employment in QTIME $=27$ & BPEMP_ES27 & 00208 & 8 & $\mathrm{~N}$ \\
\hline Month 1 employment in QTIME $=28$ & BPEMP_ES28 & 00216 & 8 & $\mathrm{~N}$ \\
\hline Month 1 employment in QTIME $=29$ & BPEMP_ES29 & 00224 & 8 & $\mathrm{~N}$ \\
\hline
\end{tabular}


CHAPTER 4. EMPLOYMENT HISTORY FILES (EHF)

\begin{tabular}{|c|c|c|c|c|}
\hline Field name & $\begin{array}{l}\text { Data dictionary } \\
\text { reference name }\end{array}$ & $\begin{array}{l}\text { Starting } \\
\text { position }\end{array}$ & $\begin{array}{l}\text { Field } \\
\text { size }\end{array}$ & $\begin{array}{l}\text { Data } \\
\text { type }\end{array}$ \\
\hline Month 1 employment in QTIME $=3$ & BPEMP_ES3 & 00016 & 8 & $\mathrm{~N}$ \\
\hline Month 1 employment in QTIME $=30$ & BPEMP_ES30 & 00232 & 8 & $\mathrm{~N}$ \\
\hline Month 1 employment in QTIME $=31$ & BPEMP_ES31 & 00240 & 8 & $\mathrm{~N}$ \\
\hline Month 1 employment in QTIME $=32$ & BPEMP_ES32 & 00248 & 8 & $\mathrm{~N}$ \\
\hline Month 1 employment in QTIME $=33$ & BPEMP_ES33 & 00256 & 8 & $\mathrm{~N}$ \\
\hline Month 1 employment in QTIME $=34$ & BPEMP_ES34 & 00264 & 8 & $\mathrm{~N}$ \\
\hline Month 1 employment in QTIME $=35$ & BPEMP_ES35 & 00272 & 8 & $\mathrm{~N}$ \\
\hline Month 1 employment in QTIME $=36$ & BPEMP_ES36 & 00280 & 8 & $\mathrm{~N}$ \\
\hline Month 1 employment in QTIME $=37$ & BPEMP_ES37 & 00288 & 8 & $\mathrm{~N}$ \\
\hline Month 1 employment in QTIME $=38$ & BPEMP_ES38 & 00296 & 8 & $\mathrm{~N}$ \\
\hline Month 1 employment in QTIME $=39$ & BPEMP_ES39 & 00304 & 8 & $\mathrm{~N}$ \\
\hline Month 1 employment in QTIME $=4$ & BPEMP_ES4 & 00024 & 8 & $\mathrm{~N}$ \\
\hline Month 1 employment in QTIME $=40$ & BPEMP_ES40 & 00312 & 8 & $\mathrm{~N}$ \\
\hline Month 1 employment in QTIME $=41$ & BPEMP_ES41 & 00320 & 8 & $\mathrm{~N}$ \\
\hline Month 1 employment in QTIME $=42$ & BPEMP_ES42 & 00328 & 8 & $\mathrm{~N}$ \\
\hline Month 1 employment in QTIME $=43$ & BPEMP_ES43 & 00336 & 8 & $\mathrm{~N}$ \\
\hline Month 1 employment in QTIME $=44$ & BPEMP_ES44 & 00344 & 8 & $\mathrm{~N}$ \\
\hline Month 1 employment in QTIME $=45$ & BPEMP_ES45 & 00352 & 8 & $\mathrm{~N}$ \\
\hline Month 1 employment in QTIME $=46$ & BPEMP_ES46 & 00360 & 8 & $\mathrm{~N}$ \\
\hline Month 1 employment in QTIME $=47$ & BPEMP_ES47 & 00368 & 8 & $\mathrm{~N}$ \\
\hline Month 1 employment in QTIME $=48$ & BPEMP_ES48 & 00376 & 8 & $\mathrm{~N}$ \\
\hline Month 1 employment in QTIME $=49$ & BPEMP_ES49 & 00384 & 8 & $\mathrm{~N}$ \\
\hline Month 1 employment in QTIME $=5$ & BPEMP_ES5 & 00032 & 8 & $\mathrm{~N}$ \\
\hline Month 1 employment in QTIME $=50$ & BPEMP_ES50 & 00392 & 8 & $\mathrm{~N}$ \\
\hline Month 1 employment in QTIME $=51$ & BPEMP_ES51 & 00400 & 8 & $\mathrm{~N}$ \\
\hline Month 1 employment in QTIME $=52$ & BPEMP_ES52 & 00408 & 8 & $\mathrm{~N}$ \\
\hline Month 1 employment in QTIME $=53$ & BPEMP_ES53 & 00416 & 8 & $\mathrm{~N}$ \\
\hline Month 1 employment in QTIME $=54$ & BPEMP_ES54 & 00424 & 8 & $\mathrm{~N}$ \\
\hline Month 1 employment in QTIME $=55$ & BPEMP_ES55 & 00432 & 8 & $\mathrm{~N}$ \\
\hline Month 1 employment in QTIME $=56$ & BPEMP_ES56 & 00440 & 8 & $\mathrm{~N}$ \\
\hline Month 1 employment in QTIME $=57$ & BPEMP_ES57 & 00448 & 8 & $\mathrm{~N}$ \\
\hline Month 1 employment in QTIME $=58$ & BPEMP_ES58 & 00456 & 8 & $\mathrm{~N}$ \\
\hline Month 1 employment in QTIME $=59$ & BPEMP_ES59 & 00464 & 8 & $\mathrm{~N}$ \\
\hline Month 1 employment in QTIME $=6$ & BPEMP_ES6 & 00040 & 8 & $\mathrm{~N}$ \\
\hline Month 1 employment in QTIME $=60$ & BPEMP_ES60 & 00472 & 8 & $\mathrm{~N}$ \\
\hline Month 1 employment in QTIME $=61$ & BPEMP_ES61 & 00480 & 8 & $\mathrm{~N}$ \\
\hline Month 1 employment in QTIME $=62$ & BPEMP_ES62 & 00488 & 8 & $\mathrm{~N}$ \\
\hline Month 1 employment in QTIME $=63$ & BPEMP_ES63 & 00496 & 8 & $\mathrm{~N}$ \\
\hline Month 1 employment in QTIME $=64$ & BPEMP_ES64 & 00504 & 8 & $\mathrm{~N}$ \\
\hline Month 1 employment in QTIME $=65$ & BPEMP_ES65 & 00512 & 8 & $\mathrm{~N}$ \\
\hline Month 1 employment in QTIME $=66$ & BPEMP_ES66 & 00520 & 8 & $\mathrm{~N}$ \\
\hline Month 1 employment in QTIME $=67$ & BPEMP_ES67 & 00528 & 8 & $\mathrm{~N}$ \\
\hline Month 1 employment in QTIME $=68$ & BPEMP_ES68 & 00536 & 8 & $\mathrm{~N}$ \\
\hline Month 1 employment in QTIME $=69$ & BPEMP_ES69 & 00544 & 8 & $\mathrm{~N}$ \\
\hline Month 1 employment in QTIME=7 & BPEMP_ES7 & 00048 & 8 & $\mathrm{~N}$ \\
\hline Month 1 employment in QTIME $=70$ & BPEMP_ES70 & 00552 & 8 & $\mathrm{~N}$ \\
\hline Month 1 employment in QTIME $=71$ & BPEMP_ES71 & 00560 & 8 & $\mathrm{~N}$ \\
\hline Month 1 employment in QTIME $=72$ & BPEMP_ES72 & 00568 & 8 & $\mathrm{~N}$ \\
\hline Month 1 employment in QTIME $=73$ & BPEMP_ES73 & 00576 & 8 & $\mathrm{~N}$ \\
\hline Month 1 employment in QTIME $=74$ & BPEMP_ES74 & 00584 & 8 & $\mathrm{~N}$ \\
\hline
\end{tabular}


CHAPTER 4. EMPLOYMENT HISTORY FILES (EHF)

\begin{tabular}{|c|c|c|c|c|}
\hline Field name & $\begin{array}{l}\text { Data dictionary } \\
\text { reference name }\end{array}$ & $\begin{array}{l}\text { Starting } \\
\text { position }\end{array}$ & $\begin{array}{l}\text { Field } \\
\text { size }\end{array}$ & $\begin{array}{l}\text { Data } \\
\text { type }\end{array}$ \\
\hline Month 1 employment in QTIME $=75$ & BPEMP_ES75 & 00592 & 8 & $\mathrm{~N}$ \\
\hline Month 1 employment in QTIME $=76$ & BPEMP_ES76 & 00600 & 8 & $\mathrm{~N}$ \\
\hline Month 1 employment in QTIME $=77$ & BPEMP_ES77 & 00608 & 8 & $\mathrm{~N}$ \\
\hline Month 1 employment in QTIME $=78$ & BPEMP_ES78 & 00616 & 8 & $\mathrm{~N}$ \\
\hline Month 1 employment in QTIME $=79$ & BPEMP_ES79 & 00624 & 8 & $\mathrm{~N}$ \\
\hline Month 1 employment in QTIME $=8$ & BPEMP_ES8 & 00056 & 8 & $\mathrm{~N}$ \\
\hline Month 1 employment in QTIME $=80$ & BPEMP_ES80 & 00632 & 8 & $\mathrm{~N}$ \\
\hline Month 1 employment in QTIME $=9$ & BPEMP_ES9 & 00064 & 8 & $\mathrm{~N}$ \\
\hline Number of quarters with positive employment & ACTIVE_QTRS_ES & 01942 & 3 & $\mathrm{~N}$ \\
\hline SEIN was ever had multiple units & EVER_MU & 01928 & 8 & $\mathrm{~N}$ \\
\hline State Employer ID Number & SEIN & 01945 & 12 & $\mathrm{~A} / \mathrm{N}$ \\
\hline
\end{tabular}


CHAPTER 4. EMPLOYMENT HISTORY FILES (EHF)

\subsubsection{Summary information on datasets}

Table 4.7: File information, by state, for EHF

\begin{tabular}{|c|c|c|c|c|c|c|}
\hline State & & $\begin{array}{r}\text { Number of } \\
\text { datafiles }\end{array}$ & Records & $\begin{array}{r}\text { Filesizes } \\
(\mathrm{MB}) \\
\end{array}$ & Start & End \\
\hline Covered states & & 217 & $2,838,350,408$ & $418,570.64$ & 1985Q2 & 2004Q3 \\
\hline Alabama & $\mathrm{AL}$ & 7 & $22,419,226$ & $2,578.44$ & 2001Q1 & 2004Q2 \\
\hline Arkansas & $\mathrm{AR}$ & 7 & $9,519,686$ & $1,044.09$ & 2002Q3 & 2004Q2 \\
\hline California & $\mathrm{CA}$ & 7 & $514,071,832$ & $76,263.99$ & 1991Q1 & 2003Q4 \\
\hline Colorado & $\mathrm{CO}$ & 7 & $90,966,637$ & $14,970.98$ & 1990Q1 & 2004Q1 \\
\hline Delaware & $\mathrm{DE}$ & 7 & $7,640,788$ & 911.26 & 1997Q1 & 2004Q1 \\
\hline Florida & FL & 7 & $256,230,604$ & $39,224.97$ & 1989Q1 & 2004Q1 \\
\hline Iowa & IA & 7 & $25,761,052$ & $3,200.69$ & 1990Q1 & 2004Q1 \\
\hline Idaho & ID & 7 & $23,835,178$ & $3,816.40$ & 1990Q1 & 2004Q1 \\
\hline Illinois & IL & 7 & $221,251,965$ & $33,438.76$ & 1990Q1 & 2004Q1 \\
\hline Indiana & IN & 7 & $114,988,266$ & $17,429.23$ & 1990Q1 & 2004Q1 \\
\hline Kansas & KS & 7 & $52,731,691$ & $8,172.11$ & 1990Q1 & 2004Q1 \\
\hline Kentucky & $\mathrm{K}$ & 7 & $42,071,468$ & $5,037.72$ & 1996Q4 & 2004Q1 \\
\hline Maryland & $\mathrm{Ml}$ & 7 & $115,760,015$ & $20,485.74$ & 1985Q2 & 2004Q2 \\
\hline Maine & $\mathrm{M}$ & 7 & $14,680,364$ & $1,938.88$ & 199 & 2004Q1 \\
\hline Minnesota & $\mathrm{M}$ & 7 & $76,484,001$ & $10,400.03$ & 199 & 2004Q3 \\
\hline Misso & $\mathrm{M}$ & 7 & $106,408,441$ & $16,866.77$ & 199 & 2004Q1 \\
\hline Mont & $\mathrm{M}$ & 7 & 13,6 & $2,006.10$ & 199 & 2004Q1 \\
\hline North Carolina & $\mathrm{N}$ & 7 & 140,709, & $21,001.80$ & 199 & 2003Q4 \\
\hline North Dakota & $\mathrm{Nl}$ & 7 & $6,327,983$ & 778.26 & 1998Q1 & 2004Q2 \\
\hline New Jersey & NJ & 7 & $87,722,728$ & $11,467.09$ & 1995Q1 & 2004Q1 \\
\hline New Mexico & $\mathrm{NI}$ & 7 & $1,480,296$ & $2,925.88$ & 1990Q1 & 2004Q1 \\
\hline Oklahoma & $\mathrm{OH}$ & 7 & $1,756,391$ & $2,573.13$ & 1999Q1 & 2004Q1 \\
\hline Oregon & $\mathrm{Ol}$ & 7 & $1,857,523$ & $9,536.13$ & 1990Q1 & 2004Q1 \\
\hline Pennsylvan & PA & 7 & $188,590,880$ & $27,341.23$ & 1991Q1 & 2004Q1 \\
\hline South Carolina & $\mathrm{SC}$ & 7 & $39,151,294$ & $4,754.95$ & 1998Q1 & 2004Q3 \\
\hline Texas & $\mathrm{T}$ & 7 & $269,205,201$ & $37,549.96$ & 1990Q1 & 2004Q2 \\
\hline Virginia & $\mathrm{V}$ & 7 & $64,226,246$ & $7,831.45$ & 1995Q3 & 2004Q1 \\
\hline Vermont & VT & 7 & $4,456,337$ & 521.20 & 2000Q1 & 2004Q1 \\
\hline Washington & WA & 7 & $112,085,555$ & $18,187.27$ & 1990Q1 & 2004Q1 \\
\hline Wisconsin & WI & 7 & $97,269,196$ & $14,389.28$ & 1990Q1 & 2004Q1 \\
\hline West Virgi & WV & 7 & $15,039,244$ & $1,926.86$ & 1990Q1 & 2004Q1 \\
\hline
\end{tabular}




\subsection{NOTES}

Table 4.8: UI/EHF Summary of Information and Known Issues with Data Coverage and Quality

\begin{tabular}{l|l}
\hline State & Known Data Quality Issues (UI/EHF) \\
\hline CA & None \\
60-70\% hole in UI data in 1993:3. 20\% unresolved \\
identifier mismatch on UI in [90:1-90:3] \\
(1) There appear to be changes being made in the \\
firm identifiers on the ES202 and UI data in the \\
mid-to-late 1990s. Specifically it looks as though \\
some changes are made on the identifiers in the \\
ES202 in 1996 and in 1997 the UI data is corrected \\
in kind. In the ES202 data, 14\% of firms die in \\
1995:4 and are born in 1996:1, indicating a shift \\
in some firm identifiers. A similar change in mag- \\
nitude occurs in the UI data between 1997:1 and \\
1997:4. Between these years, the rate of match be- \\
tween the UI and ES202 SEINs is somewhat poor \\
( $10 \%$ of UI SEINs do not appear on the ES202 be- \\
tween 1996:1 and 1997:3), although it is quite good \\
both before and after. (2) The match between the \\
ES202 and UI data is not good in 2002:4-2003:3, \\
with 13-20\% of UI SEINs not appearing in the ES- \\
202 data. \\
None \\
1990 UI data has firm identifier problems on ap- \\
proximately 40\% of the records. Because of these \\
problems, this year is not included in the EHF.
\end{tabular}

IL Small hole in UI data in 1990:1 ( $10 \%$ missing). 1992:1 and 1993:1 are also missing UI wage records.

IN None

KS Large holes in KS UI data at 1990:1 ( $i 50 \%$ missing) and 1992:4 (25\% missing)

KY UI identifier problem in 2000:3-2001:2 likely, due to $10 \%, 15 \%$ death rates in 2000:3, 2000:4, followed by $11 \%, 14 \%$ birth rates in 2001:1 and 2001:2. (Normal is 3-7\% births/deaths in a particular quarter)

MD None

ME None

MN None

MO 1994:4 UI data is small (approximately 70\% sample).
Recommendation to Researchers

Researchers should generally avoid use of pre-1994 EHF data in CO.

While not a big enough problem to recommend avoiding use of these date ranges in FL, be aware that changes in firm identifiers in the mid-1990s will bias worker flow measures during this period.

Researchers should generally avoid use of 1990 ID EHF data, which should not be too much of an issue as ES202 information is missing for this year in ID.

Note to researchers: These problems bias worker flows in those quarters, also full quarter employment in early years of IL data.

Researchers should generally avoid use of 1990 and 1992 KS EHF data; this problem will also bias full quarter employment and flows in 1993.

Note to researchers: These problems bias worker flows in those quarters, also full quarter employment during 2000-2001 KY data.

Researchers should generally avoid use of 1994 MO EHF data; this problem will also bias some full quarter employment and flows measures in 1995. 


\begin{tabular}{|c|c|c|}
\hline State & Known Data Quality Issues (UI/EHF) & Recommendation to Researchers \\
\hline $\mathrm{NC}$ & $\begin{array}{l}\text { * ES202 show persistently lower employment } \\
\text { than UI, by about } 14 \% \text {, except for 1991:1-1992:3 } \\
\text { (around 0\%) and 2002:1-2002:4 (5-8\%). Warnings } \\
\text { are generated when it goes above } 15 \% \text {. * Pay- } \\
\text { roll is typically } 6-8 \% \text { higher on ES202 compared } \\
\text { to UI except for 1991:1-1992:3, where it is } 20- \\
30 \% \text { higher. There are also significant, but not } \\
\text { as large deviations in 2002:1-2003:1. * Based on } \\
\text { the BLS PU records, the ES202 data series looks } \\
\text { fine: ES202 sums rarely go above 1\% (Test 13-1 } \\
\text { and 13-2) } \\
\text { Conclusion: we are still missing wage records in } \\
\text { the early periods, and some in later periods as } \\
\text { well. The most recent wage records actually look } \\
\text { coherent with the longest time series, but } 2002 \text { is } \\
\text { a small problem. }\end{array}$ & $\begin{array}{l}\text { Note to Researchers: Similar to problems in early } \\
\text { years of IL, these issues bias worker flows in those } \\
\text { quarters, also full quarter employment. }\end{array}$ \\
\hline NJ & $\begin{array}{l}\text { Small holes in NJ UI data at 1998:3 ( } 5 \%) \text { and } \\
1999: 1(8-10 \%) \text { and 2003:1 }(10 \%)\end{array}$ & $\begin{array}{l}\text { Note to Researchers: Problem probably small } \\
\text { enough to ignore for most research purposes. }\end{array}$ \\
\hline NM & None & \\
\hline OK & None & \\
\hline OR & $1994: 1$ is small, but not terribly so. & $\begin{array}{l}\text { Note to Researchers: Problem probably small } \\
\text { enough to ignore for most research purposes. }\end{array}$ \\
\hline PA & UI wage records are $1 \%$ sample for $1996: 4$ & $\begin{array}{l}\text { Note to Researchers: Generally avoid use of } 1996 \\
\text { PA annual earnings (particularly earnings changes } \\
\text { between 1995-1996, 1996-1997, which will be bi- } \\
\text { ased), this problem will also bias some flows and } \\
\text { full quarter employment measures in } 1996 \text { and } \\
\text { 1997. }\end{array}$ \\
\hline $\mathrm{TX}$ & None & \\
\hline VA & $\begin{array}{l}1998: 1 \text { is small, and 1998:2 also looks on the small } \\
\text { side. }\end{array}$ & $\begin{array}{l}\text { Note to Researchers: Problems probably small } \\
\text { enough to ignore for most research purposes. }\end{array}$ \\
\hline WA & None & \\
\hline WI & None & \\
\hline WV & None & \\
\hline
\end{tabular}


CHAPTER 4. EMPLOYMENT HISTORY FILES (EHF) 


\section{Chapter 5. Geo-coded Address List (GAL)}

\subsection{OVERVIEW}

\subsubsection{Definition of GAL}

The Geocoded Address List (GAL) is a data set containing unique commercial and residential addresses in a state geocoded to the Census Block and latitude/longitude coordinates. It consists of the address list (GAL) and a crosswalk for each processed file-year. The GAL contains each unique address, identified by a GAL identifier called galid, its geocodes, a flag for each file-year in which it appears, data quality indicators, and data processing information, including the release date of the Geographic Reference File (GRF). The GAL Crosswalk contains the ID of each input entity and the ID of its address (galid).

Input Data The input data consists of addresses, geocodes, and coordinates. Currently, the source files providing addresses consist of the following (future work will add the Non-employer file):

ACS-POW American Community Survey Place of Work (2001 and later)

AHS American Housing Survey (2002)

ES202 Employment Security form 202 (all available years 1990 and later)

SSEL Business Register (Standard Statistical Establishment List 1990 and later)

MAF Master Address File (the year following the year of the desired geographic vintage)

Geocodes The source files providing geocodes and coordinates are the following:

GCP the databases of Group1's Geographic Coding Plus software

MAF Master Address File

GRF-C Geographic Reference File, Codes (encompassed in the BMF)

WIB-C Workforce Investment Board, Codes (encompassed in the BMF)

BMF Block Map File

\subsubsection{Update frequency}

The internal use GAL is produced monthly. The RDC version is produced occassionally, usually at the same time as the other LEHD-provided RDC files.

\subsubsection{Acquisition process}

In the S2004 Infrastructure Files, the most recent available GAL at the time of transfer is used. In the future, the RDC version of the GAL will be produced as part of the LEHD Infrastructure files, and will be coordinated with other LEHD Infrastructure files. 


\subsubsection{Processing description}

All internal processing variables (parsed addresses in particular) are available on the RDC. All crosswalks to input files (for instance, the BR) are available as well. Note that a researcher needs to request the input files separately, and not all input files may be available in the RDC environment.

The Census-internal GAL is considered commingled data, i.e., it contains information protected both under Title 13 and Title 26. Because projects requesting Title 26 data are handled differently from projects requesting only Title 13 information, the GAL is split. Before transferring the GAL to the RDC environment, all variables that refer to Title 26 data are split off, and stored in a separate file (gal_ZZ_t26flags.sas7bdat, Section 5.3.5). Furthermore, all records sourced exclusively from Title 26 data are removed from the main GAL dataset, and stored separately (gal_ZZ_t26.sas7bdat, Section 5.3.4). Section 5.4.1 describes the program used to split the data from the internal-use commingled file. Section 5.4.2 provides a sample program to join all three components together again. 


\subsection{DETAILS}

The following document was prepared by Marc Roemer, U.S. Census Bureau. It provides a general overview of how the GAL files are created.

The Geocoded Address List (GAL) is a data set containing unique commercial and residential addresses in a state geocoded to the Census Block and latitude/longitude coordinates. The file encompasses addresses from the state ES202 data, the Business Register, the Census Bureau's Master Address File (MAF), the American Community Survey Place of Work file (ACS-POW), and others. Addresses from these source files go through Code1, Vality standardizer, Vality matching for unduplication, and several other steps in SAS. This document refers to one year's data from a source file as a file-year (for example, the 1995 ES202).

The job stream follows the steps below using the indicated software.

- Step 1: Create input (SAS).

- Step 2: Standardize and geocode addresses (Code1).

- Step 3: Parse and standardize address elements (Vality Standardize).

- Step 4: Match addresses, flag masters and duplicates (Vality Unduplicate).

- Step 5: Create preliminary crosswalk and unique address list with address identifier (SAS).

- Step 6: Set file-year flags, create GAL Crosswalks containing the input identifier and address identifier (SAS).

- Step 7: Retrieve and derive block codes and coordinates from the MAF (SAS).

- Step 8: Impute block within known tract (SAS).

- Step 9: Create GAL by adding higher-level geocodes by block (SAS).

- Step 10: Delete intermediate data files and create links.

The final output consists of the address list and a crosswalk for each processed file-year. The GAL contains each address, its geocodes, a flag for each file-year in which it appears, data quality indicators, and data processing information. The GAL Crosswalk contains the ID of each input entity and the ID of its address. The following section describes the GAL's content.

\subsubsection{Important Variables}

Unique identifier The variable galid is the unique address identifier on the GAL, a 26-character string consisting of the letter 'A' in the first column followed by the 2-character state FIPS code and a zero-padded sequential number. The galid is created each time a GAL is created. There's no consistency in the galid between versions or vintages of the GAL.

Geographic vintage The release date (year) of the GRF identifies the geographic vintage. In the GAL the vintage becomes the variable a_vintage.

Geographic codes The variable a_geocode is FIPS-state(2)\|FIPS-county(3)\|Census-tract(6), and it uniquely identifies the Census tract in the U.S. The tract is the lowest level of geography recommended for analysis. The Census block within the tract is a_block. The uncertainties in block-coding make block-level analysis questionable. However, geocoding to the block allows us to add all the higher-level geocodes to the addresses. The variable a_block_src generated in Steps 7 and 8 describes the source of the block-code. 
Figure 5.1: GAL Processing

Flowchart for Adding WIBs to GAL/LEG Processing - 09/12/05
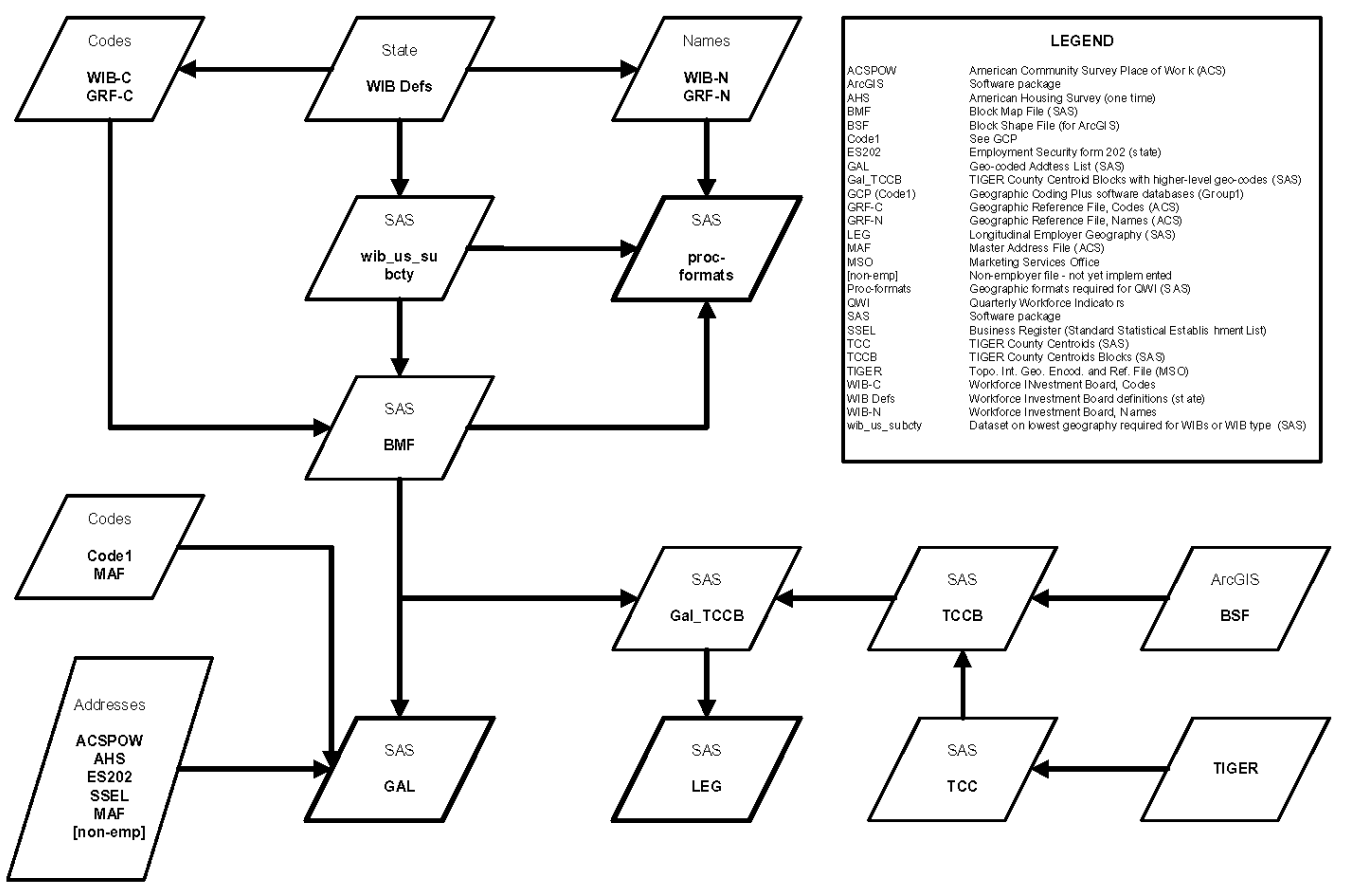

Page 1

Source: Longitudinal Employer-Household Dynamics (LEHD) Frogram, Census Bureau 


\begin{tabular}{|c|c|c|}
\hline & Typical & \\
\hline Value & Percent & Meaning \\
\hline $\mathrm{C}$ & 12.20 & $\begin{array}{l}\text { Code1, or the address matches an address for } \\
\text { which Code1 supplied the block code }\end{array}$ \\
\hline M & 81.86 & $\begin{array}{l}\text { The MAF - the address is a MAF address or } \\
\text { matches a MAF address }\end{array}$ \\
\hline $\mathrm{E}$ & 0.00 & $\begin{array}{l}\text { The MAF, the street address is exactly the same } \\
\text { as a MAF address in the same tract }\end{array}$ \\
\hline $\mathrm{W}$ & 0.03 & $\begin{array}{l}\text { The MAF, the street address is between } 2 \mathrm{MAF} \\
\text { addresses on the same block face }\end{array}$ \\
\hline $\mathrm{O}$ & 1.23 & $\begin{array}{l}\text { Imputed by the distribution of commercial ad- } \\
\text { dresses in the tract }\end{array}$ \\
\hline $\mathrm{S}$ & 1.17 & $\begin{array}{l}\text { Imputed by the distribution of residential ad- } \\
\text { dresses in the tract }\end{array}$ \\
\hline I & 0.01 & $\begin{array}{l}\text { Imputed by the distribution of mixed-use ad- } \\
\text { dresses in the tract }\end{array}$ \\
\hline $\mathrm{D}$ & 0.00 & $\begin{array}{l}\text { Imputed by the distribution of all addresses in the } \\
\text { tract }\end{array}$ \\
\hline missing & 3.50 & Block code is missing \\
\hline
\end{tabular}

In all states observed so far except California, no address required the 'D' method. That is, almost every tract where an address lacks a block code contains commercial, residential, and mixed-use addresses.

The Census Bureau splits blocks to accommodate changes in political boundaries. Most commonly, these are place boundaries (a place is a city, village, or similar municipality). The resulting block parts are identified by 2 suffixes, each taking a value from A to Z. The GAL assigns the block part directly from the MAF, or by adopting the one whose internal point is closest to the address by the straight-line distance. The variables a_block_suf 1 and a_block_suf2 identify the block part, and a_block_suf_src generated in Step 9 describes the method used to assign it.

$\begin{array}{lrl} & \text { Typical } & \\ \text { Value } & \text { Percent } & \text { Meaning } \\ \mathrm{A} & 1.50 & \text { Assigned by distance } \\ \mathrm{M} & 4.18 & \text { The MAF - the address is a MAF address or } \\ & & \text { matches a MAF address } \\ \text { missing } & 94.32 & \text { Not a split block }\end{array}$

The GAL also provides the following basic geographic variables:

$\begin{array}{ll}\text { a_ssccc } & \text { FIPS-state }(2) \| \text { FIPS-county }(3) \\ \text { a_st } & \text { FIPS state }(2) \\ \text { a_cty } & \text { FIPS county within the state }(3) \\ \text { a_tract } & \text { Census tract within the county }(6)\end{array}$

Higher-level geographic codes originate from the Block Map File (BMF) and attach to the GAL in Step 9. The BMF is an extract of the GRF-C (Geographic Reference File - Codes). All these geocodes are character variables. FIPS (Federal Information Processing Standard) codes are unique within the U.S.; Census codes are not.

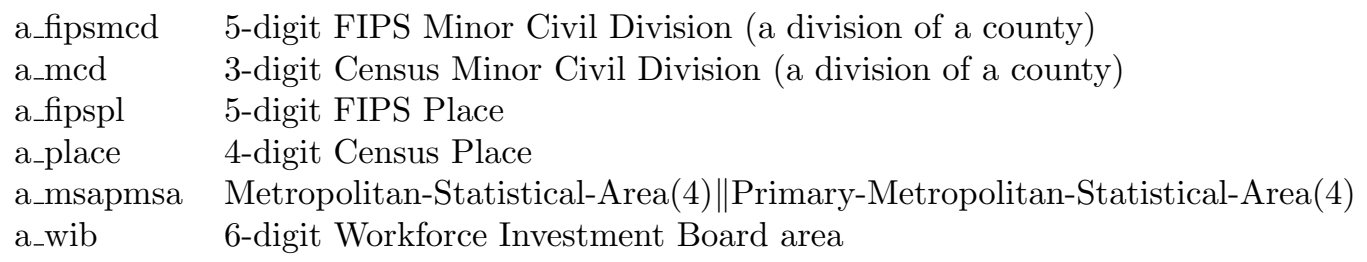


Geographic coordinates The coordinates of each address are in the variables a_latitude and a_longitude. These variables are numeric with 6 implied decimals (divide by 1,000,000 to convert them). The coordinates are not as accurate as 6 decimal places implies. An indication of their quality is in the variable a_geoqual, a numeric variable taking values from 1 to 9 and generated in Steps 7, 8, and 9:

$\begin{array}{lrl} & \text { Typical } & \\ \text { Value } & \text { Percent } & \text { Meaning } \\ 1 & 80.15 & \text { Rooftop or MAF (most accurate) } \\ 2 & 1.59 & \text { ZIP4 or block face, block face is certain } \\ 3 & 10.12 & \text { Block group is certain } \\ 4 & 4.65 & \text { Tract is certain } \\ 9 & 3.50 & \text { Coordinates are missing }\end{array}$

The format 'agqual' provided by 'format_geo.sas' in '/programs/projects/auxiliary/Formats' contains the meanings of the a_geoqual values listed above.

Two other variables give information about the coordinates. The flag a_latlong_src indicates their source:

$\begin{array}{lrl} & \text { Typical } & \\ \text { Value } & \text { Percent } & \text { Meaning } \\ \mathrm{B} & 14.77 & \text { Block (or block part) internal point } \\ \mathrm{C} & 70.04 & \text { Code1 } \\ \mathrm{D} & 0.03 & \text { Derived } \\ \mathrm{M} & 11.66 & \text { the MAF } \\ \text { missing } & 3.50 & \text { Coordinates are missing }\end{array}$

Few addresses have a_latlong_src equal to 'D'. Deriving coordinates occurs only if they're still missing after Code1 processing and direct extraction from the MAF, but the tract is known. In this case, the flag a_latlong_drv generated in Step 7 describes the derivation method:

\begin{tabular}{|c|c|c|}
\hline & Typical & \\
\hline Value & Percent & Meaning \\
\hline $\mathrm{F}$ & 0.00 & Adopted from the only address on the block face \\
\hline $\mathrm{P}$ & 0.04 & $\begin{array}{l}\text { Extrapolated between } 2 \text { addresses on the block } \\
\text { face }\end{array}$ \\
\hline nissin & 99.96 & Derivation not performed \\
\hline
\end{tabular}

In GAL Version 1, deriving coordinates and block codes by these methods was an important means of block-coding. It rarely operates now, since Code1 began providing block codes. Nevertheless, GAL Version 3 still exhausts all methods of assigning block-codes and coordinates before resorting to imputation.

File-year flags A set of flags generated in Step 6 indicates what file-years an address appears in. The names of the flags conform to the naming convention [f] [yyyy] for the source file [f] and year [yyyy], where $[f]$ takes the following values:

$\begin{array}{ll}\text { Business Register } & \mathrm{f}=\mathrm{b} \\ \text { ES202 } & \mathrm{f}=\mathrm{e} \\ \text { Master Address File } & \mathrm{f}=\mathrm{m} \\ \text { American Community Survey - Place of Work } & \mathrm{f}=\mathrm{p} \\ \text { American Housing Survey } & \mathrm{f}=\mathrm{h}\end{array}$

For example, the flag variable b1997 equals 1 if the address is on the 1997 Business Register; otherwise it equals 0. Note that if a [LEHD] state partner supplies 1991 ES202 data with no address information, e1991 will be 0 for all addresses. Typically, the e [yyyy] flags equal 1 for between 3 and 6 percent of addresses, the b[yyyy] flags equal 1 for between 4 and 10 percent, and the m[yyyy] flag is 1 for between 80 and 90 percent. The $\mathrm{p}$ [yyyy] and $\mathrm{h}$ [yyyy] flags equal 1 for less than 1 percent of addresses because the ACS-POW and AHS data are sample surveys. 


\subsubsection{Other Variables}

occupant_type The variable occupant_type, recoded from the file-year flags in Step 8, indicates whether an address is commercial, residential, or mixed-use.

bigsrcid The tracking ID bigsrcid, created in Step 1, uniquely identifies the entity that supplied the address. It consists of [f] , [yyyy], the unique ID from the input file, zero-padding, and for some source files, a flag indicating which set of variables supplied the address. For addresses originating in the Business Register, another flag indicates the single-unit data set or the multi-unit data set. This tracking ID variable is useful for debugging.

This variable is only available GAL_ZZ_2003_T26FLAGS.

srcmast A diagnostic variable srcmast contains [f] [yyyy], indicating the file-year that supplied this address. Bear in mind that it's often arbitrary which observation becomes the master address for a set of duplicates in Step 1 and Step 4, so bigsrcid and srcmast don't indicate anything special about an address or an entity. They simply identify the origin of an address that became a master address in unduplication.

This variable is only available GAL_ZZ_2003_T26FLAGS.

Code 1 variables The names of Code1 variables contain the prefix c1_. They impart mostly diagnostic information from Code1 processing. They could be useful for development work or address research.

For records sourced exclusively from the BR, these variables are available on GAL_ZZ_2003_T26. For records sourced exclusively from the ES202! (ES202!), some variables were blanked on GAL_ZZ_2003 and are available on GAL_ZZ_2003_ES202ONLY to Census personnel only. Code1 diagnostic codes remain available to all researchers.

Vality variables The parsed address elements from Step 3 sit in the variables named with the prefix $v_{-}$. They could be useful for development work, particularly in improving the parsing routine.

For records sourced exclusively from the BR, these variables are available on GAL_ZZ_2003_T26. For

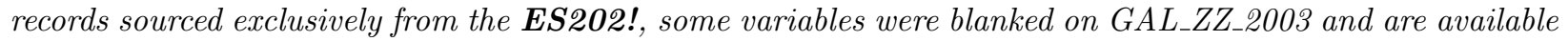
on GAL_ZZ_2003_ES202ONLY to Census personnel only. Vality diagnostic codes remain available to all researchers.

\subsubsection{Accessing the GAL: the GAL Crosswalks}

The GAL Crosswalks allow you to extract geographic and address information about any entity whose address went into the GAL. Each crosswalk contains the identifiers of the entity, its galid, and sometimes flags. To attach geocodes, coordinates, or address information to an entity, merge the GAL Crosswalk to the GAL by galid, outputting only observations existing on the GAL Crosswalk. Then merge the resulting file to the entities of interest using the entity identifiers. An entity whose address wasn't processed (because it's out of state or lacks address information) will have blank GAL data.

- For the AHS, the entity ID variables are control and year.

- For the ES202, the entity ID variables are sein, seinunit, year, and quarter. The flag variable e_flag indicates whether the address came from the address_street1, address_state, and address_zip9 variables (e_flag=P for physical address) or from the ui_address_street1, ui_address_state, and ui_address_zip9 variables (e_flag=M for mailing address).

- For the ACS-POW data, the entity ID variables are acsfileseq, cmid, seq, and pnum.

- For the Business Register, the entity ID variables are cfn, year, and singmult. The flag variable singmult indicates whether the entity resides in the single-unit (su) or the multi-unit $(\mathrm{mu})$ data set. Another flag variable $b \_f l a g$ indicates whether the address originated from the variables pstreet, 
pplce, pst, and pzip (b_flag=P for physical address) or street, plce, st, and zip (b_flag=M for mailing address). .

- For the MAF, mafid and year identify entities.

\subsubsection{Resources for geographic information}

The best place for information about Census geography is

$$
\text { http://www.census.gov/geo/www/reference.html. }
$$

Especially informative is the Geographic Areas Reference Manual (GARM), at

http://www.census.gov/geo/www/garm.html 


\subsection{DATA SET DESCRIPTIONS}

\subsubsection{Naming scheme}

All GAL files are labelled with the geovintage used in the creation, i.e., 2003, and except for the main dataset, a suffix, composed of a dataset abbreviation and a calendar year:

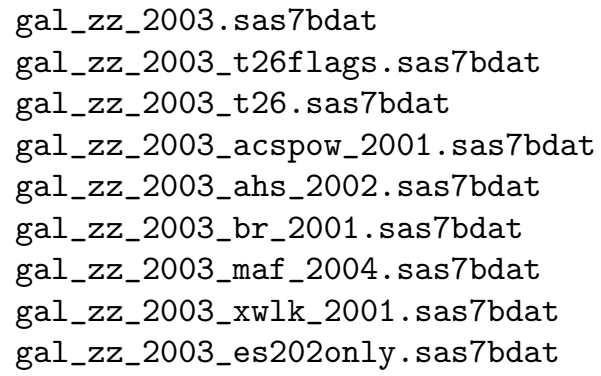

ZZ stands for the state postal abbreviation, and YYYY for a calendar year. Not all files are available for all states. In particular, LEHD-related crosswalks are only available for states actively participating with LEHD at the time of creation of the GAL.

\begin{tabular}{l|l|l}
\hline Suffix & Crosswalk to: & Availability \\
\hline acspow & American Community Survey & $2001-2005$ \\
& Place-of-Work Coding & \\
ahs & American Housing Survey & as of 2002 \\
br & Business Register (ex-SSEL) & $1990-2001$ \\
maf & (Census) Master Address File & as of 2004 \\
xwalk & LEHD ES-202 & varies by state; consult LEHD- \\
& & ES-202 documentation \\
\hline
\end{tabular}

Files with suffixes t26, t26flags, and tccb are not cross-walks. Consult Sections 5.3.4, 5.3.5, and 5.3.7, respectively.

\subsubsection{Data location}

The files are stored in two main directories, with state-specific subdirectories:

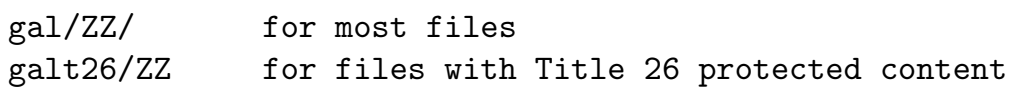

On the RDC network, both directories can be found under

/mixed/lehd/current

Files reserved for Census internal projects can be found in

$$
\text { galcc/ZZ }
$$

For the exact location, consult with the RDC administrator. 


\subsubsection{Main dataset: GAL_ZZ_2003}

This file does not contain data protected exclusively under Title 26. Consult Section 5.3.4 and 5.3.5. This file also does not report any address data sourced exclusively from ES-202. If a field contains address data sourced exclusively from ES-202, the values have been blanked on this file, and preserved in GAL_ZZ_2003_ES2020NLY (see Section 5.3.6).

\section{Record identifier: GALID}

Sort order: GALID

File indexes: none

Entity unique address

Unique Entity Key GALID

\begin{tabular}{|c|c|c|c|c|}
\hline Field name & $\begin{array}{l}\text { Data dictionary } \\
\text { reference name }\end{array}$ & $\begin{array}{l}\text { Starting } \\
\text { position }\end{array}$ & $\begin{array}{l}\text { Field } \\
\text { size }\end{array}$ & $\begin{array}{l}\text { Data } \\
\text { type }\end{array}$ \\
\hline 3-digit Census MCD & A_MCD & 00612 & 3 & $\mathrm{~A} / \mathrm{N}$ \\
\hline 4-digit Census Place & A_PLACE & 00620 & 4 & $\mathrm{~A} / \mathrm{N}$ \\
\hline 5-digit FIPS MCD & A_FIPSMCD & 00607 & 5 & $\mathrm{~A} / \mathrm{N}$ \\
\hline 5-digit FIPS Place & A_FIPSPL & 00615 & 5 & $\mathrm{~A} / \mathrm{N}$ \\
\hline 6-character Traffic Analysis Zone (leading blanks) & A_TAZ & 00596 & 6 & $\mathrm{~A} / \mathrm{N}$ \\
\hline Address on AHS $2002=1 ;$ else $=0$ & H2002 & 00561 & 1 & $\mathrm{~A} / \mathrm{N}$ \\
\hline Address on ES202 year YYYY $=1$; else $=0$ & EYYYY & 00554 & 1 & $\mathrm{~A} / \mathrm{N}$ \\
\hline Address on MAF $2004=1$; else $=0$ & M2004 & 00562 & 1 & $\mathrm{~A} / \mathrm{N}$ \\
\hline Address on ACS-POW year YYYY $=1$; else $=0$ & PYYYY & 00563 & 1 & $\mathrm{~A} / \mathrm{N}$ \\
\hline Census Block suffix 1 & A_BLOCK_SUF1 & 00585 & 1 & $\mathrm{~A} / \mathrm{N}$ \\
\hline Census Block suffix 2 & A_BLOCK_SUF2 & 00586 & 1 & $\mathrm{~A} / \mathrm{N}$ \\
\hline Census block within tract & A_BLOCK & 00581 & 4 & $\mathrm{~A} / \mathrm{N}$ \\
\hline Census tract within county & A_TRACT & 00590 & 6 & $\mathrm{~A} / \mathrm{N}$ \\
\hline Code1 Census block id 3 digit & C1_BLOCK & 00489 & 3 & $\mathrm{~A} / \mathrm{N}$ \\
\hline Code1 Census block id 4 digit & C1_BLOCK4 & 00032 & 4 & $\mathrm{~A} / \mathrm{N}$ \\
\hline Code1 Census geocode (tract) & C1_GEOCODE & 00477 & 12 & $\mathrm{~A} / \mathrm{N}$ \\
\hline Code1 USPS record type & C1_USPSRECTYPE & 00467 & 1 & $\mathrm{~A} / \mathrm{N}$ \\
\hline Code1 ZIP & C1_ZIP & 00457 & 5 & $\mathrm{~A} / \mathrm{N}$ \\
\hline Code1 ZIP code status & C1_ZIP_STATUS & 00471 & 1 & $\mathrm{~A} / \mathrm{N}$ \\
\hline Code1 ZIP return code & C1_ZIP_RC & 00021 & 1 & $\mathrm{~A} / \mathrm{N}$ \\
\hline Code1 ZIP source & C1_ZIP_SRC & 00466 & 1 & $\mathrm{~A} / \mathrm{N}$ \\
\hline Code1 ZIP +4 code & C1_ZIP4 & 00462 & 4 & $\mathrm{~A} / \mathrm{N}$ \\
\hline Code1 ZIP4 return code & C1_ZIP4_RC & 00022 & 1 & $\mathrm{~A} / \mathrm{N}$ \\
\hline Code1 address correctness score & C1_ADDRESS_CS & 00469 & 1 & $\mathrm{~A} / \mathrm{N}$ \\
\hline Code1 address return code & C1_ADDRESS_RC & 00017 & 1 & $\mathrm{~A} / \mathrm{N}$ \\
\hline Code1 address w/apt & C1_ADDRESS & 00357 & 70 & $\mathrm{~A} / \mathrm{N}$ \\
\hline Code1 alias/base return code & C1_ALIAS_RC & 00018 & 1 & $\mathrm{~A} / \mathrm{N}$ \\
\hline Code1 apartment return code & C1_APT_RC & 00026 & 1 & $\mathrm{~A} / \mathrm{N}$ \\
\hline Code1 carrier route return code & C1_CARRTE_RC & 00023 & 1 & $\mathrm{~A} / \mathrm{N}$ \\
\hline Code1 city name & C1_CITY & 00427 & 28 & $\mathrm{~A} / \mathrm{N}$ \\
\hline Code1 city/state return code & C1_CITYSTATE_RC & 00020 & 1 & $\mathrm{~A} / \mathrm{N}$ \\
\hline Code1 directional return code & C1_DIRECTIONAL & RC 00024 & 1 & $\mathrm{~A} / \mathrm{N}$ \\
\hline Code1 dropped information code & C1_DROPPEDINFO & RC 00019 & 1 & $\mathrm{~A} / \mathrm{N}$ \\
\hline Code1 general return code & C1_GENERAL_RC & 00016 & 1 & $\mathrm{~A} / \mathrm{N}$ \\
\hline Code1 geocode return code & C1_GEO_RC & 00476 & 1 & $\mathrm{~A} / \mathrm{N}$ \\
\hline
\end{tabular}

Page 140 
CHAPTER 5. GEO-CODED ADDRESS LIST (GAL)

\begin{tabular}{|c|c|c|c|c|}
\hline Field name & \begin{tabular}{l|l} 
Data dictionary & $\mathrm{S}$ \\
reference name & $\mathrm{p}$ \\
\end{tabular} & $\begin{array}{l}\text { Starting } \\
\text { position }\end{array}$ & $\begin{array}{l}\text { Field } \\
\text { size }\end{array}$ & $\begin{array}{l}\text { Data } \\
\text { type }\end{array}$ \\
\hline Code1 lat/long coordinate & C1_LATLONG & 00492 & 20 & $\mathrm{~A} / \mathrm{N}$ \\
\hline Code1 lat/long level & C1_LATLONG_RC & 00512 & 1 & $\mathrm{~A} / \mathrm{N}$ \\
\hline Code1 master file vintage & C1_VINTDATE & 00472 & 4 & $\mathrm{~A} / \mathrm{N}$ \\
\hline Code1 overall correctness & C1_OVERALL_RC & 00468 & 1 & $\mathrm{~A} / \mathrm{N}$ \\
\hline Code1 state abbrev & C1_STATE & 00455 & 2 & $\mathrm{~A} / \mathrm{N}$ \\
\hline Code1 street name correctness score & C1_STREETNAME_CS & is 00470 & 1 & $\mathrm{~A} / \mathrm{N}$ \\
\hline Code1 suffix return code & C1_SUFFIX_RC & 00025 & 1 & $\mathrm{~A} / \mathrm{N}$ \\
\hline Describes source of block coding & A_BLOCK_SRC & 00587 & 1 & $\mathrm{~A} / \mathrm{N}$ \\
\hline Commercial, Mixed, or Residential & OCCUPANT_TYPE & 00568 & 1 & $\mathrm{~A} / \mathrm{N}$ \\
\hline FIPS county within state & A_CTY & 00604 & 3 & $\mathrm{~A} / \mathrm{N}$ \\
\hline FIPS state & A_ST & 00602 & 2 & $\mathrm{~A} / \mathrm{N}$ \\
\hline 5-digit FIPS (state and county) & A_SSCCC & 00638 & 5 & $\mathrm{~A} / \mathrm{N}$ \\
\hline Full geocode (incl. tract code) & A_GEOCODE & 00569 & 11 & $\mathrm{~A} / \mathrm{N}$ \\
\hline Latitude, 6 implied decimal places & A_LATITUDE & 00000 & 8 & $\mathrm{~N}$ \\
\hline Longitude, 6 implied decimal places & A_LONGITUDE & 00008 & 8 & $\mathrm{~N}$ \\
\hline MSA-PMSA & A_MSAPMSA & 00624 & 8 & $\mathrm{~A} / \mathrm{N}$ \\
\hline Maf, Code1, Derived, Block (or part) internal point & A_LATLONG_SRC & 00580 & 1 & $\mathrm{~A} / \mathrm{N}$ \\
\hline Maf; Assigned by distance & A_BLOCK_SUF_SRC & 00589 & 1 & $\mathrm{~A} / \mathrm{N}$ \\
\hline Quality of lat/long & A_GEOQUAL & 00646 & 3 & $\mathrm{~N}$ \\
\hline Unique GAL address ID & GALID & 00513 & 29 & $\mathrm{~A} / \mathrm{N}$ \\
\hline Vality additional address info & V_ADDADDR & 00220 & 35 & $\mathrm{~A} / \mathrm{N}$ \\
\hline Vality address type & V_ADDRTYP & 00255 & 1 & $\mathrm{~A} / \mathrm{N}$ \\
\hline Vality box type & V_BTYPE & 00128 & 7 & $\mathrm{~A} / \mathrm{N}$ \\
\hline Vality box value & V_BVAL & 00135 & 10 & $\mathrm{~A} / \mathrm{N}$ \\
\hline Vality building name & V_BUILDN & 00190 & 30 & $\mathrm{~A} / \mathrm{N}$ \\
\hline Vality floor type & V_FTYPE & 00145 & 5 & $\mathrm{~A} / \mathrm{N}$ \\
\hline Vality floor value & V_FVAL & 00150 & 10 & $\mathrm{~A} / \mathrm{N}$ \\
\hline Vality house number & V_HNUM & 00036 & 10 & $\mathrm{~A} / \mathrm{N}$ \\
\hline Vality house number suffix & V_HNUMS & 00046 & 10 & $\mathrm{~A} / \mathrm{N}$ \\
\hline Vality input pattern & V_INPATT & 00311 & 20 & $\mathrm{~A} / \mathrm{N}$ \\
\hline Vality multi-unit type & V_MUTYPE & 00175 & 5 & $\mathrm{~A} / \mathrm{N}$ \\
\hline Vality multi-unit value & V_MUVAL & 00180 & 10 & $\mathrm{~A} / \mathrm{N}$ \\
\hline Vality rural route type & V_RTYPE & 00115 & 3 & $\mathrm{~A} / \mathrm{N}$ \\
\hline Vality rural route value & V_RVAL & 00118 & 10 & $\mathrm{~A} / \mathrm{N}$ \\
\hline Vality street name & V_SNAME & 00080 & 25 & $\mathrm{~A} / \mathrm{N}$ \\
\hline Vality street prefix - directional & V_SPRED & 00056 & 2 & $\mathrm{~A} / \mathrm{N}$ \\
\hline Vality street prefix - type & V_SPRET & 00060 & 20 & $\mathrm{~A} / \mathrm{N}$ \\
\hline Vality street suffix - directional & V_SSUFD & 00058 & 2 & $\mathrm{~A} / \mathrm{N}$ \\
\hline Vality street suffix - qualifier & V_SSUFQ & 00110 & 5 & $\mathrm{~A} / \mathrm{N}$ \\
\hline Vality street suffix - type & V_SSUFT & 00105 & 5 & $\mathrm{~A} / \mathrm{N}$ \\
\hline Vality unhandled data & V_UNDATA & 00276 & 35 & $\mathrm{~A} / \mathrm{N}$ \\
\hline Vality unhandled pattern & V_UNPATT & 00256 & 20 & $\mathrm{~A} / \mathrm{N}$ \\
\hline Vality unit type & V_UTYPE & 00160 & 5 & $\mathrm{~A} / \mathrm{N}$ \\
\hline Vality unit value & V_UVAL & 00165 & 10 & $\mathrm{~A} / \mathrm{N}$ \\
\hline Vintage of Census geography (GRF) & A_VINTAGE & 00643 & 3 & $\mathrm{~N}$ \\
\hline Workforce Investment Board area & A_WIB & 00632 & 6 & $\mathrm{~A} / \mathrm{N}$ \\
\hline only addr on blockFace; extraPolation & A_LATLONG_DRV & 00588 & 1 & $\mathrm{~A} / \mathrm{N}$ \\
\hline
\end{tabular}




\subsubsection{Auxiliary dataset: GAL_ZZ_2003_T26}

This file has the same column structure as the main file, but contains all records sourced exclusively from Title 26-protected information. The columns are described in Section 5.3.3.

Record identifier: GALID

Sort order: GALID

File indexes: none

Entity unique address

Unique Entity Key GALID 
CHAPTER 5. GEO-CODED ADDRESS LIST (GAL)

\subsubsection{Auxiliary dataset: GAL_ZZ_2003_T26flags}

This file contains all Business Register-related flags, for all GAL records.

Record identifier: GALID

Sort order: GALID

File indexes: none

Entity unique address

Unique Entity Key GALID

\begin{tabular}{|c|c|c|c|c|}
\hline Field name & $\begin{array}{l}\text { Data dictionary } \\
\text { reference name }\end{array}$ & $\begin{array}{l}\text { Starting } \\
\text { position }\end{array}$ & $\begin{array}{l}\text { Field } \\
\text { size }\end{array}$ & $\begin{array}{l}\text { Data } \\
\text { type }\end{array}$ \\
\hline Address on SSEL $1990=1 ;$ else $=0$ & B1990 & 00029 & 1 & $\mathrm{~A} / \mathrm{N}$ \\
\hline Address on SSEL $1991=1$; else $=0$ & B1991 & 00030 & 1 & $\mathrm{~A} / \mathrm{N}$ \\
\hline Address on SSEL $1992=1 ;$ else $=0$ & B1992 & 00031 & 1 & $\mathrm{~A} / \mathrm{N}$ \\
\hline Address on SSEL $1993=1 ;$ else $=0$ & В1993 & 00032 & 1 & $\mathrm{~A} / \mathrm{N}$ \\
\hline Address on SSEL $1994=1 ;$ else $=0$ & B1994 & 00033 & 1 & $\mathrm{~A} / \mathrm{N}$ \\
\hline Address on SSEL $1995=1$; else $=0$ & B1995 & 00034 & 1 & $\mathrm{~A} / \mathrm{N}$ \\
\hline Address on SSEL $1996=1$; else $=0$ & B1996 & 00035 & 1 & $\mathrm{~A} / \mathrm{N}$ \\
\hline Address on SSEL $1997=1 ;$ else $=0$ & B1997 & 00036 & 1 & $\mathrm{~A} / \mathrm{N}$ \\
\hline Address on SSEL $1998=1 ;$ else $=0$ & B1998 & 00037 & 1 & $\mathrm{~A} / \mathrm{N}$ \\
\hline Address on SSEL $1999=1$; else $=0$ & B1999 & 00038 & 1 & $\mathrm{~A} / \mathrm{N}$ \\
\hline Address on SSEL $2000=1$; else $=0$ & B2000 & 00039 & 1 & $\mathrm{~A} / \mathrm{N}$ \\
\hline Address on SSEL $2001=1 ;$ else $=0$ & B2001 & 00040 & 1 & $\mathrm{~A} / \mathrm{N}$ \\
\hline Tracking ID & BIGSRCID & 00331 & 26 & $\mathrm{~A} / \mathrm{N}$ \\
\hline address & GALID & 00000 & 29 & $\mathrm{~A} / \mathrm{N}$ \\
\hline \multicolumn{5}{|l|}{ 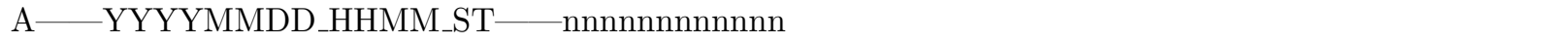 } \\
\hline Source file of this address & SRCMAST & 00027 & 5 & $\mathrm{~A} / \mathrm{N}$ \\
\hline
\end{tabular}




\subsubsection{Auxiliary dataset: GAL_ZZ_2003_ES202ONLY}

This file contains address information sourced exclusively from ES-202 files, which have been blanked on GAL_ZZ_2003. This file is only accessible to Census-internal projects.

Record identifier: GALID

Sort order: GALID

File indexes: none

Entity unique address

Unique Entity Key GALID

\begin{tabular}{l|l|c|r|r}
\hline \multicolumn{1}{c|}{ Field name } & $\begin{array}{l}\text { Data dictionary } \\
\text { reference name }\end{array}$ & $\begin{array}{l}\text { Starting } \\
\text { position }\end{array}$ & $\begin{array}{l}\text { Field } \\
\text { size }\end{array}$ & $\begin{array}{l}\text { Data } \\
\text { type }\end{array}$ \\
\hline & C1_ZIP & 00457 & 5 & A/N \\
Code1 ZIP & & & & \\
Code1 ZIP+4 code & C1_ZIP4 & 00462 & 4 & $\mathrm{~A} / \mathrm{N}$ \\
Code1 address w/apt & C1_ADDRESS & 00357 & 70 & $\mathrm{~A} / \mathrm{N}$ \\
Code1 city name & C1_CITY & 00427 & 28 & $\mathrm{~A} / \mathrm{N}$ \\
Code1 state abbrev & C1_STATE & 00455 & 2 & $\mathrm{~A} / \mathrm{N}$ \\
Unique GAL address ID & GALID & 00513 & 29 & $\mathrm{~A} / \mathrm{N}$ \\
Vality additional address info & V_ADDADDR & 00220 & 35 & $\mathrm{~A} / \mathrm{N}$ \\
Vality box value & V_BVAL & 00135 & 10 & $\mathrm{~A} / \mathrm{N}$ \\
Vality building name & V_BUILDN & 00190 & 30 & $\mathrm{~A} / \mathrm{N}$ \\
Vality floor value & V_FVAL & 00150 & 10 & $\mathrm{~A} / \mathrm{N}$ \\
Vality house number & V_HNUM & 00036 & 10 & $\mathrm{~A} / \mathrm{N}$ \\
Vality house number suffix & V_HNUMS & 00046 & 10 & $\mathrm{~A} / \mathrm{N}$ \\
Vality multi-unit value & V_MUVAL & 00180 & 10 & $\mathrm{~A} / \mathrm{N}$ \\
Vality rural route value & V_RVAL & 00118 & 10 & $\mathrm{~A} / \mathrm{N}$ \\
Vality street name & V_SNAME & 00080 & 25 & $\mathrm{~A} / \mathrm{N}$ \\
Vality street prefix - directional & V_SPRED & 00056 & 2 & $\mathrm{~A} / \mathrm{N}$ \\
Vality street prefix - type & V_SPRET & 00060 & 20 & $\mathrm{~A} / \mathrm{N}$ \\
Vality street suffix - directional & V_SSUFD & 00058 & 2 & $\mathrm{~A} / \mathrm{N}$ \\
Vality street suffix - qualifier & V_SSUFQ & 00110 & 5 & $\mathrm{~A} / \mathrm{N}$ \\
Vality street suffix - type & V_SSUFT & 00105 & 5 & $\mathrm{~A} / \mathrm{N}$ \\
Vality unhandled data & V_UNDATA & 00276 & 35 & $\mathrm{~A} / \mathrm{N}$ \\
Vality unhandled pattern & V_UNPATT & 00256 & 20 & $\mathrm{~A} / \mathrm{N}$ \\
Vality unit value & V_UVAL & 00165 & 10 & $\mathrm{~A} / \mathrm{N}$
\end{tabular}


CHAPTER 5. GEO-CODED ADDRESS LIST (GAL)

\subsubsection{Auxiliary dataset: GAL_ZZ_2003_TCCB}

The TCCB file provides county centroids in a structure similar to the main GAL file.

Record identifier: GALID

Sort order: GALID

File indexes: none

Entity unique address

Unique Entity Key GALID (merge or concat?)

\begin{tabular}{l|l|c|c|c}
\hline \multicolumn{1}{c|}{ Field name } & $\begin{array}{l}\text { Data dictionary } \\
\text { reference name }\end{array}$ & $\begin{array}{l}\text { Starting } \\
\text { position }\end{array}$ & $\begin{array}{l}\text { Field } \\
\text { size }\end{array}$ & $\begin{array}{l}\text { Data } \\
\text { type }\end{array}$ \\
\hline & A_BLOCK_SUF1 & 00092 & 1 & A/N \\
& A_BLOCK_SUF2 & 00093 & 1 & A/N \\
3-digit Census MCD & A_MCD & 00085 & 3 & A/N \\
4-digit Census Place & A_PLACE & 00088 & 4 & A/N \\
5-digit FIPS MCD & A_FIPSMCD & 00075 & 5 & A/N \\
5-digit FIPS Place & A_FIPSPL & 00080 & 5 & A/N \\
A=Arcview & A_BLOCK_SRC & 00060 & 1 & A/N \\
Census block within tract & A_BLOCK & 00056 & 4 & A/N \\
Full geocode (incl. tract) & A_GEOCODE & 00045 & 11 & A/N \\
Latitude, 6 implied decimal places & A_LATITUDE & 00000 & 8 & $\mathrm{~N}$ \\
Longitude, 6 implied decimal places & A_LONGITUDE & 00008 & 8 & $\mathrm{~N}$ \\
MSA-PMSA & A_MSAPMSA & 00061 & 8 & A/N \\
Quality of lat/long & A_GEOQUAL & 00094 & 3 & $\mathrm{~N}$ \\
Unique GAL address ID & GALID & 00016 & 29 & A/N \\
Workforce Investment Board (WIB) area & A_WIB & 00069 & 6 & A/N
\end{tabular}




\subsubsection{ACS Place-of-work Crosswalk: GAL_ZZ_2003_POW_YYYY}

There is one ACS-POW Crosswalk per year of input data YYYY. Files are named gal_ZZ_2003_pow_YYYY.

Record identifier: cmid, seq, pnum

Sort order: cmid, seq, and pnum

File indexes: none

Entity Entity on ACS

Unique Entity Key cmid, seq, pnum, acsfileseq

\begin{tabular}{l|l|r|r|r}
\hline \multicolumn{1}{c|}{ Field name } & $\begin{array}{l}\text { Data dictionary } \\
\text { reference name }\end{array}$ & $\begin{array}{l}\text { Starting } \\
\text { position }\end{array}$ & $\begin{array}{l}\text { Field } \\
\text { size }\end{array}$ & $\begin{array}{l}\text { Data } \\
\text { type }\end{array}$ \\
\hline ACS file sequence number & ACSFILESEQ & 00041 & 2 & $\mathrm{~A} / \mathrm{N}$ \\
Address ID & GALID & 00000 & 29 & $\mathrm{~A} / \mathrm{N}$ \\
Continuous measurement ID & CMID & 00029 & 9 & $\mathrm{~A} / \mathrm{N}$ \\
Person number & PNUM & 00039 & 2 & $\mathrm{~A} / \mathrm{N}$ \\
Sequence number & SEQ & 00038 & 1 & $\mathrm{~A} / \mathrm{N}$
\end{tabular}


CHAPTER 5. GEO-CODED ADDRESS LIST (GAL)

\subsubsection{AHS Crosswalk: GAL_ZZ_2003_AHS_YYYY}

There is one AHS Crosswalk, tagged with the year YYYY the input dataset was captured. The file is called gal_ZZ_2003_ahs_YYYY.

Record identifier: control (year)

Sort order: control

File indexes: none

Entity Entity on AHS

Unique Entity Key control (year)

\begin{tabular}{|c|c|c|c|c|}
\hline Field name & $\begin{array}{l}\text { Data dictionary } \\
\text { reference name }\end{array}$ & $\begin{array}{l}\text { Starting } \\
\text { position }\end{array}$ & $\begin{array}{l}\text { Field } \\
\text { size }\end{array}$ & $\begin{array}{l}\text { Data } \\
\text { type }\end{array}$ \\
\hline & CONTROL & 00033 & 13 & $\mathrm{~A} / \mathrm{N}$ \\
\hline Address ID & GALID & 00000 & 29 & $\mathrm{~A} / \mathrm{N}$ \\
\hline Year YYYY & YEAR & 00029 & 4 & $\mathrm{~A} / \mathrm{N}$ \\
\hline
\end{tabular}




\subsubsection{Business Register Crosswalk: GAL_ZZ_2003_BR_YYYY}

There is one BR Crosswalk per year YYYY of input data. The files are called gal_ZZ_2003_br_YYYY. The entire file is considered FTI.

Record identifier: cfn, year singmult

Sort order: $\mathrm{cfn}$

File indexes: none

Entity Establishment

Unique Entity Key cfn

\begin{tabular}{l|l|c|c|c}
\hline \multicolumn{1}{c|}{ Field name } & $\begin{array}{l}\text { Data dictionary } \\
\text { reference name }\end{array}$ & $\begin{array}{l}\text { Starting } \\
\text { position }\end{array}$ & $\begin{array}{l}\text { Field } \\
\text { size }\end{array}$ & $\begin{array}{l}\text { Data } \\
\text { type }\end{array}$ \\
\hline Address ID & GALID & 00000 & 29 & A/N \\
Census File Number & CFN & 00033 & 10 & A/N \\
$\mathrm{P}=$ physical,M=mailing & B_FLAG & 00044 & 1 & $\mathrm{~A} / \mathrm{N}$ \\
$\mathrm{S}=$ su file,M=mu file & SINGMULT & 00043 & 1 & $\mathrm{~A} / \mathrm{N}$ \\
Year YYYY & YEAR & 00029 & 4 & $\mathrm{~A} / \mathrm{N}$
\end{tabular}


CHAPTER 5. GEO-CODED ADDRESS LIST (GAL)

\subsubsection{ES202 Crosswalk: GAL_ZZ_2003_XWALK_YYYY}

There is one ES202 Crosswalk per year YYYY of input data. The files are called gal_ZZ_2003_Xwalk_YYYY.

Record identifier: sein, seinunit, year, quarter

Sort order: sein seinunit

File indexes: none

Entity Reporting unit (SESA)

Unique Entity Key sein, seinunit, year, quarter

\begin{tabular}{l|l|c|c|c}
\hline \multicolumn{1}{c|}{ Field name } & $\begin{array}{l}\text { Data dictionary } \\
\text { reference name }\end{array}$ & $\begin{array}{l}\text { Starting } \\
\text { position }\end{array}$ & $\begin{array}{l}\text { Field } \\
\text { size }\end{array}$ & $\begin{array}{l}\text { Data } \\
\text { type }\end{array}$ \\
\hline Address ID & GALID & 00000 & 29 & $\mathrm{~A} / \mathrm{N}$ \\
P=physical,M=mailing & E_FLAG & 00046 & 1 & $\mathrm{~A} / \mathrm{N}$ \\
Quarter (numeric) & QUARTER & 00050 & 3 & $\mathrm{~N}$ \\
State Employer ID Number & SEIN & 00029 & 12 & $\mathrm{~A} / \mathrm{N}$ \\
State UI Reporting Unit Number & SEINUNIT & 00041 & 5 & $\mathrm{~A} / \mathrm{N}$ \\
Year YYYY & YEAR & 00047 & 3 & $\mathrm{~N}$
\end{tabular}




\subsubsection{MAF Crosswalk: GAL_ZZ_2003_MAF_2004}

The crosswalk allows for linking back to the Census Master Address File (MAF) (2004 version). The file is called gal_ZZ_2003_maf_2004.

Record identifier: mafid year

Sort order: mafid year

File indexes: none

Entity mafid and year

Unique Entity Key mafid year

\begin{tabular}{l|l|c|l|l}
\hline \multicolumn{1}{c|}{ Field name } & $\begin{array}{l}\text { Data dictionary } \\
\text { reference name }\end{array}$ & $\begin{array}{l}\text { Starting } \\
\text { position }\end{array}$ & $\begin{array}{l}\text { Field } \\
\text { size }\end{array}$ & $\begin{array}{l}\text { Data } \\
\text { type }\end{array}$ \\
\hline Address ID & GALID & 00000 & 29 & A/N \\
Master Address File ID & MAFID & 00033 & 12 & A/N \\
Year YYYY & YEAR & 00029 & 4 & A/N
\end{tabular}




\subsection{PROGRAMS}

\subsubsection{Separating Title 26 information}

/* Time-stamp: <06/10/07 20:50:46 vilhuber> */

/* \$Id: split_gal_t26.tex 417 2011-04-13 20:47:13Z vilhu001 \$*/

$\%$ macro split_gal_t26 (state=, outlib=WORK, outt $26=$ WORK) ;

libname INPUTS "/mixedtmp/lehd2/s2004/gal_commingled/\&state./";

libname OUTPUTS "/mixedtmp/lehd2/s2004/gal/\&state./";

libname OUTT26 "/mixedtmp/lehd2/s2004/galt26/\&state./";

options compress=yes;

data \&outlib..gal_\&state._2003

(drop=b1: b2: label="Free of T26-only-sourced records and columns")

\&outt26. gal_\&state._2003_t26

(drop=b1: b2: label="T26-only-sourced records")

\&outt26.gal_\&state._2003_t26flags

(keep=galid b1: b2: compress=no label="T26-related flags only");

set INPUTS.gal_\&state._2003;

Define lengths and labels.

length flag_t26 3 ;

label flag_t26= "Contains only T26-sourced information";

array t26flags b1: b2:;

array others e1: e2: h2: m2: p2: ;

hit_br=0;

hit_others $=0$;

see if we have BR information

do over t26flags;

if t26flags='1' then hit_br=1;

end;

see if we have any other information

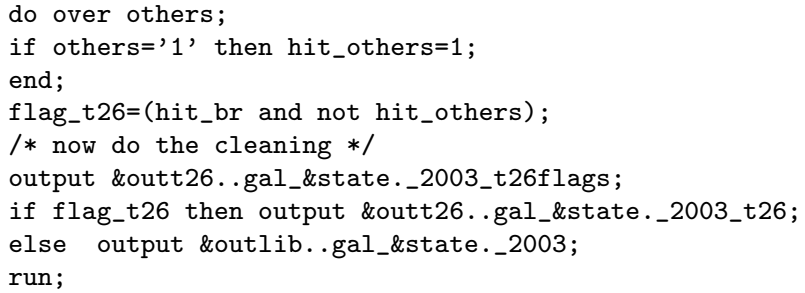

now sort the files

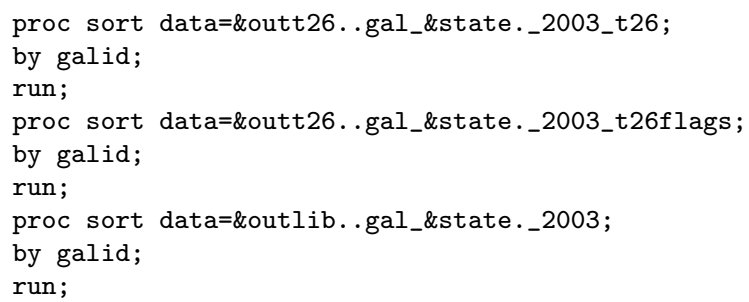

Some info on the files.

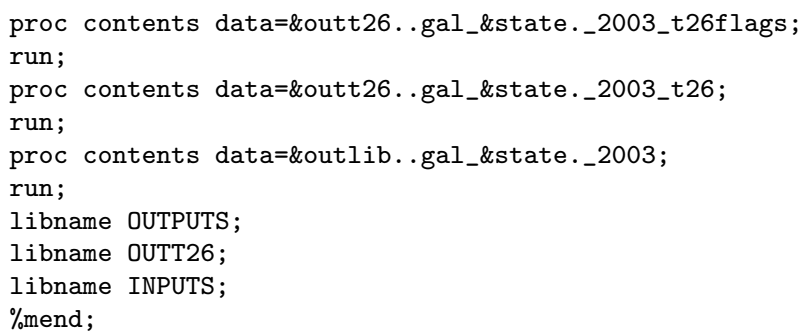




\subsubsection{Recombining GAL component files}

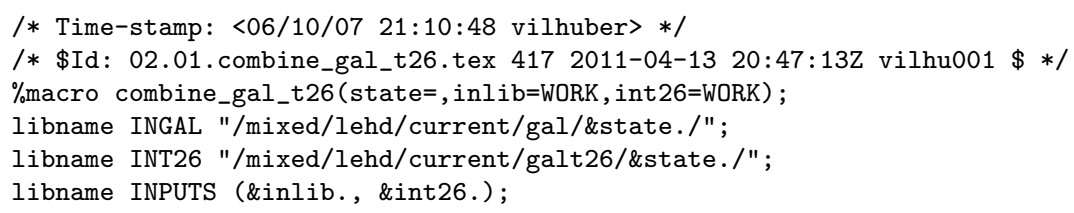

Adjust this to suit your needs

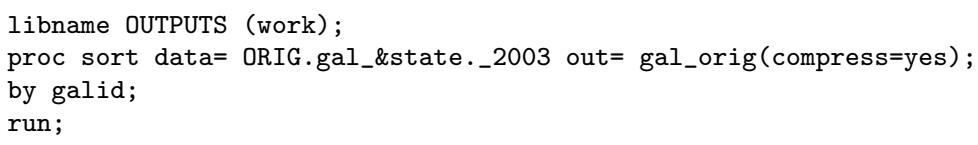

First, put the two halves together this could have been an append as well, but this puts it into the right sort order

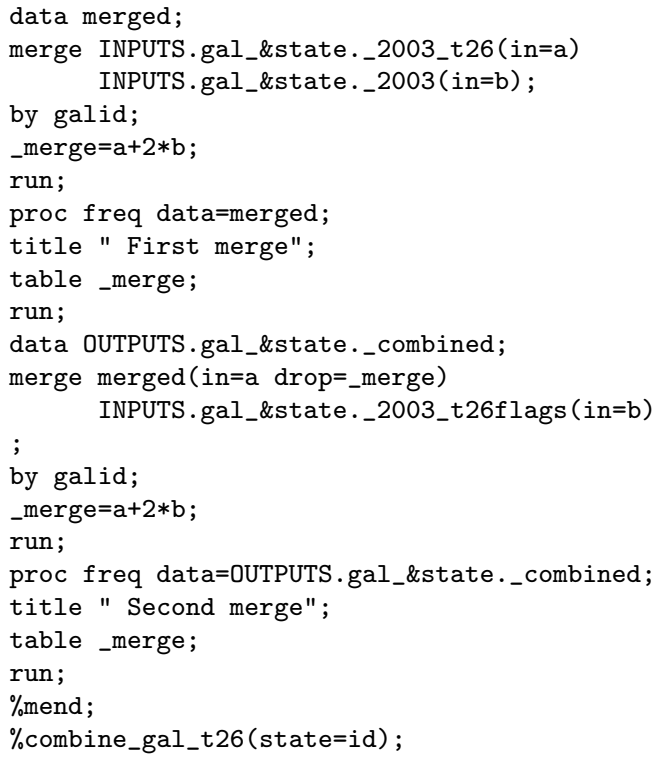


CHAPTER 5. GEO-CODED ADDRESS LIST (GAL)

\section{$\mathbf{5 . 5}$ NOTES}

Revision : 420 


\section{Chapter 6. Individual Characteristics File (ICF)}

\subsection{OVERVIEW}

The Individual Characteristics File (ICF) for each state contains one record for every person who is ever employed in that state over the time period spanned by the state's unemployment insurance records.

The ICF is constructed in the following manner. First, the universe of individuals is defined by compiling the list of unique PIKs from the EHF. Demographic information from the PCF is then merged on by PIK, and records without a valid match flagged. PIK-survey identifier crosswalks link the CPS and SIPP ID variables into the ICF, and sex and age information from the CPS is used to complement and verify the PCF-provided information.

\subsubsection{Age and sex imputation}

Approximately $3 \%$ of the PIKs found in the UI wage records do not link to the PCF. Multiple imputation methods are used to impute date of birth and sex for these individuals. To impute sex, the probability of being male is estimated using a state-specific logit model:

$$
P(\text { male })=f\left(X_{i s} \beta_{s}\right)
$$

where $X_{i s}$ contains a full set of yearly log earnings and squared log earnings, and full set of employment indicators covering the time period spanned by the state's records, for each individual $i$ with strictly positive earnings within state $s$ and non-missing PCF sex. The state-specific $\hat{\beta}_{s}$ as estimated from Equation (6.1) is then used to predict the probability of being male for individuals with missing sex within state $s$, and sex is assigned as

$$
\text { male if } X_{i s} \hat{\beta}_{s} \geq \mu_{l}
$$

where $\mu_{l} \sim U[0,1]$ is one of $l=1, \ldots, 10$ independent draws from the distribution. Thus, each individual with missing sex is assigned ten independent missing data implicates, all of which are used in the QWI processing. ${ }^{1}$

The imputation of date of birth is done in a similar fashion using a multinomial logit to predict the probability of being in one of eight age categories and then assigning an age based on this probability and the distribution of ages within the category. Again, the missing data imputation occurs ten times.

If an individual is missing sex or birth date in the PCF, but not in the CPS, then the CPS values are used, not the imputed values. Also, before the imputation model for date of birth is implemented, basic editing of the date of birth variable takes place to account for obvious coding errors, such as a negative age at the time when UI earnings are first reported for the individual. In those relatively rare cases where the date

\footnotetext{
${ }^{1}$ Note that this imputation does not account for estimation error in $\hat{\beta}$. This was one of the first missing data imputations developed at LEHD. At the time, techniques for sampling from the posterior predictive distribution of a binary outcome where the likelihood function is based on a logistic regression were not feasible on the LEHD computer system. Since only three percent of the observations in the ICF are subject to this missing data edit, it was implemented as described in the text. A longitudinal, enhanced ICF is under development. All missing data imputations in the new ICF will be performed by sampling from an appropriate posterior predictive distribution. This will properly account for estimation error.
} 
of birth information is deemed unrealistic, it is set to missing and imputed based on the model described above.

\subsubsection{Place of residence imputation}

Place of residence information on the ICF is derived from the StARS (Statistical Administrative Records System), which for the vast majority of the individuals found in the UI wage records contains information on the place of residence down to the exact geographical coordinates. However, in less than ten percent of all cases the geography information is incomplete or missing. The QWI estimation relies on completed place of residence information. Because this information is a critical conditioning variable in the unit-to-worker (U2W) imputation model, all missing residential addresses are imputed.

County of residence is imputed based on a categorical model of the data that is a fully-saturated contingency table. Separately for each state, unique combinations of categories of sex, age, race, income and county of work are used to form $i=1, \ldots, I$ populations. For each sample $i$, the probability of residing in a particular county as of $1999, \pi_{i j}$, is estimated by the sample proportion, $p_{i j}=n_{i j} / n_{i}$, where $j=1, \ldots, J$ indexes all the counties in the state plus an extra category for out-of-state residents.

County of residence is then imputed based on

$$
\text { county }=j \text { if } P_{i j-1} \leq u_{k}<P_{i j}
$$

where $P_{i}$ is the CDF corresponding to $p_{i}$ for the $i$ th population and $\mu_{k l} \sim U[0,1]$ is one of $k=1, \ldots, 10$ independent draws for the $l$ th individual belonging to the $i$ th population. ${ }^{2}$

In its current version no geography below the county level is imputed and in those cases where exact geographical coordinates are incomplete the centroid of the finest geographical area is used. Thus, in cases where no geography information is available this amounts to the centroid of the imputed county. Geographical coordinates are not assigned to individuals whose county of residence has been imputed to be out-of-state.

\subsubsection{Education imputation}

The imputation model for education relies on a statistical match between the Decennial Census 1990 and LEHD data. The probability of belonging to one of 13 education categories is estimated using 1990 Decennial data conditional on characteristics that are common to both Decennial and LEHD data, using a state-specific logit model:

$$
P(\text { educat })=f\left(Z_{i s} \gamma_{s}\right)
$$

where $Z_{i s}$ contains age categories, earnings categories, and industry dummies for individuals age 14 and older in the 1990 Census Long Form residing in the state being estimated, and who reported strictly positive wage earnings. The education category is imputed based on

$$
\text { educat }=j \text { if } c p_{j-1} \leq \mu_{l}<c p_{j}
$$

where $c p_{j}=Z_{i s} \hat{\gamma}_{s}$ and $\mu_{l} \sim U[0,1]$ is one of $l=11, \ldots, 20$ independent draws, and $i \in E H F .^{3}$

\footnotetext{
${ }^{2}$ The longitudinal, enhanced ICF that is under development augments the model in the text with a Dirichlet prior distribution for the $P_{i j}$ s. The imputations are then made by sampling from the posterior predictive distribution, which is also Dirichlet.

${ }^{3}$ In the longitudinally enhanced ICF that is under development, this imputation is replaced by a probablistic record link to Census 2000 long form data. Approximately one person in six acquires directly reported educational attainment as of 2000. The remaining individuals get 10 multiple imputations from a Dirichlet-Multinomial posterior predictive distribution.
} 


\subsection{DATA SET DESCRIPTIONS}

\subsubsection{Unique record identifier}

The unique record identifier within each ICF file is the $\mathbf{P}$ ! $(\mathbf{P}$ !)IK. However, in the current ICF scheme, a person may have (possibly inconsistent) records in multiple states. Each file therefore also contains a state variable. The combination PIK - state is unique across all states, within the set of ICF files, and should be used when concatenating or otherwise combining records from multiple states.

\subsubsection{Naming scheme}

There are five files in the ICF/ICFT26 group:

icf_zz.sas7bdat

icf_zz_implicates_age_sex.sas7bdat

icf_zz_implicates_county.sas7bdat

icf_zz_implicates_education.sas7bdat

icf_zz_t26.sas7bdat

ZZ stands for the state postal abbreviation. You will find zero-observation SAS datasets attached to this document - see the attachment tab.

\subsubsection{Data location}

The files are stored in two main directories, with state-specific subdirectories:

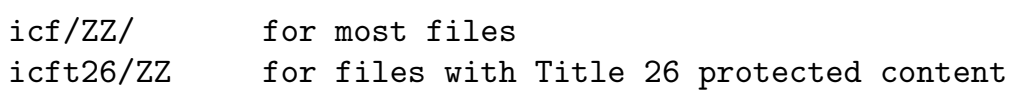

On the RDC network, both directories can be found under

/mixed/lehd/current

\subsubsection{Main dataset: $\mathrm{ICF}_{\mathrm{zz}}$}

This is the core dataset, containing all observed non-FTI and the first implicate for imputed variables.

\section{Record identifier PIK}

Sort order PIK

Entity PIK

Unique Entity Key PIK

\begin{tabular}{|c|c|c|c|c|}
\hline Field name & $\begin{array}{l}\text { Data dictionary } \\
\text { reference name }\end{array}$ & $\begin{array}{l}\text { Starting } \\
\text { position }\end{array}$ & $\begin{array}{l}\text { Field } \\
\text { size }\end{array}$ & $\begin{array}{l}\text { Data } \\
\text { type }\end{array}$ \\
\hline $\begin{array}{l}\text { CPS Household ID for the first time this Pik matches } \\
\text { CPS }\end{array}$ & HID1 & 00113 & & $\mathrm{~A} / \mathrm{N}$ \\
\hline $\begin{array}{l}\text { CPS Household ID for the second time this Pik } \\
\text { matches CPS }\end{array}$ & HID2 & 00120 & & $\mathrm{~A} / \mathrm{N}$ \\
\hline CPS Person ID variable for first time Pik matches CPS & PPOSOLD1 & 00118 & & $\mathrm{~A} / \mathrm{N}$ \\
\hline $\begin{array}{l}\text { CPS Person ID variable for second time Pik matches } \\
\text { CPS }\end{array}$ & PPOSOLD2 & 00125 & & $\mathrm{~A} / \mathrm{N}$ \\
\hline $\begin{array}{l}\text { LEHD-OVERVIEW-S2004 } \\
\text { Revision : } 420\end{array}$ & & & & Page 157 \\
\hline
\end{tabular}


CHAPTER 6. INDIVIDUAL CHARACTERISTICS FILE (ICF)

\begin{tabular}{|c|c|c|c|c|}
\hline Field name & \begin{tabular}{l|l} 
Data dictionary & \\
reference name & 1
\end{tabular} & $\begin{array}{l}\text { Starting } \\
\text { position }\end{array}$ & $\begin{array}{l}\text { Field } \\
\text { size }\end{array}$ & $\begin{array}{l}\text { Data } \\
\text { type }\end{array}$ \\
\hline Census numident race codes $=$ bestrace var & RACE & 00112 & 1 & $\mathrm{~A} / \mathrm{N}$ \\
\hline Citizen Change Date Century & CITIZCC & 00085 & 2 & $\mathrm{~A} / \mathrm{N}$ \\
\hline Citizen Change Date Year & CITIZYY & 00088 & 2 & $\mathrm{~A} / \mathrm{N}$ \\
\hline DOB missing due to no numident match & DOBMISSING_NOMA] & тTC00111 & 1 & $\mathrm{~A} / \mathrm{N}$ \\
\hline Date of birth has been edited & DOBEDIT & 00109 & 1 & $\mathrm{~A} / \mathrm{N}$ \\
\hline Date of birth imputation flag & DOBIMPUTED & 00083 & 1 & $\mathrm{~A} / \mathrm{N}$ \\
\hline Date of birth missing in Numident & DOBMISSING & 00110 & 1 & $\mathrm{~A} / \mathrm{N}$ \\
\hline Date of birth, sas format & DOB & 00000 & 8 & $\mathrm{~N}$ \\
\hline Ever Alien Flag & ALIEN & 00084 & 1 & $\mathrm{~A} / \mathrm{N}$ \\
\hline First Internal SIPP ID matched to PIK & SIPPINTID1 & 00127 & 19 & $\mathrm{~A} / \mathrm{N}$ \\
\hline First year this Pik matches CPS & YEARCPS1 & 00033 & 3 & $\mathrm{~N}$ \\
\hline Fourth Internal SIPP ID matched to PIK & SIPPINTID4 & 00184 & 19 & $\mathrm{~A} / \mathrm{N}$ \\
\hline Gender imputation flag & SEXIMPUTED & 00082 & 1 & $\mathrm{~A} / \mathrm{N}$ \\
\hline Illegal SSN Range Flag & SSNFLAG & 00203 & 1 & $\mathrm{~A} / \mathrm{N}$ \\
\hline Imputed education length & EDIMP1 & 00069 & 3 & $\mathrm{~N}$ \\
\hline Month of first time this Pik matches CPS & MNTHCPS1 & 00039 & 3 & $\mathrm{~N}$ \\
\hline Month of second time this Pik matches CPS & MNTHCPS2 & 00042 & 3 & $\mathrm{~N}$ \\
\hline $\begin{array}{l}\text { Number of SIPP Panels where Duplicate INTIDs } \\
\text { match to PIK }\end{array}$ & DUPINSIPPPANEL & 00054 & 3 & $\mathrm{~N}$ \\
\hline Number of SIPP Panels where this PIK is found & COUNT_SIPPPANELS & S $\quad 00051$ & 3 & $\mathrm{~N}$ \\
\hline Numident variable $=$ gender & SEX & 00081 & 1 & $\mathrm{~A} / \mathrm{N}$ \\
\hline POB foreign indicator & POBFIN & 00102 & 1 & $\mathrm{~A} / \mathrm{N}$ \\
\hline $\begin{array}{l}\text { Pik duplicated across years,mapped to multiple CPS } \\
\text { IDs, different years }\end{array}$ & CPSDUPIKCY & 00024 & 3 & $\mathrm{~N}$ \\
\hline $\begin{array}{l}\text { Pik duplicated within year,mapped to multiple CPS } \\
\text { IDs,single year }\end{array}$ & CPSDUPIK1 & 00027 & 3 & $\mathrm{~N}$ \\
\hline $\begin{array}{l}\text { Pik duplicated within year,mapped to multiple CPS } \\
\text { IDs,single year }\end{array}$ & CPSDUPIK2 & 00030 & 3 & $\mathrm{~N}$ \\
\hline Protected Identification Key & PIK & 00072 & 9 & $\mathrm{~A} / \mathrm{N}$ \\
\hline SAS Date Value Date of Death & DOD & 00008 & 8 & $\mathrm{~N}$ \\
\hline SIPP PANEL of first INTID & PANELSIPP1 & 00057 & 3 & $\mathrm{~N}$ \\
\hline SIPP PANEL of first INTID & PANELSIPP2 & 00060 & 3 & $\mathrm{~N}$ \\
\hline SIPP PANEL of first INTID & PANELSIPP3 & 00063 & 3 & $\mathrm{~N}$ \\
\hline SIPP PANEL of first INTID & PANELSIPP 4 & 00066 & 3 & $\mathrm{~N}$ \\
\hline Second Internal SIPP ID matched to PIK & SIPPINTID2 & 00146 & 19 & $\mathrm{~A} / \mathrm{N}$ \\
\hline Second year this Pik matches CPS & YEARCPS2 & 00036 & 3 & $\mathrm{~N}$ \\
\hline State & STATE & 00016 & 8 & $\mathrm{~N}$ \\
\hline Third Internal SIPP ID matched to PIK & SIPPINTID3 & 00165 & 19 & $\mathrm{~A} / \mathrm{N}$ \\
\hline Year of latest PCF extract & YOPCF & 00045 & 3 & $\mathrm{~N}$ \\
\hline Year of latest StAR extract & YOSE & 00048 & 3 & $\mathrm{~N}$ \\
\hline citizen code & CITIZEN & 00087 & 1 & $\mathrm{~A} / \mathrm{N}$ \\
\hline city,county of birth & POBCITY & 00090 & 12 & $\mathrm{~A} / \mathrm{N}$ \\
\hline source of data & SOURCE & 00105 & 2 & $\mathrm{~A} / \mathrm{N}$ \\
\hline intry of birth & POBST & 00103 & 2 & $\mathrm{~A} / \mathrm{N}$ \\
\hline type of source & SOURCETP & 00107 & 2 & $\mathrm{~A} / \mathrm{N}$ \\
\hline
\end{tabular}


CHAPTER 6. INDIVIDUAL CHARACTERISTICS FILE (ICF)

\subsubsection{Age and sex implicates: ICF_zz_implicates_age_sex}

The first implicate for both date of birth and sex are stored on the main ICF file as DOB and SEx. Imputed values are flagged by the appropriate flag. Other implicates are found in this file, and can be merged on when required.

\section{Record identifier PIK}

\section{Sort order PIK}

Entity PIK

\section{Unique Entity Key PIK}

\begin{tabular}{c|l|c|c|c}
\hline \multicolumn{1}{c}{ Field name } & $\begin{array}{l}\text { Data dictionary } \\
\text { reference name }\end{array}$ & $\begin{array}{c}\text { Starting } \\
\text { position }\end{array}$ & $\begin{array}{l}\text { Field } \\
\text { size }\end{array}$ & $\begin{array}{l}\text { Data } \\
\text { type }\end{array}$ \\
\hline Date of birth imputation flag & DOBIMPUTED & 00082 & 1 & $\mathrm{~A} / \mathrm{N}$ \\
Date of birth, SAS format (Implicate 10) & DOB10 & 00064 & 8 & $\mathrm{~N}$ \\
Date of birth, SAS format (Implicate 2) & DOB2 & 00000 & 8 & $\mathrm{~N}$ \\
Date of birth, SAS format (Implicate 3) & DOB3 & 00008 & 8 & $\mathrm{~N}$ \\
Date of birth, SAS format (Implicate 4) & DOB4 & 00016 & 8 & $\mathrm{~N}$ \\
Date of birth, SAS format (Implicate 5) & DOB5 & 00024 & 8 & $\mathrm{~N}$ \\
Date of birth, SAS format (Implicate 6) & DOB6 & 00032 & 8 & $\mathrm{~N}$ \\
Date of birth, SAS format (Implicate 7) & DOB7 & 00040 & 8 & $\mathrm{~N}$ \\
Date of birth, SAS format (Implicate 8) & DOB8 & 00048 & 8 & $\mathrm{~N}$ \\
Date of birth, SAS format (Implicate 9) & DOB9 & 00056 & 8 & $\mathrm{~N}$ \\
Gender imputation flag & SEXIMPUTED & 00081 & 1 & $\mathrm{~A} / \mathrm{N}$ \\
Numident variable=gender (Implicate 10) & SEX10 & 00091 & 1 & $\mathrm{~A} / \mathrm{N}$ \\
Numident variable=gender (Implicate 2) & SEX2 & 00083 & 1 & $\mathrm{~A} / \mathrm{N}$ \\
Numident variable=gender (Implicate 3) & SEX3 & 00084 & 1 & $\mathrm{~A} / \mathrm{N}$ \\
Numident variable=gender (Implicate 4) & SEX4 & 00085 & 1 & $\mathrm{~A} / \mathrm{N}$ \\
Numident variable=gender (Implicate 5) & SEX5 & 00086 & 1 & $\mathrm{~A} / \mathrm{N}$ \\
Numident variable=gender (Implicate 6) & SEX6 & 00087 & 1 & $\mathrm{~A} / \mathrm{N}$ \\
Numident variable=gender (Implicate 7) & SEX7 & 00088 & 1 & $\mathrm{~A} / \mathrm{N}$ \\
Numident variable=gender (Implicate 8) & SEX8 & 00089 & 1 & $\mathrm{~A} / \mathrm{N}$ \\
Numident variable=gender (Implicate 9) & SEX9 & 00090 & 1 & $\mathrm{~A} / \mathrm{N}$ \\
Protected Identification Key & PIK & 00072 & 9 & $\mathrm{~A} / \mathrm{N}$
\end{tabular}




\subsubsection{Residence implicates: ICF_zz_implicates_county}

The first implicate is stored on the main ICF file as COUNTY_LIVE. Imputed values are flagged there by an appropriate flag COUNTYLIVEIMPUTED. Other implicates are found in this file, and can be merged on when required.

\section{Record identifier PIK}

Sort order PIK

Entity PIK

Unique Entity Key PIK

\begin{tabular}{l|l|c|c|c}
\hline \multicolumn{1}{c|}{ Field name } & $\begin{array}{l}\text { Data dictionary } \\
\text { reference name }\end{array}$ & $\begin{array}{l}\text { Starting } \\
\text { position }\end{array}$ & $\begin{array}{l}\text { Field } \\
\text { size }\end{array}$ & $\begin{array}{l}\text { Data } \\
\text { type }\end{array}$ \\
\hline County of Residence (implicate 10) run & COUNTY_LIVE10 & 00049 & 5 & $\mathrm{~A} / \mathrm{N}$ \\
County of Residence (implicate 2) & COUNTY_LIVE2 & 00009 & 5 & $\mathrm{~A} / \mathrm{N}$ \\
County of Residence (implicate 3) & COUNTY_LIVE3 & 00014 & 5 & $\mathrm{~A} / \mathrm{N}$ \\
County of Residence (implicate 4) & COUNTY_LIVE4 & 00019 & 5 & $\mathrm{~A} / \mathrm{N}$ \\
County of Residence (implicate 5) & COUNTY_LIVE5 & 00024 & 5 & $\mathrm{~A} / \mathrm{N}$ \\
County of Residence (implicate 6) & COUNTY_LIVE6 & 00029 & 5 & $\mathrm{~A} / \mathrm{N}$ \\
County of Residence (implicate 7) & COUNTY_LIVE7 & 00034 & 5 & $\mathrm{~A} / \mathrm{N}$ \\
County of Residence (implicate 8) & COUNTY_LIVE8 & 00039 & 5 & $\mathrm{~A} / \mathrm{N}$ \\
County of Residence (implicate 9) & COUNTY_LIVE9 & 00044 & 5 & $\mathrm{~A} / \mathrm{N}$ \\
County of Residence imputation flag & COUNTYLIVEIMPUTED00054 & 1 & $\mathrm{~A} / \mathrm{N}$ \\
Protected Identification Key & PIK & 00000 & 9 & $\mathrm{~A} / \mathrm{N}$
\end{tabular}


CHAPTER 6. INDIVIDUAL CHARACTERISTICS FILE (ICF)

\subsubsection{Education implicates: ICF_zz_implicates_education}

The first implicate is stored on the main ICF file as EDIMP1. No flag exists, since all values are imputed. Other implicates are found in this file, and can be merged on when required.

\section{Record identifier PIK}

Sort order PIK

Entity PIK

Unique Entity Key PIK

\begin{tabular}{|c|c|c|c|c|}
\hline Field name & $\begin{array}{l}\text { Data dictionary } \\
\text { reference name }\end{array}$ & $\begin{array}{l}\text { Starting } \\
\text { position }\end{array}$ & $\begin{array}{l}\text { Field } \\
\text { size }\end{array}$ & $\begin{array}{l}\text { Data } \\
\text { type }\end{array}$ \\
\hline Imputed education length (implicate 10) run & EDIMP10 & 00024 & 3 & $\mathrm{~N}$ \\
\hline Imputed education length (implicate 2) & EDIMP 2 & 00000 & 3 & $\mathrm{~N}$ \\
\hline Imputed education length (implicate 3) & EDIMP3 & 00003 & 3 & $\mathrm{~N}$ \\
\hline Imputed education length (implicate 4) & EDIMP4 & 00006 & 3 & $\mathrm{~N}$ \\
\hline Imputed education length (implicate 5) & EDIMP5 & 00009 & 3 & $\mathrm{~N}$ \\
\hline Imputed education length (implicate 6) & EDIMP6 & 00012 & 3 & $\mathrm{~N}$ \\
\hline Imputed education length (implicate 7) & EDIMP7 & 00015 & 3 & $\mathrm{~N}$ \\
\hline Imputed education length (implicate 8) & EDIMP8 & 00018 & 3 & $\mathrm{~N}$ \\
\hline Imputed education length (implicate 9) & EDIMP9 & 00021 & 3 & $\mathrm{~N}$ \\
\hline Protected Identification Key & PIK & 00027 & 9 & $\mathrm{~A} / \mathrm{N}$ \\
\hline
\end{tabular}




\subsubsection{Title 26 information: ICF_zz_t26}

FTI has been removed from the core ICF, and stored separately. Note that in the RDC network, this file is stored under a separate set of permissions, and if users require access to this information, need to request access to an additional group. T26 variables are starred below.

\section{Record identifier PIK}

\section{Sort order PIK}

Entity PIK

\section{Unique Entity Key PIK}

\begin{tabular}{|c|c|c|c|c|}
\hline Field name & $\begin{array}{l}\text { Data dictionary } \\
\text { reference name }\end{array}$ & $\begin{array}{l}\text { Starting } \\
\text { position }\end{array}$ & $\begin{array}{l}\text { Field } \\
\text { size }\end{array}$ & $\begin{array}{l}\text { Data } \\
\text { type }\end{array}$ \\
\hline Admin record huid & HUID_1999 $*$ & 00047 & 35 & $\mathrm{~A} / \mathrm{N}$ \\
\hline Admin record source of huid & HUIDSRC_1999 * & 00082 & 7 & $\mathrm{~A} / \mathrm{N}$ \\
\hline Basic street address conflict flag & HSRC23_1999 * & 00089 & 7 & $\mathrm{~A} / \mathrm{N}$ \\
\hline County of Residence as of year 1999:2 & COUNTY_LIVE $*$ & 00041 & 5 & $\mathrm{~A} / \mathrm{N}$ \\
\hline County of Residence imputation flag & COUNTYLIVEIMPU & TED00046 & 1 & $\mathrm{~A} / \mathrm{N}$ \\
\hline Flag quality of latitude/longitude of residence & FLAG_LATLONG & 00000 & 8 & $\mathrm{~N}$ \\
\hline Latitude of residence, 6 implied decimal places & $\begin{array}{l}\text { LATITUDE_LIVE } \\
*\end{array}$ & 00008 & 8 & $\mathrm{~N}$ \\
\hline Longitude of residence, 6 implied decimal places & $\begin{array}{l}\text { LONGITUDE_LIVE } \\
*\end{array}$ & 00016 & 8 & $\mathrm{~N}$ \\
\hline Protected I & PIK & 00032 & 9 & $\mathrm{~A} / \mathrm{N}$ \\
\hline State (derived from UI wage records) & STATE & 00024 & 8 & $\mathrm{~N}$ \\
\hline
\end{tabular}


CHAPTER 6. INDIVIDUAL CHARACTERISTICS FILE (ICF)

\subsubsection{Summary information on datasets}

Table 6.6: File information, by state, by group, for ICF

\begin{tabular}{|c|c|c|c|c|c|c|c|}
\hline State & & Group & $\begin{array}{r}\text { Number of } \\
\text { datafiles }\end{array}$ & Records & $\begin{array}{r}\text { Filesizes } \\
(\mathrm{MB}) \\
\end{array}$ & Start & End \\
\hline Covered states & & & 62 & $402,634,528$ & $42,070.20$ & 1985Q2 & 2004Q3 \\
\hline Alabama & $\mathrm{AL}$ & icf & 1 & $2,921,217$ & 374.87 & 2001Q1 & 2004Q2 \\
\hline Alabama & $\mathrm{AL}$ & icft26 & 1 & $2,921,217$ & 241.36 & 2001Q1 & 2004Q2 \\
\hline Arkansas & $\mathrm{AR}$ & icf & 1 & $1,590,571$ & 204.77 & 2002Q3 & 2004Q2 \\
\hline Arkansas & $\mathrm{AR}$ & icft26 & 1 & $1,590,571$ & 131.44 & 2002Q3 & 2004Q2 \\
\hline California & CA & icf & 1 & $34,012,258$ & $4,336.96$ & 1991Q3 & 2003Q4 \\
\hline California & $\mathrm{CA}$ & icft26 & 1 & $34,012,258$ & $2,676.46$ & 1991Q3 & 2003Q4 \\
\hline Colorado & $\mathrm{CO}$ & $\operatorname{icf}$ & 1 & $6,729,548$ & 858.27 & 1990Q1 & 2004Q1 \\
\hline Colorado & $\mathrm{CO}$ & icft26 & 1 & $6,729,548$ & 541.36 & 1990Q1 & 2004Q1 \\
\hline Delaware & $\mathrm{DE}$ & $\operatorname{icf}$ & 1 & 806,071 & 103.29 & 1998Q3 & 2004Q1 \\
\hline Delaware & $\mathrm{DE}$ & icft26 & 1 & 806,071 & 66.38 & 1998Q3 & 2004Q1 \\
\hline Florida & FL & $\operatorname{icf}$ & 1 & $18,252,091$ & $2,320.04$ & 1992Q4 & 2004Q1 \\
\hline Florida & FL & icft26 & 1 & $18,252,091$ & $1,461.77$ & 1992Q4 & 2004Q1 \\
\hline Iowa & IA & $\operatorname{icf}$ & 1 & $2,505,678$ & 321.18 & 1998Q4 & 2004Q1 \\
\hline Iowa & IA & icft26 & 1 & $2,505,678$ & 208.41 & 1998Q4 & 2004Q1 \\
\hline Idaho & ID & $\operatorname{icf}$ & 1 & $1,730,508$ & 221.52 & 1990Q1 & 2004Q1 \\
\hline Idaho & ID & icft2 & 1 & $1,730,508$ & 140.14 & 1990Q1 & 2004Q1 \\
\hline Illinois & IL & $\operatorname{icf}$ & 1 & $13,875,529$ & $1,767.07$ & 1990Q1 & 2004Q1 \\
\hline Illinois & IL & icft2 & 1 & $13,875,529$ & $1,121.48$ & 1990Q1 & 2004Q1 \\
\hline Indiana & IN & icf & 1 & $6,810,867$ & 873.73 & 1990Q1 & 2004Q1 \\
\hline Indian & IN & icft2 & 1 & 77 & 563.23 & 1990Q1 & 2004Q1 \\
\hline Kansas & $\mathrm{K}$ & icf & 1 & 3,8 & 498.09 & 1990Q1 & 2004Q1 \\
\hline Kansa & $\mathrm{K}$ & icft2 & 1 & 3,8 & 315.27 & 199 & 2004Q1 \\
\hline Kentucky & $\mathrm{K}$ & icf & 1 & 3,58 & 460.12 & 199 & 2004Q1 \\
\hline Kent & $\mathrm{K}$ & icft: & 1 & 3,5 & 295.99 & 199 & 2004Q1 \\
\hline Maryland & MD & icf & 1 & 7,23 & 925.88 & 1985Q2 & 2004Q2 \\
\hline Maryland & MD & icft2 & 1 & 7,235 & 587.50 & 198 & 2004Q2 \\
\hline Maine & $\mathrm{ME}$ & icf & 1 & $1,206,021$ & 154.18 & 1996Q1 & 2004Q1 \\
\hline Maine & $\mathrm{ME}$ & icft: & 1 & $1,206,021$ & 98.00 & 1996Q1 & 2004Q1 \\
\hline Minnesota & MN & icf & 1 & $5,019,721$ & 642.09 & 1994Q3 & 2004Q3 \\
\hline Minnesota & MN & icft: & 1 & $5,019,721$ & 412.84 & 1994Q3 & 2004Q3 \\
\hline Missouri & MO & icf & 1 & 881 & 865.16 & 1990Q1 & 2004Q1 \\
\hline Missouri & MO & icft: & 1 & 6.75 & 554.58 & 1990Q1 & 2004Q1 \\
\hline Montana & MT & icf & 1 & 11 & 136.60 & 19 & 2004Q1 \\
\hline Montana & MT & icft2 & 1 & 11 & 87.54 & 1993Q1 & 2004Q1 \\
\hline North Carolina & $\mathrm{NC}$ & icf & 1 & 9,630 & $1,241.21$ & 199 & 2003Q4 \\
\hline North Carolina & $\mathrm{NC}$ & icft: & 1 & $9,630,526$ & 784.52 & 195 & 2003Q4 \\
\hline North Dakota & ND & icf & 1 & 608,486 & 77.91 & 1998Q1 & 2004Q2 \\
\hline North Dakota & ND & icfts & 1 & 486 & 50.66 & 1998Q1 & 2004Q2 \\
\hline New Jersey & NJ & icf & 1 & $7,895,006$ & $1,006.49$ & 1996Q1 & 2004Q1 \\
\hline New Jersey & NJ & icft & 1 & 006 & 636.09 & 199 & 2004Q1 \\
\hline New Mexico & NI & icf & 1 & 84 & 245.76 & & 2004Q1 \\
\hline New Mexico & NM & ic & 1 & & 157.04 & 1995Q3 & 2004Q1 \\
\hline Oklahom & $\mathrm{O}$ & is & 1 & $2,429,028$ & 310.80 & 2000Q1 & 2004Q1 \\
\hline Oklahoma & OK & icft26 & 1 & $2,429,028$ & 201.34 & 2000Q1 & 2004Q1 \\
\hline
\end{tabular}


CHAPTER 6. INDIVIDUAL CHARACTERISTICS FILE (ICF)

Table 6.6 - Continued

\begin{tabular}{|c|c|c|c|c|c|c|c|}
\hline State & & Group & $\begin{array}{r}\text { Number of } \\
\text { datafiles }\end{array}$ & Records & $\begin{array}{r}\text { Filesizes } \\
(\mathrm{MB}) \\
\end{array}$ & Start & End \\
\hline Oregon & OR & icf & 1 & $4,374,229$ & 563.52 & 1991Q1 & 2004Q1 \\
\hline Oregon & OR & icft26 & 1 & $4,374,229$ & 357.90 & 1991Q1 & 2004Q1 \\
\hline Pennsylvania & PA & icf & 1 & $11,983,407$ & $1,534.79$ & 1991Q1 & 2004Q1 \\
\hline Pennsylvania & PA & icft26 & 1 & $11,983,407$ & 982.91 & 1991Q1 & 2004Q1 \\
\hline South Carolina & $\mathrm{SC}$ & icf & 1 & $3,799,229$ & 490.79 & 1998Q1 & 2004Q3 \\
\hline South Carolina & $\mathrm{SC}$ & icft26 & 1 & $3,799,229$ & 314.05 & 1998Q1 & 2004Q3 \\
\hline Texas & $\mathrm{TX}$ & icf & 1 & $19,411,438$ & $2,480.27$ & 1995Q1 & 2004Q2 \\
\hline Texas & $\mathrm{TX}$ & icft26 & 1 & $19,411,438$ & $1,560.38$ & 1995Q1 & 2004Q2 \\
\hline Virginia & VA & icf & 1 & $6,452,661$ & 831.88 & 1998Q1 & 2004Q1 \\
\hline Virginia & VA & icft26 & 1 & $6,452,661$ & 535.44 & 1998Q1 & 2004Q1 \\
\hline Vermont & VT & icf & 1 & 529,721 & 67.96 & 2000Q1 & 2004Q1 \\
\hline Vermont & $\mathrm{VT}$ & icft26 & 1 & 529,721 & 43.27 & 2000Q1 & 2004Q1 \\
\hline Washington & WA & icf & 1 & $7,438,184$ & 957.54 & 1990Q1 & 2004Q1 \\
\hline Washington & WA & icft26 & 1 & $7,438,184$ & 605.27 & 1990Q1 & 2004Q1 \\
\hline Wisconsin & WI & icf & 1 & $5,437,229$ & 702.99 & 1990Q1 & 2004Q1 \\
\hline Wisconsin & WI & icft26 & 1 & $5,437,229$ & 460.19 & 1990Q1 & 2004Q1 \\
\hline West Virginia & $\mathrm{WV}$ & icf & 1 & $1,428,748$ & 183.60 & 1997Q1 & 2004Q1 \\
\hline West Virginia & WV & icft26 & 1 & $1,428,748$ & 118.07 & 1997Q1 & 2004Q1 \\
\hline
\end{tabular}




\subsection{HELPFUL PROGRAMS}

The following programs might be found to be useful when using the data.

\subsubsection{Recombining T26 data with the core ICF}

The following program allows users to combine the Title 26 variables with the core ICF. This program was used in slightly modified form for quality assurance during the preparation of the data for the RDC environment.

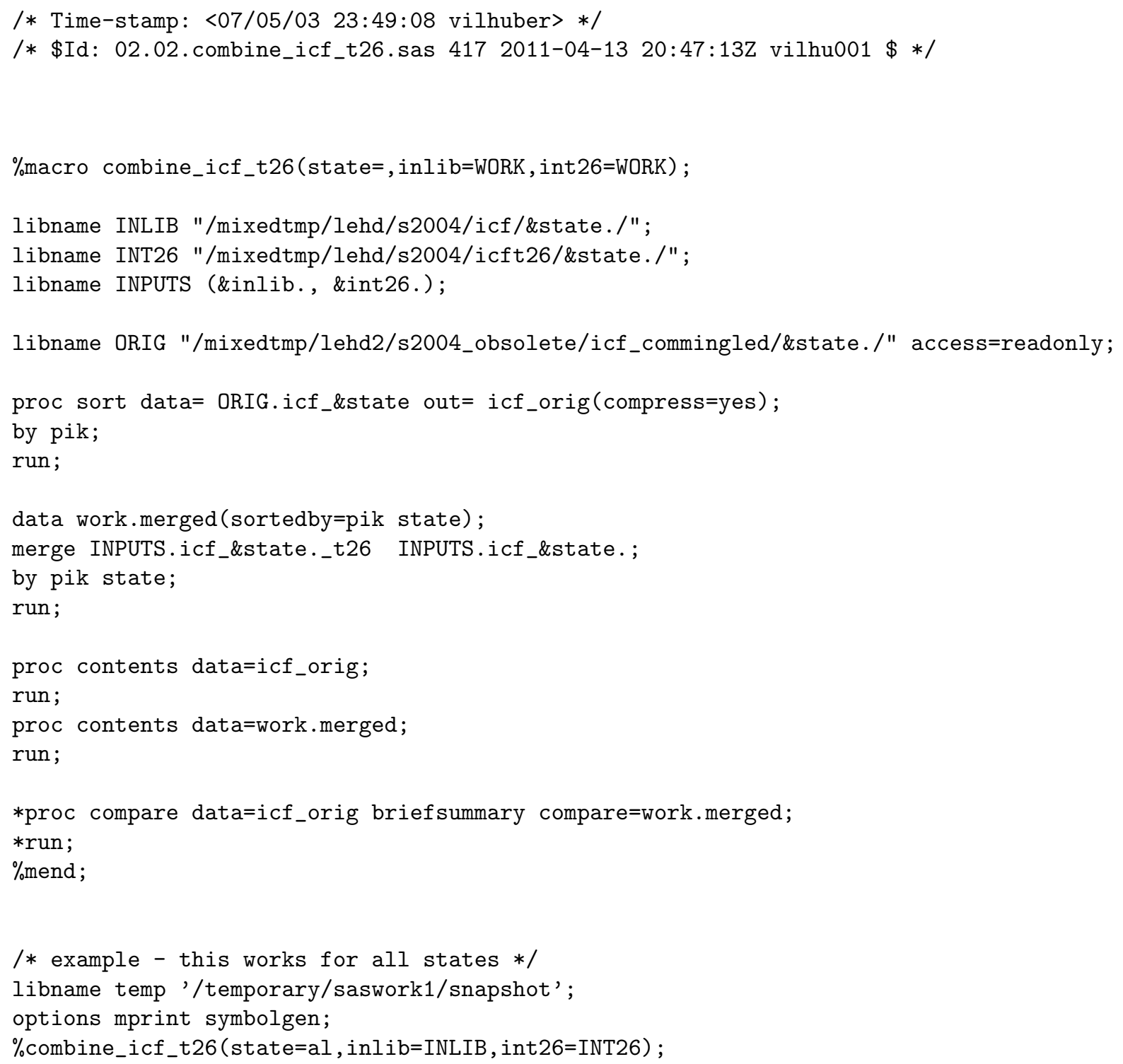

\subsubsection{Selecting a random subsample of persons}

The following program allows users to select a random sample of approximately one percent of individuals on the ICF. It relies on the fact that the first two characters of the PIK are approximately uniformly distributed on $[00,99]$. Note that 'AA' is a valid value for the first two characters and denotes individuals for whom no valid SSN was on file. Occurrence of such "pseudo-PIKs" varies by state. 
$\%$ let state=ca;

libname INLIB "/mixed/lehd/s2004/icf/\&state./";

data my_icf;

set INLIB.icf_\&state. (where= $\left.\left(\operatorname{substr}(P I K, 1,2)={ }^{\prime} 01^{\prime}\right)\right)$;

run; 
CHAPTER 6. INDIVIDUAL CHARACTERISTICS FILE (ICF)

6.4 NOTES 
CHAPTER 6. INDIVIDUAL CHARACTERISTICS FILE (ICF) 


\section{Chapter 7. \\ Quarterly Workforce Indicators - SEINUNIT file (QWI)}

\subsection{OVERVIEW}

The QWI are a set of economic indicators - including employment, job creation, wages, and worker turnover

- that can be queried by different levels of geography - state, county, metro, and workforce investment area - as well as by detailed industry, gender, and age of workers. The SEINUNIT file is the core dataset from which publication tables are tabulated. Public-use tabulations are not available in the RDC. 


\subsection{DATA SET DESCRIPTIONS}

\subsubsection{Coverage of QWI}

QWI data are available for all states that are LED-state partners, however, not every state is currently a LED-state partner. The QWI are built upon wage records in the UI system and information from state ES-202 data. The universe of QWI data is UI-covered earnings. UI coverage is broad, covering over $90 \%$ of total wage and salary civilian jobs.

When QWI private industry employment numbers are compared with other employment data, exclusions to UI coverage should be taken into account. Federal government employment is not generally included. Exempted employment varies slightly from state to state due to variations in state unemployment laws, but generally also excludes many farmers and agricultural employees, domestic workers, self-employed nonagricultural workers, members of the Armed Services, some state and local government employees as well as certain types of nonprofit employers and religious organizations (which are given a choice of coverage or noncoverage in a number of states). See "Employment that is not covered by state unemployment" (LEHD TP-2007-04) for a more detailed discussion.

\subsubsection{Naming scheme}

Describe the naming scheme.

qwi_zz_seinunit.sas7bdat

ZZ stands for the state postal abbreviation, and YYYY for a calendar year. You will find zero-observation SAS datasets attached to this document - see the attachment tab.

\subsubsection{Data location}

The files are stored in two main directories, with state-specific subdirectories:

qwi/ZZ/

On the RDC network, the directory can be found under

/mixed/lehd/current

\subsubsection{Main dataset: QWI_ZZ_SEINUNIT}

The QWI_ZZ_SEINUNIT file (LEHD internal name: UFFb) is a file at the SEINUNIT level, providing detailed statistics for an establishment (SEIN + SEINUNIT) at every combination of SEX x AGEGROUP. Age groups are defined using the WIA categorization. The agegroup and sex margins are represented as variable arrays in the UFFb.

Record identifier YEAR QUARTER SEIN SEINUNIT

Sort order YEAR QUARTER SEIN SEINUNIT

Entity Establishment

Unique Entity Key SEIN SEINUNIT

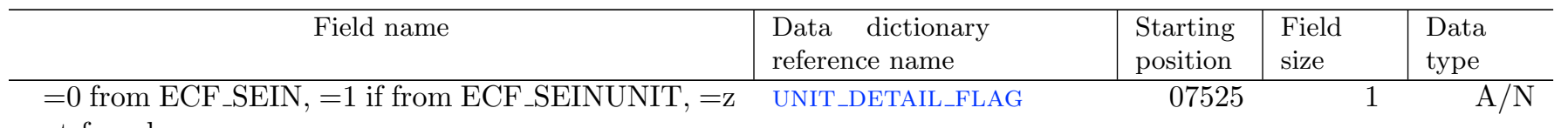
not found 


\begin{tabular}{|c|c|c|c|c|}
\hline Field name & $\begin{array}{l}\text { Data dictionary } \\
\text { reference name }\end{array}$ & $\begin{array}{l}\text { Starting } \\
\text { position }\end{array}$ & $\begin{array}{l}\text { Field } \\
\text { size }\end{array}$ & $\begin{array}{l}\text { Data } \\
\text { type }\end{array}$ \\
\hline Accessions for Female and age $14-18$ & A_A2A01 & 01880 & 4 & $\mathrm{~N}$ \\
\hline Accessions for Female and age 14-99 & A_A2A00 & 01868 & 4 & $\mathrm{~N}$ \\
\hline Accessions for Female and age 19-21 & A_A2A02 & 01892 & 4 & $\mathrm{~N}$ \\
\hline Accessions for Female and age 22-24 & A_A2A03 & 01904 & 4 & $\mathrm{~N}$ \\
\hline Accessions for Female and age 25-34 & A_A2A04 & 01916 & 4 & $\mathrm{~N}$ \\
\hline Accessions for Female and age $35-44$ & A_A2A 05 & 01928 & 4 & $\mathrm{~N}$ \\
\hline Accessions for Female and age $45-54$ & A_A2A06 & 01940 & 4 & $\mathrm{~N}$ \\
\hline Accessions for Female and age $55-64$ & A_A2A07 & 01952 & 4 & $\mathrm{~N}$ \\
\hline Accessions for Female and age 65-99 & A_A2A08 & 01964 & 4 & $\mathrm{~N}$ \\
\hline Accessions for Male and Female and age 14-18 & A_A0A01 & 01872 & 4 & $\mathrm{~N}$ \\
\hline Accessions for Male and Female and age 14-99 & A_A0A00 & 01860 & 4 & $\mathrm{~N}$ \\
\hline Accessions for Male and Female and age 19-21 & A_A0A02 & 01884 & 4 & $\mathrm{~N}$ \\
\hline Accessions for Male and Female and age 22-24 & A_A0A03 & 01896 & 4 & $\mathrm{~N}$ \\
\hline Accessions for Male and Female and age 25-34 & A_A0A04 & 01908 & 4 & $\mathrm{~N}$ \\
\hline Accessions for Male and Female and age 35-44 & A_A0A05 & 01920 & 4 & $\mathrm{~N}$ \\
\hline Accessions for Male and Female and age 45-54 & A_A0A06 & 01932 & 4 & $\mathrm{~N}$ \\
\hline Accessions for Male and Female and age 55-64 & A_A0A07 & 01944 & 4 & $\mathrm{~N}$ \\
\hline Accessions for Male and Female and age 65-99 & A_A0A08 & 01956 & 4 & $\mathrm{~N}$ \\
\hline Accessions for Male and age 14-18 & A_A1A01 & 01876 & 4 & $\mathrm{~N}$ \\
\hline Accessions for Male and age 14-99 & A_A1A00 & 01864 & 4 & $\mathrm{~N}$ \\
\hline Accessions for Male and age 19-21 & A_A $1 \mathrm{~A} 02$ & 01888 & 4 & $\mathrm{~N}$ \\
\hline Accessions for Male and age $22-24$ & A_A1A03 & 01900 & 4 & $\mathrm{~N}$ \\
\hline Accessions for Male and age 25-34 & A_A $1 \mathrm{~A} 04$ & 01912 & 4 & $\mathrm{~N}$ \\
\hline Accessions for Male and age $35-44$ & A_A 1 A 05 & 01924 & 4 & $\mathrm{~N}$ \\
\hline Accessions for Male and age $45-54$ & A_A1A06 & 01936 & 4 & $\mathrm{~N}$ \\
\hline Accessions for Male and age 55-64 & A_A1A07 & 01948 & 4 & $\mathrm{~N}$ \\
\hline Accessions for Male and age 65-99 & A_A1A08 & 01960 & 4 & $\mathrm{~N}$ \\
\hline $\begin{array}{l}\text { Alternate definition of B that does not reflect flow sup- } \\
\text { pression for Female and }\end{array}$ & BDOT_A2A01 & 05120 & 4 & $\mathrm{~N}$ \\
\hline $\begin{array}{l}\text { Alternate definition of B that does not reflect flow sup- } \\
\text { pression for Female and }\end{array}$ & BDOT_A2A00 & 05108 & 4 & $\mathrm{~N}$ \\
\hline $\begin{array}{l}\text { Alternate definition of B that does not reflect flow sup- } \\
\text { pression for Female and }\end{array}$ & BDOT_A2A02 & 05132 & 4 & $\mathrm{~N}$ \\
\hline $\begin{array}{l}\text { Alternate definition of B that does not reflect flow sup- } \\
\text { pression for Female and }\end{array}$ & BDOT_A2A03 & 05144 & 4 & $\mathrm{~N}$ \\
\hline $\begin{array}{l}\text { Alternate definition of B that does not reflect flow sup- } \\
\text { pression for Female and }\end{array}$ & BDOT_A2A04 & 05156 & 4 & $\mathrm{~N}$ \\
\hline $\begin{array}{l}\text { Alternate definition of B that does not reflect flow sup- } \\
\text { pression for Female and }\end{array}$ & BDOT_A2A05 & 05168 & 4 & $\mathrm{~N}$ \\
\hline $\begin{array}{l}\text { Alternate definition of B that does not reflect flow sup- } \\
\text { pression for Female and }\end{array}$ & BDOT_A2A06 & 05180 & 4 & $\mathrm{~N}$ \\
\hline $\begin{array}{l}\text { Alternate definition of B that does not reflect flow sup- } \\
\text { pression for Female and }\end{array}$ & BDOT_A2A07 & 05192 & 4 & $\mathrm{~N}$ \\
\hline $\begin{array}{l}\text { Alternate definition of B that does not reflect flow sup- } \\
\text { pression for Female and }\end{array}$ & BDOT_A2A08 & 05204 & 4 & $\mathrm{~N}$ \\
\hline $\begin{array}{l}\text { Alternate definition of B that does not reflect flow sup- } \\
\text { pression for Male and Fe }\end{array}$ & BDOT_A0A01 & 05112 & 4 & $\mathrm{~N}$ \\
\hline Alternate definition of B that does not reflect flow sup- & BDOT_A0A00 & 05100 & 4 & $\mathrm{~N}$ \\
\hline
\end{tabular}




\begin{tabular}{|c|c|c|c|c|}
\hline Field name & $\begin{array}{l}\text { Data dictionary } \\
\text { reference name }\end{array}$ & $\begin{array}{l}\text { Starting } \\
\text { position }\end{array}$ & $\begin{array}{l}\text { Field } \\
\text { size }\end{array}$ & $\begin{array}{l}\text { Data } \\
\text { type }\end{array}$ \\
\hline $\begin{array}{l}\text { Alternate definition of B that does not reflect flow sup- } \\
\text { pression for Male and Fe }\end{array}$ & BDOT_A0A02 & 05124 & 4 & $\mathrm{~N}$ \\
\hline $\begin{array}{l}\text { Alternate definition of B that does not reflect flow sup- } \\
\text { pression for Male and Fe }\end{array}$ & BDOT_A0A03 & 05136 & 4 & $\mathrm{~N}$ \\
\hline $\begin{array}{l}\text { Alternate definition of B that does not reflect flow sup- } \\
\text { pression for Male and Fe }\end{array}$ & BDOT_A0A04 & 05148 & 4 & $\mathrm{~N}$ \\
\hline $\begin{array}{l}\text { Alternate definition of B that does not reflect flow sup- } \\
\text { pression for Male and Fe }\end{array}$ & BDOT_A0A05 & 05160 & 4 & $\mathrm{~N}$ \\
\hline $\begin{array}{l}\text { Alternate definition of B that does not reflect flow sup- } \\
\text { pression for Male and Fe }\end{array}$ & BDOT_A0A06 & 05172 & 4 & $\mathrm{~N}$ \\
\hline $\begin{array}{l}\text { Alternate definition of B that does not reflect flow sup- } \\
\text { pression for Male and Fe }\end{array}$ & BDOT_A0A07 & 05184 & 4 & $\mathrm{~N}$ \\
\hline $\begin{array}{l}\text { Alternate definition of B that does not reflect flow sup- } \\
\text { pression for Male and Fe }\end{array}$ & BDOT_A0A08 & 05196 & 4 & $\mathrm{~N}$ \\
\hline $\begin{array}{l}\text { Alternate definition of B that does not reflect flow sup- } \\
\text { pression for Male and ag }\end{array}$ & BDOT_A1A01 & 05116 & 4 & $\mathrm{~N}$ \\
\hline $\begin{array}{l}\text { Alternate definition of B that does not reflect flow sup- } \\
\text { pression for Male and ag }\end{array}$ & BDOT_A1A00 & 05104 & 4 & $\mathrm{~N}$ \\
\hline $\begin{array}{l}\text { Alternate definition of B that does not reflect flow sup- } \\
\text { pression for Male and ag }\end{array}$ & BDOT_A1A02 & 05128 & 4 & $\mathrm{~N}$ \\
\hline $\begin{array}{l}\text { Alternate definition of B that does not reflect flow sup- } \\
\text { pression for Male and ag }\end{array}$ & BDOT_A1A03 & 05140 & 4 & $\mathrm{~N}$ \\
\hline $\begin{array}{l}\text { Alternate definition of B that does not reflect flow sup- } \\
\text { pression for Male and ag }\end{array}$ & BDOT_A1A04 & 05152 & 4 & $\mathrm{~N}$ \\
\hline $\begin{array}{l}\text { Alternate definition of B that does not reflect flow sup- } \\
\text { pression for Male and ag }\end{array}$ & BDOT_A1A05 & 05164 & 4 & $\mathrm{~N}$ \\
\hline $\begin{array}{l}\text { Alternate definition of B that does not reflect flow sup- } \\
\text { pression for Male and ag }\end{array}$ & BDOT_A1A06 & 05176 & 4 & $\mathrm{~N}$ \\
\hline $\begin{array}{l}\text { Alternate definition of B that does not reflect flow sup- } \\
\text { pression for Male and ag }\end{array}$ & BDOT_A1A07 & 05188 & 4 & $\mathrm{~N}$ \\
\hline $\begin{array}{l}\text { Alternate definition of B that does not reflect flow sup- } \\
\text { pression for Male and ag }\end{array}$ & BDOT_A1A08 & 05200 & 4 & $\mathrm{~N}$ \\
\hline $\begin{array}{l}\text { Alternate definition of } \mathrm{E} \text { that does not reflect flow sup- } \\
\text { pression for Female and }\end{array}$ & EDOT_A2A01 & 05228 & 4 & $\mathrm{~N}$ \\
\hline $\begin{array}{l}\text { Alternate definition of } \mathrm{E} \text { that does not reflect flow sup- } \\
\text { pression for Female and }\end{array}$ & EDOT_A2A00 & 05216 & 4 & $\mathrm{~N}$ \\
\hline $\begin{array}{l}\text { Alternate definition of } \mathrm{E} \text { that does not reflect flow sup- } \\
\text { pression for Female and }\end{array}$ & EDOT_A2A02 & 05240 & 4 & $\mathrm{~N}$ \\
\hline $\begin{array}{l}\text { Alternate definition of } \mathrm{E} \text { that does not reflect flow sup- } \\
\text { pression for Female and }\end{array}$ & EDOT_A2A03 & 05252 & 4 & $\mathrm{~N}$ \\
\hline $\begin{array}{l}\text { Alternate definition of E that does not reflect flow sup- } \\
\text { pression for Female and }\end{array}$ & EDOT_A2A04 & 05264 & 4 & $\mathrm{~N}$ \\
\hline $\begin{array}{l}\text { Alternate definition of } \mathrm{E} \text { that does not reflect flow sup- } \\
\text { pression for Female and }\end{array}$ & EDOT_A2A05 & 05276 & 4 & $\mathrm{~N}$ \\
\hline $\begin{array}{l}\text { Alternate definition of } \mathrm{E} \text { that does not reflect flow sup- } \\
\text { pression for Female and }\end{array}$ & EDOT_A2A06 & 05288 & 4 & $\mathrm{~N}$ \\
\hline $\begin{array}{l}\text { Alternate definition of } \mathrm{E} \text { that does not reflect flow sup- } \\
\text { pression for Female and }\end{array}$ & EDOT_A2A07 & 05300 & 4 & $\mathrm{~N}$ \\
\hline Alternate definition of E that does not reflect flow sup- & EDOT_A2A08 & 05312 & 4 & $\mathrm{~N}$ \\
\hline
\end{tabular}




\begin{tabular}{|c|c|c|c|c|}
\hline Field name & $\begin{array}{l}\text { Data dictionary } \\
\text { reference name }\end{array}$ & $\begin{array}{l}\text { Starting } \\
\text { position }\end{array}$ & $\begin{array}{l}\text { Field } \\
\text { size }\end{array}$ & $\begin{array}{l}\text { Data } \\
\text { type }\end{array}$ \\
\hline $\begin{array}{l}\text { Alternate definition of } \mathrm{E} \text { that does not reflect flow sup- } \\
\text { pression for Male and Fe }\end{array}$ & EDOT_A0A01 & 05220 & 4 & $\mathrm{~N}$ \\
\hline $\begin{array}{l}\text { Alternate definition of } \mathrm{E} \text { that does not reflect flow sup- } \\
\text { pression for Male and Fe }\end{array}$ & EDOT_A0A00 & 05208 & 4 & $\mathrm{~N}$ \\
\hline $\begin{array}{l}\text { Alternate definition of } \mathrm{E} \text { that does not reflect flow sup- } \\
\text { pression for Male and Fe }\end{array}$ & EDOT_A0A02 & 05232 & 4 & $\mathrm{~N}$ \\
\hline $\begin{array}{l}\text { Alternate definition of E that does not reflect flow sup- } \\
\text { pression for Male and Fe }\end{array}$ & EDOT_A0A03 & 05244 & 4 & $\mathrm{~N}$ \\
\hline $\begin{array}{l}\text { Alternate definition of E that does not reflect flow sup- } \\
\text { pression for Male and Fe }\end{array}$ & EDOT_A0A04 & 05256 & 4 & $\mathrm{~N}$ \\
\hline $\begin{array}{l}\text { Alternate definition of E that does not reflect flow sup- } \\
\text { pression for Male and Fe }\end{array}$ & EDOT_A0A05 & 05268 & 4 & $\mathrm{~N}$ \\
\hline $\begin{array}{l}\text { Alternate definition of E that does not reflect flow sup- } \\
\text { pression for Male and Fe }\end{array}$ & EDOT_A0A06 & 05280 & 4 & $\mathrm{~N}$ \\
\hline $\begin{array}{l}\text { Alternate definition of } \mathrm{E} \text { that does not reflect flow sup- } \\
\text { pression for Male and Fe }\end{array}$ & EDOT_A0A07 & 05292 & 4 & $\mathrm{~N}$ \\
\hline $\begin{array}{l}\text { Alternate definition of } \mathrm{E} \text { that does not reflect flow sup- } \\
\text { pression for Male and Fe }\end{array}$ & EDOT_A0A08 & 05304 & 4 & $\mathrm{~N}$ \\
\hline $\begin{array}{l}\text { Alternate definition of } \mathrm{E} \text { that does not reflect flow sup- } \\
\text { pression for Male and ag }\end{array}$ & EDOT_A1A01 & 05224 & 4 & $\mathrm{~N}$ \\
\hline $\begin{array}{l}\text { Alternate definition of } \mathrm{E} \text { that does not reflect flow sup- } \\
\text { pression for Male and ag }\end{array}$ & EDOT_A1A00 & 05212 & 4 & $\mathrm{~N}$ \\
\hline $\begin{array}{l}\text { Alternate definition of E that does not reflect flow sup- } \\
\text { pression for Male and ag }\end{array}$ & EDOT_A1A02 & 05236 & 4 & $\mathrm{~N}$ \\
\hline $\begin{array}{l}\text { Alternate definition of E that does not reflect flow sup- } \\
\text { pression for Male and ag }\end{array}$ & EDOT_A1A03 & 05248 & 4 & $\mathrm{~N}$ \\
\hline $\begin{array}{l}\text { Alternate definition of E that does not reflect flow sup- } \\
\text { pression for Male and ag }\end{array}$ & EDOT_A1A04 & 05260 & 4 & $\mathrm{~N}$ \\
\hline $\begin{array}{l}\text { Alternate definition of } \mathrm{E} \text { that does not reflect flow sup- } \\
\text { pression for Male and ag }\end{array}$ & EDOT_A1A05 & 05272 & 4 & $\mathrm{~N}$ \\
\hline $\begin{array}{l}\text { Alternate definition of } \mathrm{E} \text { that does not reflect flow sup- } \\
\text { pression for Male and ag }\end{array}$ & EDOT_A1A06 & 05284 & 4 & $\mathrm{~N}$ \\
\hline $\begin{array}{l}\text { Alternate definition of E that does not reflect flow sup- } \\
\text { pression for Male and ag }\end{array}$ & EDOT_A1A07 & 05296 & 4 & $\mathrm{~N}$ \\
\hline $\begin{array}{l}\text { Alternate definition of E that does not reflect flow sup- } \\
\text { pression for Male and ag }\end{array}$ & EDOT_A1A08 & 05308 & 4 & $\mathrm{~N}$ \\
\hline $\begin{array}{l}\text { Alternate definition of } \mathrm{F} \text { that does not reflect flow sup- } \\
\text { pression for Female and }\end{array}$ & FDOT_A2A01 & 05336 & 4 & $\mathrm{~N}$ \\
\hline $\begin{array}{l}\text { Alternate definition of } \mathrm{F} \text { that does not reflect flow sup- } \\
\text { pression for Female and }\end{array}$ & FDOT_A2A00 & 05324 & 4 & $\mathrm{~N}$ \\
\hline $\begin{array}{l}\text { Alternate definition of } \mathrm{F} \text { that does not reflect flow sup- } \\
\text { pression for Female and }\end{array}$ & FDOT_A2A02 & 05348 & 4 & $\mathrm{~N}$ \\
\hline $\begin{array}{l}\text { Alternate definition of } \mathrm{F} \text { that does not reflect flow sup- } \\
\text { pression for Female and }\end{array}$ & FDOT_A2A03 & 05360 & 4 & $\mathrm{~N}$ \\
\hline $\begin{array}{l}\text { Alternate definition of } \mathrm{F} \text { that does not reflect flow sup- } \\
\text { pression for Female and }\end{array}$ & FDOT_A2A04 & 05372 & 4 & $\mathrm{~N}$ \\
\hline $\begin{array}{l}\text { Alternate definition of } \mathrm{F} \text { that does not reflect flow sup- } \\
\text { pression for Female and }\end{array}$ & FDOT_A2A 05 & 05384 & 4 & $\mathrm{~N}$ \\
\hline Alternate definition of $\mathrm{F}$ that does not reflect flow sup- & FDOT_A2A06 & 05396 & 4 & $\mathrm{~N}$ \\
\hline
\end{tabular}




\begin{tabular}{|c|c|c|c|c|}
\hline Field name & $\begin{array}{l}\text { Data dictionary } \\
\text { reference name }\end{array}$ & $\begin{array}{l}\text { Starting } \\
\text { position }\end{array}$ & $\begin{array}{l}\text { Field } \\
\text { size }\end{array}$ & $\begin{array}{l}\text { Data } \\
\text { type }\end{array}$ \\
\hline $\begin{array}{l}\text { Alternate definition of } \mathrm{F} \text { that does not reflect flow sup- } \\
\text { pression for Female and }\end{array}$ & FDOT_A2A07 & 05408 & 4 & $\mathrm{~N}$ \\
\hline $\begin{array}{l}\text { Alternate definition of } \mathrm{F} \text { that does not reflect flow sup- } \\
\text { pression for Female and }\end{array}$ & FDOT_A2A08 & 05420 & 4 & $\mathrm{~N}$ \\
\hline $\begin{array}{l}\text { Alternate definition of } \mathrm{F} \text { that does not reflect flow sup- } \\
\text { pression for Male and Fe }\end{array}$ & FDOT_A0A01 & 05328 & 4 & $\mathrm{~N}$ \\
\hline $\begin{array}{l}\text { Alternate definition of } \mathrm{F} \text { that does not reflect flow sup- } \\
\text { pression for Male and Fe }\end{array}$ & FDOT_A0A00 & 05316 & 4 & $\mathrm{~N}$ \\
\hline $\begin{array}{l}\text { Alternate definition of } \mathrm{F} \text { that does not reflect flow sup- } \\
\text { pression for Male and Fe }\end{array}$ & FDOT_A0A02 & 05340 & 4 & $\mathrm{~N}$ \\
\hline $\begin{array}{l}\text { Alternate definition of } \mathrm{F} \text { that does not reflect flow sup- } \\
\text { pression for Male and Fe }\end{array}$ & FDOT_A0A03 & 05352 & 4 & $\mathrm{~N}$ \\
\hline $\begin{array}{l}\text { Alternate definition of } \mathrm{F} \text { that does not reflect flow sup- } \\
\text { pression for Male and Fe }\end{array}$ & FDOT_A0A04 & 05364 & 4 & $\mathrm{~N}$ \\
\hline $\begin{array}{l}\text { Alternate definition of } \mathrm{F} \text { that does not reflect flow sup- } \\
\text { pression for Male and Fe }\end{array}$ & FDOT_A0A05 & 05376 & 4 & $\mathrm{~N}$ \\
\hline $\begin{array}{l}\text { Alternate definition of } \mathrm{F} \text { that does not reflect flow sup- } \\
\text { pression for Male and Fe }\end{array}$ & FDOT_A0A06 & 05388 & 4 & $\mathrm{~N}$ \\
\hline $\begin{array}{l}\text { Alternate definition of } \mathrm{F} \text { that does not reflect flow sup- } \\
\text { pression for Male and } \mathrm{Fe}\end{array}$ & FDOT_A0A07 & 05400 & 4 & $\mathrm{~N}$ \\
\hline $\begin{array}{l}\text { Alternate definition of } \mathrm{F} \text { that does not reflect flow sup- } \\
\text { pression for Male and Fe }\end{array}$ & FDOT_A0A08 & 05412 & 4 & $\mathrm{~N}$ \\
\hline $\begin{array}{l}\text { Alternate definition of } \mathrm{F} \text { that does not reflect flow sup- } \\
\text { pression for Male and ag }\end{array}$ & FDOT_A1A01 & 05332 & 4 & $\mathrm{~N}$ \\
\hline $\begin{array}{l}\text { Alternate definition of } \mathrm{F} \text { that does not reflect flow sup- } \\
\text { pression for Male and ag }\end{array}$ & FDOT_A1A00 & 05320 & 4 & $\mathrm{~N}$ \\
\hline $\begin{array}{l}\text { Alternate definition of } \mathrm{F} \text { that does not reflect flow sup- } \\
\text { pression for Male and ag }\end{array}$ & FDOT_A1A02 & 05344 & 4 & $\mathrm{~N}$ \\
\hline $\begin{array}{l}\text { Alternate definition of } \mathrm{F} \text { that does not reflect flow sup- } \\
\text { pression for Male and ag }\end{array}$ & FDOT_A1A03 & 05356 & 4 & $\mathrm{~N}$ \\
\hline $\begin{array}{l}\text { Alternate definition of } \mathrm{F} \text { that does not reflect flow sup- } \\
\text { pression for Male and ag }\end{array}$ & FDOT_A1A04 & 05368 & 4 & $\mathrm{~N}$ \\
\hline $\begin{array}{l}\text { Alternate definition of } \mathrm{F} \text { that does not reflect flow sup- } \\
\text { pression for Male and ag }\end{array}$ & FDOT_A1A05 & 05380 & 4 & $\mathrm{~N}$ \\
\hline $\begin{array}{l}\text { Alternate definition of } \mathrm{F} \text { that does not reflect flow sup- } \\
\text { pression for Male and ag }\end{array}$ & FDOT_A1A06 & 05392 & 4 & $\mathrm{~N}$ \\
\hline $\begin{array}{l}\text { Alternate definition of } \mathrm{F} \text { that does not reflect flow sup- } \\
\text { pression for Male and ag }\end{array}$ & FDOT_A1A07 & 05404 & 4 & $\mathrm{~N}$ \\
\hline $\begin{array}{l}\text { Alternate definition of } \mathrm{F} \text { that does not reflect flow sup- } \\
\text { pression for Male and ag }\end{array}$ & FDOT_A1A08 & 05416 & 4 & $\mathrm{~N}$ \\
\hline Average accession rate for Female and age 14-18 & $\mathrm{AR} \_\mathrm{A} 2 \mathrm{~A} 01$ & 01988 & 4 & $\mathrm{~N}$ \\
\hline Average accession rate for Female and age 14-99 & AR_A2A00 & 01976 & 4 & $\mathrm{~N}$ \\
\hline Average accession rate for Female and age 19-21 & $\mathrm{AR} \_\mathrm{A} 2 \mathrm{~A} 02$ & 02000 & 4 & $\mathrm{~N}$ \\
\hline Average accession rate for Female and age 22-24 & AR_A2A03 & 02012 & 4 & $\mathrm{~N}$ \\
\hline Average accession rate for Female and age 25-34 & $\mathrm{AR} \_\mathrm{A} 2 \mathrm{~A} 04$ & 02024 & 4 & $\mathrm{~N}$ \\
\hline Average accession rate for Female and age 35-44 & $\mathrm{AR} \_\mathrm{A} 2 \mathrm{~A} 05$ & 02036 & 4 & $\mathrm{~N}$ \\
\hline Average accession rate for Female and age 45-54 & AR_A2A06 & 02048 & 4 & $\mathrm{~N}$ \\
\hline Average accession rate for Female and age 55-64 & AR_A2A07 & 02060 & 4 & $\mathrm{~N}$ \\
\hline Average accession rate for Female and age 65-99 & AR_A2A08 & 02072 & 4 & $\mathrm{~N}$ \\
\hline
\end{tabular}




\begin{tabular}{|c|c|c|c|c|}
\hline Field name & $\begin{array}{l}\text { Data dictionary } \\
\text { reference name }\end{array}$ & $\begin{array}{l}\text { Starting } \\
\text { position }\end{array}$ & $\begin{array}{l}\text { Field } \\
\text { size }\end{array}$ & $\begin{array}{l}\text { Data } \\
\text { type }\end{array}$ \\
\hline $\begin{array}{l}\text { Average accession rate for Male and Female and age } \\
14-18\end{array}$ & AR_A0A01 & 01980 & 4 & $\mathrm{~N}$ \\
\hline $\begin{array}{l}\text { Average accession rate for Male and Female and age } \\
14-99\end{array}$ & AR_A0A00 & 01968 & 4 & $\mathrm{~N}$ \\
\hline $\begin{array}{l}\text { Average accession rate for Male and Female and age } \\
19-21\end{array}$ & AR_A0A02 & 01992 & 4 & $\mathrm{~N}$ \\
\hline $\begin{array}{l}\text { Average accession rate for Male and Female and age } \\
22-24\end{array}$ & AR_A0A03 & 02004 & 4 & $\mathrm{~N}$ \\
\hline $\begin{array}{l}\text { Average accession rate for Male and Female and age } \\
25-34\end{array}$ & AR_A0A04 & 02016 & 4 & $\mathrm{~N}$ \\
\hline $\begin{array}{l}\text { Average accession rate for Male and Female and age } \\
35-44\end{array}$ & AR_A0A05 & 02028 & 4 & $\mathrm{~N}$ \\
\hline $\begin{array}{l}\text { Average accession rate for Male and Female and age } \\
45-54\end{array}$ & AR_A0A06 & 02040 & 4 & $\mathrm{~N}$ \\
\hline $\begin{array}{l}\text { Average accession rate for Male and Female and age } \\
55-64\end{array}$ & AR_A0A07 & 02052 & 4 & $\mathrm{~N}$ \\
\hline $\begin{array}{l}\text { Average accession rate for Male and Female and age } \\
65-99\end{array}$ & AR_A0A08 & 02064 & 4 & $\mathrm{~N}$ \\
\hline Average accession rate for Male and age 14-18 & AR_A1A01 & 01984 & 4 & $\mathrm{~N}$ \\
\hline Average accession rate for Male and age 14-99 & AR_A1A00 & 01972 & 4 & $\mathrm{~N}$ \\
\hline Average accession rate for Male and age 19-21 & AR_A1A02 & 01996 & 4 & $\mathrm{~N}$ \\
\hline Average accession rate for Male and age $22-24$ & AR_A1A03 & 02008 & 4 & $\mathrm{~N}$ \\
\hline Average accession rate for Male and age 25-34 & AR_A1A04 & 02020 & 4 & $\mathrm{~N}$ \\
\hline Average accession rate for Male and age $35-44$ & AR_A1A05 & 02032 & 4 & $\mathrm{~N}$ \\
\hline Average accession rate for Male and age $45-54$ & AR_A1A06 & 02044 & 4 & $\mathrm{~N}$ \\
\hline Average accession rate for Male and age 55-64 & AR_A1A07 & 02056 & 4 & $\mathrm{~N}$ \\
\hline Average accession rate for Male and age 65-99 & AR_A1A08 & 02068 & 4 & $\mathrm{~N}$ \\
\hline Average employment for Female and age $14-18$ & EBAR_A2A01 & 00584 & 4 & $\mathrm{~N}$ \\
\hline Average employment for Female and age 14-99 & EBAR_A2A00 & 00572 & 4 & $\mathrm{~N}$ \\
\hline Average employment for Female and age 19-21 & EBAR_A2A02 & 00596 & 4 & $\mathrm{~N}$ \\
\hline Average employment for Female and age 22-24 & EBAR_A2A03 & 00608 & 4 & $\mathrm{~N}$ \\
\hline Average employment for Female and age 25-34 & EBAR_A2A04 & 00620 & 4 & $\mathrm{~N}$ \\
\hline Average employment for Female and age 35-44 & EBAR_A2A05 & 00632 & 4 & $\mathrm{~N}$ \\
\hline Average employment for Female and age $45-54$ & EBAR_A2A06 & 00644 & 4 & $\mathrm{~N}$ \\
\hline Average employment for Female and age 55-64 & EBAR_A2A07 & 00656 & 4 & $\mathrm{~N}$ \\
\hline Average employment for Female and age 65-99 & EBAR_A2A08 & 00668 & 4 & $\mathrm{~N}$ \\
\hline $\begin{array}{l}\text { Average employment for Male and Female and age 14- } \\
18\end{array}$ & EBAR_A0A01 & 00576 & 4 & $\mathrm{~N}$ \\
\hline $\begin{array}{l}\text { Average employment for Male and Female and age 14- } \\
99\end{array}$ & EBAR_A0A00 & 00564 & 4 & $\mathrm{~N}$ \\
\hline $\begin{array}{l}\text { Average employment for Male and Female and age 19- } \\
21\end{array}$ & EBAR_A0A02 & 00588 & 4 & $\mathrm{~N}$ \\
\hline $\begin{array}{l}\text { Average employment for Male and Female and age 22- } \\
24\end{array}$ & EBAR_A0A03 & 00600 & 4 & $\mathrm{~N}$ \\
\hline $\begin{array}{l}\text { Average employment for Male and Female and age 25- } \\
34\end{array}$ & EBAR_A0A04 & 00612 & 4 & $\mathrm{~N}$ \\
\hline $\begin{array}{l}\text { Average employment for Male and Female and age 35- } \\
44\end{array}$ & EBAR_A0A05 & 00624 & 4 & $\mathrm{~N}$ \\
\hline $\begin{array}{l}\text { Average employment for Male and Female and age 45- } \\
54\end{array}$ & EBAR_A0A06 & 00636 & 4 & $\mathrm{~N}$ \\
\hline
\end{tabular}


CHAPTER 7. QUARTERLY WORKFORCE INDICATORS - SEINUNIT FILE (QWI)

\begin{tabular}{|c|c|c|c|c|}
\hline Field name & $\begin{array}{l}\text { Data dictionary } \\
\text { reference name }\end{array}$ & $\begin{array}{l}\text { Starting } \\
\text { position }\end{array}$ & $\begin{array}{l}\text { Field } \\
\text { size }\end{array}$ & $\begin{array}{l}\text { Data } \\
\text { type }\end{array}$ \\
\hline $\begin{array}{l}\text { Average employment for Male and Female and age 55- } \\
64\end{array}$ & EBAR_A0A07 & 00648 & 4 & $\mathrm{~N}$ \\
\hline $\begin{array}{l}\text { Average employment for Male and Female and age 65- } \\
99\end{array}$ & EBAR_A0A08 & 00660 & 4 & $\mathrm{~N}$ \\
\hline Average employment for Male and age 14-18 & EBAR_A1A01 & 00580 & 4 & $\mathrm{~N}$ \\
\hline Average employment for Male and age 14-99 & EBAR_A1A00 & 00568 & 4 & $\mathrm{~N}$ \\
\hline Average employment for Male and age 19-21 & EBAR_A1A02 & 00592 & 4 & $\mathrm{~N}$ \\
\hline Average employment for Male and age $22-24$ & EBAR_A1A03 & 00604 & 4 & $\mathrm{~N}$ \\
\hline Average employment for Male and age 25-34 & EBAR_A1A04 & 00616 & 4 & $\mathrm{~N}$ \\
\hline Average employment for Male and age 35-44 & EBAR_A1A05 & 00628 & 4 & $\mathrm{~N}$ \\
\hline Average employment for Male and age $45-54$ & EBAR_A1A06 & 00640 & 4 & $\mathrm{~N}$ \\
\hline Average employment for Male and age 55-64 & EBAR_A1A07 & 00652 & 4 & $\mathrm{~N}$ \\
\hline Average employment for Male and age 65-99 & EBAR_A1A08 & 00664 & 4 & $\mathrm{~N}$ \\
\hline $\begin{array}{l}\text { Average full-quarter employment for Female and age } \\
14-18\end{array}$ & FBAR_A2A01 & 01232 & 4 & $\mathrm{~N}$ \\
\hline $\begin{array}{l}\text { Average full-quarter employment for Female and age } \\
\text { 14-99 }\end{array}$ & FBAR_A2A00 & 01220 & 4 & $\mathrm{~N}$ \\
\hline $\begin{array}{l}\text { Average full-quarter employment for Female and age } \\
19-21\end{array}$ & FBAR_A2A02 & 01244 & 4 & $\mathrm{~N}$ \\
\hline $\begin{array}{l}\text { Average full-quarter employment for Female and age } \\
22-24\end{array}$ & FBAR_A2A03 & 01256 & 4 & $\mathrm{~N}$ \\
\hline $\begin{array}{l}\text { Average full-quarter employment for Female and age } \\
25-34\end{array}$ & FBAR_A2A04 & 01268 & 4 & $\mathrm{~N}$ \\
\hline $\begin{array}{l}\text { Average full-quarter employment for Female and age } \\
35-44\end{array}$ & FBAR_A2A05 & 01280 & 4 & $\mathrm{~N}$ \\
\hline $\begin{array}{l}\text { Average full-quarter employment for Female and age } \\
45-54\end{array}$ & FBAR_A2A06 & 01292 & 4 & $\mathrm{~N}$ \\
\hline $\begin{array}{l}\text { Average full-quarter employment for Female and age } \\
55-64\end{array}$ & FBAR_A2A07 & 01304 & 4 & $\mathrm{~N}$ \\
\hline $\begin{array}{l}\text { Average full-quarter employment for Female and age } \\
65-99\end{array}$ & FBAR_A2A08 & 01316 & 4 & $\mathrm{~N}$ \\
\hline $\begin{array}{l}\text { Average full-quarter employment for Male and Female } \\
\text { and age 14-18 }\end{array}$ & FBAR_A0A01 & 01224 & 4 & $\mathrm{~N}$ \\
\hline $\begin{array}{l}\text { Average full-quarter employment for Male and Female } \\
\text { and age 14-99 }\end{array}$ & FBAR_A0A00 & 01212 & 4 & $\mathrm{~N}$ \\
\hline $\begin{array}{l}\text { Average full-quarter employment for Male and Female } \\
\text { and age 19-21 }\end{array}$ & FBAR_A0A02 & 01236 & 4 & $\mathrm{~N}$ \\
\hline $\begin{array}{l}\text { Average full-quarter employment for Male and Female } \\
\text { and age } 22-24\end{array}$ & FBAR_A0A03 & 01248 & 4 & $\mathrm{~N}$ \\
\hline $\begin{array}{l}\text { Average full-quarter employment for Male and Female } \\
\text { and age 25-34 }\end{array}$ & FBAR_A0A04 & 01260 & 4 & $\mathrm{~N}$ \\
\hline $\begin{array}{l}\text { Average full-quarter employment for Male and Female } \\
\text { and age } 35-44\end{array}$ & FBAR_A0A05 & 01272 & 4 & $\mathrm{~N}$ \\
\hline $\begin{array}{l}\text { Average full-quarter employment for Male and Female } \\
\text { and age } 45-54\end{array}$ & FBAR_A0A06 & 01284 & 4 & $\mathrm{~N}$ \\
\hline $\begin{array}{l}\text { Average full-quarter employment for Male and Female } \\
\text { and age } 55-64\end{array}$ & FBAR_A0A07 & 01296 & 4 & $\mathrm{~N}$ \\
\hline $\begin{array}{l}\text { Average full-quarter employment for Male and Female } \\
\text { and age } 65-99\end{array}$ & FBAR_A0A08 & 01308 & 4 & $\mathrm{~N}$ \\
\hline
\end{tabular}




\begin{tabular}{|c|c|c|c|c|}
\hline Field name & $\begin{array}{l}\text { Data dictionary } \\
\text { reference name }\end{array}$ & $\begin{array}{l}\text { Starting } \\
\text { position }\end{array}$ & $\begin{array}{l}\text { Field } \\
\text { size }\end{array}$ & $\begin{array}{l}\text { Data } \\
\text { type }\end{array}$ \\
\hline $\begin{array}{l}\text { Average full-quarter employment for Male and age 14- } \\
18\end{array}$ & FBAR_A1A01 & 01228 & 4 & $\mathrm{~N}$ \\
\hline $\begin{array}{l}\text { Average full-quarter employment for Male and age 14- } \\
99\end{array}$ & FBAR_A1A00 & 01216 & 4 & $\mathrm{~N}$ \\
\hline $\begin{array}{l}\text { Average full-quarter employment for Male and age 19- } \\
21\end{array}$ & FBAR_A1A02 & 01240 & 4 & $\mathrm{~N}$ \\
\hline $\begin{array}{l}\text { Average full-quarter employment for Male and age } 22 \text { - } \\
24\end{array}$ & FBAR_A1A03 & 01252 & 4 & $\mathrm{~N}$ \\
\hline $\begin{array}{l}\text { Average full-quarter employment for Male and age 25- } \\
34\end{array}$ & FBAR_A1A04 & 01264 & 4 & $\mathrm{~N}$ \\
\hline $\begin{array}{l}\text { Average full-quarter employment for Male and age } 35 \text { - } \\
44\end{array}$ & FBAR_A1A05 & 01276 & 4 & $\mathrm{~N}$ \\
\hline $\begin{array}{l}\text { Average full-quarter employment for Male and age 45- } \\
54\end{array}$ & FBAR_A1A06 & 01288 & 4 & $\mathrm{~N}$ \\
\hline $\begin{array}{l}\text { Average full-quarter employment for Male and age } 55 \text { - } \\
64\end{array}$ & FBAR_A1A07 & 01300 & 4 & $\mathrm{~N}$ \\
\hline $\begin{array}{l}\text { Average full-quarter employment for Male and age } 65 \text { - } \\
99\end{array}$ & FBAR_A1A08 & 01312 & 4 & $\mathrm{~N}$ \\
\hline $\begin{array}{l}\text { Average full-quarter employment growth rate for Fe- } \\
\text { male and age } 14-18\end{array}$ & FG_A2A01 & 01340 & 4 & $\mathrm{~N}$ \\
\hline $\begin{array}{l}\text { Average full-quarter employment growth rate for Fe- } \\
\text { male and age 14-99 }\end{array}$ & FG_A2A00 & 01328 & 4 & $\mathrm{~N}$ \\
\hline $\begin{array}{l}\text { Average full-quarter employment growth rate for Fe- } \\
\text { male and age } 19-21\end{array}$ & FG_A2A02 & 01352 & 4 & $\mathrm{~N}$ \\
\hline $\begin{array}{l}\text { Average full-quarter employment growth rate for Fe- } \\
\text { male and age } 22-24\end{array}$ & FG_A2A03 & 01364 & 4 & $\mathrm{~N}$ \\
\hline $\begin{array}{l}\text { Average full-quarter employment growth rate for Fe- } \\
\text { male and age } 25-34\end{array}$ & FG_A2A04 & 01376 & 4 & $\mathrm{~N}$ \\
\hline $\begin{array}{l}\text { Average full-quarter employment growth rate for Fe- } \\
\text { male and age } 35-44\end{array}$ & FG_A2A05 & 01388 & 4 & $\mathrm{~N}$ \\
\hline $\begin{array}{l}\text { Average full-quarter employment growth rate for Fe- } \\
\text { male and age } 45-54\end{array}$ & FG_A2A06 & 01400 & 4 & $\mathrm{~N}$ \\
\hline $\begin{array}{l}\text { Average full-quarter employment growth rate for Fe- } \\
\text { male and age } 55-64\end{array}$ & FG_A2A07 & 01412 & 4 & $\mathrm{~N}$ \\
\hline $\begin{array}{l}\text { Average full-quarter employment growth rate for Fe- } \\
\text { male and age } 65-99\end{array}$ & FG_A2A08 & 01424 & 4 & $\mathrm{~N}$ \\
\hline $\begin{array}{l}\text { Average full-quarter employment growth rate for Male } \\
\text { and Female and age 14-18 }\end{array}$ & FG_A0A01 & 01332 & 4 & $\mathrm{~N}$ \\
\hline $\begin{array}{l}\text { Average full-quarter employment growth rate for Male } \\
\text { and Female and age 14-99 }\end{array}$ & FG_A0A00 & 01320 & 4 & $\mathrm{~N}$ \\
\hline $\begin{array}{l}\text { Average full-quarter employment growth rate for Male } \\
\text { and Female and age 19-21 }\end{array}$ & FG_A0A02 & 01344 & 4 & $\mathrm{~N}$ \\
\hline $\begin{array}{l}\text { Average full-quarter employment growth rate for Male } \\
\text { and Female and age } 22-24\end{array}$ & FG_A0A03 & 01356 & 4 & $\mathrm{~N}$ \\
\hline $\begin{array}{l}\text { Average full-quarter employment growth rate for Male } \\
\text { and Female and age } 25-34\end{array}$ & FG_A0A04 & 01368 & 4 & $\mathrm{~N}$ \\
\hline $\begin{array}{l}\text { Average full-quarter employment growth rate for Male } \\
\text { and Female and age } 35-44\end{array}$ & FG_A0A05 & 01380 & 4 & $\mathrm{~N}$ \\
\hline $\begin{array}{l}\text { Average full-quarter employment growth rate for Male } \\
\text { and Female and age } 45-54\end{array}$ & FG_A0A06 & 01392 & 4 & $\mathrm{~N}$ \\
\hline
\end{tabular}




\begin{tabular}{|c|c|c|c|c|}
\hline Field name & $\begin{array}{l}\text { Data dictionary } \\
\text { reference name }\end{array}$ & $\begin{array}{l}\text { Starting } \\
\text { position }\end{array}$ & $\begin{array}{l}\text { Field } \\
\text { size }\end{array}$ & $\begin{array}{l}\text { Data } \\
\text { type }\end{array}$ \\
\hline $\begin{array}{l}\text { Average full-quarter employment growth rate for Male } \\
\text { and Female and age } 55-64\end{array}$ & FG_A0A07 & 01404 & 4 & $\mathrm{~N}$ \\
\hline $\begin{array}{l}\text { Average full-quarter employment growth rate for Male } \\
\text { and Female and age } 65-99\end{array}$ & FG_A0A08 & 01416 & 4 & $\mathrm{~N}$ \\
\hline $\begin{array}{l}\text { Average full-quarter employment growth rate for Male } \\
\text { and age 14-18 }\end{array}$ & FG_A1A01 & 01336 & 4 & $\mathrm{~N}$ \\
\hline $\begin{array}{l}\text { Average full-quarter employment growth rate for Male } \\
\text { and age 14-99 }\end{array}$ & FG_A1A00 & 01324 & 4 & $\mathrm{~N}$ \\
\hline $\begin{array}{l}\text { Average full-quarter employment growth rate for Male } \\
\text { and age 19-21 }\end{array}$ & FG_A1A02 & 01348 & 4 & $\mathrm{~N}$ \\
\hline $\begin{array}{l}\text { Average full-quarter employment growth rate for Male } \\
\text { and age } 22-24\end{array}$ & FG_A1A03 & 01360 & 4 & $\mathrm{~N}$ \\
\hline $\begin{array}{l}\text { Average full-quarter employment growth rate for Male } \\
\text { and age } 25-34\end{array}$ & FG_A1A04 & 01372 & 4 & $\mathrm{~N}$ \\
\hline $\begin{array}{l}\text { Average full-quarter employment growth rate for Male } \\
\text { and age } 35-44\end{array}$ & FG_A1A05 & 01384 & 4 & $\mathrm{~N}$ \\
\hline $\begin{array}{l}\text { Average full-quarter employment growth rate for Male } \\
\text { and age } 45-54\end{array}$ & FG_A1A06 & 01396 & 4 & $\mathrm{~N}$ \\
\hline $\begin{array}{l}\text { Average full-quarter employment growth rate for Male } \\
\text { and age } 55-64\end{array}$ & FG_A1A07 & 01408 & 4 & $\mathrm{~N}$ \\
\hline $\begin{array}{l}\text { Average full-quarter employment growth rate for Male } \\
\text { and age } 65-99\end{array}$ & FG_A1A08 & 01420 & 4 & $\mathrm{~N}$ \\
\hline $\begin{array}{l}\text { Average full-quarter job creation rate for Female and } \\
\text { age } 14-18\end{array}$ & FJCR_A2A01 & 01556 & 4 & $\mathrm{~N}$ \\
\hline $\begin{array}{l}\text { Average full-quarter job creation rate for Female and } \\
\text { age 14-99 }\end{array}$ & FJCR_A2A00 & 01544 & 4 & $\mathrm{~N}$ \\
\hline $\begin{array}{l}\text { Average full-quarter job creation rate for Female and } \\
\text { age } 19-21\end{array}$ & FJCR_A2A02 & 01568 & 4 & $\mathrm{~N}$ \\
\hline $\begin{array}{l}\text { Average full-quarter job creation rate for Female and } \\
\text { age } 22-24\end{array}$ & FJCR_A2A03 & 01580 & 4 & $\mathrm{~N}$ \\
\hline $\begin{array}{l}\text { Average full-quarter job creation rate for Female and } \\
\text { age } 25-34\end{array}$ & FJCR_A2A04 & 01592 & 4 & $\mathrm{~N}$ \\
\hline $\begin{array}{l}\text { Average full-quarter job creation rate for Female and } \\
\text { age } 35-44\end{array}$ & FJCR_A2A05 & 01604 & 4 & $\mathrm{~N}$ \\
\hline $\begin{array}{l}\text { Average full-quarter job creation rate for Female and } \\
\text { age } 45-54\end{array}$ & FJCR_A2A06 & 01616 & 4 & $\mathrm{~N}$ \\
\hline $\begin{array}{l}\text { Average full-quarter job creation rate for Female and } \\
\text { age } 55-64\end{array}$ & FJCR_A2A07 & 01628 & 4 & $\mathrm{~N}$ \\
\hline $\begin{array}{l}\text { Average full-quarter job creation rate for Female and } \\
\text { age } 65-99\end{array}$ & FJCR_A2A08 & 01640 & 4 & $\mathrm{~N}$ \\
\hline $\begin{array}{l}\text { Average full-quarter job creation rate for Male and } \\
\text { Female and age 14-18 }\end{array}$ & FJCR_A0A01 & 01548 & 4 & $\mathrm{~N}$ \\
\hline $\begin{array}{l}\text { Average full-quarter job creation rate for Male and } \\
\text { Female and age 14-99 }\end{array}$ & FJCR_A0A00 & 01536 & 4 & $\mathrm{~N}$ \\
\hline $\begin{array}{l}\text { Average full-quarter job creation rate for Male and } \\
\text { Female and age 19-21 }\end{array}$ & FJCR_A0A02 & 01560 & 4 & $\mathrm{~N}$ \\
\hline $\begin{array}{l}\text { Average full-quarter job creation rate for Male and } \\
\text { Female and age } 22-24\end{array}$ & FJCR_A0A03 & 01572 & 4 & $\mathrm{~N}$ \\
\hline $\begin{array}{l}\text { Average full-quarter job creation rate for Male and } \\
\text { Female and age } 25-34\end{array}$ & FJCR_A0A04 & 01584 & 4 & $\mathrm{~N}$ \\
\hline
\end{tabular}




\begin{tabular}{|c|c|c|c|c|}
\hline Field name & $\begin{array}{l}\text { Data dictionary } \\
\text { reference name }\end{array}$ & $\begin{array}{l}\text { Starting } \\
\text { position }\end{array}$ & $\begin{array}{l}\text { Field } \\
\text { size }\end{array}$ & $\begin{array}{l}\text { Data } \\
\text { type }\end{array}$ \\
\hline $\begin{array}{l}\text { Average full-quarter job creation rate for Male and } \\
\text { Female and age } 35-44\end{array}$ & FJCR_A0A05 & 01596 & 4 & $\mathrm{~N}$ \\
\hline $\begin{array}{l}\text { Average full-quarter job creation rate for Male and } \\
\text { Female and age } 45-54\end{array}$ & FJCR_A0A06 & 01608 & 4 & $\mathrm{~N}$ \\
\hline $\begin{array}{l}\text { Average full-quarter job creation rate for Male and } \\
\text { Female and age } 55-64\end{array}$ & FJCR_A0A07 & 01620 & 4 & $\mathrm{~N}$ \\
\hline $\begin{array}{l}\text { Average full-quarter job creation rate for Male and } \\
\text { Female and age } 65-99\end{array}$ & FJCR_A0A08 & 01632 & 4 & $\mathrm{~N}$ \\
\hline $\begin{array}{l}\text { Average full-quarter job creation rate for Male and age } \\
14-18\end{array}$ & FJCR_A1A01 & 01552 & 4 & $\mathrm{~N}$ \\
\hline $\begin{array}{l}\text { Average full-quarter job creation rate for Male and age } \\
14-99\end{array}$ & FJCR_A1A00 & 01540 & 4 & $\mathrm{~N}$ \\
\hline $\begin{array}{l}\text { Average full-quarter job creation rate for Male and age } \\
19-21\end{array}$ & FJCR_A1A02 & 01564 & 4 & $\mathrm{~N}$ \\
\hline $\begin{array}{l}\text { Average full-quarter job creation rate for Male and age } \\
22-24\end{array}$ & FJCR_A1A03 & 01576 & 4 & $\mathrm{~N}$ \\
\hline $\begin{array}{l}\text { Average full-quarter job creation rate for Male and age } \\
25-34\end{array}$ & FJCR_A1A04 & 01588 & 4 & $\mathrm{~N}$ \\
\hline $\begin{array}{l}\text { Average full-quarter job creation rate for Male and age } \\
35-44\end{array}$ & FJCR_A1A05 & 01600 & 4 & $\mathrm{~N}$ \\
\hline $\begin{array}{l}\text { Average full-quarter job creation rate for Male and age } \\
45-54\end{array}$ & FJCR_A1A06 & 01612 & 4 & $\mathrm{~N}$ \\
\hline $\begin{array}{l}\text { Average full-quarter job creation rate for Male and age } \\
55-64\end{array}$ & FJCR_A1A07 & 01624 & 4 & $\mathrm{~N}$ \\
\hline $\begin{array}{l}\text { Average full-quarter job creation rate for Male and age } \\
65-99\end{array}$ & FJCR_A1A08 & 01636 & 4 & $\mathrm{~N}$ \\
\hline $\begin{array}{l}\text { Average full-quarter job destruction rate for Female } \\
\text { and age 14-18 }\end{array}$ & FJDR_A2A01 & 01772 & 4 & $\mathrm{~N}$ \\
\hline $\begin{array}{l}\text { Average full-quarter job destruction rate for Female } \\
\text { and age 14-99 }\end{array}$ & FJDR_A2A00 & 01760 & 4 & $\mathrm{~N}$ \\
\hline $\begin{array}{l}\text { Average full-quarter job destruction rate for Female } \\
\text { and age } 19-21\end{array}$ & FJDR_A2A02 & 01784 & 4 & $\mathrm{~N}$ \\
\hline $\begin{array}{l}\text { Average full-quarter job destruction rate for Female } \\
\text { and age } 22-24\end{array}$ & FJDR_A2A03 & 01796 & 4 & $\mathrm{~N}$ \\
\hline $\begin{array}{l}\text { Average full-quarter job destruction rate for Female } \\
\text { and age } 25-34\end{array}$ & FJDR_A2A04 & 01808 & 4 & $\mathrm{~N}$ \\
\hline $\begin{array}{l}\text { Average full-quarter job destruction rate for Female } \\
\text { and age } 35-44\end{array}$ & FJDR_A2A05 & 01820 & 4 & $\mathrm{~N}$ \\
\hline $\begin{array}{l}\text { Average full-quarter job destruction rate for Female } \\
\text { and age } 45-54\end{array}$ & FJDR_A2A06 & 01832 & 4 & $\mathrm{~N}$ \\
\hline $\begin{array}{l}\text { Average full-quarter job destruction rate for Female } \\
\text { and age } 55-64\end{array}$ & FJDR_A2A07 & 01844 & 4 & $\mathrm{~N}$ \\
\hline $\begin{array}{l}\text { Average full-quarter job destruction rate for Female } \\
\text { and age } 65-99\end{array}$ & FJDR_A2A08 & 01856 & 4 & $\mathrm{~N}$ \\
\hline $\begin{array}{l}\text { Average full-quarter job destruction rate for Male and } \\
\text { Female and age 14-18 }\end{array}$ & FJDR_A0A01 & 01764 & 4 & $\mathrm{~N}$ \\
\hline $\begin{array}{l}\text { Average full-quarter job destruction rate for Male and } \\
\text { Female and age 14-99 }\end{array}$ & FJDR_A0A00 & 01752 & 4 & $\mathrm{~N}$ \\
\hline Average full-quarter job destruction rate for Male and & FJDR_A0A02 & 01776 & 4 & $\mathrm{~N}$ \\
\hline
\end{tabular}


CHAPTER 7. QUARTERLY WORKFORCE INDICATORS - SEINUNIT FILE (QWI)

\begin{tabular}{|c|c|c|c|c|}
\hline Field name & $\begin{array}{l}\text { Data dictionary } \\
\text { reference name }\end{array}$ & $\begin{array}{l}\text { Starting } \\
\text { position }\end{array}$ & $\begin{array}{l}\text { Field } \\
\text { size }\end{array}$ & $\begin{array}{l}\text { Data } \\
\text { type }\end{array}$ \\
\hline $\begin{array}{l}\text { Average full-quarter job destruction rate for Male and } \\
\text { Female and age } 22-24\end{array}$ & FJDR_A0A03 & 01788 & 4 & $\mathrm{~N}$ \\
\hline $\begin{array}{l}\text { Average full-quarter job destruction rate for Male and } \\
\text { Female and age } 25-34\end{array}$ & FJDR_A0A04 & 01800 & 4 & $\mathrm{~N}$ \\
\hline $\begin{array}{l}\text { Average full-quarter job destruction rate for Male and } \\
\text { Female and age } 35-44\end{array}$ & FJDR_A0A05 & 01812 & 4 & $\mathrm{~N}$ \\
\hline $\begin{array}{l}\text { Average full-quarter job destruction rate for Male and } \\
\text { Female and age } 45-54\end{array}$ & F.JDR_A0A06 & 01824 & 4 & $\mathrm{~N}$ \\
\hline $\begin{array}{l}\text { Average full-quarter job destruction rate for Male and } \\
\text { Female and age } 55-64\end{array}$ & FJDR_A0A07 & 01836 & 4 & $\mathrm{~N}$ \\
\hline $\begin{array}{l}\text { Average full-quarter job destruction rate for Male and } \\
\text { Female and age } 65-99\end{array}$ & FJDR_A0A08 & 01848 & 4 & $\mathrm{~N}$ \\
\hline $\begin{array}{l}\text { Average full-quarter job destruction rate for Male and } \\
\text { age 14-18 }\end{array}$ & FJDR_A1A01 & 01768 & 4 & $\mathrm{~N}$ \\
\hline $\begin{array}{l}\text { Average full-quarter job destruction rate for Male and } \\
\text { age 14-99 }\end{array}$ & FJDR_A1A00 & 01756 & 4 & $\mathrm{~N}$ \\
\hline $\begin{array}{l}\text { Average full-quarter job destruction rate for Male and } \\
\text { age 19-21 }\end{array}$ & FJDR_A1A02 & 01780 & 4 & $\mathrm{~N}$ \\
\hline $\begin{array}{l}\text { Average full-quarter job destruction rate for Male and } \\
\text { age } 22-24\end{array}$ & FJDR_A1A03 & 01792 & 4 & $\mathrm{~N}$ \\
\hline $\begin{array}{l}\text { Average full-quarter job destruction rate for Male and } \\
\text { age } 25-34\end{array}$ & FJDR_A1A04 & 01804 & 4 & $\mathrm{~N}$ \\
\hline $\begin{array}{l}\text { Average full-quarter job destruction rate for Male and } \\
\text { age } 35-44\end{array}$ & FJDR_A1A05 & 01816 & 4 & $\mathrm{~N}$ \\
\hline $\begin{array}{l}\text { Average full-quarter job destruction rate for Male and } \\
\text { age } 45-54\end{array}$ & FJDR_A1A06 & 01828 & 4 & $\mathrm{~N}$ \\
\hline $\begin{array}{l}\text { Average full-quarter job destruction rate for Male and } \\
\text { age } 55-64\end{array}$ & FJDR_A1A07 & 01840 & 4 & $\mathrm{~N}$ \\
\hline $\begin{array}{l}\text { Average full-quarter job destruction rate for Male and } \\
\text { age } 65-99\end{array}$ & FJDR_A1A08 & 01852 & 4 & $\mathrm{~N}$ \\
\hline Average job creation rate for Female and age 14-18 & JCR_A2A01 & 00800 & 4 & $\mathrm{~N}$ \\
\hline Average job creation rate for Female and age 14-99 & JCR_A2A00 & 00788 & 4 & $\mathrm{~N}$ \\
\hline Average job creation rate for Female and age 19-21 & JCR_A2A02 & 00812 & 4 & $\mathrm{~N}$ \\
\hline Average job creation rate for Female and age $22-24$ & JCR_A2A03 & 00824 & 4 & $\mathrm{~N}$ \\
\hline Average job creation rate for Female and age $25-34$ & JCR_A2A04 & 00836 & 4 & $\mathrm{~N}$ \\
\hline Average job creation rate for Female and age $35-44$ & JCR_A2A05 & 00848 & 4 & $\mathrm{~N}$ \\
\hline Average job creation rate for Female and age $45-54$ & JCR_A2A06 & 00860 & 4 & $\mathrm{~N}$ \\
\hline Average job creation rate for Female and age 55-64 & JCR_A2A07 & 00872 & 4 & $\mathrm{~N}$ \\
\hline Average job creation rate for Female and age 65-99 & JCR_A2A08 & 00884 & 4 & $\mathrm{~N}$ \\
\hline $\begin{array}{l}\text { Average job creation rate for Male and Female and age } \\
14-18\end{array}$ & JCR_A0A01 & 00792 & 4 & $\mathrm{~N}$ \\
\hline $\begin{array}{l}\text { Average job creation rate for Male and Female and age } \\
\text { 14-99 }\end{array}$ & JCR_A0A00 & 00780 & 4 & $\mathrm{~N}$ \\
\hline $\begin{array}{l}\text { Average job creation rate for Male and Female and age } \\
19-21\end{array}$ & JCR_A0A02 & 00804 & 4 & $\mathrm{~N}$ \\
\hline $\begin{array}{l}\text { Average job creation rate for Male and Female and age } \\
22-24\end{array}$ & JCR_A0A03 & 00816 & 4 & $\mathrm{~N}$ \\
\hline Average job creation rate for Male and Female and age & JCR_A0A04 & 00828 & 4 & $\mathrm{~N}$ \\
\hline
\end{tabular}




\begin{tabular}{|c|c|c|c|c|}
\hline Field name & $\begin{array}{l}\text { Data dictionary } \\
\text { reference name }\end{array}$ & $\begin{array}{l}\text { Starting } \\
\text { position }\end{array}$ & $\begin{array}{l}\text { Field } \\
\text { size }\end{array}$ & $\begin{array}{l}\text { Data } \\
\text { type }\end{array}$ \\
\hline $\begin{array}{l}\text { Average job creation rate for Male and Female and age } \\
35-44\end{array}$ & JCR_A0A05 & 00840 & 4 & $\mathrm{~N}$ \\
\hline $\begin{array}{l}\text { Average job creation rate for Male and Female and age } \\
45-54\end{array}$ & JCR_A0A06 & 00852 & 4 & $\mathrm{~N}$ \\
\hline $\begin{array}{l}\text { Average job creation rate for Male and Female and age } \\
55-64\end{array}$ & JCR_A0A07 & 00864 & 4 & $\mathrm{~N}$ \\
\hline $\begin{array}{l}\text { Average job creation rate for Male and Female and age } \\
65-99\end{array}$ & JCR_A0A08 & 00876 & 4 & $\mathrm{~N}$ \\
\hline Average job creation rate for Male and age $14-18$ & JCR_A1A01 & 00796 & 4 & $\mathrm{~N}$ \\
\hline Average job creation rate for Male and age 14-99 & JCR_A1A00 & 00784 & 4 & $\mathrm{~N}$ \\
\hline Average job creation rate for Male and age 19-21 & JCR_A1A02 & 00808 & 4 & $\mathrm{~N}$ \\
\hline Average job creation rate for Male and age 22-24 & JCR_A1A03 & 00820 & 4 & $\mathrm{~N}$ \\
\hline Average job creation rate for Male and age 25-34 & JCR_A1A04 & 00832 & 4 & $\mathrm{~N}$ \\
\hline Average job creation rate for Male and age 35-44 & JCR_A1A05 & 00844 & 4 & $\mathrm{~N}$ \\
\hline Average job creation rate for Male and age $45-54$ & JCR_A1A06 & 00856 & 4 & $\mathrm{~N}$ \\
\hline Average job creation rate for Male and age 55-64 & JCR_A1A07 & 00868 & 4 & $\mathrm{~N}$ \\
\hline Average job creation rate for Male and age 65-99 & JCR_A1A08 & 00880 & 4 & $\mathrm{~N}$ \\
\hline Average job destruction rate for Female and age 14-18 & JDR_A2A01 & 01016 & 4 & $\mathrm{~N}$ \\
\hline Average job destruction rate for Female and age 14-99 & JDR_A2A00 & 01004 & 4 & $\mathrm{~N}$ \\
\hline Average job destruction rate for Female and age 19-21 & JDR_A2A02 & 01028 & 4 & $\mathrm{~N}$ \\
\hline Average job destruction rate for Female and age 22-24 & JDR_A2A03 & 01040 & 4 & $\mathrm{~N}$ \\
\hline Average job destruction rate for Female and age $25-34$ & JDR_A2A04 & 01052 & 4 & $\mathrm{~N}$ \\
\hline Average job destruction rate for Female and age $35-44$ & JDR_A2A05 & 01064 & 4 & $\mathrm{~N}$ \\
\hline Average job destruction rate for Female and age $45-54$ & JDR_A2A06 & 01076 & 4 & $\mathrm{~N}$ \\
\hline Average job destruction rate for Female and age 55-64 & JDR_A2A07 & 01088 & 4 & $\mathrm{~N}$ \\
\hline Average job destruction rate for Female and age 65-99 & JDR_A2A08 & 01100 & 4 & $\mathrm{~N}$ \\
\hline $\begin{array}{l}\text { Average job destruction rate for Male and Female and } \\
\text { age } 14-18\end{array}$ & JDR_A0A01 & 01008 & 4 & $\mathrm{~N}$ \\
\hline $\begin{array}{l}\text { Average job destruction rate for Male and Female and } \\
\text { age 14-99 }\end{array}$ & JDR_A0A00 & 00996 & 4 & $\mathrm{~N}$ \\
\hline $\begin{array}{l}\text { Average job destruction rate for Male and Female and } \\
\text { age } 19-21\end{array}$ & JDR_A0A02 & 01020 & 4 & $\mathrm{~N}$ \\
\hline $\begin{array}{l}\text { Average job destruction rate for Male and Female and } \\
\text { age } 22-24\end{array}$ & JDR_A0A03 & 01032 & 4 & $\mathrm{~N}$ \\
\hline $\begin{array}{l}\text { Average job destruction rate for Male and Female and } \\
\text { age } 25-34\end{array}$ & JDR_A0A04 & 01044 & 4 & $\mathrm{~N}$ \\
\hline $\begin{array}{l}\text { Average job destruction rate for Male and Female and } \\
\text { age } 35-44\end{array}$ & JDR_A0A05 & 01056 & 4 & $\mathrm{~N}$ \\
\hline $\begin{array}{l}\text { Average job destruction rate for Male and Female and } \\
\text { age } 45-54\end{array}$ & JDR_A0A06 & 01068 & 4 & $\mathrm{~N}$ \\
\hline
\end{tabular}




\begin{tabular}{|c|c|c|c|c|}
\hline Field name & $\begin{array}{l}\text { Data dictionary } \\
\text { reference name }\end{array}$ & $\begin{array}{l}\text { Starting } \\
\text { position }\end{array}$ & $\begin{array}{l}\text { Field } \\
\text { size }\end{array}$ & $\begin{array}{l}\text { Data } \\
\text { type }\end{array}$ \\
\hline $\begin{array}{l}\text { Average job destruction rate for Male and Female and } \\
\text { age } 55-64\end{array}$ & JDR_A0A07 & 01080 & 4 & $\mathrm{~N}$ \\
\hline $\begin{array}{l}\text { Average job destruction rate for Male and Female and } \\
\text { age } 65-99\end{array}$ & JDR_A0A08 & 01092 & 4 & $\mathrm{~N}$ \\
\hline Average job destruction rate for Male and age $14-18$ & JDR_A1A01 & 01012 & 4 & $\mathrm{~N}$ \\
\hline Average job destruction rate for Male and age 14-99 & JDR_A1A00 & 01000 & 4 & $\mathrm{~N}$ \\
\hline Average job destruction rate for Male and age 19-21 & JDR_A1A02 & 01024 & 4 & $\mathrm{~N}$ \\
\hline Average job destruction rate for Male and age 22-24 & JDR_A1A03 & 01036 & 4 & $\mathrm{~N}$ \\
\hline Average job destruction rate for Male and age 25 - 34 & JDR_A1A04 & 01048 & 4 & $\mathrm{~N}$ \\
\hline Average job destruction rate for Male and age $35-44$ & JDR_A 1 A05 & 01060 & 4 & $\mathrm{~N}$ \\
\hline Average job destruction rate for Male and age $45-54$ & JDR_A1A06 & 01072 & 4 & $\mathrm{~N}$ \\
\hline Average job destruction rate for Male and age $55-64$ & JDR_A1A07 & 01084 & 4 & $\mathrm{~N}$ \\
\hline Average job destruction rate for Male and age 65-99 & JDR_A1A08 & 01096 & 4 & $\mathrm{~N}$ \\
\hline $\begin{array}{l}\text { Average rate of flow into full-quarter employment for } \\
\text { Female and age 14-18 }\end{array}$ & FAR_A2A01 & 02744 & 4 & $\mathrm{~N}$ \\
\hline $\begin{array}{l}\text { Average rate of flow into full-quarter employment for } \\
\text { Female and age 14-99 }\end{array}$ & FAR_A2A00 & 02732 & 4 & $\mathrm{~N}$ \\
\hline $\begin{array}{l}\text { Average rate of flow into full-quarter employment for } \\
\text { Female and age 19-21 }\end{array}$ & FAR_A2A02 & 02756 & 4 & $\mathrm{~N}$ \\
\hline $\begin{array}{l}\text { Average rate of flow into full-quarter employment for } \\
\text { Female and age } 22-24\end{array}$ & FAR_A2A03 & 02768 & 4 & $\mathrm{~N}$ \\
\hline $\begin{array}{l}\text { Average rate of flow into full-quarter employment for } \\
\text { Female and age } 25-34\end{array}$ & FAR_A2A04 & 02780 & 4 & $\mathrm{~N}$ \\
\hline $\begin{array}{l}\text { Average rate of flow into full-quarter employment for } \\
\text { Female and age } 35-44\end{array}$ & FAR_A2A05 & 02792 & 4 & $\mathrm{~N}$ \\
\hline $\begin{array}{l}\text { Average rate of flow into full-quarter employment for } \\
\text { Female and age } 45-54\end{array}$ & FAR_A2A06 & 02804 & 4 & $\mathrm{~N}$ \\
\hline $\begin{array}{l}\text { Average rate of flow into full-quarter employment for } \\
\text { Female and age } 55-64\end{array}$ & FAR_A2A07 & 02816 & 4 & $\mathrm{~N}$ \\
\hline $\begin{array}{l}\text { Average rate of flow into full-quarter employment for } \\
\text { Female and age } 65-99\end{array}$ & FAR_A2A08 & 02828 & 4 & $\mathrm{~N}$ \\
\hline $\begin{array}{l}\text { Average rate of flow into full-quarter employment for } \\
\text { Male and Female and age } 14\end{array}$ & FAR_A0A01 & 02736 & 4 & $\mathrm{~N}$ \\
\hline $\begin{array}{l}\text { Average rate of flow into full-quarter employment for } \\
\text { Male and Female and age } 14\end{array}$ & FAR_A0A00 & 02724 & 4 & $\mathrm{~N}$ \\
\hline $\begin{array}{l}\text { Average rate of flow into full-quarter employment for } \\
\text { Male and Female and age } 19\end{array}$ & FAR_A0A02 & 02748 & 4 & $\mathrm{~N}$ \\
\hline $\begin{array}{l}\text { Average rate of flow into full-quarter employment for } \\
\text { Male and Female and age } 22\end{array}$ & FAR_A0A03 & 02760 & 4 & $\mathrm{~N}$ \\
\hline $\begin{array}{l}\text { Average rate of flow into full-quarter employment for } \\
\text { Male and Female and age } 25\end{array}$ & FAR_A0A04 & 02772 & 4 & $\mathrm{~N}$ \\
\hline $\begin{array}{l}\text { Average rate of flow into full-quarter employment for } \\
\text { Male and Female and age } 35\end{array}$ & FAR_A0A05 & 02784 & 4 & $\mathrm{~N}$ \\
\hline $\begin{array}{l}\text { Average rate of flow into full-quarter employment for } \\
\text { Male and Female and age } 45\end{array}$ & FAR_A0A06 & 02796 & 4 & $\mathrm{~N}$ \\
\hline $\begin{array}{l}\text { Average rate of flow into full-quarter employment for } \\
\text { Male and Female and age } 55\end{array}$ & FAR_A0A07 & 02808 & 4 & $\mathrm{~N}$ \\
\hline Average rate of flow into full-quarter employment for & FAR_A0A08 & 02820 & 4 & $\mathrm{~N}$ \\
\hline
\end{tabular}




\begin{tabular}{|c|c|c|c|c|}
\hline Field name & $\begin{array}{l}\text { Data dictionary } \\
\text { reference name }\end{array}$ & $\begin{array}{l}\text { Starting } \\
\text { position }\end{array}$ & $\begin{array}{l}\text { Field } \\
\text { size }\end{array}$ & $\begin{array}{l}\text { Data } \\
\text { type }\end{array}$ \\
\hline $\begin{array}{l}\text { Average rate of flow into full-quarter employment for } \\
\text { Male and age } 14-18\end{array}$ & FAR_A1A01 & 02740 & 4 & $\mathrm{~N}$ \\
\hline $\begin{array}{l}\text { Average rate of flow into full-quarter employment for } \\
\text { Male and age 14-99 }\end{array}$ & FAR_A1A00 & 02728 & 4 & $\mathrm{~N}$ \\
\hline $\begin{array}{l}\text { Average rate of flow into full-quarter employment for } \\
\text { Male and age 19-21 }\end{array}$ & FAR_A1A02 & 02752 & 4 & $\mathrm{~N}$ \\
\hline $\begin{array}{l}\text { Average rate of flow into full-quarter employment for } \\
\text { Male and age } 22-24\end{array}$ & FAR_A1A03 & 02764 & 4 & $\mathrm{~N}$ \\
\hline $\begin{array}{l}\text { Average rate of flow into full-quarter employment for } \\
\text { Male and age } 25-34\end{array}$ & FAR_A1A04 & 02776 & 4 & $\mathrm{~N}$ \\
\hline $\begin{array}{l}\text { Average rate of flow into full-quarter employment for } \\
\text { Male and age } 35-44\end{array}$ & FAR_A1A05 & 02788 & 4 & $\mathrm{~N}$ \\
\hline $\begin{array}{l}\text { Average rate of flow into full-quarter employment for } \\
\text { Male and age } 45-54\end{array}$ & FAR_A1A06 & 02800 & 4 & $\mathrm{~N}$ \\
\hline $\begin{array}{l}\text { Average rate of flow into full-quarter employment for } \\
\text { Male and age } 55-64\end{array}$ & FAR_A1A07 & 02812 & 4 & $\mathrm{~N}$ \\
\hline $\begin{array}{l}\text { Average rate of flow into full-quarter employment for } \\
\text { Male and age } 65-99\end{array}$ & FAR_A1A08 & 02824 & 4 & $\mathrm{~N}$ \\
\hline $\begin{array}{l}\text { Average rate of flow out of full-quarter employment } \\
\text { for Female and age 14-18 }\end{array}$ & FSR_A2A01 & 02960 & 4 & $\mathrm{~N}$ \\
\hline $\begin{array}{l}\text { Average rate of flow out of full-quarter employment } \\
\text { for Female and age 14-99 }\end{array}$ & FSR_A2A00 & 02948 & 4 & $\mathrm{~N}$ \\
\hline $\begin{array}{l}\text { Average rate of flow out of full-quarter employment } \\
\text { for Female and age 19-21 }\end{array}$ & FSR_A2A02 & 02972 & 4 & $\mathrm{~N}$ \\
\hline $\begin{array}{l}\text { Average rate of flow out of full-quarter employment } \\
\text { for Female and age } 22-24\end{array}$ & FSR_A2A03 & 02984 & 4 & $\mathrm{~N}$ \\
\hline $\begin{array}{l}\text { Average rate of flow out of full-quarter employment } \\
\text { for Female and age } 25-34\end{array}$ & FSR_A2A04 & 02996 & 4 & $\mathrm{~N}$ \\
\hline $\begin{array}{l}\text { Average rate of flow out of full-quarter employment } \\
\text { for Female and age } 35-44\end{array}$ & FSR_A $2 \mathrm{~A} 05$ & 03008 & 4 & $\mathrm{~N}$ \\
\hline $\begin{array}{l}\text { Average rate of flow out of full-quarter employment } \\
\text { for Female and age } 45-54\end{array}$ & FSR_A2A06 & 03020 & 4 & $\mathrm{~N}$ \\
\hline $\begin{array}{l}\text { Average rate of flow out of full-quarter employment } \\
\text { for Female and age } 55-64\end{array}$ & FSR_A2A07 & 03032 & 4 & $\mathrm{~N}$ \\
\hline $\begin{array}{l}\text { Average rate of flow out of full-quarter employment } \\
\text { for Female and age } 65-99\end{array}$ & FSR_A2A08 & 03044 & 4 & $\mathrm{~N}$ \\
\hline $\begin{array}{l}\text { Average rate of flow out of full-quarter employment } \\
\text { for Male and Female and age }\end{array}$ & FSR_A0A01 & 02952 & 4 & $\mathrm{~N}$ \\
\hline $\begin{array}{l}\text { Average rate of flow out of full-quarter employment } \\
\text { for Male and Female and age }\end{array}$ & FSR_A0A00 & 02940 & 4 & $\mathrm{~N}$ \\
\hline $\begin{array}{l}\text { Average rate of flow out of full-quarter employment } \\
\text { for Male and Female and age }\end{array}$ & FSR_A0A02 & 02964 & 4 & $\mathrm{~N}$ \\
\hline $\begin{array}{l}\text { Average rate of flow out of full-quarter employment } \\
\text { for Male and Female and age }\end{array}$ & FSR_A0A03 & 02976 & 4 & $\mathrm{~N}$ \\
\hline $\begin{array}{l}\text { Average rate of flow out of full-quarter employment } \\
\text { for Male and Female and age }\end{array}$ & FSR_A0A04 & 02988 & 4 & $\mathrm{~N}$ \\
\hline $\begin{array}{l}\text { Average rate of flow out of full-quarter employment } \\
\text { for Male and Female and age }\end{array}$ & FSR_A0A05 & 03000 & 4 & $\mathrm{~N}$ \\
\hline Average rate of flow out of full-quarter employment & FSR_A0A06 & 03012 & 4 & $\mathrm{~N}$ \\
\hline
\end{tabular}




\begin{tabular}{|c|c|c|c|c|}
\hline Field name & $\begin{array}{l}\text { Data dictionary } \\
\text { reference name }\end{array}$ & $\begin{array}{l}\text { Starting } \\
\text { position }\end{array}$ & $\begin{array}{l}\text { Field } \\
\text { size }\end{array}$ & $\begin{array}{l}\text { Data } \\
\text { type }\end{array}$ \\
\hline $\begin{array}{l}\text { Average rate of flow out of full-quarter employment } \\
\text { for Male and Female and age }\end{array}$ & FSR_A0A07 & 03024 & 4 & $\mathrm{~N}$ \\
\hline $\begin{array}{l}\text { Average rate of flow out of full-quarter employment } \\
\text { for Male and Female and age }\end{array}$ & FSR_A0A08 & 03036 & 4 & $\mathrm{~N}$ \\
\hline $\begin{array}{l}\text { Average rate of flow out of full-quarter employment } \\
\text { for Male and age 14-18 }\end{array}$ & FSR_A1A01 & 02956 & 4 & $\mathrm{~N}$ \\
\hline $\begin{array}{l}\text { Average rate of flow out of full-quarter employment } \\
\text { for Male and age 14-99 }\end{array}$ & FSR_A1A00 & 02944 & 4 & $\mathrm{~N}$ \\
\hline $\begin{array}{l}\text { Average rate of flow out of full-quarter employment } \\
\text { for Male and age 19-21 }\end{array}$ & FSR_A1A02 & 02968 & 4 & $\mathrm{~N}$ \\
\hline $\begin{array}{l}\text { Average rate of flow out of full-quarter employment } \\
\text { for Male and age } 22-24\end{array}$ & FSR_A1A03 & 02980 & 4 & $\mathrm{~N}$ \\
\hline $\begin{array}{l}\text { Average rate of flow out of full-quarter employment } \\
\text { for Male and age } 25-34\end{array}$ & FSR_A1A04 & 02992 & 4 & $\mathrm{~N}$ \\
\hline $\begin{array}{l}\text { Average rate of flow out of full-quarter employment } \\
\text { for Male and age } 35-44\end{array}$ & FSR_A $1 \mathrm{~A} 05$ & 03004 & 4 & $\mathrm{~N}$ \\
\hline $\begin{array}{l}\text { Average rate of flow out of full-quarter employment } \\
\text { for Male and age } 45-54\end{array}$ & FSR_A1A06 & 03016 & 4 & $\mathrm{~N}$ \\
\hline $\begin{array}{l}\text { Average rate of flow out of full-quarter employment } \\
\text { for Male and age } 55-64\end{array}$ & FSR_A1A07 & 03028 & 4 & $\mathrm{~N}$ \\
\hline $\begin{array}{l}\text { Average rate of flow out of full-quarter employment } \\
\text { for Male and age } 65-99\end{array}$ & FSR_A1A08 & 03040 & 4 & $\mathrm{~N}$ \\
\hline Average separation rate for Female and age 14-18 & SR_A2A01 & 02204 & 4 & $\mathrm{~N}$ \\
\hline Average separation rate for Female and age 14-99 & SR_A2A00 & 02192 & 4 & $\mathrm{~N}$ \\
\hline Average separation rate for Female and age 19-21 & SR_A2A02 & 02216 & 4 & $\mathrm{~N}$ \\
\hline Average separation rate for Female and age 22-24 & SR_A2A03 & 02228 & 4 & $\mathrm{~N}$ \\
\hline Average separation rate for Female and age 25-34 & SR_A2A04 & 02240 & 4 & $\mathrm{~N}$ \\
\hline Average separation rate for Female and age 35-44 & SR_A2A05 & 02252 & 4 & $\mathrm{~N}$ \\
\hline Average separation rate for Female and age $45-54$ & SR_A2A06 & 02264 & 4 & $\mathrm{~N}$ \\
\hline Average separation rate for Female and age 55-64 & SR_A2A07 & 02276 & 4 & $\mathrm{~N}$ \\
\hline Average separation rate for Female and age 65-99 & SR_A2A08 & 02288 & 4 & $\mathrm{~N}$ \\
\hline $\begin{array}{l}\text { Average separation rate for Male and Female and age } \\
14-18\end{array}$ & SR_A0A01 & 02196 & 4 & $\mathrm{~N}$ \\
\hline $\begin{array}{l}\text { Average separation rate for Male and Female and age } \\
\text { 14-99 }\end{array}$ & SR_A0A00 & 02184 & 4 & $\mathrm{~N}$ \\
\hline $\begin{array}{l}\text { Average separation rate for Male and Female and age } \\
19-21\end{array}$ & SR_A0A02 & 02208 & 4 & $\mathrm{~N}$ \\
\hline $\begin{array}{l}\text { Average separation rate for Male and Female and age } \\
22-24\end{array}$ & SR_A0A03 & 02220 & 4 & $\mathrm{~N}$ \\
\hline $\begin{array}{l}\text { Average separation rate for Male and Female and age } \\
25-34\end{array}$ & SR_A0A04 & 02232 & 4 & $\mathrm{~N}$ \\
\hline $\begin{array}{l}\text { Average separation rate for Male and Female and age } \\
35-44\end{array}$ & SR_A0A05 & 02244 & 4 & $\mathrm{~N}$ \\
\hline $\begin{array}{l}\text { Average separation rate for Male and Female and age } \\
45-54\end{array}$ & SR_A0A06 & 02256 & 4 & $\mathrm{~N}$ \\
\hline $\begin{array}{l}\text { Average separation rate for Male and Female and age } \\
55-64\end{array}$ & SR_A0A07 & 02268 & 4 & $\mathrm{~N}$ \\
\hline $\begin{array}{l}\text { Average separation rate for Male and Female and age } \\
65-99\end{array}$ & SR_A0A08 & 02280 & 4 & $\mathrm{~N}$ \\
\hline Average separation rate for Male and age 14-18 & SR_A1A01 & 02200 & 4 & $\mathrm{~N}$ \\
\hline
\end{tabular}




\begin{tabular}{|c|c|c|c|c|}
\hline Field name & $\begin{array}{l}\text { Data dictionary } \\
\text { reference name }\end{array}$ & $\begin{array}{l}\text { Starting } \\
\text { position }\end{array}$ & $\begin{array}{l}\text { Field } \\
\text { size }\end{array}$ & $\begin{array}{l}\text { Data } \\
\text { type }\end{array}$ \\
\hline Average separation rate for Male and age $14-99$ & SR_A1A00 & 02188 & 4 & $\mathrm{~N}$ \\
\hline Average separation rate for Male and age 19-21 & SR_A1A02 & 02212 & 4 & $\mathrm{~N}$ \\
\hline Average separation rate for Male and age $22-24$ & SR_A1A03 & 02224 & 4 & $\mathrm{~N}$ \\
\hline Average separation rate for Male and age $25-34$ & SR_A1A04 & 02236 & 4 & $\mathrm{~N}$ \\
\hline Average separation rate for Male and age $35-44$ & SR_A1A05 & 02248 & 4 & $\mathrm{~N}$ \\
\hline Average separation rate for Male and age $45-54$ & SR_A1A06 & 02260 & 4 & $\mathrm{~N}$ \\
\hline Average separation rate for Male and age $55-64$ & SR_A1A07 & 02272 & 4 & $\mathrm{~N}$ \\
\hline Average separation rate for Male and age 65-99 & SR_A1A08 & 02284 & 4 & $\mathrm{~N}$ \\
\hline $\begin{array}{l}\text { Beginning-of-period employment for Female and age } \\
14-18\end{array}$ & B_A2A01 & 00044 & 4 & $\mathrm{~N}$ \\
\hline $\begin{array}{l}\text { Beginning-of-period employment for Female and age } \\
\text { 14-99 }\end{array}$ & B_A2A00 & 00032 & 4 & $\mathrm{~N}$ \\
\hline $\begin{array}{l}\text { Beginning-of-period employment for Female and age } \\
19-21\end{array}$ & B_A2A02 & 00056 & 4 & $\mathrm{~N}$ \\
\hline $\begin{array}{l}\text { Beginning-of-period employment for Female and age } \\
22-24\end{array}$ & B_A2A03 & 00068 & 4 & $\mathrm{~N}$ \\
\hline $\begin{array}{l}\text { Beginning-of-period employment for Female and age } \\
25-34\end{array}$ & B_A2A04 & 00080 & 4 & $\mathrm{~N}$ \\
\hline $\begin{array}{l}\text { Beginning-of-period employment for Female and age } \\
35-44\end{array}$ & B_A2A05 & 00092 & 4 & $\mathrm{~N}$ \\
\hline $\begin{array}{l}\text { Beginning-of-period employment for Female and age } \\
45-54\end{array}$ & B_A2A06 & 00104 & 4 & $\mathrm{~N}$ \\
\hline $\begin{array}{l}\text { Beginning-of-period employment for Female and age } \\
55-64\end{array}$ & B_A2A07 & 00116 & 4 & $\mathrm{~N}$ \\
\hline $\begin{array}{l}\text { Beginning-of-period employment for Female and age } \\
65-99\end{array}$ & B_A2A08 & 00128 & 4 & $\mathrm{~N}$ \\
\hline $\begin{array}{l}\text { Beginning-of-period employment for Male and Female } \\
\text { and age 14-18 }\end{array}$ & B_A0A01 & 00036 & 4 & $\mathrm{~N}$ \\
\hline $\begin{array}{l}\text { Beginning-of-period employment for Male and Female } \\
\text { and age 14-99 }\end{array}$ & B_A0A00 & 00024 & 4 & $\mathrm{~N}$ \\
\hline $\begin{array}{l}\text { Beginning-of-period employment for Male and Female } \\
\text { and age 19-21 }\end{array}$ & B_A0A02 & 00048 & 4 & $\mathrm{~N}$ \\
\hline $\begin{array}{l}\text { Beginning-of-period employment for Male and Female } \\
\text { and age 22-24 }\end{array}$ & B_A0A03 & 00060 & 4 & $\mathrm{~N}$ \\
\hline $\begin{array}{l}\text { Beginning-of-period employment for Male and Female } \\
\text { and age 25-34 }\end{array}$ & B_A0A04 & 00072 & 4 & $\mathrm{~N}$ \\
\hline $\begin{array}{l}\text { Beginning-of-period employment for Male and Female } \\
\text { and age } 35-44\end{array}$ & B_A0A05 & 00084 & 4 & $\mathrm{~N}$ \\
\hline $\begin{array}{l}\text { Beginning-of-period employment for Male and Female } \\
\text { and age } 45-54\end{array}$ & B_A0A06 & 00096 & 4 & $\mathrm{~N}$ \\
\hline $\begin{array}{l}\text { Beginning-of-period employment for Male and Female } \\
\text { and age } 55-64\end{array}$ & B_A0A07 & 00108 & 4 & $\mathrm{~N}$ \\
\hline $\begin{array}{l}\text { Beginning-of-period employment for Male and Female } \\
\text { and age 65-99 }\end{array}$ & B_A0A08 & 00120 & 4 & $\mathrm{~N}$ \\
\hline $\begin{array}{l}\text { Beginning-of-period employment for Male and age 14- } \\
18\end{array}$ & B_A1A01 & 00040 & 4 & $\mathrm{~N}$ \\
\hline $\begin{array}{l}\text { Beginning-of-period employment for Male and age 14- } \\
99\end{array}$ & B_A $1 \mathrm{~A} 00$ & 00028 & 4 & $\mathrm{~N}$ \\
\hline Beginning-of-period employment for Male and age 19- & B_A $1 \mathrm{~A} 02$ & 00052 & 4 & $\mathrm{~N}$ \\
\hline
\end{tabular}




\begin{tabular}{|c|c|c|c|c|}
\hline Field name & $\begin{array}{l}\text { Data dictionary } \\
\text { reference name }\end{array}$ & $\begin{array}{l}\text { Starting } \\
\text { position }\end{array}$ & $\begin{array}{l}\text { Field } \\
\text { size }\end{array}$ & $\begin{array}{l}\text { Data } \\
\text { type }\end{array}$ \\
\hline $\begin{array}{l}\text { Beginning-of-period employment for Male and age 22- } \\
24\end{array}$ & B_A1A03 & 00064 & 4 & $\mathrm{~N}$ \\
\hline $\begin{array}{l}\text { Beginning-of-period employment for Male and age 25- } \\
34\end{array}$ & B_A1A04 & 00076 & 4 & $\mathrm{~N}$ \\
\hline $\begin{array}{l}\text { Beginning-of-period employment for Male and age 35- } \\
44\end{array}$ & B_A1A05 & 00088 & 4 & $\mathrm{~N}$ \\
\hline $\begin{array}{l}\text { Beginning-of-period employment for Male and age 45- } \\
54\end{array}$ & B_A1A06 & 00100 & 4 & $\mathrm{~N}$ \\
\hline $\begin{array}{l}\text { Beginning-of-period employment for Male and age 55- } \\
64\end{array}$ & B_A1A07 & 00112 & 4 & $\mathrm{~N}$ \\
\hline $\begin{array}{l}\text { Beginning-of-period employment for Male and age 65- } \\
99\end{array}$ & B_A1A08 & 00124 & 4 & $\mathrm{~N}$ \\
\hline $\begin{array}{l}\text { Change in total earnings for accessions for Female and } \\
\text { age 14-18 }\end{array}$ & DWA_A2A01 & 03824 & 4 & $\mathrm{~N}$ \\
\hline $\begin{array}{l}\text { Change in total earnings for accessions for Female and } \\
\text { age 14-99 }\end{array}$ & DWA_A2A00 & 03812 & 4 & $\mathrm{~N}$ \\
\hline $\begin{array}{l}\text { Change in total earnings for accessions for Female and } \\
\text { age 19-21 }\end{array}$ & DWA_A2A02 & 03836 & 4 & $\mathrm{~N}$ \\
\hline $\begin{array}{l}\text { Change in total earnings for accessions for Female and } \\
\text { age } 22-24\end{array}$ & DWA_A2A03 & 03848 & 4 & $\mathrm{~N}$ \\
\hline $\begin{array}{l}\text { Change in total earnings for accessions for Female and } \\
\text { age } 25-34\end{array}$ & DWA_A2A04 & 03860 & 4 & $\mathrm{~N}$ \\
\hline $\begin{array}{l}\text { Change in total earnings for accessions for Female and } \\
\text { age } 35-44\end{array}$ & DWA_A2A05 & 03872 & 4 & $\mathrm{~N}$ \\
\hline $\begin{array}{l}\text { Change in total earnings for accessions for Female and } \\
\text { age } 45-54\end{array}$ & DWA_A2A06 & 03884 & 4 & $\mathrm{~N}$ \\
\hline $\begin{array}{l}\text { Change in total earnings for accessions for Female and } \\
\text { age 55-64 }\end{array}$ & DWA_A2A07 & 03896 & 4 & $\mathrm{~N}$ \\
\hline $\begin{array}{l}\text { Change in total earnings for accessions for Female and } \\
\text { age } 65-99\end{array}$ & DWA_A2A08 & 03908 & 4 & $\mathrm{~N}$ \\
\hline $\begin{array}{l}\text { Change in total earnings for accessions for Male and } \\
\text { Female and age 14-18 }\end{array}$ & DWA_A0A01 & 03816 & 4 & $\mathrm{~N}$ \\
\hline $\begin{array}{l}\text { Change in total earnings for accessions for Male and } \\
\text { Female and age 14-99 }\end{array}$ & DWA_A0A00 & 03804 & 4 & $\mathrm{~N}$ \\
\hline $\begin{array}{l}\text { Change in total earnings for accessions for Male and } \\
\text { Female and age 19-21 }\end{array}$ & DWA_A0A02 & 03828 & 4 & $\mathrm{~N}$ \\
\hline $\begin{array}{l}\text { Change in total earnings for accessions for Male and } \\
\text { Female and age } 22-24\end{array}$ & DWA_A0A03 & 03840 & 4 & $\mathrm{~N}$ \\
\hline $\begin{array}{l}\text { Change in total earnings for accessions for Male and } \\
\text { Female and age } 25-34\end{array}$ & DWA_A0A04 & 03852 & 4 & $\mathrm{~N}$ \\
\hline $\begin{array}{l}\text { Change in total earnings for accessions for Male and } \\
\text { Female and age } 35-44\end{array}$ & DWA_A0A05 & 03864 & 4 & $\mathrm{~N}$ \\
\hline $\begin{array}{l}\text { Change in total earnings for accessions for Male and } \\
\text { Female and age } 45-54\end{array}$ & DWA_A0A06 & 03876 & 4 & $\mathrm{~N}$ \\
\hline $\begin{array}{l}\text { Change in total earnings for accessions for Male and } \\
\text { Female and age } 55-64\end{array}$ & DWA_A0A07 & 03888 & 4 & $\mathrm{~N}$ \\
\hline $\begin{array}{l}\text { Change in total earnings for accessions for Male and } \\
\text { Female and age } 65-99\end{array}$ & DWA_A0A08 & 03900 & 4 & $\mathrm{~N}$ \\
\hline $\begin{array}{l}\text { Change in total earnings for accessions for Male and } \\
\text { age } 14-18\end{array}$ & DWA_A1A01 & 03820 & 4 & $\mathrm{~N}$ \\
\hline
\end{tabular}




\begin{tabular}{|c|c|c|c|c|}
\hline Field name & $\begin{array}{l}\text { Data dictionary } \\
\text { reference name }\end{array}$ & $\begin{array}{l}\text { Starting } \\
\text { position }\end{array}$ & $\begin{array}{l}\text { Field } \\
\text { size }\end{array}$ & $\begin{array}{l}\text { Data } \\
\text { type }\end{array}$ \\
\hline $\begin{array}{l}\text { Change in total earnings for accessions for Male and } \\
\text { age 14-99 }\end{array}$ & DWA_A1A00 & 03808 & 4 & $\mathrm{~N}$ \\
\hline $\begin{array}{l}\text { Change in total earnings for accessions for Male and } \\
\text { age } 19-21\end{array}$ & DWA_A1A02 & 03832 & 4 & $\mathrm{~N}$ \\
\hline $\begin{array}{l}\text { Change in total earnings for accessions for Male and } \\
\text { age } 22-24\end{array}$ & DWA_A1A03 & 03844 & 4 & $\mathrm{~N}$ \\
\hline $\begin{array}{l}\text { Change in total earnings for accessions for Male and } \\
\text { age 25-34 }\end{array}$ & DWA_A1A04 & 03856 & 4 & $\mathrm{~N}$ \\
\hline $\begin{array}{l}\text { Change in total earnings for accessions for Male and } \\
\text { age } 35-44\end{array}$ & DWA_A1A05 & 03868 & 4 & $\mathrm{~N}$ \\
\hline $\begin{array}{l}\text { Change in total earnings for accessions for Male and } \\
\text { age } 45-54\end{array}$ & DWA_A1A06 & 03880 & 4 & $\mathrm{~N}$ \\
\hline $\begin{array}{l}\text { Change in total earnings for accessions for Male and } \\
\text { age 55-64 }\end{array}$ & DWA_A1A07 & 03892 & 4 & $\mathrm{~N}$ \\
\hline $\begin{array}{l}\text { Change in total earnings for accessions for Male and } \\
\text { age } 65-99\end{array}$ & DWA_A1A08 & 03904 & 4 & $\mathrm{~N}$ \\
\hline $\begin{array}{l}\text { Change in total earnings for full-quarter separations } \\
\text { for Female and age 14-18 }\end{array}$ & DWFS_A2A01 & 04904 & 4 & $\mathrm{~N}$ \\
\hline $\begin{array}{l}\text { Change in total earnings for full-quarter separations } \\
\text { for Female and age 14-99 }\end{array}$ & DWFS_A2A00 & 04892 & 4 & $\mathrm{~N}$ \\
\hline $\begin{array}{l}\text { Change in total earnings for full-quarter separations } \\
\text { for Female and age 19-21 }\end{array}$ & DWFS_A2A02 & 04916 & 4 & $\mathrm{~N}$ \\
\hline $\begin{array}{l}\text { Change in total earnings for full-quarter separations } \\
\text { for Female and age } 22-24\end{array}$ & DWFS_A2A03 & 04928 & 4 & $\mathrm{~N}$ \\
\hline $\begin{array}{l}\text { Change in total earnings for full-quarter separations } \\
\text { for Female and age } 25-34\end{array}$ & DWFS_A2A04 & 04940 & 4 & $\mathrm{~N}$ \\
\hline $\begin{array}{l}\text { Change in total earnings for full-quarter separations } \\
\text { for Female and age } 35-44\end{array}$ & DWFS_A2A05 & 04952 & 4 & $\mathrm{~N}$ \\
\hline $\begin{array}{l}\text { Change in total earnings for full-quarter separations } \\
\text { for Female and age } 45-54\end{array}$ & DWFS_A2A06 & 04964 & 4 & $\mathrm{~N}$ \\
\hline $\begin{array}{l}\text { Change in total earnings for full-quarter separations } \\
\text { for Female and age 55-64 }\end{array}$ & DWFS_A2A07 & 04976 & 4 & $\mathrm{~N}$ \\
\hline $\begin{array}{l}\text { Change in total earnings for full-quarter separations } \\
\text { for Female and age } 65-99\end{array}$ & DWFS_A2A08 & 04988 & 4 & $\mathrm{~N}$ \\
\hline $\begin{array}{l}\text { Change in total earnings for full-quarter separations } \\
\text { for Male and Female and ag }\end{array}$ & DWFS_A0A01 & 04896 & 4 & $\mathrm{~N}$ \\
\hline $\begin{array}{l}\text { Change in total earnings for full-quarter separations } \\
\text { for Male and Female and ag }\end{array}$ & DWFS_A0A00 & 04884 & 4 & $\mathrm{~N}$ \\
\hline $\begin{array}{l}\text { Change in total earnings for full-quarter separations } \\
\text { for Male and Female and ag }\end{array}$ & DWFS_A0A02 & 04908 & 4 & $\mathrm{~N}$ \\
\hline $\begin{array}{l}\text { Change in total earnings for full-quarter separations } \\
\text { for Male and Female and ag }\end{array}$ & DWFS_A0A03 & 04920 & 4 & $\mathrm{~N}$ \\
\hline $\begin{array}{l}\text { Change in total earnings for full-quarter separations } \\
\text { for Male and Female and ag }\end{array}$ & DWFS_A0A04 & 04932 & 4 & $\mathrm{~N}$ \\
\hline $\begin{array}{l}\text { Change in total earnings for full-quarter separations } \\
\text { for Male and Female and ag }\end{array}$ & DWFS_A0A05 & 04944 & 4 & $\mathrm{~N}$ \\
\hline $\begin{array}{l}\text { Change in total earnings for full-quarter separations } \\
\text { for Male and Female and ag }\end{array}$ & DWFS_A0A06 & 04956 & 4 & $\mathrm{~N}$ \\
\hline Change in total earnings for full-quarter separations & DWFS_A0A07 & 04968 & 4 & $\mathrm{~N}$ \\
\hline
\end{tabular}




\begin{tabular}{|c|c|c|c|c|}
\hline Field name & $\begin{array}{l}\text { Data dictionary } \\
\text { reference name }\end{array}$ & $\begin{array}{l}\text { Starting } \\
\text { position }\end{array}$ & $\begin{array}{l}\text { Field } \\
\text { size }\end{array}$ & $\begin{array}{l}\text { Data } \\
\text { type }\end{array}$ \\
\hline $\begin{array}{l}\text { Change in total earnings for full-quarter separations } \\
\text { for Male and Female and ag }\end{array}$ & DWFS_A0A08 & 04980 & 4 & $\mathrm{~N}$ \\
\hline $\begin{array}{l}\text { Change in total earnings for full-quarter separations } \\
\text { for Male and age 14-18 }\end{array}$ & DWFS_A1A01 & 04900 & 4 & $\mathrm{~N}$ \\
\hline $\begin{array}{l}\text { Change in total earnings for full-quarter separations } \\
\text { for Male and age 14-99 }\end{array}$ & DWFS_A1A00 & 04888 & 4 & $\mathrm{~N}$ \\
\hline $\begin{array}{l}\text { Change in total earnings for full-quarter separations } \\
\text { for Male and age 19-21 }\end{array}$ & DWFS_A1A02 & 04912 & 4 & $\mathrm{~N}$ \\
\hline $\begin{array}{l}\text { Change in total earnings for full-quarter separations } \\
\text { for Male and age } 22-24\end{array}$ & DWFS_A1A03 & 04924 & 4 & $\mathrm{~N}$ \\
\hline $\begin{array}{l}\text { Change in total earnings for full-quarter separations } \\
\text { for Male and age } 25-34\end{array}$ & DWFS_A1A04 & 04936 & 4 & $\mathrm{~N}$ \\
\hline $\begin{array}{l}\text { Change in total earnings for full-quarter separations } \\
\text { for Male and age } 35-44\end{array}$ & DWFS_A1A05 & 04948 & 4 & $\mathrm{~N}$ \\
\hline $\begin{array}{l}\text { Change in total earnings for full-quarter separations } \\
\text { for Male and age } 45-54\end{array}$ & DWFS_A1A06 & 04960 & 4 & $\mathrm{~N}$ \\
\hline $\begin{array}{l}\text { Change in total earnings for full-quarter separations } \\
\text { for Male and age } 55-64\end{array}$ & DWFS_A1A07 & 04972 & 4 & $\mathrm{~N}$ \\
\hline $\begin{array}{l}\text { Change in total earnings for full-quarter separations } \\
\text { for Male and age } 65-99\end{array}$ & DWFS_A1A08 & 04984 & 4 & $\mathrm{~N}$ \\
\hline $\begin{array}{l}\text { Change in total earnings for separations for Female } \\
\text { and age 14-18 }\end{array}$ & DWS_A2A01 & 04688 & 4 & $\mathrm{~N}$ \\
\hline $\begin{array}{l}\text { Change in total earnings for separations for Female } \\
\text { and age 14-99 }\end{array}$ & DWS_A2A00 & 04676 & 4 & $\mathrm{~N}$ \\
\hline $\begin{array}{l}\text { Change in total earnings for separations for Female } \\
\text { and age 19-21 }\end{array}$ & DWS_A2A02 & 04700 & 4 & $\mathrm{~N}$ \\
\hline $\begin{array}{l}\text { Change in total earnings for separations for Female } \\
\text { and age } 22-24\end{array}$ & DWS_A2A03 & 04712 & 4 & $\mathrm{~N}$ \\
\hline $\begin{array}{l}\text { Change in total earnings for separations for Female } \\
\text { and age 25-34 }\end{array}$ & DWS_A2A04 & 04724 & 4 & $\mathrm{~N}$ \\
\hline $\begin{array}{l}\text { Change in total earnings for separations for Female } \\
\text { and age } 35-44\end{array}$ & DWS_A2A 05 & 04736 & 4 & $\mathrm{~N}$ \\
\hline $\begin{array}{l}\text { Change in total earnings for separations for Female } \\
\text { and age } 45-54\end{array}$ & DWS_A2A06 & 04748 & 4 & $\mathrm{~N}$ \\
\hline $\begin{array}{l}\text { Change in total earnings for separations for Female } \\
\text { and age } 55-64\end{array}$ & DWS_A2A07 & 04760 & 4 & $\mathrm{~N}$ \\
\hline $\begin{array}{l}\text { Change in total earnings for separations for Female } \\
\text { and age } 65-99\end{array}$ & DWS_A2A08 & 04772 & 4 & $\mathrm{~N}$ \\
\hline $\begin{array}{l}\text { Change in total earnings for separations for Male and } \\
\text { Female and age } 14-18\end{array}$ & DWS_A0A01 & 04680 & 4 & $\mathrm{~N}$ \\
\hline $\begin{array}{l}\text { Change in total earnings for separations for Male and } \\
\text { Female and age 14-99 }\end{array}$ & DWS_A0A00 & 04668 & 4 & $\mathrm{~N}$ \\
\hline $\begin{array}{l}\text { Change in total earnings for separations for Male and } \\
\text { Female and age } 19-21\end{array}$ & DWS_A0A02 & 04692 & 4 & $\mathrm{~N}$ \\
\hline $\begin{array}{l}\text { Change in total earnings for separations for Male and } \\
\text { Female and age } 22-24\end{array}$ & DWS_A0A03 & 04704 & 4 & $\mathrm{~N}$ \\
\hline $\begin{array}{l}\text { Change in total earnings for separations for Male and } \\
\text { Female and age } 25-34\end{array}$ & DWS_A0A04 & 04716 & 4 & $\mathrm{~N}$ \\
\hline $\begin{array}{l}\text { Change in total earnings for separations for Male and } \\
\text { Female and age } 35-44\end{array}$ & DWS_A0A05 & 04728 & 4 & $\mathrm{~N}$ \\
\hline
\end{tabular}




\begin{tabular}{|c|c|c|c|c|}
\hline Field name & $\begin{array}{l}\text { Data dictionary } \\
\text { reference name }\end{array}$ & $\begin{array}{l}\text { Starting } \\
\text { position }\end{array}$ & $\begin{array}{l}\text { Field } \\
\text { size }\end{array}$ & $\begin{array}{l}\text { Data } \\
\text { type }\end{array}$ \\
\hline $\begin{array}{l}\text { Change in total earnings for separations for Male and } \\
\text { Female and age } 45-54\end{array}$ & DWS_A0A06 & 04740 & 4 & $\mathrm{~N}$ \\
\hline $\begin{array}{l}\text { Change in total earnings for separations for Male and } \\
\text { Female and age } 55-64\end{array}$ & DWS_A0A07 & 04752 & 4 & $\mathrm{~N}$ \\
\hline $\begin{array}{l}\text { Change in total earnings for separations for Male and } \\
\text { Female and age } 65-99\end{array}$ & DWS_A0A08 & 04764 & 4 & $\mathrm{~N}$ \\
\hline $\begin{array}{l}\text { Change in total earnings for separations for Male and } \\
\text { age } 14-18\end{array}$ & DWS_A1A01 & 04684 & 4 & $\mathrm{~N}$ \\
\hline $\begin{array}{l}\text { Change in total earnings for separations for Male and } \\
\text { age 14-99 }\end{array}$ & DWS_A1A00 & 04672 & 4 & $\mathrm{~N}$ \\
\hline $\begin{array}{l}\text { Change in total earnings for separations for Male and } \\
\text { age } 19-21\end{array}$ & DWS_A1A02 & 04696 & 4 & $\mathrm{~N}$ \\
\hline $\begin{array}{l}\text { Change in total earnings for separations for Male and } \\
\text { age 22-24 }\end{array}$ & DWS_A1A03 & 04708 & 4 & $\mathrm{~N}$ \\
\hline $\begin{array}{l}\text { Change in total earnings for separations for Male and } \\
\text { age 25-34 }\end{array}$ & DWS_A1A04 & 04720 & 4 & $\mathrm{~N}$ \\
\hline $\begin{array}{l}\text { Change in total earnings for separations for Male and } \\
\text { age } 35-44\end{array}$ & DWS_A1A05 & 04732 & 4 & $\mathrm{~N}$ \\
\hline $\begin{array}{l}\text { Change in total earnings for separations for Male and } \\
\text { age } 45-54\end{array}$ & DWS_A1A06 & 04744 & 4 & $\mathrm{~N}$ \\
\hline $\begin{array}{l}\text { Change in total earnings for separations for Male and } \\
\text { age } 55-64\end{array}$ & DWS_A1A07 & 04756 & 4 & $\mathrm{~N}$ \\
\hline $\begin{array}{l}\text { Change in total earnings for separations for Male and } \\
\text { age } 65-99\end{array}$ & DWS_A1A08 & 04768 & 4 & $\mathrm{~N}$ \\
\hline $\begin{array}{l}\text { Change in total earnings for transits to full-quarter } \\
\text { status for Female and age }\end{array}$ & DWFA_A2A01 & 04148 & 4 & $\mathrm{~N}$ \\
\hline $\begin{array}{l}\text { Change in total earnings for transits to full-quarter } \\
\text { status for Female and age }\end{array}$ & DWFA_A2A00 & 04136 & 4 & $\mathrm{~N}$ \\
\hline $\begin{array}{l}\text { Change in total earnings for transits to full-quarter } \\
\text { status for Female and age }\end{array}$ & DWFA_A2A02 & 04160 & 4 & $\mathrm{~N}$ \\
\hline $\begin{array}{l}\text { Change in total earnings for transits to full-quarter } \\
\text { status for Female and age }\end{array}$ & DWFA_A2A03 & 04172 & 4 & $\mathrm{~N}$ \\
\hline $\begin{array}{l}\text { Change in total earnings for transits to full-quarter } \\
\text { status for Female and age }\end{array}$ & DWFA_A2A04 & 04184 & 4 & $\mathrm{~N}$ \\
\hline $\begin{array}{l}\text { Change in total earnings for transits to full-quarter } \\
\text { status for Female and age }\end{array}$ & DWFA_A2A05 & 04196 & 4 & $\mathrm{~N}$ \\
\hline $\begin{array}{l}\text { Change in total earnings for transits to full-quarter } \\
\text { status for Female and age }\end{array}$ & DWFA_A2A06 & 04208 & 4 & $\mathrm{~N}$ \\
\hline $\begin{array}{l}\text { Change in total earnings for transits to full-quarter } \\
\text { status for Female and age }\end{array}$ & DWFA_A2A07 & 04220 & 4 & $\mathrm{~N}$ \\
\hline $\begin{array}{l}\text { Change in total earnings for transits to full-quarter } \\
\text { status for Female and age }\end{array}$ & DWFA_A2A08 & 04232 & 4 & $\mathrm{~N}$ \\
\hline $\begin{array}{l}\text { Change in total earnings for transits to full-quarter } \\
\text { status for Male and Female }\end{array}$ & DWFA_A0A01 & 04140 & 4 & $\mathrm{~N}$ \\
\hline $\begin{array}{l}\text { Change in total earnings for transits to full-quarter } \\
\text { status for Male and Female }\end{array}$ & DWFA_A0A00 & 04128 & 4 & $\mathrm{~N}$ \\
\hline $\begin{array}{l}\text { Change in total earnings for transits to full-quarter } \\
\text { status for Male and Female }\end{array}$ & DWFA_A0A02 & 04152 & 4 & $\mathrm{~N}$ \\
\hline Change in total earnings for transits to full-quarter & DWFA_A0A03 & 04164 & 4 & $\mathrm{~N}$ \\
\hline
\end{tabular}




\begin{tabular}{|c|c|c|c|c|}
\hline Field name & $\begin{array}{l}\text { Data dictionary } \\
\text { reference name }\end{array}$ & $\begin{array}{l}\text { Starting } \\
\text { position }\end{array}$ & $\begin{array}{l}\text { Field } \\
\text { size }\end{array}$ & $\begin{array}{l}\text { Data } \\
\text { type }\end{array}$ \\
\hline $\begin{array}{l}\text { Change in total earnings for transits to full-quarter } \\
\text { status for Male and Female }\end{array}$ & DWFA_A0A04 & 04176 & 4 & $\mathrm{~N}$ \\
\hline $\begin{array}{l}\text { Change in total earnings for transits to full-quarter } \\
\text { status for Male and Female }\end{array}$ & DWFA_A0A05 & 04188 & 4 & $\mathrm{~N}$ \\
\hline $\begin{array}{l}\text { Change in total earnings for transits to full-quarter } \\
\text { status for Male and Female }\end{array}$ & DWFA_A0A06 & 04200 & 4 & $\mathrm{~N}$ \\
\hline $\begin{array}{l}\text { Change in total earnings for transits to full-quarter } \\
\text { status for Male and Female }\end{array}$ & DWFA_A0A07 & 04212 & 4 & $\mathrm{~N}$ \\
\hline $\begin{array}{l}\text { Change in total earnings for transits to full-quarter } \\
\text { status for Male and Female }\end{array}$ & DWFA_A0A08 & 04224 & 4 & $\mathrm{~N}$ \\
\hline $\begin{array}{l}\text { Change in total earnings for transits to full-quarter } \\
\text { status for Male and age } 14\end{array}$ & DWFA_A1A01 & 04144 & 4 & $\mathrm{~N}$ \\
\hline $\begin{array}{l}\text { Change in total earnings for transits to full-quarter } \\
\text { status for Male and age } 14\end{array}$ & DWFA_A1A00 & 04132 & 4 & $\mathrm{~N}$ \\
\hline $\begin{array}{l}\text { Change in total earnings for transits to full-quarter } \\
\text { status for Male and age } 19\end{array}$ & DWFA_A1A02 & 04156 & 4 & $\mathrm{~N}$ \\
\hline $\begin{array}{l}\text { Change in total earnings for transits to full-quarter } \\
\text { status for Male and age } 22\end{array}$ & DWFA_A1A03 & 04168 & 4 & $\mathrm{~N}$ \\
\hline $\begin{array}{l}\text { Change in total earnings for transits to full-quarter } \\
\text { status for Male and age } 25\end{array}$ & DWFA_A1A04 & 04180 & 4 & $\mathrm{~N}$ \\
\hline $\begin{array}{l}\text { Change in total earnings for transits to full-quarter } \\
\text { status for Male and age } 35\end{array}$ & DWFA_A1A05 & 04192 & 4 & $\mathrm{~N}$ \\
\hline $\begin{array}{l}\text { Change in total earnings for transits to full-quarter } \\
\text { status for Male and age } 45\end{array}$ & DWFA_A1A06 & 04204 & 4 & $\mathrm{~N}$ \\
\hline $\begin{array}{l}\text { Change in total earnings for transits to full-quarter } \\
\text { status for Male and age } 55\end{array}$ & DWFA_A1A07 & 04216 & 4 & $\mathrm{~N}$ \\
\hline $\begin{array}{l}\text { Change in total earnings for transits to full-quarter } \\
\text { status for Male and age } 65\end{array}$ & DWFA_A1A08 & 04228 & 4 & $\mathrm{~N}$ \\
\hline Cleaned GEO FIPS County CCC & LEG_COUNTY & 07498 & 3 & $\mathrm{~A} / \mathrm{N}$ \\
\hline Cleaned OWNER_CODE O & ES_OWNER_CODE & 07493 & 1 & $\mathrm{~A} / \mathrm{N}$ \\
\hline Cleaned SIC Code IIII & ES_SIC & 07494 & 4 & $\mathrm{~A} / \mathrm{N}$ \\
\hline ES202 FIPS State SS & ES_STATE & 07526 & 2 & $\mathrm{~A} / \mathrm{N}$ \\
\hline $\begin{array}{l}\text { Employment any time during the period for Female } \\
\text { and age 14-18 }\end{array}$ & M_A2A01 & 00260 & 4 & $\mathrm{~N}$ \\
\hline $\begin{array}{l}\text { Employment any time during the period for Female } \\
\text { and age 14-99 }\end{array}$ & M_A2A00 & 00248 & 4 & $\mathrm{~N}$ \\
\hline $\begin{array}{l}\text { Employment any time during the period for Female } \\
\text { and age } 19-21\end{array}$ & M_A2A02 & 00272 & 4 & $\mathrm{~N}$ \\
\hline $\begin{array}{l}\text { Employment any time during the period for Female } \\
\text { and age } 22-24\end{array}$ & M_A2A03 & 00284 & 4 & $\mathrm{~N}$ \\
\hline $\begin{array}{l}\text { Employment any time during the period for Female } \\
\text { and age } 25-34\end{array}$ & M_A2A04 & 00296 & 4 & $\mathrm{~N}$ \\
\hline $\begin{array}{l}\text { Employment any time during the period for Female } \\
\text { and age } 35-44\end{array}$ & M_A2A05 & 00308 & 4 & $\mathrm{~N}$ \\
\hline $\begin{array}{l}\text { Employment any time during the period for Female } \\
\text { and age } 45-54\end{array}$ & M_A2A06 & 00320 & 4 & $\mathrm{~N}$ \\
\hline $\begin{array}{l}\text { Employment any time during the period for Female } \\
\text { and age 55-64 }\end{array}$ & M_A2A07 & 00332 & 4 & $\mathrm{~N}$ \\
\hline $\begin{array}{l}\text { Employment any time during the period for Female } \\
\text { and age } 65-99\end{array}$ & M_A2A08 & 00344 & 4 & $\mathrm{~N}$ \\
\hline
\end{tabular}




\begin{tabular}{|c|c|c|c|c|}
\hline Field name & $\begin{array}{l}\text { Data dictionary } \\
\text { reference name }\end{array}$ & $\begin{array}{l}\text { Starting } \\
\text { position }\end{array}$ & $\begin{array}{l}\text { Field } \\
\text { size }\end{array}$ & $\begin{array}{l}\text { Data } \\
\text { type }\end{array}$ \\
\hline $\begin{array}{l}\text { Employment any time during the period for Male and } \\
\text { Female and age 14-18 }\end{array}$ & M_A0A01 & 00252 & 4 & $\mathrm{~N}$ \\
\hline $\begin{array}{l}\text { Employment any time during the period for Male and } \\
\text { Female and age 14-99 }\end{array}$ & M_A0A00 & 00240 & 4 & $\mathrm{~N}$ \\
\hline $\begin{array}{l}\text { Employment any time during the period for Male and } \\
\text { Female and age 19-21 }\end{array}$ & M_A0A02 & 00264 & 4 & $\mathrm{~N}$ \\
\hline $\begin{array}{l}\text { Employment any time during the period for Male and } \\
\text { Female and age } 22-24\end{array}$ & M_A0A03 & 00276 & 4 & $\mathrm{~N}$ \\
\hline $\begin{array}{l}\text { Employment any time during the period for Male and } \\
\text { Female and age 25-34 }\end{array}$ & M_A0A04 & 00288 & 4 & $\mathrm{~N}$ \\
\hline $\begin{array}{l}\text { Employment any time during the period for Male and } \\
\text { Female and age } 35-44\end{array}$ & M_A0A05 & 00300 & 4 & $\mathrm{~N}$ \\
\hline $\begin{array}{l}\text { Employment any time during the period for Male and } \\
\text { Female and age } 45-54\end{array}$ & M_A0A06 & 00312 & 4 & $\mathrm{~N}$ \\
\hline $\begin{array}{l}\text { Employment any time during the period for Male and } \\
\text { Female and age 55-64 }\end{array}$ & M_A0A07 & 00324 & 4 & $\mathrm{~N}$ \\
\hline $\begin{array}{l}\text { Employment any time during the period for Male and } \\
\text { Female and age } 65-99\end{array}$ & M_A0A08 & 00336 & 4 & $\mathrm{~N}$ \\
\hline $\begin{array}{l}\text { Employment any time during the period for Male and } \\
\text { age 14-18 }\end{array}$ & M_A1A01 & 00256 & 4 & $\mathrm{~N}$ \\
\hline $\begin{array}{l}\text { Employment any time during the period for Male and } \\
\text { age 14-99 }\end{array}$ & M_A1A00 & 00244 & 4 & $\mathrm{~N}$ \\
\hline $\begin{array}{l}\text { Employment any time during the period for Male and } \\
\text { age } 19-21\end{array}$ & M_A1A02 & 00268 & 4 & $\mathrm{~N}$ \\
\hline $\begin{array}{l}\text { Employment any time during the period for Male and } \\
\text { age } 22-24\end{array}$ & M_A1A03 & 00280 & 4 & $\mathrm{~N}$ \\
\hline $\begin{array}{l}\text { Employment any time during the period for Male and } \\
\text { age } 25-34\end{array}$ & M_A1A04 & 00292 & 4 & $\mathrm{~N}$ \\
\hline $\begin{array}{l}\text { Employment any time during the period for Male and } \\
\text { age } 35-44\end{array}$ & M_A1A05 & 00304 & 4 & $\mathrm{~N}$ \\
\hline $\begin{array}{l}\text { Employment any time during the period for Male and } \\
\text { age } 45-54\end{array}$ & M_A1A06 & 00316 & 4 & $\mathrm{~N}$ \\
\hline $\begin{array}{l}\text { Employment any time during the period for Male and } \\
\text { age 55-64 }\end{array}$ & M_A1A07 & 00328 & 4 & $\mathrm{~N}$ \\
\hline $\begin{array}{l}\text { Employment any time during the period for Male and } \\
\text { age } 65-99\end{array}$ & M_A1A08 & 00340 & 4 & $\mathrm{~N}$ \\
\hline End-of-period employment for Female and age 14-18 & E_A2A01 & 00152 & 4 & $\mathrm{~N}$ \\
\hline End-of-period employment for Female and age 14-99 & E_A2A00 & 00140 & 4 & $\mathrm{~N}$ \\
\hline End-of-period employment for Female and age 19-21 & E_A2A02 & 00164 & 4 & $\mathrm{~N}$ \\
\hline End-of-period employment for Female and age $22-24$ & E_A2A03 & 00176 & 4 & $\mathrm{~N}$ \\
\hline End-of-period employment for Female and age 25-34 & E_A2A04 & 00188 & 4 & $\mathrm{~N}$ \\
\hline End-of-period employment for Female and age $35-44$ & E_A2A05 & 00200 & 4 & $\mathrm{~N}$ \\
\hline End-of-period employment for Female and age $45-54$ & E_A2A06 & 00212 & 4 & $\mathrm{~N}$ \\
\hline End-of-period employment for Female and age $55-64$ & E_A2A07 & 00224 & 4 & $\mathrm{~N}$ \\
\hline End-of-period employment for Female and age 65-99 & E_A2A08 & 00236 & 4 & $\mathrm{~N}$ \\
\hline $\begin{array}{l}\text { End-of-period employment for Male and Female and } \\
\text { age 14-18 }\end{array}$ & E_A0A01 & 00144 & 4 & $\mathrm{~N}$ \\
\hline $\begin{array}{l}\text { End-of-period employment for Male and Female and } \\
\text { age 14-99 }\end{array}$ & E_A0A00 & 00132 & 4 & $\mathrm{~N}$ \\
\hline
\end{tabular}


CHAPTER 7. QUARTERLY WORKFORCE INDICATORS - SEINUNIT FILE (QWI)

\begin{tabular}{|c|c|c|c|c|}
\hline Field name & $\begin{array}{l}\text { Data dictionary } \\
\text { reference name }\end{array}$ & $\begin{array}{l}\text { Starting } \\
\text { position }\end{array}$ & $\begin{array}{l}\text { Field } \\
\text { size }\end{array}$ & $\begin{array}{l}\text { Data } \\
\text { type }\end{array}$ \\
\hline $\begin{array}{l}\text { End-of-period employment for Male and Female and } \\
\text { age 19-21 }\end{array}$ & E_A0A02 & 00156 & 4 & $\mathrm{~N}$ \\
\hline $\begin{array}{l}\text { End-of-period employment for Male and Female and } \\
\text { age 22-24 }\end{array}$ & E_A0A03 & 00168 & 4 & $\mathrm{~N}$ \\
\hline $\begin{array}{l}\text { End-of-period employment for Male and Female and } \\
\text { age 25-34 }\end{array}$ & E_A0A04 & 00180 & 4 & $\mathrm{~N}$ \\
\hline $\begin{array}{l}\text { End-of-period employment for Male and Female and } \\
\text { age 35-44 }\end{array}$ & E_A0A05 & 00192 & 4 & $\mathrm{~N}$ \\
\hline $\begin{array}{l}\text { End-of-period employment for Male and Female and } \\
\text { age 45-54 }\end{array}$ & E_A0A06 & 00204 & 4 & $\mathrm{~N}$ \\
\hline $\begin{array}{l}\text { End-of-period employment for Male and Female and } \\
\text { age 55-64 }\end{array}$ & E_A0A07 & 00216 & 4 & $\mathrm{~N}$ \\
\hline $\begin{array}{l}\text { End-of-period employment for Male and Female and } \\
\text { age 65-99 }\end{array}$ & E_A0A08 & 00228 & 4 & $\mathrm{~N}$ \\
\hline End-of-period employment for Male and age 14-18 & E_A1A01 & 00148 & 4 & $\mathrm{~N}$ \\
\hline End-of-period employment for Male and age 14-99 & E_A1A00 & 00136 & 4 & $\mathrm{~N}$ \\
\hline End-of-period employment for Male and age 19-21 & E_A1A02 & 00160 & 4 & $\mathrm{~N}$ \\
\hline End-of-period employment for Male and age 22-24 & E_A1A03 & 00172 & 4 & $\mathrm{~N}$ \\
\hline End-of-period employment for Male and age 25-34 & E_A1A04 & 00184 & 4 & $\mathrm{~N}$ \\
\hline End-of-period employment for Male and age 35-44 & E_A1A05 & 00196 & 4 & $\mathrm{~N}$ \\
\hline End-of-period employment for Male and age 45-54 & E_A1A06 & 00208 & 4 & $\mathrm{~N}$ \\
\hline End-of-period employment for Male and age 55-64 & E_A1A07 & 00220 & 4 & $\mathrm{~N}$ \\
\hline End-of-period employment for Male and age 65-99 & E_A1A08 & 00232 & 4 & $\mathrm{~N}$ \\
\hline Final 2002 NAICS Code NNNNNN & ES_NAICS_FNL2002 & 07528 & 6 & $\mathrm{~A} / \mathrm{N}$ \\
\hline $\begin{array}{l}\text { Flow into consecutive quarter employment for Female } \\
\text { and age } 14-18\end{array}$ & CA_A2A01 & 03068 & 4 & $\mathrm{~N}$ \\
\hline $\begin{array}{l}\text { Flow into consecutive quarter employment for Female } \\
\text { and age 14-99 }\end{array}$ & CA_A2A00 & 03056 & 4 & $\mathrm{~N}$ \\
\hline $\begin{array}{l}\text { Flow into consecutive quarter employment for Female } \\
\text { and age 19-21 }\end{array}$ & CA_A2A02 & 03080 & 4 & $\mathrm{~N}$ \\
\hline $\begin{array}{l}\text { Flow into consecutive quarter employment for Female } \\
\text { and age } 22-24\end{array}$ & CA_A2A03 & 03092 & 4 & $\mathrm{~N}$ \\
\hline $\begin{array}{l}\text { Flow into consecutive quarter employment for Female } \\
\text { and age } 25-34\end{array}$ & CA_A2A04 & 03104 & 4 & $\mathrm{~N}$ \\
\hline $\begin{array}{l}\text { Flow into consecutive quarter employment for Female } \\
\text { and age } 35-44\end{array}$ & CA_A2A05 & 03116 & 4 & $\mathrm{~N}$ \\
\hline $\begin{array}{l}\text { Flow into consecutive quarter employment for Female } \\
\text { and age } 45-54\end{array}$ & CA_A2A06 & 03128 & 4 & $\mathrm{~N}$ \\
\hline $\begin{array}{l}\text { Flow into consecutive quarter employment for Female } \\
\text { and age } 55-64\end{array}$ & CA_A2A07 & 03140 & 4 & $\mathrm{~N}$ \\
\hline $\begin{array}{l}\text { Flow into consecutive quarter employment for Female } \\
\text { and age } 65-99\end{array}$ & CA_A2A08 & 03152 & 4 & $\mathrm{~N}$ \\
\hline $\begin{array}{l}\text { Flow into consecutive quarter employment for Male } \\
\text { and Female and age 14-18 }\end{array}$ & CA_A0A01 & 03060 & 4 & $\mathrm{~N}$ \\
\hline $\begin{array}{l}\text { Flow into consecutive quarter employment for Male } \\
\text { and Female and age 14-99 }\end{array}$ & CA_A0A00 & 03048 & 4 & $\mathrm{~N}$ \\
\hline $\begin{array}{l}\text { Flow into consecutive quarter employment for Male } \\
\text { and Female and age 19-21 }\end{array}$ & CA_A0A02 & 03072 & 4 & $\mathrm{~N}$ \\
\hline $\begin{array}{l}\text { Flow into consecutive quarter employment for Male } \\
\text { and Female and age } 22-24\end{array}$ & CA_A0A03 & 03084 & 4 & $\mathrm{~N}$ \\
\hline
\end{tabular}




\begin{tabular}{|c|c|c|c|c|}
\hline Field name & $\begin{array}{l}\text { Data dictionary } \\
\text { reference name }\end{array}$ & $\begin{array}{l}\text { Starting } \\
\text { position }\end{array}$ & $\begin{array}{l}\text { Field } \\
\text { size }\end{array}$ & $\begin{array}{l}\text { Data } \\
\text { type }\end{array}$ \\
\hline $\begin{array}{l}\text { Flow into consecutive quarter employment for Male } \\
\text { and Female and age } 25-34\end{array}$ & CA_A0A04 & 03096 & 4 & $\mathrm{~N}$ \\
\hline $\begin{array}{l}\text { Flow into consecutive quarter employment for Male } \\
\text { and Female and age } 35-44\end{array}$ & CA_A0A05 & 03108 & 4 & $\mathrm{~N}$ \\
\hline $\begin{array}{l}\text { Flow into consecutive quarter employment for Male } \\
\text { and Female and age } 45-54\end{array}$ & CA_A0A06 & 03120 & 4 & $\mathrm{~N}$ \\
\hline $\begin{array}{l}\text { Flow into consecutive quarter employment for Male } \\
\text { and Female and age } 55-64\end{array}$ & CA_A0A07 & 03132 & 4 & $\mathrm{~N}$ \\
\hline $\begin{array}{l}\text { Flow into consecutive quarter employment for Male } \\
\text { and Female and age } 65-99\end{array}$ & CA_A0A08 & 03144 & 4 & $\mathrm{~N}$ \\
\hline $\begin{array}{l}\text { Flow into consecutive quarter employment for Male } \\
\text { and age 14-18 }\end{array}$ & CA_A1A01 & 03064 & 4 & $\mathrm{~N}$ \\
\hline $\begin{array}{l}\text { Flow into consecutive quarter employment for Male } \\
\text { and age 14-99 }\end{array}$ & CA_A1A00 & 03052 & 4 & $\mathrm{~N}$ \\
\hline $\begin{array}{l}\text { Flow into consecutive quarter employment for Male } \\
\text { and age 19-21 }\end{array}$ & CA_A1A02 & 03076 & 4 & $\mathrm{~N}$ \\
\hline $\begin{array}{l}\text { Flow into consecutive quarter employment for Male } \\
\text { and age } 22-24\end{array}$ & CA_A1A03 & 03088 & 4 & $\mathrm{~N}$ \\
\hline $\begin{array}{l}\text { Flow into consecutive quarter employment for Male } \\
\text { and age 25-34 }\end{array}$ & CA_A1A04 & 03100 & 4 & $\mathrm{~N}$ \\
\hline $\begin{array}{l}\text { Flow into consecutive quarter employment for Male } \\
\text { and age } 35-44\end{array}$ & CA_A1A05 & 03112 & 4 & $\mathrm{~N}$ \\
\hline $\begin{array}{l}\text { Flow into consecutive quarter employment for Male } \\
\text { and age } 45-54\end{array}$ & CA_A1A06 & 03124 & 4 & $\mathrm{~N}$ \\
\hline $\begin{array}{l}\text { Flow into consecutive quarter employment for Male } \\
\text { and age } 55-64\end{array}$ & CA_A1A07 & 03136 & 4 & $\mathrm{~N}$ \\
\hline $\begin{array}{l}\text { Flow into consecutive quarter employment for Male } \\
\text { and age } 65-99\end{array}$ & CA_A1A08 & 03148 & 4 & $\mathrm{~N}$ \\
\hline $\begin{array}{l}\text { Flow into full-quarter employment for Female and age } \\
14-18\end{array}$ & FA_A2A01 & 02636 & 4 & $\mathrm{~N}$ \\
\hline $\begin{array}{l}\text { Flow into full-quarter employment for Female and age } \\
\text { 14-99 }\end{array}$ & FA_A2A00 & 02624 & 4 & $\mathrm{~N}$ \\
\hline $\begin{array}{l}\text { Flow into full-quarter employment for Female and age } \\
19-21\end{array}$ & FA_A2A02 & 02648 & 4 & $\mathrm{~N}$ \\
\hline $\begin{array}{l}\text { Flow into full-quarter employment for Female and age } \\
22-24\end{array}$ & FA_A2A03 & 02660 & 4 & $\mathrm{~N}$ \\
\hline $\begin{array}{l}\text { Flow into full-quarter employment for Female and age } \\
25-34\end{array}$ & FA_A2A04 & 02672 & 4 & $\mathrm{~N}$ \\
\hline $\begin{array}{l}\text { Flow into full-quarter employment for Female and age } \\
35-44\end{array}$ & FA_A2A05 & 02684 & 4 & $\mathrm{~N}$ \\
\hline $\begin{array}{l}\text { Flow into full-quarter employment for Female and age } \\
45-54\end{array}$ & FA_A2A06 & 02696 & 4 & $\mathrm{~N}$ \\
\hline $\begin{array}{l}\text { Flow into full-quarter employment for Female and age } \\
55-64\end{array}$ & FA_A2A07 & 02708 & 4 & $\mathrm{~N}$ \\
\hline $\begin{array}{l}\text { Flow into full-quarter employment for Female and age } \\
65-99\end{array}$ & FA_A2A08 & 02720 & 4 & $\mathrm{~N}$ \\
\hline $\begin{array}{l}\text { Flow into full-quarter employment for Male and Fe- } \\
\text { male and age 14-18 }\end{array}$ & FA_A0A01 & 02628 & 4 & $\mathrm{~N}$ \\
\hline $\begin{array}{l}\text { Flow into full-quarter employment for Male and Fe- } \\
\text { male and age 14-99 }\end{array}$ & FA_A0A00 & 02616 & 4 & $\mathrm{~N}$ \\
\hline
\end{tabular}




\begin{tabular}{|c|c|c|c|c|}
\hline Field name & $\begin{array}{l}\text { Data dictionary } \\
\text { reference name }\end{array}$ & $\begin{array}{l}\text { Starting } \\
\text { position }\end{array}$ & $\begin{array}{l}\text { Field } \\
\text { size }\end{array}$ & $\begin{array}{l}\text { Data } \\
\text { type }\end{array}$ \\
\hline $\begin{array}{l}\text { Flow into full-quarter employment for Male and Fe- } \\
\text { male and age 19-21 }\end{array}$ & FA_A0A02 & 02640 & 4 & $\mathrm{~N}$ \\
\hline $\begin{array}{l}\text { Flow into full-quarter employment for Male and Fe- } \\
\text { male and age } 22-24\end{array}$ & FA_A0A03 & 02652 & 4 & $\mathrm{~N}$ \\
\hline $\begin{array}{l}\text { Flow into full-quarter employment for Male and Fe- } \\
\text { male and age } 25-34\end{array}$ & FA_A0A04 & 02664 & 4 & $\mathrm{~N}$ \\
\hline $\begin{array}{l}\text { Flow into full-quarter employment for Male and Fe- } \\
\text { male and age } 35-44\end{array}$ & FA_A0A05 & 02676 & 4 & $\mathrm{~N}$ \\
\hline $\begin{array}{l}\text { Flow into full-quarter employment for Male and Fe- } \\
\text { male and age } 45-54\end{array}$ & FA_A0A06 & 02688 & 4 & $\mathrm{~N}$ \\
\hline $\begin{array}{l}\text { Flow into full-quarter employment for Male and Fe- } \\
\text { male and age 55-64 }\end{array}$ & FA_A0A07 & 02700 & 4 & $\mathrm{~N}$ \\
\hline $\begin{array}{l}\text { Flow into full-quarter employment for Male and Fe- } \\
\text { male and age } 65-99\end{array}$ & FA_A0A08 & 02712 & 4 & $\mathrm{~N}$ \\
\hline $\begin{array}{l}\text { Flow into full-quarter employment for Male and age } \\
14-18\end{array}$ & FA_A1A01 & 02632 & 4 & $\mathrm{~N}$ \\
\hline $\begin{array}{l}\text { Flow into full-quarter employment for Male and age } \\
14-99\end{array}$ & FA_A1A00 & 02620 & 4 & $\mathrm{~N}$ \\
\hline $\begin{array}{l}\text { Flow into full-quarter employment for Male and age } \\
19-21\end{array}$ & FA_A1A02 & 02644 & 4 & $\mathrm{~N}$ \\
\hline $\begin{array}{l}\text { Flow into full-quarter employment for Male and age } \\
22-24\end{array}$ & FA_A1A03 & 02656 & 4 & $\mathrm{~N}$ \\
\hline $\begin{array}{l}\text { Flow into full-quarter employment for Male and age } \\
25-34\end{array}$ & FA_A1A04 & 02668 & 4 & $\mathrm{~N}$ \\
\hline $\begin{array}{l}\text { Flow into full-quarter employment for Male and age } \\
35-44\end{array}$ & FA_A1A05 & 02680 & 4 & $\mathrm{~N}$ \\
\hline $\begin{array}{l}\text { Flow into full-quarter employment for Male and age } \\
45-54\end{array}$ & FA_A1A06 & 02692 & 4 & $\mathrm{~N}$ \\
\hline $\begin{array}{l}\text { Flow into full-quarter employment for Male and age } \\
55-64\end{array}$ & FA_A1A07 & 02704 & 4 & $\mathrm{~N}$ \\
\hline $\begin{array}{l}\text { Flow into full-quarter employment for Male and age } \\
65-99\end{array}$ & FA_A1A08 & 02716 & 4 & $\mathrm{~N}$ \\
\hline $\begin{array}{l}\text { Flow out of consecutive quarter employment for Fe- } \\
\text { male and age } 14-18\end{array}$ & CS_A2A01 & 03176 & 4 & $\mathrm{~N}$ \\
\hline $\begin{array}{l}\text { Flow out of consecutive quarter employment for Fe- } \\
\text { male and age 14-99 }\end{array}$ & CS_A2A00 & 03164 & 4 & $\mathrm{~N}$ \\
\hline $\begin{array}{l}\text { Flow out of consecutive quarter employment for Fe- } \\
\text { male and age 19-21 }\end{array}$ & CS_A2A02 & 03188 & 4 & $\mathrm{~N}$ \\
\hline $\begin{array}{l}\text { Flow out of consecutive quarter employment for Fe- } \\
\text { male and age } 22-24\end{array}$ & CS_A2A03 & 03200 & 4 & $\mathrm{~N}$ \\
\hline $\begin{array}{l}\text { Flow out of consecutive quarter employment for Fe- } \\
\text { male and age } 25-34\end{array}$ & CS_A2A04 & 03212 & 4 & $\mathrm{~N}$ \\
\hline $\begin{array}{l}\text { Flow out of consecutive quarter employment for Fe- } \\
\text { male and age } 35-44\end{array}$ & CS_A2A05 & 03224 & 4 & $\mathrm{~N}$ \\
\hline $\begin{array}{l}\text { Flow out of consecutive quarter employment for Fe- } \\
\text { male and age } 45-54\end{array}$ & CS_A2A06 & 03236 & 4 & $\mathrm{~N}$ \\
\hline $\begin{array}{l}\text { Flow out of consecutive quarter employment for Fe- } \\
\text { male and age } 55-64\end{array}$ & CS_A2A07 & 03248 & 4 & $\mathrm{~N}$ \\
\hline $\begin{array}{l}\text { Flow out of consecutive quarter employment for Fe- } \\
\text { male and age } 65-99\end{array}$ & CS_A2A08 & 03260 & 4 & $\mathrm{~N}$ \\
\hline
\end{tabular}




\begin{tabular}{|c|c|c|c|c|}
\hline Field name & $\begin{array}{l}\text { Data dictionary } \\
\text { reference name }\end{array}$ & $\begin{array}{l}\text { Starting } \\
\text { position }\end{array}$ & $\begin{array}{l}\text { Field } \\
\text { size }\end{array}$ & $\begin{array}{l}\text { Data } \\
\text { type }\end{array}$ \\
\hline $\begin{array}{l}\text { Flow out of consecutive quarter employment for Male } \\
\text { and Female and age } 14-18\end{array}$ & CS_A0A01 & 03168 & 4 & $\mathrm{~N}$ \\
\hline $\begin{array}{l}\text { Flow out of consecutive quarter employment for Male } \\
\text { and Female and age 14-99 }\end{array}$ & CS_A0A00 & 03156 & 4 & $\mathrm{~N}$ \\
\hline $\begin{array}{l}\text { Flow out of consecutive quarter employment for Male } \\
\text { and Female and age 19-21 }\end{array}$ & CS_A0A02 & 03180 & 4 & $\mathrm{~N}$ \\
\hline $\begin{array}{l}\text { Flow out of consecutive quarter employment for Male } \\
\text { and Female and age } 22-24\end{array}$ & CS_A0A03 & 03192 & 4 & $\mathrm{~N}$ \\
\hline $\begin{array}{l}\text { Flow out of consecutive quarter employment for Male } \\
\text { and Female and age } 25-34\end{array}$ & CS_A0A04 & 03204 & 4 & $\mathrm{~N}$ \\
\hline $\begin{array}{l}\text { Flow out of consecutive quarter employment for Male } \\
\text { and Female and age } 35-44\end{array}$ & CS_A0A05 & 03216 & 4 & $\mathrm{~N}$ \\
\hline $\begin{array}{l}\text { Flow out of consecutive quarter employment for Male } \\
\text { and Female and age } 45-54\end{array}$ & CS_A0A06 & 03228 & 4 & $\mathrm{~N}$ \\
\hline $\begin{array}{l}\text { Flow out of consecutive quarter employment for Male } \\
\text { and Female and age } 55-64\end{array}$ & CS_A0A07 & 03240 & 4 & $\mathrm{~N}$ \\
\hline $\begin{array}{l}\text { Flow out of consecutive quarter employment for Male } \\
\text { and Female and age } 65-99\end{array}$ & CS_A0A08 & 03252 & 4 & $\mathrm{~N}$ \\
\hline $\begin{array}{l}\text { Flow out of consecutive quarter employment for Male } \\
\text { and age 14-18 }\end{array}$ & CS_A1A01 & 03172 & 4 & $\mathrm{~N}$ \\
\hline $\begin{array}{l}\text { Flow out of consecutive quarter employment for Male } \\
\text { and age 14-99 }\end{array}$ & CS_A1A00 & 03160 & 4 & $\mathrm{~N}$ \\
\hline $\begin{array}{l}\text { Flow out of consecutive quarter employment for Male } \\
\text { and age 19-21 }\end{array}$ & CS_A1A02 & 03184 & 4 & $\mathrm{~N}$ \\
\hline $\begin{array}{l}\text { Flow out of consecutive quarter employment for Male } \\
\text { and age } 22-24\end{array}$ & CS_A1A03 & 03196 & 4 & $\mathrm{~N}$ \\
\hline $\begin{array}{l}\text { Flow out of consecutive quarter employment for Male } \\
\text { and age } 25-34\end{array}$ & CS_A1A04 & 03208 & 4 & $\mathrm{~N}$ \\
\hline $\begin{array}{l}\text { Flow out of consecutive quarter employment for Male } \\
\text { and age } 35-44\end{array}$ & CS_A1A05 & 03220 & 4 & $\mathrm{~N}$ \\
\hline $\begin{array}{l}\text { Flow out of consecutive quarter employment for Male } \\
\text { and age } 45-54\end{array}$ & CS_A1A06 & 03232 & 4 & $\mathrm{~N}$ \\
\hline $\begin{array}{l}\text { Flow out of consecutive quarter employment for Male } \\
\text { and age } 55-64\end{array}$ & CS_A1A07 & 03244 & 4 & $\mathrm{~N}$ \\
\hline $\begin{array}{l}\text { Flow out of consecutive quarter employment for Male } \\
\text { and age } 65-99\end{array}$ & CS_A1A08 & 03256 & 4 & $\mathrm{~N}$ \\
\hline $\begin{array}{l}\text { Flow out of full-quarter employment for Female and } \\
\text { age 14-18 }\end{array}$ & FS_A2A01 & 02852 & 4 & $\mathrm{~N}$ \\
\hline $\begin{array}{l}\text { Flow out of full-quarter employment for Female and } \\
\text { age 14-99 }\end{array}$ & FS_A2A00 & 02840 & 4 & $\mathrm{~N}$ \\
\hline $\begin{array}{l}\text { Flow out of full-quarter employment for Female and } \\
\text { age } 19-21\end{array}$ & FS_A2A02 & 02864 & 4 & $\mathrm{~N}$ \\
\hline $\begin{array}{l}\text { Flow out of full-quarter employment for Female and } \\
\text { age } 22-24\end{array}$ & FS_A2A03 & 02876 & 4 & $\mathrm{~N}$ \\
\hline $\begin{array}{l}\text { Flow out of full-quarter employment for Female and } \\
\text { age } 25-34\end{array}$ & FS_A2A04 & 02888 & 4 & $\mathrm{~N}$ \\
\hline $\begin{array}{l}\text { Flow out of full-quarter employment for Female and } \\
\text { age } 35-44\end{array}$ & FS_A2A05 & 02900 & 4 & $\mathrm{~N}$ \\
\hline $\begin{array}{l}\text { Flow out of full-quarter employment for Female and } \\
\text { age } 45-54\end{array}$ & FS_A2A06 & 02912 & 4 & $\mathrm{~N}$ \\
\hline
\end{tabular}




\begin{tabular}{|c|c|c|c|c|}
\hline Field name & $\begin{array}{l}\text { Data dictionary } \\
\text { reference name }\end{array}$ & $\begin{array}{l}\text { Starting } \\
\text { position }\end{array}$ & $\begin{array}{l}\text { Field } \\
\text { size }\end{array}$ & $\begin{array}{l}\text { Data } \\
\text { type }\end{array}$ \\
\hline $\begin{array}{l}\text { Flow out of full-quarter employment for Female and } \\
\text { age } 55-64\end{array}$ & FS_A2A07 & 02924 & 4 & $\mathrm{~N}$ \\
\hline $\begin{array}{l}\text { Flow out of full-quarter employment for Female and } \\
\text { age } 65-99\end{array}$ & FS_A2A08 & 02936 & 4 & $\mathrm{~N}$ \\
\hline $\begin{array}{l}\text { Flow out of full-quarter employment for Male and Fe- } \\
\text { male and age 14-18 }\end{array}$ & FS_A0A01 & 02844 & 4 & $\mathrm{~N}$ \\
\hline $\begin{array}{l}\text { Flow out of full-quarter employment for Male and Fe- } \\
\text { male and age 14-99 }\end{array}$ & FS_A0A00 & 02832 & 4 & $\mathrm{~N}$ \\
\hline $\begin{array}{l}\text { Flow out of full-quarter employment for Male and Fe- } \\
\text { male and age 19-21 }\end{array}$ & FS_A0A02 & 02856 & 4 & $\mathrm{~N}$ \\
\hline $\begin{array}{l}\text { Flow out of full-quarter employment for Male and Fe- } \\
\text { male and age } 22-24\end{array}$ & FS_A0A03 & 02868 & 4 & $\mathrm{~N}$ \\
\hline $\begin{array}{l}\text { Flow out of full-quarter employment for Male and Fe- } \\
\text { male and age } 25-34\end{array}$ & FS_A0A04 & 02880 & 4 & $\mathrm{~N}$ \\
\hline $\begin{array}{l}\text { Flow out of full-quarter employment for Male and Fe- } \\
\text { male and age } 35-44\end{array}$ & FS_A0A05 & 02892 & 4 & $\mathrm{~N}$ \\
\hline $\begin{array}{l}\text { Flow out of full-quarter employment for Male and Fe- } \\
\text { male and age } 45-54\end{array}$ & FS_A0A06 & 02904 & 4 & $\mathrm{~N}$ \\
\hline $\begin{array}{l}\text { Flow out of full-quarter employment for Male and Fe- } \\
\text { male and age 55-64 }\end{array}$ & FS_A0A07 & 02916 & 4 & $\mathrm{~N}$ \\
\hline $\begin{array}{l}\text { Flow out of full-quarter employment for Male and Fe- } \\
\text { male and age } 65-99\end{array}$ & FS_A0A08 & 02928 & 4 & $\mathrm{~N}$ \\
\hline $\begin{array}{l}\text { Flow out of full-quarter employment for Male and age } \\
14-18\end{array}$ & FS_A1A01 & 02848 & 4 & $\mathrm{~N}$ \\
\hline $\begin{array}{l}\text { Flow out of full-quarter employment for Male and age } \\
14-99\end{array}$ & FS_A1A00 & 02836 & 4 & $\mathrm{~N}$ \\
\hline $\begin{array}{l}\text { Flow out of full-quarter employment for Male and age } \\
19-21\end{array}$ & FS_A1A02 & 02860 & 4 & $\mathrm{~N}$ \\
\hline $\begin{array}{l}\text { Flow out of full-quarter employment for Male and age } \\
22-24\end{array}$ & FS_A1A03 & 02872 & 4 & $\mathrm{~N}$ \\
\hline $\begin{array}{l}\text { Flow out of full-quarter employment for Male and age } \\
25-34\end{array}$ & FS_A1A04 & 02884 & 4 & $\mathrm{~N}$ \\
\hline $\begin{array}{l}\text { Flow out of full-quarter employment for Male and age } \\
35-44\end{array}$ & FS_A1A05 & 02896 & 4 & $\mathrm{~N}$ \\
\hline $\begin{array}{l}\text { Flow out of full-quarter employment for Male and age } \\
45-54\end{array}$ & FS_A1A06 & 02908 & 4 & $\mathrm{~N}$ \\
\hline $\begin{array}{l}\text { Flow out of full-quarter employment for Male and age } \\
55-64\end{array}$ & FS_A1A07 & 02920 & 4 & $\mathrm{~N}$ \\
\hline $\begin{array}{l}\text { Flow out of full-quarter employment for Male and age } \\
65-99\end{array}$ & FS_A1A08 & 02932 & 4 & $\mathrm{~N}$ \\
\hline Full-quarter employment for Female and age 14-18 & F_A2A01 & 00368 & 4 & $\mathrm{~N}$ \\
\hline Full-quarter employment for Female and age 14-99 & F_A2A00 & 00356 & 4 & $\mathrm{~N}$ \\
\hline Full-quarter employment for Female and age 19-21 & F_A2A02 & 00380 & 4 & $\mathrm{~N}$ \\
\hline Full-quarter employment for Female and age 22-24 & F_A2A03 & 00392 & 4 & $\mathrm{~N}$ \\
\hline Full-quarter employment for Female and age 25-34 & $\mathrm{F} \_\mathrm{A} 2 \mathrm{~A} 04$ & 00404 & 4 & $\mathrm{~N}$ \\
\hline Full-quarter employment for Female and age 35-44 & F_A2A05 & 00416 & 4 & $\mathrm{~N}$ \\
\hline Full-quarter employment for Female and age 45-54 & F_A2A06 & 00428 & 4 & $\mathrm{~N}$ \\
\hline Full-quarter employment for Female and age 55-64 & F_A2A07 & 00440 & 4 & $\mathrm{~N}$ \\
\hline Full-quarter employment for Female and age 65-99 & F_A2A08 & 00452 & 4 & $\mathrm{~N}$ \\
\hline
\end{tabular}




\begin{tabular}{|c|c|c|c|c|}
\hline Field name & $\begin{array}{l}\text { Data dictionary } \\
\text { reference name }\end{array}$ & $\begin{array}{l}\text { Starting } \\
\text { position }\end{array}$ & $\begin{array}{l}\text { Field } \\
\text { size }\end{array}$ & $\begin{array}{l}\text { Data } \\
\text { type }\end{array}$ \\
\hline $\begin{array}{l}\text { Full-quarter employment for Male and Female and age } \\
\text { 14-18 }\end{array}$ & F_A0A01 & 00360 & 4 & $\mathrm{~N}$ \\
\hline $\begin{array}{l}\text { Full-quarter employment for Male and Female and age } \\
\text { 14-99 }\end{array}$ & F_A0A00 & 00348 & 4 & $\mathrm{~N}$ \\
\hline $\begin{array}{l}\text { Full-quarter employment for Male and Female and age } \\
\text { 19-21 }\end{array}$ & F_A0A02 & 00372 & 4 & $\mathrm{~N}$ \\
\hline $\begin{array}{l}\text { Full-quarter employment for Male and Female and age } \\
22-24\end{array}$ & F_A0A03 & 00384 & 4 & $\mathrm{~N}$ \\
\hline $\begin{array}{l}\text { Full-quarter employment for Male and Female and age } \\
25-34\end{array}$ & F_A0A04 & 00396 & 4 & $\mathrm{~N}$ \\
\hline $\begin{array}{l}\text { Full-quarter employment for Male and Female and age } \\
35-44\end{array}$ & F_A0A05 & 00408 & 4 & $\mathrm{~N}$ \\
\hline $\begin{array}{l}\text { Full-quarter employment for Male and Female and age } \\
45-54\end{array}$ & F_A0A06 & 00420 & 4 & $\mathrm{~N}$ \\
\hline $\begin{array}{l}\text { Full-quarter employment for Male and Female and age } \\
55-64\end{array}$ & F_A0A07 & 00432 & 4 & $\mathrm{~N}$ \\
\hline $\begin{array}{l}\text { Full-quarter employment for Male and Female and age } \\
65-99\end{array}$ & F_A0A08 & 00444 & 4 & $\mathrm{~N}$ \\
\hline Full-quarter employment for Male and age 14-18 & $\mathrm{F}_{-} \mathrm{A} 1 \mathrm{~A} 01$ & 00364 & 4 & $\mathrm{~N}$ \\
\hline Full-quarter employment for Male and age 14-99 & F_A1A00 & 00352 & 4 & $\mathrm{~N}$ \\
\hline Full-quarter employment for Male and age 19-21 & $\mathrm{F} \_\mathrm{A} 1 \mathrm{~A} 02$ & 00376 & 4 & $\mathrm{~N}$ \\
\hline Full-quarter employment for Male and age 22-24 & F_A1A03 & 00388 & 4 & $\mathrm{~N}$ \\
\hline Full-quarter employment for Male and age 25-34 & F_A1A04 & 00400 & 4 & $\mathrm{~N}$ \\
\hline Full-quarter employment for Male and age 35-44 & F_A1A05 & 00412 & 4 & $\mathrm{~N}$ \\
\hline Full-quarter employment for Male and age $45-54$ & F_A1A06 & 00424 & 4 & $\mathrm{~N}$ \\
\hline Full-quarter employment for Male and age 55-64 & F_A1A07 & 00436 & 4 & $\mathrm{~N}$ \\
\hline Full-quarter employment for Male and age 65-99 & F_A1A08 & 00448 & 4 & $\mathrm{~N}$ \\
\hline Full-quarter job creation for Female and age $14-18$ & FJC_A2A01 & 01448 & 4 & $\mathrm{~N}$ \\
\hline Full-quarter job creation for Female and age 14-99 & FJC_A2A00 & 01436 & 4 & $\mathrm{~N}$ \\
\hline Full-quarter job creation for Female and age 19-21 & FJC_A2A02 & 01460 & 4 & $\mathrm{~N}$ \\
\hline Full-quarter job creation for Female and age $22-24$ & FJC_A2A03 & 01472 & 4 & $\mathrm{~N}$ \\
\hline Full-quarter job creation for Female and age $25-34$ & FJC_A2A04 & 01484 & 4 & $\mathrm{~N}$ \\
\hline Full-quarter job creation for Female and age $35-44$ & FJC_A2A05 & 01496 & 4 & $\mathrm{~N}$ \\
\hline Full-quarter job creation for Female and age $45-54$ & FJC_A2A06 & 01508 & 4 & $\mathrm{~N}$ \\
\hline Full-quarter job creation for Female and age $55-64$ & FJC_A2A07 & 01520 & 4 & $\mathrm{~N}$ \\
\hline Full-quarter job creation for Female and age $65-99$ & FJC_A2A08 & 01532 & 4 & $\mathrm{~N}$ \\
\hline $\begin{array}{l}\text { Full-quarter job creation for Male and Female and age } \\
14-18\end{array}$ & FJC_A0A01 & 01440 & 4 & $\mathrm{~N}$ \\
\hline $\begin{array}{l}\text { Full-quarter job creation for Male and Female and age } \\
14-99\end{array}$ & FJC_A0A00 & 01428 & 4 & $\mathrm{~N}$ \\
\hline $\begin{array}{l}\text { Full-quarter job creation for Male and Female and age } \\
19-21\end{array}$ & FJC_A0A02 & 01452 & 4 & $\mathrm{~N}$ \\
\hline $\begin{array}{l}\text { Full-quarter job creation for Male and Female and age } \\
22-24\end{array}$ & FJC_A0A03 & 01464 & 4 & $\mathrm{~N}$ \\
\hline $\begin{array}{l}\text { Full-quarter job creation for Male and Female and age } \\
25-34\end{array}$ & FJC_A0A04 & 01476 & 4 & $\mathrm{~N}$ \\
\hline $\begin{array}{l}\text { Full-quarter job creation for Male and Female and age } \\
35-44\end{array}$ & FJC_A0A05 & 01488 & 4 & $\mathrm{~N}$ \\
\hline $\begin{array}{l}\text { Full-quarter job creation for Male and Female and age } \\
45-54\end{array}$ & FJC_A0A06 & 01500 & 4 & $\mathrm{~N}$ \\
\hline
\end{tabular}


CHAPTER 7. QUARTERLY WORKFORCE INDICATORS - SEINUNIT FILE (QWI)

\begin{tabular}{|c|c|c|c|c|}
\hline Field name & $\begin{array}{l}\text { Data dictionary } \\
\text { reference name }\end{array}$ & $\begin{array}{l}\text { Starting } \\
\text { position }\end{array}$ & $\begin{array}{l}\text { Field } \\
\text { size }\end{array}$ & $\begin{array}{l}\text { Data } \\
\text { type }\end{array}$ \\
\hline $\begin{array}{l}\text { Full-quarter job creation for Male and Female and age } \\
55-64\end{array}$ & FJC_A0A07 & 01512 & 4 & $\mathrm{~N}$ \\
\hline $\begin{array}{l}\text { Full-quarter job creation for Male and Female and age } \\
65-99\end{array}$ & FJC_A0A08 & 01524 & 4 & $\mathrm{~N}$ \\
\hline Full-quarter job creation for Male and age 14-18 & FJC_A1A01 & 01444 & 4 & $\mathrm{~N}$ \\
\hline Full-quarter job creation for Male and age 14-99 & FJC_A1A00 & 01432 & 4 & $\mathrm{~N}$ \\
\hline Full-quarter job creation for Male and age 19-21 & FJC_A1A02 & 01456 & 4 & $\mathrm{~N}$ \\
\hline Full-quarter job creation for Male and age $22-24$ & FJC_A1A03 & 01468 & 4 & $\mathrm{~N}$ \\
\hline Full-quarter job creation for Male and age 25-34 & FJC_A1A04 & 01480 & 4 & $\mathrm{~N}$ \\
\hline Full-quarter job creation for Male and age $35-44$ & FJC_A1A05 & 01492 & 4 & $\mathrm{~N}$ \\
\hline Full-quarter job creation for Male and age $45-54$ & FJC_A1A06 & 01504 & 4 & $\mathrm{~N}$ \\
\hline Full-quarter job creation for Male and age $55-64$ & FJC_A1A07 & 01516 & 4 & $\mathrm{~N}$ \\
\hline Full-quarter job creation for Male and age $65-99$ & FJC_A1A08 & 01528 & 4 & $\mathrm{~N}$ \\
\hline Full-quarter job destruction for Female and age 14-18 & FJD_A2A01 & 01664 & 4 & $\mathrm{~N}$ \\
\hline Full-quarter job destruction for Female and age 14-99 & FJD_A2A00 & 01652 & 4 & $\mathrm{~N}$ \\
\hline Full-quarter job destruction for Female and age 19-21 & FJD_A2A02 & 01676 & 4 & $\mathrm{~N}$ \\
\hline Full-quarter job destruction for Female and age 22-24 & FJD_A2A03 & 01688 & 4 & $\mathrm{~N}$ \\
\hline Full-quarter job destruction for Female and age 25-34 & FJD_A2A04 & 01700 & 4 & $\mathrm{~N}$ \\
\hline Full-quarter job destruction for Female and age 35-44 & FJD_A2A05 & 01712 & 4 & $\mathrm{~N}$ \\
\hline Full-quarter job destruction for Female and age $45-54$ & FJD_A2A06 & 01724 & 4 & $\mathrm{~N}$ \\
\hline Full-quarter job destruction for Female and age 55-64 & FJD_A2A07 & 01736 & 4 & $\mathrm{~N}$ \\
\hline Full-quarter job destruction for Female and age 65-99 & FJD_A2A08 & 01748 & 4 & $\mathrm{~N}$ \\
\hline $\begin{array}{l}\text { Full-quarter job destruction for Male and Female and } \\
\text { age 14-18 }\end{array}$ & FJD_A0A01 & 01656 & 4 & $\mathrm{~N}$ \\
\hline $\begin{array}{l}\text { Full-quarter job destruction for Male and Female and } \\
\text { age 14-99 }\end{array}$ & FJD_A0A00 & 01644 & 4 & $\mathrm{~N}$ \\
\hline $\begin{array}{l}\text { Full-quarter job destruction for Male and Female and } \\
\text { age } 19-21\end{array}$ & FJD_A0A02 & 01668 & 4 & $\mathrm{~N}$ \\
\hline $\begin{array}{l}\text { Full-quarter job destruction for Male and Female and } \\
\text { age } 22-24\end{array}$ & FJD_A0A03 & 01680 & 4 & $\mathrm{~N}$ \\
\hline $\begin{array}{l}\text { Full-quarter job destruction for Male and Female and } \\
\text { age } 25-34\end{array}$ & FJD_A0A04 & 01692 & 4 & $\mathrm{~N}$ \\
\hline $\begin{array}{l}\text { Full-quarter job destruction for Male and Female and } \\
\text { age } 35-44\end{array}$ & FJD_A0A05 & 01704 & 4 & $\mathrm{~N}$ \\
\hline $\begin{array}{l}\text { Full-quarter job destruction for Male and Female and } \\
\text { age } 45-54\end{array}$ & FJD_A0A06 & 01716 & 4 & $\mathrm{~N}$ \\
\hline $\begin{array}{l}\text { Full-quarter job destruction for Male and Female and } \\
\text { age } 55-64\end{array}$ & FJD_A0A07 & 01728 & 4 & $\mathrm{~N}$ \\
\hline $\begin{array}{l}\text { Full-quarter job destruction for Male and Female and } \\
\text { age } 65-99\end{array}$ & FJD_A0A08 & 01740 & 4 & $\mathrm{~N}$ \\
\hline Full-quarter job destruction for Male and age 14-18 & FJD_A1A01 & 01660 & 4 & $\mathrm{~N}$ \\
\hline Full-quarter job destruction for Male and age 14-99 & FJD_A1A00 & 01648 & 4 & $\mathrm{~N}$ \\
\hline Full-quarter job destruction for Male and age 19-21 & FJD_A1A02 & 01672 & 4 & $\mathrm{~N}$ \\
\hline Full-quarter job destruction for Male and age 22-24 & FJD_A1A03 & 01684 & 4 & $\mathrm{~N}$ \\
\hline Full-quarter job destruction for Male and age 25-34 & FJD_A1A04 & 01696 & 4 & $\mathrm{~N}$ \\
\hline Full-quarter job destruction for Male and age 35-44 & FJD_A1A05 & 01708 & 4 & $\mathrm{~N}$ \\
\hline Full-quarter job destruction for Male and age $45-54$ & FJD_A1A06 & 01720 & 4 & $\mathrm{~N}$ \\
\hline Full-quarter job destruction for Male and age 55-64 & FJD_A1A07 & 01732 & 4 & $\mathrm{~N}$ \\
\hline Full-quarter job destruction for Male and age 65-99 & FJD_A1A08 & 01744 & 4 & $\mathrm{~N}$ \\
\hline Full-quarter new hires for Female and age 14-18 & H3_A2A01 & 02420 & 4 & $\mathrm{~N}$ \\
\hline
\end{tabular}




\begin{tabular}{|c|c|c|c|c|}
\hline Field name & $\begin{array}{l}\text { Data dictionary } \\
\text { reference name }\end{array}$ & $\begin{array}{l}\text { Starting } \\
\text { position }\end{array}$ & $\begin{array}{l}\text { Field } \\
\text { size }\end{array}$ & $\begin{array}{l}\text { Data } \\
\text { type }\end{array}$ \\
\hline Full-quarter new hires for Female and age 14-99 & H3_A2A00 & 02408 & 4 & $\mathrm{~N}$ \\
\hline Full-quarter new hires for Female and age 19-21 & H3_A2A02 & 02432 & 4 & $\mathrm{~N}$ \\
\hline Full-quarter new hires for Female and age $22-24$ & H3_A2A03 & 02444 & 4 & $\mathrm{~N}$ \\
\hline Full-quarter new hires for Female and age 25-34 & H3_A2A04 & 02456 & 4 & $\mathrm{~N}$ \\
\hline Full-quarter new hires for Female and age $35-44$ & H3_A2A05 & 02468 & 4 & $\mathrm{~N}$ \\
\hline Full-quarter new hires for Female and age $45-54$ & H3_A2A06 & 02480 & 4 & $\mathrm{~N}$ \\
\hline Full-quarter new hires for Female and age 55-64 & H3_A2A07 & 02492 & 4 & $\mathrm{~N}$ \\
\hline Full-quarter new hires for Female and age 65-99 & H3_A2A08 & 02504 & 4 & $\mathrm{~N}$ \\
\hline $\begin{array}{l}\text { Full-quarter new hires for Male and Female and age } \\
14-18\end{array}$ & H3_A0A01 & 02412 & 4 & $\mathrm{~N}$ \\
\hline $\begin{array}{l}\text { Full-quarter new hires for Male and Female and age } \\
14-99\end{array}$ & H3_A0A00 & 02400 & 4 & $\mathrm{~N}$ \\
\hline $\begin{array}{l}\text { Full-quarter new hires for Male and Female and age } \\
19-21\end{array}$ & H3_A0A02 & 02424 & 4 & $\mathrm{~N}$ \\
\hline $\begin{array}{l}\text { Full-quarter new hires for Male and Female and age } \\
22-24\end{array}$ & H3_A0A03 & 02436 & 4 & $\mathrm{~N}$ \\
\hline $\begin{array}{l}\text { Full-quarter new hires for Male and Female and age } \\
25-34\end{array}$ & H3_A0A04 & 02448 & 4 & $\mathrm{~N}$ \\
\hline $\begin{array}{l}\text { Full-quarter new hires for Male and Female and age } \\
35-44\end{array}$ & H3_A0A05 & 02460 & 4 & $\mathrm{~N}$ \\
\hline $\begin{array}{l}\text { Full-quarter new hires for Male and Female and age } \\
45-54\end{array}$ & H3_A0A06 & 02472 & 4 & $\mathrm{~N}$ \\
\hline $\begin{array}{l}\text { Full-quarter new hires for Male and Female and age } \\
55-64\end{array}$ & H3_A0A07 & 02484 & 4 & $\mathrm{~N}$ \\
\hline $\begin{array}{l}\text { Full-quarter new hires for Male and Female and age } \\
65-99\end{array}$ & H3_A0A08 & 02496 & 4 & $\mathrm{~N}$ \\
\hline Full-quarter new hires for Male and age 14-18 & H3_A1A01 & 02416 & 4 & $\mathrm{~N}$ \\
\hline Full-quarter new hires for Male and age 14-99 & H3_A1A00 & 02404 & 4 & $\mathrm{~N}$ \\
\hline Full-quarter new hires for Male and age 19-21 & H3_A1A02 & 02428 & 4 & $\mathrm{~N}$ \\
\hline Full-quarter new hires for Male and age 22-24 & H3_A1A03 & 02440 & 4 & $\mathrm{~N}$ \\
\hline Full-quarter new hires for Male and age 25-34 & H3_A1A04 & 02452 & 4 & $\mathrm{~N}$ \\
\hline Full-quarter new hires for Male and age 35-44 & H3_A1A05 & 02464 & 4 & $\mathrm{~N}$ \\
\hline Full-quarter new hires for Male and age $45-54$ & H3_A1A06 & 02476 & 4 & $\mathrm{~N}$ \\
\hline Full-quarter new hires for Male and age $55-64$ & H3_A1A07 & 02488 & 4 & $\mathrm{~N}$ \\
\hline Full-quarter new hires for Male and age 65-99 & H3_A1A08 & 02500 & 4 & $\mathrm{~N}$ \\
\hline Job creation for Female and age $14-18$ & JC_A2A01 & 00692 & 4 & $\mathrm{~N}$ \\
\hline Job creation for Female and age $14-99$ & JC_A2A00 & 00680 & 4 & $\mathrm{~N}$ \\
\hline Job creation for Female and age 19-21 & JC_A2A02 & 00704 & 4 & $\mathrm{~N}$ \\
\hline Job creation for Female and age $22-24$ & JC_A2A03 & 00716 & 4 & $\mathrm{~N}$ \\
\hline Job creation for Female and age $25-34$ & JC_A2A04 & 00728 & 4 & $\mathrm{~N}$ \\
\hline Job creation for Female and age $35-44$ & JC_A2A05 & 00740 & 4 & $\mathrm{~N}$ \\
\hline Job creation for Female and age $45-54$ & JC_A2A06 & 00752 & 4 & $\mathrm{~N}$ \\
\hline Job creation for Female and age $55-64$ & JC_A2A07 & 00764 & 4 & $\mathrm{~N}$ \\
\hline Job creation for Female and age $65-99$ & JC_A2A08 & 00776 & 4 & $\mathrm{~N}$ \\
\hline Job creation for Male and Female and age 14-18 & JC_A0A01 & 00684 & 4 & $\mathrm{~N}$ \\
\hline Job creation for Male and Female and age 14-99 & JC_A0A00 & 00672 & 4 & $\mathrm{~N}$ \\
\hline Job creation for Male and Female and age 19-21 & JC_A0A02 & 00696 & 4 & $\mathrm{~N}$ \\
\hline Job creation for Male and Female and age $22-24$ & JC_A0A03 & 00708 & 4 & $\mathrm{~N}$ \\
\hline Job creation for Male and Female and age 25-34 & JC_A0A04 & 00720 & 4 & $\mathrm{~N}$ \\
\hline Job creation for Male and Female and age $35-44$ & JC_A0A05 & 00732 & 4 & $\mathrm{~N}$ \\
\hline
\end{tabular}




\begin{tabular}{|c|c|c|c|c|}
\hline Field name & $\begin{array}{l}\text { Data dictionary } \\
\text { reference name }\end{array}$ & $\begin{array}{l}\text { Starting } \\
\text { position }\end{array}$ & $\begin{array}{l}\text { Field } \\
\text { size }\end{array}$ & $\begin{array}{l}\text { Data } \\
\text { type }\end{array}$ \\
\hline Job creation for Male and Female and age 45-54 & JC_A0A06 & 00744 & 4 & $\mathrm{~N}$ \\
\hline Job creation for Male and Female and age 55-64 & JC_A0A07 & 00756 & 4 & $\mathrm{~N}$ \\
\hline Job creation for Male and Female and age 65-99 & JC_A0A08 & 00768 & 4 & $\mathrm{~N}$ \\
\hline Job creation for Male and age $14-18$ & JC_A1A01 & 00688 & 4 & $\mathrm{~N}$ \\
\hline Job creation for Male and age 14-99 & JC_A1A00 & 00676 & 4 & $\mathrm{~N}$ \\
\hline Job creation for Male and age $19-21$ & JC_A1A02 & 00700 & 4 & $\mathrm{~N}$ \\
\hline Job creation for Male and age $22-24$ & JC_A1A03 & 00712 & 4 & $\mathrm{~N}$ \\
\hline Job creation for Male and age $25-34$ & JC_A1A04 & 00724 & 4 & $\mathrm{~N}$ \\
\hline Job creation for Male and age $35-44$ & JC_A1A05 & 00736 & 4 & $\mathrm{~N}$ \\
\hline Job creation for Male and age $45-54$ & JC_A1A06 & 00748 & 4 & $\mathrm{~N}$ \\
\hline Job creation for Male and age $55-64$ & JC_A1A07 & 00760 & 4 & $\mathrm{~N}$ \\
\hline Job creation for Male and age $65-99$ & JC_A1A08 & 00772 & 4 & $\mathrm{~N}$ \\
\hline Job destruction for Female and age 14-18 & JD_A2A01 & 00908 & 4 & $\mathrm{~N}$ \\
\hline Job destruction for Female and age 14-99 & JD_A2A00 & 00896 & 4 & $\mathrm{~N}$ \\
\hline Job destruction for Female and age 19-21 & JD_A2A02 & 00920 & 4 & $\mathrm{~N}$ \\
\hline Job destruction for Female and age 22-24 & JD_A2A03 & 00932 & 4 & $\mathrm{~N}$ \\
\hline Job destruction for Female and age 25-34 & JD_A2A04 & 00944 & 4 & $\mathrm{~N}$ \\
\hline Job destruction for Female and age 35-44 & JD_A2A05 & 00956 & 4 & $\mathrm{~N}$ \\
\hline Job destruction for Female and age $45-54$ & JD_A2A06 & 00968 & 4 & $\mathrm{~N}$ \\
\hline Job destruction for Female and age 55-64 & JD_A2A07 & 00980 & 4 & $\mathrm{~N}$ \\
\hline Job destruction for Female and age $65-99$ & JD_A2A08 & 00992 & 4 & $\mathrm{~N}$ \\
\hline Job destruction for Male and Female and age $14-18$ & JD_A0A01 & 00900 & 4 & $\mathrm{~N}$ \\
\hline Job destruction for Male and Female and age 14-99 & JD_A0A00 & 00888 & 4 & $\mathrm{~N}$ \\
\hline Job destruction for Male and Female and age 19-21 & JD_A0A02 & 00912 & 4 & $\mathrm{~N}$ \\
\hline Job destruction for Male and Female and age 22-24 & JD_A0A03 & 00924 & 4 & $\mathrm{~N}$ \\
\hline Job destruction for Male and Female and age 25-34 & JD_A0A04 & 00936 & 4 & $\mathrm{~N}$ \\
\hline Job destruction for Male and Female and age 35-44 & JD_A0A05 & 00948 & 4 & $\mathrm{~N}$ \\
\hline Job destruction for Male and Female and age $45-54$ & JD_A0A06 & 00960 & 4 & $\mathrm{~N}$ \\
\hline Job destruction for Male and Female and age 55-64 & JD_A0A07 & 00972 & 4 & $\mathrm{~N}$ \\
\hline Job destruction for Male and Female and age 65-99 & JD_A0A08 & 00984 & 4 & $\mathrm{~N}$ \\
\hline Job destruction for Male and age $14-18$ & JD_A1A01 & 00904 & 4 & $\mathrm{~N}$ \\
\hline Job destruction for Male and age 14-99 & JD_A1A00 & 00892 & 4 & $\mathrm{~N}$ \\
\hline Job destruction for Male and age 19-21 & JD_A1A02 & 00916 & 4 & $\mathrm{~N}$ \\
\hline Job destruction for Male and age $22-24$ & JD_A1A03 & 00928 & 4 & $\mathrm{~N}$ \\
\hline Job destruction for Male and age $25-34$ & JD_A1A04 & 00940 & 4 & $\mathrm{~N}$ \\
\hline Job destruction for Male and age $35-44$ & JD_A1A05 & 00952 & 4 & $\mathrm{~N}$ \\
\hline Job destruction for Male and age $45-54$ & JD_A1A06 & 00964 & 4 & $\mathrm{~N}$ \\
\hline Job destruction for Male and age $55-64$ & JD_A1A07 & 00976 & 4 & $\mathrm{~N}$ \\
\hline Job destruction for Male and age $65-99$ & JD_A1A08 & 00988 & 4 & $\mathrm{~N}$ \\
\hline MSAPMSA metro area code, mmmmmmmm & LEG_MSAPMSA & 07501 & 8 & $\mathrm{~A} / \mathrm{N}$ \\
\hline $\begin{array}{l}\text { Net change in full-quarter employment for Female and } \\
\text { age 14-18 }\end{array}$ & FJF_A2A01 & 01124 & 4 & $\mathrm{~N}$ \\
\hline $\begin{array}{l}\text { Net change in full-quarter employment for Female and } \\
\text { age 14-99 }\end{array}$ & FJF_A2A00 & 01112 & 4 & $\mathrm{~N}$ \\
\hline $\begin{array}{l}\text { Net change in full-quarter employment for Female and } \\
\text { age } 19-21\end{array}$ & FJF_A2A02 & 01136 & 4 & $\mathrm{~N}$ \\
\hline $\begin{array}{l}\text { Net change in full-quarter employment for Female and } \\
\text { age } 22-24\end{array}$ & FJF_A2A03 & 01148 & 4 & $\mathrm{~N}$ \\
\hline Net change in full-quarter employment for Female and & FJF_A2A04 & 01160 & 4 & $\mathrm{~N}$ \\
\hline
\end{tabular}




\begin{tabular}{|c|c|c|c|c|}
\hline Field name & $\begin{array}{l}\text { Data dictionary } \\
\text { reference name }\end{array}$ & $\begin{array}{l}\text { Starting } \\
\text { position }\end{array}$ & $\begin{array}{l}\text { Field } \\
\text { size }\end{array}$ & $\begin{array}{l}\text { Data } \\
\text { type }\end{array}$ \\
\hline $\begin{array}{l}\text { Net change in full-quarter employment for Female and } \\
\text { age } 35-44\end{array}$ & FJF_A2A05 & 01172 & 4 & $\mathrm{~N}$ \\
\hline $\begin{array}{l}\text { Net change in full-quarter employment for Female and } \\
\text { age } 45-54\end{array}$ & FJF_A2A06 & 01184 & 4 & $\mathrm{~N}$ \\
\hline $\begin{array}{l}\text { Net change in full-quarter employment for Female and } \\
\text { age } 55-64\end{array}$ & FJF_A2A07 & 01196 & 4 & $\mathrm{~N}$ \\
\hline $\begin{array}{l}\text { Net change in full-quarter employment for Female and } \\
\text { age 65-99 }\end{array}$ & FJF_A2A08 & 01208 & 4 & $\mathrm{~N}$ \\
\hline $\begin{array}{l}\text { Net change in full-quarter employment for Male and } \\
\text { Female and age 14-18 }\end{array}$ & FJF_A0A01 & 01116 & 4 & $\mathrm{~N}$ \\
\hline $\begin{array}{l}\text { Net change in full-quarter employment for Male and } \\
\text { Female and age 14-99 }\end{array}$ & FJF_A0A00 & 01104 & 4 & $\mathrm{~N}$ \\
\hline $\begin{array}{l}\text { Net change in full-quarter employment for Male and } \\
\text { Female and age 19-21 }\end{array}$ & FJF_A0A02 & 01128 & 4 & $\mathrm{~N}$ \\
\hline $\begin{array}{l}\text { Net change in full-quarter employment for Male and } \\
\text { Female and age } 22-24\end{array}$ & FJF_A0A03 & 01140 & 4 & $\mathrm{~N}$ \\
\hline $\begin{array}{l}\text { Net change in full-quarter employment for Male and } \\
\text { Female and age } 25-34\end{array}$ & FJF_A0A04 & 01152 & 4 & $\mathrm{~N}$ \\
\hline $\begin{array}{l}\text { Net change in full-quarter employment for Male and } \\
\text { Female and age } 35-44\end{array}$ & FJF_A0A 05 & 01164 & 4 & $\mathrm{~N}$ \\
\hline $\begin{array}{l}\text { Net change in full-quarter employment for Male and } \\
\text { Female and age } 45-54\end{array}$ & FJF_A0A06 & 01176 & 4 & $\mathrm{~N}$ \\
\hline $\begin{array}{l}\text { Net change in full-quarter employment for Male and } \\
\text { Female and age 55-64 }\end{array}$ & FJF_A0A07 & 01188 & 4 & $\mathrm{~N}$ \\
\hline $\begin{array}{l}\text { Net change in full-quarter employment for Male and } \\
\text { Female and age } 65-99\end{array}$ & FJF_A0A08 & 01200 & 4 & $\mathrm{~N}$ \\
\hline $\begin{array}{l}\text { Net change in full-quarter employment for Male and } \\
\text { age 14-18 }\end{array}$ & FJF_A1A01 & 01120 & 4 & $\mathrm{~N}$ \\
\hline $\begin{array}{l}\text { Net change in full-quarter employment for Male and } \\
\text { age 14-99 }\end{array}$ & FJF_A $1 \mathrm{~A} 00$ & 01108 & 4 & $\mathrm{~N}$ \\
\hline $\begin{array}{l}\text { Net change in full-quarter employment for Male and } \\
\text { age 19-21 }\end{array}$ & FJF_A1A02 & 01132 & 4 & $\mathrm{~N}$ \\
\hline $\begin{array}{l}\text { Net change in full-quarter employment for Male and } \\
\text { age } 22-24\end{array}$ & FJF_A1A03 & 01144 & 4 & $\mathrm{~N}$ \\
\hline $\begin{array}{l}\text { Net change in full-quarter employment for Male and } \\
\text { age } 25-34\end{array}$ & FJF_A1A04 & 01156 & 4 & $\mathrm{~N}$ \\
\hline $\begin{array}{l}\text { Net change in full-quarter employment for Male and } \\
\text { age } 35-44\end{array}$ & FJF_A $1 \mathrm{~A} 05$ & 01168 & 4 & $\mathrm{~N}$ \\
\hline $\begin{array}{l}\text { Net change in full-quarter employment for Male and } \\
\text { age } 45-54\end{array}$ & FJF_A1A06 & 01180 & 4 & $\mathrm{~N}$ \\
\hline $\begin{array}{l}\text { Net change in full-quarter employment for Male and } \\
\text { age } 55-64\end{array}$ & FJF_A $1 \mathrm{~A} 07$ & 01192 & 4 & $\mathrm{~N}$ \\
\hline $\begin{array}{l}\text { Net change in full-quarter employment for Male and } \\
\text { age 65-99 }\end{array}$ & FJF_A1A08 & 01204 & 4 & $\mathrm{~N}$ \\
\hline Net job flows for Female and age 14-18 & $\mathrm{JF} \_\mathrm{A} 2 \mathrm{~A} 01$ & 00476 & 4 & $\mathrm{~N}$ \\
\hline Net job flows for Female and age 14-99 & JF_A2A00 & 00464 & 4 & $\mathrm{~N}$ \\
\hline Net job flows for Female and age 19-21 & JF_A2A02 & 00488 & 4 & $\mathrm{~N}$ \\
\hline Net job flows for Female and age 22-24 & JF_A2A03 & 00500 & 4 & $\mathrm{~N}$ \\
\hline Net job flows for Female and age 25-34 & JF_A2A04 & 00512 & 4 & $\mathrm{~N}$ \\
\hline Net job flows for Female and age 35-44 & JF_A2A05 & 00524 & 4 & $\mathrm{~N}$ \\
\hline
\end{tabular}


CHAPTER 7. QUARTERLY WORKFORCE INDICATORS - SEINUNIT FILE (QWI)

\begin{tabular}{|c|c|c|c|c|}
\hline Field name & $\begin{array}{l}\text { Data dictionary } \\
\text { reference name }\end{array}$ & $\begin{array}{l}\text { Starting } \\
\text { position }\end{array}$ & $\begin{array}{l}\text { Field } \\
\text { size }\end{array}$ & $\begin{array}{l}\text { Data } \\
\text { type }\end{array}$ \\
\hline Net job flows for Female and age $45-54$ & JF_A2A06 & 00536 & 4 & $\mathrm{~N}$ \\
\hline Net job flows for Female and age 55-64 & JF_A2A07 & 00548 & 4 & $\mathrm{~N}$ \\
\hline Net job flows for Female and age $65-99$ & JF_A2A08 & 00560 & 4 & $\mathrm{~N}$ \\
\hline Net job flows for Male and Female and age 14-18 & JF_A0A01 & 00468 & 4 & $\mathrm{~N}$ \\
\hline Net job flows for Male and Female and age 14-99 & JF_A0A00 & 00456 & 4 & $\mathrm{~N}$ \\
\hline Net job flows for Male and Female and age 19-21 & JF_A0A02 & 00480 & 4 & $\mathrm{~N}$ \\
\hline Net job flows for Male and Female and age 22-24 & JF_A0A03 & 00492 & 4 & $\mathrm{~N}$ \\
\hline Net job flows for Male and Female and age 25-34 & JF_A0A04 & 00504 & 4 & $\mathrm{~N}$ \\
\hline Net job flows for Male and Female and age $35-44$ & JF_A0A05 & 00516 & 4 & $\mathrm{~N}$ \\
\hline Net job flows for Male and Female and age $45-54$ & JF_A0A06 & 00528 & 4 & $\mathrm{~N}$ \\
\hline Net job flows for Male and Female and age $55-64$ & JF_A0A07 & 00540 & 4 & $\mathrm{~N}$ \\
\hline Net job flows for Male and Female and age $65-99$ & JF_A0A08 & 00552 & 4 & $\mathrm{~N}$ \\
\hline Net job flows for Male and age $14-18$ & JF_A1A01 & 00472 & 4 & $\mathrm{~N}$ \\
\hline Net job flows for Male and age 14-99 & JF_A1A00 & 00460 & 4 & $\mathrm{~N}$ \\
\hline Net job flows for Male and age 19-21 & JF_A1A02 & 00484 & 4 & $\mathrm{~N}$ \\
\hline Net job flows for Male and age 22-24 & JF_A1A03 & 00496 & 4 & $\mathrm{~N}$ \\
\hline Net job flows for Male and age 25-34 & JF_A1A04 & 00508 & 4 & $\mathrm{~N}$ \\
\hline Net job flows for Male and age 35-44 & JF_A1A05 & 00520 & 4 & $\mathrm{~N}$ \\
\hline Net job flows for Male and age $45-54$ & JF_A1A06 & 00532 & 4 & $\mathrm{~N}$ \\
\hline Net job flows for Male and age $55-64$ & JF_A1A07 & 00544 & 4 & $\mathrm{~N}$ \\
\hline Net job flows for Male and age $65-99$ & JF_A1A08 & 00556 & 4 & $\mathrm{~N}$ \\
\hline New hires for Female and age $14-18$ & H_A2A01 & 02312 & 4 & $\mathrm{~N}$ \\
\hline New hires for Female and age 14-99 & H_A2A00 & 02300 & 4 & $\mathrm{~N}$ \\
\hline New hires for Female and age 19-21 & H_A2A02 & 02324 & 4 & $\mathrm{~N}$ \\
\hline New hires for Female and age $22-24$ & H_A2A03 & 02336 & 4 & $\mathrm{~N}$ \\
\hline New hires for Female and age $25-34$ & H_A2A04 & 02348 & 4 & $\mathrm{~N}$ \\
\hline New hires for Female and age $35-44$ & H_A2A05 & 02360 & 4 & $\mathrm{~N}$ \\
\hline New hires for Female and age $45-54$ & H_A2A06 & 02372 & 4 & $\mathrm{~N}$ \\
\hline New hires for Female and age $55-64$ & H_A2A07 & 02384 & 4 & $\mathrm{~N}$ \\
\hline New hires for Female and age $65-99$ & H_A2A08 & 02396 & 4 & $\mathrm{~N}$ \\
\hline New hires for Male and Female and age $14-18$ & H_A0A01 & 02304 & 4 & $\mathrm{~N}$ \\
\hline New hires for Male and Female and age 14-99 & H_A0A00 & 02292 & 4 & $\mathrm{~N}$ \\
\hline New hires for Male and Female and age 19-21 & H_A0A02 & 02316 & 4 & $\mathrm{~N}$ \\
\hline New hires for Male and Female and age 22-24 & H_A0A03 & 02328 & 4 & $\mathrm{~N}$ \\
\hline New hires for Male and Female and age 25-34 & H_A0A04 & 02340 & 4 & $\mathrm{~N}$ \\
\hline New hires for Male and Female and age 35-44 & H_A0A05 & 02352 & 4 & $\mathrm{~N}$ \\
\hline New hires for Male and Female and age $45-54$ & H_A0A06 & 02364 & 4 & $\mathrm{~N}$ \\
\hline New hires for Male and Female and age 55-64 & H_A0A07 & 02376 & 4 & $\mathrm{~N}$ \\
\hline New hires for Male and Female and age 65-99 & H_A0A08 & 02388 & 4 & $\mathrm{~N}$ \\
\hline New hires for Male and age $14-18$ & H_A1A01 & 02308 & 4 & $\mathrm{~N}$ \\
\hline New hires for Male and age $14-99$ & H_A1A00 & 02296 & 4 & $\mathrm{~N}$ \\
\hline New hires for Male and age 19-21 & H_A1A02 & 02320 & 4 & $\mathrm{~N}$ \\
\hline New hires for Male and age $22-24$ & H_A1A03 & 02332 & 4 & $\mathrm{~N}$ \\
\hline New hires for Male and age 25-34 & H_A1A04 & 02344 & 4 & $\mathrm{~N}$ \\
\hline New hires for Male and age $35-44$ & H_A 1 A 05 & 02356 & 4 & $\mathrm{~N}$ \\
\hline New hires for Male and age $45-54$ & H_A1A06 & 02368 & 4 & $\mathrm{~N}$ \\
\hline New hires for Male and age $55-64$ & H_A1A07 & 02380 & 4 & $\mathrm{~N}$ \\
\hline New hires for Male and age 65-99 & H_A1A08 & 02392 & 4 & $\mathrm{~N}$ \\
\hline QWI weight correction factor & QWI_WCF & 00008 & 8 & $\mathrm{~N}$ \\
\hline Quarter QQ & QUARTER & 07537 & 3 & $\mathrm{~N}$ \\
\hline
\end{tabular}


CHAPTER 7. QUARTERLY WORKFORCE INDICATORS - SEINUNIT FILE (QWI)

\begin{tabular}{|c|c|c|c|c|}
\hline Field name & $\begin{array}{l}\text { Data dictionary } \\
\text { reference name }\end{array}$ & $\begin{array}{l}\text { Starting } \\
\text { position }\end{array}$ & $\begin{array}{l}\text { Field } \\
\text { size }\end{array}$ & $\begin{array}{l}\text { Data } \\
\text { type }\end{array}$ \\
\hline Recalls for Female and age $14-18$ & R_A2A01 & 02528 & 4 & $\mathrm{~N}$ \\
\hline Recalls for Female and age 14-99 & R_A2A00 & 02516 & 4 & $\mathrm{~N}$ \\
\hline Recalls for Female and age 19-21 & R_A2A02 & 02540 & 4 & $\mathrm{~N}$ \\
\hline Recalls for Female and age 22-24 & R_A2A03 & 02552 & 4 & $\mathrm{~N}$ \\
\hline Recalls for Female and age 25-34 & R_A2A04 & 02564 & 4 & $\mathrm{~N}$ \\
\hline Recalls for Female and age 35-44 & R_A2A05 & 02576 & 4 & $\mathrm{~N}$ \\
\hline Recalls for Female and age 45-54 & R_A2A06 & 02588 & 4 & $\mathrm{~N}$ \\
\hline Recalls for Female and age 55-64 & R_A2A07 & 02600 & 4 & $\mathrm{~N}$ \\
\hline Recalls for Female and age 65-99 & R_A2A08 & 02612 & 4 & $\mathrm{~N}$ \\
\hline Recalls for Male and Female and age 14-18 & R_A0A01 & 02520 & 4 & $\mathrm{~N}$ \\
\hline Recalls for Male and Female and age 14-99 & R_A0A00 & 02508 & 4 & $\mathrm{~N}$ \\
\hline Recalls for Male and Female and age 19-21 & R_A0A02 & 02532 & 4 & $\mathrm{~N}$ \\
\hline Recalls for Male and Female and age 22-24 & R_A0A03 & 02544 & 4 & $\mathrm{~N}$ \\
\hline Recalls for Male and Female and age 25-34 & R_A0A04 & 02556 & 4 & $\mathrm{~N}$ \\
\hline Recalls for Male and Female and age 35-44 & R_A0A05 & 02568 & 4 & $\mathrm{~N}$ \\
\hline Recalls for Male and Female and age 45-54 & R_A0A06 & 02580 & 4 & $\mathrm{~N}$ \\
\hline Recalls for Male and Female and age 55-64 & R_A0A07 & 02592 & 4 & $\mathrm{~N}$ \\
\hline Recalls for Male and Female and age 65-99 & R_A0A08 & 02604 & 4 & $\mathrm{~N}$ \\
\hline Recalls for Male and age 14-18 & R_A1A01 & 02524 & 4 & $\mathrm{~N}$ \\
\hline Recalls for Male and age 14-99 & R_A1A00 & 02512 & 4 & $\mathrm{~N}$ \\
\hline Recalls for Male and age 19-21 & R_A1A02 & 02536 & 4 & $\mathrm{~N}$ \\
\hline Recalls for Male and age 22-24 & R_A1A03 & 02548 & 4 & $\mathrm{~N}$ \\
\hline Recalls for Male and age 25-34 & R_A1A04 & 02560 & 4 & $\mathrm{~N}$ \\
\hline Recalls for Male and age 35-44 & R_A1A05 & 02572 & 4 & $\mathrm{~N}$ \\
\hline Recalls for Male and age 45-54 & R_A1A06 & 02584 & 4 & $\mathrm{~N}$ \\
\hline Recalls for Male and age 55-64 & R_A1A07 & 02596 & 4 & $\mathrm{~N}$ \\
\hline Recalls for Male and age 65-99 & R_A1A08 & 02608 & 4 & $\mathrm{~N}$ \\
\hline Separations for Female and age $14-18$ & S_A2A01 & 02096 & 4 & $\mathrm{~N}$ \\
\hline Separations for Female and age 14-99 & S_A2A00 & 02084 & 4 & $\mathrm{~N}$ \\
\hline Separations for Female and age 19-21 & S_A2A02 & 02108 & 4 & $\mathrm{~N}$ \\
\hline Separations for Female and age 22-24 & S_A2A03 & 02120 & 4 & $\mathrm{~N}$ \\
\hline Separations for Female and age 25-34 & S_A2A04 & 02132 & 4 & $\mathrm{~N}$ \\
\hline Separations for Female and age $35-44$ & S_A2A05 & 02144 & 4 & $\mathrm{~N}$ \\
\hline Separations for Female and age $45-54$ & S_A2A06 & 02156 & 4 & $\mathrm{~N}$ \\
\hline Separations for Female and age 55-64 & S_A $2 \mathrm{~A} 07$ & 02168 & 4 & $\mathrm{~N}$ \\
\hline Separations for Female and age $65-99$ & S_A2A08 & 02180 & 4 & $\mathrm{~N}$ \\
\hline Separations for Male and Female and age 14-18 & S_A0A01 & 02088 & 4 & $\mathrm{~N}$ \\
\hline Separations for Male and Female and age 14-99 & S_A0A00 & 02076 & 4 & $\mathrm{~N}$ \\
\hline Separations for Male and Female and age 19-21 & S_A0A02 & 02100 & 4 & $\mathrm{~N}$ \\
\hline Separations for Male and Female and age 22-24 & S_A0A03 & 02112 & 4 & $\mathrm{~N}$ \\
\hline Separations for Male and Female and age 25-34 & S_A0A04 & 02124 & 4 & $\mathrm{~N}$ \\
\hline Separations for Male and Female and age 35-44 & S_A0A05 & 02136 & 4 & $\mathrm{~N}$ \\
\hline Separations for Male and Female and age $45-54$ & S_A0A06 & 02148 & 4 & $\mathrm{~N}$ \\
\hline Separations for Male and Female and age 55-64 & S_A0A07 & 02160 & 4 & $\mathrm{~N}$ \\
\hline Separations for Male and Female and age 65-99 & S_A0A08 & 02172 & 4 & $\mathrm{~N}$ \\
\hline Separations for Male and age 14-18 & S_A1A01 & 02092 & 4 & $\mathrm{~N}$ \\
\hline Separations for Male and age $14-99$ & S_A1A00 & 02080 & 4 & $\mathrm{~N}$ \\
\hline Separations for Male and age 19-21 & S_A1A02 & 02104 & 4 & $\mathrm{~N}$ \\
\hline Separations for Male and age $22-24$ & S_A1A03 & 02116 & 4 & $\mathrm{~N}$ \\
\hline Separations for Male and age 25-34 & S_A1A04 & 02128 & 4 & $\mathrm{~N}$ \\
\hline
\end{tabular}




\begin{tabular}{|c|c|c|c|c|}
\hline Field name & $\begin{array}{l}\text { Data dictionary } \\
\text { reference name }\end{array}$ & $\begin{array}{l}\text { Starting } \\
\text { position }\end{array}$ & $\begin{array}{l}\text { Field } \\
\text { size }\end{array}$ & $\begin{array}{l}\text { Data } \\
\text { type }\end{array}$ \\
\hline Separations for Male and age 35-44 & S_A1A05 & 02140 & 4 & $\mathrm{~N}$ \\
\hline Separations for Male and age $45-54$ & S_A1A06 & 02152 & 4 & $\mathrm{~N}$ \\
\hline Separations for Male and age 55-64 & S_A1A07 & 02164 & 4 & $\mathrm{~N}$ \\
\hline Separations for Male and age $65-99$ & S_A1A08 & 02176 & 4 & $\mathrm{~N}$ \\
\hline State Employer ID Number & SEIN & 07476 & 12 & $\mathrm{~A} / \mathrm{N}$ \\
\hline State UI Reporting Unit Number & SEINUNIT & 07488 & 5 & $\mathrm{~A} / \mathrm{N}$ \\
\hline Sub-county geocode & LEG_SUBCTYGEO & 07509 & 10 & $\mathrm{~A} / \mathrm{N}$ \\
\hline $\begin{array}{l}\text { Sum of log of earnings of beginning-of-period employ- } \\
\text { ment for Female and age 14-1 }\end{array}$ & LNWB_A2A01 & 05444 & 4 & $\mathrm{~N}$ \\
\hline $\begin{array}{l}\text { Sum of log of earnings of beginning-of-period employ- } \\
\text { ment for Female and age 14-9 }\end{array}$ & LNWB_A2A00 & 05432 & 4 & $\mathrm{~N}$ \\
\hline $\begin{array}{l}\text { Sum of log of earnings of beginning-of-period employ- } \\
\text { ment for Female and age 19-2 }\end{array}$ & LNWB_A2A02 & 05456 & 4 & $\mathrm{~N}$ \\
\hline $\begin{array}{l}\text { Sum of log of earnings of beginning-of-period employ- } \\
\text { ment for Female and age } 22-2\end{array}$ & LNWB_A2A03 & 05468 & 4 & $\mathrm{~N}$ \\
\hline $\begin{array}{l}\text { Sum of log of earnings of beginning-of-period employ- } \\
\text { ment for Female and age } 25-3\end{array}$ & LNWB_A2A04 & 05480 & 4 & $\mathrm{~N}$ \\
\hline $\begin{array}{l}\text { Sum of log of earnings of beginning-of-period employ- } \\
\text { ment for Female and age } 35-4\end{array}$ & LNWB_A2A05 & 05492 & 4 & $\mathrm{~N}$ \\
\hline $\begin{array}{l}\text { Sum of log of earnings of beginning-of-period employ- } \\
\text { ment for Female and age } 45-5\end{array}$ & LNWB_A2A06 & 05504 & 4 & $\mathrm{~N}$ \\
\hline $\begin{array}{l}\text { Sum of log of earnings of beginning-of-period employ- } \\
\text { ment for Female and age } 55-6\end{array}$ & LNWB_A2A07 & 05516 & 4 & $\mathrm{~N}$ \\
\hline $\begin{array}{l}\text { Sum of log of earnings of beginning-of-period employ- } \\
\text { ment for Female and age } 65-9\end{array}$ & LNWB_A2A08 & 05528 & 4 & $\mathrm{~N}$ \\
\hline $\begin{array}{l}\text { Sum of log of earnings of beginning-of-period employ- } \\
\text { ment for Male and Female and }\end{array}$ & LNWB_A0A01 & 05436 & 4 & $\mathrm{~N}$ \\
\hline $\begin{array}{l}\text { Sum of log of earnings of beginning-of-period employ- } \\
\text { ment for Male and Female and }\end{array}$ & LNWB_A0A00 & 05424 & 4 & $\mathrm{~N}$ \\
\hline $\begin{array}{l}\text { Sum of log of earnings of beginning-of-period employ- } \\
\text { ment for Male and Female and }\end{array}$ & LNWB_A0A02 & 05448 & 4 & $\mathrm{~N}$ \\
\hline $\begin{array}{l}\text { Sum of log of earnings of beginning-of-period employ- } \\
\text { ment for Male and Female and }\end{array}$ & LNWB_A0A03 & 05460 & 4 & $\mathrm{~N}$ \\
\hline $\begin{array}{l}\text { Sum of log of earnings of beginning-of-period employ- } \\
\text { ment for Male and Female and }\end{array}$ & LNWB_A0A04 & 05472 & 4 & $\mathrm{~N}$ \\
\hline $\begin{array}{l}\text { Sum of log of earnings of beginning-of-period employ- } \\
\text { ment for Male and Female and }\end{array}$ & LNWB_A0A05 & 05484 & 4 & $\mathrm{~N}$ \\
\hline $\begin{array}{l}\text { Sum of log of earnings of beginning-of-period employ- } \\
\text { ment for Male and Female and }\end{array}$ & LNWB_A0A06 & 05496 & 4 & $\mathrm{~N}$ \\
\hline $\begin{array}{l}\text { Sum of log of earnings of beginning-of-period employ- } \\
\text { ment for Male and Female and }\end{array}$ & LNWB_A0A07 & 05508 & 4 & $\mathrm{~N}$ \\
\hline $\begin{array}{l}\text { Sum of log of earnings of beginning-of-period employ- } \\
\text { ment for Male and Female and }\end{array}$ & LNWB_A0A08 & 05520 & 4 & $\mathrm{~N}$ \\
\hline $\begin{array}{l}\text { Sum of log of earnings of beginning-of-period employ- } \\
\text { ment for Male and age 14-18 }\end{array}$ & LNWB_A1A01 & 05440 & 4 & $\mathrm{~N}$ \\
\hline $\begin{array}{l}\text { Sum of log of earnings of beginning-of-period employ- } \\
\text { ment for Male and age 14-99 }\end{array}$ & LNWB_A1A00 & 05428 & 4 & $\mathrm{~N}$ \\
\hline Sum of log of earnings of beginning-of-period employ- & LNWB_A1A02 & 05452 & 4 & $\mathrm{~N}$ \\
\hline
\end{tabular}




\begin{tabular}{|c|c|c|c|c|}
\hline Field name & $\begin{array}{l}\text { Data dictionary } \\
\text { reference name }\end{array}$ & $\begin{array}{l}\text { Starting } \\
\text { position }\end{array}$ & $\begin{array}{l}\text { Field } \\
\text { size }\end{array}$ & $\begin{array}{l}\text { Data } \\
\text { type }\end{array}$ \\
\hline $\begin{array}{l}\text { Sum of log of earnings of beginning-of-period employ- } \\
\text { ment for Male and age } 22-24\end{array}$ & LNWB_A1A03 & 05464 & 4 & $\mathrm{~N}$ \\
\hline $\begin{array}{l}\text { Sum of log of earnings of beginning-of-period employ- } \\
\text { ment for Male and age 25-34 }\end{array}$ & LNWB_A1A04 & 05476 & 4 & $\mathrm{~N}$ \\
\hline $\begin{array}{l}\text { Sum of log of earnings of beginning-of-period employ- } \\
\text { ment for Male and age } 35-44\end{array}$ & LNWB_A1A05 & 05488 & 4 & $\mathrm{~N}$ \\
\hline $\begin{array}{l}\text { Sum of log of earnings of beginning-of-period employ- } \\
\text { ment for Male and age } 45-54\end{array}$ & LNWB_A1A06 & 05500 & 4 & $\mathrm{~N}$ \\
\hline $\begin{array}{l}\text { Sum of log of earnings of beginning-of-period employ- } \\
\text { ment for Male and age } 55-64\end{array}$ & LNWB_A1A07 & 05512 & 4 & $\mathrm{~N}$ \\
\hline $\begin{array}{l}\text { Sum of log of earnings of beginning-of-period employ- } \\
\text { ment for Male and age } 65-99\end{array}$ & LNWB_A1A08 & 05524 & 4 & $\mathrm{~N}$ \\
\hline $\begin{array}{l}\text { Sum of log of earnings of end-of-period employment } \\
\text { for Female and age 14-18 }\end{array}$ & LNWE_A2A01 & 05984 & 4 & $\mathrm{~N}$ \\
\hline $\begin{array}{l}\text { Sum of log of earnings of end-of-period employment } \\
\text { for Female and age 14-99 }\end{array}$ & LNWE_A2A00 & 05972 & 4 & $\mathrm{~N}$ \\
\hline $\begin{array}{l}\text { Sum of log of earnings of end-of-period employment } \\
\text { for Female and age 19-21 }\end{array}$ & LNWE_A2A02 & 05996 & 4 & $\mathrm{~N}$ \\
\hline $\begin{array}{l}\text { Sum of log of earnings of end-of-period employment } \\
\text { for Female and age } 22-24\end{array}$ & LNWE_A2A03 & 06008 & 4 & $\mathrm{~N}$ \\
\hline $\begin{array}{l}\text { Sum of log of earnings of end-of-period employment } \\
\text { for Female and age 25-34 }\end{array}$ & LNWE_A2A04 & 06020 & 4 & $\mathrm{~N}$ \\
\hline $\begin{array}{l}\text { Sum of log of earnings of end-of-period employment } \\
\text { for Female and age } 35-44\end{array}$ & LNWE_A2A05 & 06032 & 4 & $\mathrm{~N}$ \\
\hline $\begin{array}{l}\text { Sum of log of earnings of end-of-period employment } \\
\text { for Female and age } 45-54\end{array}$ & LNWE_A2A06 & 06044 & 4 & $\mathrm{~N}$ \\
\hline $\begin{array}{l}\text { Sum of log of earnings of end-of-period employment } \\
\text { for Female and age 55-64 }\end{array}$ & LNWE_A2A07 & 06056 & 4 & $\mathrm{~N}$ \\
\hline $\begin{array}{l}\text { Sum of log of earnings of end-of-period employment } \\
\text { for Female and age } 65-99\end{array}$ & LNWE_A2A08 & 06068 & 4 & $\mathrm{~N}$ \\
\hline $\begin{array}{l}\text { Sum of log of earnings of end-of-period employment } \\
\text { for Male and Female and age } 1\end{array}$ & LNWE_A0A01 & 05976 & 4 & $\mathrm{~N}$ \\
\hline $\begin{array}{l}\text { Sum of log of earnings of end-of-period employment } \\
\text { for Male and Female and age } 1\end{array}$ & LNWE_A0A00 & 05964 & 4 & $\mathrm{~N}$ \\
\hline $\begin{array}{l}\text { Sum of log of earnings of end-of-period employment } \\
\text { for Male and Female and age } 1\end{array}$ & LNWE_A0A02 & 05988 & 4 & $\mathrm{~N}$ \\
\hline $\begin{array}{l}\text { Sum of log of earnings of end-of-period employment } \\
\text { for Male and Female and age } 2\end{array}$ & LNWE_A0A03 & 06000 & 4 & $\mathrm{~N}$ \\
\hline $\begin{array}{l}\text { Sum of log of earnings of end-of-period employment } \\
\text { for Male and Female and age } 2\end{array}$ & LNWE_A0A04 & 06012 & 4 & $\mathrm{~N}$ \\
\hline $\begin{array}{l}\text { Sum of log of earnings of end-of-period employment } \\
\text { for Male and Female and age } 3\end{array}$ & LNWE_A0A05 & 06024 & 4 & $\mathrm{~N}$ \\
\hline $\begin{array}{l}\text { Sum of log of earnings of end-of-period employment } \\
\text { for Male and Female and age } 4\end{array}$ & LNWE_A0A06 & 06036 & 4 & $\mathrm{~N}$ \\
\hline $\begin{array}{l}\text { Sum of log of earnings of end-of-period employment } \\
\text { for Male and Female and age } 5\end{array}$ & LNWE_A0A07 & 06048 & 4 & $\mathrm{~N}$ \\
\hline $\begin{array}{l}\text { Sum of log of earnings of end-of-period employment } \\
\text { for Male and Female and age } 6\end{array}$ & LNWE_A0A08 & 06060 & 4 & $\mathrm{~N}$ \\
\hline Sum of log of earnings of end-of-period employment & LNWE_A1A01 & 05980 & 4 & $\mathrm{~N}$ \\
\hline
\end{tabular}




\begin{tabular}{|c|c|c|c|c|}
\hline Field name & $\begin{array}{l}\text { Data dictionary } \\
\text { reference name }\end{array}$ & $\begin{array}{l}\text { Starting } \\
\text { position }\end{array}$ & $\begin{array}{l}\text { Field } \\
\text { size }\end{array}$ & $\begin{array}{l}\text { Data } \\
\text { type }\end{array}$ \\
\hline $\begin{array}{l}\text { Sum of log of earnings of end-of-period employment } \\
\text { for Male and age 14-99 }\end{array}$ & LNWE_A1A00 & 05968 & 4 & $\mathrm{~N}$ \\
\hline $\begin{array}{l}\text { Sum of log of earnings of end-of-period employment } \\
\text { for Male and age 19-21 }\end{array}$ & LNWE_A1A02 & 05992 & 4 & $\mathrm{~N}$ \\
\hline $\begin{array}{l}\text { Sum of log of earnings of end-of-period employment } \\
\text { for Male and age } 22-24\end{array}$ & LNWE_A1A03 & 06004 & 4 & $\mathrm{~N}$ \\
\hline $\begin{array}{l}\text { Sum of log of earnings of end-of-period employment } \\
\text { for Male and age 25-34 }\end{array}$ & LNWE_A1A04 & 06016 & 4 & $\mathrm{~N}$ \\
\hline $\begin{array}{l}\text { Sum of log of earnings of end-of-period employment } \\
\text { for Male and age } 35-44\end{array}$ & LNWE_A1A05 & 06028 & 4 & $\mathrm{~N}$ \\
\hline $\begin{array}{l}\text { Sum of log of earnings of end-of-period employment } \\
\text { for Male and age } 45-54\end{array}$ & LNWE_A1A06 & 06040 & 4 & $\mathrm{~N}$ \\
\hline $\begin{array}{l}\text { Sum of log of earnings of end-of-period employment } \\
\text { for Male and age } 55-64\end{array}$ & LNWE_A1A07 & 06052 & 4 & $\mathrm{~N}$ \\
\hline $\begin{array}{l}\text { Sum of log of earnings of end-of-period employment } \\
\text { for Male and age } 65-99\end{array}$ & LNWE_A1A08 & 06064 & 4 & $\mathrm{~N}$ \\
\hline $\begin{array}{l}\text { Sum of log of earnings of full-quarter employment for } \\
\text { Female and age 14-18 }\end{array}$ & LNWF_A2A01 & 06524 & 4 & $\mathrm{~N}$ \\
\hline $\begin{array}{l}\text { Sum of log of earnings of full-quarter employment for } \\
\text { Female and age 14-99 }\end{array}$ & LNWF_A2A00 & 06512 & 4 & $\mathrm{~N}$ \\
\hline $\begin{array}{l}\text { Sum of log of earnings of full-quarter employment for } \\
\text { Female and age 19-21 }\end{array}$ & LNWF_A2A02 & 06536 & 4 & $\mathrm{~N}$ \\
\hline $\begin{array}{l}\text { Sum of log of earnings of full-quarter employment for } \\
\text { Female and age } 22-24\end{array}$ & LNWF_A2A03 & 06548 & 4 & $\mathrm{~N}$ \\
\hline $\begin{array}{l}\text { Sum of log of earnings of full-quarter employment for } \\
\text { Female and age 25-34 }\end{array}$ & LNWF_A2A04 & 06560 & 4 & $\mathrm{~N}$ \\
\hline $\begin{array}{l}\text { Sum of log of earnings of full-quarter employment for } \\
\text { Female and age } 35-44\end{array}$ & LNWF_A2A05 & 06572 & 4 & $\mathrm{~N}$ \\
\hline $\begin{array}{l}\text { Sum of log of earnings of full-quarter employment for } \\
\text { Female and age } 45-54\end{array}$ & LNWF_A2A06 & 06584 & 4 & $\mathrm{~N}$ \\
\hline $\begin{array}{l}\text { Sum of log of earnings of full-quarter employment for } \\
\text { Female and age 55-64 }\end{array}$ & LNWF_A2A07 & 06596 & 4 & $\mathrm{~N}$ \\
\hline $\begin{array}{l}\text { Sum of log of earnings of full-quarter employment for } \\
\text { Female and age 65-99 }\end{array}$ & LNWF_A2A08 & 06608 & 4 & $\mathrm{~N}$ \\
\hline $\begin{array}{l}\text { Sum of log of earnings of full-quarter employment for } \\
\text { Male and Female and age } 14\end{array}$ & LNWF_A0A01 & 06516 & 4 & $\mathrm{~N}$ \\
\hline $\begin{array}{l}\text { Sum of log of earnings of full-quarter employment for } \\
\text { Male and Female and age } 14\end{array}$ & LNWF_A0A00 & 06504 & 4 & $\mathrm{~N}$ \\
\hline $\begin{array}{l}\text { Sum of log of earnings of full-quarter employment for } \\
\text { Male and Female and age } 19\end{array}$ & LNWF_A0A02 & 06528 & 4 & $\mathrm{~N}$ \\
\hline $\begin{array}{l}\text { Sum of log of earnings of full-quarter employment for } \\
\text { Male and Female and age } 22\end{array}$ & LNWF_A0A03 & 06540 & 4 & $\mathrm{~N}$ \\
\hline $\begin{array}{l}\text { Sum of log of earnings of full-quarter employment for } \\
\text { Male and Female and age } 25\end{array}$ & LNWF_A0A04 & 06552 & 4 & $\mathrm{~N}$ \\
\hline $\begin{array}{l}\text { Sum of log of earnings of full-quarter employment for } \\
\text { Male and Female and age } 35\end{array}$ & LNWF_A0A05 & 06564 & 4 & $\mathrm{~N}$ \\
\hline $\begin{array}{l}\text { Sum of log of earnings of full-quarter employment for } \\
\text { Male and Female and age } 45\end{array}$ & LNWF_A0A06 & 06576 & 4 & $\mathrm{~N}$ \\
\hline Sum of log of earnings of full-quarter employment for & LNWF_A0A07 & 06588 & 4 & $\mathrm{~N}$ \\
\hline
\end{tabular}




\begin{tabular}{|c|c|c|c|c|}
\hline Field name & $\begin{array}{l}\text { Data dictionary } \\
\text { reference name }\end{array}$ & $\begin{array}{l}\text { Starting } \\
\text { position }\end{array}$ & $\begin{array}{l}\text { Field } \\
\text { size }\end{array}$ & $\begin{array}{l}\text { Data } \\
\text { type }\end{array}$ \\
\hline $\begin{array}{l}\text { Sum of log of earnings of full-quarter employment for } \\
\text { Male and Female and age } 65\end{array}$ & LNWF_A0A08 & 06600 & 4 & $\mathrm{~N}$ \\
\hline $\begin{array}{l}\text { Sum of log of earnings of full-quarter employment for } \\
\text { Male and age 14-18 }\end{array}$ & LNWF_A1A01 & 06520 & 4 & $\mathrm{~N}$ \\
\hline $\begin{array}{l}\text { Sum of log of earnings of full-quarter employment for } \\
\text { Male and age 14-99 }\end{array}$ & LNWF_A1A00 & 06508 & 4 & $\mathrm{~N}$ \\
\hline $\begin{array}{l}\text { Sum of log of earnings of full-quarter employment for } \\
\text { Male and age 19-21 }\end{array}$ & LNWF_A1A02 & 06532 & 4 & $\mathrm{~N}$ \\
\hline $\begin{array}{l}\text { Sum of log of earnings of full-quarter employment for } \\
\text { Male and age } 22-24\end{array}$ & LNWF_A1A03 & 06544 & 4 & $\mathrm{~N}$ \\
\hline $\begin{array}{l}\text { Sum of log of earnings of full-quarter employment for } \\
\text { Male and age 25-34 }\end{array}$ & LNWF_A1A04 & 06556 & 4 & $\mathrm{~N}$ \\
\hline $\begin{array}{l}\text { Sum of log of earnings of full-quarter employment for } \\
\text { Male and age } 35-44\end{array}$ & LNWF_A1A05 & 06568 & 4 & $\mathrm{~N}$ \\
\hline $\begin{array}{l}\text { Sum of log of earnings of full-quarter employment for } \\
\text { Male and age } 45-54\end{array}$ & LNWF_A1A06 & 06580 & 4 & $\mathrm{~N}$ \\
\hline $\begin{array}{l}\text { Sum of log of earnings of full-quarter employment for } \\
\text { Male and age } 55-64\end{array}$ & LNWF_A1A07 & 06592 & 4 & $\mathrm{~N}$ \\
\hline $\begin{array}{l}\text { Sum of log of earnings of full-quarter employment for } \\
\text { Male and age } 65-99\end{array}$ & LNWF_A1A08 & 06604 & 4 & $\mathrm{~N}$ \\
\hline $\begin{array}{l}\text { Sum of log of lag earnings of beginning-of-period em- } \\
\text { ployment for Female and age }\end{array}$ & LNWBLG_A2A01 & 05552 & 4 & $\mathrm{~N}$ \\
\hline $\begin{array}{l}\text { Sum of log of lag earnings of beginning-of-period em- } \\
\text { ployment for Female and age }\end{array}$ & LNWBLG_A2A00 & 05540 & 4 & $\mathrm{~N}$ \\
\hline $\begin{array}{l}\text { Sum of log of lag earnings of beginning-of-period em- } \\
\text { ployment for Female and age }\end{array}$ & LNWBLG_A2A02 & 05564 & 4 & $\mathrm{~N}$ \\
\hline $\begin{array}{l}\text { Sum of log of lag earnings of beginning-of-period em- } \\
\text { ployment for Female and age }\end{array}$ & LNWBLG_A2A03 & 05576 & 4 & $\mathrm{~N}$ \\
\hline $\begin{array}{l}\text { Sum of log of lag earnings of beginning-of-period em- } \\
\text { ployment for Female and age }\end{array}$ & LNWBLG_A2A04 & 05588 & 4 & $\mathrm{~N}$ \\
\hline $\begin{array}{l}\text { Sum of log of lag earnings of beginning-of-period em- } \\
\text { ployment for Female and age }\end{array}$ & LNWBLG_A2A05 & 05600 & 4 & $\mathrm{~N}$ \\
\hline $\begin{array}{l}\text { Sum of log of lag earnings of beginning-of-period em- } \\
\text { ployment for Female and age }\end{array}$ & LNWBLG_A2A06 & 05612 & 4 & $\mathrm{~N}$ \\
\hline $\begin{array}{l}\text { Sum of log of lag earnings of beginning-of-period em- } \\
\text { ployment for Female and age }\end{array}$ & LNWBLG_A2A07 & 05624 & 4 & $\mathrm{~N}$ \\
\hline $\begin{array}{l}\text { Sum of log of lag earnings of beginning-of-period em- } \\
\text { ployment for Female and age }\end{array}$ & LNWBLG_A2A08 & 05636 & 4 & $\mathrm{~N}$ \\
\hline $\begin{array}{l}\text { Sum of log of lag earnings of beginning-of-period em- } \\
\text { ployment for Male and Female }\end{array}$ & LNWBLG_A0A01 & 05544 & 4 & $\mathrm{~N}$ \\
\hline $\begin{array}{l}\text { Sum of log of lag earnings of beginning-of-period em- } \\
\text { ployment for Male and Female }\end{array}$ & LNWBLG_A0A00 & 05532 & 4 & $\mathrm{~N}$ \\
\hline $\begin{array}{l}\text { Sum of log of lag earnings of beginning-of-period em- } \\
\text { ployment for Male and Female }\end{array}$ & LNWBLG_A0A02 & 05556 & 4 & $\mathrm{~N}$ \\
\hline $\begin{array}{l}\text { Sum of log of lag earnings of beginning-of-period em- } \\
\text { ployment for Male and Female }\end{array}$ & LNWBLG_A0A03 & 05568 & 4 & $\mathrm{~N}$ \\
\hline $\begin{array}{l}\text { Sum of log of lag earnings of beginning-of-period em- } \\
\text { ployment for Male and Female }\end{array}$ & LNWBLG_A0A04 & 05580 & 4 & $\mathrm{~N}$ \\
\hline Sum of log of lag earnings of beginning-of-period em- & LNWBLG_A0A05 & 05592 & 4 & $\mathrm{~N}$ \\
\hline
\end{tabular}




\begin{tabular}{|c|c|c|c|c|}
\hline Field name & $\begin{array}{l}\text { Data dictionary } \\
\text { reference name }\end{array}$ & $\begin{array}{l}\text { Starting } \\
\text { position }\end{array}$ & $\begin{array}{l}\text { Field } \\
\text { size }\end{array}$ & $\begin{array}{l}\text { Data } \\
\text { type }\end{array}$ \\
\hline $\begin{array}{l}\text { Sum of log of lag earnings of beginning-of-period em- } \\
\text { ployment for Male and Female }\end{array}$ & LNWBLG_A0A06 & 05604 & 4 & $\mathrm{~N}$ \\
\hline $\begin{array}{l}\text { Sum of log of lag earnings of beginning-of-period em- } \\
\text { ployment for Male and Female }\end{array}$ & LNWBLG_A0A07 & 05616 & 4 & $\mathrm{~N}$ \\
\hline $\begin{array}{l}\text { Sum of log of lag earnings of beginning-of-period em- } \\
\text { ployment for Male and Female }\end{array}$ & LNWBLG_A0A08 & 05628 & 4 & $\mathrm{~N}$ \\
\hline $\begin{array}{l}\text { Sum of log of lag earnings of beginning-of-period em- } \\
\text { ployment for Male and age } 14\end{array}$ & LNWBLG_A1A01 & 05548 & 4 & $\mathrm{~N}$ \\
\hline $\begin{array}{l}\text { Sum of log of lag earnings of beginning-of-period em- } \\
\text { ployment for Male and age } 14\end{array}$ & LNWBLG_A1A00 & 05536 & 4 & $\mathrm{~N}$ \\
\hline $\begin{array}{l}\text { Sum of log of lag earnings of beginning-of-period em- } \\
\text { ployment for Male and age } 19\end{array}$ & LNWBLG_A1A02 & 05560 & 4 & $\mathrm{~N}$ \\
\hline $\begin{array}{l}\text { Sum of log of lag earnings of beginning-of-period em- } \\
\text { ployment for Male and age } 22\end{array}$ & LNWBLG_A1A03 & 05572 & 4 & $\mathrm{~N}$ \\
\hline $\begin{array}{l}\text { Sum of log of lag earnings of beginning-of-period em- } \\
\text { ployment for Male and age } 25\end{array}$ & LNWBLG_A1A04 & 05584 & 4 & $\mathrm{~N}$ \\
\hline $\begin{array}{l}\text { Sum of log of lag earnings of beginning-of-period em- } \\
\text { ployment for Male and age } 35\end{array}$ & LNWBLG_A1A05 & 05596 & 4 & $\mathrm{~N}$ \\
\hline $\begin{array}{l}\text { Sum of log of lag earnings of beginning-of-period em- } \\
\text { ployment for Male and age } 45\end{array}$ & LNWBLG_A1A06 & 05608 & 4 & $\mathrm{~N}$ \\
\hline $\begin{array}{l}\text { Sum of log of lag earnings of beginning-of-period em- } \\
\text { ployment for Male and age } 55\end{array}$ & LNWBLG_A1A07 & 05620 & 4 & $\mathrm{~N}$ \\
\hline $\begin{array}{l}\text { Sum of log of lag earnings of beginning-of-period em- } \\
\text { ployment for Male and age } 65\end{array}$ & LNWBLG_A1A08 & 05632 & 4 & $\mathrm{~N}$ \\
\hline $\begin{array}{l}\text { Sum of log of lag earnings of full-quarter employment } \\
\text { for Female and age 14-18 }\end{array}$ & LNWFLG_A2A01 & 06740 & 4 & $\mathrm{~N}$ \\
\hline $\begin{array}{l}\text { Sum of log of lag earnings of full-quarter employment } \\
\text { for Female and age 14-99 }\end{array}$ & LNWFLG_A2A00 & 06728 & 4 & $\mathrm{~N}$ \\
\hline $\begin{array}{l}\text { Sum of log of lag earnings of full-quarter employment } \\
\text { for Female and age 19-21 }\end{array}$ & LNWFLG_A2A02 & 06752 & 4 & $\mathrm{~N}$ \\
\hline $\begin{array}{l}\text { Sum of log of lag earnings of full-quarter employment } \\
\text { for Female and age } 22-24\end{array}$ & LNWFLG_A2A03 & 06764 & 4 & $\mathrm{~N}$ \\
\hline $\begin{array}{l}\text { Sum of log of lag earnings of full-quarter employment } \\
\text { for Female and age 25-34 }\end{array}$ & LNWFLG_A2A04 & 06776 & 4 & $\mathrm{~N}$ \\
\hline $\begin{array}{l}\text { Sum of log of lag earnings of full-quarter employment } \\
\text { for Female and age } 35-44\end{array}$ & LNWFLG_A2A05 & 06788 & 4 & $\mathrm{~N}$ \\
\hline $\begin{array}{l}\text { Sum of log of lag earnings of full-quarter employment } \\
\text { for Female and age 45-54 }\end{array}$ & LNWFLG_A2A06 & 06800 & 4 & $\mathrm{~N}$ \\
\hline $\begin{array}{l}\text { Sum of log of lag earnings of full-quarter employment } \\
\text { for Female and age } 55-64\end{array}$ & LNWFLG_A2A07 & 06812 & 4 & $\mathrm{~N}$ \\
\hline $\begin{array}{l}\text { Sum of log of lag earnings of full-quarter employment } \\
\text { for Female and age } 65-99\end{array}$ & LNWFLG_A2A08 & 06824 & 4 & $\mathrm{~N}$ \\
\hline $\begin{array}{l}\text { Sum of log of lag earnings of full-quarter employment } \\
\text { for Male and Female and ag }\end{array}$ & LNWFLG_A0A01 & 06732 & 4 & $\mathrm{~N}$ \\
\hline $\begin{array}{l}\text { Sum of log of lag earnings of full-quarter employment } \\
\text { for Male and Female and ag }\end{array}$ & LNWFLG_A0A00 & 06720 & 4 & $\mathrm{~N}$ \\
\hline $\begin{array}{l}\text { Sum of log of lag earnings of full-quarter employment } \\
\text { for Male and Female and ag }\end{array}$ & LNWFLG_A0A02 & 06744 & 4 & $\mathrm{~N}$ \\
\hline $\begin{array}{l}\text { Sum of log of lag earnings of full-quarter employment } \\
\text { for Male and Female and a }\end{array}$ & LNWFLG_A0A03 & 06756 & 4 & $\mathrm{~N}$ \\
\hline
\end{tabular}




\begin{tabular}{|c|c|c|c|c|}
\hline Field name & $\begin{array}{l}\text { Data dictionary } \\
\text { reference name }\end{array}$ & $\begin{array}{l}\text { Starting } \\
\text { position }\end{array}$ & $\begin{array}{l}\text { Field } \\
\text { size }\end{array}$ & $\begin{array}{l}\text { Data } \\
\text { type }\end{array}$ \\
\hline $\begin{array}{l}\text { Sum of log of lag earnings of full-quarter employment } \\
\text { for Male and Female and ag }\end{array}$ & LNWFLG_A0A04 & 06768 & 4 & $\mathrm{~N}$ \\
\hline $\begin{array}{l}\text { Sum of log of lag earnings of full-quarter employment } \\
\text { for Male and Female and ag }\end{array}$ & LNWFLG_A0A05 & 06780 & 4 & $\mathrm{~N}$ \\
\hline $\begin{array}{l}\text { Sum of log of lag earnings of full-quarter employment } \\
\text { for Male and Female and ag }\end{array}$ & LNWFLG_A0A06 & 06792 & 4 & $\mathrm{~N}$ \\
\hline $\begin{array}{l}\text { Sum of log of lag earnings of full-quarter employment } \\
\text { for Male and Female and ag }\end{array}$ & LNWFLG_A0A07 & 06804 & 4 & $\mathrm{~N}$ \\
\hline $\begin{array}{l}\text { Sum of log of lag earnings of full-quarter employment } \\
\text { for Male and Female and ag }\end{array}$ & LNWFLG_A0A08 & 06816 & 4 & $\mathrm{~N}$ \\
\hline $\begin{array}{l}\text { Sum of log of lag earnings of full-quarter employment } \\
\text { for Male and age 14-18 }\end{array}$ & LNWFLG_A1A01 & 06736 & 4 & $\mathrm{~N}$ \\
\hline $\begin{array}{l}\text { Sum of log of lag earnings of full-quarter employment } \\
\text { for Male and age 14-99 }\end{array}$ & LNWFLG_A1A00 & 06724 & 4 & $\mathrm{~N}$ \\
\hline $\begin{array}{l}\text { Sum of log of lag earnings of full-quarter employment } \\
\text { for Male and age 19-21 }\end{array}$ & LNWFLG_A1A02 & 06748 & 4 & $\mathrm{~N}$ \\
\hline $\begin{array}{l}\text { Sum of log of lag earnings of full-quarter employment } \\
\text { for Male and age } 22-24\end{array}$ & LNWFLG_A1A03 & 06760 & 4 & $\mathrm{~N}$ \\
\hline $\begin{array}{l}\text { Sum of log of lag earnings of full-quarter employment } \\
\text { for Male and age } 25-34\end{array}$ & LNWFLG_A1A04 & 06772 & 4 & $\mathrm{~N}$ \\
\hline $\begin{array}{l}\text { Sum of log of lag earnings of full-quarter employment } \\
\text { for Male and age } 35-44\end{array}$ & LNWFLG_A1A05 & 06784 & 4 & $\mathrm{~N}$ \\
\hline $\begin{array}{l}\text { Sum of log of lag earnings of full-quarter employment } \\
\text { for Male and age } 45-54\end{array}$ & LNWFLG_A1A06 & 06796 & 4 & $\mathrm{~N}$ \\
\hline $\begin{array}{l}\text { Sum of log of lag earnings of full-quarter employment } \\
\text { for Male and age } 55-64\end{array}$ & LNWFLG_A1A07 & 06808 & 4 & $\mathrm{~N}$ \\
\hline $\begin{array}{l}\text { Sum of log of lag earnings of full-quarter employment } \\
\text { for Male and age } 65-99\end{array}$ & LNWFLG_A1A08 & 06820 & 4 & $\mathrm{~N}$ \\
\hline $\begin{array}{l}\text { Sum of log of lead earnings of end-of-period employ- } \\
\text { ment for Female and age 14-18 }\end{array}$ & LNWELD_A2A01 & 06092 & 4 & $\mathrm{~N}$ \\
\hline $\begin{array}{l}\text { Sum of log of lead earnings of end-of-period employ- } \\
\text { ment for Female and age 14-99 }\end{array}$ & LNWELD_A2A00 & 06080 & 4 & $\mathrm{~N}$ \\
\hline $\begin{array}{l}\text { Sum of log of lead earnings of end-of-period employ- } \\
\text { ment for Female and age 19-21 }\end{array}$ & LNWELD_A2A02 & 06104 & 4 & $\mathrm{~N}$ \\
\hline $\begin{array}{l}\text { Sum of log of lead earnings of end-of-period employ- } \\
\text { ment for Female and age } 22-24\end{array}$ & LNWELD_A2A03 & 06116 & 4 & $\mathrm{~N}$ \\
\hline $\begin{array}{l}\text { Sum of log of lead earnings of end-of-period employ- } \\
\text { ment for Female and age 25-34 }\end{array}$ & LNWELD_A2A04 & 06128 & 4 & $\mathrm{~N}$ \\
\hline $\begin{array}{l}\text { Sum of log of lead earnings of end-of-period employ- } \\
\text { ment for Female and age } 35-44\end{array}$ & LNWELD_A2A05 & 06140 & 4 & $\mathrm{~N}$ \\
\hline $\begin{array}{l}\text { Sum of log of lead earnings of end-of-period employ- } \\
\text { ment for Female and age 45-54 }\end{array}$ & LNWELD_A2A06 & 06152 & 4 & $\mathrm{~N}$ \\
\hline $\begin{array}{l}\text { Sum of log of lead earnings of end-of-period employ- } \\
\text { ment for Female and age 55-64 }\end{array}$ & LNWELD_A2A07 & 06164 & 4 & $\mathrm{~N}$ \\
\hline $\begin{array}{l}\text { Sum of log of lead earnings of end-of-period employ- } \\
\text { ment for Female and age } 65-99\end{array}$ & LNWELD_A2A08 & 06176 & 4 & $\mathrm{~N}$ \\
\hline $\begin{array}{l}\text { Sum of log of lead earnings of end-of-period employ- } \\
\text { ment for Male and Female and }\end{array}$ & LNWELD_A0A01 & 06084 & 4 & $\mathrm{~N}$ \\
\hline $\begin{array}{l}\text { Sum of log of lead earnings of end-of-period employ- } \\
\text { ment for Male and Female and }\end{array}$ & LNWELD_A0A00 & 06072 & 4 & $\mathrm{~N}$ \\
\hline
\end{tabular}




\begin{tabular}{|c|c|c|c|c|}
\hline Field name & $\begin{array}{l}\text { Data dictionary } \\
\text { reference name }\end{array}$ & $\begin{array}{l}\text { Starting } \\
\text { position }\end{array}$ & $\begin{array}{l}\text { Field } \\
\text { size }\end{array}$ & $\begin{array}{l}\text { Data } \\
\text { type }\end{array}$ \\
\hline $\begin{array}{l}\text { Sum of log of lead earnings of end-of-period employ- } \\
\text { ment for Male and Female and }\end{array}$ & LNWELD_A0A02 & 06096 & 4 & $\mathrm{~N}$ \\
\hline $\begin{array}{l}\text { Sum of log of lead earnings of end-of-period employ- } \\
\text { ment for Male and Female and }\end{array}$ & LNWELD_A0A03 & 06108 & 4 & $\mathrm{~N}$ \\
\hline $\begin{array}{l}\text { Sum of log of lead earnings of end-of-period employ- } \\
\text { ment for Male and Female and }\end{array}$ & LNWELD_A0A04 & 06120 & 4 & $\mathrm{~N}$ \\
\hline $\begin{array}{l}\text { Sum of log of lead earnings of end-of-period employ- } \\
\text { ment for Male and Female and }\end{array}$ & LNWELD_A0A05 & 06132 & 4 & $\mathrm{~N}$ \\
\hline $\begin{array}{l}\text { Sum of log of lead earnings of end-of-period employ- } \\
\text { ment for Male and Female and }\end{array}$ & LNWELD_A0A06 & 06144 & 4 & $\mathrm{~N}$ \\
\hline $\begin{array}{l}\text { Sum of log of lead earnings of end-of-period employ- } \\
\text { ment for Male and Female and }\end{array}$ & LNWELD_A0A07 & 06156 & 4 & $\mathrm{~N}$ \\
\hline $\begin{array}{l}\text { Sum of log of lead earnings of end-of-period employ- } \\
\text { ment for Male and Female and }\end{array}$ & LNWELD_A0A08 & 06168 & 4 & $\mathrm{~N}$ \\
\hline $\begin{array}{l}\text { Sum of log of lead earnings of end-of-period employ- } \\
\text { ment for Male and age 14-18 }\end{array}$ & LNWELD_A1A01 & 06088 & 4 & $\mathrm{~N}$ \\
\hline $\begin{array}{l}\text { Sum of log of lead earnings of end-of-period employ- } \\
\text { ment for Male and age 14-99 }\end{array}$ & LNWELD_A1A00 & 06076 & 4 & $\mathrm{~N}$ \\
\hline $\begin{array}{l}\text { Sum of log of lead earnings of end-of-period employ- } \\
\text { ment for Male and age 19-21 }\end{array}$ & LNWELD_A1A02 & 06100 & 4 & $\mathrm{~N}$ \\
\hline $\begin{array}{l}\text { Sum of log of lead earnings of end-of-period employ- } \\
\text { ment for Male and age } 22-24\end{array}$ & LNWELD_A1A03 & 06112 & 4 & $\mathrm{~N}$ \\
\hline $\begin{array}{l}\text { Sum of log of lead earnings of end-of-period employ- } \\
\text { ment for Male and age 25-34 }\end{array}$ & LNWELD_A1A04 & 06124 & 4 & $\mathrm{~N}$ \\
\hline $\begin{array}{l}\text { Sum of log of lead earnings of end-of-period employ- } \\
\text { ment for Male and age } 35-44\end{array}$ & LNWELD_A1A05 & 06136 & 4 & $\mathrm{~N}$ \\
\hline $\begin{array}{l}\text { Sum of log of lead earnings of end-of-period employ- } \\
\text { ment for Male and age } 45-54\end{array}$ & LNWELD_A1A06 & 06148 & 4 & $\mathrm{~N}$ \\
\hline $\begin{array}{l}\text { Sum of log of lead earnings of end-of-period employ- } \\
\text { ment for Male and age 55-64 }\end{array}$ & LNWELD_A1A07 & 06160 & 4 & $\mathrm{~N}$ \\
\hline $\begin{array}{l}\text { Sum of log of lead earnings of end-of-period employ- } \\
\text { ment for Male and age } 65-99\end{array}$ & LNWELD_A1A08 & 06172 & 4 & $\mathrm{~N}$ \\
\hline $\begin{array}{l}\text { Sum of log of lead earnings of full-quarter employment } \\
\text { for Female and age 14-18 }\end{array}$ & LNWFLD_A2A01 & 06632 & 4 & $\mathrm{~N}$ \\
\hline $\begin{array}{l}\text { Sum of log of lead earnings of full-quarter employment } \\
\text { for Female and age 14-99 }\end{array}$ & LNWFLD_A2A00 & 06620 & 4 & $\mathrm{~N}$ \\
\hline $\begin{array}{l}\text { Sum of log of lead earnings of full-quarter employment } \\
\text { for Female and age 19-21 }\end{array}$ & LNWFLD_A2A02 & 06644 & 4 & $\mathrm{~N}$ \\
\hline $\begin{array}{l}\text { Sum of log of lead earnings of full-quarter employment } \\
\text { for Female and age } 22-24\end{array}$ & LNWFLD_A2A03 & 06656 & 4 & $\mathrm{~N}$ \\
\hline $\begin{array}{l}\text { Sum of log of lead earnings of full-quarter employment } \\
\text { for Female and age 25-34 }\end{array}$ & LNWFLD_A2A04 & 06668 & 4 & $\mathrm{~N}$ \\
\hline $\begin{array}{l}\text { Sum of log of lead earnings of full-quarter employment } \\
\text { for Female and age 35-44 }\end{array}$ & LNWFLD_A2A05 & 06680 & 4 & $\mathrm{~N}$ \\
\hline $\begin{array}{l}\text { Sum of log of lead earnings of full-quarter employment } \\
\text { for Female and age } 45-54\end{array}$ & LNWFLD_A2A06 & 06692 & 4 & $\mathrm{~N}$ \\
\hline $\begin{array}{l}\text { Sum of log of lead earnings of full-quarter employment } \\
\text { for Female and age } 55-64\end{array}$ & LNWFLD_A2A07 & 06704 & 4 & $\mathrm{~N}$ \\
\hline $\begin{array}{l}\text { Sum of log of lead earnings of full-quarter employment } \\
\text { for Female and age } 65-99\end{array}$ & LNWFLD_A2A08 & 06716 & 4 & $\mathrm{~N}$ \\
\hline
\end{tabular}




\begin{tabular}{|c|c|c|c|c|}
\hline Field name & $\begin{array}{l}\text { Data dictionary } \\
\text { reference name }\end{array}$ & $\begin{array}{l}\text { Starting } \\
\text { position }\end{array}$ & $\begin{array}{l}\text { Field } \\
\text { size }\end{array}$ & $\begin{array}{l}\text { Data } \\
\text { type }\end{array}$ \\
\hline $\begin{array}{l}\text { Sum of log of lead earnings of full-quarter employment } \\
\text { for Male and Female and a }\end{array}$ & LNWFLD_A0A01 & 06624 & 4 & $\mathrm{~N}$ \\
\hline $\begin{array}{l}\text { Sum of log of lead earnings of full-quarter employment } \\
\text { for Male and Female and a }\end{array}$ & LNWFLD_A0A00 & 06612 & 4 & $\mathrm{~N}$ \\
\hline $\begin{array}{l}\text { Sum of log of lead earnings of full-quarter employment } \\
\text { for Male and Female and a }\end{array}$ & LNWFLD_A0A02 & 06636 & 4 & $\mathrm{~N}$ \\
\hline $\begin{array}{l}\text { Sum of log of lead earnings of full-quarter employment } \\
\text { for Male and Female and a }\end{array}$ & LNWFLD_A0A03 & 06648 & 4 & $\mathrm{~N}$ \\
\hline $\begin{array}{l}\text { Sum of log of lead earnings of full-quarter employment } \\
\text { for Male and Female and a }\end{array}$ & LNWFLD_A0A04 & 06660 & 4 & $\mathrm{~N}$ \\
\hline $\begin{array}{l}\text { Sum of log of lead earnings of full-quarter employment } \\
\text { for Male and Female and a }\end{array}$ & LNWFLD_A0A05 & 06672 & 4 & $\mathrm{~N}$ \\
\hline $\begin{array}{l}\text { Sum of log of lead earnings of full-quarter employment } \\
\text { for Male and Female and a }\end{array}$ & LNWFLD_A0A06 & 06684 & 4 & $\mathrm{~N}$ \\
\hline $\begin{array}{l}\text { Sum of log of lead earnings of full-quarter employment } \\
\text { for Male and Female and a }\end{array}$ & LNWFLD_A0A07 & 06696 & 4 & $\mathrm{~N}$ \\
\hline $\begin{array}{l}\text { Sum of log of lead earnings of full-quarter employment } \\
\text { for Male and Female and a }\end{array}$ & LNWFLD_A0A08 & 06708 & 4 & $\mathrm{~N}$ \\
\hline $\begin{array}{l}\text { Sum of log of lead earnings of full-quarter employment } \\
\text { for Male and age 14-18 }\end{array}$ & LNWFLD_A1A01 & 06628 & 4 & $\mathrm{~N}$ \\
\hline $\begin{array}{l}\text { Sum of log of lead earnings of full-quarter employment } \\
\text { for Male and age 14-99 }\end{array}$ & LNWFLD_A1A00 & 06616 & 4 & $\mathrm{~N}$ \\
\hline $\begin{array}{l}\text { Sum of log of lead earnings of full-quarter employment } \\
\text { for Male and age 19-21 }\end{array}$ & LNWFLD_A1A02 & 06640 & 4 & $\mathrm{~N}$ \\
\hline $\begin{array}{l}\text { Sum of log of lead earnings of full-quarter employment } \\
\text { for Male and age } 22-24\end{array}$ & LNWFLD_A1A03 & 06652 & 4 & $\mathrm{~N}$ \\
\hline $\begin{array}{l}\text { Sum of log of lead earnings of full-quarter employment } \\
\text { for Male and age 25-34 }\end{array}$ & LNWFLD_A1A04 & 06664 & 4 & $\mathrm{~N}$ \\
\hline $\begin{array}{l}\text { Sum of log of lead earnings of full-quarter employment } \\
\text { for Male and age 35-44 }\end{array}$ & LNWFLD_A1A05 & 06676 & 4 & $\mathrm{~N}$ \\
\hline $\begin{array}{l}\text { Sum of log of lead earnings of full-quarter employment } \\
\text { for Male and age } 45-54\end{array}$ & LNWFLD_A1A06 & 06688 & 4 & $\mathrm{~N}$ \\
\hline $\begin{array}{l}\text { Sum of log of lead earnings of full-quarter employment } \\
\text { for Male and age 55-64 }\end{array}$ & LNWFLD_A1A07 & 06700 & 4 & $\mathrm{~N}$ \\
\hline $\begin{array}{l}\text { Sum of log of lead earnings of full-quarter employment } \\
\text { for Male and age 65-99 }\end{array}$ & LNWFLD_A1A08 & 06712 & 4 & $\mathrm{~N}$ \\
\hline Total earnings of separations for Female and age 14-18 & WS_A2A01 & 04580 & 4 & $\mathrm{~N}$ \\
\hline Total earnings of separations for Female and age 14-99 & WS_A2A00 & 04568 & 4 & $\mathrm{~N}$ \\
\hline Total earnings of separations for Female and age 19-21 & WS_A2A02 & 04592 & 4 & $\mathrm{~N}$ \\
\hline Total earnings of separations for Female and age $22-24$ & WS_A2A03 & 04604 & 4 & $\mathrm{~N}$ \\
\hline Total earnings of separations for Female and age 25-34 & WS_A2A04 & 04616 & 4 & $\mathrm{~N}$ \\
\hline Total earnings of separations for Female and age $35-44$ & WS_A2A05 & 04628 & 4 & $\mathrm{~N}$ \\
\hline Total earnings of separations for Female and age $45-54$ & WS_A2A06 & 04640 & 4 & $\mathrm{~N}$ \\
\hline
\end{tabular}


CHAPTER 7. QUARTERLY WORKFORCE INDICATORS - SEINUNIT FILE (QWI)

\begin{tabular}{|c|c|c|c|c|}
\hline Field name & $\begin{array}{l}\text { Data dictionary } \\
\text { reference name }\end{array}$ & $\begin{array}{l}\text { Starting } \\
\text { position }\end{array}$ & $\begin{array}{l}\text { Field } \\
\text { size }\end{array}$ & $\begin{array}{l}\text { Data } \\
\text { type }\end{array}$ \\
\hline Total earnings of separations for Female and age 55-64 & WS_A2A07 & 04652 & 4 & $\mathrm{~N}$ \\
\hline Total earnings of separations for Female and age 65-99 & WS_A2A08 & 04664 & 4 & $\mathrm{~N}$ \\
\hline $\begin{array}{l}\text { Total earnings of separations for Male and Female and } \\
\text { age 14-18 }\end{array}$ & WS_A0A01 & 04572 & 4 & $\mathrm{~N}$ \\
\hline $\begin{array}{l}\text { Total earnings of separations for Male and Female and } \\
\text { age 14-99 }\end{array}$ & WS_A0A00 & 04560 & 4 & $\mathrm{~N}$ \\
\hline $\begin{array}{l}\text { Total earnings of separations for Male and Female and } \\
\text { age 19-21 }\end{array}$ & WS_A0A02 & 04584 & 4 & $\mathrm{~N}$ \\
\hline $\begin{array}{l}\text { Total earnings of separations for Male and Female and } \\
\text { age } 22-24\end{array}$ & WS_A0A03 & 04596 & 4 & $\mathrm{~N}$ \\
\hline $\begin{array}{l}\text { Total earnings of separations for Male and Female and } \\
\text { age } 25-34\end{array}$ & WS_A0A04 & 04608 & 4 & $\mathrm{~N}$ \\
\hline $\begin{array}{l}\text { Total earnings of separations for Male and Female and } \\
\text { age } 35-44\end{array}$ & WS_A0A05 & 04620 & 4 & $\mathrm{~N}$ \\
\hline $\begin{array}{l}\text { Total earnings of separations for Male and Female and } \\
\text { age } 45-54\end{array}$ & WS_A0A06 & 04632 & 4 & $\mathrm{~N}$ \\
\hline $\begin{array}{l}\text { Total earnings of separations for Male and Female and } \\
\text { age } 55-64\end{array}$ & WS_A0A07 & 04644 & 4 & $\mathrm{~N}$ \\
\hline $\begin{array}{l}\text { Total earnings of separations for Male and Female and } \\
\text { age } 65-99\end{array}$ & WS_A0A08 & 04656 & 4 & $\mathrm{~N}$ \\
\hline Total earnings of separations for Male and age 14-18 & WS_A1A01 & 04576 & 4 & $\mathrm{~N}$ \\
\hline Total earnings of separations for Male and age 14-99 & WS_A1A00 & 04564 & 4 & $\mathrm{~N}$ \\
\hline Total earnings of separations for Male and age 19-21 & WS_A1A02 & 04588 & 4 & $\mathrm{~N}$ \\
\hline Total earnings of separations for Male and age 22-24 & WS_A1A03 & 04600 & 4 & $\mathrm{~N}$ \\
\hline Total earnings of separations for Male and age 25-34 & WS_A1A04 & 04612 & 4 & $\mathrm{~N}$ \\
\hline Total earnings of separations for Male and age $35-44$ & WS_A1A05 & 04624 & 4 & $\mathrm{~N}$ \\
\hline Total earnings of separations for Male and age $45-54$ & WS_A1A06 & 04636 & 4 & $\mathrm{~N}$ \\
\hline Total earnings of separations for Male and age 55-64 & WS_A1A07 & 04648 & 4 & $\mathrm{~N}$ \\
\hline Total earnings of separations for Male and age 65-99 & WS_A1A08 & 04660 & 4 & $\mathrm{~N}$ \\
\hline $\begin{array}{l}\text { Total earnings of separations from full-quarter status } \\
\text { (most recent full quarter }\end{array}$ & WFS_A2A01 & 04796 & 4 & $\mathrm{~N}$ \\
\hline $\begin{array}{l}\text { Total earnings of separations from full-quarter status } \\
\text { (most recent full quarter }\end{array}$ & WFS_A2A00 & 04784 & 4 & $\mathrm{~N}$ \\
\hline $\begin{array}{l}\text { Total earnings of separations from full-quarter status } \\
\text { (most recent full quarter }\end{array}$ & WFS_A2A02 & 04808 & 4 & $\mathrm{~N}$ \\
\hline $\begin{array}{l}\text { Total earnings of separations from full-quarter status } \\
\text { (most recent full quarter }\end{array}$ & WFS_A2A03 & 04820 & 4 & $\mathrm{~N}$ \\
\hline $\begin{array}{l}\text { Total earnings of separations from full-quarter status } \\
\text { (most recent full quarter }\end{array}$ & WFS_A2A04 & 04832 & 4 & $\mathrm{~N}$ \\
\hline $\begin{array}{l}\text { Total earnings of separations from full-quarter status } \\
\text { (most recent full quarter }\end{array}$ & WFS_A2A05 & 04844 & 4 & $\mathrm{~N}$ \\
\hline $\begin{array}{l}\text { Total earnings of separations from full-quarter status } \\
\text { (most recent full quarter }\end{array}$ & WFS_A2A06 & 04856 & 4 & $\mathrm{~N}$ \\
\hline $\begin{array}{l}\text { Total earnings of separations from full-quarter status } \\
\text { (most recent full quarter }\end{array}$ & WFS_A2A07 & 04868 & 4 & $\mathrm{~N}$ \\
\hline Total earnings of separations from full-quarter status & WFS_A2A08 & 04880 & 4 & $\mathrm{~N}$ \\
\hline
\end{tabular}




\begin{tabular}{|c|c|c|c|c|}
\hline Field name & $\begin{array}{l}\text { Data dictionary } \\
\text { reference name }\end{array}$ & $\begin{array}{l}\text { Starting } \\
\text { position }\end{array}$ & $\begin{array}{l}\text { Field } \\
\text { size }\end{array}$ & $\begin{array}{l}\text { Data } \\
\text { type }\end{array}$ \\
\hline $\begin{array}{l}\text { Total earnings of separations from full-quarter status } \\
\text { (most recent full quarter }\end{array}$ & WFS_A0A01 & 04788 & 4 & N18 \\
\hline $\begin{array}{l}\text { Total earnings of separations from full-quarter status } \\
\text { (most recent full quarter }\end{array}$ & WFS_A0A00 & 04776 & 4 & N99 \\
\hline $\begin{array}{l}\text { Total earnings of separations from full-quarter status } \\
\text { (most recent full quarter }\end{array}$ & WFS_A0A02 & 04800 & 4 & N21 \\
\hline $\begin{array}{l}\text { Total earnings of separations from full-quarter status } \\
\text { (most recent full quarter }\end{array}$ & WFS_A0A03 & 04812 & 4 & N24 \\
\hline $\begin{array}{l}\text { Total earnings of separations from full-quarter status } \\
\text { (most recent full quarter }\end{array}$ & WFS_A0A04 & 04824 & 4 & N34 \\
\hline $\begin{array}{l}\text { Total earnings of separations from full-quarter status } \\
\text { (most recent full quarter }\end{array}$ & WFS_A0A05 & 04836 & 4 & N44 \\
\hline $\begin{array}{l}\text { Total earnings of separations from full-quarter status } \\
\text { (most recent full quarter }\end{array}$ & WFS_A0A06 & 04848 & 4 & N54 \\
\hline $\begin{array}{l}\text { Total earnings of separations from full-quarter status } \\
\text { (most recent full quarter }\end{array}$ & WFS_A0A07 & 04860 & 4 & N64 \\
\hline $\begin{array}{l}\text { Total earnings of separations from full-quarter status } \\
\text { (most recent full quarter }\end{array}$ & WFS_A0A08 & 04872 & 4 & N99 \\
\hline $\begin{array}{l}\text { Total earnings of separations from full-quarter status } \\
\text { (most recent full quarter }\end{array}$ & WFS_A1A01 & 04792 & 4 & $\mathrm{~N}$ \\
\hline $\begin{array}{l}\text { Total earnings of separations from full-quarter status } \\
\text { (most recent full quarter }\end{array}$ & WFS_A1A00 & 04780 & 4 & $\mathrm{~N}$ \\
\hline $\begin{array}{l}\text { Total earnings of separations from full-quarter status } \\
\text { (most recent full quarter }\end{array}$ & WFS_A1A02 & 04804 & 4 & $\mathrm{~N}$ \\
\hline $\begin{array}{l}\text { Total earnings of separations from full-quarter status } \\
\text { (most recent full quarter }\end{array}$ & WFS_A1A03 & 04816 & 4 & $\mathrm{~N}$ \\
\hline $\begin{array}{l}\text { Total earnings of separations from full-quarter status } \\
\text { (most recent full quarter }\end{array}$ & WFS_A1A04 & 04828 & 4 & $\mathrm{~N}$ \\
\hline $\begin{array}{l}\text { Total earnings of separations from full-quarter status } \\
\text { (most recent full quarter }\end{array}$ & WFS_A1A05 & 04840 & 4 & $\mathrm{~N}$ \\
\hline $\begin{array}{l}\text { Total earnings of separations from full-quarter status } \\
\text { (most recent full quarter }\end{array}$ & WFS_A1A06 & 04852 & 4 & $\mathrm{~N}$ \\
\hline $\begin{array}{l}\text { Total earnings of separations from full-quarter status } \\
\text { (most recent full quarter }\end{array}$ & WFS_A1A07 & 04864 & 4 & $\mathrm{~N}$ \\
\hline $\begin{array}{l}\text { Total earnings of separations from full-quarter status } \\
\text { (most recent full quarter }\end{array}$ & WFS_A1A08 & 04876 & 4 & $\mathrm{~N}$ \\
\hline Total payroll of accessions for Female and age 14-18 & WA_A2A01 & 03716 & 4 & $\mathrm{~N}$ \\
\hline Total payroll of accessions for Female and age 14-99 & WA_A2A00 & 03704 & 4 & $\mathrm{~N}$ \\
\hline Total payroll of accessions for Female and age 19-21 & WA_A2A02 & 03728 & 4 & $\mathrm{~N}$ \\
\hline Total payroll of accessions for Female and age 22-24 & WA_A2A03 & 03740 & 4 & $\mathrm{~N}$ \\
\hline Total payroll of accessions for Female and age 25-34 & WA_A2A04 & 03752 & 4 & $\mathrm{~N}$ \\
\hline Total payroll of accessions for Female and age 35-44 & WA_A2A05 & 03764 & 4 & $\mathrm{~N}$ \\
\hline Total payroll of accessions for Female and age $45-54$ & WA_A2A06 & 03776 & 4 & $\mathrm{~N}$ \\
\hline Total payroll of accessions for Female and age $55-64$ & WA_A2A07 & 03788 & 4 & $\mathrm{~N}$ \\
\hline Total payroll of accessions for Female and age 65-99 & WA_A2A08 & 03800 & 4 & $\mathrm{~N}$ \\
\hline $\begin{array}{l}\text { Total payroll of accessions for Male and Female and } \\
\text { age 14-18 }\end{array}$ & WA_A0A01 & 03708 & 4 & $\mathrm{~N}$ \\
\hline Total payroll of accessions for Male and Female and & WA_A0A00 & 03696 & 4 & $\mathrm{~N}$ \\
\hline
\end{tabular}


CHAPTER 7. QUARTERLY WORKFORCE INDICATORS - SEINUNIT FILE (QWI)

\begin{tabular}{|c|c|c|c|c|}
\hline Field name & $\begin{array}{l}\text { Data dictionary } \\
\text { reference name }\end{array}$ & $\begin{array}{l}\text { Starting } \\
\text { position }\end{array}$ & $\begin{array}{l}\text { Field } \\
\text { size }\end{array}$ & $\begin{array}{l}\text { Data } \\
\text { type }\end{array}$ \\
\hline $\begin{array}{l}\text { Total payroll of accessions for Male and Female and } \\
\text { age 19-21 }\end{array}$ & WA_A0A02 & 03720 & 4 & $\mathrm{~N}$ \\
\hline $\begin{array}{l}\text { Total payroll of accessions for Male and Female and } \\
\text { age } 22-24\end{array}$ & WA_A0A03 & 03732 & 4 & $\mathrm{~N}$ \\
\hline $\begin{array}{l}\text { Total payroll of accessions for Male and Female and } \\
\text { age 25-34 }\end{array}$ & WA_A0A04 & 03744 & 4 & $\mathrm{~N}$ \\
\hline $\begin{array}{l}\text { Total payroll of accessions for Male and Female and } \\
\text { age 35-44 }\end{array}$ & WA_A0A05 & 03756 & 4 & $\mathrm{~N}$ \\
\hline $\begin{array}{l}\text { Total payroll of accessions for Male and Female and } \\
\text { age 45-54 }\end{array}$ & WA_A0A06 & 03768 & 4 & $\mathrm{~N}$ \\
\hline $\begin{array}{l}\text { Total payroll of accessions for Male and Female and } \\
\text { age } 55-64\end{array}$ & WA_A0A07 & 03780 & 4 & $\mathrm{~N}$ \\
\hline $\begin{array}{l}\text { Total payroll of accessions for Male and Female and } \\
\text { age 65-99 }\end{array}$ & WA_A0A08 & 03792 & 4 & $\mathrm{~N}$ \\
\hline Total payroll of accessions for Male and age 14-18 & WA_A1A01 & 03712 & 4 & $\mathrm{~N}$ \\
\hline Total payroll of accessions for Male and age 14-99 & WA_A1A00 & 03700 & 4 & $\mathrm{~N}$ \\
\hline Total payroll of accessions for Male and age 19-21 & WA_A1A02 & 03724 & 4 & $\mathrm{~N}$ \\
\hline Total payroll of accessions for Male and age 22-24 & WA_A1A03 & 03736 & 4 & $\mathrm{~N}$ \\
\hline Total payroll of accessions for Male and age 25-34 & WA_A1A04 & 03748 & 4 & $\mathrm{~N}$ \\
\hline Total payroll of accessions for Male and age 35-44 & WA_A1A05 & 03760 & 4 & $\mathrm{~N}$ \\
\hline Total payroll of accessions for Male and age $45-54$ & WA_A1A06 & 03772 & 4 & $\mathrm{~N}$ \\
\hline Total payroll of accessions for Male and age 55-64 & WA_A1A07 & 03784 & 4 & $\mathrm{~N}$ \\
\hline Total payroll of accessions for Male and age 65-99 & WA_A1A08 & 03796 & 4 & $\mathrm{~N}$ \\
\hline Total payroll of all employees for Female and age 14-18 & W1_A2A01 & 03284 & 4 & $\mathrm{~N}$ \\
\hline Total payroll of all employees for Female and age 14-99 & W1_A2A00 & 03272 & 4 & $\mathrm{~N}$ \\
\hline Total payroll of all employees for Female and age 19-21 & W1_A2A02 & 03296 & 4 & $\mathrm{~N}$ \\
\hline Total payroll of all employees for Female and age 22-24 & W1_A2A03 & 03308 & 4 & $\mathrm{~N}$ \\
\hline Total payroll of all employees for Female and age 25-34 & W1_A2A04 & 03320 & 4 & $\mathrm{~N}$ \\
\hline Total payroll of all employees for Female and age 35-44 & W1_A2A05 & 03332 & 4 & $\mathrm{~N}$ \\
\hline Total payroll of all employees for Female and age $45-54$ & W1_A2A06 & 03344 & 4 & $\mathrm{~N}$ \\
\hline Total payroll of all employees for Female and age 55-64 & W1_A2A07 & 03356 & 4 & $\mathrm{~N}$ \\
\hline Total payroll of all employees for Female and age 65-99 & W1_A2A08 & 03368 & 4 & $\mathrm{~N}$ \\
\hline $\begin{array}{l}\text { Total payroll of all employees for Male and Female and } \\
\text { age 14-18 }\end{array}$ & W1_A0A01 & 03276 & 4 & $\mathrm{~N}$ \\
\hline $\begin{array}{l}\text { Total payroll of all employees for Male and Female and } \\
\text { age 14-99 }\end{array}$ & W1_A0A00 & 03264 & 4 & $\mathrm{~N}$ \\
\hline $\begin{array}{l}\text { Total payroll of all employees for Male and Female and } \\
\text { age 19-21 }\end{array}$ & W1_A0A02 & 03288 & 4 & $\mathrm{~N}$ \\
\hline $\begin{array}{l}\text { Total payroll of all employees for Male and Female and } \\
\text { age 22-24 }\end{array}$ & W1_A0A03 & 03300 & 4 & $\mathrm{~N}$ \\
\hline
\end{tabular}




\begin{tabular}{|c|c|c|c|c|}
\hline Field name & $\begin{array}{l}\text { Data dictionary } \\
\text { reference name }\end{array}$ & $\begin{array}{l}\text { Starting } \\
\text { position }\end{array}$ & $\begin{array}{l}\text { Field } \\
\text { size }\end{array}$ & $\begin{array}{l}\text { Data } \\
\text { type }\end{array}$ \\
\hline $\begin{array}{l}\text { Total payroll of all employees for Male and Female and } \\
\text { age } 25-34\end{array}$ & W1_A0A04 & 03312 & 4 & $\mathrm{~N}$ \\
\hline $\begin{array}{l}\text { Total payroll of all employees for Male and Female and } \\
\text { age } 35-44\end{array}$ & W1_A0A05 & 03324 & 4 & $\mathrm{~N}$ \\
\hline $\begin{array}{l}\text { Total payroll of all employees for Male and Female and } \\
\text { age } 45-54\end{array}$ & W1_A0A06 & 03336 & 4 & $\mathrm{~N}$ \\
\hline $\begin{array}{l}\text { Total payroll of all employees for Male and Female and } \\
\text { age 55-64 }\end{array}$ & W1_A0A07 & 03348 & 4 & $\mathrm{~N}$ \\
\hline $\begin{array}{l}\text { Total payroll of all employees for Male and Female and } \\
\text { age } 65-99\end{array}$ & W1_A0A08 & 03360 & 4 & $\mathrm{~N}$ \\
\hline Total payroll of all employees for Male and age 14-18 & W1_A1A01 & 03280 & 4 & $\mathrm{~N}$ \\
\hline Total payroll of all employees for Male and age 14-99 & W1_A1A00 & 03268 & 4 & $\mathrm{~N}$ \\
\hline Total payroll of all employees for Male and age 19-21 & W1_A1A02 & 03292 & 4 & $\mathrm{~N}$ \\
\hline Total payroll of all employees for Male and age $22-24$ & W1_A1A03 & 03304 & 4 & $\mathrm{~N}$ \\
\hline Total payroll of all employees for Male and age 25-34 & W1_A1A04 & 03316 & 4 & $\mathrm{~N}$ \\
\hline Total payroll of all employees for Male and age 35-44 & W1_A1A05 & 03328 & 4 & $\mathrm{~N}$ \\
\hline Total payroll of all employees for Male and age $45-54$ & W1_A1A06 & 03340 & 4 & $\mathrm{~N}$ \\
\hline Total payroll of all employees for Male and age 55-64 & W1_A1A07 & 03352 & 4 & $\mathrm{~N}$ \\
\hline Total payroll of all employees for Male and age 65-99 & W1_A1A08 & 03364 & 4 & $\mathrm{~N}$ \\
\hline $\begin{array}{l}\text { Total payroll of end-of-period employees for Female } \\
\text { and age 14-18 }\end{array}$ & W2_A2A01 & 03392 & 4 & $\mathrm{~N}$ \\
\hline $\begin{array}{l}\text { Total payroll of end-of-period employees for Female } \\
\text { and age 14-99 }\end{array}$ & W2_A2A00 & 03380 & 4 & $\mathrm{~N}$ \\
\hline $\begin{array}{l}\text { Total payroll of end-of-period employees for Female } \\
\text { and age 19-21 }\end{array}$ & W2_A2A02 & 03404 & 4 & $\mathrm{~N}$ \\
\hline $\begin{array}{l}\text { Total payroll of end-of-period employees for Female } \\
\text { and age } 22-24\end{array}$ & W2_A2A03 & 03416 & 4 & $\mathrm{~N}$ \\
\hline $\begin{array}{l}\text { Total payroll of end-of-period employees for Female } \\
\text { and age } 25-34\end{array}$ & W2_A2A04 & 03428 & 4 & $\mathrm{~N}$ \\
\hline $\begin{array}{l}\text { Total payroll of end-of-period employees for Female } \\
\text { and age } 35-44\end{array}$ & W2_A2A05 & 03440 & 4 & $\mathrm{~N}$ \\
\hline $\begin{array}{l}\text { Total payroll of end-of-period employees for Female } \\
\text { and age } 45-54\end{array}$ & W2_A2A06 & 03452 & 4 & $\mathrm{~N}$ \\
\hline $\begin{array}{l}\text { Total payroll of end-of-period employees for Female } \\
\text { and age 55-64 }\end{array}$ & W2_A2A07 & 03464 & 4 & $\mathrm{~N}$ \\
\hline $\begin{array}{l}\text { Total payroll of end-of-period employees for Female } \\
\text { and age } 65-99\end{array}$ & W2_A2A08 & 03476 & 4 & $\mathrm{~N}$ \\
\hline $\begin{array}{l}\text { Total payroll of end-of-period employees for Male and } \\
\text { Female and age 14-18 }\end{array}$ & W2_A0A01 & 03384 & 4 & $\mathrm{~N}$ \\
\hline $\begin{array}{l}\text { Total payroll of end-of-period employees for Male and } \\
\text { Female and age 14-99 }\end{array}$ & W2_A0A00 & 03372 & 4 & $\mathrm{~N}$ \\
\hline $\begin{array}{l}\text { Total payroll of end-of-period employees for Male and } \\
\text { Female and age 19-21 }\end{array}$ & W2_A0A02 & 03396 & 4 & $\mathrm{~N}$ \\
\hline $\begin{array}{l}\text { Total payroll of end-of-period employees for Male and } \\
\text { Female and age } 22-24\end{array}$ & W2_A0A03 & 03408 & 4 & $\mathrm{~N}$ \\
\hline $\begin{array}{l}\text { Total payroll of end-of-period employees for Male and } \\
\text { Female and age 25-34 }\end{array}$ & W2_A0A04 & 03420 & 4 & $\mathrm{~N}$ \\
\hline Total payroll of end-of-period employees for Male and & W2_A0A05 & 03432 & 4 & $\mathrm{~N}$ \\
\hline
\end{tabular}




\begin{tabular}{|c|c|c|c|c|}
\hline Field name & $\begin{array}{l}\text { Data dictionary } \\
\text { reference name }\end{array}$ & $\begin{array}{l}\text { Starting } \\
\text { position }\end{array}$ & $\begin{array}{l}\text { Field } \\
\text { size }\end{array}$ & $\begin{array}{l}\text { Data } \\
\text { type }\end{array}$ \\
\hline $\begin{array}{l}\text { Total payroll of end-of-period employees for Male and } \\
\text { Female and age } 45-54\end{array}$ & W2_A0A06 & 03444 & 4 & $\mathrm{~N}$ \\
\hline $\begin{array}{l}\text { Total payroll of end-of-period employees for Male and } \\
\text { Female and age 55-64 }\end{array}$ & W2_A0A07 & 03456 & 4 & $\mathrm{~N}$ \\
\hline $\begin{array}{l}\text { Total payroll of end-of-period employees for Male and } \\
\text { Female and age } 65-99\end{array}$ & W2_A0A08 & 03468 & 4 & $\mathrm{~N}$ \\
\hline $\begin{array}{l}\text { Total payroll of end-of-period employees for Male and } \\
\text { age } 14-18\end{array}$ & W2_A1A01 & 03388 & 4 & $\mathrm{~N}$ \\
\hline $\begin{array}{l}\text { Total payroll of end-of-period employees for Male and } \\
\text { age 14-99 }\end{array}$ & W2_A1A00 & 03376 & 4 & $\mathrm{~N}$ \\
\hline $\begin{array}{l}\text { Total payroll of end-of-period employees for Male and } \\
\text { age 19-21 }\end{array}$ & W2_A1A02 & 03400 & 4 & $\mathrm{~N}$ \\
\hline $\begin{array}{l}\text { Total payroll of end-of-period employees for Male and } \\
\text { age } 22-24\end{array}$ & W2_A1A03 & 03412 & 4 & $\mathrm{~N}$ \\
\hline $\begin{array}{l}\text { Total payroll of end-of-period employees for Male and } \\
\text { age 25-34 }\end{array}$ & W2_A1A04 & 03424 & 4 & $\mathrm{~N}$ \\
\hline $\begin{array}{l}\text { Total payroll of end-of-period employees for Male and } \\
\text { age } 35-44\end{array}$ & W2_A1A05 & 03436 & 4 & $\mathrm{~N}$ \\
\hline $\begin{array}{l}\text { Total payroll of end-of-period employees for Male and } \\
\text { age } 45-54\end{array}$ & W2_A1A06 & 03448 & 4 & $\mathrm{~N}$ \\
\hline $\begin{array}{l}\text { Total payroll of end-of-period employees for Male and } \\
\text { age } 55-64\end{array}$ & W2_A1A07 & 03460 & 4 & $\mathrm{~N}$ \\
\hline $\begin{array}{l}\text { Total payroll of end-of-period employees for Male and } \\
\text { age } 65-99\end{array}$ & W2_A1A08 & 03472 & 4 & $\mathrm{~N}$ \\
\hline $\begin{array}{l}\text { Total payroll of full-quarter employees for Female and } \\
\text { age 14-18 }\end{array}$ & W3_A2A01 & 03500 & 4 & $\mathrm{~N}$ \\
\hline $\begin{array}{l}\text { Total payroll of full-quarter employees for Female and } \\
\text { age 14-99 }\end{array}$ & W3_A2A00 & 03488 & 4 & $\mathrm{~N}$ \\
\hline $\begin{array}{l}\text { Total payroll of full-quarter employees for Female and } \\
\text { age 19-21 }\end{array}$ & W3_A2A02 & 03512 & 4 & $\mathrm{~N}$ \\
\hline $\begin{array}{l}\text { Total payroll of full-quarter employees for Female and } \\
\text { age } 22-24\end{array}$ & W3_A2A03 & 03524 & 4 & $\mathrm{~N}$ \\
\hline $\begin{array}{l}\text { Total payroll of full-quarter employees for Female and } \\
\text { age 25-34 }\end{array}$ & W3_A2A04 & 03536 & 4 & $\mathrm{~N}$ \\
\hline $\begin{array}{l}\text { Total payroll of full-quarter employees for Female and } \\
\text { age } 35-44\end{array}$ & W3_A2A05 & 03548 & 4 & $\mathrm{~N}$ \\
\hline $\begin{array}{l}\text { Total payroll of full-quarter employees for Female and } \\
\text { age } 45-54\end{array}$ & W3_A2A06 & 03560 & 4 & $\mathrm{~N}$ \\
\hline $\begin{array}{l}\text { Total payroll of full-quarter employees for Female and } \\
\text { age } 55-64\end{array}$ & W3_A2A07 & 03572 & 4 & $\mathrm{~N}$ \\
\hline $\begin{array}{l}\text { Total payroll of full-quarter employees for Female and } \\
\text { age } 65-99\end{array}$ & W3_A2A08 & 03584 & 4 & $\mathrm{~N}$ \\
\hline $\begin{array}{l}\text { Total payroll of full-quarter employees for Male and } \\
\text { Female and age 14-18 }\end{array}$ & W3_A0A01 & 03492 & 4 & $\mathrm{~N}$ \\
\hline $\begin{array}{l}\text { Total payroll of full-quarter employees for Male and } \\
\text { Female and age 14-99 }\end{array}$ & W3_A0A00 & 03480 & 4 & $\mathrm{~N}$ \\
\hline $\begin{array}{l}\text { Total payroll of full-quarter employees for Male and } \\
\text { Female and age 19-21 }\end{array}$ & W3_A0A02 & 03504 & 4 & $\mathrm{~N}$ \\
\hline $\begin{array}{l}\text { Total payroll of full-quarter employees for Male and } \\
\text { Female and age } 22-24\end{array}$ & W3_A0A03 & 03516 & 4 & $\mathrm{~N}$ \\
\hline
\end{tabular}




\begin{tabular}{|c|c|c|c|c|}
\hline Field name & $\begin{array}{l}\text { Data dictionary } \\
\text { reference name }\end{array}$ & $\begin{array}{l}\text { Starting } \\
\text { position }\end{array}$ & $\begin{array}{l}\text { Field } \\
\text { size }\end{array}$ & $\begin{array}{l}\text { Data } \\
\text { type }\end{array}$ \\
\hline $\begin{array}{l}\text { Total payroll of full-quarter employees for Male and } \\
\text { Female and age } 25-34\end{array}$ & W3_A0A04 & 03528 & 4 & $\mathrm{~N}$ \\
\hline $\begin{array}{l}\text { Total payroll of full-quarter employees for Male and } \\
\text { Female and age } 35-44\end{array}$ & W3_A0A05 & 03540 & 4 & $\mathrm{~N}$ \\
\hline $\begin{array}{l}\text { Total payroll of full-quarter employees for Male and } \\
\text { Female and age } 45-54\end{array}$ & W3_A0A06 & 03552 & 4 & $\mathrm{~N}$ \\
\hline $\begin{array}{l}\text { Total payroll of full-quarter employees for Male and } \\
\text { Female and age } 55-64\end{array}$ & W3_A0A07 & 03564 & 4 & $\mathrm{~N}$ \\
\hline $\begin{array}{l}\text { Total payroll of full-quarter employees for Male and } \\
\text { Female and age } 65-99\end{array}$ & W3_A0A08 & 03576 & 4 & $\mathrm{~N}$ \\
\hline $\begin{array}{l}\text { Total payroll of full-quarter employees for Male and } \\
\text { age 14-18 }\end{array}$ & W3_A1A01 & 03496 & 4 & $\mathrm{~N}$ \\
\hline $\begin{array}{l}\text { Total payroll of full-quarter employees for Male and } \\
\text { age 14-99 }\end{array}$ & W3_A1A00 & 03484 & 4 & $\mathrm{~N}$ \\
\hline $\begin{array}{l}\text { Total payroll of full-quarter employees for Male and } \\
\text { age 19-21 }\end{array}$ & W3_A1A02 & 03508 & 4 & $\mathrm{~N}$ \\
\hline $\begin{array}{l}\text { Total payroll of full-quarter employees for Male and } \\
\text { age } 22-24\end{array}$ & W3_A1A03 & 03520 & 4 & $\mathrm{~N}$ \\
\hline $\begin{array}{l}\text { Total payroll of full-quarter employees for Male and } \\
\text { age 25-34 }\end{array}$ & W3_A1A04 & 03532 & 4 & $\mathrm{~N}$ \\
\hline $\begin{array}{l}\text { Total payroll of full-quarter employees for Male and } \\
\text { age } 35-44\end{array}$ & W3_A1A05 & 03544 & 4 & $\mathrm{~N}$ \\
\hline $\begin{array}{l}\text { Total payroll of full-quarter employees for Male and } \\
\text { age } 45-54\end{array}$ & W3_A1A06 & 03556 & 4 & $\mathrm{~N}$ \\
\hline $\begin{array}{l}\text { Total payroll of full-quarter employees for Male and } \\
\text { age } 55-64\end{array}$ & W3_A1A07 & 03568 & 4 & $\mathrm{~N}$ \\
\hline $\begin{array}{l}\text { Total payroll of full-quarter employees for Male and } \\
\text { age 65-99 }\end{array}$ & W3_A1A08 & 03580 & 4 & $\mathrm{~N}$ \\
\hline $\begin{array}{l}\text { Total payroll of new hires to full-quarter status for } \\
\text { Female and age 14-18 }\end{array}$ & WH3_A2A01 & 03608 & 4 & $\mathrm{~N}$ \\
\hline $\begin{array}{l}\text { Total payroll of new hires to full-quarter status for } \\
\text { Female and age 14-99 }\end{array}$ & WH3_A2A00 & 03596 & 4 & $\mathrm{~N}$ \\
\hline $\begin{array}{l}\text { Total payroll of new hires to full-quarter status for } \\
\text { Female and age 19-21 }\end{array}$ & WH3_A2A02 & 03620 & 4 & $\mathrm{~N}$ \\
\hline $\begin{array}{l}\text { Total payroll of new hires to full-quarter status for } \\
\text { Female and age } 22-24\end{array}$ & WH3_A2A03 & 03632 & 4 & $\mathrm{~N}$ \\
\hline $\begin{array}{l}\text { Total payroll of new hires to full-quarter status for } \\
\text { Female and age } 25-34\end{array}$ & WH3_A2A04 & 03644 & 4 & $\mathrm{~N}$ \\
\hline $\begin{array}{l}\text { Total payroll of new hires to full-quarter status for } \\
\text { Female and age } 35-44\end{array}$ & WH3_A2A05 & 03656 & 4 & $\mathrm{~N}$ \\
\hline $\begin{array}{l}\text { Total payroll of new hires to full-quarter status for } \\
\text { Female and age } 45-54\end{array}$ & WH3_A2A06 & 03668 & 4 & $\mathrm{~N}$ \\
\hline $\begin{array}{l}\text { Total payroll of new hires to full-quarter status for } \\
\text { Female and age } 55-64\end{array}$ & WH3_A2A07 & 03680 & 4 & $\mathrm{~N}$ \\
\hline $\begin{array}{l}\text { Total payroll of new hires to full-quarter status for } \\
\text { Female and age } 65-99\end{array}$ & WH3_A2A08 & 03692 & 4 & $\mathrm{~N}$ \\
\hline $\begin{array}{l}\text { Total payroll of new hires to full-quarter status for } \\
\text { Male and Female and age } 14\end{array}$ & WH3_A0A01 & 03600 & 4 & $\mathrm{~N}$ \\
\hline Total payroll of new hires to full-quarter status for & WH3_A0A00 & 03588 & 4 & $\mathrm{~N}$ \\
\hline
\end{tabular}




\begin{tabular}{|c|c|c|c|c|}
\hline Field name & $\begin{array}{l}\text { Data dictionary } \\
\text { reference name }\end{array}$ & $\begin{array}{l}\text { Starting } \\
\text { position }\end{array}$ & $\begin{array}{l}\text { Field } \\
\text { size }\end{array}$ & $\begin{array}{l}\text { Data } \\
\text { type }\end{array}$ \\
\hline $\begin{array}{l}\text { Total payroll of new hires to full-quarter status for } \\
\text { Male and Female and age } 19\end{array}$ & WH3_A0A02 & 03612 & 4 & $\mathrm{~N}$ \\
\hline $\begin{array}{l}\text { Total payroll of new hires to full-quarter status for } \\
\text { Male and Female and age } 22\end{array}$ & WH3_A0A03 & 03624 & 4 & $\mathrm{~N}$ \\
\hline $\begin{array}{l}\text { Total payroll of new hires to full-quarter status for } \\
\text { Male and Female and age } 25\end{array}$ & WH3_A0A04 & 03636 & 4 & $\mathrm{~N}$ \\
\hline $\begin{array}{l}\text { Total payroll of new hires to full-quarter status for } \\
\text { Male and Female and age } 35\end{array}$ & WH3_A0A05 & 03648 & 4 & $\mathrm{~N}$ \\
\hline $\begin{array}{l}\text { Total payroll of new hires to full-quarter status for } \\
\text { Male and Female and age } 45\end{array}$ & WH3_A0A06 & 03660 & 4 & $\mathrm{~N}$ \\
\hline $\begin{array}{l}\text { Total payroll of new hires to full-quarter status for } \\
\text { Male and Female and age } 55\end{array}$ & WH3_A0A07 & 03672 & 4 & $\mathrm{~N}$ \\
\hline $\begin{array}{l}\text { Total payroll of new hires to full-quarter status for } \\
\text { Male and Female and age } 65\end{array}$ & WH3_A0A08 & 03684 & 4 & $\mathrm{~N}$ \\
\hline $\begin{array}{l}\text { Total payroll of new hires to full-quarter status for } \\
\text { Male and age 14-18 }\end{array}$ & WH3_A1A01 & 03604 & 4 & $\mathrm{~N}$ \\
\hline $\begin{array}{l}\text { Total payroll of new hires to full-quarter status for } \\
\text { Male and age 14-99 }\end{array}$ & WH3_A1A00 & 03592 & 4 & $\mathrm{~N}$ \\
\hline $\begin{array}{l}\text { Total payroll of new hires to full-quarter status for } \\
\text { Male and age 19-21 }\end{array}$ & WH3_A1A02 & 03616 & 4 & $\mathrm{~N}$ \\
\hline $\begin{array}{l}\text { Total payroll of new hires to full-quarter status for } \\
\text { Male and age } 22-24\end{array}$ & WH3_A1A03 & 03628 & 4 & $\mathrm{~N}$ \\
\hline $\begin{array}{l}\text { Total payroll of new hires to full-quarter status for } \\
\text { Male and age } 25-34\end{array}$ & WH3_A1A04 & 03640 & 4 & $\mathrm{~N}$ \\
\hline $\begin{array}{l}\text { Total payroll of new hires to full-quarter status for } \\
\text { Male and age } 35-44\end{array}$ & WH3_A1A05 & 03652 & 4 & $\mathrm{~N}$ \\
\hline $\begin{array}{l}\text { Total payroll of new hires to full-quarter status for } \\
\text { Male and age } 45-54\end{array}$ & WH3_A1A06 & 03664 & 4 & $\mathrm{~N}$ \\
\hline $\begin{array}{l}\text { Total payroll of new hires to full-quarter status for } \\
\text { Male and age } 55-64\end{array}$ & WH3_A1A07 & 03676 & 4 & $\mathrm{~N}$ \\
\hline $\begin{array}{l}\text { Total payroll of new hires to full-quarter status for } \\
\text { Male and age } 65-99\end{array}$ & WH3_A1A08 & 03688 & 4 & $\mathrm{~N}$ \\
\hline $\begin{array}{l}\text { Total payroll of transits to consecutive-quarter status } \\
\text { for Female and age 14-18 }\end{array}$ & WCA_A2A01 & 03932 & 4 & $\mathrm{~N}$ \\
\hline $\begin{array}{l}\text { Total payroll of transits to consecutive-quarter status } \\
\text { for Female and age 14-99 }\end{array}$ & WCA_A2A00 & 03920 & 4 & $\mathrm{~N}$ \\
\hline $\begin{array}{l}\text { Total payroll of transits to consecutive-quarter status } \\
\text { for Female and age 19-21 }\end{array}$ & WCA_A2A02 & 03944 & 4 & $\mathrm{~N}$ \\
\hline $\begin{array}{l}\text { Total payroll of transits to consecutive-quarter status } \\
\text { for Female and age } 22-24\end{array}$ & WCA_A2A03 & 03956 & 4 & $\mathrm{~N}$ \\
\hline $\begin{array}{l}\text { Total payroll of transits to consecutive-quarter status } \\
\text { for Female and age } 25-34\end{array}$ & WCA_A2A04 & 03968 & 4 & $\mathrm{~N}$ \\
\hline $\begin{array}{l}\text { Total payroll of transits to consecutive-quarter status } \\
\text { for Female and age } 35-44\end{array}$ & WCA_A2A05 & 03980 & 4 & $\mathrm{~N}$ \\
\hline $\begin{array}{l}\text { Total payroll of transits to consecutive-quarter status } \\
\text { for Female and age } 45-54\end{array}$ & WCA_A2A06 & 03992 & 4 & $\mathrm{~N}$ \\
\hline $\begin{array}{l}\text { Total payroll of transits to consecutive-quarter status } \\
\text { for Female and age } 55-64\end{array}$ & WCA_A2A07 & 04004 & 4 & $\mathrm{~N}$ \\
\hline Total payroll of transits to consecutive-quarter status & WCA_A2A08 & 04016 & 4 & $\mathrm{~N}$ \\
\hline
\end{tabular}




\begin{tabular}{|c|c|c|c|c|}
\hline Field name & $\begin{array}{l}\text { Data dictionary } \\
\text { reference name }\end{array}$ & $\begin{array}{l}\text { Starting } \\
\text { position }\end{array}$ & $\begin{array}{l}\text { Field } \\
\text { size }\end{array}$ & $\begin{array}{l}\text { Data } \\
\text { type }\end{array}$ \\
\hline $\begin{array}{l}\text { Total payroll of transits to consecutive-quarter status } \\
\text { for Male and Female and }\end{array}$ & WCA_A0A01 & 03924 & 4 & $\mathrm{~N}$ \\
\hline $\begin{array}{l}\text { Total payroll of transits to consecutive-quarter status } \\
\text { for Male and Female and }\end{array}$ & WCA_A0A00 & 03912 & 4 & $\mathrm{~N}$ \\
\hline $\begin{array}{l}\text { Total payroll of transits to consecutive-quarter status } \\
\text { for Male and Female and }\end{array}$ & WCA_A0A02 & 03936 & 4 & $\mathrm{~N}$ \\
\hline $\begin{array}{l}\text { Total payroll of transits to consecutive-quarter status } \\
\text { for Male and Female and }\end{array}$ & WCA_A0A03 & 03948 & 4 & $\mathrm{~N}$ \\
\hline $\begin{array}{l}\text { Total payroll of transits to consecutive-quarter status } \\
\text { for Male and Female and }\end{array}$ & WCA_A0A04 & 03960 & 4 & $\mathrm{~N}$ \\
\hline $\begin{array}{l}\text { Total payroll of transits to consecutive-quarter status } \\
\text { for Male and Female and }\end{array}$ & WCA_A0A05 & 03972 & 4 & $\mathrm{~N}$ \\
\hline $\begin{array}{l}\text { Total payroll of transits to consecutive-quarter status } \\
\text { for Male and Female and }\end{array}$ & WCA_A0A06 & 03984 & 4 & $\mathrm{~N}$ \\
\hline $\begin{array}{l}\text { Total payroll of transits to consecutive-quarter status } \\
\text { for Male and Female and }\end{array}$ & WCA_A0A07 & 03996 & 4 & $\mathrm{~N}$ \\
\hline $\begin{array}{l}\text { Total payroll of transits to consecutive-quarter status } \\
\text { for Male and Female and }\end{array}$ & WCA_A0A08 & 04008 & 4 & $\mathrm{~N}$ \\
\hline $\begin{array}{l}\text { Total payroll of transits to consecutive-quarter status } \\
\text { for Male and age 14-18 }\end{array}$ & WCA_A1A01 & 03928 & 4 & $\mathrm{~N}$ \\
\hline $\begin{array}{l}\text { Total payroll of transits to consecutive-quarter status } \\
\text { for Male and age 14-99 }\end{array}$ & WCA_A1A00 & 03916 & 4 & $\mathrm{~N}$ \\
\hline $\begin{array}{l}\text { Total payroll of transits to consecutive-quarter status } \\
\text { for Male and age } 19-21\end{array}$ & WCA_A1A02 & 03940 & 4 & $\mathrm{~N}$ \\
\hline $\begin{array}{l}\text { Total payroll of transits to consecutive-quarter status } \\
\text { for Male and age } 22-24\end{array}$ & WCA_A1A03 & 03952 & 4 & $\mathrm{~N}$ \\
\hline $\begin{array}{l}\text { Total payroll of transits to consecutive-quarter status } \\
\text { for Male and age 25-34 }\end{array}$ & WCA_A1A04 & 03964 & 4 & $\mathrm{~N}$ \\
\hline $\begin{array}{l}\text { Total payroll of transits to consecutive-quarter status } \\
\text { for Male and age } 35-44\end{array}$ & WCA_A1A05 & 03976 & 4 & $\mathrm{~N}$ \\
\hline $\begin{array}{l}\text { Total payroll of transits to consecutive-quarter status } \\
\text { for Male and age } 45-54\end{array}$ & WCA_A1A06 & 03988 & 4 & $\mathrm{~N}$ \\
\hline $\begin{array}{l}\text { Total payroll of transits to consecutive-quarter status } \\
\text { for Male and age } 55-64\end{array}$ & WCA_A1A07 & 04000 & 4 & $\mathrm{~N}$ \\
\hline $\begin{array}{l}\text { Total payroll of transits to consecutive-quarter status } \\
\text { for Male and age } 65-99\end{array}$ & WCA_A1A08 & 04012 & 4 & $\mathrm{~N}$ \\
\hline $\begin{array}{l}\text { Total payroll of transits to full-quarter status for Fe- } \\
\text { male and age 14-18 }\end{array}$ & WFA_A2A01 & 04040 & 4 & $\mathrm{~N}$ \\
\hline $\begin{array}{l}\text { Total payroll of transits to full-quarter status for Fe- } \\
\text { male and age 14-99 }\end{array}$ & WFA_A2A00 & 04028 & 4 & $\mathrm{~N}$ \\
\hline $\begin{array}{l}\text { Total payroll of transits to full-quarter status for Fe- } \\
\text { male and age 19-21 }\end{array}$ & WFA_A2A02 & 04052 & 4 & $\mathrm{~N}$ \\
\hline $\begin{array}{l}\text { Total payroll of transits to full-quarter status for Fe- } \\
\text { male and age } 22-24\end{array}$ & WFA_A2A03 & 04064 & 4 & $\mathrm{~N}$ \\
\hline $\begin{array}{l}\text { Total payroll of transits to full-quarter status for Fe- } \\
\text { male and age } 25-34\end{array}$ & WFA_A2A04 & 04076 & 4 & $\mathrm{~N}$ \\
\hline $\begin{array}{l}\text { Total payroll of transits to full-quarter status for Fe- } \\
\text { male and age } 35-44\end{array}$ & WFA_A2A05 & 04088 & 4 & $\mathrm{~N}$ \\
\hline $\begin{array}{l}\text { Total payroll of transits to full-quarter status for Fe- } \\
\text { male and age } 45-54\end{array}$ & WFA_A2A06 & 04100 & 4 & $\mathrm{~N}$ \\
\hline
\end{tabular}




\begin{tabular}{|c|c|c|c|c|}
\hline Field name & $\begin{array}{l}\text { Data dictionary } \\
\text { reference name }\end{array}$ & $\begin{array}{l}\text { Starting } \\
\text { position }\end{array}$ & $\begin{array}{l}\text { Field } \\
\text { size }\end{array}$ & $\begin{array}{l}\text { Data } \\
\text { type }\end{array}$ \\
\hline $\begin{array}{l}\text { Total payroll of transits to full-quarter status for Fe- } \\
\text { male and age } 55-64\end{array}$ & WFA_A2A07 & 04112 & 4 & $\mathrm{~N}$ \\
\hline $\begin{array}{l}\text { Total payroll of transits to full-quarter status for Fe- } \\
\text { male and age } 65-99\end{array}$ & WFA_A2A08 & 04124 & 4 & $\mathrm{~N}$ \\
\hline $\begin{array}{l}\text { Total payroll of transits to full-quarter status for Male } \\
\text { and Female and age 14- }\end{array}$ & WFA_A0A01 & 04032 & 4 & $\mathrm{~N}$ \\
\hline $\begin{array}{l}\text { Total payroll of transits to full-quarter status for Male } \\
\text { and Female and age 14- }\end{array}$ & WFA_A0A00 & 04020 & 4 & $\mathrm{~N}$ \\
\hline $\begin{array}{l}\text { Total payroll of transits to full-quarter status for Male } \\
\text { and Female and age 19- }\end{array}$ & WFA_A0A02 & 04044 & 4 & $\mathrm{~N}$ \\
\hline $\begin{array}{l}\text { Total payroll of transits to full-quarter status for Male } \\
\text { and Female and age 22- }\end{array}$ & WFA_A0A03 & 04056 & 4 & $\mathrm{~N}$ \\
\hline $\begin{array}{l}\text { Total payroll of transits to full-quarter status for Male } \\
\text { and Female and age 25- }\end{array}$ & WFA_A0A04 & 04068 & 4 & $\mathrm{~N}$ \\
\hline $\begin{array}{l}\text { Total payroll of transits to full-quarter status for Male } \\
\text { and Female and age 35- }\end{array}$ & WFA_A0A05 & 04080 & 4 & $\mathrm{~N}$ \\
\hline $\begin{array}{l}\text { Total payroll of transits to full-quarter status for Male } \\
\text { and Female and age 45- }\end{array}$ & WFA_A0A06 & 04092 & 4 & $\mathrm{~N}$ \\
\hline $\begin{array}{l}\text { Total payroll of transits to full-quarter status for Male } \\
\text { and Female and age } 55-\end{array}$ & WFA_A0A07 & 04104 & 4 & $\mathrm{~N}$ \\
\hline $\begin{array}{l}\text { Total payroll of transits to full-quarter status for Male } \\
\text { and Female and age } 65-\end{array}$ & WFA_A0A08 & 04116 & 4 & $\mathrm{~N}$ \\
\hline $\begin{array}{l}\text { Total payroll of transits to full-quarter status for Male } \\
\text { and age 14-18 }\end{array}$ & WFA_A1A01 & 04036 & 4 & $\mathrm{~N}$ \\
\hline $\begin{array}{l}\text { Total payroll of transits to full-quarter status for Male } \\
\text { and age 14-99 }\end{array}$ & WFA_A1A00 & 04024 & 4 & $\mathrm{~N}$ \\
\hline $\begin{array}{l}\text { Total payroll of transits to full-quarter status for Male } \\
\text { and age 19-21 }\end{array}$ & WFA_A1A02 & 04048 & 4 & $\mathrm{~N}$ \\
\hline $\begin{array}{l}\text { Total payroll of transits to full-quarter status for Male } \\
\text { and age } 22-24\end{array}$ & WFA_A1A03 & 04060 & 4 & $\mathrm{~N}$ \\
\hline $\begin{array}{l}\text { Total payroll of transits to full-quarter status for Male } \\
\text { and age } 25-34\end{array}$ & WFA_A1A04 & 04072 & 4 & $\mathrm{~N}$ \\
\hline $\begin{array}{l}\text { Total payroll of transits to full-quarter status for Male } \\
\text { and age } 35-44\end{array}$ & WFA_A1A05 & 04084 & 4 & $\mathrm{~N}$ \\
\hline $\begin{array}{l}\text { Total payroll of transits to full-quarter status for Male } \\
\text { and age } 45-54\end{array}$ & WFA_A1A06 & 04096 & 4 & $\mathrm{~N}$ \\
\hline $\begin{array}{l}\text { Total payroll of transits to full-quarter status for Male } \\
\text { and age } 55-64\end{array}$ & WFA_A1A07 & 04108 & 4 & $\mathrm{~N}$ \\
\hline $\begin{array}{l}\text { Total payroll of transits to full-quarter status for Male } \\
\text { and age } 65-99\end{array}$ & WFA_A1A08 & 04120 & 4 & $\mathrm{~N}$ \\
\hline $\begin{array}{l}\text { Total periods of non-employment for accessions for Fe- } \\
\text { male and age 14-18 }\end{array}$ & NA_A2A01 & 04256 & 4 & $\mathrm{~N}$ \\
\hline $\begin{array}{l}\text { Total periods of non-employment for accessions for Fe- } \\
\text { male and age 14-99 }\end{array}$ & NA_A2A00 & 04244 & 4 & $\mathrm{~N}$ \\
\hline $\begin{array}{l}\text { Total periods of non-employment for accessions for Fe- } \\
\text { male and age 19-21 }\end{array}$ & NA_A2A02 & 04268 & 4 & $\mathrm{~N}$ \\
\hline $\begin{array}{l}\text { Total periods of non-employment for accessions for Fe- } \\
\text { male and age } 22-24\end{array}$ & NA_A2A03 & 04280 & 4 & $\mathrm{~N}$ \\
\hline $\begin{array}{l}\text { Total periods of non-employment for accessions for Fe- } \\
\text { male and age 25-34 }\end{array}$ & NA_A2A04 & 04292 & 4 & $\mathrm{~N}$ \\
\hline
\end{tabular}




\begin{tabular}{|c|c|c|c|c|}
\hline Field name & $\begin{array}{l}\text { Data dictionary } \\
\text { reference name }\end{array}$ & $\begin{array}{l}\text { Starting } \\
\text { position }\end{array}$ & $\begin{array}{l}\text { Field } \\
\text { size }\end{array}$ & $\begin{array}{l}\text { Data } \\
\text { type }\end{array}$ \\
\hline $\begin{array}{l}\text { Total periods of non-employment for accessions for } \mathrm{Fe}- \\
\text { male and age } 35-44\end{array}$ & NA_A2A05 & 04304 & 4 & $\mathrm{~N}$ \\
\hline $\begin{array}{l}\text { Total periods of non-employment for accessions for } \mathrm{Fe}- \\
\text { male and age } 45-54\end{array}$ & NA_A2A06 & 04316 & 4 & $\mathrm{~N}$ \\
\hline $\begin{array}{l}\text { Total periods of non-employment for accessions for Fe- } \\
\text { male and age } 55-64\end{array}$ & NA_A2A07 & 04328 & 4 & $\mathrm{~N}$ \\
\hline $\begin{array}{l}\text { Total periods of non-employment for accessions for } \mathrm{Fe}- \\
\text { male and age } 65-99\end{array}$ & NA_A2A08 & 04340 & 4 & $\mathrm{~N}$ \\
\hline $\begin{array}{l}\text { Total periods of non-employment for accessions for } \\
\text { Male and Female and age 14-18 }\end{array}$ & NA_A0A01 & 04248 & 4 & $\mathrm{~N}$ \\
\hline $\begin{array}{l}\text { Total periods of non-employment for accessions for } \\
\text { Male and Female and age 14-99 }\end{array}$ & NA_A0A00 & 04236 & 4 & $\mathrm{~N}$ \\
\hline $\begin{array}{l}\text { Total periods of non-employment for accessions for } \\
\text { Male and Female and age 19-21 }\end{array}$ & NA_A0A02 & 04260 & 4 & $\mathrm{~N}$ \\
\hline $\begin{array}{l}\text { Total periods of non-employment for accessions for } \\
\text { Male and Female and age } 22-24\end{array}$ & NA_A0A03 & 04272 & 4 & $\mathrm{~N}$ \\
\hline $\begin{array}{l}\text { Total periods of non-employment for accessions for } \\
\text { Male and Female and age 25-34 }\end{array}$ & NA_A0A04 & 04284 & 4 & $\mathrm{~N}$ \\
\hline $\begin{array}{l}\text { Total periods of non-employment for accessions for } \\
\text { Male and Female and age } 35-44\end{array}$ & NA_A0A05 & 04296 & 4 & $\mathrm{~N}$ \\
\hline $\begin{array}{l}\text { Total periods of non-employment for accessions for } \\
\text { Male and Female and age } 45-54\end{array}$ & NA_A0A06 & 04308 & 4 & $\mathrm{~N}$ \\
\hline $\begin{array}{l}\text { Total periods of non-employment for accessions for } \\
\text { Male and Female and age } 55-64\end{array}$ & NA_A0A07 & 04320 & 4 & $\mathrm{~N}$ \\
\hline $\begin{array}{l}\text { Total periods of non-employment for accessions for } \\
\text { Male and Female and age } 65-99\end{array}$ & NA_A0A08 & 04332 & 4 & $\mathrm{~N}$ \\
\hline $\begin{array}{l}\text { Total periods of non-employment for accessions for } \\
\text { Male and age 14-18 }\end{array}$ & NA_A1A01 & 04252 & 4 & $\mathrm{~N}$ \\
\hline $\begin{array}{l}\text { Total periods of non-employment for accessions for } \\
\text { Male and age 14-99 }\end{array}$ & NA_A1A00 & 04240 & 4 & $\mathrm{~N}$ \\
\hline $\begin{array}{l}\text { Total periods of non-employment for accessions for } \\
\text { Male and age 19-21 }\end{array}$ & NA_A1A02 & 04264 & 4 & $\mathrm{~N}$ \\
\hline $\begin{array}{l}\text { Total periods of non-employment for accessions for } \\
\text { Male and age } 22-24\end{array}$ & NA_A1A03 & 04276 & 4 & $\mathrm{~N}$ \\
\hline $\begin{array}{l}\text { Total periods of non-employment for accessions for } \\
\text { Male and age } 25-34\end{array}$ & NA_A1A04 & 04288 & 4 & $\mathrm{~N}$ \\
\hline $\begin{array}{l}\text { Total periods of non-employment for accessions for } \\
\text { Male and age } 35-44\end{array}$ & NA_A1A05 & 04300 & 4 & $\mathrm{~N}$ \\
\hline $\begin{array}{l}\text { Total periods of non-employment for accessions for } \\
\text { Male and age } 45-54\end{array}$ & NA_A1A06 & 04312 & 4 & $\mathrm{~N}$ \\
\hline $\begin{array}{l}\text { Total periods of non-employment for accessions for } \\
\text { Male and age } 55-64\end{array}$ & NA_A1A07 & 04324 & 4 & $\mathrm{~N}$ \\
\hline $\begin{array}{l}\text { Total periods of non-employment for accessions for } \\
\text { Male and age } 65-99\end{array}$ & NA_A1A08 & 04336 & 4 & $\mathrm{~N}$ \\
\hline $\begin{array}{l}\text { Total periods of non-employment for new hires (last } \\
\text { four quarters) for Female an }\end{array}$ & NH_A2A01 & 04364 & 4 & $\mathrm{~N}$ \\
\hline $\begin{array}{l}\text { Total periods of non-employment for new hires (last } \\
\text { four quarters) for Female an }\end{array}$ & NH_A2A00 & 04352 & 4 & $\mathrm{~N}$ \\
\hline Total periods of non-employment for new hires (last & NH_A2A02 & 04376 & 4 & $\mathrm{~N}$ \\
\hline
\end{tabular}




\begin{tabular}{|c|c|c|c|c|}
\hline Field name & $\begin{array}{l}\text { Data dictionary } \\
\text { reference name }\end{array}$ & $\begin{array}{l}\text { Starting } \\
\text { position }\end{array}$ & $\begin{array}{l}\text { Field } \\
\text { size }\end{array}$ & $\begin{array}{l}\text { Data } \\
\text { type }\end{array}$ \\
\hline $\begin{array}{l}\text { Total periods of non-employment for new hires (last } \\
\text { four quarters) for Female an }\end{array}$ & NH_A2A03 & 04388 & 4 & $\mathrm{~N}$ \\
\hline $\begin{array}{l}\text { Total periods of non-employment for new hires (last } \\
\text { four quarters) for Female an }\end{array}$ & NH_A2A04 & 04400 & 4 & $\mathrm{~N}$ \\
\hline $\begin{array}{l}\text { Total periods of non-employment for new hires (last } \\
\text { four quarters) for Female an }\end{array}$ & NH_A2A05 & 04412 & 4 & $\mathrm{~N}$ \\
\hline $\begin{array}{l}\text { Total periods of non-employment for new hires (last } \\
\text { four quarters) for Female an }\end{array}$ & NH_A2A06 & 04424 & 4 & $\mathrm{~N}$ \\
\hline $\begin{array}{l}\text { Total periods of non-employment for new hires (last } \\
\text { four quarters) for Female an }\end{array}$ & NH_A2A07 & 04436 & 4 & $\mathrm{~N}$ \\
\hline $\begin{array}{l}\text { Total periods of non-employment for new hires (last } \\
\text { four quarters) for Female an }\end{array}$ & NH_A2A08 & 04448 & 4 & $\mathrm{~N}$ \\
\hline $\begin{array}{l}\text { Total periods of non-employment for new hires (last } \\
\text { four quarters) for Male and }\end{array}$ & NH_A0A01 & 04356 & 4 & $\mathrm{~N}$ \\
\hline $\begin{array}{l}\text { Total periods of non-employment for new hires (last } \\
\text { four quarters) for Male and }\end{array}$ & NH_A0A00 & 04344 & 4 & $\mathrm{~N}$ \\
\hline $\begin{array}{l}\text { Total periods of non-employment for new hires (last } \\
\text { four quarters) for Male and }\end{array}$ & NH_A0A02 & 04368 & 4 & $\mathrm{~N}$ \\
\hline $\begin{array}{l}\text { Total periods of non-employment for new hires (last } \\
\text { four quarters) for Male and }\end{array}$ & NH_A0A03 & 04380 & 4 & $\mathrm{~N}$ \\
\hline $\begin{array}{l}\text { Total periods of non-employment for new hires (last } \\
\text { four quarters) for Male and }\end{array}$ & NH_A0A04 & 04392 & 4 & $\mathrm{~N}$ \\
\hline $\begin{array}{l}\text { Total periods of non-employment for new hires (last } \\
\text { four quarters) for Male and }\end{array}$ & NH_A0A05 & 04404 & 4 & $\mathrm{~N}$ \\
\hline $\begin{array}{l}\text { Total periods of non-employment for new hires (last } \\
\text { four quarters) for Male and }\end{array}$ & NH_A0A06 & 04416 & 4 & $\mathrm{~N}$ \\
\hline $\begin{array}{l}\text { Total periods of non-employment for new hires (last } \\
\text { four quarters) for Male and }\end{array}$ & NH_A0A07 & 04428 & 4 & $\mathrm{~N}$ \\
\hline $\begin{array}{l}\text { Total periods of non-employment for new hires (last } \\
\text { four quarters) for Male and }\end{array}$ & NH_A0A08 & 04440 & 4 & $\mathrm{~N}$ \\
\hline $\begin{array}{l}\text { Total periods of non-employment for new hires (last } \\
\text { four quarters) for Male and }\end{array}$ & NH_A1A01 & 04360 & 4 & $\mathrm{~N}$ \\
\hline $\begin{array}{l}\text { Total periods of non-employment for new hires (last } \\
\text { four quarters) for Male and }\end{array}$ & NH_A1A00 & 04348 & 4 & $\mathrm{~N}$ \\
\hline $\begin{array}{l}\text { Total periods of non-employment for new hires (last } \\
\text { four quarters) for Male and }\end{array}$ & NH_A1A02 & 04372 & 4 & $\mathrm{~N}$ \\
\hline $\begin{array}{l}\text { Total periods of non-employment for new hires (last } \\
\text { four quarters) for Male and }\end{array}$ & NH_A1A03 & 04384 & 4 & $\mathrm{~N}$ \\
\hline $\begin{array}{l}\text { Total periods of non-employment for new hires (last } \\
\text { four quarters) for Male and }\end{array}$ & NH_A1A04 & 04396 & 4 & $\mathrm{~N}$ \\
\hline $\begin{array}{l}\text { Total periods of non-employment for new hires (last } \\
\text { four quarters) for Male and }\end{array}$ & NH_A1A05 & 04408 & 4 & $\mathrm{~N}$ \\
\hline $\begin{array}{l}\text { Total periods of non-employment for new hires (last } \\
\text { four quarters) for Male and }\end{array}$ & NH_A1A06 & 04420 & 4 & $\mathrm{~N}$ \\
\hline $\begin{array}{l}\text { Total periods of non-employment for new hires (last } \\
\text { four quarters) for Male and }\end{array}$ & NH_A1A07 & 04432 & 4 & $\mathrm{~N}$ \\
\hline $\begin{array}{l}\text { Total periods of non-employment for new hires (last } \\
\text { four quarters) for Male and }\end{array}$ & NH_A1A08 & 04444 & 4 & $\mathrm{~N}$ \\
\hline Total periods of non-employment for recalls (last four & NR_A2A01 & 04472 & 4 & $\mathrm{~N}$ \\
\hline
\end{tabular}




\begin{tabular}{|c|c|c|c|c|}
\hline Field name & $\begin{array}{l}\text { Data dictionary } \\
\text { reference name }\end{array}$ & $\begin{array}{l}\text { Starting } \\
\text { position }\end{array}$ & $\begin{array}{l}\text { Field } \\
\text { size }\end{array}$ & $\begin{array}{l}\text { Data } \\
\text { type }\end{array}$ \\
\hline $\begin{array}{l}\text { Total periods of non-employment for recalls (last four } \\
\text { quarters) for Female and }\end{array}$ & NR_A2A00 & 04460 & 4 & $\mathrm{~N}$ \\
\hline $\begin{array}{l}\text { Total periods of non-employment for recalls (last four } \\
\text { quarters) for Female and }\end{array}$ & NR_A2A02 & 04484 & 4 & $\mathrm{~N}$ \\
\hline $\begin{array}{l}\text { Total periods of non-employment for recalls (last four } \\
\text { quarters) for Female and }\end{array}$ & NR_A2A03 & 04496 & 4 & $\mathrm{~N}$ \\
\hline $\begin{array}{l}\text { Total periods of non-employment for recalls (last four } \\
\text { quarters) for Female and }\end{array}$ & NR_A2A04 & 04508 & 4 & $\mathrm{~N}$ \\
\hline $\begin{array}{l}\text { Total periods of non-employment for recalls (last four } \\
\text { quarters) for Female and }\end{array}$ & NR_A2A05 & 04520 & 4 & $\mathrm{~N}$ \\
\hline $\begin{array}{l}\text { Total periods of non-employment for recalls (last four } \\
\text { quarters) for Female and }\end{array}$ & NR_A2A06 & 04532 & 4 & $\mathrm{~N}$ \\
\hline $\begin{array}{l}\text { Total periods of non-employment for recalls (last four } \\
\text { quarters) for Female and }\end{array}$ & NR_A2A07 & 04544 & 4 & $\mathrm{~N}$ \\
\hline $\begin{array}{l}\text { Total periods of non-employment for recalls (last four } \\
\text { quarters) for Female and }\end{array}$ & NR_A2A08 & 04556 & 4 & $\mathrm{~N}$ \\
\hline $\begin{array}{l}\text { Total periods of non-employment for recalls (last four } \\
\text { quarters) for Male and Fe }\end{array}$ & NR_A0A01 & 04464 & 4 & $\mathrm{~N}$ \\
\hline $\begin{array}{l}\text { Total periods of non-employment for recalls (last four } \\
\text { quarters) for Male and Fe }\end{array}$ & NR_A0A00 & 04452 & 4 & $\mathrm{~N}$ \\
\hline $\begin{array}{l}\text { Total periods of non-employment for recalls (last four } \\
\text { quarters) for Male and Fe }\end{array}$ & NR_A0A02 & 04476 & 4 & $\mathrm{~N}$ \\
\hline $\begin{array}{l}\text { Total periods of non-employment for recalls (last four } \\
\text { quarters) for Male and Fe }\end{array}$ & NR_A0A03 & 04488 & 4 & $\mathrm{~N}$ \\
\hline $\begin{array}{l}\text { Total periods of non-employment for recalls (last four } \\
\text { quarters) for Male and Fe }\end{array}$ & NR_A0A04 & 04500 & 4 & $\mathrm{~N}$ \\
\hline $\begin{array}{l}\text { Total periods of non-employment for recalls (last four } \\
\text { quarters) for Male and Fe }\end{array}$ & NR_A0A05 & 04512 & 4 & $\mathrm{~N}$ \\
\hline $\begin{array}{l}\text { Total periods of non-employment for recalls (last four } \\
\text { quarters) for Male and Fe }\end{array}$ & NR_A0A06 & 04524 & 4 & $\mathrm{~N}$ \\
\hline $\begin{array}{l}\text { Total periods of non-employment for recalls (last four } \\
\text { quarters) for Male and Fe }\end{array}$ & NR_A0A07 & 04536 & 4 & $\mathrm{~N}$ \\
\hline $\begin{array}{l}\text { Total periods of non-employment for recalls (last four } \\
\text { quarters) for Male and Fe }\end{array}$ & NR_A0A08 & 04548 & 4 & $\mathrm{~N}$ \\
\hline $\begin{array}{l}\text { Total periods of non-employment for recalls (last four } \\
\text { quarters) for Male and ag }\end{array}$ & NR_A1A01 & 04468 & 4 & $\mathrm{~N}$ \\
\hline $\begin{array}{l}\text { Total periods of non-employment for recalls (last four } \\
\text { quarters) for Male and ag }\end{array}$ & NR_A1A00 & 04456 & 4 & $\mathrm{~N}$ \\
\hline $\begin{array}{l}\text { Total periods of non-employment for recalls (last four } \\
\text { quarters) for Male and ag }\end{array}$ & NR_A1A02 & 04480 & 4 & $\mathrm{~N}$ \\
\hline $\begin{array}{l}\text { Total periods of non-employment for recalls (last four } \\
\text { quarters) for Male and ag }\end{array}$ & NR_A1A03 & 04492 & 4 & $\mathrm{~N}$ \\
\hline $\begin{array}{l}\text { Total periods of non-employment for recalls (last four } \\
\text { quarters) for Male and ag }\end{array}$ & NR_A1A04 & 04504 & 4 & $\mathrm{~N}$ \\
\hline $\begin{array}{l}\text { Total periods of non-employment for recalls (last four } \\
\text { quarters) for Male and ag }\end{array}$ & NR_A1A05 & 04516 & 4 & $\mathrm{~N}$ \\
\hline $\begin{array}{l}\text { Total periods of non-employment for recalls (last four } \\
\text { quarters) for Male and ag }\end{array}$ & NR_A1A06 & 04528 & 4 & $\mathrm{~N}$ \\
\hline Total periods of non-employment for recalls (last four & NR_A1A07 & 04540 & 4 & $\mathrm{~N}$ \\
\hline
\end{tabular}




\begin{tabular}{|c|c|c|c|c|}
\hline Field name & $\begin{array}{l}\text { Data dictionary } \\
\text { reference name }\end{array}$ & $\begin{array}{l}\text { Starting } \\
\text { position }\end{array}$ & $\begin{array}{l}\text { Field } \\
\text { size }\end{array}$ & $\begin{array}{l}\text { Data } \\
\text { type }\end{array}$ \\
\hline $\begin{array}{l}\text { Total periods of non-employment for recalls (last four } \\
\text { quarters) for Male and ag }\end{array}$ & NR_A1A08 & 04552 & 4 & $\mathrm{~N}$ \\
\hline $\begin{array}{l}\text { Total periods of non-employment for separations for } \\
\text { Female and age } 14-18\end{array}$ & NS_A2A01 & 05012 & 4 & $\mathrm{~N}$ \\
\hline $\begin{array}{l}\text { Total periods of non-employment for separations for } \\
\text { Female and age 14-99 }\end{array}$ & NS_A2A00 & 05000 & 4 & $\mathrm{~N}$ \\
\hline $\begin{array}{l}\text { Total periods of non-employment for separations for } \\
\text { Female and age 19-21 }\end{array}$ & NS_A2A02 & 05024 & 4 & $\mathrm{~N}$ \\
\hline $\begin{array}{l}\text { Total periods of non-employment for separations for } \\
\text { Female and age } 22-24\end{array}$ & NS_A2A03 & 05036 & 4 & $\mathrm{~N}$ \\
\hline $\begin{array}{l}\text { Total periods of non-employment for separations for } \\
\text { Female and age } 25-34\end{array}$ & NS_A2A04 & 05048 & 4 & $\mathrm{~N}$ \\
\hline $\begin{array}{l}\text { Total periods of non-employment for separations for } \\
\text { Female and age } 35-44\end{array}$ & NS_A2A05 & 05060 & 4 & $\mathrm{~N}$ \\
\hline $\begin{array}{l}\text { Total periods of non-employment for separations for } \\
\text { Female and age } 45-54\end{array}$ & NS_A2A06 & 05072 & 4 & $\mathrm{~N}$ \\
\hline $\begin{array}{l}\text { Total periods of non-employment for separations for } \\
\text { Female and age } 55-64\end{array}$ & NS_A2A07 & 05084 & 4 & $\mathrm{~N}$ \\
\hline $\begin{array}{l}\text { Total periods of non-employment for separations for } \\
\text { Female and age } 65-99\end{array}$ & NS_A2A08 & 05096 & 4 & $\mathrm{~N}$ \\
\hline $\begin{array}{l}\text { Total periods of non-employment for separations for } \\
\text { Male and Female and age 14-1 }\end{array}$ & NS_A0A01 & 05004 & 4 & $\mathrm{~N}$ \\
\hline $\begin{array}{l}\text { Total periods of non-employment for separations for } \\
\text { Male and Female and age 14-9 }\end{array}$ & NS_A0A00 & 04992 & 4 & $\mathrm{~N}$ \\
\hline $\begin{array}{l}\text { Total periods of non-employment for separations for } \\
\text { Male and Female and age 19-2 }\end{array}$ & NS_A0A02 & 05016 & 4 & $\mathrm{~N}$ \\
\hline $\begin{array}{l}\text { Total periods of non-employment for separations for } \\
\text { Male and Female and age } 22-2\end{array}$ & NS_A0A03 & 05028 & 4 & $\mathrm{~N}$ \\
\hline $\begin{array}{l}\text { Total periods of non-employment for separations for } \\
\text { Male and Female and age } 25-3\end{array}$ & NS_A0A04 & 05040 & 4 & $\mathrm{~N}$ \\
\hline $\begin{array}{l}\text { Total periods of non-employment for separations for } \\
\text { Male and Female and age } 35-4\end{array}$ & NS_A0A05 & 05052 & 4 & $\mathrm{~N}$ \\
\hline $\begin{array}{l}\text { Total periods of non-employment for separations for } \\
\text { Male and Female and age } 45-5\end{array}$ & NS_A0A06 & 05064 & 4 & $\mathrm{~N}$ \\
\hline $\begin{array}{l}\text { Total periods of non-employment for separations for } \\
\text { Male and Female and age 55-6 }\end{array}$ & NS_A0A07 & 05076 & 4 & $\mathrm{~N}$ \\
\hline $\begin{array}{l}\text { Total periods of non-employment for separations for } \\
\text { Male and Female and age } 65-9\end{array}$ & NS_A0A08 & 05088 & 4 & $\mathrm{~N}$ \\
\hline $\begin{array}{l}\text { Total periods of non-employment for separations for } \\
\text { Male and age } 14-18\end{array}$ & NS_A1A01 & 05008 & 4 & $\mathrm{~N}$ \\
\hline $\begin{array}{l}\text { Total periods of non-employment for separations for } \\
\text { Male and age 14-99 }\end{array}$ & NS_A1A00 & 04996 & 4 & $\mathrm{~N}$ \\
\hline $\begin{array}{l}\text { Total periods of non-employment for separations for } \\
\text { Male and age 19-21 }\end{array}$ & NS_A1A02 & 05020 & 4 & $\mathrm{~N}$ \\
\hline $\begin{array}{l}\text { Total periods of non-employment for separations for } \\
\text { Male and age } 22-24\end{array}$ & NS_A1A03 & 05032 & 4 & $\mathrm{~N}$ \\
\hline $\begin{array}{l}\text { Total periods of non-employment for separations for } \\
\text { Male and age } 25-34\end{array}$ & NS_A1A04 & 05044 & 4 & $\mathrm{~N}$ \\
\hline Total periods of non-employment for separations for & NS_A1A05 & 05056 & 4 & $\mathrm{~N}$ \\
\hline
\end{tabular}


CHAPTER 7. QUARTERLY WORKFORCE INDICATORS - SEINUNIT FILE (QWI)

\begin{tabular}{|c|c|c|c|c|}
\hline Field name & $\begin{array}{l}\text { Data dictionary } \\
\text { reference name }\end{array}$ & $\begin{array}{l}\text { Starting } \\
\text { position }\end{array}$ & $\begin{array}{l}\text { Field } \\
\text { size }\end{array}$ & $\begin{array}{l}\text { Data } \\
\text { type }\end{array}$ \\
\hline $\begin{array}{l}\text { Total periods of non-employment for separations for } \\
\text { Male and age } 45-54\end{array}$ & NS_A1A06 & 05068 & 4 & $\mathrm{~N}$ \\
\hline $\begin{array}{l}\text { Total periods of non-employment for separations for } \\
\text { Male and age } 55-64\end{array}$ & NS_A1A07 & 05080 & 4 & $\mathrm{~N}$ \\
\hline $\begin{array}{l}\text { Total periods of non-employment for separations for } \\
\text { Male and age } 65-99\end{array}$ & NS_A1A08 & 05092 & 4 & $\mathrm{~N}$ \\
\hline WIB code, wwwwww & LEG_WIB & 07519 & 6 & $\mathrm{~A} / \mathrm{N}$ \\
\hline $\begin{array}{l}\text { Weight such that weighted sum of } \text { B_UI }_{-}= \\
\text {sum(month1_BLS) }\end{array}$ & QWI_UNIT_WEIGHT & 00000 & 8 & $\mathrm{~N}$ \\
\hline Year YYYY & YEAR & 07534 & 3 & $\mathrm{~N}$ \\
\hline lnwb*lnwb for Female and age $14-18$ & LNWB2_A2A01 & 05660 & 4 & $\mathrm{~N}$ \\
\hline lnwb*lnwb for Female and age 14-99 & LNWB2_A2A00 & 05648 & 4 & $\mathrm{~N}$ \\
\hline lnwb*lnwb for Female and age 19-21 & LNWB2_A2A02 & 05672 & 4 & $\mathrm{~N}$ \\
\hline lnwb*lnwb for Female and age 22-24 & LNWB2_A2A03 & 05684 & 4 & $\mathrm{~N}$ \\
\hline lnwb*lnwb for Female and age 25-34 & LNWB2_A2A04 & 05696 & 4 & $\mathrm{~N}$ \\
\hline lnwb*lnwb for Female and age $35-44$ & LNWB2_A2A05 & 05708 & 4 & $\mathrm{~N}$ \\
\hline lnwb*lnwb for Female and age $45-54$ & LNWB2_A2A06 & 05720 & 4 & $\mathrm{~N}$ \\
\hline lnwb*lnwb for Female and age 55-64 & LNWB2_A2A07 & 05732 & 4 & $\mathrm{~N}$ \\
\hline lnwb*lnwb for Female and age $65-99$ & LNWB2_A2A08 & 05744 & 4 & $\mathrm{~N}$ \\
\hline lnwb*lnwb for Male and Female and age 14-18 & LNWB2_A0A01 & 05652 & 4 & $\mathrm{~N}$ \\
\hline lnwb*lnwb for Male and Female and age 14-99 & LNWB2_A0A00 & 05640 & 4 & $\mathrm{~N}$ \\
\hline lnwb*lnwb for Male and Female and age 19-21 & LNWB2_A0A02 & 05664 & 4 & $\mathrm{~N}$ \\
\hline lnwb*lnwb for Male and Female and age $22-24$ & LNWB2_A0A03 & 05676 & 4 & $\mathrm{~N}$ \\
\hline lnwb*lnwb for Male and Female and age $25-34$ & LNWB2_A0A04 & 05688 & 4 & $\mathrm{~N}$ \\
\hline lnwb*lnwb for Male and Female and age $35-44$ & LNWB2_A0A05 & 05700 & 4 & $\mathrm{~N}$ \\
\hline lnwb*lnwb for Male and Female and age $45-54$ & LNWB2_A0A06 & 05712 & 4 & $\mathrm{~N}$ \\
\hline lnwb*lnwb for Male and Female and age 55-64 & LNWB2_A0A07 & 05724 & 4 & $\mathrm{~N}$ \\
\hline lnwb*lnwb for Male and Female and age $65-99$ & LNWB2_A0A08 & 05736 & 4 & $\mathrm{~N}$ \\
\hline lnwb*lnwb for Male and age $14-18$ & LNWB2_A1A01 & 05656 & 4 & $\mathrm{~N}$ \\
\hline lnwb*lnwb for Male and age 14-99 & LNWB2_A1A00 & 05644 & 4 & $\mathrm{~N}$ \\
\hline lnwb*lnwb for Male and age 19-21 & LNWB2_A1A02 & 05668 & 4 & $\mathrm{~N}$ \\
\hline lnwb*lnwb for Male and age $22-24$ & LNWB2_A1A03 & 05680 & 4 & $\mathrm{~N}$ \\
\hline lnwb*lnwb for Male and age $25-34$ & LNWB2_A1A04 & 05692 & 4 & $\mathrm{~N}$ \\
\hline lnwb*lnwb for Male and age $35-44$ & LNWB2_A1A05 & 05704 & 4 & $\mathrm{~N}$ \\
\hline lnwb*lnwb for Male and age $45-54$ & LNWB2_A1A06 & 05716 & 4 & $\mathrm{~N}$ \\
\hline lnwb*lnwb for Male and age 55-64 & LNWB2_A1A07 & 05728 & 4 & $\mathrm{~N}$ \\
\hline lnwb*lnwb for Male and age $65-99$ & LNWB2_A1A08 & 05740 & 4 & $\mathrm{~N}$ \\
\hline lnwb*lnwblg for Female and age $14-18$ & LNWB_LNWBLG_A2A01 & 05768 & 4 & $\mathrm{~N}$ \\
\hline lnwb*lnwblg for Female and age 14-99 & LNWB_LNWBLG_A2A00 & 05756 & 4 & $\mathrm{~N}$ \\
\hline lnwb*lnwblg for Female and age 19-21 & LNWB_LNWBLG_A2A02 & 05780 & 4 & $\mathrm{~N}$ \\
\hline lnwb*lnwblg for Female and age $22-24$ & LNWB_LNWBLG_A2A03 & 05792 & 4 & $\mathrm{~N}$ \\
\hline lnwb*lnwblg for Female and age $25-34$ & LNWB_LNWBLG_A2A04 & 05804 & 4 & $\mathrm{~N}$ \\
\hline lnwb*lnwblg for Female and age $35-44$ & LNWB_LNWBLG_A2A05 & 05816 & 4 & $\mathrm{~N}$ \\
\hline lnwb*lnwblg for Female and age $45-54$ & LNWB_LNWBLG_A2A06 & 05828 & 4 & $\mathrm{~N}$ \\
\hline lnwb*lnwblg for Female and age 55-64 & LNWB_LNWBLG_A2A07 & 05840 & 4 & $\mathrm{~N}$ \\
\hline lnwb*lnwblg for Female and age $65-99$ & LNWB_LNWBLG_A2A08 & 05852 & 4 & $\mathrm{~N}$ \\
\hline lnwb*lnwblg for Male and Female and age 14-18 & LNWB_LNWBLG_A0A01 & 05760 & 4 & $\mathrm{~N}$ \\
\hline lnwb*lnwblg for Male and Female and age 14-99 & LNWB_LNWBLG_A0A00 & 05748 & 4 & $\mathrm{~N}$ \\
\hline lnwb*lnwblg for Male and Female and age 19-21 & LNWB_LNWBLG_A0A02 & 05772 & 4 & $\mathrm{~N}$ \\
\hline lnwb*lnwblg for Male and Female and age 22-24 & LNWB_LNWBLG_A0A03 & 05784 & 4 & $\mathrm{~N}$ \\
\hline
\end{tabular}


CHAPTER 7. QUARTERLY WORKFORCE INDICATORS - SEINUNIT FILE (QWI)

\begin{tabular}{|c|c|c|c|c|}
\hline Field name & $\begin{array}{l}\text { Data dictionary } \\
\text { reference name }\end{array}$ & $\begin{array}{l}\text { Starting } \\
\text { position }\end{array}$ & $\begin{array}{l}\text { Field } \\
\text { size }\end{array}$ & $\begin{array}{l}\text { Data } \\
\text { type }\end{array}$ \\
\hline lnwb*lnwblg for Male and Female and age $25-34$ & $\begin{array}{l}\text { LNWB_LNWBLG_A0A04 } \\
\end{array}$ & 05796 & 4 & $\mathrm{~N}$ \\
\hline lnwb*lnwblg for Male and Female and age $35-44$ & LNWB_LNWBLG_A0A05 & 05808 & 4 & $\mathrm{~N}$ \\
\hline lnwb*lnwblg for Male and Female and age $45-54$ & LNWB_LNWBLG_A0A06 & 05820 & 4 & $\mathrm{~N}$ \\
\hline lnwb*lnwblg for Male and Female and age $55-64$ & LNWB_LNWBLG_A0A07 & 05832 & 4 & $\mathrm{~N}$ \\
\hline lnwb*lnwblg for Male and Female and age $65-99$ & LNWB_LNWBLG_A0A08 & 05844 & 4 & $\mathrm{~N}$ \\
\hline $\operatorname{lnwb} \ln w b l g$ for Male and age $14-18$ & LNWB_LNWBLG_A1A01 & 05764 & 4 & $\mathrm{~N}$ \\
\hline lnwb*lnwblg for Male and age 14-99 & LNWB_LNWBLG_A1A00 & 05752 & 4 & $\mathrm{~N}$ \\
\hline lnwb*lnwblg for Male and age 19-21 & LNWB_LNWBLG_A1A02 & 05776 & 4 & $\mathrm{~N}$ \\
\hline lnwb*lnwblg for Male and age $22-24$ & LNWB_LNWBLG_A1A03 & 05788 & 4 & $\mathrm{~N}$ \\
\hline lnwb*lnwblg for Male and age $25-34$ & LNWB_LNWBLG_A1A04 & 05800 & 4 & $\mathrm{~N}$ \\
\hline lnwb*lnwblg for Male and age $35-44$ & LNWB_LNWBLG_A1A05 & 05812 & 4 & $\mathrm{~N}$ \\
\hline lnwb*lnwblg for Male and age 45-54 & LNWB_LNWBLG_A1A06 & 05824 & 4 & $\mathrm{~N}$ \\
\hline lnwb*lnwblg for Male and age 55-64 & LNWB_LNWBLG_A1A07 & 05836 & 4 & $\mathrm{~N}$ \\
\hline lnwb*lnwblg for Male and age $65-99$ & LNWB_LNWBLG_A1A08 & 05848 & 4 & $\mathrm{~N}$ \\
\hline lnwblg*lnwblg for Female and age 14-18 & LNWBLG2_A2A01 & 05876 & 4 & $\mathrm{~N}$ \\
\hline lnwblg*lnwblg for Female and age 14-99 & LNWBLG2_A2A00 & 05864 & 4 & $\mathrm{~N}$ \\
\hline lnwblg*lnwblg for Female and age 19-21 & LNWBLG2_A2A02 & 05888 & 4 & $\mathrm{~N}$ \\
\hline lnwblg*lnwblg for Female and age 22-24 & LNWBLG2_A2A03 & 05900 & 4 & $\mathrm{~N}$ \\
\hline lnwblg*lnwblg for Female and age 25-34 & LNWBLG2_A2A04 & 05912 & 4 & $\mathrm{~N}$ \\
\hline lnwblg*lnwblg for Female and age $35-44$ & LNWBLG2_A2A05 & 05924 & 4 & $\mathrm{~N}$ \\
\hline lnwblg*lnwblg for Female and age 45-54 & LNWBLG2_A2A06 & 05936 & 4 & $\mathrm{~N}$ \\
\hline lnwblg*lnwblg for Female and age 55-64 & LNWBLG2_A2A07 & 05948 & 4 & $\mathrm{~N}$ \\
\hline lnwblg*lnwblg for Female and age 65-99 & LNWBLG2_A2A08 & 05960 & 4 & $\mathrm{~N}$ \\
\hline lnwblg*Inwblg for Male and Female and age 14-18 & LNWBLG2_A0A01 & 05868 & 4 & $\mathrm{~N}$ \\
\hline lnwblg*lnwblg for Male and Female and age 14-99 & LNWBLG2_A0A00 & 05856 & 4 & $\mathrm{~N}$ \\
\hline lnwblg*lnwblg for Male and Female and age 19-21 & LNWBLG2_A0A02 & 05880 & 4 & $\mathrm{~N}$ \\
\hline lnwblg*Inwblg for Male and Female and age 22-24 & LNWBLG2_A0A03 & 05892 & 4 & $\mathrm{~N}$ \\
\hline lnwblg*Inwblg for Male and Female and age 25-34 & LNWBLG2_A0A04 & 05904 & 4 & $\mathrm{~N}$ \\
\hline lnwblg*Inwblg for Male and Female and age $35-44$ & LNWBLG2_A0A05 & 05916 & 4 & $\mathrm{~N}$ \\
\hline lnwblg*lnwblg for Male and Female and age 45-54 & LNWBLG2_A0A06 & 05928 & 4 & $\mathrm{~N}$ \\
\hline lnwblg*lnwblg for Male and Female and age 55-64 & LNWBLG2_A0A07 & 05940 & 4 & $\mathrm{~N}$ \\
\hline lnwblg*lnwblg for Male and Female and age 65-99 & LNWBLG2_A0A08 & 05952 & 4 & $\mathrm{~N}$ \\
\hline 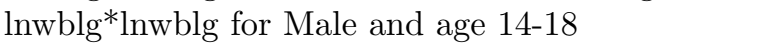 & LNWBLG2_A1A01 & 05872 & 4 & $\mathrm{~N}$ \\
\hline lnwblg*lnwblg for Male and age 14-99 & LNWBLG2_A1A00 & 05860 & 4 & $\mathrm{~N}$ \\
\hline lnwblg*lnwblg for Male and age 19-21 & LNWBLG2_A1A02 & 05884 & 4 & $\mathrm{~N}$ \\
\hline lnwblg*lnwblg for Male and age 22-24 & LNWBLG2_A1A03 & 05896 & 4 & $\mathrm{~N}$ \\
\hline lnwblg*lnwblg for Male and age 25-34 & LNWBLG2_A1A04 & 05908 & 4 & $\mathrm{~N}$ \\
\hline lnwblg*lnwblg for Male and age 35-44 & LNWBLG2_A1A05 & 05920 & 4 & $\mathrm{~N}$ \\
\hline lnwblg*lnwblg for Male and age $45-54$ & LNWBLG2_A1A06 & 05932 & 4 & $\mathrm{~N}$ \\
\hline lnwblg*lnwblg for Male and age 55-64 & LNWBLG2_A1A07 & 05944 & 4 & $\mathrm{~N}$ \\
\hline lnwblg*lnwblg for Male and age $65-99$ & LNWBLG2_A1A08 & 05956 & 4 & $\mathrm{~N}$ \\
\hline lnwe*lnwe for Female and age $14-18$ & LNWE2_A2A01 & 06200 & 4 & $\mathrm{~N}$ \\
\hline lnwe*lnwe for Female and age 14-99 & LNWE2_A2A00 & 06188 & 4 & $\mathrm{~N}$ \\
\hline lnwe*lnwe for Female and age 19-21 & LNWE2_A2A02 & 06212 & 4 & $\mathrm{~N}$ \\
\hline lnwe*lnwe for Female and age 22-24 & LNWE2_A2A03 & 06224 & 4 & $\mathrm{~N}$ \\
\hline lnwe*lnwe for Female and age $25-34$ & LNWE2_A2A04 & 06236 & 4 & $\mathrm{~N}$ \\
\hline lnwe*lnwe for Female and age $35-44$ & LNWE2_A2A05 & 06248 & 4 & $\mathrm{~N}$ \\
\hline lnwe*lnwe for Female and age $45-54$ & LNWE2_A2A06 & 06260 & 4 & $\mathrm{~N}$ \\
\hline lnwe*lnwe for Female and age $55-64$ & LNWE2_A2A07 & 06272 & 4 & $\mathrm{~N}$ \\
\hline lnwe*lnwe for Female and age $65-99$ & LNWE2_A2A08 & 06284 & 4 & $\mathrm{~N}$ \\
\hline
\end{tabular}


CHAPTER 7. QUARTERLY WORKFORCE INDICATORS - SEINUNIT FILE (QWI)

\begin{tabular}{|c|c|c|c|c|}
\hline Field name & $\begin{array}{l}\text { Data dictionary } \\
\text { reference name }\end{array}$ & $\begin{array}{l}\text { Starting } \\
\text { position }\end{array}$ & $\begin{array}{l}\text { Field } \\
\text { size }\end{array}$ & $\begin{array}{l}\text { Data } \\
\text { type }\end{array}$ \\
\hline lnwe*lnwe for Male and Female and age $14-18$ & LNWE2_A0A01 & 06192 & 4 & $\mathrm{~N}$ \\
\hline lnwe*lnwe for Male and Female and age 14-99 & LNWE2_A0A00 & 06180 & 4 & $\mathrm{~N}$ \\
\hline lnwe*lnwe for Male and Female and age 19-21 & LNWE2_A0A02 & 06204 & 4 & $\mathrm{~N}$ \\
\hline lnwe*lnwe for Male and Female and age 22-24 & LNWE2_A0A03 & 06216 & 4 & $\mathrm{~N}$ \\
\hline lnwe*lnwe for Male and Female and age $25-34$ & LNWE2_A0A04 & 06228 & 4 & $\mathrm{~N}$ \\
\hline lnwe*lnwe for Male and Female and age $35-44$ & LNWE2_A0A05 & 06240 & 4 & $\mathrm{~N}$ \\
\hline lnwe*lnwe for Male and Female and age $45-54$ & LNWE2_A0A06 & 06252 & 4 & $\mathrm{~N}$ \\
\hline lnwe*lnwe for Male and Female and age 55-64 & LNWE2_A0A07 & 06264 & 4 & $\mathrm{~N}$ \\
\hline lnwe*lnwe for Male and Female and age 65-99 & LNWE2_A0A08 & 06276 & 4 & $\mathrm{~N}$ \\
\hline lnwe*lnwe for Male and age $14-18$ & LNWE2_A1A01 & 06196 & 4 & $\mathrm{~N}$ \\
\hline lnwe*lnwe for Male and age 14-99 & LNWE2_A1A00 & 06184 & 4 & $\mathrm{~N}$ \\
\hline lnwe*lnwe for Male and age 19-21 & LNWE2_A1A02 & 06208 & 4 & $\mathrm{~N}$ \\
\hline lnwe*lnwe for Male and age $22-24$ & LNWE2_A1A03 & 06220 & 4 & $\mathrm{~N}$ \\
\hline lnwe*lnwe for Male and age $25-34$ & LNWE2_A1A04 & 06232 & 4 & $\mathrm{~N}$ \\
\hline lnwe*lnwe for Male and age $35-44$ & LNWE2_A1A05 & 06244 & 4 & $\mathrm{~N}$ \\
\hline lnwe*lnwe for Male and age $45-54$ & LNWE2_A1A06 & 06256 & 4 & $\mathrm{~N}$ \\
\hline lnwe*lnwe for Male and age 55-64 & LNWE2_A1A07 & 06268 & 4 & $\mathrm{~N}$ \\
\hline lnwe*lnwe for Male and age $65-99$ & LNWE2_A1A08 & 06280 & 4 & $\mathrm{~N}$ \\
\hline lnwe*lnweld for Female and age 14-18 & LNWE_LNWELD_A2A01 & 06308 & 4 & $\mathrm{~N}$ \\
\hline lnwe*lnweld for Female and age 14-99 & LNWE_LNWELD_A2A00 & 06296 & 4 & $\mathrm{~N}$ \\
\hline lnwe*lnweld for Female and age 19-21 & LNWE_LNWELD_A2A02 & 06320 & 4 & $\mathrm{~N}$ \\
\hline lnwe*lnweld for Female and age $22-24$ & LNWE_LNWELD_A2A03 & 06332 & 4 & $\mathrm{~N}$ \\
\hline lnwe*lnweld for Female and age $25-34$ & LNWE_LNWELD_A2A04 & 06344 & 4 & $\mathrm{~N}$ \\
\hline lnwe*lnweld for Female and age $35-44$ & LNWE_LNWELD_A2A05 & 06356 & 4 & $\mathrm{~N}$ \\
\hline lnwe*lnweld for Female and age $45-54$ & LNWE_LNWELD_A2A06 & 06368 & 4 & $\mathrm{~N}$ \\
\hline lnwe*lnweld for Female and age 55-64 & LNWE_LNWELD_A2A07 & 06380 & 4 & $\mathrm{~N}$ \\
\hline lnwe*lnweld for Female and age $65-99$ & LNWE_LNWELD_A2A08 & 06392 & 4 & $\mathrm{~N}$ \\
\hline lnwe*lnweld for Male and Female and age 14-18 & LNWE_LNWELD_A0A01 & 06300 & 4 & $\mathrm{~N}$ \\
\hline lnwe*lnweld for Male and Female and age 14-99 & LNWE_LNWELD_A0A00 & 06288 & 4 & $\mathrm{~N}$ \\
\hline lnwe*lnweld for Male and Female and age 19-21 & LNWE_LNWELD_A0A02 & 06312 & 4 & $\mathrm{~N}$ \\
\hline lnwe*lnweld for Male and Female and age 22-24 & LNWE_LNWELD_A0A03 & 06324 & 4 & $\mathrm{~N}$ \\
\hline lnwe*lnweld for Male and Female and age 25-34 & LNWE_LNWELD_A0A04 & 06336 & 4 & $\mathrm{~N}$ \\
\hline lnwe*lnweld for Male and Female and age 35-44 & LNWE_LNWELD_A0A05 & 06348 & 4 & $\mathrm{~N}$ \\
\hline lnwe*lnweld for Male and Female and age 45-54 & LNWE_LNWELD_A0A06 & 06360 & 4 & $\mathrm{~N}$ \\
\hline lnwe*lnweld for Male and Female and age 55-64 & LNWE_LNWELD_A0A07 & 06372 & 4 & $\mathrm{~N}$ \\
\hline lnwe*lnweld for Male and Female and age 65-99 & LNWE_LNWELD_A0A08 & 06384 & 4 & $\mathrm{~N}$ \\
\hline lnwe*lnweld for Male and age 14-18 & LNWE_LNWELD_A1A01 & 06304 & 4 & $\mathrm{~N}$ \\
\hline lnwe*lnweld for Male and age 14-99 & LNWE_LNWELD_A $1 \mathrm{~A} 00$ & 06292 & 4 & $\mathrm{~N}$ \\
\hline lnwe*lnweld for Male and age 19-21 & LNWE_LNWELD_A1A02 & 06316 & 4 & $\mathrm{~N}$ \\
\hline lnwe*lnweld for Male and age $22-24$ & LNWE_LNWELD_A1A03 & 06328 & 4 & $\mathrm{~N}$ \\
\hline lnwe*lnweld for Male and age $25-34$ & LNWE_LNWELD_A1A04 & 06340 & 4 & $\mathrm{~N}$ \\
\hline lnwe*lnweld for Male and age $35-44$ & LNWE_LNWELD_A1A05 & 06352 & 4 & $\mathrm{~N}$ \\
\hline lnwe*lnweld for Male and age $45-54$ & LNWE_LNWELD_A1A06 & 06364 & 4 & $\mathrm{~N}$ \\
\hline lnwe*lnweld for Male and age 55-64 & LNWE_LNWELD_A1A07 & 06376 & 4 & $\mathrm{~N}$ \\
\hline lnwe*lnweld for Male and age 65-99 & LNWE_LNWELD_A1A08 & 06388 & 4 & $\mathrm{~N}$ \\
\hline lnweld*lnweld for Female and age 14-18 & LNWELD2_A2A01 & 06416 & 4 & $\mathrm{~N}$ \\
\hline lnweld*lnweld for Female and age 14-99 & LNWELD2_A2A00 & 06404 & 4 & $\mathrm{~N}$ \\
\hline lnweld*lnweld for Female and age 19-21 & LNWELD2_A2A02 & 06428 & 4 & $\mathrm{~N}$ \\
\hline lnweld*lnweld for Female and age $22-24$ & LNWELD2_A2A03 & 06440 & 4 & $\mathrm{~N}$ \\
\hline lnweld*lnweld for Female and age 25-34 & LNWELD2_A2A04 & 06452 & 4 & $\mathrm{~N}$ \\
\hline
\end{tabular}


CHAPTER 7. QUARTERLY WORKFORCE INDICATORS - SEINUNIT FILE (QWI)

\begin{tabular}{|c|c|c|c|c|}
\hline Field name & $\begin{array}{l}\text { Data dictionary } \\
\text { reference name }\end{array}$ & $\begin{array}{l}\text { Starting } \\
\text { position }\end{array}$ & $\begin{array}{l}\text { Field } \\
\text { size }\end{array}$ & $\begin{array}{l}\text { Data } \\
\text { type }\end{array}$ \\
\hline lnweld*Inweld for Female and age 35-44 & LNWELD2_A2A05 & 06464 & 4 & $\mathrm{~N}$ \\
\hline lnweld*Inweld for Female and age $45-54$ & LNWELD2_A2A06 & 06476 & 4 & $\mathrm{~N}$ \\
\hline lnweld*lnweld for Female and age 55-64 & LNWELD2_A2A07 & 06488 & 4 & $\mathrm{~N}$ \\
\hline lnweld*lnweld for Female and age 65-99 & LNWELD2_A2A08 & 06500 & 4 & $\mathrm{~N}$ \\
\hline lnweld*lnweld for Male and Female and age 14-18 & LNWELD2_A0A01 & 06408 & 4 & $\mathrm{~N}$ \\
\hline lnweld*lnweld for Male and Female and age 14-99 & LNWELD2_A0A00 & 06396 & 4 & $\mathrm{~N}$ \\
\hline lnweld*lnweld for Male and Female and age 19-21 & LNWELD2_A0A02 & 06420 & 4 & $\mathrm{~N}$ \\
\hline lnweld*lnweld for Male and Female and age 22-24 & LNWELD2_A0A03 & 06432 & 4 & $\mathrm{~N}$ \\
\hline lnweld*lnweld for Male and Female and age 25-34 & LNWELD2_A0A04 & 06444 & 4 & $\mathrm{~N}$ \\
\hline lnweld*lnweld for Male and Female and age 35-44 & LNWELD2_A0A05 & 06456 & 4 & $\mathrm{~N}$ \\
\hline lnweld*lnweld for Male and Female and age 45-54 & LNWELD2_A0A06 & 06468 & 4 & $\mathrm{~N}$ \\
\hline lnweld*lnweld for Male and Female and age $55-64$ & LNWELD2_A0A07 & 06480 & 4 & $\mathrm{~N}$ \\
\hline lnweld*lnweld for Male and Female and age 65-99 & LNWELD2_A0A08 & 06492 & 4 & $\mathrm{~N}$ \\
\hline lnweld*lnweld for Male and age 14-18 & LNWELD2_A1A01 & 06412 & 4 & $\mathrm{~N}$ \\
\hline lnweld*Inweld for Male and age 14-99 & LNWELD2_A1A00 & 06400 & 4 & $\mathrm{~N}$ \\
\hline lnweld*Inweld for Male and age 19-21 & LNWELD2_A1A02 & 06424 & 4 & $\mathrm{~N}$ \\
\hline lnweld*Inweld for Male and age 22-24 & LNWELD2_A1A03 & 06436 & 4 & $\mathrm{~N}$ \\
\hline lnweld*lnweld for Male and age 25-34 & LNWELD2_A1A04 & 06448 & 4 & $\mathrm{~N}$ \\
\hline lnweld*lnweld for Male and age 35-44 & LNWELD2_A1A05 & 06460 & 4 & $\mathrm{~N}$ \\
\hline lnweld*lnweld for Male and age 45-54 & LNWELD2_A1A06 & 06472 & 4 & $\mathrm{~N}$ \\
\hline lnweld*lnweld for Male and age 55-64 & LNWELD2_A1A07 & 06484 & 4 & $\mathrm{~N}$ \\
\hline lnweld*lnweld for Male and age 65-99 & LNWELD2_A1A08 & 06496 & 4 & $\mathrm{~N}$ \\
\hline lnwf*lnwf for Female and age 14-18 & LNWF2_A2A01 & 06848 & 4 & $\mathrm{~N}$ \\
\hline lnwf*lnwf for Female and age 14-99 & LNWF2_A2A00 & 06836 & 4 & $\mathrm{~N}$ \\
\hline lnwf*lnwf for Female and age 19-21 & LNWF2_A2A02 & 06860 & 4 & $\mathrm{~N}$ \\
\hline lnwf*lnwf for Female and age 22-24 & LNWF2_A2A03 & 06872 & 4 & $\mathrm{~N}$ \\
\hline lnwf*lnwf for Female and age 25-34 & LNWF2_A2A04 & 06884 & 4 & $\mathrm{~N}$ \\
\hline lnwf*lnwf for Female and age $35-44$ & LNWF2_A2A05 & 06896 & 4 & $\mathrm{~N}$ \\
\hline lnwf*lnwf for Female and age $45-54$ & LNWF2_A2A06 & 06908 & 4 & $\mathrm{~N}$ \\
\hline lnwf*lnwf for Female and age 55-64 & LNWF2_A2A07 & 06920 & 4 & $\mathrm{~N}$ \\
\hline lnwf*lnwf for Female and age $65-99$ & LNWF2_A2A08 & 06932 & 4 & $\mathrm{~N}$ \\
\hline lnwf*lnwf for Male and Female and age 14-18 & LNWF2_A0A01 & 06840 & 4 & $\mathrm{~N}$ \\
\hline lnwf*lnwf for Male and Female and age 14-99 & LNWF2_A0A00 & 06828 & 4 & $\mathrm{~N}$ \\
\hline lnwf*lnwf for Male and Female and age 19-21 & LNWF2_A0A02 & 06852 & 4 & $\mathrm{~N}$ \\
\hline lnwf*lnwf for Male and Female and age 22-24 & LNWF2_A0A03 & 06864 & 4 & $\mathrm{~N}$ \\
\hline lnwf*lnwf for Male and Female and age 25-34 & LNWF2_A0A04 & 06876 & 4 & $\mathrm{~N}$ \\
\hline lnwf*lnwf for Male and Female and age $35-44$ & LNWF2_A0A05 & 06888 & 4 & $\mathrm{~N}$ \\
\hline lnwf*lnwf for Male and Female and age $45-54$ & LNWF2_A0A06 & 06900 & 4 & $\mathrm{~N}$ \\
\hline lnwf*lnwf for Male and Female and age 55-64 & LNWF2_A0A07 & 06912 & 4 & $\mathrm{~N}$ \\
\hline lnwf*lnwf for Male and Female and age 65-99 & LNWF2_A0A08 & 06924 & 4 & $\mathrm{~N}$ \\
\hline lnwf*lnwf for Male and age 14-18 & LNWF2_A1A01 & 06844 & 4 & $\mathrm{~N}$ \\
\hline lnwf*lnwf for Male and age 14-99 & LNWF2_A1A00 & 06832 & 4 & $\mathrm{~N}$ \\
\hline lnwf*lnwf for Male and age 19-21 & LNWF2_A1A02 & 06856 & 4 & $\mathrm{~N}$ \\
\hline lnwf*lnwf for Male and age $22-24$ & LNWF2_A1A03 & 06868 & 4 & $\mathrm{~N}$ \\
\hline lnwf*lnwf for Male and age $25-34$ & LNWF2_A1A04 & 06880 & 4 & $\mathrm{~N}$ \\
\hline lnwf*lnwf for Male and age 35-44 & LNWF2_A $1 \mathrm{~A} 05$ & 06892 & 4 & $\mathrm{~N}$ \\
\hline lnwf*lnwf for Male and age $45-54$ & LNWF2_A1A06 & 06904 & 4 & $\mathrm{~N}$ \\
\hline lnwf*lnwf for Male and age $55-64$ & LNWF2_A1A07 & 06916 & 4 & $\mathrm{~N}$ \\
\hline lnwf*lnwf for Male and age $65-99$ & LNWF2_A1A08 & 06928 & 4 & $\mathrm{~N}$ \\
\hline lnwf*lnwfld for Female and age 14-18 & LNWF_LNWFLD_A2A01 & 07172 & 4 & $\mathrm{~N}$ \\
\hline
\end{tabular}


CHAPTER 7. QUARTERLY WORKFORCE INDICATORS - SEINUNIT FILE (QWI)

\begin{tabular}{|c|c|c|c|c|}
\hline Field name & $\begin{array}{l}\text { Data dictionary } \\
\text { reference name }\end{array}$ & $\begin{array}{l}\text { Starting } \\
\text { position }\end{array}$ & $\begin{array}{l}\text { Field } \\
\text { size }\end{array}$ & $\begin{array}{l}\text { Data } \\
\text { type }\end{array}$ \\
\hline lnwf*lnwfld for Female and age 14-99 & LNWF_LNWFLD_A2A00 & 07160 & 4 & $\mathrm{~N}$ \\
\hline lnwf*lnwfld for Female and age 19-21 & LNWF_LNWFLD_A2A02 & 07184 & 4 & $\mathrm{~N}$ \\
\hline lnwf*lnwfld for Female and age 22-24 & LNWF_LNWFLD_A2A03 & 07196 & 4 & $\mathrm{~N}$ \\
\hline lnwf*lnwfld for Female and age $25-34$ & LNWF_LNWFLD_A2A04 & 07208 & 4 & $\mathrm{~N}$ \\
\hline lnwf*lnwfld for Female and age $35-44$ & LNWF_LNWFLD_A2A05 & 07220 & 4 & $\mathrm{~N}$ \\
\hline lnwf*lnwfld for Female and age 45-54 & LNWF_LNWFLD_A2A06 & 07232 & 4 & $\mathrm{~N}$ \\
\hline lnwf*lnwfld for Female and age $55-64$ & LNWF_LNWFLD_A2A07 & 07244 & 4 & $\mathrm{~N}$ \\
\hline lnwf*lnwfld for Female and age 65-99 & LNWF_LNWFLD_A2A08 & 07256 & 4 & $\mathrm{~N}$ \\
\hline lnwf*lnwfld for Male and Female and age 14-18 & LNWF_LNWFLD_A0A01 & 07164 & 4 & $\mathrm{~N}$ \\
\hline lnwf*lnwfld for Male and Female and age 14-99 & LNWF_LNWFLD_A0A00 & 07152 & 4 & $\mathrm{~N}$ \\
\hline lnwf*lnwfld for Male and Female and age 19-21 & LNWF_LNWFLD_A0A02 & 07176 & 4 & $\mathrm{~N}$ \\
\hline lnwf*lnwfld for Male and Female and age 22-24 & LNWF_LNWFLD_A0A03 & 07188 & 4 & $\mathrm{~N}$ \\
\hline lnwf*lnwfld for Male and Female and age 25-34 & LNWF_LNWFLD_A0A04 & 07200 & 4 & $\mathrm{~N}$ \\
\hline lnwf*lnwfld for Male and Female and age 35-44 & LNWF_LNWFLD_A0A05 & 07212 & 4 & $\mathrm{~N}$ \\
\hline lnwf*lnwfld for Male and Female and age 45-54 & LNWF_LNWFLD_A0A06 & 07224 & 4 & $\mathrm{~N}$ \\
\hline lnwf*lnwfld for Male and Female and age 55-64 & LNWF_LNWFLD_A0A07 & 07236 & 4 & $\mathrm{~N}$ \\
\hline lnwf*lnwfld for Male and Female and age 65-99 & LNWF_LNWFLD_A0A08 & 07248 & 4 & $\mathrm{~N}$ \\
\hline lnwf*lnwfld for Male and age $14-18$ & LNWF_LNWFLD_A1A01 & 07168 & 4 & $\mathrm{~N}$ \\
\hline lnwf*lnwfld for Male and age 14-99 & LNWF_LNWFLD_A1A00 & 07156 & 4 & $\mathrm{~N}$ \\
\hline lnwf*lnwfld for Male and age 19-21 & LNWF_LNWFLD_A1A02 & 07180 & 4 & $\mathrm{~N}$ \\
\hline lnwf*lnwfld for Male and age 22-24 & LNWF_LNWFLD_A1A03 & 07192 & 4 & $\mathrm{~N}$ \\
\hline lnwf*lnwfld for Male and age 25-34 & LNWF_LNWFLD_A1A04 & 07204 & 4 & $\mathrm{~N}$ \\
\hline lnwf*lnwfld for Male and age 35-44 & LNWF_LNWFLD_A1A05 & 07216 & 4 & $\mathrm{~N}$ \\
\hline lnwf*lnwfld for Male and age $45-54$ & LNWF_LNWFLD_A1A06 & 07228 & 4 & $\mathrm{~N}$ \\
\hline lnwf*lnwfld for Male and age 55-64 & LNWF_LNWFLD_A1A07 & 07240 & 4 & $\mathrm{~N}$ \\
\hline lnwf*lnwfld for Male and age $65-99$ & LNWF_LNWFLD_A1A08 & 07252 & 4 & $\mathrm{~N}$ \\
\hline lnwf*lnwflg for Female and age $14-18$ & LNWF_LNWFLG_A2A01 & 07280 & 4 & $\mathrm{~N}$ \\
\hline lnwf*lnwflg for Female and age 14-99 & LNWF_LNWFLG_A2A00 & 07268 & 4 & $\mathrm{~N}$ \\
\hline lnwf*lnwflg for Female and age 19-21 & LNWF_LNWFLG_A2A02 & 07292 & 4 & $\mathrm{~N}$ \\
\hline lnwf*lnwflg for Female and age 22-24 & LNWF_LNWFLG_A2A03 & 07304 & 4 & $\mathrm{~N}$ \\
\hline lnwf*lnwflg for Female and age $25-34$ & LNWF_LNWFLG_A2A04 & 07316 & 4 & $\mathrm{~N}$ \\
\hline lnwf*lnwflg for Female and age 35-44 & LNWF_LNWFLG_A2A05 & 07328 & 4 & $\mathrm{~N}$ \\
\hline lnwf*lnwflg for Female and age 45-54 & LNWF_LNWFLG_A2A06 & 07340 & 4 & $\mathrm{~N}$ \\
\hline lnwf*lnwflg for Female and age 55-64 & LNWF_LNWFLG_A2A07 & 07352 & 4 & $\mathrm{~N}$ \\
\hline lnwf*lnwflg for Female and age 65-99 & LNWF_LNWFLG_A2A08 & 07364 & 4 & $\mathrm{~N}$ \\
\hline lnwf*lnwflg for Male and Female and age 14-18 & LNWF_LNWFLG_A0A01 & 07272 & 4 & $\mathrm{~N}$ \\
\hline lnwf*Inwflg for Male and Female and age 14-99 & LNWF_LNWFLG_A0A00 & 07260 & 4 & $\mathrm{~N}$ \\
\hline lnwf*lnwflg for Male and Female and age 19-21 & LNWF_LNWFLG_A0A02 & 07284 & 4 & $\mathrm{~N}$ \\
\hline lnwf*lnwflg for Male and Female and age 22-24 & LNWF_LNWFLG_A0A03 & 07296 & 4 & $\mathrm{~N}$ \\
\hline lnwf*lnwflg for Male and Female and age 25-34 & LNWF_LNWFLG_A0A04 & 07308 & 4 & $\mathrm{~N}$ \\
\hline lnwf*lnwflg for Male and Female and age 35-44 & LNWF_LNWFLG_A0A05 & 07320 & 4 & $\mathrm{~N}$ \\
\hline lnwf*lnwflg for Male and Female and age $45-54$ & LNWF_LNWFLG_A0A06 & 07332 & 4 & $\mathrm{~N}$ \\
\hline lnwf*lnwflg for Male and Female and age 55-64 & LNWF_LNWFLG_A0A07 & 07344 & 4 & $\mathrm{~N}$ \\
\hline lnwf*lnwflg for Male and Female and age 65-99 & LNWF_LNWFLG_A0A08 & 07356 & 4 & $\mathrm{~N}$ \\
\hline lnwf*lnwflg for Male and age 14-18 & LNWF_LNWFLG_A1A01 & 07276 & 4 & $\mathrm{~N}$ \\
\hline lnwf*lnwflg for Male and age 14-99 & LNWF_LNWFLG_A1A00 & 07264 & 4 & $\mathrm{~N}$ \\
\hline lnwf*lnwflg for Male and age 19-21 & LNWF_LNWFLG_A1A02 & 07288 & 4 & $\mathrm{~N}$ \\
\hline lnwf*lnwflg for Male and age 22-24 & LNWF_LNWFLG_A1A03 & 07300 & 4 & $\mathrm{~N}$ \\
\hline lnwf*lnwflg for Male and age 25-34 & LNWF_LNWFLG_A1A04 & 07312 & 4 & $\mathrm{~N}$ \\
\hline lnwf*lnwflg for Male and age $35-44$ & LNWF_LNWFLG_A1A05 & 07324 & 4 & $\mathrm{~N}$ \\
\hline
\end{tabular}


CHAPTER 7. QUARTERLY WORKFORCE INDICATORS - SEINUNIT FILE (QWI)

\begin{tabular}{|c|c|c|c|c|}
\hline Field name & $\begin{array}{l}\text { Data dictionary } \\
\text { reference name }\end{array}$ & $\begin{array}{l}\text { Starting } \\
\text { position }\end{array}$ & $\begin{array}{l}\text { Field } \\
\text { size }\end{array}$ & $\begin{array}{l}\text { Data } \\
\text { type }\end{array}$ \\
\hline lnwf*lnwflg for Male and age 45-54 & LNWF_LNWFLG_A1A06 & 07336 & 4 & $\mathrm{~N}$ \\
\hline lnwf*lnwflg for Male and age 55-64 & LNWF_LNWFLG_A1A07 & 07348 & 4 & $\mathrm{~N}$ \\
\hline lnwf*lnwflg for Male and age $65-99$ & LNWF_LNWFLG_A1A08 & 07360 & 4 & $\mathrm{~N}$ \\
\hline lnwfld*lnwfld for Female and age 14-18 & LNWFLD2_A2A01 & 06956 & 4 & $\mathrm{~N}$ \\
\hline lnwfld*lnwfld for Female and age 14-99 & LNWFLD2_A2A00 & 06944 & 4 & $\mathrm{~N}$ \\
\hline lnwfld*lnwfld for Female and age 19-21 & LNWFLD2_A2A02 & 06968 & 4 & $\mathrm{~N}$ \\
\hline lnwfld*lnwfld for Female and age $22-24$ & LNWFLD2_A2A03 & 06980 & 4 & $\mathrm{~N}$ \\
\hline lnwfld*lnwfld for Female and age $25-34$ & LNWFLD2_A2A04 & 06992 & 4 & $\mathrm{~N}$ \\
\hline lnwfld*lnwfld for Female and age $35-44$ & LNWFLD2_A2A05 & 07004 & 4 & $\mathrm{~N}$ \\
\hline lnwfld*lnwfld for Female and age $45-54$ & LNWFLD2_A2A06 & 07016 & 4 & $\mathrm{~N}$ \\
\hline lnwfld*lnwfld for Female and age 55-64 & LNWFLD2_A2A07 & 07028 & 4 & $\mathrm{~N}$ \\
\hline lnwfld*lnwfld for Female and age $65-99$ & LNWFLD2_A2A08 & 07040 & 4 & $\mathrm{~N}$ \\
\hline lnwfld*lnwfld for Male and Female and age 14-18 & LNWFLD2_A0A01 & 06948 & 4 & $\mathrm{~N}$ \\
\hline lnwfld*lnwfld for Male and Female and age 14-99 & LNWFLD2_A0A00 & 06936 & 4 & $\mathrm{~N}$ \\
\hline lnwfld*lnwfld for Male and Female and age 19-21 & LNWFLD2_A0A02 & 06960 & 4 & $\mathrm{~N}$ \\
\hline lnwfld*lnwfld for Male and Female and age 22-24 & LNWFLD2_A0A03 & 06972 & 4 & $\mathrm{~N}$ \\
\hline lnwfld*Inwfld for Male and Female and age 25-34 & LNWFLD2_A0A04 & 06984 & 4 & $\mathrm{~N}$ \\
\hline lnwfld*lnwfld for Male and Female and age 35-44 & LNWFLD2_A0A05 & 06996 & 4 & $\mathrm{~N}$ \\
\hline lnwfld*lnwfld for Male and Female and age 45-54 & LNWFLD2_A0A06 & 07008 & 4 & $\mathrm{~N}$ \\
\hline lnwfld*lnwfld for Male and Female and age 55-64 & LNWFLD2_A0A07 & 07020 & 4 & $\mathrm{~N}$ \\
\hline lnwfld*lnwfld for Male and Female and age 65-99 & LNWFLD2_A0A08 & 07032 & 4 & $\mathrm{~N}$ \\
\hline lnwfld*lnwfld for Male and age 14-18 & LNWFLD2_A1A01 & 06952 & 4 & $\mathrm{~N}$ \\
\hline lnwfld*lnwfld for Male and age 14-99 & LNWFLD2_A1A00 & 06940 & 4 & $\mathrm{~N}$ \\
\hline lnwfld*lnwfld for Male and age 19-21 & LNWFLD2_A1A02 & 06964 & 4 & $\mathrm{~N}$ \\
\hline lnwfld*lnwfld for Male and age 22-24 & LNWFLD2_A1A03 & 06976 & 4 & $\mathrm{~N}$ \\
\hline lnwfld*lnwfld for Male and age 25-34 & LNWFLD2_A1A04 & 06988 & 4 & $\mathrm{~N}$ \\
\hline lnwfld*lnwfld for Male and age 35-44 & LNWFLD2_A1A05 & 07000 & 4 & $\mathrm{~N}$ \\
\hline lnwfld*lnwfld for Male and age 45-54 & LNWFLD2_A1A06 & 07012 & 4 & $\mathrm{~N}$ \\
\hline lnwfld*lnwfld for Male and age 55-64 & LNWFLD2_A1A07 & 07024 & 4 & $\mathrm{~N}$ \\
\hline lnwfld*lnwfld for Male and age 65-99 & LNWFLD2_A1A08 & 07036 & 4 & $\mathrm{~N}$ \\
\hline lnwfld*lnwflg for Female and age $14-18$ & LNWFLD_LNWFLG_A2A01 & 07388 & 4 & $\mathrm{~N}$ \\
\hline lnwfld*lnwflg for Female and age 14-99 & LNWFLD_LNWFLG_A2A00 & 07376 & 4 & $\mathrm{~N}$ \\
\hline lnwfld*lnwflg for Female and age 19-21 & LNWFLD_LNWFLG_A2A02 & 07400 & 4 & $\mathrm{~N}$ \\
\hline lnwfld*lnwflg for Female and age $22-24$ & LNWFLD_LNWFLG_A2A03 & 07412 & 4 & $\mathrm{~N}$ \\
\hline lnwfld*lnwflg for Female and age $25-34$ & LNWFLD_LNWFLG_A2A04 & 07424 & 4 & $\mathrm{~N}$ \\
\hline lnwfld*lnwflg for Female and age $35-44$ & LNWFLD_LNWFLG_A2A05 & 07436 & 4 & $\mathrm{~N}$ \\
\hline lnwfld*lnwflg for Female and age $45-54$ & LNWFLD_LNWFLG_A2A06 & 07448 & 4 & $\mathrm{~N}$ \\
\hline lnwfld*lnwflg for Female and age $55-64$ & LNWFLD_LNWFLG_A2A07 & 07460 & 4 & $\mathrm{~N}$ \\
\hline lnwfld*lnwflg for Female and age $65-99$ & LNWFLD_LNWFLG_A2A08 & 07472 & 4 & $\mathrm{~N}$ \\
\hline lnwfld*lnwflg for Male and Female and age 14-18 & LNWFLD_LNWFLG_A0A01 & 07380 & 4 & $\mathrm{~N}$ \\
\hline lnwfld*lnwflg for Male and Female and age 14-99 & LNWFLD_LNWFLG_A0A00 & 07368 & 4 & $\mathrm{~N}$ \\
\hline lnwfld*lnwflg for Male and Female and age 19-21 & LNWFLD_LNWFLG_A0A02 & 07392 & 4 & $\mathrm{~N}$ \\
\hline lnwfld*lnwflg for Male and Female and age 22-24 & LNWFLD_LNWFLG_A0A03 & 07404 & 4 & $\mathrm{~N}$ \\
\hline lnwfld*lnwflg for Male and Female and age 25-34 & LNWFLD_LNWFLG_A0A04 & 07416 & 4 & $\mathrm{~N}$ \\
\hline lnwfld*lnwflg for Male and Female and age 35-44 & LNWFLD_LNWFLG_A0A05 & 07428 & 4 & $\mathrm{~N}$ \\
\hline lnwfld*lnwflg for Male and Female and age 45-54 & LNWFLD_LNWFLG_A0A06 & 07440 & 4 & $\mathrm{~N}$ \\
\hline lnwfld*lnwflg for Male and Female and age 55-64 & LNWFLD_LNWFLG_A0A07 & 07452 & 4 & $\mathrm{~N}$ \\
\hline lnwfld*lnwflg for Male and Female and age 65-99 & LNWFLD_LNWFLG_A0A08 & 07464 & 4 & $\mathrm{~N}$ \\
\hline lnwfld*lnwflg for Male and age $14-18$ & LNWFLD_LNWFLG_A1A01 & 07384 & 4 & $\mathrm{~N}$ \\
\hline lnwfld*lnwflg for Male and age 14-99 & LNWFLD_LNWFLG_A1A00 & 07372 & 4 & $\mathrm{~N}$ \\
\hline
\end{tabular}


CHAPTER 7. QUARTERLY WORKFORCE INDICATORS - SEINUNIT FILE (QWI)

\begin{tabular}{|c|c|c|c|c|}
\hline Field name & $\begin{array}{l}\text { Data dictionary } \\
\text { reference name }\end{array}$ & $\begin{array}{l}\text { Starting } \\
\text { position }\end{array}$ & $\begin{array}{l}\text { Field } \\
\text { size }\end{array}$ & $\begin{array}{l}\text { Data } \\
\text { type }\end{array}$ \\
\hline lnwfld*lnwflg for Male and age 19-21 & $\begin{array}{l}\text { LNWFLD_LNWFLG_A1A02 } \\
\end{array}$ & 07396 & 4 & $\mathrm{~N}$ \\
\hline lnwfld*lnwflg for Male and age 22-24 & LNWFLD_LNWFLG_A1A03 & 07408 & 4 & $\mathrm{~N}$ \\
\hline lnwfld*lnwflg for Male and age 25-34 & LNWFLD_LNWFLG_A1A04 & 07420 & 4 & $\mathrm{~N}$ \\
\hline lnwfld*lnwflg for Male and age 35-44 & LNWFLD_LNWFLG_A1A05 & 07432 & 4 & $\mathrm{~N}$ \\
\hline lnwfld*lnwflg for Male and age 45-54 & LNWFLD_LNWFLG_A1A06 & 07444 & 4 & $\mathrm{~N}$ \\
\hline lnwfld*lnwflg for Male and age 55-64 & LNWFLD_LNWFLG_A1A07 & 07456 & 4 & $\mathrm{~N}$ \\
\hline lnwfld*lnwflg for Male and age $65-99$ & LNWFLD_LNWFLG_A1A08 & 07468 & 4 & $\mathrm{~N}$ \\
\hline lnwflg*lnwflg for Female and age 14-18 & LNWFLG2_A2A01 & 07064 & 4 & $\mathrm{~N}$ \\
\hline lnwflg*lnwflg for Female and age 14-99 & LNWFLG2_A2A00 & 07052 & 4 & $\mathrm{~N}$ \\
\hline lnwflg*lnwflg for Female and age 19-21 & LNWFLG2_A2A02 & 07076 & 4 & $\mathrm{~N}$ \\
\hline lnwflg*lnwflg for Female and age $22-24$ & LNWFLG2_A2A03 & 07088 & 4 & $\mathrm{~N}$ \\
\hline lnwflg*lnwflg for Female and age 25-34 & LNWFLG2_A2A04 & 07100 & 4 & $\mathrm{~N}$ \\
\hline lnwflg*lnwflg for Female and age $35-44$ & LNWFLG2_A2A05 & 07112 & 4 & $\mathrm{~N}$ \\
\hline lnwflg*lnwflg for Female and age $45-54$ & LNWFLG2_A2A06 & 07124 & 4 & $\mathrm{~N}$ \\
\hline lnwflg*lnwflg for Female and age 55-64 & LNWFLG2_A2A07 & 07136 & 4 & $\mathrm{~N}$ \\
\hline lnwflg*lnwflg for Female and age $65-99$ & LNWFLG2_A2A08 & 07148 & 4 & $\mathrm{~N}$ \\
\hline lnwflg*Inwflg for Male and Female and age 14-18 & LNWFLG2_A0A01 & 07056 & 4 & $\mathrm{~N}$ \\
\hline lnwflg*Inwflg for Male and Female and age 14-99 & LNWFLG2_A0A00 & 07044 & 4 & $\mathrm{~N}$ \\
\hline lnwflg*Inwflg for Male and Female and age 19-21 & LNWFLG2_A0A02 & 07068 & 4 & $\mathrm{~N}$ \\
\hline lnwflg*Inwflg for Male and Female and age 22-24 & LNWFLG2_A0A03 & 07080 & 4 & $\mathrm{~N}$ \\
\hline lnwflg*Inwflg for Male and Female and age 25-34 & LNWFLG2_A0A04 & 07092 & 4 & $\mathrm{~N}$ \\
\hline lnwflg*Inwflg for Male and Female and age 35-44 & LNWFLG2_A0A05 & 07104 & 4 & $\mathrm{~N}$ \\
\hline lnwflg*lnwflg for Male and Female and age 45-54 & LNWFLG2_A0A06 & 07116 & 4 & $\mathrm{~N}$ \\
\hline lnwflg*lnwflg for Male and Female and age 55-64 & LNWFLG2_A0A07 & 07128 & 4 & $\mathrm{~N}$ \\
\hline lnwflg*Inwflg for Male and Female and age 65-99 & LNWFLG2_A0A08 & 07140 & 4 & $\mathrm{~N}$ \\
\hline lnwflg*lnwflg for Male and age 14-18 & LNWFLG2_A1A01 & 07060 & 4 & $\mathrm{~N}$ \\
\hline lnwflg*lnwflg for Male and age 14-99 & LNWFLG2_A1A00 & 07048 & 4 & $\mathrm{~N}$ \\
\hline lnwflg*lnwflg for Male and age 19-21 & LNWFLG2_A1A02 & 07072 & 4 & $\mathrm{~N}$ \\
\hline lnwflg*lnwflg for Male and age 22-24 & LNWFLG2_A1A03 & 07084 & 4 & $\mathrm{~N}$ \\
\hline lnwflg*lnwflg for Male and age 25-34 & LNWFLG2_A1A04 & 07096 & 4 & $\mathrm{~N}$ \\
\hline lnwflg*lnwflg for Male and age $35-44$ & LNWFLG2_A1A05 & 07108 & 4 & $\mathrm{~N}$ \\
\hline lnwflg*lnwflg for Male and age 45-54 & LNWFLG2_A1A06 & 07120 & 4 & $\mathrm{~N}$ \\
\hline lnwflg*lnwflg for Male and age 55-64 & LNWFLG2_A1A07 & 07132 & 4 & $\mathrm{~N}$ \\
\hline lnwflg*lnwflg for Male and age $65-99$ & LNWFLG2_A1A08 & 07144 & 4 & $\mathrm{~N}$ \\
\hline qwi_wcf*qwi_unit_weight & QWI_FINAL_WEIGHT & 00016 & 8 & $\mathrm{~N}$ \\
\hline
\end{tabular}


CHAPTER 7. QUARTERLY WORKFORCE INDICATORS - SEINUNIT FILE (QWI)

\subsubsection{Summary information on datasets}

Table 7.2: File information, by state, for QWI

\begin{tabular}{|c|c|c|c|c|c|c|}
\hline State & & $\begin{array}{r}\text { Number of } \\
\text { datafiles }\end{array}$ & Records & $\begin{array}{r}\text { Filesizes } \\
(\mathrm{MB})\end{array}$ & Start & End \\
\hline Covered states & & 26 & $166,312,551$ & $583,715.02$ & 1990Q1 & 2004Q3 \\
\hline Alabama & $\mathrm{AL}$ & & & & 2001Q1 & 2004Q2 \\
\hline Arkansas & $\mathrm{AR}$ & 1 & 534,484 & $4,176.01$ & 2002Q3 & 2004Q1 \\
\hline California & $\mathrm{CA}$ & 1 & $43,638,767$ & $89,783.13$ & 1991Q3 & 2003Q4 \\
\hline Colorado & $\mathrm{CO}$ & 1 & $5,605,248$ & $43,791.32$ & 1993Q2 & 2004Q1 \\
\hline Delaware & $\mathrm{DE}$ & 1 & 535,373 & $1,078.45$ & 1998Q3 & 2004Q1 \\
\hline Florida & FL & 1 & $17,786,826$ & $36,987.38$ & 1992Q4 & 2004Q1 \\
\hline Iowa & IA & 1 & $1,962,014$ & $15,328.57$ & 1998Q4 & 2004Q1 \\
\hline Idaho & ID & 1 & $2,019,670$ & $15,779.01$ & 1991Q1 & 2004Q1 \\
\hline Illinois & IL & ( & & & 1990Q1 & 2004Q1 \\
\hline Indiana & IN & 1 & $3,605,097$ & $8,238.45$ & 1998Q1 & 2004Q1 \\
\hline Kansas & $\mathrm{KS}$ & & & & 1993Q1 & 2004Q1 \\
\hline Kentucky & KY & 1 & $1,250,675$ & $2,841.88$ & 2001Q1 & 2004Q1 \\
\hline Maryland & MD & & & & 1990Q1 & 2004Q1 \\
\hline Maine & $\mathrm{ME}$ & 1 & $1,342,283$ & $10,486.88$ & 1996Q1 & 2004Q1 \\
\hline Minnesota & MN & 1 & $4,748,456$ & $9,316.32$ & 1994Q3 & 2004Q3 \\
\hline Missouri & MO & 1 & $5,669,283$ & $44,291.57$ & 1995Q1 & 2004Q1 \\
\hline Montana & MT & 1 & $1,412,306$ & $11,033.95$ & 1993Q1 & 2004Q1 \\
\hline North Carolina & $\mathrm{NC}$ & 1 & $10,150,481$ & $22,599.01$ & 1991Q1 & 2003Q4 \\
\hline North Dakota & ND & 1 & 546,389 & $4,269.01$ & 1998Q1 & 2004Q2 \\
\hline New Jersey & NJ & 1 & $6,707,798$ & $52,405.01$ & 1996Q1 & 2004Q1 \\
\hline New Mexico & NM & 1 & $1,578,333$ & $12,331.07$ & 1995Q3 & 2004Q1 \\
\hline Oklahoma & OK & 1 & $1,511,516$ & $11,809.07$ & 1999Q1 & 2004Q1 \\
\hline Oregon & OR & 1 & $5,424,000$ & $42,375.32$ & 1991Q1 & 2004Q1 \\
\hline Pennsylvania & $\mathrm{PA}$ & 1 & $8,660,512$ & $19,016.32$ & 1997Q1 & 2004Q1 \\
\hline South Carolina & $\mathrm{SC}$ & & & & 1998Q1 & 2004Q3 \\
\hline Texas & $\mathrm{TX}$ & 1 & $18,074,151$ & $40,863.13$ & 1995Q1 & 2004Q2 \\
\hline Virginia & VA & 1 & $4,572,014$ & $35,719.20$ & 1995Q3 & 2004Q1 \\
\hline Vermont & VT & 1 & 397,798 & $3,108.13$ & 2000Q1 & 2004Q1 \\
\hline Washington & WA & 1 & $9,536,038$ & $19,100.45$ & 1990Q1 & 2004Q1 \\
\hline Wisconsin & WI & 1 & $7,712,727$ & $16,593.01$ & 1990Q1 & 2004Q1 \\
\hline West Virginia & WV & 1 & $1,330,312$ & $10,393.38$ & 1997Q1 & 2004Q1 \\
\hline
\end{tabular}




\section{$7.3 \quad$ NOTES}

- Alabama (AL), Kansas (KS), and South Carolina (SC) are currently missing from data archive. A request has been put in to include them. 
CHAPTER 7. QUARTERLY WORKFORCE INDICATORS - SEINUNIT FILE (QWI) 


\section{Chapter 8.}

\section{Unit-to-Worker Impute - Job location impute $(\mathrm{U} 2 \mathrm{~W})$}

\subsection{OVERVIEW}

A primary objective of the QWI is to provide employment, job and worker flows, and wage measures at a very detailed levels of geography (place-of-work) and industry. The structure of the administrative data received by LEHD from state partners, however, poses a challenge to achieving this goal. QWI measures are primarily based on the processing of UI wage records which report, with the exception of Minnesota, only the legal employer (SEIN) of the workers. The ES-202 micro-data, however, are comprised of establishmentlevel records which provide the geographic and industry detail needed to produce the QWI. For employers operating only one establishment within a state, the assignment of establishment-level characteristics to UI wage records is straightforward because there is no distinction between the employer and the establishment. However, approximately 30 to 40 percent of state-level employment is concentrated in employers that operate more than one establishment in that state. For these multi-unit employers, the SEIN on workers' wage records identifies the legal employer in the ES-202 data, but not the employing establishment (place-of-work). Thus, establishment level characteristics-geography and industry, in particular-are missing data for these multiunit job histories.

In order to impute establishment-level characteristics to job histories of multi-unit employers, a nonignorable missing data model with multiple imputation was developed. The model imputes establishmentof-employment using two key characteristics available in the LEHD Infrastructure Files: 1) distance between place-of-work and place-of-residence and 2) the distribution of employment across establishments of multiunit employers. The distance to work model is estimated using data from Minnesota, where both the SEIN and SEINUNIT identifiers appear on a UI wage record. Then, the posterior distribution of the parameters from this estimation, combined with the actual SEIN and SEINUNIT employment histories from the ES-202 data, are used for multiple imputation of the SEINUNIT associated with for workers in a given SEIN in the data from states other than Minnesota. ${ }^{1}$ Emerging from this process is an output file, called the Unit-toWorker (U2W) file, containing ten imputed establishments for each worker of a multi-unit employer. These implicates are then used in the downstream processing of the QWI.

The U2W process relies on information from each of the four Infrastructure Files-ECF, GAL, EHF, and ICF-as well as the auxiliary SPF file. Within the ECF, the universe of multi-unit employers is identified. For these employers, the ECF also provides establishment-level employment, date-of-birth, and geocodes (which are acquired from the GAL). The SPF contains information on predecessor relationships which may lead to the revision of date-of-birth implied by the ECF. Finally, job histories in the EHF in conjunction with place-of-residence information stored in the ICF provide the necessary worker information needed to estimate and apply the imputation model.

\footnotetext{
${ }^{1}$ The actual SEINUNIT coded on the UI wage records is used for Minnesota, and would be used for any other state that provided such data. Note that there are occasional, and rare, discrepancies between the unit structure on the Minnesota wage records and the unit structure on the Minnesota ES-202 data for the same quarter. These discrepancies are resolved during the initial processing of the Minnesota data in its state-specific readin procedures.
} 


\subsubsection{A probability model for employment location}

\subsubsection{Definitions}

Let $i=1, \ldots, I$ index workers, $j=1, \ldots, J$ index employers (SEINs), and $t=1, \ldots, T$ index time (quarters). Let $R_{j t}$ denote the number of active establishments at employer $j$ in quarter $t$, let $\mathfrak{R}=\max _{j, t} R_{j t}$, and $r=1, \ldots, \mathfrak{R}$ index establishments. Note that the index $r$ is nested within $j$. Let $N_{j r t}$ denote the quarter $t$ employment of establishment $r$ in employer $j$. Finally, if worker $i$ was employed at employer $j$ in $t$, denote by $y_{i j t}$ the establishment at which the worker was employed.

Let $\mathcal{J}_{t}$ denote the set of employers active in quarter $t$, let $\mathcal{I}_{j t}$ denote the set of individuals employed at employer $j$ in quarter $t$, let $\mathcal{R}_{j t}$ denote the set of active $\left(N_{j r t}>0\right)$ establishments at employer $j$ in $t$, and let $\mathcal{R}_{j t}^{i} \subset \mathcal{R}_{j t}$ denote the set of active establishments that are feasible for worker $i$. Feasibility is defined as follows. An establishment $r \in \mathcal{R}_{j t}^{i}$ if $N_{j r s}>0$ for every quarter $s$ that $i$ was employed at $j$.

\subsubsection{The probability model}

Let $p_{i j r t}=\operatorname{Pr}\left(y_{i j t}=r\right)$. At the core of the model is the probability statement:

$$
p_{i j r t}=\frac{e^{\alpha_{j r t}+x_{i j r t}^{\prime} \beta}}{\sum_{s \in \mathcal{R}_{j t}^{i}} e^{\alpha_{j s t}+x_{i j s t}^{\prime} \beta}}
$$

where $\alpha_{j r t}$ is a establishment- and quarter-specific effect, $x_{i j r t}$ is a time-varying vector of characteristics of the worker and establishment, and $\beta$ measures the effect of characteristics on the probability of being employed at a particular establishment. In the current implementation, $x_{i j r t}$ is a linear spline in the (greatcircle) distance between worker $i$ 's residence and the physical location of establishment $r$. The spline has knots at 25, 50, and 100 miles.

Using (8.1), the following likelihood is defined

$$
p(y \mid \alpha, \beta, x)=\prod_{t=1}^{T} \prod_{j \in \mathcal{J}_{t}} \prod_{i \in \mathcal{I}_{j t}} \prod_{r \in \mathcal{R}_{j t}^{i}}\left(p_{i j r t}\right)^{d_{i j r t}}
$$

where

$$
d_{i j r t}= \begin{cases}1 & \text { if } y_{i j t}=r \\ 0 & \text { otherwise }\end{cases}
$$

and where $y$ is the appropriately-dimensioned vector of the outcome variables $y_{i j t}, \alpha$ is the appropriatelydimensioned vector of the $\alpha_{j r t}$, and $x$ is the appropriately-dimensioned matrix of characteristics $x_{i j r t}$. For $\alpha_{j r t}$, a hierarchical Bayesian model based on employment counts $N_{j r t}$ is specified.

The object of interest is the joint posterior distribution of $\alpha$ and $\beta$. A uniform prior on $\beta, p(\beta) \propto 1$ is assumed. The characterization of $p(\alpha, \beta \mid x, y, N)$ is based on the factorization

$$
\begin{aligned}
p(\alpha, \beta \mid x, y, N) & =p(\alpha \mid N) p(\beta \mid \alpha, x, y) \\
& \propto p(\alpha \mid N) p(\beta) p(y \mid \alpha, \beta, x) \\
& \propto p(\alpha \mid N) p(y \mid \alpha, \beta, x) .
\end{aligned}
$$

Thus, the joint posterior (8.4) is completely characterized by the posterior of $\alpha$ and the likelihood of $y$ in (8.2). Note (8.2) and (8.4) assume that the employment counts $N$ affect employment location $y$ only through the parameters $\alpha$.

\subsubsection{Estimation}

The joint posterior $p(\alpha, \beta \mid x, y, N)$ is approximated at the posterior mode. In particular, we estimate the posterior mode of $p(\beta \mid \alpha, x, y)$ evaluated at the posterior mode of $\alpha$. From these we compute the posterior 
modal values of the $\alpha_{j r t}$, then, maximize the log posterior density

$$
\log p(\beta \mid \alpha, x, y) \propto \sum_{t=1}^{T} \sum_{j \in \mathcal{J}_{t}} \sum_{i \in \mathcal{I}_{j t}} \sum_{r \in \mathcal{R}_{j t}^{i}} d_{i j r t}\left(\alpha_{j r t}+x_{i j r t}^{\prime} \beta-\log \left(\sum_{s \in \mathcal{R}_{j t}^{i}} e^{\alpha_{j s t}+x_{i j s t}^{\prime} \beta}\right)\right)
$$

which is evaluated at the posterior modal values of the $\alpha_{j r t}$, using a modified Newton-Raphson method. The mode-finding exercise is based on the gradient and Hessian of (8.5). In practice, (8.5) is estimated for three employer employment size classes: 1-100 employees, 101-500 employees, and greater than 500 employees, using data for Minnesota.

\subsubsection{Imputing place of work}

After estimating the probability model using Minnesota data, the posterior distribution of the estimated $\beta$ parameters is combined with the entity specific posterior distribution of the $\alpha$ parameters in the imputation process for other states. A brief outline of the imputation method, as it relates to the probability model previously discussed, is provided in this section. Emphasis is placed on not only the imputation process itself, but also the preparation of input data.

\subsubsection{Sketch of the imputation method}

Ignoring temporal considerations, 10 implicates are generated as follows. First, using the posterior mean and variance of $\beta$ estimated from the Minnesota data, we take 10 draws of $\beta$ from the normal approximation (at the mode) to $p(\beta \mid \alpha, x, y)$. Next, using ES-202 employment counts for the establishments, we compute 10 values of $\alpha_{j t}$ based on the hierarchical model for these parameters. Note that these are draws from the exact posterior distribution of the $\alpha_{j r t}$. The drawn values of $\alpha$ and $\beta$ are used to draw 10 imputed values of place of work from the asymptotic approximation to the posterior predictive distribution

$$
p(\tilde{y} \mid x, y)=\iint p(\tilde{y} \mid \alpha, \beta, x, y) p(\alpha \mid N) p(\beta \mid \alpha, x, y) d \alpha d \beta \text {. }
$$

\subsubsection{Implementation}

Establishment data Using state-level micro-data, the set of employers (SEINs) that ever operate more that one establishment in a given quarter is identified; these SEINs represent the set of ever-multi-unit employers defined above as the set $\mathcal{J}_{t}$. For each of these employers, its establishment-level records are identified. For each establishment, latitude and longitude coordinates, parent employer (SEIN) employment, and ES202 month-one employment $^{2}$ for the entire history of the establishment are retained. Those establishments with positive month-one employment in a given quarter characterize $\mathcal{R}_{j t}$, the set of all active establishments. An establishment birth date is identified and, in most cases, is the first quarter in the ES-202 time series in which the establishment has positive month-one employment. For some employers, predecessor relationships are identified in the SPF; in those instances, the establishment date-of-birth is adjusted to coincided with that of the predecessor's.

Worker data The EHF provides the earnings histories for employees of the ever-multi-unit employers. For each in-scope job (a worker-employer pair), one observation is generated for the end of each job spell, where a job spell is defined as a continuum of quarters of positive earnings for worker at a particular employer during which there are no more than 3 consecutive periods of non-positive earnings. ${ }^{3}$ The start date of the

\footnotetext{
${ }^{2}$ In rare instances where no ES-202 employment is available, an alternative employment measure based on UI wage record counts may be used.

${ }^{3} \mathrm{~A}$ new hire is defined in the QWI as a worker who accedes to a firm in the current period but was not employed by the same firm in any of the 4 previous periods. A new job spell is created if, for example, a worker leaves a firm for more than 4 quarters and is subsequently re-employed by the same firm.
} 
job history is identified as the first quarter of positive earnings; the end date is the last date of positive earnings. ${ }^{4}$ These job spells characterize the set $\mathcal{I}_{j t}$

Candidates Once the universe of establishments and workers is identified, data are combined and a priori restrictions and feasibility assumptions are imposed. For each quarter of the date series, the history of every job spell that ends in that quarter is compared to the history of every active (in terms of ES-202 first month employment) establishment of the employing employer (SEIN). The start date of the job spell is compared to the birth date of each establishment. Establishments that were born after the start of a job spell are immediately discarded from the set of candidate establishments. The remaining establishments constitute the set $\mathcal{R}_{j t}^{i} \subset \mathcal{R}_{j t}$ for a job spell (worker) at a given employer. ${ }^{5}$

Given the structure of the pairing of job spells with candidate establishments, it is clear that within job spell changes of establishment are ruled-out. An establishment is imputed once for each job spell, ${ }^{6}$ thereby creating no spurious labor market transitions.

Imputation and output data Once the input data are organized, a set of 10 imputed establishment identifiers are generated for each job spell ending in every quarter for which both ES-202 and UI wage records exist. For each quarter, implicate, and size class, $s=1,2,3$, the parameters on the linear spline in distance between place-of-work and place-of-residence $\hat{\beta}^{s}$ are sampled from the normal approximation of the posterior predictive distribution of $\beta^{s}$ conditional on Minnesota $(M N)$

$$
p\left(\beta^{s} \mid \alpha_{M N}, x_{M N}, y_{M N}\right)
$$

The draws from this distribution vary across implicates, but not across time, employers, and individuals. Next, for each employer $j$ at time $t$, a set of $\hat{\alpha}_{j r t}$ are drawn from

$$
p\left(\alpha_{S T} \mid N_{S T}\right)
$$

which are based on the ES-202 month-one employment totals $\left(N_{j r t}\right)$ for all candidate establishments $r_{j t} \subset$ $\mathcal{R}_{j t}$ at employer $j$ within the state $(S T)$ being processed. The initial draws of $\hat{\alpha}_{j r t}$ from this distribution vary across time and employers but not across job spells. Combining (8.7) and (8.8) yields

$$
\begin{aligned}
& p\left(\alpha_{S T} \mid N_{S T}\right) p\left(\beta^{s} \mid \alpha_{M N}, x_{M N}, y_{M N}\right) \\
\approx & p\left(\alpha_{S T} \mid N_{S T}\right) p\left(\beta^{s} \mid \alpha_{S T}, x_{S T}, y_{S T}\right) \\
= & p\left(\alpha_{S T}, \beta_{S T} \mid x_{S T}, y_{S T}, N_{S T}\right)
\end{aligned}
$$

an approximation of the joint posterior distribution of $\alpha$ and $\beta^{s}$ (8.4) conditional on data from the state being processed.

The draws $\hat{\beta}^{s}$ and $\hat{\alpha}_{j r t}$ in conjunction with the establishment, employer, and job spell data are used to construct the $p_{i j r t}$ in (8.1) for all candidate establishments $r \in \mathcal{R}_{j t}^{i}$. For each job spell and candidate establishment combination, the $\hat{\beta}^{s}$ are applied to the calculated distance between place-of-residence (of the worker holding the job spell) and the location of the establishment, where the choice of $\hat{\beta}^{s}$ depends on the size class of the establishment's parent employer. For each combination an $\hat{\alpha}_{j r t}$ is drawn which is based primarily on the size (in terms of employment) of the establishment relative to other active establishments at the parent employer. In conjunction, these determine the conditional probability $p_{i j r t}$ of a candidate establishment's assignment to a given job spell. Finally, from this distribution of probabilities is drawn an establishment of employment.

\footnotetext{
${ }^{4}$ By definition, an end-date for a job spell is not assigned in cases where a quarter of positive earnings at a firm is succeeded by 4 or fewer quarters of non-employment and subsequent re-employment by the same firm.

${ }^{5}$ The sample of UI wage and QCEW data chosen for processing of the QWI is such that the start and end dates are the same. Birth and death dates of establishments are, more precisely, the dates associated with the beginning and ending of employment activity observed in the data. The same is true for the dates assigned to the job spells.

${ }^{6}$ More specifically, an establishment is imputed to a job spell only once within each implicate.
} 
CHAPTER 8. UNIT-TO-WORKER IMPUTE - JOB LOCATION IMPUTE (U2W)

The imputation process yields a data file containing a set of 10 imputed establishment identifiers for each job spell. In a very small set of cases, the model fails to impute an establishment to a job spell. This is often due to unanticipated idiosyncrasies in the underlying administrative data. Furthermore, across states, the proportion of these failures relative to successful imputation is well under $0.5 \%$. For these job spells, a dummy establishment identifier is assigned and in downstream processing, the employment-weighted modal employer-level characteristics are used. 


\subsection{DATA SET DESCRIPTIONS}

\subsubsection{Naming scheme}

The U2W contains a single file per state:

u2w_zz.sas7bdat

ZZ stands for the state postal abbreviation. You will find zero-observation SAS datasets attached to this document - see the attachment tab.

\subsubsection{Data location}

The files are stored in a main directory, with state-specific subdirectories:

$\mathrm{u} 2 \mathrm{w} / \mathrm{ZZ/}$

On the RDC network, the directory can be found under

/mixed/lehd/current

\subsubsection{Main dataset: $\mathrm{u} 2 \mathrm{w} \_\mathrm{zz}$}

This files contain the 10 imputed establishment identifiers are generated for each job spell.

Record identifier PIK SEIN NEW_HIST_FLAG

Sort order PIK SEIN NEW_HIST_FLAG

Entity Job spell

Unique Entity Key PIK SEIN

\begin{tabular}{|c|c|c|c|c|}
\hline Field name & $\begin{array}{l}\text { Data dictionary } \\
\text { reference name }\end{array}$ & $\begin{array}{l}\text { Starting } \\
\text { position }\end{array}$ & $\begin{array}{l}\text { Field } \\
\text { size }\end{array}$ & $\begin{array}{l}\text { Data } \\
\text { type }\end{array}$ \\
\hline Start of spell YYYY.F (e.g. 2000Q2 = 2000.25) & FIRST_DATE & 00008 & 3 & $\mathrm{~N}$ \\
\hline End of spell YYYY.F (e.g. 2000Q4 = 2000.75) & LAST_DATE & 00011 & 3 & $\mathrm{~N}$ \\
\hline Spell number for same SEIN & NEW_HIST_FLAG & 00014 & 3 & $\mathrm{~N}$ \\
\hline Protected Identification Key & PIK & 00017 & 9 & $\mathrm{~A} / \mathrm{N}$ \\
\hline State Employer Identification Number & SEIN & 00026 & 12 & $\mathrm{~A} / \mathrm{N}$ \\
\hline State UI Reporting Unit Number (Impute 1) & IMPUTED_UNIT_1 & 00038 & 5 & $\mathrm{~A} / \mathrm{N}$ \\
\hline State UI Reporting Unit Number (Impute 10) & IMPUTED_UNIT_10 & 00083 & 5 & $\mathrm{~A} / \mathrm{N}$ \\
\hline State UI Reporting Unit Number (Impute 2) & IMPUTED_UNIT_2 & 00043 & 5 & $\mathrm{~A} / \mathrm{N}$ \\
\hline State UI Reporting Unit Number (Impute 3) & IMPUTED_UNIT_3 & 00048 & 5 & $\mathrm{~A} / \mathrm{N}$ \\
\hline State UI Reporting Unit Number (Impute 4) & IMPUTED_UNIT_4 & 00053 & 5 & $\mathrm{~A} / \mathrm{N}$ \\
\hline State UI Reporting Unit Number (Impute 5) & IMPUTED_UNIT_5 & 00058 & 5 & $\mathrm{~A} / \mathrm{N}$ \\
\hline State UI Reporting Unit Number (Impute 6) & IMPUTED_UNIT_6 & 00063 & 5 & $\mathrm{~A} / \mathrm{N}$ \\
\hline State UI Reporting Unit Number (Impute 7) & IMPUTED_UNIT_7 & 00068 & 5 & $\mathrm{~A} / \mathrm{N}$ \\
\hline State UI Reporting Unit Number (Impute 8) & IMPUTED_UNIT_8 & 00073 & 5 & $\mathrm{~A} / \mathrm{N}$ \\
\hline State UI Reporting Unit Number (Impute 9) & IMPUTED_UNIT_9 & 00078 & 5 & $\mathrm{~A} / \mathrm{N}$ \\
\hline
\end{tabular}


CHAPTER 8. UNIT-TO-WORKER IMPUTE - JOB LOCATION IMPUTE (U2W)

\subsubsection{Summary information on datasets}

Table 8.2: File information, by state, for U2W

\begin{tabular}{|c|c|c|c|c|c|c|}
\hline State & & $\begin{array}{r}\text { Number of } \\
\text { datafiles }\end{array}$ & Records & $\begin{array}{r}\text { Filesizes } \\
(\mathrm{MB})\end{array}$ & Start & End \\
\hline Covered states & & 30 & $261,358,423$ & $42,100.78$ & 1990Q1 & 2004Q3 \\
\hline Alabama & $\mathrm{AL}$ & 1 & $2,832,386$ & 456.27 & 2001Q1 & 2004Q2 \\
\hline Arkansas & AR & 1 & $1,071,394$ & 172.60 & 2002Q3 & 2004Q1 \\
\hline California & $\mathrm{CA}$ & 1 & $51,688,741$ & $8,326.16$ & 1991Q3 & 2003Q4 \\
\hline Colorado & $\mathrm{CO}$ & 1 & $8,225,917$ & $1,325.07$ & 1993Q2 & 2004Q1 \\
\hline Delaware & $\mathrm{DE}$ & 1 & 401,043 & 64.62 & 1998Q3 & 2004Q1 \\
\hline Florida & FL & 1 & $26,225,278$ & $4,224.45$ & 1992Q4 & 2004Q1 \\
\hline Iowa & IA & 1 & $3,315,824$ & 534.13 & 1998Q4 & 2004Q1 \\
\hline Idaho & ID & 1 & $1,975,273$ & 318.20 & 1991Q1 & 2004Q1 \\
\hline Illinois & IL & 1 & $16,180,380$ & $2,606.40$ & 1990Q1 & 2004Q1 \\
\hline Indiana & IN & 1 & $6,700,422$ & $1,079.34$ & 1998Q1 & 2004Q1 \\
\hline Kansas & KS & 1 & $3,848,376$ & 619.93 & 1993Q1 & 2004Q1 \\
\hline Kentucky & $\mathrm{KY}$ & 1 & $2,306,302$ & 371.52 & 2001Q1 & 2004Q1 \\
\hline Maryland & $\mathrm{MD}$ & 1 & $7,276,859$ & $1,172.20$ & 1990Q1 & 2004Q1 \\
\hline Maine & $\mathrm{ME}$ & 1 & $1,202,672$ & 193.74 & 1996Q1 & 2004Q1 \\
\hline Missouri & $\mathrm{MO}$ & 1 & $9,635,562$ & $1,552.13$ & 1995Q1 & 2004Q1 \\
\hline Montana & $\mathrm{MT}$ & 1 & 839,330 & 135.23 & 1993Q1 & 2004Q1 \\
\hline North Carolina & $\mathrm{NC}$ & 1 & $18,248,391$ & $2,939.51$ & 1991Q1 & 2003Q4 \\
\hline North Dakota & ND & 1 & 520,281 & 83.82 & 1998Q1 & 2004Q2 \\
\hline New Jersey & NJ & 1 & $7,415,146$ & $1,194.48$ & 1996Q1 & 2004Q1 \\
\hline New Mexico & NM & 1 & $1,705,814$ & 274.79 & 1995Q3 & 2004Q1 \\
\hline Oklahoma & OK & 1 & $2,133,936$ & 343.76 & 2000Q1 & 2004Q1 \\
\hline Oregon & OR & 1 & $5,830,196$ & 939.16 & 1991Q1 & 2004Q1 \\
\hline Pennsylvania & $\mathrm{PA}$ & 1 & $12,941,320$ & $2,084.63$ & 1997Q1 & 2004Q1 \\
\hline South Carolina & $\mathrm{SC}$ & 1 & $3,516,612$ & 566.48 & 1998Q1 & 2004Q3 \\
\hline Texas & $\mathrm{TX}$ & 1 & $37,414,591$ & $6,026.85$ & 1995Q1 & 2004Q2 \\
\hline Virginia & VA & 1 & $6,990,886$ & $1,126.13$ & 1998Q1 & 2004Q1 \\
\hline Vermont & $\mathrm{VT}$ & 1 & 299,844 & 48.32 & 2000Q1 & 2004Q1 \\
\hline Washington & WA & 1 & $8,811,217$ & $1,419.35$ & 1990Q1 & 2004Q1 \\
\hline Wisconsin & WI & 1 & $10,109,963$ & $1,628.55$ & 1990Q1 & 2004Q1 \\
\hline West Virginia & WV & 1 & $1,694,467$ & 272.96 & 1997Q1 & 2004Q1 \\
\hline
\end{tabular}


CHAPTER 8. UNIT-TO-WORKER IMPUTE - JOB LOCATION IMPUTE (U2W)

\section{$8.3 \quad$ NOTES}


CHAPTER 8. UNIT-TO-WORKER IMPUTE - JOB LOCATION IMPUTE (U2W)

Space for your notes

Revision : 420 


\subsection{ACRONYMS USED}

ASM Annual Survey of Manufacturers

BED Business Employment Dynamics

BES Business Expenditure Survey

BLS Bureau of Labor Statistics

BR Business Register, formerly known as the SSEL

BRB Business Register Bridge

CBSA Core-Based Statistical Area

CES Center for Economic Studies

CEW Covered Employment and Wages

CFN Census File Number

CM Census of Manufactures

CPS Current Population Survey

DRB Disclosure Review Board

ECF Employer Characteristics File

ES-202 ES-202. An older name for the QCEW program

EHF Employment History Files

EIN (federal) Employer Identification Number

FIPS Federal Information Processing Standards codes issued by National Institute of Standards and Technology (NIST)

FTI Federal Tax Information, typically covered under Title 26, U.S.C.

GAL Geocoded Address List

ICF Individual Characteristics File

IRS Internal Revenue Service

IRS Internal Revenue Service

LDB Longitudinal Data Base

LED Local Employment Dynamics

LEHD Longitudinal Employer-Household Dynamics

LMI Labor Market Information

MAF Master Address File

MN Minnesota

MOU Memorandum of Understanding 
MSA Metropolitan Statistical Area

NAICS North American Industry Coding System

NIST National Institute of Standards and Technology

OTM OnTheMap

PHF Person History File

PIK Protected Identity Key

PPN Permanent Plant Number

QCEW Quarterly Census of Employment and Wages, managed by the Bureau of Labor Statistics (BLS)

QWI Quarterly Workforce Indicators

RDC Research Data Center

SEIN State employer identification number. It is constructed from the state Federal Information Processing Standards (FIPS) code and the UI account number. The BLS refers to the UI account number in combination with the reporting unit number as SESA-ID

SEINUNIT SEIN reporting unit

SESA State Employment Security Agency

SIC Standard Industry Classification

SIPP Survey of Income and Program Participation

SPF Successor-Predecessor File

SSA Social Security Administration

SSN Social Security Number

U2W Unit-to-Worker Impute

UI unemployment insurance 
CHAPTER 8. UNIT-TO-WORKER IMPUTE - JOB LOCATION IMPUTE (U2W) 


\section{Bibliography}

Abowd, J. M., B. E. Stephens, and L. Vilhuber (2006). Confidentiality protection in the Census Bureau's Quarterly Workforce Indicators. Technical Paper TP-2006-02, LEHD, U.S. Census Bureau.

Abowd, J. M., B. E. Stephens, L. Vilhuber, F. Andersson, K. L. McKinney, M. Roemer, and S. D. Woodcock (2006). The LEHD infrastructure files and the creation of the Quarterly Workforce Indicators. Technical paper TP-2006-01, U.S. Census Bureau, LEHD and Cornell University.

Abowd, J. M., B. E. Stephens, L. Vilhuber, F. Andersson, K. L. McKinney, M. Roemer, and S. D. Woodcock (2009). The LEHD infrastructure files and the creation of the Quarterly Workforce Indicators. In T. Dunne, J. B. Jensen, and M. J. Roberts (Eds.), Timothy Dunne, J. Bradford Jensen, and Mark J. Roberts. University of Chicago Press. 


\section{$8.5 \quad$ ERRATA}

\section{Release 165:}

- ICF: county_live and countyliveimputed were wrongly attributed to the FTI-free file. county_live is FTI.

Please report any additional errors to the authors of this document. 
BIBLIOGRAPHY

\$Id: overview_master.tex 420 2011-04-13 20:49:33Z vilhu001 \$ 